\title{
UM ESTUDO SOBRE MODELOS MECÂNICO-PROBABILÍSTICOS PARA PÓRTICOS DE CONCRETO ARMADO
}

\author{
Rodrigo de Carvalho Soares
}

Tese apresentada à Escola de Engenharia de São Carlos, da Universidade de São Paulo, como parte dos requisitos para obtenção do título de Doutor em Engenharia de Estruturas

ORIENTADOR: Prof. Dr. Wilson Sergio Venturini

São Carlos 
À minha esposa, Aninha, e à toda minha família que é a base da minha orientação. 
Ao Professor, orientador e amigo Wilson Sergio Venturini, pessoa que muito estimo e admiro, pela excelente orientação e confiança depositada em mim.

À minha esposa pela paciência, apoio e compreensão necessários para o desenvolvimento da tese.

Ao meu pai e amigo pelo eterno suporte técnico.

À minha família pelo suporte psicológico durante a elaboração do trabalho.

À Professora Ana Lúcia H.C. El Debs pelo contínuo apoio e auxílio na minha orientação.

Aos meus amigos do SET pelo ótimo convívio que alivia a dureza do trabalho.

Aos Professores Maurice Lemaire e Alaa Mohamed do "Institut Français de Mécanique Avancée", Clermont Ferrant, França, pelo suporte técnico que contribuiu magnificamente para a qualidade da tese.

Aos Professores Giuliano Augusti e Marcelo Ciampoli da "Universitá di Roma, La Sapienza", Roma, Itália, pela contribuição significativa à tese.

Aos professores, funcionários e colegas do SET que contribuíram de uma forma ou de outra para a elaboração desse trabalho.

A população brasileira pelo suporte financeiro indireto. trabalho.

À FAPESP pelo suporte financeiro, sem o qual seria difícil elaborar esse 


\section{Sumário}

Lista de abreviaturas e siglas.......................................................................... vii

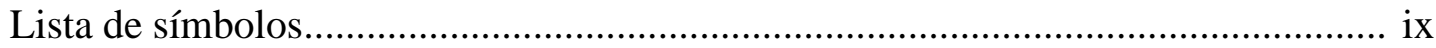

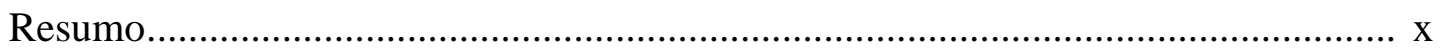

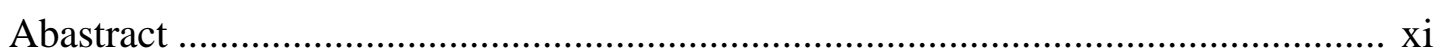

Capítulo 1 Introdução................................................................................ 1

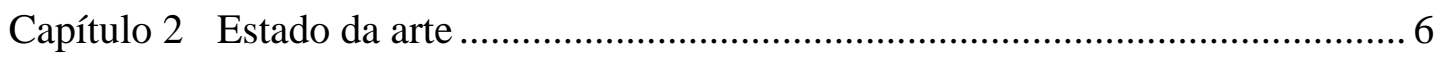

2.1 Definição de incertezas aleatórias ou estocásticas .......................................... 6

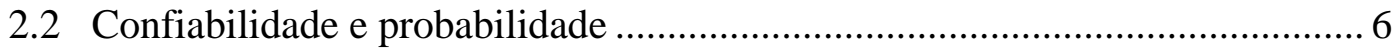

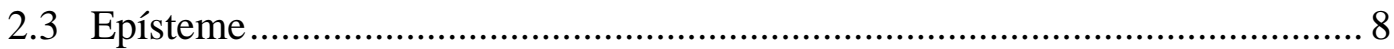

2.4 Análise de diagramas de eventos e de falhas .............................................. 9

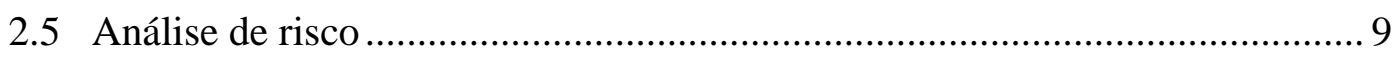

2.5.1 Análise formal de risco ................................................................... 11

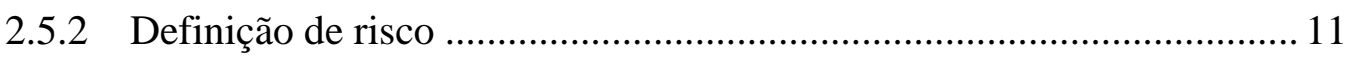

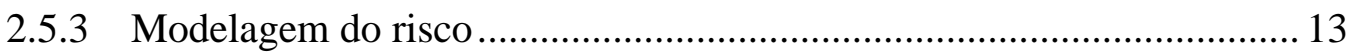

2.5.4 Análise de risco quantitativo .............................................................. 13

2.5.5 Métodos de integração de confiabilidade estrutural em metodologias práticas de análise de risco quantitativo........................................................... 14

2.5.6 Características especiais de confiabilidade estrutural .......................... 15

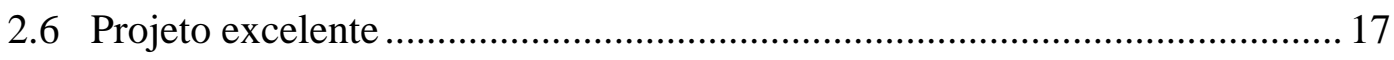

2.7 Análise de sensibilidade e análise de confiabilidade ................................ 17

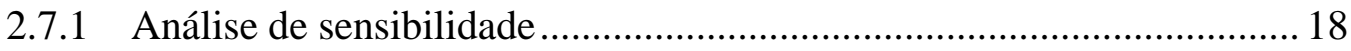


2.7.2 Análise de confiabilidade 18

2.8 Índice de confiabilidade

2.9 Métodos disponíveis para estimar a confiabilidade estrutural 22

2.9.1 Método de Simulação de Monte Carlo. 27

2.9.2 Método de Simulação utilizando Amostra por Importância 27

2.10 Níveis de confiabilidade 29

2.11 Combinação do método dos elementos finitos com SRM 29

2.12 Pontos de projeto múltiplos em confiabilidade de primeira e segunda ordem 30

2.13 Estabelecendo distribuições de probabilidade............................................ 32

2.14 Modelos de incertezas versos modelos de imprecisão ................................ 34

2.15 Características estatísticas de variáveis de projeto..................................... 35

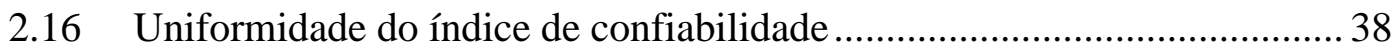

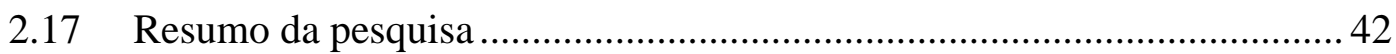

Capítulo 3 Modelos mecânicos para pórticos de concreto armado........................... 44

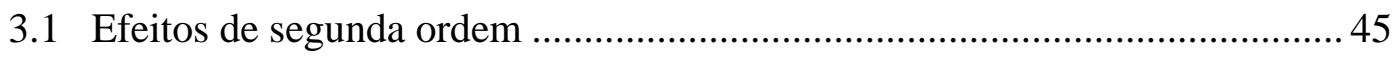

3.1.1 Implementação dos efeitos de segunda ordem utilizando matrizes incrementais

3.1.2 Efeitos de Segunda ordem utilizando sistema de coordenadas corrotacionais .....

3.2 Não-linearidade física

3.2.1 Modelo baseado em inércia equivalente ............................................55

3.2.2 Modelo baseado em relações constitutivas ........................................ 57

3.2.2.1 Equações constitutivas para o concreto......................................... 58

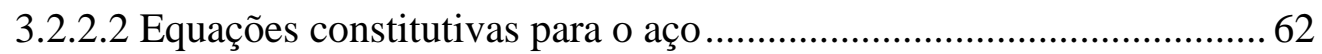


Capítulo 4 Um método de simulação

4.1 Princípio do modelo

4.2 Gerador Aleatório 66

4.3 Algoritmo proposto 67

Capítulo 5 Método de superfície de resposta (RSM) 71

5.1 Forma da superfície de resposta 73

5.2 Desenvolvimento da superfície de resposta 74

5.3 Construção de uma superfície de resposta 75

5.3.1 Definição do espaço de trabalho 75

5.3.2 Princípio 76

5.4 Transformações de distribuições de probabilidade 76

5.4.1 Variáveis aleatórias independentes 77

5.4.1.1 Distribuição normal equivalente 78

5.4.2 Variáveis aleatórias correlacionadas 79

5.4.2.1 Transformação de Rosenblatt. 80

5.4.2.2 Transformação de Nataf 80

5.5 Plano de experiência 83

5.6 Aproximações de pontos a uma superfície. 88

5.7 Cálculo do índice de confiabilidade 90

5.7.1 Algoritmo de Rackwitz \& Fiessler. 91

5.7.2 Algoritmo de Madsen et al 93

5.7.3 Algoritmo de Thoft-Christensen e Murotsu 94

5.7.4 Método do Gradiente utilizando a hessiana do problema de otimização95

5.8 Cálculo da probabilidade de ruína. 97

5.8.1 Método de confiabilidade de primeira ordem - FORM 97 
5.8.2 Método de confiabilidade de segunda ordem - SORM .99

5.9 Formulação do Problema 102

5.10 Metodologia da versão final do STST 103

5.10.1 Busca da solicitação (S) 104

5.10.2 Busca da resistência (R) 104

5.10.3 Cálculo do índice de confiabilidade $\beta$ 105

5.11 Exemplo de aplicação do RSM 105

5.12 Conclusões 105

Capítulo 6 Análise de sensibilidade das variáveis 108

6.1 Estudo da sensibilidade mecânica 108

6.2 Medidas de sensibilidade da confiabilidade 109

6.2.1 Cosseno diretor $(\alpha)$ 110

6.2.2 Sensibilidade dos parâmetros de distribuição 111

6.2.3 Sensibilidade da probabilidade de falha 112

6.2.4 Sensibilidade dos parâmetros da função de desempenho.

6.2.5 Elasticidade dos parâmetros 113

6.3 Análise de sensibilidade utilizando um SFEM 114

Capítulo 7 Calibração de coeficientes parciais de segurança. 118

7.1 Princípios de métodos de calibração 119

7.2 Procedimentos de métodos de calibração. 120

Capítulo 8 Otimização e confiabilidade estrutural acopladas 122

Capítulo 9 Análise estatística de colunas de concreto armado 132

9.1 Variação do índice de confiabilidade em colunas de CA segundo normas propostas 134

9.2 Proposta de coeficiente de variação constante para o concreto. 144 
9.3 Análise de coeficiente de segurança parcial variado para o concreto 157

9.4 Redução consistente do módulo de elasticidade secante do concreto. 162

9.5 Análise de sensibilidade de colunas de concreto armado 168

9.6 Confiabilidade entre modelos para concreto 172

9.7 Conclusões 173

Capítulo 10 Estudo estatístico de pórticos de concreto armado. 175

Capítulo 11 Desempenho do RSM 187

11.1 Pórtico 1 187

11.2 Coluna 193

11.3 Pórtico 2 196

Capítulo 12 Conclusões e idéias a serem desenvolvidas em trabalhos futuros 200

12.1 Modelos mecânicos e dos materiais 201

12.2 Modelos de confiabilidade 203

12.3 Modelos mecânico-confiabilísticos 205

Anexo A Trabalhos recentes em confiabilidade estrutural 207

Anexo B Distribuições de probabilidade.

Anexo C Coeficiente f, transformação de Nataf. 222

Anexo D Plano de experiência 225

Bibliografia 244

Apêndice I Exemplo de transformação isoprobabilística de variáveis aleatórias independentes. I

Apêndice II Exemplo de transformação isoprobabilística utilizando o método de distribuição normal equivalente. III Apêndice III Exemplo prático de utilização de plano de experiência ...................... V Apêndice IV Exemplo de aplicação do $R S M$.......................................................... VI 


\section{Lista de abreviaturas e siglas}

BEM método dos elementos de contorno

COV coeficiente de variação

CRSM método de superfície de resposta cúbica

EP plano de experiência

ETA diagrama de análise de eventos

FEM método dos elementos finitos

FORM método de confiabilidade de primeira ordem

FS superfície limite, ou superfície de falha, ou superfície de ruína

FTA diagrama de análise de ruínas

$\mathrm{G}(\mathrm{X})$ função que representa a superfície limite (FS) da estrutura no espaço físico

$\mathrm{H}(\mathrm{U})$ função que representa a superfície limite (FS) da estrutura no espaço reduzido

IFMA "Institut Français de Mécanique Avancée", situado em Clermont Ferrant, França

NLF não-linearidade física

NLG não-linearidade geométrica

p.d.f. função de densidade de probabilidade de ligação da variável aleatória básica X

$\mathrm{P}_{\mathrm{f}} \quad$ probabilidade de ruína, ou probabilidade de atingir um determinado limite, ou probabilidade de falha

QRA análise de risco quantitativo

QRS superfície de resposta quadrática

QRSM método de superfície de resposta quadrática

$\mathrm{R} \quad$ recursos, em termos estrtuturais resistência

$\mathrm{R}_{\mathrm{el}} \quad$ confiabilidade da estrutura

RM método de confiabilidade

RS superfície de resposta mecânica da estrutura

RSM método de superfícies de respostas

S necessidade, em termos de estruturas é a solicitação ou a resposta da estrtura para determinado cenário

SFEM método dos elementos finitos estocásticos

SLS estado limite de serviço 
SORM método de confiabilidade de segunda ordem

SQP "Sequential Quadratic Program"

SRM método de confiabilidade estrutural

SSCs sistemas estruturais e componenetes

STST software mecânicoprobabilístico desenvolvido na tese

ULS estado limite último

VA variável aleatória 


\section{Lista de símbolos}

$\mathrm{f}_{\mathrm{X}}(\mathrm{x}) \quad$ função de densidade de probabilidade de ligação da variável aleatória básica $X$

$\mathrm{F}_{\mathrm{X}}(\mathrm{x}) \quad$ função de distribuição de probabilidade acumulada da variável aleatória básica X no espaço físico

$\phi_{(v)} \quad$ função de distribuição de probabilidade normal padrão

$\Omega \quad$ domínio da análise

$\beta \quad \quad$ índice de confiabilidade de Hasofer \& Lind

$\mathrm{P}^{*} \quad$ ponto de projeto ou ponto de ruína mais provável

x variável aleatória no espaço físico, ou variável de projeto, ou variável básica

u variável aleatória no espaço reduzido

$\overline{\mathrm{x}}, \mu \quad$ média da variável aleatória $\mathrm{x}$

$\sigma \quad$ desvio padrão da variável aleatória $\mathrm{x}$

$\gamma \quad$ coeficiente parcial de segurança

$\mathrm{V}, \sigma^{2} \quad$ variância da variável aleatória

E(.) expectância matemática

$\mathrm{P}_{\text {crit }} \quad$ carga que conduz a estrutura ao estado limite estabelecido

$\mathrm{X}$ vetor das variáveis aleatórias no espaço físico

U vetor das variáveis aleatórias no espaço reduzido

$\mathrm{T}$ transformação isoprobabilística

$\rho_{12} \quad$ coeficiente de correlação no espaço físico

$\rho_{0,12} \quad$ coeficiente de correlação no espaço reduzido

CV coeficinte de variação

$\mathrm{Q}(\mathrm{X})$ função que representa a resposta aproximada da superfície de resposta mecânica da estrutura

$\mathrm{R} \quad$ resposta mecânica da estrutura

$\alpha \quad$ cosseno diretor da variável aleatória no espaço reduzido ou fator de sensibilidade da variável

$\mathrm{T}($.$) transformação isoprobabilística$ 


\section{Resumo}

SOARES, R.C. (2001) Um estudo sobre modelos mecânico-probabilísticos para pórticos de concreto armado. Tese (doutorado) - Escola de Engenheria de São Carlos, Universidade de São Paulo.

Em geral, o índice de confiabilidade e consequentemente a probabilidade de atingir-se um estado limite em estruturas não são uniformes ao introduzir-se a segurança através de coeficientes parciais aplicados à resistência e às ações como propostos pelas normas nacionais e internacionais. A falta de um maior conhecimento das variáveis estruturais pode conduzir o projeto a soluções distantes das ótimas em termos de custos e principalmente à falta de conhecimento do nível de segurança que a estrutura se encontra. A introdução da segurança no projeto estrutural através de métodos probabilísticos permite desenvolvê-lo de maneira mais consciente, possibilitando estimar a probabilidade de falha da estrutura para diversos estados limites. Nesse contexto insere-se o presente trabalho. Inicialmente introduzse conceitos estatísticos no âmbito global necessários para desenvolver um estudo mecânico-probabilístico. Posteriormente esses conceitos são direcionados para pórticos de concreto armado, mostrando alguns procedimentos possíveis para desenvolver algoritmos capazes de fazer análise probabilística dessas estruturas. Um outro assunto abordado é a análise de sensibilidade das variáveis de projeto, onde procedimentos necessários para desenvolver algoritmos são desenvolvidos. O caminho da otimização acoplada ao problema mecânico-probabilístico também é brevemente indicado. Um outro assunto abordado refere-se à análise de modelos mecânicos não-lineares existentes para estrutura aporticada de concreto armado, agora abordando-os estatisticamente. Sugere-se como conclusões de uma análise paramétrica um novo modelo para aceitação do concreto na obra. Ainda como resultado dessa análise, um modelo simplificado para redução da rigidez dos elementos de barra ao realizar os cálculos no regime linear é sugerido. 


\section{Abstract}

SOARES, R.C. (2001) One study about mechanic probabilistic models to reinforced concrete frames. Thesis (PHd) - School of Engineering of São Carlos, University of São Paulo.

Using partial coefficients to reduce or to increase structure design parameter values, as proposed by the Brazilian and by other international codes, in general, does not lead to uniform reliability indices and consequently does not guarantee desired failure probability of the structures. The lack of structural variable knowledge may lead to not optmized designs in terms of either minimum cost or ideal shape. Moreover, it mainly can lead to structures for which the safety level is completely unknown. Introducing safety in structural designs by using probabilistic methods leads to more accurate procedure in terms of knowing the failure probabilities, which is the main objective of the present work. Initially, the statistic concepts, necessary to develop a mechanic-probabilistic study in the general sense, are introduced and discussed. Then, they are particularized to plane reinforced concrete frames. Some possible procedures are adopted to develop mechanical-probabilistic algorithms dedicated to this specific probabilistic analysis. Sensibility analysis of the design variables is another subject discussed in this work, with emphasis on the procedures used to develop the corresponding software. In addition, the work briefly describes the optimization and mechanical-reliability problem coupling, as well as non-linear mechanical models of this particular reinforced concrete structure now seen under a statistical view. A new model to accept the two first statistical moments of concrete strength is suggested on the basis of a parametric analysis. As another consequence of this analysis, a simplified model to compute stiffness reduction of concrete bar element is also suggested.

: reliability, statistic, non-linear, reinforced concrete, optimization. 


\section{Capítulo 1 Introdução}

O surgimento dos computadores pessoais no final dos anos setenta e sua impressionante evolução até os dias de hoje estão exigindo uma rápida transformação nas metodologias empregadas até então em projetos estruturais e, em particular, nos projetos de estruturas de edifícios. Modelos de cálculo que se baseavam em hipóteses bastante simplificadoras estão sendo substituídos por outros que conseguem representar mais fielmente o comportamento estrutural. Embora hajam especialistas que, muitas vezes, por si mesmo conseguem se adequar à nova realidade, é absolutamente necessário que as novas concepções e facilidades sejam levadas à grande maioria dos profissionais da área, e principalmente que as instituições de ensino de engenharia se capacitem para poder oferecer aos alunos procedimentos e conceitos mais modernos. O impacto devido ao avanço da eletrônica no ensino da engenharia já é sentido; entretanto, pode-se verificar que as adaptações e transformações são lentas e muitas vezes difíceis de serem introduzidas.

Nesta tese, pretende-se introduzir modelos de cálculo que concebem a aleatoriedade das variáveis de projeto. Em particular, será dado ênfase à contribuição no contexto da análise estrutural de edifícios de concerto armado; este estudo limitase às estruturas bidimensionais (pórticos planos), levando-se em conta a aleatoriedade das variáveis envolvidas, tanto para a definição dos limites de uso da estrutura quanto para a avaliação de sua capacidade última. A ênfase é dada à necessidade do estabelecimento de modelos que quantifiquem com mais precisão e confiança a rigidez das estruturas, suas deslocabilidades e limites de resistência e de utilização, considerando-se as diversas variáveis dentro de um contexto estatístico.

Ao adotar modelos que considerem as variabilidades dos parâmetros estruturais e das solicitações, obviamente permite-se uma avaliação mais confiável e realista da capacidade última da estrutura. Assim, a busca de modelos que permitam, de forma aproximada, a análise global da estrutura e também de cada membro individual é 
essencial. No caso das verificações dos limites de utilização um procedimento similar será procurado, cujo objetivo é definir um modelo estrutural que leve em conta a aleatoriedade intrínseca de cada parâmetro. Embora o modelo que represente a resposta de uma estrutura de concreto armado, considerando apenas os aspectos da mecânica estrutural e dos materiais, seja sempre o mesmo para qualquer situação de carregamento, as considerações sobre as probabilidades admitidas para cada caso, estado limite último ou de utilização, vão levar a modelos globais diferenciados. São esses modelos globais da estrutura em situações de utilização e de limite de resistência que serão procurados no decorrer deste trabalho.

Um dos elementos básicos que merece atenção para o desenvolvimento da pesquisa proposta é o conhecimento dos modelos relativos à confiabilidade estrutural. A teoria da confiabilidade é nada mais que um julgamento matemático no contexto dos problemas de engenharia, isto é, transforma a experiência adquirida durante o desenvolvimento da humanidade em modelos matemáticos. Para controle e garantia de qualidade em soluções de problemas teóricos sofisticados, a probabilidade e a estatística são ferramentas fundamentais, já que, como se sabe as variáveis envolvidas nesses problemas em geral são associadas a variações em torno dos seus valores médios. Para a transformação de experiências da engenharia em modelos matemáticos, segundo TICHÝ (1993), é necessário que se leve em consideração os seguintes conceitos gerais: a) estatística matemática e teoria da probabilidade; b) concepção em termos de sistemas (verificar as seqüências de falha da estrutura chegando a uma probabilidade global de atingir o estado limite pré definido); c) introdução consistente do tempo, o qual pode ser considerado como uma dimensão adicional (cada variável aleatória é considerada no problema estatístico como uma dimensão do problema). Adiciona-se ainda a importância de se conhecer e definir os domínios dos modos de falha.

Nos problemas de engenharia, para possibilitar a análise estatística, o conhecimento da probabilidade de um evento associado ao problema é fundamental, assim como a introdução de conceitos de probabilidades anterior e posterior. A primeira é baseada na experiência e vivência prática, enquanto a segunda é baseada em análises de medidas e observações (teoria de Bayes). A respeito de eventos que 
dependam do conhecimento de sua história, utilizam-se valores adotados nas normas brasileiras e recomendações internacionais.

$\mathrm{Na}$ literatura especializada há diversos métodos que podem ser empregados na análise de confiabilidade estrutural, dentre eles pode-se citar: métodos de Momentos, métodos baseados em simulações de Monte Carlo pura ou com amostra reduzida, "Fuzzy Logic", "Fuzzy Set”, Método das Superfícies de Respostas, etc., que são classificados como métodos probabilísticos.

O número de pesquisas em confiabilidade aplicada a estruturas é bastante crescente do começo da década de setenta até os dias atuais. Este elevado número de pesquisas mostra que há um razoável interesse mundial nessa área. Verifica-se também que grande parte das publicações foram feitas em simpósios, conferências e revistas, o que reforça ainda mais a importância do estudo neste assunto.

A respeito dos tipos estruturais (pórticos, treliças, pavimentos, pontes, etc.) encontrados na bibliografia, verificou-se que não há predominância entre eles. Em geral, estuda-se tipos estruturais, não uma estrutura única. Salienta-se que hoje muitas pesquisas se dedicam ao estudo de solicitação dinâmica. A maioria dos modelos desenvolvidos ou utilizados baseia-se em análise probabilística aproximada, seja utilizando a estatística clássica (não há a priori conhecimentos adicionais das variáveis aleatórias) ou a bayesiana (há a priori conhecimentos adicionais das variáveis aleatórias, por exemplo sabe-se que a variável pertence aos números inteiros positivos). Com relação aos materiais, na grande maioria dos exemplos examinados não há uma definição específica, necessita-se apenas fornecer um modelo constitutivo adequado. Entre os materiais previamente definidos, o número de pesquisas em concreto armado vem em primeiro lugar, seguido dos materiais compostos, concreto protendido e aço. Em relação aos tipos de análises dos materiais, geralmente são empregados modelos não-linear, precisando apenas de um critério adequado para o material em estudo, em geral a superfície limite $F S$ é predefinida. Superfície limite é a superfície que estabelece a fronteira entre o domínio de falha e o domínio de segurança da estrutura em análise. Observou-se nos trabalhos consultados que a FS da estrutura é definida para verificação do estado limite último, na sua grande maioria, ou do estado em serviço, sendo raros os 
trabalhos que apresentam ambos os estados limites.

Entre os métodos probabilísticos mais utilizados destacam-se métodos baseados em simulações de Monte Carlo e modelos analíticos os quais utilizam algoritmos de otimização para estimar a confiabilidade da estrutura. Os métodos seguem tanto a estatística clássica como a bayesiana.

A bibliografia apresenta uma diversidade grande de métodos para determinar a probabilidade de falha de uma estrutura. Em geral, para um mesmo tipo de estrutura são utilizados métodos estatísticos diferentes, não havendo uma linha clara de preferência entre os métodos a serem utilizados. Isto ao mesmo tempo que traz dificuldades para a pesquisa em andamento, mostra que ainda há muito a saber para uma implementação mais precisa dos conceitos estatísticos nas estruturas. Neste trabalho, propõem-se modelos de análise de confiabilidade para tratamento estatístico das variáveis envolvidas, os quais são formulados utilizando o método de simulações de Monte Carlo e o Método de Superfícies de Respostas adicionado a algoritmos de otimização para estimar o índice de confiabilidade.

No Brasil a inclusão de tratamento estatístico no cálculo estrutural é praticamente nula e as pesquisas no assunto ainda estão em fase inicial. Poucos centros de pesquisa estudam o assunto, entre eles a Universidade Federal do Rio Grande do Sul, algumas pesquisas na COPPE, mais especificamente com estruturas Offshore, e um início de pesquisa na UFMG e na EPUSP.

Em particular pretende-se abordar nessa pesquisa alguns assuntos de interesse no campo estatístico, tais como: propor modelos para estimar a confiabilidade de estruturas para um estado limite qualquer, definido pelo usuário; analisar coeficientes parciais de segurança (redutor das resistências e amplificador das ações) propostos por Normas nacionais e internacionais; propor modificações na aceitação do concreto na obra para garantir maior uniformidade na probabilidade de ruína da estrutura; introduzir uma discussão sobre os coeficientes parciais de segurança para colunas de concreto armado que conduzam a estrutura a uma probabilidade de falha mais uniforme que as obtidas utilizando os coeficientes atuais; enfim, iniciar uma discussão sobre o assunto que é de grande interesse na área de projetos estruturais.

Esta tese a princípio poderia se direcionar para três campos de pesquisa: 
métodos numéricos; concreto armado e modelos estatísticos. Entretanto, o principal objetivo da pesquisa é aplicar modelos estatísticos em estruturas de concreto armado utilizando métodos numéricos para determinar a solução mecânica do problema. A essa união será denominada modelo mecânico-confiabilístico ou mecânico-estatístico ou ainda mecânico-probabilístico. 


\section{Capítulo 2 Estado da arte}

A objetivo dessa revisão bibliográfica é mostrar os principais assuntos que estão sendo pesquisados até o momento e comentar um pouco sobre eles, não se limitando apenas ao assunto desenvolvido nessa tese. É importante saber quais são as preocupações dos pesquisadores e ter uma visão geral do assunto pesquisado para melhor desenvolver o trabalho. Neste âmbito, serão comentados e definidos alguns itens que podem parecer não estarem diretamente ligados a esse trabalho em particular, mas, que podem ser de grande ajuda na busca da quantificação da confiabilidade estrutural.

\subsection{Definição de incertezas aleatórias ou estocásticas}

De acordo com NILSEN et al. (1998), incertezas aleatórias ou estocásticas são propriedades fundamentais de uma quantidade decorrentes de aleatoriedades inerentes às propriedades de interesse, tais como a flutuação da velocidade do vento, a soma de precipitação pluviométrica e as propriedades de materiais como concreto e aço. Desses exemplos, fica claro que esse tipo de incerteza inerente às propriedades de interesse pode ser dividido em duas categorias: independentes da influência da atividade humana ou aquelas onde a atividade humana pode ter uma grande influência, como na propriedade dos materiais.

\subsection{Confiabilidade e probabilidade}

Segundo $^{1}$, uma simples definição de confiabilidade pode ser dada por: $a$ probabilidade de sobrevivência de um componente ou um sistema desde que utilizado de acordo com as especificações de projeto. Ou seja, confiabilidade é dada pelo complemento da probabilidade de ruína.

\footnotetext{
${ }^{1}$ MOHAMED, A. RYFES Theoretical manual. version 1.0. LaRAMA - Laboratoire de Recherches et Applications en Mécanique Avancée. Clermont Ferrant. France.
} 


$$
\mathrm{R}_{\mathrm{el}}=1-\mathrm{P}_{\mathrm{f}}
$$

Onde $\mathrm{R}_{\mathrm{el}}$ é a confiabilidade e $\mathrm{P}_{\mathrm{f}}$ é a probabilidade de ruína. Para ruína, pode-se definir como: a incapacidade do componente ou do sistema de funcionar como foi projetado.

Então, a condição de ruína deve ser definida com respeito a um cenário de ruína ou modo de ruína específico. Para clarear esta idéia, suponha-se uma simples estrutura cuja função é suportar cargas permanentes e acidentais; considera-se a ruína da estrutura sob essas cargas como a condição de ruína e calcula-se a sua probabilidade. Ou seja, para o cálculo dessa probabilidade não foram levadas em consideração outras variáveis, tais como deterioração dos materiais, alteração ou imprecisão na geometria, etc. Para cada cenário de ruína há uma correspondente probabilidade. A probabilidade de ruína global é obtida por união e interseção dos modos de ruína de cada cenário.

O significado exato do termo probabilidade é difícil de ser compreendido, uma variedade de definições tem sido proposta por muitos pesquisadores e na literatura esse tópico tem sido frequentemente discutido por Bayesianos e Frequentistas ou Clássicos. O importante é que se escolha uma definição estritamente compatível com o uso desejável da palavra probabilidade de acordo com o problema de risco. Normalmente não se define probabilidade, defini-la é problemático pois podem-se levantar muitas questões, especialmente quando essas probabilidades são comparadas com critérios de aceitação.

Segundo JCSS (1996), em termos de teoria de confiabilidade, a confiabilidade mínima requerida corresponde a uma probabilidade máxima de ruína aceita, relacionada a um estado limite particular (fronteira entre o domínio seguro e nãoseguro) ou ao colapso global da estrutura para um período de tempo especificado.

Em princípio, esta probabilidade de ruína deve ser considerada para todos os riscos possíveis, incluindo a presença de cargas extremas, baixas qualidades dos materiais e erros grosseiros. Na prática, entretanto, o Eurocode propõe:

$\checkmark$ um conjunto de suposições para um dado nível de mão-de-obra mínima e administração de qualidade e;

$\checkmark$ requisitos de probabilidade de ruína formal, condicional sobre essas suposições, 
resultando em um conjunto de regras de projetos e fatores parciais.

O projetista deve ter certeza que, até o ponto que ele é capaz de controlar, as suposições devem ser cumpridas.

Em geral, a confiabilidade estrutural pode ser calculada pelo complemento da probabilidade de ruína da estrutura, a qual pode ser quantitativamente expressa por:

$$
P_{f}=P[G(X) \leq 0]=\int_{G(X) \leq 0} \ldots \int_{X} f_{X}(x) d x
$$

onde $\mathrm{G}(\mathrm{X})$ é a função de estado limite da estrutura; $\mathrm{f}_{\mathrm{X}}(\mathrm{x})$ é a função de densidade de probabilidade de ligação da variável aleatória básica $\mathrm{X}$ que é dado de entrada do problema, tal como os parâmetros de projeto.

\subsection{Epistemologia}

De acordo com a filosofia, epistemologia é o estudo crítico dos princípios, hipóteses e resultados da ciência. Pode ser definido como o conhecimento que o analista tem sobre as variáveis envolvidas. Para qualquer modelo de confiabilidade utilizado, é essencial conhecer as características estatísticas das variáveis consideradas aleatórias.

De acordo com NILSEN et al. (1998), epísteme é o conhecimento do analista sobre a quantidade. Em alguns casos, o conhecimento pode ser melhorado por medidas adquiridas na própria estrutura, ou outros tipos de pesquisas, como bibliografias, ensaios em laboratórios, etc. A principal necessidade de conhecimento diz respeito às incertezas da quantidade inicial envolvidas em eventos futuros, ou seja, incertezas em variáveis que influem diretamente na resposta estrutural, tais como: peso e tamanho de estruturas complexas, resistência dos elementos estruturais, etc.

O conhecimento das variáveis pode ser dividido em duas categorias: julgamento fundamentado ou probabilidade posterior ou ainda probabilidade objetiva e julgamento técnico ou probabilidade anterior ou ainda grau de convicção.

De acordo com HOKSTAD et al. (1998), julgamento fundamentado é aquele obtido por um acúmulo de informações bem estruturado e documentado das variáveis de projeto. Baseado nessas informações, é possível futuramente recalcular e analisar os resultados. Julgamento técnico é uma aproximação não-estruturada sem 
documentação ou explicação dos julgamentos do objeto em análise. Baseia-se na experiência do analista.

\subsection{Análise de diagramas de eventos e de falhas}

O cálculo da probabilidade de ruína de uma estrutura está associado à igualdade ou ultrapassagem dos esforços internos sobre as resistências dos materiais. Em estruturas com alto grau de hiperasticidade ou em estruturas onde é possível a formação de mecanismos, a seção de ruína pode mudar ao longo do cálculo mecânico-probabilístico; quando isso ocorre, pode-se utilizar técnicas de análise de diagrama de eventos (ETA) ou análise de diagrama de ruínas (FTA) para determinar a probabilidade de ruína global da estrutura.

Segundo PAPAZAGLOU ${ }^{\mathrm{a}, \mathrm{b}}$ (1998), ETA são diagramas ramificados que se referem a eventos complexos que podem ser discretizados em termos de seus resultados (respostas) e possivelmente em termos de suas distinções em uma série de eventos simples. Apesar de sua generalidade, o termo análise de diagrama de eventos (event tree analysis) tem sido principalmente usado em referência a modelos lógicos descrevendo o desempenho de um sistema complexo. Enquanto que FTA (fault tree analysis) são análise de diagramas que se referem a eventos complexos que podem ser discretizados em termos de suas ruínas e possivelmente em termos de suas distinções em uma série de eventos simples.

\subsection{Análise de risco}

Uma preocupação que se percebeu em grande parte dos trabalhos pesquisados foi com relação à quantificação do risco. Devido ao grande número de pesquisas no sentido de análise de risco quantitativo (QRA), será dedicada uma pequena parte da pesquisa a esse assunto.

Muitos sistemas dos dias de hoje, como estruturas por exemplo, são bem mais seguras que a 50 ou 100 anos atrás, o que é natural, pois vivemos numa mudança contínua do mundo e a tendência é cada vez mais conhecer os materiais, modelos de cálculo, concepção da estrutura, etc. A velocidade de evolução de organizações industriais, e em particular da globalização de companhias, juntamente com o aumento de escala e complexidade de muitos processos de geração de risco, trazem 
novos desafios para analistas de risco, que têm como objetivo identificar, modelar e quantificar riscos, e para cientistas sociais que têm como objetivo entender as percepções do público às respostas dos azares da vida.

Segundo CHEOK et al. (1998), para as propostas de aplicações de processos reguladores de risco quantificável, uma das principais atividades é a classificação ou categorização de sistemas estruturais e componentes (SSCs, Structural Systems and Components) os quais dizem respeito a risco significativo ou não desprezível, ou a segurança significativa. A proposta de classificação é, em geral, organizar os itens em ordem crescente ou decrescente de importância, enquanto a de categorização é alocar estes itens em dois ou mais grupos, de acordo com algum critério. Dependendo da aplicação analisada, pode ser mais apropriado categorizar ou classificar SSCs com respeito à importância do risco ou à importância da segurança.

No trabalho de NILSEN et al. (1998), discute-se o uso de métodos desenvolvidos para o cálculo de confiabilidade de estruturas como uma ferramenta geral para calcular probabilidades no contexto de análise quantitativa de risco. Para aplicar esses métodos o analista precisa modelar o sistema, as incertezas e os parâmetros de correlação separadamente e sistematicamente. Isto é assegurado ao modelar sistemas por combinações lógicas de funções de estado limite e modelar incertezas por fixação de distribuições de probabilidade marginal e medidas de correlação adequadas. Essas propriedades podem permitir ao analista incluir mais conhecimentos na análise, comparados a modelos tradicionalmente aplicados em análise de risco quantitativo. Portanto, a teoria da probabilidade permite considerações subjetivas serem incluídas na análise de risco de uma forma consistente.

De acordo com AVEN \& KURT (1998), um dos problemas fundamentais para quantificar o risco estrutural apresenta-se quando são expressos e interpretados os resultados. Discute-se naquele artigo o que significa a incerteza dos números gerados e conclui-se que na prática não há alternativa para se livrar dessas incertezas, mas pode-se adotar uma aproximação o mais próxima possível da realidade, focando quantidades observadas e usando conhecimentos prévios das variáveis envolvidas (probabilidade subjetiva ou Bayesiana). 
A probabilidade de teoria subjetiva provém de um coerente julgamento do trabalho estrutural, o qual constitui uma parte significativa das informações que são necessárias ao projeto. Entretanto, não é claro o verdadeiro significado de medida da aproximação bayesiana com relação a análise de risco, sendo necessária uma apresentação mais atrativa da aproximação bayesiana para poder utilizá-la na análise de risco.

VATN (1998) discute alguns aspectos filosóficos sobre critério de aceitação de risco e a regra da teoria de decisão estatística com administração de risco, concentrando seu artigo em atividades de petróleo.

Todas as atividades envolvem risco. O ideal é eliminá-lo, mas como isso não é possível, deve-se aceitar algum risco. A questão de aceitar o risco tem sido extensivamente discutida na literatura, e um interessante ponto de vista é dado pelo livro "Acceptable risk" de Fichhoff et al. 'A reivindicação do risco nunca deve ser aceita incondicionalmente. Risco só é aceito se algum benefício pode compensá-lo'. Ou seja, a decisão de risco é aceita, não o próprio risco. Portanto, aceitar o risco é um problema de decisão, isto é, uma escolha de alternativas.

\subsubsection{Análise formal de risco}

A análise formal tenta resolver problemas de decisão utilizando princípios formais de racionalidade, os quais baseiam-se em comparar vantagens e desvantagens das variáveis de projeto. $\mathrm{Na}$ análise formal alguns passos devem ser seguidos, tais como: definir a importância das variáveis; definir quais as variáveis envolvidas e como considerá-las; quais as consequências que as respostas estruturais podem causar; e identificar as variáveis que otimizem o problema.

\subsubsection{Definição de risco}

Risco pode ser definido de várias formas, sua definição depende das circunstâncias. Antes de definir risco será definido evento acidental e consequência.

Evento acidental (AE): um evento não esperado que pode levar a perda da vida humana, prejudicar o meio ambiente ou gerar algum prejuízo econômico, etc. A palavra azar pode ser utilizada neste contexto.

Consequência $(C)$ : um possível resultado de um evento acidental, ou seja, o AE 
seria a causa e a consequência o efeito.

Risco: de acordo com a definição de VATN (1998), risco é definido relativo a evento acidental. Os eventos acidentais são pontos isolados no processo de análise de risco. O risco associado a um evento acidental é uma combinação de probabilidades dos eventos acidentais, ou frequências de eventos acidentais, com a magnitude das consequências de ocorrências. As consequências representam efeitos diferentes, isto é, perda da vida, poluição do meio ambiente, etc., consequentemente o risco envolve um espectro de consequências, sendo assim, multidimensional. Considere $\operatorname{Pr}\left(\mathrm{E}_{\mathrm{i}}\right)$ como a probabilidade de um evento acidental número i ocorrer num período de tempo específico. Dado que $\mathrm{E}_{\mathrm{i}}$ ocorreu, as consequências são incertas, e então descritas por uma função de densidade de probabilidade única, $\pi\left(\mathrm{C}_{1}, \mathrm{C}_{2}, \ldots \mathrm{E}_{\mathrm{i}}\right)$. $\mathrm{O}$ risco para o evento acidental i é definido por:

$$
\mathrm{R}_{\mathrm{i}}=\mathrm{P}_{\mathrm{r}}\left(\mathrm{E}_{\mathrm{i}}\right) \otimes\left[\pi\left(\mathrm{C}_{1}, \mathrm{C}_{2}, \ldots \backslash \mathrm{E}_{\mathrm{i}}\right)\right]
$$

onde $\otimes$ é um operador multiplicativo. Em aplicações práticas é comum derivar a função de densidade de probabilidade marginal, $\pi\left(\mathrm{C}_{\mathrm{j}}, \mathrm{E}_{\mathrm{i}}\right)$, por cada consequência,

$$
\mathrm{R}_{\mathrm{i}}=\mathrm{P}_{\mathrm{r}}\left(\mathrm{E}_{\mathrm{i}}\right) \otimes\left[\pi^{\prime}\left(\mathrm{C}_{1} \backslash \mathrm{E}_{\mathrm{i}}\right), \pi^{\prime}\left(\mathrm{C}_{2} \backslash \mathrm{E}_{\mathrm{i}}\right), \ldots\right]
$$

Para descrever o risco total, o risco associado a cada evento acidental deve ser somado a todos eventos acidentais. Quantificar o risco em um número único não é recomendado porque isto requereria um procedimento de ponderação o qual necessariamente envolveria valores impostos. Valores impostos não devem ser integrados em definição de risco, mas são usados quando se definem critérios de aceitação.

A norma da Noruega, NS5814, afirma que 'Risco é definido como uma lista de consequências e suas probabilidades'. Nesse caso, o risco é definido por $\left[\left(\mathrm{p}_{1} \mathrm{C}_{1}\right),\left(\mathrm{p}_{2} \mathrm{C}_{2}\right), \ldots\right]$, onde $\mathrm{p}_{\mathrm{j}}=\operatorname{Pr}\left(\mathrm{C}_{\mathrm{j}}\right)$ é a probabilidade de ocorrência de consequência $\mathrm{C}_{\mathrm{j}}$.

Pela definição da Noruega, é natural pensar em consequências como eventos, enquanto que pela primeira definição, as consequências representam tipicamente variáveis aleatórias. 


\subsubsection{Modelagem do risco}

Segundo VRIJLING et al. (1998), na maioria dos estudos práticos o risco é dado numa forma numérica na qual relaciona-se o número de mortes $(\mathrm{N})$ com sua frequência de ocorrência (F) representados pela curva FN. Para facilitar a análise, utiliza-se algumas ferramentas provenientes da teoria da probabilidade para desenhar a curva FN modificada, onde as abcissas são representadas pela função de densidade de probabilidade (p.d.f.) do número de mortes $\mathrm{f}_{\mathrm{Ndij}}(\mathrm{x})$, e as ordenadas pelo complemento $1-\mathrm{F}_{\mathrm{Ndij}}(\mathrm{x})$. Um exemplo de uma curva $\mathrm{FN}$ pode ser visto no Gráfico 2.1 .

A p.d.f. do número de mortes $\mathrm{N}_{\mathrm{dij}}$ dado um acidente para uma atividade $\mathrm{i}$ em um lugar $\mathrm{j}$ pode ter muitas formas. Alguns tipos dessas curvas pode ser a p.d.f. condicional de Dirac, que limita os resultados em exatamente $\mathrm{N}$ fatalidades. Uma outra possibilidade que é utilizada em muitas respostas são a p.d.f. exponencial e a log-normal.
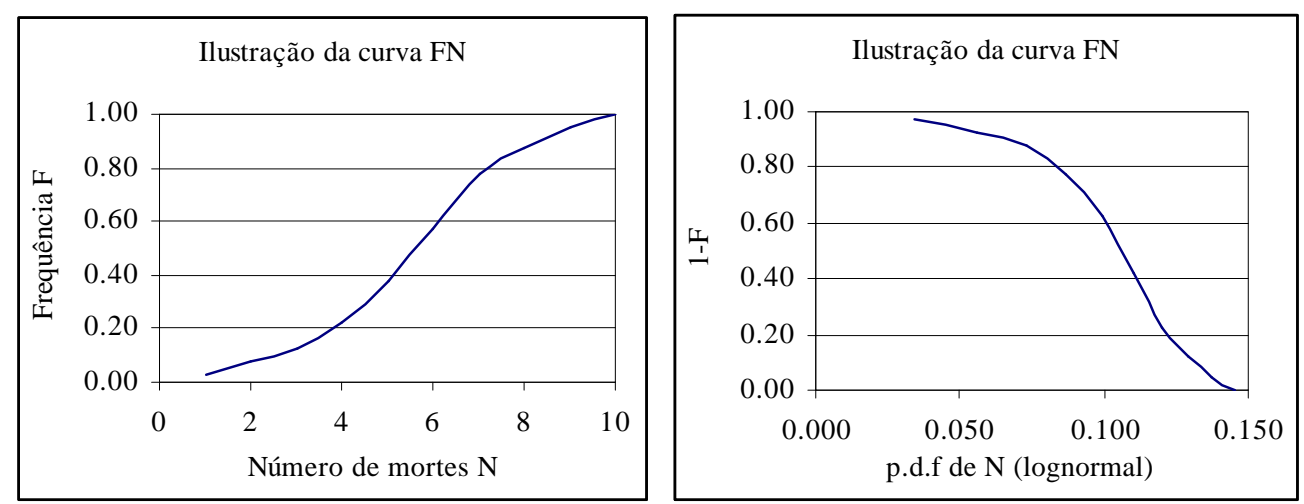

Gráfico 2.1 Exemplo de uma curva FN

\subsubsection{Análise de risco quantitativo}

A proposta de execução de uma análise de risco é identificar eventos acidentais que podem ocorrer durante a atividade que é analisada, e avaliar em que extensão esses eventos podem acontecer. O objetivo da análise é apresentar resultados que são apropriados como suporte para decisões a serem tomadas na escolha entre diferentes soluções e ações, ou simplesmente apresentar mais informações sobre os riscos envolvidos na atividade analisada.

$\mathrm{Na}$ análise de risco quantitativo, as verossímeis de consequências indesejáveis 
relevantes são descritas por medidas quantitativas. Medidas usuais de verossimilhança são probabilidades e frequências. A frequência de eventos raros típicos tratados na análise de risco é quase sempre pequena, isto é, menor que 0.1 . Isso pode ser comparado com a probabilidade do evento ocorrer no período de tempo que é considerado.

De acordo com NILSEN et al. (1998), as subatividades essenciais numa metodologia típica de QRA são:

$\checkmark$ identificação de eventos indesejáveis;

$\checkmark$ análise de causas;

$\checkmark$ análise de consequências;

$\checkmark$ apresentação de resultados.

Os eventos indesejados podem ser identificados primeiro utilizando modelos de ruína, seus efeitos e uma análise crítica destes. A possibilidade de causa dos eventos indesejados e as probabilidades associadas são acessadas em análise de causa usando uma metodologia FTA. Os possíveis cenários que podem levar a eventos indesejados e verossimilhanças associadas são encontrados na análise de consequências, sendo uma técnica comum para isso a ETA. Combinando os resultados provenientes desses três campos de atividades tem-se o resultado da análise total.

Uma atividade crucial em QRA é determinar probabilidades de diferentes níveis, isto é, para eventos de base em diagramas de ruínas (failure trees) e para pontos de ramificação em diagrama de eventos (event trees).

\subsubsection{Métodos de integração de confiabilidade estrutural em metodologias práticas de análise de risco quantitativo}

Para discutir como métodos de confiabilidade estrutural podem ser utilizados em QRA, é necessário um conceito claro de incerteza, probabilidade e risco. Em QRA, há uma característica falta de dados de experiências relevantes e consequentemente são requeridas informações subjetivas em termos de julgamentos técnicos ou opiniões de especialistas e julgamentos fundamentados. Já que há a necessidade de opiniões de especialistas, a teoria clássica de probabilidade parece inadequada por ser definida como propriedade determinística do sistema ao se introduzir informações subjetivas. Se os dados são pobres, a estimativa de 
probabilidade está sujeita a grandes incertezas estatísticas, consequentemente uma estimativa consistente da contribuição proveniente do modelo de incerteza é impossível. Por outro lado, na subjetiva teoria bayesiana de probabilidade, a probabilidade é interpretada como o quanto o analista acredita na ocorrência do evento, e é consequentemente condicionado à soma de informações utilizadas na análise. Desse modo, a probabilidade compreende uma total medida da incerteza.

SRM ("Structural Reliability Methods") são ferramentas para cálculo de probabilidade. Além dos SRM, há vários outros modelos de confiabilidade para a obtenção da confiabilidade de um sistema, por exemplo: modelos de tempo de vida para equipamentos eletrônicos e mecânicos, modelos de confiabilidade para "software", modelos de avaliação para sistemas de suporte, modelos para calcular a confiabilidade de ações humanas, etc. Esses modelos podem ser usados para calcular probabilidades isoladas, as quais são fornecidas aos diferentes métodos usados em QRA, como para eventos de base em FTA e pontos de ramos em ETA.

Uma característica especial dos SRM é que a influência proveniente de variáveis aleatórias e modelos de ruínas pode ser levada em consideração para análises isoladas. Logo, usando SRM, a divisão de eventos em subeventos detalhados de mesma extensão quase sempre não é necessária como em FTA e ETA, possibilitando trocar um conjunto de análises de diagramas de ruínas ou diagramas de eventos por uma análise única baseada em SRM.

\subsubsection{Características especiais de confiabilidade estrutural}

Em análise de risco quantitativo pode-se utilizar as técnicas FTA e ETA para modelar a interação de diferentes subeventos, e para determinar probabilidades de eventos com um apropriado nível de detalhes. São usadas regras elementares de cálculo de probabilidade para derivar a probabilidade do evento principal, que é o que interessa ao analista, e consequentemente trabalhar com probabilidades provenientes de subeventos.

Diferentes modelos de probabilidade são desenvolvidos para capacitar o analista a modelar suas incertezas observando a ocorrência de eventos de categorias diferentes, em uma grande variedade de sistemas. Consequentemente estas são ferramentas úteis para calcular as probabilidades dos subeventos em FTA e ETA. 
Pode ocorrer problemas quando o analista de incertezas observa um evento, de qualquer nível, envolvendo diretamente incertezas relacionadas a quantidades severamente incertas (falta de conhecimentos mínimos necessários a análise probabilística, como os dois primeiros momentos por exemplo), especialmente se estas têm uma natureza contínua. Pode ser difícil de encontrar um modelo próprio que inclua todas as variáveis de influência de maneira sistemática. A solução usual em cada situação é dividir o evento em subeventos, os quais podem ser analisados um a um, e modelar a interação por FTA ou ETA. Em certos casos, entretanto, isso não pode ser feito de uma forma consistente ou apropriada para a natureza do sistema. Como consequência dessa falta de modelos apropriados, a aproximação escolhida quase sempre envolve um julgamento direto de probabilidade, depois de uma compreensiva consideração (julgamento técnico) de todas as circunstâncias influentes. Nesse tipo de problema, onde variáveis fortemente aleatórias influenciam significativamente na probabilidade dos eventos, é adequado o uso de SRM.

A aproximação que é baseada em uma transmissão direta de probabilidade implica em uma avaliação de uma complexa soma de informações, resultando diretamente em uma imagem de probabilidade. A aproximação baseada em SRM, por outro lado, permite um tratamento sistemático de informações, construindo um modelo matemático segmentado. Isto pode introduzir incertezas referentes às variáveis cujo conhecimento é mantido à parte do conhecimento do sistema. A análise desse modelo, usualmente realizada por computador, permite estimar a probabilidade requerida.

Os SRM são mais avançados e sistemáticos que o método de associação direta; isso não significa que seja o mais recomendado para resolver qualquer tipo de problema. Usando SRM, o analista tem que definir os termos do evento em um conjunto de funções de estado limite, e descrever suas incertezas referentes a todas as variáveis nas distribuições de probabilidade. O estabelecimento de um modelo como esse pode ser um processo que consome muitos recursos. A complexidade do problema e a forma com a qual o analista define as incertezas são fatores importantes quando se calcula aproximações alternativas, que para serem calculadas devem dispor de conhecimentos e experiências sobre o evento. Para a escolha do método, o 
analista deve considerar algumas probabilidades específicas no contexto global da análise. Depois dessas considerações, a descrição das incertezas mais diretamente relacionadas ao evento com alguma variante do método direto, em muitos casos é a aproximação mais apropriada.

\subsection{Projeto excelente}

O’CONNOR (1998) explica em seu artigo como os níveis de confiabilidade e segurança são obtidos. A obtenção da qualidade é consequência de princípios básicos de excelência em projetos, produção, suporte e manutenção; que têm como base melhorias contínuas e por entendimento que excelência e melhoria induzem a redução de custos. Esses princípios são comparados com os métodos que estão sendo desenvolvidos e padronizados, em particular padrões militares para confiabilidade, ISO 9000, e casos de regulamentação de segurança. O artigo conclui que a rigor, aproximações padronizadas são errôneas e não produtivas, e recomenda que elas devem ser trocadas por uma filosofia baseada na realidade do desempenho humano.

\subsection{Análise de sensibilidade e análise de confiabilidade}

Ao elaborar um projeto de cálculo de estruturas, o engenheiro procura estimar o consumo de materiais, ou recursos (R), e as solicitações estruturais, ou necessidades (S), os quais obedecem a um certo conjunto de regras nas quais estão embutidos os riscos admitidos. Esse conjunto de regras, assim como a experiência dos projetistas, permitem justificar soluções, mas praticamente nunca estimam o nível de risco. Essa discussão conduz a: análise de sensibilidade e análise de confiabilidade.

A análise de sensibilidade permite avaliar a variação de parâmetros de entrada de um dado cálculo de deslocamentos, deformações, tensões, etc., com respeito a alguns parâmetros característicos, tais como médias e variâncias de dados.

O objetivo da análise de confiabilidade é comparar necessidades S com recursos $\mathrm{R}$ (esforços internos com resistências no caso de mecânica estrutural). O objetivo é então resolver a expressão:

$$
\mathrm{P}_{\mathrm{f}}=\operatorname{Prob}(\mathrm{S} \geq \mathrm{R})
$$

A análise de sensibilidade é uma parte natural da análise de confiabilidade padrão, a qual se baseia em cálculo de valores médios das variáveis de projeto. A 
análise de confiabilidade em geral usa cálculo de pontos de projeto. Ponto de projeto é o ponto solução, ou ponto no qual associa-se a probabilidade de ruína da estrutura. Este ponto, em geral, localiza-se em pequenos quantis das funções de densidade de probabilidade das variáveis de projeto.

As duas análises dependem do cálculo da probabilidade. Para resolver esse tipo de problema podem-se utilizar métodos de simulação ou métodos analíticos, cabendo ao analista escolher o mais adequado à estrutura em análise.

\subsubsection{Análise de sensibilidade}

O principal objetivo da análise de sensibilidade é conhecer o peso de cada uma das variáveis de projeto, ou seja, estudar a influência de sua variação sobre o sistema.

A importância de uma variável é definida através da função que representa a superfície de ruína, estudo que se chama 'estudo da sensibilidade mecânica', o qual traduz o comportamento mecânico do sistema, sendo um estudo puramente determinístico. Um outro item que é importante para definir a importância de uma variável é o índice de confiabilidade do sistema, estudo que se chama 'estudo da sensibilidade da confiabilidade'.

O objetivo do estudo da sensibilidade mecânica é avaliar a variação da função de desempenho com a evolução de uma variável.

As medidas de sensibilidade indicam ao projetista o melhor caminho para aumentar a segurança ou reduzir custos sem afetar a segurança. Existem várias medidas importantes: fator de sensibilidade que é dado pelo cosseno diretor do índice de confiabilidade; sensibilidade dos parâmetros de distribuição, sensibilidade da probabilidade de ruína, sensibilidade dos parâmetros da função de desempenho e elasticidade dos parâmetros. No decorrer da tese há um capítulo dedicado ao estudo da sensibilidade no qual todos esses conceitos serão vistos de forma detalhada.

\subsubsection{Análise de confiabilidade}

Os principais interesses da análise de confiabilidade segundo MOHAMED, A. (1999), são:

$\checkmark$ Fornecer um bom conhecimento das incertezas no comportamento estrutural.

$\checkmark$ Proporcionar um tratamento realístico das incertezas e calibrar os coeficientes 
parciais de segurança.

$\checkmark$ Pode oferecer uma real medida de segurança e consequentemente pode melhorar a estimativa do risco.

$\checkmark$ O projeto pode ser melhor dimensionado e consequentemente mais econômico, possibilitando uma distribuição ótima de materiais entre os elementos estruturais.

$\checkmark$ Possibilitar a administração de um sistema existente com um custo ótimo.

$\checkmark$ Garantir que a análise de confiabilidade seja facilitada na elaboração do projeto.

De acordo com LEMAIRE (1997), do ponto de vista da mecânica estrutural, a necessidade ou demanda (S) é uma função de variáveis de deslocamentos, deformações e tensões. O recurso $(\mathrm{R})$ é uma função de variáveis aleatórias caracterizando a capacidade resistente da seção ou da estrutura. O principal objetivo do projeto da mecânica estrutural é fazer com que o recurso seja superior à demanda, ou seja, R maior que $\mathrm{S}$. Resumindo em simples palavras, para saber se a estrutura pertence ao domínio de ruína ou de segurança, é suficiente verificar se o recurso é superior à demanda, sendo a probabilidade de ruína $\mathrm{P}_{\mathrm{f}}$ dada pela equação (2.5).

Para situações bem definidas em relação à segurança, nas quais as variáveis de projeto são valores determinísticos, é possível distinguir dois estados únicos: o estado seguro e o estado de ruína. Já em situações onde as variáveis de projeto representamse por valores médios associados as suas respectivas variâncias, não é possível distinguir dois estados únicos, e sim uma infinidade de estados, alguns deles pertencentes ao domínio de segurança e outros ao domínio de ruína. Nessas situações insere-se o estudo da confiabilidade estrutural.

$\mathrm{Na}$ prática da engenharia estrutural, escolhem-se coeficientes parciais de segurança com os quais expressa-se a incapacidade de estimar R e S, reduzindo-se, dessa forma, o recurso idealizado e aumentando a demanda idealizada. Em termos de pesquisa, não se pensa mais em justificar todos os projetos pela estimativa de $\mathrm{P}_{\mathrm{f}}$, a qual permanece reservada para situações excepcionais. Procuram-se expressões baseadas em códigos e normas assegurando confiabilidade suficiente, demonstradas por uma calibragem adequada para calcular uma aproximação de $\mathrm{P}_{\mathrm{f}}$ (a aproximação de $\mathrm{P}_{\mathrm{f}}$ pode ser calculada a partir do índice de confiabilidade, isto será visto em itens posteriores). 
De forma geral, um projeto é verificado por um modelo de cálculo de $\mathrm{S}$ e um modelo de cálculo de R. Se $\Psi(.$.$) é a função representativa do modelo mecânico, há$ uma relação tal que:

$$
\Psi\left(\mathrm{t}, \mathrm{R}_{(\mathrm{t})}, \mathrm{S}_{(\mathrm{t})}\right)=0
$$

O sucesso de um projeto pode ser verificado com a verificação da equação:

$$
\mathrm{G}\left(\mathrm{S}_{(\mathrm{t})}, \mathrm{R}_{(\mathrm{t})}\right)>0, \forall \mathrm{t} \in[0, \mathrm{~T}]
$$

onde T é o tempo de vida previsto.

Apenas considerando um caso independente do tempo ou escolhendo um dado prescrito fornecido $t_{0}$, a probabilidade de ruína é verificada pela relação:

$$
P_{\mathrm{f}}=\operatorname{Prob}\left(\mathrm{G}_{\left(\mathrm{x}_{\mathrm{i}}\right)} \leq 0\right)=\int_{\Omega} \mathrm{f}_{\mathrm{x}_{\mathrm{i}}}\left(\mathrm{x}_{\mathrm{i}}\right) \mathrm{dx}_{1} \mathrm{dx}_{2} \ldots \mathrm{dx} \mathrm{x}_{\mathrm{n}}
$$

onde $\mathrm{G}$ é uma função aleatória de variáveis $\mathrm{x}_{\mathrm{i}}$ e $\Omega$ é a parte do espaço das variáveis aleatórias correspondentes às realizações de ruína.

Para especificar a expressão de $\mathrm{P}_{\mathrm{f}}$ é simples, mas sua resolução envolve muitas operações difíceis levando-se em consideração a complexidade da expressão de $\Omega$ e a determinação da densidade de probabilidade $\mathrm{f}_{\mathrm{x}(\mathrm{x})}$.

De acordo com LEMAIRE (1997), o objetivo dos métodos atuais para resolver a equação (2.8) é evitar o método de simulação de Monte Carlo (seja puro ou modificado), pois as estruturas apresentam complexidade do modelo mecânico com consequente forte esforço computacional para a solução numérica. O método de simulação de Monte Carlo exige um número grande de processamentos de uma mesma estrutura para obter a resposta precisa.

As aproximações utilizadas atualmente para resolver esse problema envolvem dois passos:

$\checkmark \quad$ calcular o índice de confiabilidade $\beta$ (podem-se usar métodos de confiabilidade de primeira e segunda ordem);

$\checkmark$ estimar uma aproximação da probabilidade de ruína (a probabilidade de ruína é obtida para o mínimo valor de $\beta$, onde $\beta$ é definido pela distância do centro do sistema de coordenadas ao ponto de ruína mais provável no espaço normal padrão).

Enquanto que na análise de sensibilidade trabalha-se com a variação das 
variáveis de projeto, na análise de confiabilidade introduzem-se a idéia de cenário de ruína e o ponto de ruína mais provável $\left(\mathrm{P}^{*}\right)$, denominado ponto de projeto. $\mathrm{Na}$ análise de sensibilidade conserva-se todo seu interesse quando é calculada em torno de $\mathrm{P}^{*}$, e não apenas em torno do ponto médio.

Ao ser feita uma análise da sensibilidade sem introduzir a análise da confiabilidade, é possível apenas fazer um estudo da sensibilidade mecânica da estrutura. Já com a introdução da análise de confiabilidade, pode ser feito um estudo da sensibilidade da própria confiabilidade, analisando médias e desvios padrão de variáveis aleatórias e parâmetros determinísticos da função $G_{\left(x_{i}\right)}$. O estudo da sensibilidade será detalhado em capítulo posterior.

\section{8 Índice de confiabilidade}

A primeira definição de índice de confiabilidade pode ser atribuída à Rzhanitzyn, mas quem resumiu e popularizou esta característica de segurança foi Cornell, appud LEMAIRE (1997). Segundo Cornell, o índice de confiabilidade foi definido da seguinte forma: Considere $\mathrm{G}\left(\mathrm{x}_{\mathrm{i}}\right)$ a superfície de ruína no espaço físico de uma determinada estrutura cuja resistência é representada por $\mathrm{R}\left(\mathrm{x}_{\mathrm{i}}\right)$ e solicitação por $\mathrm{S}\left(\mathrm{x}_{\mathrm{i}}\right) \cdot \mathrm{G}\left(\mathrm{x}_{\mathrm{i}}\right)$ é escrita como segue:

$$
\mathrm{G}\left(\mathrm{x}_{\mathrm{i}}\right)=\mathrm{R}\left(\mathrm{x}_{\mathrm{i}}\right)-\mathrm{S}\left(\mathrm{x}_{\mathrm{i}}\right)
$$

No caso de variáveis aleatórias gaussianas e a função $\mathrm{G}\left(\mathrm{x}_{\mathrm{i}}\right)$ ser linear, obtémse o seguinte resultado:

$$
P_{f}=\operatorname{Prob}(G(x) \leq 0)=\phi(-\beta) \quad \operatorname{com} \quad \beta=\frac{\bar{x}}{\sigma_{x}}
$$

onde $\overline{\mathrm{x}}$ e $\sigma_{\mathrm{x}}$ são, respectivamente, a média e o desvio padrão da variável aleatória $\mathrm{x}_{\mathrm{i}} \mathrm{e}$ $\phi$ é a função de distribuição de Gauss de uma variável aleatória $u_{i}$, a qual tem média nula e desvio padrão unitário.

Inicialmente, esta aproximação foi erroneamente generalizada. Entretanto, após algum tempo foi corretamente definida por Hasofer \& Lind, appud LEMAIRE (1997), que propuseram escolher um espaço de funções normais Gaussianas (média nula, desvio padrão unitário, $\mathrm{N}(0,1))$ para representar a definição de $\beta$ independente da representação no espaço físico. Este espaço é denominado espaço reduzido, 
espaço normalizado, espaço normal padrão, ou simplesmente padronizado.

Transformações isoprobabilísticas (T) através das quais passa-se do espaço físico para o normal padrão e vice-versa, serão apresentadas posteriormente nessa tese. No espaço normal padrão a variável aleatória x é representada pela variável u, obedecendo a seguinte relação:

$$
\mathrm{H}\left(\mathrm{u}_{\mathrm{i}}\right)=\mathrm{G}\left(\mathrm{T}_{\left(\mathrm{x}_{\mathrm{i}}\right)}\right)=0
$$

O índice de confiabilidade é corretamente definido como a menor distância da origem à $\mathrm{H}\left(\mathrm{u}_{\mathrm{i}}\left(\mathrm{x}_{\mathrm{i}}\right)\right)=0$, onde $\mathrm{H}$ é a superfície de ruína.

$$
\beta=\min \sqrt{\left(\sum_{i=1}^{n} u_{i}^{2}\right)} \quad \text { com } \quad H\left(u_{i}\right) \leq 0
$$

O ponto de ruína mais provável, definido com o retorno das coordenadas ótimas no espaço normal padrão u para o espaço físico $\mathrm{x}$, é chamado de ponto de projeto $\mathrm{P}^{*}$.

\subsection{Métodos disponíveis para estimar a confiabilidade estrutural}

Recentemente, progressos substanciais têm sido feitos na estimativa da confiabilidade de estruturas sob incertezas, tendo sido consideradas várias configurações de sistemas estruturais. Algoritmos têm sido desenvolvidos para estimar a confiabilidade de elementos e de sistemas. Estes métodos geralmente podem ser agrupados em duas categorias: métodos analíticos que não utilizam geradores aleatórios e métodos de simulação, que utilizam geradores aleatórios.

Os métodos analíticos em geral incluem ou técnicas de sequências de ruínas ou configurações estáveis, probabilísticas ou determinísticas, ou técnicas de programação matemática. Através de métodos analíticos apresentam-se elegantes aproximações de manuseio de sistemas de problemas de confiabilidade. Um dos problemas desses métodos é que estruturas práticas apresentam numerosas sequências de ruína. A probabilidade computacional de sistemas de ruína envolve união e interseção de eventos de ruína múltiplos e apenas limites aproximados podem ser computados. Como exemplo dessa aproximação, os métodos "branch" e "bound" fornecem um procedimento sistemático e racional de identificar as várias sequências de ruína de uma estrutura. Eles envolvem duas operações principais, 
nomeadas "the branching operation" ou operação ramificada e "the bounding operation" ou operação fronteira ou limite.

$\mathrm{Na}$ operação ramificada inicia-se com uma estrutura intacta, e, baseado nas probabilidades de falha inicial dos elementos que compõem a estrutura, é imposto que a seção mais provável de ruína atinja seu estado limite último. Devido à hiperasticidade e consequente redistribuição dos esforços, no próximo passo iterativo, a seção mais provável de ruína pode mudar. Continua-se esse processo progressivamente até que a matriz de rigidez se torne singular e uma sequência de ruína completa seja obtida. A operação ramificada é realizada até que todas as combinações (sequências) possíveis de rupturas sejam realizadas. A presença de cargas permanentes associadas a diferentes cargas variáveis é computada pelo método ao formar uma sequência para cada caso de carga. Nesse método, os elementos podem ter diferentes probabilidades de ruína, as quais são atribuídas aos elementos naturalmente. Se um determinado elemento tem uma maior probabilidade de ruína, o mesmo conterá a seção de falha da estrutura em repetidas sequências.

Para tornar a operação ramificada mais eficiente, foi introduzida a operação fronteira ou de truncamento. Essa operação foi formulada para descartar as sequências de ruínas insignificantes comparando suas probabilidades de ruína com a probabilidade de ruína do sistema $\mathrm{P}_{\mathrm{f}}$, da qual já se conhece a princípio a ordem de grandeza. Para estruturas de barra, por exemplo, a priori estudam-se as possíveis combinações últimas de rótulas e verifica-se os possíveis caminhos de ruína. Colocando em ordem decrescente de probabilidade de ruína, a iésima sequência de ruína é ignorada se sua probabilidade de ruína satisfaz o seguinte critério:

$$
\mathrm{P}_{\mathrm{i}}<\gamma \mathrm{P}_{\mathrm{f}}
$$

onde $\gamma$ é um parâmetro escolhido baseado num grau de precisão desejado. Se $\mathrm{P}_{\mathrm{f}}$ é desconhecido, considera-se $\mathrm{P}_{\mathrm{f}}^{*}$ no seu lugar, onde $\mathrm{P}_{\mathrm{f}}^{*}$ é a máxima probabilidade de ruína estimada para o sistema. O carregamento é imposto da mesma forma que na operação ramificada, ressaltando apenas os carregamentos supostos mais críticos.

A precisão e eficiência das operações de fronteira dependem do quanto $\mathrm{P}_{\mathrm{f}}^{*}$ é próximo de $\mathrm{P}_{\mathrm{f}}$. Outras aproximações dessas operações são: a escolha do parâmetro $\gamma$ (introduz alguma arbitrariedade nos resultados); aproximação numérica da integral 
multinormal para estimar a união de probabilidade de eventos de ruína; e a confiabilidade do sistema estimada pode ser computada usando apenas aproximações de fronteira.

Na categoria de simulação, a média e a covariância da resposta juntas com a probabilidade de ruína de um cenário, são estimadas por simulação de um grande número de realizações. A necessidade do uso de modelos não-lineares complexos e o valor de probabilidade associada muito pequeno, da ordem de $10^{-3}$ à $10^{-6}$, muitas vezes impossibilita esse tipo de estudo em situações práticas. Entretanto, técnicas de simulação podem ser mais facilmente aplicadas para probabilidades pequenas se são aplicadas técnicas de redução da variância. Esse é o motivo pelo qual métodos de aproximações têm sido desenvolvidos e têm demonstrado sua eficiência em muitos problemas no campo da mecânica estrutural.

O método de simulação mais utilizado é o de Monte Carlo, o qual é robusto e produz uma estimativa única da probabilidade de ruína. Um grande número de aproximações tem sido desenvolvido usando uma versão básica simples desse método. Para sistemas estruturais práticos de confiabilidade, a simulação simples de Monte Carlo pode ser computacionalmente custosa e ineficiente, embora muitas vezes são utilizadas para aferir outros métodos. Para superar essas dificuldades, têm sido desenvolvidas estratégias de amostra por importância ("Importance Sample"). Amostra por importância é uma eficiente técnica de simulação a qual se baseia apenas em informações essenciais ao modelo.

Os métodos de confiabilidade estrutural (SRM) representam uma ferramenta para cálculo probabilístico de eventos que satisfazem certas condições impostas. Para ser possível usar SRM, a ocorrência do evento deve ser completamente dependente da resposta de um conjunto de variáveis aleatórias, ou seja, as variáveis básicas ou variáveis de projeto (X). Em seguida, deve ser possível descrever as condições sobre as quais os eventos ocorrem e o espaço do evento, usando um conjunto de funções de estado limite $(\mathrm{G}(\mathrm{X}))$, conectadas logicamente com uniões e interseções.

O primeiro passo para a aplicação de SRM é determinar as variáveis básicas, ou seja, as variáveis aleatórias que têm impacto significativo na probabilidade. Em seguida, estabelecem-se as funções de estado limite em termos de relações 
determinísticas entre as variáveis básicas, representando mecanismos casuais em diferentes modelos do sistema, que podem gerar o evento. A totalidade do espaço do evento é definida por uma combinação lógica de condições baseadas nas funções de estado limite. Finalmente, a incerteza referente ao evento é descrita em termos de uma distribuição de probabilidade ou densidade para cada uma das variáveis básicas. Se existem efeitos de correlação entre as variáveis, eles são descritos pelo uso de medidas de correlação com a covariância ou coeficientes de correlação.

A solução analítica de um problema de probabilidade é da forma:

$$
P_{f}=\int_{G(X) \leq 0} \ldots f_{X} f_{X}(x) d x
$$

onde $G(X)$ é a função de estado limite e $f_{X}(x)$ é a função de densidade de probabilidade conjunta das variáveis básicas representadas pelo vetor $\mathrm{X}$.

Quando se têm integrais complexas, muitas vezes a solução analítica da expressão (2.14) não é possível, situação que acontece na maioria dos problemas de engenharia estrutural. Para integrais complexas, em geral quando não há solução analítica, a expressão (2.14) é usualmente resolvida por dois caminhos: integrações numéricas utilizando Simulação de Monte Carlo ou Amostra por Importância por exemplo, e aproximações analíticas que calculam a probabilidade de ruína através do índice de confiabilidade utilizando métodos como o FORM (First Order Reliability Method) e o SORM (Second Order Reliability Method).

Segundo LI \& PHAM (1995), a maioria dos códigos de projeto onde aproximações de confiabilidade têm sido incorporadas baseia-se no método conhecido por Método de Segundo Momento de Primeira Ordem. Este método é tido como método de segundo momento por utilizar os dois primeiros momentos da estatística, ou seja, média e desvio padrão. É considerado de primeira ordem devido a superfície limite ser considerada linear. De acordo com esse método, a probabilidade de ruína da estrutura pode ser calculada por:

$$
P_{f}=P[G(R, S) \leq 0]=\phi\left(\frac{0-\mu_{G}}{\sigma_{G}}\right)=\phi(-\beta)
$$


onde $\mu$ e $\sigma$ significam, respectivamente, a média e o desvio padrão da variável aleatória; $\phi$ é a função de distribuição normal padrão; e $\beta$ é conhecido como índice de confiabilidade, o qual neste método é definido por:

$$
\beta=\frac{\mu_{\mathrm{G}}}{\sigma_{\mathrm{G}}}
$$

Se for assumido que ambos, o efeito de carga $\mathrm{S}$ e a resistência estrutural R, são variáveis log-normais, a equação (2.16) é expressa por:

$$
\beta=\frac{\ln \left(\frac{\mu_{\mathrm{R}}}{\mu_{\mathrm{S}}}\right)}{\sqrt{\mathrm{V}_{\mathrm{R}}^{2}+\mathrm{V}_{\mathrm{S}}^{2}}}
$$

onde $\mathrm{V}^{2}$ é variância da variável aleatória.

Em algumas situações particulares, é possível o cálculo direto da probabilidade de ruína , nessas situações o índice de confiabilidade pode facilmente ser obtido por:

$$
\beta=-\phi^{-1}\left(\mathrm{P}_{\mathrm{f}}\right)
$$

O método de integração numérica é a solução direta da integral multidimensional. Ele fornece bom resultado de acordo com a solução numérica da expressão exata da probabilidade de ruína. Consiste em integrar todo o domínio de ruína; a densidade de probabilidade conjunta é calculada para cada ponto de integração; a integração pode ser feita por interpolação linear ou quadrática entre os pontos armazenados.

$$
P_{\mathrm{f}}=\int_{\Omega_{\mathrm{f}}} \mathrm{f}_{\mathrm{X}_{1}, \mathrm{X}_{2}, \cdots, \mathrm{X}_{\mathrm{n}}}\left(\mathrm{x}_{1}, \mathrm{x}_{2}, \ldots, \mathrm{x}_{\mathrm{n}}\right) \mathrm{dx}_{1} \mathrm{dx}_{2} \ldots \mathrm{dx_{ \textrm {n } }}
$$

onde $\Omega_{\mathrm{f}}$ é o domínio de ruína.

Do ponto de vista prático este método em geral não é recomendado pois exige um alto custo computacional. Entretanto é um método útil para comparar resultados como forma de validação de modelos.

Os métodos clássicos de integração por simulação foram pesquisados em MOHAMED, A (1999). Eles são apenas outras alternativas para integração numérica que resulta na probabilidade de falha da estrutura. $\mathrm{O}$ procedimento consiste em inserir conjuntos de amostras no sistema e verificar que resultados cada um deles fornecem. Através desses resultados, sabe-se o número de eventos que estão no 
domínio de ruína e os que pertencem ao domínio de sucesso. Com esse número podese facilmente estimar a percentagem de ruína.

\subsubsection{Método de Simulação de Monte Carlo}

É um dos métodos de simulações mais utilizados, geralmente é o caminho para obter uma estimativa muito boa da probabilidade de ruína. O princípio é calcular a expectância matemática da variável aleatória I(X) definida em seguida:

$$
\begin{array}{r}
P_{f}=\int_{\Omega_{f}} f_{X}(x) d x=\int_{R^{n}} I(x) f_{X}(x) d x=E[I(X)] \\
I(x)=\left\{\begin{array}{lll}
1 & \text { se } & x \in \Omega_{f} \\
0 & \text { se } & x \notin \Omega_{f}
\end{array}\right.
\end{array}
$$

Repetindo as análises para um grande número de simulações $\mathrm{n}_{\mathrm{s}}$, a média empírica dos valores $\mathrm{I}(\mathrm{X})$ é um estimador de $\mathrm{P}_{\mathrm{f}}$. Significa que:

$$
\mathrm{P}_{\mathrm{f}} \cong \frac{1}{\mathrm{n}_{\mathrm{s}}} \sum_{\mathrm{r}=1}^{\mathrm{n}_{\mathrm{s}}} \mathrm{I}\left(\mathrm{x}^{\mathrm{r}}\right)
$$

e a variância da variável $\mathrm{I}(\mathrm{X})$ é dada por:

$$
\sigma^{2}(I(X)) \cong \frac{1}{n_{s}^{2}}\left[\left[\sum_{r=1}^{n_{s}} I\left(X^{r}\right)\right]^{2}-\sum_{r=1}^{n_{s}} I^{2}\left(X^{r}\right)\right]
$$

Este método necessita de um gerador aleatório. Em geral, para resolver uma probabilidade de ruína da ordem de $10^{-\mathrm{n}}$, o número de simulações não deve ser inferior a $10^{(\mathrm{n}+2)}$ a $10^{(\mathrm{n}+3)}$. Como se sabe, em estruturas em geral trabalha-se com probabilidades inferiores a $10^{-3}$, mostrando claramente que este tipo de método não é dos mais eficientes. É um método útil para aferir modelos, pois oferece boa precisão em suas aproximações.

\subsubsection{Método de Simulação utilizando Amostra por Importância}

A idéia do método de amostra por importância é de reduzir o número de simulações necessárias ao utilizar o método de simulação de Monte Carlo puro descrito acima. O método pode ser interpretado como um método de redução de variância.

A probabilidade de ruína é escrita na forma: 


$$
\begin{gathered}
P_{f}=\int_{R^{n}} I(v) \frac{f_{X}(v)}{h_{V}(v)} h_{V}(v) d v=E\left[I(V) \frac{f_{X}(v)}{h_{V}(V)}\right] \\
I(v)=\left\{\begin{array}{lll}
1 & \text { se } & v \in \Omega_{f} \\
0 & \text { se } & v \notin \Omega_{f}
\end{array}\right.
\end{gathered}
$$

Um estimador de $\mathrm{P}_{\mathrm{f}}$ pode ser:

$$
P_{f} \cong \frac{1}{n_{s}} \sum_{r=1}^{n_{s}} I\left(v^{r}\right) \frac{f_{X}\left(v^{r}\right)}{h_{V}\left(v^{r}\right)}
$$

onde $\mathrm{v}^{\mathrm{r}}$ é a r-ésima amostra do vetor de variáveis $\mathrm{V}$, definido em $\mathrm{R}^{\mathrm{n}}$, com a função de densidade $\mathrm{h}_{\mathrm{V}}(\mathrm{v})$ escolhida convenientemente. A variância da estimativa da probabilidade de ruína é:

$$
\sigma^{2}\left(P_{f}\right)=\frac{1}{n_{s}\left(n_{s}-1\right)} \sum_{r=1}^{n_{s}}\left[I\left(V^{r}\right) \frac{f_{X}\left(V^{r}\right)}{h_{V}\left(V^{r}\right)}-P_{f}\right]^{2}
$$

Na última década, muitos caminhos de amostra por importância têm sido desenvolvidos. Segundo DEY \& MAHADEVAN (1998), essas alternativas podem ser divididas em 4 categorias: métodos diretos, métodos atualizados, caminhos esféricos e caminhos adaptativos. Com exceção do caminho de amostra adaptativa, a maioria dos outros métodos das três primeiras categorias requerem conhecimento inicial das regiões de ruína. Esses algoritmos baseiam-se em alguma forma de pesquisa de gradiente para identificar as regiões importantes. Isso implica que a função de estado limite seja contínua e diferenciável sobre o domínio de ruína, que é uma restrição difícil de ser satisfeita. Além disso, para problemas que envolvem um grande número de variáveis aleatórias, caminhos esféricos tendem a ser ineficientes. Nos métodos de amostra por importância mencionados, no caso de estimar a confiabilidade, os componentes individuais do estado limite são definidos explicitamente numa função de forma fechada das variáveis aleatórias de entrada. Para grandes estruturas, definir igualmente o estado limite de ruína de cada componente individual pode ser uma tarefa difícil.

DEY \& MAHADEVAN (1998) propõem um método que supera as dificuldades listadas acima, e é computacionalmente eficiente. A proposta consiste em uma técnica híbrida, onde um simples caminho de enumeração é usado para 
identificar apenas uma das sequências de ruína significantes, a qual provém de uma suposição inicial do domínio de ruína do sistema. É usada uma técnica de amostra por importância adaptativa para modificar o domínio da amostra inicial para incluir o efeito de outras sequências de ruína significantes e estimar a probabilidade de ruína do sistema.

\subsection{Níveis de confiabilidade}

A classificação dos níveis de confiabilidade é dada de acordo com as informações obtidas da estrutura estudada. Quatro níveis têm sido mencionados na literatura:

Nível 1- Os métodos de confiabilidade que usam apenas um valor característico para cada parâmetro de incerteza, são chamados de Métodos de nível I. O método dos coeficientes parciais de segurança é o caso comhecido e tido como exemplo desse nível de confiabilidade.

Nível 2- São definidos como Métodos de nível II os procedimentos que utilizam dois valores característicos para cada parâmetro de incerteza (geralmente a média e o desvio padrão). Como exemplos pertencentes a esse grupo pode-se citar os métodos que estimam índices de confiabilidade sem computar as funções de probabilidade das variáveis de incerteza envolvidas.

Nível 3- Os métodos de confiabilidade que usam probabilidade de ruína como uma medida, admitindo ainda que as funções de probabilidade dos parâmetros de incerteza são conhecidas, são chamados de Métodos de nível III.

Nível 4- Os métodos de confiabilidade onde se compara o desempenho estrutural com os princípios da análise econômica da engenharia sobre incertezas considerando custos generalizados e os problemas éticos da vida, são chamados Métodos de nível $I V$. Portanto, representam uma união da otimização com a estatística, cheganto assim ao projeto ótimo considerando as incertezas das variáveis básicas.

\subsection{Combinação do método dos elementos finitos com}

A análise de confiabilidade de materiais e estruturas requer, ambos, um modelo relevante do comportamento mecânico (cenário de ruína, funções de desempenho ou 
função de estado limite) em torno de situações críticas, e um modelo eficiente de estimação da probabilidade de ruína.

Para considerar o modelo mecânico degradado (plasticidade, dano, ruptura, flambagem), baseado em relações da mecânica do continuo e na teoria de estruturas, o método dos elementos finitos (FEM), é correntemente a solução numérica adotada.

O FEM pode ser usado em análise de sensibilidade e de confiabilidade considerando como aleatórias algumas variáveis da matriz de rigidez e do vetor das ações. Isso é chamado método dos elementos finitos estocásticos (SFEM). Esse termo reune uma grande região de métodos de acordo com o tipo de análise almejada e se as equações são escritas num conjunto contínuo ou discreto. Uma breve introdução no SFEM pode ser vista em MACIAS (1994).

Uma outra possibilidade é utilizar um método de superfícies de respostas (RSM), que permite combinar um código de elementos finitos com uma estimação da probabilidade de ruína por métodos FORM e SORM ou simplesmente por algoritmos de otimização. O RSM também pode ser considerado como um SFEM.

\subsection{Pontos de projeto múltiplos em confiabilidade de primeira e segunda ordem}

De acordo com KIUREGHIAN \& DAKESSIAN (1998), pontos de projeto múltiplos em primeira e segunda ordem podem ser definidos da seguinte maneira:

Seja o ponto de projeto, designado por u ${ }^{*}$, solução do problema de otimização restrito,

$$
\min \{\|\mathrm{U}\| \backslash \mathrm{H}(\mathrm{U}) \leq 0\}
$$

onde $\mathbf{U}$ é o vetor das variáveis no espaço normal padrão obtido por transformação isoprobabilística das variáveis aleatórias originais, sendo $\mathrm{H}(\mathrm{U})$ a função de estado limite no espaço normal padrão.

Define-se o problema de confiabilidade no espaço reduzido tal que $\mathrm{H}(\mathrm{U}) \leq 0$ representa os eventos de ruína. Para resolver a equação (2.26), pode-se utilizar uma aproximação baseada em gradiente, começando de um ponto inicial $\mathbf{U}_{\mathbf{0}}$, a partir do qual uma sequência de pontos $\mathbf{U}_{\mathbf{i}}, \mathrm{i}=1,2, \ldots$, é gerada de acordo com a regra:

$$
\mathrm{U}_{\mathrm{i}+1}=\mathrm{U}_{\mathrm{i}}+\lambda_{\mathrm{i}} \mathrm{d}_{\mathrm{i}}
$$


onde $d_{i}$ é um vetor da direção procurada e $\lambda_{i}$ é o tamanho do passo. Os algoritmos para encontrar o valor final de $U$ diferem na escolha de $d_{i}$ e $\lambda_{i}$. Por exemplo, o algoritmo iHL-RF desenvolvido por Zhang e Der Kiureghian, appud KIUREGHIAN \& DAKESSIAN (1998), sugere

$$
\mathrm{d}_{\mathrm{i}}=\frac{1}{\left\|\nabla \mathrm{H}\left(\mathrm{U}_{\mathrm{i}}\right)\right\|^{2}}\left[\mathrm{U}^{\mathrm{T}} \nabla \mathrm{H}(\mathrm{U})-\mathrm{H}\left(\mathrm{U}_{\mathrm{i}}\right)\right] \nabla \mathrm{H}\left(\mathrm{U}_{\mathrm{i}}\right)-\mathrm{U}_{\mathrm{i}}
$$

onde $\nabla \mathrm{H}(\mathrm{U})$ é o gradiente da função de estado limite. O tamanho do passo $\lambda_{\mathrm{i}}$ é definido de maneira que a inequação $m\left(U_{i}+\lambda_{i} d_{i}\right)<m\left(U_{i}\right)$ seja satisfeita, onde $\mathrm{m}(\mathrm{U})$ é:

$$
\mathrm{m}(\mathrm{U})=\frac{1}{2}\|\mathrm{U}\|^{2}+\mathrm{c}|\mathrm{H}(\mathrm{U})|
$$

sendo c um parâmetro que satisfaz à condição c $>\|\mathrm{U}\| /\|\nabla \mathrm{H}(\mathrm{U})\|$ em cada passo.

Esse algoritmo é globalmente convergente, ou seja, a sequência é de convergência garantida para um ponto de distância mínima na superfície de estado limite, isto é valido se $\mathrm{H}(\mathrm{U})$ é contínuo e diferenciável. Entretanto, se o um problema de otimização for não convexo, não é garantido que o ponto solução seja um ponto de distância mínima global.

KIUREGHIAN \& DAKESSIAN (1998) define as soluções múltiplas da equação (2.26) como $\mathbf{U}^{*}$, $, i=1,2, \ldots$. Associado a cada solução, $\mathbf{U}^{*}$, define-se a distância $\beta_{\mathrm{i}}=\|\mathrm{U}\|$, que corresponde ao índice de confiabilidade. Esses pontos de mínimo locais, $\mathbf{U}_{\mathbf{i}}^{*}$, produzem medidas de importância relativas aos pontos de projeto: quanto menor é o $\beta_{\mathrm{i}}$, mais importante é o $\mathbf{U}_{\mathrm{i}}^{*}$. $\mathrm{O}$ ponto de projeto mais próximo da origem tem o menor $\beta_{\mathrm{i}}$, esse ponto é designado ponto de projeto global, representado por $\mathrm{P}^{*}$. Os outros pontos de projeto têm uma maior distância para a origem, e são designados pontos de projeto local.

Segundo KIUREGHIAN \& DAKESSIAN (1998), a existência de pontos de projeto múltiplos podem causar os seguintes problemas no FORM e no SORM:

$\checkmark$ O algoritmo de otimização pode convergir para um ponto de projeto local. Nesse caso, as soluções obtidas utilizando-se FORM ou SORM podem não convergir à região de contribuição dominante da integral de probabilidade de ruína, sendo inadequada portanto a aproximação correspondente. 
$\checkmark$ Se o ponto de projeto global for encontrado, poderá ter contribuição significativa para a integral de probabilidade de ruína da vizinhança dos pontos de projeto local. Aproximando-se a superfície de estado limite apenas ao ponto de projeto global, essas contribuições poderão não ser levadas em consideração.

Segundo KIUREGHIAN \& DAKESSIAN (1998), até o presente momento, não se dispõe de método confiável e eficiente para encontrar todas as soluções locais da equação(2.26), ou para apurar se a solução encontrada é o ponto de projeto global. Um procedimento possível e freqüentemente sugerido é repetir a análise com diferentes pontos iniciais, verificando-se que o mesmo ponto solução seja encontrado. Métodos de otimização global são usualmente heurísticos por natureza e dependem do tipo de estrutura.

Nos problemas de confiabilidade em que existem pontos de projeto múltiplos, em geral propõe-se métodos heurísticos para busca do ponto ótimo global. No artigo de KIUREGHIAN \& DAKESSIAN (1998) um método simples dessa categoria é sugerido para encontrar os pontos de projeto múltiplos.

\subsection{Estabelecendo distribuições de probabilidade}

Para o caso de se utilizar o SRM, considera-se que as condições representativas do evento sejam descritas deterministicamente por funções de estado limite e baseadas em conhecimentos do sistema. A incerteza do analista referente ao evento é expressa por distribuição de probabilidade para os parâmetros nas funções de estado limite das variáveis básicas.

Do ponto de vista bayesiano, uma distribuição de probabilidade representa uma descrição completa da incerteza do analista estimando uma quantidade.

A incerteza total do analista com respeito a quantidades específicas é quase sempre uma mistura de incertezas aleatórias com o conhecimento prévio que o analista tem sobre as variáveis envolvidas. O analista pode tirar proveito dessa mistura para reduzir as incertezas e estabelecer distribuições de probabilidade que representem com maior precisão as variáveis envolvidas.

Para estabelecer distribuições na prática, há várias aproximações possíveis, tais como as citadas a seguir.

Uma distribuição pode ser associada diretamente a variável, refletindo a 
incerteza do analista referente ao valor da quantidade.

$\checkmark$ Pode-se escolher um tipo padrão de distribuição, onde os parâmetros são associados na base de experiências ou julgamentos. Textos específicos e reconhecidos podem ser utilizados como suporte para a escolha de um tipo de distribuição.

$\checkmark$ Se existem dados suficientes, esses podem ser representados em forma de probabilidade, escolhendo-se a distribuição mais adequada. Os parâmetros são derivados dos dados.

$\checkmark$ Simulações de Monte Carlo podem ser uma ferramenta útil em situações caracterizadas por variáveis dependentes de interações com outras variáveis severamente aleatórias.

O uso de distribuições de probabilidade em SRM capacita o analista a dar uma descrição detalhada de seus conhecimentos sobre quantidades incertas. Não é possível dar uma descrição detalhada das incertezas se a descrição é restrita a termos de medidas centrais como expectância ou média, ou mesmo se são combinadas com medidas de dispersão, como variância, desvio padrão ou o coeficiente de variação. Visto que diferentes tipos de distribuições podem ter os mesmos valores esperados e variâncias, informação extra é necessária para a forma da função de distribuição de probabilidade. Abaixo listam-se exemplos de como informações desse tipo podem ser incluídas nas distribuições.

$\checkmark$ Algumas características de variáveis aleatórias podem recomendar o uso de certos tipos de distribuições. Essas características estão descritas na literatura, por exemplo em Benjamin, J.R. e Cornall, C.A. (1970) apud NILSEN et al. (1998).

$\checkmark$ Conhecimentos sobre a dispersão podem ser expressos diretamente na forma das funções de distribuição. Dessa maneira, conhecimentos podem indicar se a densidade é simétrica ou esconsa em toda a região de resposta, e se a densidade deve ser côncava, linear ou convexa em intervalos diferentes de resposta.

$\checkmark$ Limitações específicas como a geometria da estrutura, resultados provenientes de inspeções, podem resultar em variações abruptas ou intervalos com valor nulo para a densidade de probabilidade. Em geral, e se isso é permitido pela soma de 
informações, ponderações podem ser associadas ao conhecimento relativo na parte da distribuição que tem maior influência nos resultados.

\subsection{Modelos de incertezas versos modelos de imprecisão}

De acordo com COOPER (1998), aplicações irrestritas das regras básicas de incertezas matemáticas, como cálculo probabilístico, análises de intervalos, e sistemas vagos ou "fuzzy set", podem ser imprecisas, a menos que restrições matemáticas sejam impostas.

Segundo DEVOOGHT (1998), o desenvolvimento da análise de risco tem dado muita ênfase à avaliação de leis probabilísticas. Questões sobre intervalos de confiança conduzem naturalmente à quantificação da propagação de incertezas presentes nos dados. Entretanto, já se sabe há muito tempo que os modelos usados são imperfeitos e introduzem incertezas neles próprios.

Desde que a avaliação do risco seja baseada em modelos que refletem conhecimentos parciais e eventualmente suposições conflitantes, seus resultados têm sido combinados, levando em consideração o peso relativo dado por especialistas para cada modelo. O problema é fechado e vinculado a um conjunto de opiniões de especialistas. Assim, pode-se tratar o modelo de incerteza da mesma forma que o parâmetro de incerteza, atribui-se a um modelo $\mathrm{M}_{\mathrm{i}}$ uma 'probabilidade de correção' $\mathrm{P}\left(\mathrm{M}_{\mathrm{i}}\right)$ a partir de um trabalho bayesiano. Nesse tópico ainda não há consenso, desde que, assim como outros pesquisadores estimaram, há muitos casos onde a questão de correção ficou sem sentido.

Admite-se que um modelo é uma representação imperfeita utilizando idealizações direcionadas para atingir seus objetivos, ou seja, nem menos nem mais extensivo que necessário para suas propostas. Cada modelo tem suas aproximações, algumas conhecidas para seus usuários, outras não; de fato, deve-se ter em mente quando se procede com os conceitos de modelos de incerteza ou de imprecisão.

Os modelos empregados na engenharia são usualmente modelos de baixo nível caracterizados por assumirem um grande número de simplificações e a introdução de variáveis agregadas. Alguns desses modelos baseiam-se em referências físicas como o modulo de elasticidade, por exemplo. Ou seja, constantes relacionadas às propriedades que dependem mais propriamente da composição do material que de 
constantes universais. Essas constantes tendem ao estado reduzido de parâmetros quando não têm métodos conhecidos para encontrá-las preferindo-se confiar em experimentos.

O problema de definição de níveis de teorias é obscuro pelo fato que a solução atual das equações é usualmente obtida por algoritmos numéricos, os quais sempre usam um processo de restrição de operadores e de agregação ou discretização de variáveis. Os métodos de discretização são numerosos e têm como objetivo, em geral, a conservação de um conjunto de variáveis agregadas. A diferenciação entre as incertezas dos modelos e as suas imprecisões numéricas não são sempre claras, uma vez que muitos modelos são construídos de restrições de subconjuntos das variáveis.

Uma outra questão a ser levantada refere-se a suposição de boa precisão ao realizar o cálculo mecânico de uma estrutura utilizando métodos numéricos. Além das aproximações do próprio método, utiliza-se computador para fazer milhões de operações com 16 dígitos significativos, por exemplo, onde o conhecimento dos dados se limita a 2 ou 3 dígitos.

\subsection{Características estatísticas de variáveis de projeto}

Sabe-se que os valores médios e desvios padrões assim como o restante das características dos modelos probabilísticos adotados variam de acordo com o país ou a região que está sendo feita uma análise estatística da estrutura. Consciente disso, ao longo desse item cita-se algumas características estatísticas das variáveis de projeto, com o objetivo do leitor tomar conhecimento de alguns valores adotados na bibliografia.

Segundo JCSS - Background Documentation (1996), estruturas completas assim como componentes estruturais podem ser classificados de acordo com as consequências da ruína, sendo suficiente, em geral, uma classificação de acordo com a especificada abaixo:

1 - Consequências pequenas: risco de vida baixo e pequenas e desprezíveis consequências sociais (estruturas agrícolas, silos, torres, casas para uma família).

2 - Consequências moderadas: risco de vida médio e consideráveis consequências sociais (apartamentos residenciais, escritórios, prédios industriais). 
3 - Consequências grandes: risco de vida alto ou consequências sociais muito importantes (pontes principais, teatros, hospitais, escolas).

$\checkmark$ De maneira análoga, medidas de custo podem ser subdivididas em classes: baixa, moderada e alta.

As características estatísticas das variáveis de projeto estão apresentadas resumidamente nas Tabela 2.1 à Tabela 2.9 .

Tabela 2.1 - Índices de confiabilidade $(\beta)$ relacionados a vida do projeto. JCSS - Background Documentation (1996).

\begin{tabular}{|c|c|c|c|c|}
\hline \multirow{2}{*}{$\begin{array}{c}\text { Custo relativo de } \\
\text { medida de segurança }\end{array}$} & $\begin{array}{c}\text { Estado limite de } \\
\text { serviço (irreversível) }\end{array}$ & \multicolumn{3}{|c|}{ Estado limite último } \\
\hline & & Consequências esperadas para uma ruína \\
\cline { 3 - 5 } & & Pequena & Moderada & Grande \\
\hline Elevado & 1,0 & 2,8 & 3,3 & 3,8 \\
\hline Moderado & 1,5 & 3,3 & 3,8 & 4,3 \\
\hline Baixo & 2,0 & 3,8 & 4,3 & 4,8 \\
\hline
\end{tabular}

Tabela 2.2 - Caracterização de variabilidade de tempo de cargas. JCSS - Background Documentation (1996).

\begin{tabular}{|c|c|c|c|}
\hline Ação & Permanente & Variável & Acidental \\
\hline Probabilidade de ocorrência durante 1 ano & um & substancial & pequena \\
\hline Variabilidade no tempo & pequena & grande & Usualmente grande \\
\hline
\end{tabular}

Tabela 2.3 - Características estatísticas das variáveis. JCSS - Background Documentation (1996).

\begin{tabular}{|c|c|c|c|}
\hline Variável & Média $\mu$ & Desvio padrão $\sigma$ & Distribuição \\
\hline $\begin{array}{c}\text { Carga permanente } \\
\text { (peso próprio da estrutura) }\end{array}$ & $\mathrm{G}$ & $0,05 \mathrm{G}$ & Gauss \\
\hline $\begin{array}{c}\text { Carga permanente } \\
\text { (peso de componentes não-estruturais) }\end{array}$ & $\mathrm{G}$ & $\geq 0,05 \mathrm{G}$ & Gauss \\
\hline Ação variável & & & Gauss ou Gumbel $^{*}$ \\
\hline Ação acidental & & & $\begin{array}{c}\text { Determinada diretamente } \\
\text { do valor de projeto }\end{array}$ \\
\hline
\end{tabular}

Tabela 2.4 - Características estatísticas das variáveis. Comité Euro-Internacional du Beton.(1995).

\begin{tabular}{|c|c|c|c|c|c|c|}
\hline Variável & Distribuição & Média $\mu$ & $\begin{array}{c}\text { Desvio } \\
\text { padrão } \sigma\end{array}$ & $\begin{array}{c}\text { Variância } \\
\mathrm{V}(\%)\end{array}$ & $\overline{x_{k}}$ & Fractil \% \\
\hline $\begin{array}{c}\mathrm{f}_{\mathrm{c}}(\mathrm{MPa}) \\
\mathrm{f}_{\mathrm{ct}}=0,25 \mathrm{f}_{\mathrm{c}}^{2 / 3} \\
\mathrm{E}_{\mathrm{c}}=9500 \mathrm{f}_{\mathrm{c}}^{1 / 3}\end{array}$ & Log-normal & $\mathrm{f}_{\mathrm{ck}}+8$ & 5 & ----- & $f_{c k}$ & 5 \\
\hline $\begin{array}{l}\mathrm{f}_{\mathrm{y}}(\mathrm{MPa}) \\
\mathrm{A}_{\mathrm{s}}\left(\mathrm{cm}^{2}\right)\end{array}$ & $\begin{array}{l}\text { Log-normal } \\
\text { Normal }\end{array}$ & $\begin{array}{c}f_{y k}+60 \\
\text { nom } A_{s}\end{array}$ & $\begin{array}{c}30 \\
----\end{array}$ & 2,5 & $\mathrm{f}_{\mathrm{yk}}$ & $\begin{array}{c}5 \\
50\end{array}$ \\
\hline $\begin{array}{l}\mathrm{h}, \mathrm{b}(\mathrm{mm}) \\
\mathrm{c}(\mathrm{mm})\end{array}$ & $\begin{array}{l}\text { Normal } \\
\text { Normal }\end{array}$ & $\begin{array}{l}\text { nom } b \\
\text { nom } c+5\end{array}$ & $\begin{array}{l}5 \\
5\end{array}$ & $\begin{array}{l}--- \\
---\end{array}$ & $\begin{array}{l}{ }_{n+m} b \\
\text { nom } c\end{array}$ & $\begin{array}{l}50 \\
50\end{array}$ \\
\hline $\begin{array}{c}\text { Carga permanente, } G \\
\left(\mathrm{kN} / \mathrm{m}^{2}\right)\end{array}$ & Normal & nom $G$ & 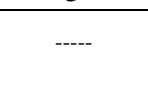 & 10 & nom $G$ & 50 \\
\hline $\begin{array}{l}\text { Carga móvel, Q } \\
\left(\mathrm{kN} / \mathrm{m}^{2}\right)\end{array}$ & Normal & $\mathrm{Q}_{\mathrm{k}} / 1,824$ & --- & 40 & $\mathrm{Q}_{\mathrm{k}}$ & 98 \\
\hline
\end{tabular}


Tabela 2.5 - Características estatísticas das variáveis. Proposta informal Institute Français de Mecanique Avanceé (IFMA). LEMAIRE (1998).

\begin{tabular}{|c|c|c|c|}
\hline Variável & Média $\mu$ & Desvio padrão $\sigma$ & Distribuição \\
\hline Carga permanente & $\mathrm{G}$ & $0,08 \mathrm{G}$ & Gauss ou log-normal \\
\hline Carga não-permanente & $\mathrm{Q}$ & 0,15 à $0,20 \mathrm{Q}$ & Gumbel \\
\hline $\begin{array}{c}\text { Resistência à compressão do } \\
\text { concreto }\end{array}$ & $\mathrm{f}_{\mathrm{cm}}$ & $0,12 \mathrm{f}_{\mathrm{cm}}$ & Normal ou Log-normal \\
\hline Resistência do aço & $\mathrm{f}_{\mathrm{ym}}$ & $0,06 \mathrm{f}_{\mathrm{ym}}$ & Normal ou Log-normal \\
\hline Geometria, $\mathrm{b}_{\mathrm{w}}$ & $\mathrm{b}_{\mathrm{w}}$ & 0,50 à $1,00 \mathrm{~cm}$ & Normal ou Log-normal \\
\hline Geometria, $\mathrm{h}$ & $\mathrm{h}$ & 0,50 à $1,00 \mathrm{~cm}$ & Normal ou Log-normal \\
\hline Geometria, distância ao CG, $\mathrm{Y}_{\mathrm{m}}$ & $\mathrm{Y}_{\mathrm{m}}$ & $\pm 2 \mathrm{~cm}$ & Uniforme \\
\hline
\end{tabular}

Tabela 2.6 - Características estatísticas das variáveis². FRANGOPOL et al. (1996)

\begin{tabular}{|c|c|c|c|c|}
\hline Variáveis aleatórias & $\begin{array}{c}\text { Valor } \\
\text { nominal }\end{array}$ & $\begin{array}{c}\text { Valor } \\
\text { médio }\end{array}$ & $\begin{array}{c}\text { Desvio } \\
\text { padrão }\end{array}$ & $\begin{array}{c}\text { Tipo de } \\
\text { distribuição }\end{array}$ \\
\hline Resistência de concreto máxima f $\mathrm{c}_{\mathrm{c}}^{\prime}(\mathrm{MPa})$ & 24.1 & 24.8 & 2.97 & Log-normal \\
\hline Resistência do aço $\mathrm{f}_{\mathrm{y}}(\mathrm{MPa})$ & 344.8 & 384.1 & 27.2 & Log-normal \\
\hline Modulo de elasticidade do aço $\mathrm{E}_{\mathrm{s}}(\mathrm{MPa})$ & 200.000 & 200.000 & 2.600 & Log-normal \\
\hline $\begin{array}{c}\text { Dimensão da seção transversal } \\
\mathrm{b}(\mathrm{cm}), \mathrm{d}(\mathrm{cm})\end{array}$ & ------- & $\begin{array}{c}\text { Nominal } \\
+0.152\end{array}$ & 0.635 & Normal \\
\hline $\begin{array}{c}\text { Cobrimento do concreto }(\mathrm{cm}) \\
\text { Erro do modelo }\end{array}$ & ------- & $\begin{array}{c}\text { Nominal } \\
+0.762\end{array}$ & 0.422 & Normal \\
\hline Força axial P $(\mathrm{kN})$ & 1.00 & 1.00 & 0.07 & Normal \\
\hline Momento fletor $\mathrm{M}(\mathrm{kN})$ & -------- & $\overline{\mathrm{P}}$ & $0.15 \overline{\mathrm{P}}$ & Log-normal \\
\hline
\end{tabular}

Tabela 2.7 - Aplicação a pórtico de concreto com 3 colunas e 6 vigas. SANG-HYO \& SEONG-WON (1997).

\begin{tabular}{|c|c|c|c|}
\hline Variável & Média $\mu$ & Desvio padrão $\sigma$ & Distribuição \\
\hline Carga permanente, ação horizontal & $\mathrm{G}$ & $0,25 \mathrm{G}$ & Gauss \\
\hline Modulo de elasticidade E, coluna & $200000\left(\mathrm{~kg} / \mathrm{cm}^{2}\right)$ & $0,10 \mathrm{E}$ & Log-normal \\
\hline Inércia I, coluna & $100000\left(\mathrm{~cm}^{4}\right)$ & $0,10 \mathrm{I}$ & Log-normal \\
\hline Modulo de elasticidade E, viga & $200000\left(\mathrm{~kg} / \mathrm{cm}^{2}\right)$ & $0,10 \mathrm{E}$ & Log-normal \\
\hline Inércia I, viga & $150000\left(\mathrm{~cm}^{4}\right)$ & $0,10 \mathrm{I}$ & Log-normal \\
\hline
\end{tabular}

Tabela 2.8 - Aplicação a treliça com 11 barras horizontais e 12 barras inclinadas. SANG-HYO \& SEONG-WON (1997).

\begin{tabular}{|c|c|c|c|}
\hline Variável & Média $\mu$ & Desvio padrão $\sigma$ & Distribuição \\
\hline Carga permanente, ação horizontal & $\mathrm{G}$ & $0,15 \mathrm{G}$ & $\begin{array}{c}\text { Tipo-I- } \\
\text { Largest }\end{array}$ \\
\hline $\begin{array}{c}\text { Modulo de elasticidade E, barras } \\
\text { principais }\end{array}$ & $2100000\left(\mathrm{~kg} / \mathrm{cm}^{2}\right)$ & $0,10 \mathrm{E}$ & Log-normal \\
\hline $\begin{array}{c}\text { Área A, barras principais } \\
\text { Modulo de elasticidade E, barras } \\
\text { diagonais }\end{array}$ & $21000000\left(\mathrm{~kg} / \mathrm{cm}^{2}\right)$ & $0,10 \mathrm{E}$ & Log-normal \\
\hline Área A, barras diagonais & $10\left(\mathrm{~cm}^{4}\right)$ & $0,10 \mathrm{~A}$ & Log-normal \\
\hline
\end{tabular}

${ }^{2}$ Extraídas de Mirza e MacGregor (1979), Mirza e Skrabek (1991), Diniz (1994), Ide (1995) e Iwaki (1996), entre outros, apud FRANGOPOL et al. (1996). 
Tabela 2.9 - Características estatísticas de cargas e resistências. SAKAMOTO et al. (1997).

\begin{tabular}{|c|c|c|c|}
\hline Variável & Média $\mu$ & Covariância & Distribuição \\
\hline Resistência & $\beta=2,5$ & 0,15 & Log-normal \\
\hline Carga permanente & $\mu_{\mathrm{D}}$ & 0,10 & Log-normal \\
\hline Carga não-permanente & $0,5 \mu_{\mathrm{D}}$ & 0,40 & Log-normal \\
\hline Ação do vento & $0,25-2,50 \mu_{\mathrm{D}}$ & 0,47 & Log-normal \\
\hline
\end{tabular}

\subsection{Uniformidade do índice de confiabilidade}

Diferentemente da grande maioria dos trabalhos pesquisados, onde em geral estimam-se índices de confiabilidade para estruturas predefinidas, FRANGOPOL; IDE; SPACONE; IWAKI. (1996) apresentam variação nas variáveis de projeto para índices de confiabilidade pré-estabelecidos. Dá-se nesse trabalho um enfoque diverso quando confrontado com outros discutidos aqui, porém bastante próxima de uma das metodologias desenvolvidas.

Através de uma análise determinística, Frangopol define superfícies de ruína para colunas de concreto armado curtas e para colunas esbeltas. As colunas são discretizadas em várias camadas com propriedades dependentes de sua história. Três casos diferentes de cargas aplicadas são examinados: aplicando carga axial e momento fletor simultaneamente; aplicando carga axial e momento fletor seqüencialmente e nessa ordem; aplicando carga axial e momento fletor sequencialmenten na ordem inversa. Na análise considera-se coluna de seção retangular sujeita à flexão uniaxial.

O software MCREL (Monte Carlo based reliability analysis) é utilizado para estimar os índices de confiabilidade de colunas de concreto armado sujeitas a cargas aleatórias. As superfícies de ruína das colunas foram definidas deterministicamente pelos autores no inicio do artigo. Portanto, a definição de superfície de ruína não vai possibilitar que se leve em conta corretamente as não-linearidades física e geométrica.

O algoritmo proposto para a obtenção dos contornos de isoconfiabilidade consiste em: assumem-se valores médios para a solicitação axial e para o momento fletor de primeira ordem. Com esses valores médios e desvios padrão predeterminados, utilizando um gerador aleatório, gera-se um valor para a força axial, $\mathrm{P}$, e o momento, M.. Verificando-se em seguida se a excentricidade e $=\mathrm{M} / \mathrm{P}$ 
coincide com $\mathrm{e}_{\mathrm{u}}=\mathrm{M}_{\mathrm{u}} / \mathrm{P}_{\mathrm{u}}$ (momento, $\mathrm{M}_{\mathrm{u}}$, e força axial de ruína, $\mathrm{P}_{\mathrm{u}}$, obtidos na análise da coluna de concreto armado), ou seja, verifica se $M_{m}$ e $P_{m}$ (valores médios) estão na mesma direção que os esforços últimos, ou de ruína. Caso e $\neq \mathrm{e}_{\mathrm{u}}$, adota -se outro valor para $v$ ( $v$ é a relação excentricidade sobre altura da seção transversal) e reiniciase o processo. Caso contrário, verifica se a solicitação axial é inferior à solicitação última; caso não seja, incrementa-se uma unidade no contador de insucessos. Então, se este ponto não é um ponto de ruína, verifica se o coeficiente de variação da amostra gerada até o momento satisfaz o predeterminado, pois este pode ser o critério de convergência adotado para a simulação de Monte Carlo. Calcula-se o índice de confiabilidade $\beta$ caso a amostra já tenha um tamanho suficiente. Ou seja, verifica se $\mathrm{COV}<\mathrm{COV}^{*}$, que é o critério de convergência para a simulação de Monte Carlo, onde $\mathrm{COV}^{*}$ é prescrito, sendo o valor do coeficiente de variação da resposta estrutural. Um valor utilizado para $\mathrm{COV}^{*}$ pode ser 0,15 . Este valor não tem fundamentação teórica, mas é um valor bastante utilizado, sendo considerado razoável. Até esse ponto é um processo usual de cálculo de índice de confiabilidade baseado em simulação, mas como Frangopol desejava determinar pares de valores médios que gerassem uma confiabilidade prescrita, $\beta^{*}$, continua o procedimento até que o $\beta$ encontrado seja igual ao $\beta$ prescrito, dentro de um erro tolerável. Assumindose vários valores iniciais de $\mathrm{M}_{\mathrm{m}}$ e $\mathrm{P}_{\mathrm{m}}$, determina-se uma superfície de confiabilidade para pares $\mathrm{MxN}$. Considerando-se diferentes valores de confiabilidade pré estabelecidos, constróem-se superfícies de confiabilidade para pares $\mathrm{MxN}$. Em seu trabalho, Frangopol et al. traçou varias superfícies de confiabilidade para índice $\beta=$ 1,$5 ; 2,5$ e 3,5 dentre os seus exemplos.

$\mathrm{Na}$ análise discutida acima, considera-se apenas solicitações como variáveis aleatórias, que se refere, na sua maior parte, ao trabalho anterior do autor (FRANGOPOL et al.,1996), onde são apresentados vários resultados para essas incertezas. No trabalho discutido, poucos resultados são apresentados considerando outras variáveis como incertezas. Na realidade, além das cargas, as dimensões e as propriedades dos materiais podem ser consideradas como variáveis aleatórias; além disso, há ainda incertezas associadas às imperfeições do modelo utilizado, entre outras. Pode-se levar em consideração todas as incertezas no procedimento descrito 
acima, bastando considerá-las como variáveis aleatórias na simulação de Monte Carlo.

Algumas das conclusões tiradas desse trabalho particular:

$\checkmark$ A confiabilidade de colunas de concreto armado pode ser computada unindo um programa de análise estrutural com um software de simulação de Monte Carlo. Podem ser incluídos na análise de confiabilidade não-linearidades dos materiais e geométricas, caminhos de carga e efeitos de correlação de cargas.

$\checkmark$ A confiabilidade de colunas de concreto armado pode ser dependente dos caminhos da carga. Por exemplo, o domínio de segurança associado a um caso de carregamento sequencial onde o momento fletor é aplicado primeiro, seguido da aplicação da força axial, é menor que o associado a um caso de carregamento proporcional ou ao associado a um caso de carregamento sequencial onde a força axial é aplicada primeiro e depois o momento fletor é aplicado.

$\checkmark$ A confiabilidade de colunas de concreto armado depende da correlação de cargas.

$\checkmark$ Para desenvolver uma análise baseada em confiabilidade mais uniforme e consistente em colunas de concreto armado, devem ser incorporados caminhos de cargas e efeitos de correlação de cargas. O desenvolvimento de técnicas eficientes baseadas em confiabilidade para respostas estruturais dependentes do caminho das cargas, especialmente no caso de colunas esbeltas, deve continuar.

O procedimento para traçar curvas de isoconfiabilidade proposto em FRANGOPOL; IDE; SPACONE; IWAKI. (1996) pode ser brevemente resumido da seguinte forma:

$$
\left\{\begin{array} { l } 
{ X _ { m } , \sigma } \\
{ X _ { u } }
\end{array} \Rightarrow \begin{array} { l } 
{ \text { geração } } \\
{ \text { aleatória } }
\end{array} \Rightarrow \left\{\begin{array}{l}
X \\
X_{u}
\end{array} \Rightarrow \operatorname{cov}<\operatorname{cov} * \Leftrightarrow \beta=\frac{\mu_{r}-\mu_{s}}{\sqrt{\sigma_{r}^{2}+\sigma_{s}^{2}}}\right.\right.
$$

onde:

$\mu_{\mathrm{r}}=$ média dos esforços resistentes, podendo ser a solicitação última definida pela superfície de ruína ou de ruptura da estrutura;

$\mu_{\mathrm{s}}=$ média dos esforços solicitantes, calculado pela média da amostra de esforços;

$\sigma_{\mathrm{r}}=$ desvio padrão dos esforços resistentes, podendo ser nulo se for definido um único valor limite na direção de $\mathrm{M}_{\mathrm{m}}$ e $\mathrm{P}_{\mathrm{m}}$; 
$\sigma_{\mathrm{s}}=$ desvio padrão dos esforços solicitantes, calculado pela média da amostra de esforços.

Neste procedimento, se $\beta=\beta^{*}$, o valor de $X_{m}$ é um ponto da curva de isoconfiabilidade.

Uma associação do procedimento proposto em FRANGOPOL; IDE; SPACONE; IWAKI. (1996) com o processo estocástico desenvolvido no Capítulo 4 dessa tese apresenta-se a seguir; onde utiliza-se a definição do $\beta$ duas vezes e trabalha-se com apenas uma amostra de cada vez, da seguinte forma:

$$
\left\{\begin{array} { l } 
{ X _ { m } , \sigma } \\
{ X _ { u } }
\end{array} \Rightarrow \begin{array} { l } 
{ \text { geração } } \\
{ \text { aleatória } }
\end{array} \Rightarrow \left\{\begin{array}{l}
X \\
X_{u}
\end{array} \Rightarrow \operatorname{cov}<\operatorname{cov}^{*} \Leftrightarrow \beta=\frac{\mu_{r}-\mu_{s}}{\sqrt{\sigma_{r}^{2}+\sigma_{s}^{2}}}\right.\right.
$$

onde:

$\mu_{\mathrm{r}}=$ média das solicitações últimas;

$\mu_{\mathrm{s}}=$ solicitação a ser determinada, solicitação última com uma probabilidade predefinida de ocorrência;

$\sigma_{\mathrm{r}}=$ desvio padrão das solicitações últimas;

$\sigma_{\mathrm{s}}=$ desvio padrão da solicitação a ser determinada; como esta solicitação é uma incógnita, pois parte-se de um $\beta$ conhecido, não há desvio padrão, então $\sigma_{\mathrm{s}}$ é nulo.

Se forem introduzidos coeficientes no cálculo das estruturas de tal forma que a resposta estrutural coincida com o $\mu_{\mathrm{s}}$ da expressão acima, obtêm-se coeficientes redutores para materiais, ou majoradores para solicitações, resultando em estruturas seguras com solicitações últimas pertencendo a curvas de isoconfiabilidade, que é o objetivo dos pesquisadores. Utiliza-se novamente a expressão de $\beta$, que passa a ser incógnita, e, supondo por exemplo que a resistência do concreto é a única variável aleatória do problema, as outras variáveis passam a ser:

$\mu_{\mathrm{r}}=$ média da amostra de resistência do concreto;

$\mu_{\mathrm{s}}=$ resistência determinada no passo anterior, resistência com uma probabilidade predefinida de ocorrência;

$\sigma_{\mathrm{r}}=$ desvio padrão da amostra de resistência do concreto;

$\sigma_{\mathrm{s}}=$ desvio padrão da resistência determinada no passo anterior, como esta resistência é um valor isolado, não é uma amostra, não ha desvio padrão, então $\sigma_{\mathrm{s}}$ é nulo.

A etapa do trabalho referente à calibração do coeficiente parcial do concreto $\gamma_{c}$ (calibração estocástica de coeficientes parciais, em parte desenvolvida com o raciocínio descrito acima) pode ser explicitada em termos probabilísticos com as 
seguintes expressões:

$$
\text { Função de estado limite : } \mathrm{G}\left(\mathrm{P}_{\mathrm{u}\left(\mathrm{f}_{\mathrm{c}}^{*}\right)}-\mathrm{P}_{\mathrm{adm}}\right)
$$

onde $\mathrm{f}_{\mathrm{c}}{ }^{*}$ é a resistência de cálculo do concreto à compressão de cálculo proposta, $\mathrm{P}_{\mathrm{u}} \mathrm{e}$ a solicitação última proposta para essa resistência de cálculo e $\mathrm{P}_{\mathrm{adm}}$ é a resistência admissível para essa resistência de cálculo proposta.

$$
\begin{gathered}
\text { se } \quad P_{u\left(f_{c}\right)}=P_{a d m} \rightarrow f_{c}=f_{c}^{*} \\
P_{f}=\operatorname{Prob}\left(G\left(P_{u\left(f_{c}^{*}\right)}-P_{a d m}\right) \leq 0\right)=\phi(-\beta) ; \quad P_{a d m} \rightarrow P_{a d m}^{*} \quad \backslash \quad \beta=\beta^{*}
\end{gathered}
$$

\subsection{Resumo da pesquisa}

Na revisão bibliográfica realizada, observou-se que há muitas pesquisas em administração de risco baseado em confiabilidade, novos modelos para definir risco ou quantificar risco, confiabilidade em estruturas nucleares e químicas, confiabilidade em sistemas de computador, em peças mecânicas sujeitas a cargas cíclicas, sistemas de reparação, muitos modelos baseados em ETA e FTA, ainda há muitos trabalhos envolvendo confiabilidade em materiais compósitos. Foram poucos os casos examinados que utilizaram algoritmos genéticos, redes neurais e "fuzzy sets”. Uma parte da pesquisa pode ser vista no Gráfico 2.2 e no Gráfico 2.3.

No Anexo A estão indicados alguns trabalhos recentes, com breve resumo de suas características. 


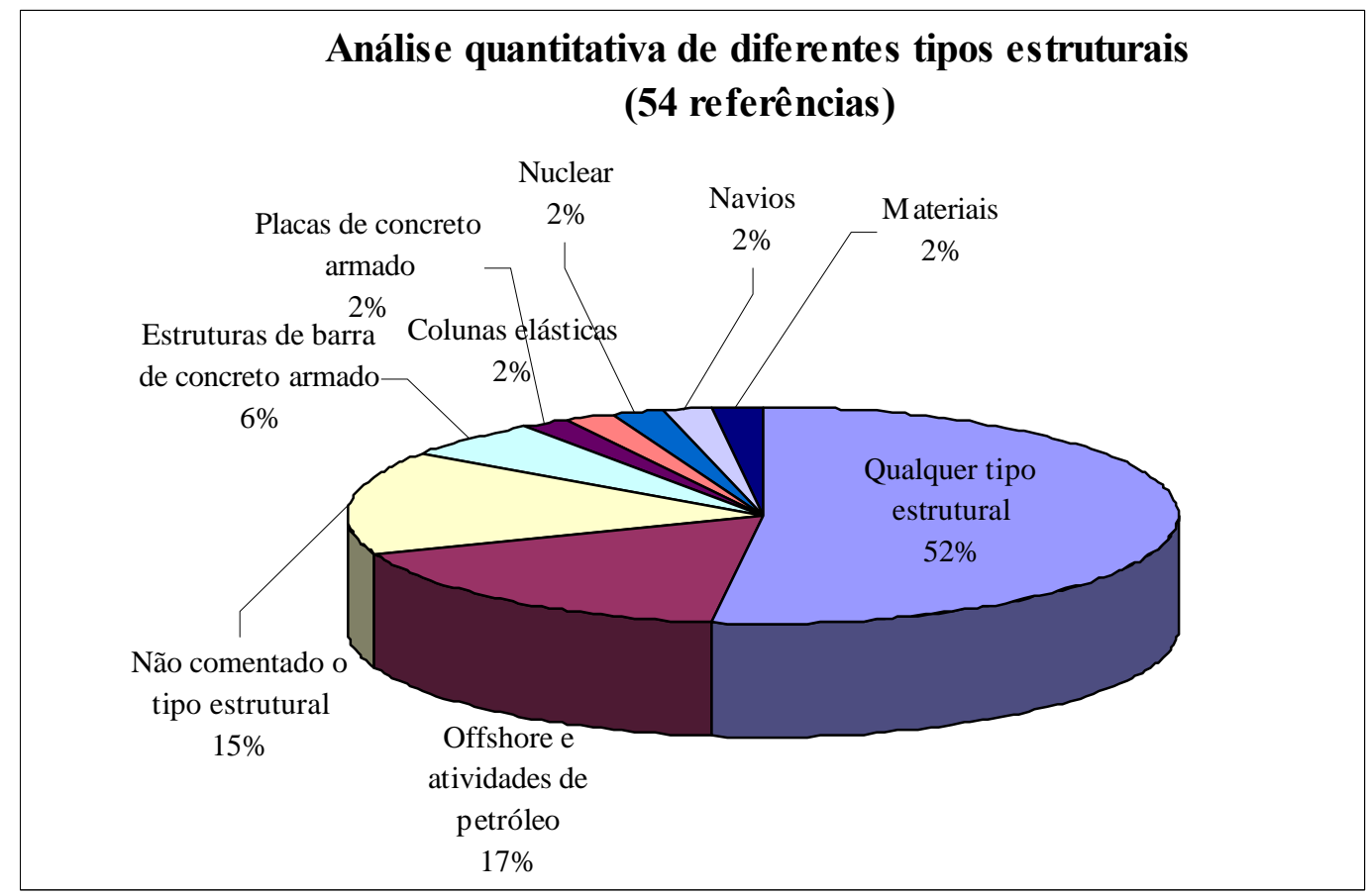

Gráfico 2.2 Tipos estruturais observados em parte da pesquisa

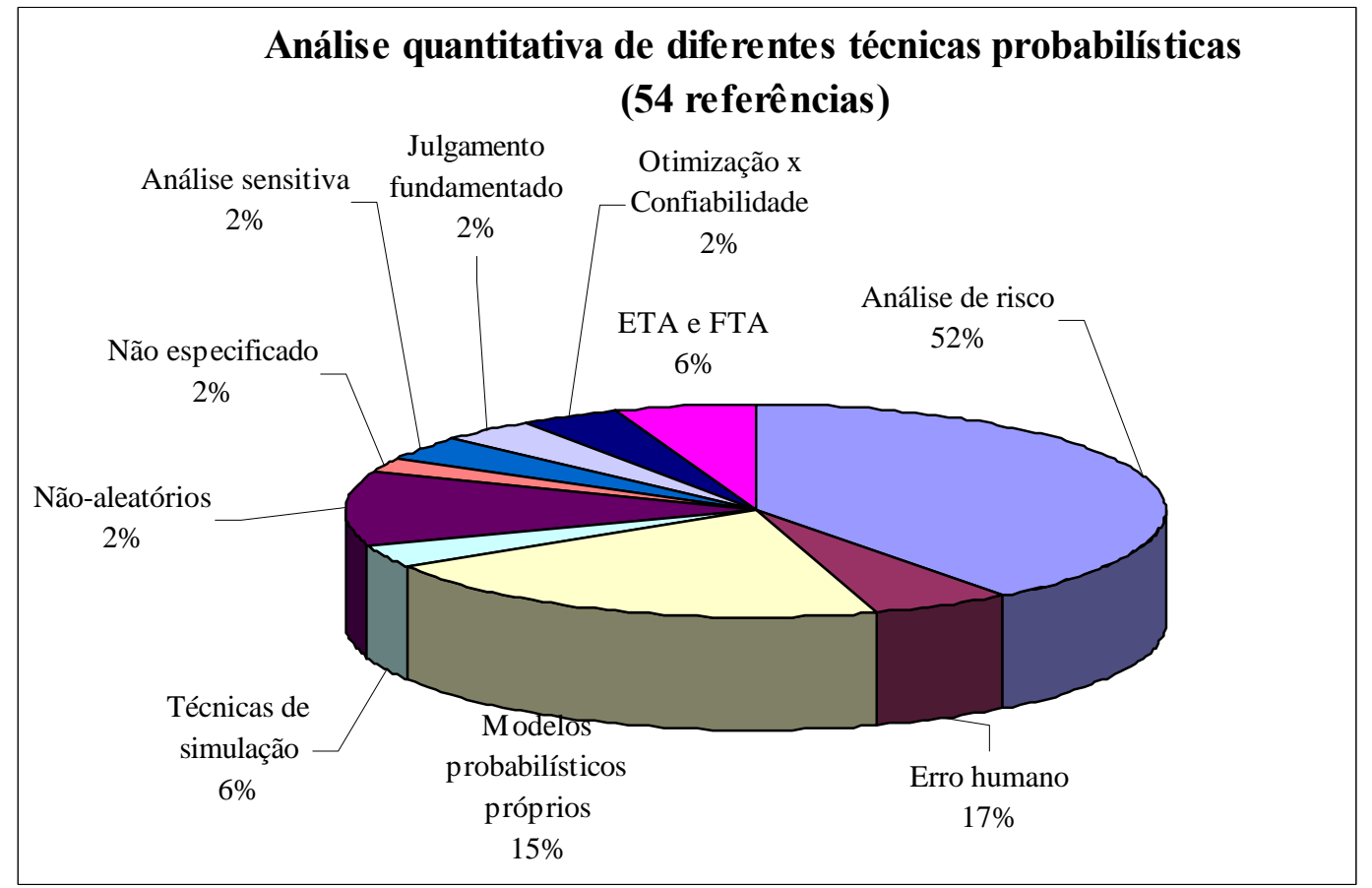

Gráfico 2.3 Modelos probabilísticos observados em parte da pesquisa 


\section{Capítulo 3 Modelos mecânicos para pórticos de concreto armado}

A incorporação dos conceitos probabilísticos nas variáveis de cálculo de estruturas não faz sentido sem o emprego de um modelo mecânico que represente com bastante precisão a resposta da estrutura. Portanto, no desenvolvimento desse trabalho foi realizado um estudo do comportamento mecânico de estruturas, em particular para pórticos planos, procurando aquele que melhor o represente.

No cálculo das estruturas de edifícios altos compostas por pórticos, é necessário uma boa modelagem da estabilidade global, pois a estrutura é solicitada simultaneamente por ações verticais e horizontais. De fato, as ações adicionais provenientes do deslocamento horizontal da estrutura ${ }^{3}$ podem ocasionar o aparecimento de acréscimos de esforços capazes de conduzi-la ao colapso. Esse tipo de análise, onde se considera o equilibrio da estrutura em sua posição deslocada, é o que se denomina análise com não-linearidade geométrica.

Por outro lado, o projetista deve levar em conta que o comportamento do material constituinte da estrutura, no caso do concreto armado há vários modelos que podem ser utilizados. O efeito da fissuração, da fluência, o escoamento das armaduras, bem como outros fatores conferem a esse material composto um comportamento claramente não-linear, caracterizando a chamada não-linearidade física.

Deve-se, portanto, ter à disposição um modelo mecânico que permite considerar a estrutura na sua configuração final de equilibrio, determinada pela nãolinearidade geométrica (NLG) e pela não-linearidade física (NLF) do material que a constitui.

\footnotetext{
${ }^{3}$ Os deslocamentos horizontais podem ser devidos à assimetria na geometria da estrutura ou no carregamento, a imperfeições geométricas ou a outros fatores diversos da ação horizontal.
} 


\subsection{Efeitos de segunda ordem}

Pode-se dizer, de modo simples, que os efeitos devidos à não-linearidade geométrica são aqueles oriundos da mudança de posição da estrutura no espaço. Esses efeitos são determinados através de uma análise, onde se considera a estrutura na sua configuração final de equilíbrio.

Nas estruturas rígidas esses efeitos são pequenos e podem ser desprezados; entretanto, nas estruturas flexíveis, tais efeitos passam a ser significativos devendo ser obrigatoriamente considerados.

As Normas mais modernas de projetos de estruturas de concreto armado já incorporam em suas prescrições diferentes métodos de análise em segunda ordem. Para avaliar esses efeitos em pórticos planos de concreto armado de edifícios de andares múltiplos têm-se procedimentos bastante simplificados, métodos do tipo PDelta, e modelos mais preciso ou métodos elaborados.

Nos métodos P-Delta pretende-se, de forma mais simples, fazer uma análise de segunda ordem. A estabilidade de um pórtico depende principalmente da interação entre as forças verticais e os deslocamentos laterais, que afetam as colunas e as vigas. Sendo assim, quando se analisam pórticos com métodos P-Delta têm-se resultados mais precisos do que se fossem analisados como colunas isoladas considerando apenas os deslocamentos dos andares.

Nos métodos P-Delta, os efeitos da não-linearidade geométrica são considerados através da aplicação das forças horizontais equivalentes produzidas pela interação do carregamento vertical na estrutura lateralmente deslocada. Os efeitos da não-linearidade física são usualmente considerados usando-se valores adequados para a rigidez (EI) equivalente dos elementos. Sendo assim, esses tipos de análises podem ser utilizados a partir de pequenas modificações da análise linear. Basta elaborar um processo iterativo utilizando um software de análise linear introduzindo incremento nas cargas oriundo dos efeitos de segunda ordem.

Salienta-se, entretanto, que tais métodos são bastante simplificados, podendo inclusive levar a resultados insatisfatórios dependendo do grau de deslocabilidade da estrutura. Esses métodos são de fácil implementação computacional, além disso o engenheiro pode facilmente determinar os esforços e deslocamentos da estrutura, 
assim como analisar os resultados.

Nos métodos elaborados se exige para uma análise não-linear mais precisa, a inclusão da não-linearidade geométrica, da não-linearidade física do material e dos efeitos reológicos. A automatização e solução do problema, levando-se em conta todos esses efeitos, ainda não representa uma prática corrente da engenharia. Além da dificuldade de automatizar um modelo mais preciso para a análise não-linear, são poucos os engenheiros que teriam condições de utilizar e avaliar seus resultados. Além dessas dificuldades, formulações mais elaboradas apresentam custo computacional mais elevado, uma vez que são iterativos ou incrementais-iterativos, e exigem análise mais minuciosas que demanda tempo que um engenheiro do meio técnico usualmente não dispõe.

Segundo o ACI 318-89, para pórticos deslocáveis, devido aos grandes efeitos na estabilidade causados pelos deslocamentos laterais dos nós, o projeto de barras de pórticos deverá ser baseado nos esforços solicitantes majorados obtidos de uma análise em segunda ordem considerando a não-linearidade do material, fissuração, efeitos das curvaturas das barras, inclinação lateral, duração do carregamento, retração, deformação lenta e interação com as fundações dos apoios. Nessa análise deverão ser apresentados resultados respaldados por experimentos. Para obterem-se resultados precisos de deslocamentos e esforços de segunda ordem, deve-se dar ênfase a valores realísticos das rigidezes das barras.

Sendo o problema de natureza não-linear, não é válido o princípio da superposição de efeitos, uma vez que passam a não mais existir relações lineares entre ações e deslocamentos na estrutura. Como conseqüência, chega-se à conclusão de que, pelo menos de uma forma imediata, tornar-se-ia inviável a utilização do método dos deslocamentos na análise de pórticos planos em teoria de segunda ordem.

$\mathrm{O}$ artifício normalmente utilizado para contornar o problema consiste na substituição do cálculo não-linear por uma sucessão de cálculos lineares em que, no decorrer de cada etapa de análise, as características não-lineares de que depende o problema são mantidas constantes para, posteriormente, com base nos resultados obtidos, serem modificadas e utilizadas no passo seguinte, viabilizando-se, dessa forma, o método dos deslocamentos. 
Deve-se acrescentar apenas que são usualmente dois os tipos de técnicas para essa análise: as iterativas e as incrementais-iterativas. Nesse trabalho em particular, é utilizado um processo incremental-iterativo, onde o cálculo linear é repetido tantas vezes quantas forem necessárias até que, em dois passos consecutivos, os resultados obtidos sejam os mesmos, a menos de um erro admissível.

Um modelo simples e razoavelmente preciso para estruturas pouco deslocáveis, que é o caso da maioria dos pórticos de concreto armado de edifícios, é a concepção da NLG através de matrizes de rigidez incrementais, como as apresentadas em CORRÊA (1991). Essas matrizes podem ser obtidas através da primeira e segunda derivadas da energia de deformação do elemento. Podendo apresentar resultados tão aproximados quanto se deseje, ou quanto menos termos do seu funcional sejam eliminados. Nessa formulação, deve-se computar a influência das deformações acumuladas até o incremento anterior. Quando a estrutura está sujeita a grandes rotações, para melhorar as aproximações pode-se utilizar a formulação lagrangiana atualizada.

Uma outra possibilidade é utilizar um modelo que utiliza coordenadas corrotacionais, que fornece resultados mais precisos no caso de grandes deslocamentos e rotações. Esse modelo foi o adotado no presente trabalho e será comentado no decorrer do capítulo.

\subsubsection{Implementação dos efeitos de segunda ordem utilizando matrizes incrementais}

Para implementação desse modelo, pode-se utilizar um processo incremental iterativo, ou mesmo apenas iterativo, onde é utilizada a matriz tangente para determinar os deslocamentos nodais, acelerando a convergência ao equilíbrio final; para verificar o equilíbrio utiliza-se a matriz secante. A transferência de energia de um incremento para o próximo é feita através de um vetor de forças normais internas acumuladas. A convergência do processo é verificada pelas normas euclidianas dos deslocamentos e das forças aplicadas. No caso de busca da solicitação última, são extrapolados os incrementos de carga até atingir a instabilidade global da estrutura, que é verificada pela singularidade da matriz de rigidez. $\mathrm{O}$ sistema de coordenadas a ser adotado é o lagrangiano, que pode ser atualizado a cada incremento de carga, ou 
simplesmente desenvolver todo processo sem atualizar as coordenadas. As matrizes assim como o desenvolvimento do método podem ser vistos em CORRÊA (1991).

\section{Implementação do processo}

$$
\mathrm{F}_{\text {incremento }}=\frac{\mathrm{F}_{\text {externa }}}{\mathrm{n}_{\text {incremento }}}
$$

$\checkmark \quad$ Inicia o processo incremental (i é o índice do incremento)

$$
\Delta \mathrm{F}^{\mathrm{t}}=\mathrm{F}_{\text {incremento }} \rightarrow \mathrm{F}_{\text {acumulada }}{ }^{\mathrm{i}}=\mathrm{F}_{\text {acumulada }}{ }^{\mathrm{i}}+\Delta \mathrm{F}^{\mathrm{i}}
$$

$\checkmark$ Início do processo iterativo (t é o índice da iteração)

$$
\begin{gathered}
\mathrm{R}_{\mathrm{t}\left(\Delta \mathrm{U}^{\mathrm{j}}\right)}^{\mathrm{j}} \rightarrow \operatorname{det}=\mid \mathrm{R}_{\mathrm{t}\left(\Delta \mathrm{U}^{\mathrm{j}}\right) \mid}^{\mathrm{j}} \quad\left\{\begin{array}{lll}
\operatorname{det} \leq 0 & \therefore & \text { instabilidade } \\
\operatorname{det}>0 & \therefore & \text { ok }
\end{array}\right. \\
\Delta \mathrm{U}^{\mathrm{j}+1}=\left(\mathrm{R}_{\mathrm{t}}^{\mathrm{j}}\right)^{-1} \cdot \Delta \mathrm{F}^{\mathrm{j}} \rightarrow \quad \mathrm{U}^{\mathrm{j}+1}=\mathrm{U}^{\mathrm{j}}+\Delta \mathrm{U}^{\mathrm{j}+1} \quad \rightarrow \quad \mathrm{F}_{\text {int }}^{\mathrm{j}+1}=\mathrm{R}_{\mathrm{S}}^{\mathrm{j}+1} \cdot \mathrm{U}^{\mathrm{j}+1} \\
\Delta \mathrm{F}^{\mathrm{j}+1}=\mathrm{F}_{\text {acum }}{ }^{\mathrm{j}+1}-\mathrm{F}_{\text {int }}^{\mathrm{j}+1} \rightarrow \mathrm{EI}_{\left(\mathrm{M}^{\mathrm{j}+1}, \mathrm{~N}^{j+1}, \mathrm{U}^{j+1}\right)} \\
\operatorname{erro}_{\mathrm{u}}^{\mathrm{j}+1}=\frac{\left\|\Delta \mathrm{U}^{\mathrm{j}+1}\right\|}{\left\|\mathrm{U}^{\mathrm{j}+1}\right\|} ; \quad \operatorname{erro}_{\mathrm{f}}^{\mathrm{j}+1}=\frac{\left\|\Delta \mathrm{F}^{\mathrm{j}+1}\right\|}{\left\|\mathrm{F}_{\text {ext }}\right\|}
\end{gathered}
$$

$\checkmark$ Se os erros em esforço e deslocamento satisfazem a uma tolerância preestabelecida, final do processo iterativo

$$
\mathrm{X}^{\mathrm{i}+1}, \mathrm{Y}^{\mathrm{i}+1}=\mathrm{X}^{\mathrm{i}}+\mathrm{U}^{\mathrm{j}+1}(\mathrm{x}), \mathrm{Y}^{\mathrm{i}}+\mathrm{U}^{\mathrm{j}+1}(\mathrm{y})
$$

$\checkmark \quad \mathrm{Se} \mathrm{F}_{\mathrm{acum}}=\mathrm{F}_{\mathrm{ext}}$, fim do processo incremental.

Onde: F: ação externa;

n: número de incrementos;

$\mathrm{R}_{\mathrm{T}}$ : matriz de rigidez tangente;

$\mathrm{R}_{\mathrm{S}}$ : matriz de rigidez secante;

$\mathrm{U}$ : deslocamento nodal;

EI: rigidez do elemento finito.

$\mathrm{O}$ procedimento descrito anteriormente pode ser realizado com apenas um incremento, desse modo, o algoritmo degenera para o processo iterativo. A seguir mostram-se graficamente os processos iterativo e incremental-iterativo. 


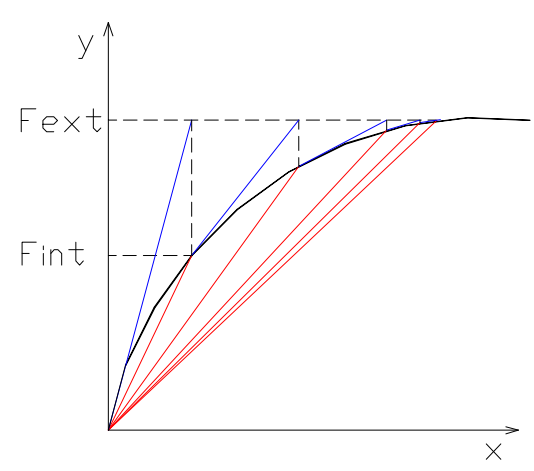

Gráfico 3.1 - Processo iterativo

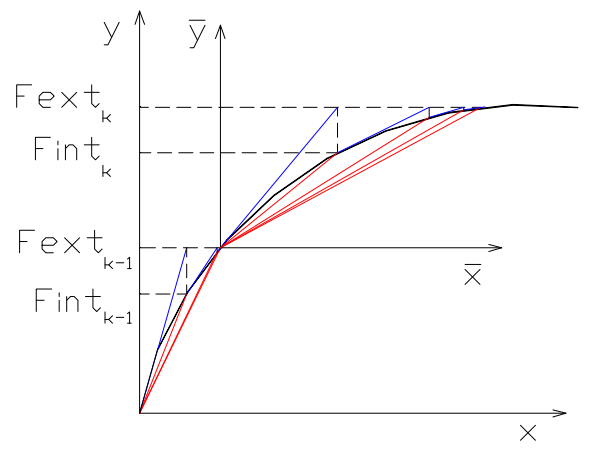

Processo incremental-iterativo

\subsubsection{Efeitos de Segunda ordem utilizando sistema de coordenadas corrotacionais}

O desenvolvimento teórico apresentado neste item foi baseado no texto apresentado em SILVA (1995). Salienta-se também que este foi o modelo não-linear geométrico adotado na versão final para modelagem mecânica do STST, nome designado ao software mecânico-confiabilístico desenvolvido nesta tese.

O desenvolvimento do modelo foi feito dentro da formulação Lagrangeana Parcialmente Atualizada, utilizando um sistema de coordenadas naturais ou corrotacionais, obtendo-se assim, de forma consistente, as equações incrementais de equilíbrio, o vetor das forças nodais internas e a matriz de rigidez tangente de um elemento finito de barra no espaço 2D para pórticos planos.

$\mathrm{Na}$ formulação Lagrageana as coordenadas dos elementos finitos não são atualizadas no processo incremental iterativo, enquanto que na Lagrageana Atualizada essas coordenadas são atualizadas em cada iteração. A idéia da formulação Lagrageana Parcialmente Atualizada é atualizar as coordenadas dos elementos finitos apenas a cada incremento. Para isso assume-se que a diferença entre as configurações de duas iterações consecutivas seja pequena, limitando portanto o tamanho dos elementos finitos.

A principal diferença entre o sistema de coordenadas corrotacionais e o cartesiano é que, ao contrário do segundo, o primeiro é solidário ao elemento, ou seja, acompanha a sua deformada.

Como simplificações, limitações e hipóteses assumidas para o modelo tem-se:

$\checkmark$ Pequenas deformações.

$\checkmark$ Pequenas rotações, da ordem de grandeza da raiz quadrada do valor absoluto da 
deformação. Essa aproximação não impede a ocorrência de grandes curvaturas, desde que os elementos finitos sejam suficientemente curtos.

$\checkmark$ Grandes deslocamentos desde que a estrutura seja bem discretizada e a carga dividida em um número suficiente de incrementos. O objetivo é fazer com que as deformações entre duas iterações consecutivas sejam praticamente as mesmas.

$\checkmark$ Hipótese cinemática de Heuler-Bernoulli-Navier: "seções transversais planas e ortogonais ao eixo da barra permanecem planas, indeformáveis e ortogonais ao eixo, após a deformação". Desta forma, a única deformação relevante a a deformação longitudinal.

O procedimento adotado exige pouco tempo de processamento, além de levar a resultados mais precisos, pois tal modelo permite grandes deslocamentos e curvaturas, desde que as discretizações geométrica e temporal sejam suficientemente refinadas. Isso é essencial para este trabalho ou qualquer outro que introduza estatística em conjunto com análise não-linear de estruturas.

Embora no tipo de estrutura estudado nesta tese as rotações e deslocamentos sejam limitados em geral pela não-linearidade física, que usualmente não permite grandes rotações e deslocamentos quando comparados com a análise não-linear geométrica isolada, optou-se por um modelo de concepção dos efeitos de segunda ordem que forneça resultados precisos, mesmo que seja limitado a passos de carga não grandes e elementos finitos de tamanho pequeno. Essa decisão permite generalizar o software desenvolvido, sem qualquer prejuízo quanto à precisão e ao custo computacional.

Considera-se o elemento linear dado na Figura 3.1, onde os graus de liberdade no sistema Cartesiano global são $\mathrm{p}_{\mathrm{i}}, \mathrm{i}=1, \ldots, 6$, enquanto $\mathrm{q}_{1} \mathrm{q}_{2}$ e $\mathrm{q}_{3}$ representam as medidas de deslocamentos no sistema corrotacional $x^{*}\left(q_{1}\right.$ é a deformação axial, $q_{2} e$ $\mathrm{q}_{3}$ representam as rotações nas extremidades das barras omitindo a movimentação de corpo rígido $\theta_{0}$ ). Os valores $\mathrm{u}^{\ell}, \mathrm{w}^{\ell}$ e $\theta^{\ell}$ são as componentes de deslocamento no sistema cartesiano local $\mathrm{x}_{\mathrm{k}}$. 


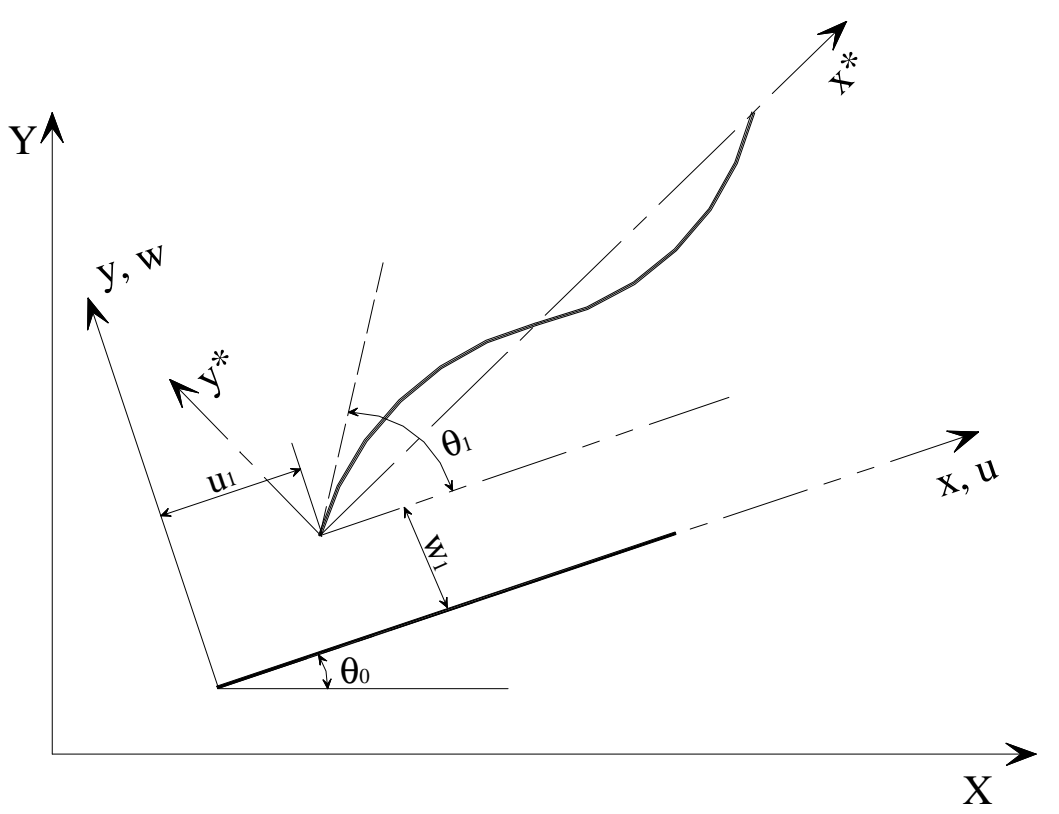

Figura 3.1 Variáveis e sistema de coordenadas

As relações entre o sistema de coordenadas natural ou corrotacional, $\mathrm{q}_{\alpha}$, e as coordenadas Cartesianas na forma incremental é dada por:

$$
\mathrm{dq}_{\alpha}=\mathrm{Bdp}_{\mathrm{i}}
$$

Onde $\mathrm{B}=\mathrm{q}_{\alpha, \mathrm{i}}$ é a matriz tangente de incidência cinemática.

A derivada segunda das coordenadas naturais , $\mathrm{q}_{\alpha}$, é conveniente representada pelas matrizes $\mathbf{G}$, tal como:

$$
G_{\alpha}=q_{\alpha, i j}=\frac{\partial q_{\alpha}}{\partial p_{i} \partial p_{j}}
$$

Adotando-se uma aproximação linear para o deslocamento axial $u$, aproximação cúbica para o deslocamento transversal w e função de forma quadrática para a rotação $\theta$, obtém-se a componente de deformação normal na direção $\mathrm{x}$, escrita em termos de deslocamentos naturais $\mathrm{q}_{\alpha}$.

Depois de descrever as relações entre os sistemas de coordenadas, o Princípio dos Trabalhos Virtuais pode ser adotado para fornecer a seguinte equação:

$$
\partial \mathrm{w}_{\mathrm{i}}=\mathrm{P}_{\mathrm{i}} \delta \mathrm{p}_{\mathrm{i}}=\int_{-\mathrm{L}_{\mathrm{b}} / 2}^{\mathrm{L}_{\mathrm{b}} / 2} \int_{\mathrm{A}_{\mathrm{r}}} \sigma \delta \varepsilon \mathrm{dA}_{\mathrm{b}} \mathrm{dx}_{\mathrm{b}}
$$

Escrevendo a variação de deformação $\delta \varepsilon$ no sistema de coordenadas Cartesiano, tem-se: 


$$
\delta \varepsilon=\varepsilon_{, \alpha} \mathrm{q}_{\alpha, i} \delta \mathrm{p}_{\mathrm{i}}
$$

Através de (3.4) e (3.3) obtém-se:

$$
P_{i}=\int_{-L_{b} / 2}^{L_{b} / 2} \int_{A_{r}} \sigma \varepsilon_{, \alpha} q_{\alpha, j} d A_{b} d x_{b}=Q_{\alpha} q_{\alpha, j}
$$

onde $\mathrm{Q}_{\alpha}$ representa as forças internas no sistema de coordenadas naturais ou corrotacionais, dado por:

$$
\mathrm{Q}_{\alpha}=\int_{-\mathrm{L}_{\mathrm{b}} / 2}^{\mathrm{L}_{\mathrm{b}} / 2} \int_{\mathrm{A}_{\mathrm{r}}} \sigma \varepsilon_{, \alpha} \mathrm{dA}_{\mathrm{b}} \mathrm{dx}_{\mathrm{b}}
$$

Efetuando a derivada de (3.5) com relação a $\mathrm{p}_{\mathrm{j}}$, pode-se escrever a matriz de rigidez tangente do elemento nas coordenadas Cartesianas.

$$
\begin{aligned}
& \mathrm{K}_{\mathrm{ij}}=\frac{\partial \mathrm{P}_{\mathrm{i}}}{\partial \mathrm{p}_{\mathrm{j}}}= \\
& \mathrm{q}_{\alpha, \mathrm{i}} \int_{-\mathrm{L}_{\mathrm{b}} / 2}^{\mathrm{L}_{\mathrm{b}} / 2} \int_{\mathrm{A}_{\mathrm{r}}} \frac{\partial \sigma}{\partial \varepsilon} \varepsilon_{, \gamma} \varepsilon_{, \alpha} \mathrm{dA}_{\mathrm{b}} \mathrm{dx} \mathrm{x}_{\mathrm{b}} \mathrm{q}_{\gamma j}+\mathrm{q}_{\alpha, \mathrm{i}} \int_{-\mathrm{L}_{\mathrm{b}} / 2}^{\mathrm{L}_{\mathrm{b}} / 2} \int_{\mathrm{A}_{\mathrm{r}}} \sigma \varepsilon_{, \alpha \gamma} \mathrm{dA} \mathrm{A}_{\mathrm{b}} \mathrm{dx} \mathrm{x}_{\mathrm{b}} \mathrm{q}_{\gamma, \mathrm{j}}+\mathrm{Q}_{\alpha} \mathrm{G}_{\alpha}
\end{aligned}
$$

onde o primeiro termo representa a matriz de rigidez linear padrão e os demais são os termos complementares devido aos efeitos geométricos.

De acordo com a hipótese cinemática de Euler-Bernoulli, a componente de deformação normal definida na direção $\mathrm{x}, \varepsilon_{\mathrm{x}}$, é a única que apresenta valor diferente de zero. Definindo o alongamento do elemento por $\lambda=\mathrm{L}_{\mathrm{f}} / \mathrm{L}_{\mathrm{b}}$, a definição geral de deformação é dada por:

$$
\varepsilon_{\mathrm{m}}=\frac{\lambda^{2 \mathrm{~m}}-1}{2 \mathrm{~m}}
$$

onde $\mathrm{L}_{\mathrm{b}}$ e $\mathrm{L}_{\mathrm{f}}$ representam os comprimentos inicial e final do elemento.

O par conjugado energeticamente adotado foi a deformação Linear e a tensão Nominal ou de Engenharia. Para essa deformação, faz-se $m=1 / 2$ em (3.8). Nesse contexto, a componente normal do tensor de deformações medida ao longo do eixo da barra é dada por:

$$
\varepsilon_{\mathrm{x}}=\frac{\Delta \ell}{\ell_{0}}=\varepsilon=\sqrt{1+2 \frac{\mathrm{du}}{\mathrm{dx}}+\left(\frac{\mathrm{du}}{\mathrm{dx}}\right)^{2}+\left(\frac{\mathrm{dw}}{\mathrm{dx}}\right)^{2}}-1
$$

Aplicando-se as relações deformação-deslocamento no campo de deslocamento local, definido em função apenas dos graus de liberdade naturais, obtém-se as 
deformações de engenharia objetivas, que são invariantes sob movimentos de corpo rígido. Os deslocamentos de corpo rígido são considerados através de uma transformação entre o sistema de coordenadas Cartesiano, que descreve a configuração indeformada, e o sistema de coordenadas corrotacional, que descreve a configuração deformada.

As equações acima foram encontradas assumindo-se o comportamento do material elástico. Para considerar o comportamento não-linear do concreto e do aço, deve ser considerado para ambos os materiais relações constitutivas próprias.

$\mathrm{O}$ critério de não-linearidade para o concreto é especificado em termos de tensões e deformações para cada ponto, enquanto que para o aço é associado para cada camada correspondente às armaduras. Portanto, pode-se obter as forças internas totais somando a resultante do concreto obtida por integração numérica do campo de tensões sobre a seção transversal com a resultante do aço. Esses valores podem ser utilizados para construir as relações momento-curvatura. $\mathrm{O}$ método das camadas pode ser utilizado para aproximar a integral das tensões ao longo da seção transversal. Seguindo este caminho, as forças internas são dadas por:

$$
\begin{gathered}
\mathrm{M}_{\mathrm{x}}=\mathrm{b}_{\mathrm{w}} \int_{-\mathrm{h} / 2}^{\mathrm{h} / 2} \sigma_{\mathrm{x}}^{\mathrm{c}} \mathrm{ydy}+\sum_{\mathrm{k}=1}^{\mathrm{Ns}} \sigma_{\mathrm{x}}^{\mathrm{sk}} \mathrm{A}_{\mathrm{sk}} \mathrm{y}_{\mathrm{sk}} \\
\mathrm{N}=\mathrm{b}_{\mathrm{w}} \int_{-\mathrm{h} / 2}^{\mathrm{h} / 2} \sigma_{\mathrm{x}}^{\mathrm{c}} \mathrm{dy}+\sum_{\mathrm{k}=1}^{\mathrm{Ns}} \sigma_{\mathrm{x}}^{\mathrm{sk}} \mathrm{A}_{\mathrm{sk}}
\end{gathered}
$$

onde $\sigma_{\mathrm{x}}^{\mathrm{c}}$ representa a componente de tensão normal de cada ponto da seção transversal, $\sigma_{\mathrm{x}}^{\mathrm{sk}}$ é a tensão no aço em uma camada localizada na posição $\mathrm{y}_{\mathrm{sk}}, \mathrm{A}_{\mathrm{sk}}$ representa a área da camada de aço e $\mathrm{N}_{\mathrm{s}}$ é o número de camadas de aço.

A implementação em linguagem de programação da formulação descrita nesse item foi iniciada por Pinto, R.S. (aluno de doutorado do departamento de estruturas da EESC-USP) tendo continuidade no presente trabalho. Maiores detalhes da formulação pode ser visto em SILVA (1995).

\subsection{Não-linearidade física}

$\mathrm{Na}$ análise estrutural dos edifícios de concreto armado, é importante que os deslocamentos laterais sejam avaliados precisamente. Isso porque, os efeitos de segunda ordem devidos aos deslocamentos horizontais da estrutura só podem ser 
corretamente avaliados se a configuração geométrica final for determinada de modo satisfatório.

Uma vez que os deslocamentos laterais resultantes de uma análise estrutural são diretamente afetados pela rigidez dos membros constituintes da estrutura, deve-se estimar essa rigidez através de processos que considerem a não-linearidade física dos materiais empregados na estrutura.

Entretanto, a consideração da NLF pode-se tornar uma tarefa trabalhosa e difícil de ser implementada em estruturas de concreto armado de grande porte. Isso porque, geralmente, emprega-se nesse tipo de análise um procedimento incremental e iterativo no qual, para cada nível de carregamento da estrutura, a rigidez dos elementos estruturais é estabelecida a partir das relações constitutivas dos materiais e da disposição de armadura no elemento. Portanto, para cada seção transversal do elemento, corresponderá um valor do produto de rigidez EI diferente, em função do nível de solicitação, da quantidade e disposição de armadura desta seção. Devido a essas dificuldades, vários vários métodos simplificados foram propostos para a determinação do produto de rigidez efetivo $\left(\mathbf{E I}_{\mathbf{e f}}\right)$ a ser considerado para os diferentes elementos estruturais. Um estudo de propostas de rigidez equivalente apresenta-se em PINTO (1997).

Neste trabalho, inicialmente pretendia-se utilizar inércia equivalente para os elementos finitos. Tais modelos podem levar a custos computacionais menores com bons resultados, tanto para o estado limite último quanto para o estado limite de utilização, além da facilidade de compreensão no meio técnico. Porém, verificou-se que, em alguns casos (estruturas com maior grau de hiperasticidade), o custo computacional foi elevado evidenciando que o processo não é adequado. Além disso, para acoplar o modelo mecânico com o de confiabilidade, é necessário trabalhar diretamente nas leis constitutivas do material, pois as aleatoriedades das resistências dos materiais são inseridas nas representações tensão-deformação. O modelo implementado, baseado nas relações constitutivas dos matérias em tensãodeformação demonstrou ter rápida convergência para todas as estruturas analisadas. A partir desse modelo mecânico, pode-se mais facilmente implementar a parte estatística das variáveis. O acoplamento dos modelos mecânicos e de confiabilidade, 
a fim de tornar-se um modelo mecânico-probabilístico, será visto em capítulos posteriores.

\subsubsection{Modelo baseado em inércia equivalente}

Como mencionada, a possibilidade de se utilizar um modelo baseado em inércia equivalente foi implementada e testada. Nesse caso, trabalha-se diretamente com a relação momento-força normal-curvatura.

O elemento finito de barra com seus respectivos graus de liberdade considerado é apresentado na Figura 3.2. Por simplicidade, porém sem perda de generalidade, apresenta seção transversal retangular, com a respectiva armadura posicionada em faixas.

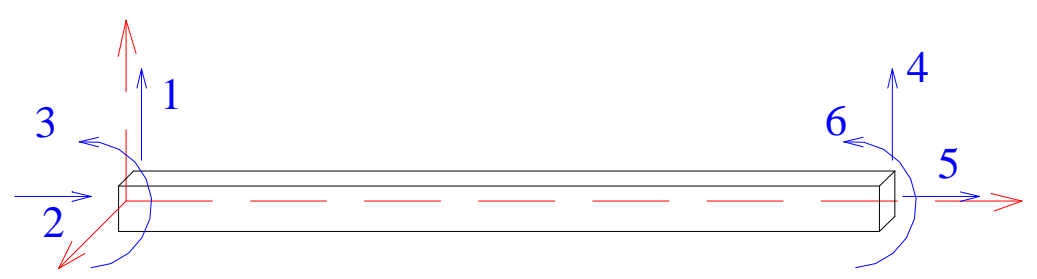

Figura 3.2 Elemento finito de barra

Para esse elemento finito determinam-se as curvaturas nas extremidades em função do esforço normal e do momento fletor. Portanto, é possível calcular curvaturas para as extremidades do elemento, no entanto existe a necessidade de se estabelecer uma curvatura única que será utilizada ao longo do elemento. Essa curvatura única ou equivalente foi considerada a curvatura média do elemento. Existem regiões no interior do elemento finito que não se encontram fissuradas. Essas regiões promovem um certo enrijecimento do elemento finito, fazendo com que a curvatura média do elemento seja inferior àquela obtida nas extremidades. Segundo o CEB, a determinação de valores médios para a flexão composta 'é difícil de se definir no presente estágio de conhecimento'. Porém, com uma subdivisão adequada da rede de elementos esse problema pode ser eliminado.

Ghali e Favre (1986) propõem a utilização da curvatura média para a flexão composta utilizando um coeficiente de interpolação $\zeta$ proposto pelo CEB para a flexão simples. Com esse coeficiente é feita uma interpolação entre as curvaturas nos estádios I e II. No modelo de rigidez equivalente já mencionado esse procedimento 
foi utilizado para interpolar a curvatura nas extremidades do elemento, com a curvatura do concreto não fissurado no interior deste (estádio I). Os detalhes do modelo para a flexão composta proposto por Ghali e Favre não serão aqui abordados, podendo ser encontrados em MACHADO (1989).

O procedimento para a obtenção da curvatura média do elemento consiste em determinar a inércia equivalente para as seções das extremidades do elemento finito, calculando-se a média. De uma forma indireta, a variação de $\mathrm{M}$ e $\mathrm{N}$ ao longo do elemento é considerada através de uma aproximação linear.

$\checkmark$ Com os esforços solicitantes nas extremidades do elemento são determinadas as respectivas curvaturas;

$\checkmark$ Calcula-se o momento de fissuração para a seção: $\mathrm{Mr}=\left(\mathrm{f}_{\mathrm{ct}}-\frac{\mathrm{N}}{\mathrm{A}_{1}}\right) \cdot \frac{\mathrm{I}_{1}}{\mathrm{y}}$

onde: $\mathrm{Mr}=$ momento de fissuração;

$\mathrm{f}_{\mathrm{ct}}=$ resistência característica à tração do concreto;

$\mathrm{A}_{1}=$ área da seção não fisssurada de concreto;

$\mathrm{I}_{1}=$ inércia da seção não fissurada de concreto;

$\mathrm{y}=$ distância do CG à fibra mais tracionada de concreto.

$\checkmark$ Calcula-se o coeficiente de interpolação para cada extremidade ou seção transversal: $\xi=1-\beta_{1} \beta_{2}\left(\frac{\mathrm{Mr}}{\mathrm{M}}\right)^{2}$

onde: $\quad M=$ momento fletor na seção transversal da extremidade do elemento;

$\beta_{1}=1$ para barras de alta aderência e 0.5 para barras lisas;

$\beta_{2}=1$ para o primeiro carregamento ou para cargas pouco repetitivas e 0.5 para cargas com um grande número de repetições ou permanentes.

$\checkmark$ Determinação da curvatura média para cada extremidade: $\frac{1}{\mathrm{r}_{\mathrm{m}}}=(1-\xi) \frac{1}{\mathrm{r}_{1}}+\xi \frac{1}{\mathrm{r}}$

onde: $1 / \mathrm{r}_{1}=$ curvatura supondo estádio I;

$1 / \mathrm{r}=$ curvatura da extremidade.

$\checkmark$ Obtenção da inércia equivalente de cada extremidade do elemento: $I_{\text {eq }}=\frac{M}{\mathrm{Ec} / \mathrm{r}_{\mathrm{m}}}$

$\checkmark$ Determinação da inércia média para o elemento através da média entre as 
inércias equivalentes de cada extremidade.

Os resultados obtidos com esse modelo mostram-se satisfatórios em parte dos casos. No entanto, o modelo pode ser melhorado quanto à obtenção da curvatura média. Optou-se pela interpolação proposta pelo CEB, que, para momentos superiores aos de fissuração, a curvatura é ponderada com a obtida supondo-se estádio I. Para melhorar o modelo, propõe-se a adoção de uma função interpoladora para as curvaturas exatas obtidas nas extremidades do elemento. É possível assim determinar curvaturas em seções internas ao elemento, permitindo o cálculo de uma curvatura média mais representativa para o elemento finito.

\subsubsection{Modelo baseado em relações constitutivas}

Devido à rápida convergência, excelente qualidade dos resultados, facilidade de implementação de novas leis constitutivas, facilidade de acoplamento com modelos de confiabilidade, etc., esse modelo foi adotado na versão final do software mecânico-probabilístico desenvolvido nesta tese. As integrações ao longo da altura das seções transversais são feitas numericamente, sendo brevemente descritas a seguir.

O processo das camadas consiste em dividir a seção transversal em faixas de tal forma que seja possível obter a resposta dessa seção a partir das respostas das camadas individuais, considerando-se as relações tensão-deformação individualmente. A utilização desse processo permite o uso de relações constitutivas uniaxiais ou biaxiais entre tensão e deformação para o concreto e o aço. As integrações na seção para obtenção das propriedades geométricas (área, momento estático e momento de inércia) e para cálculo de esforços solicitantes (força normal e memento fletor) podem ser feitas por uma somatória discreta.

Admitindo-se que as deformações são constantes nas fatias, os esforços solicitantes $\mathrm{M}$ e $\mathrm{N}$ na seção transversal são dados por:

$$
\begin{gathered}
\mathrm{M}_{\mathrm{x}}=\sum_{\mathrm{k}=1}^{\mathrm{Nc}} \sigma_{\mathrm{x}}^{\mathrm{c}} \mathrm{b}_{\mathrm{w}} \mathrm{t}_{\mathrm{ck}} \mathrm{y}_{\mathrm{ck}}+\sum_{\mathrm{k}=1}^{\mathrm{Ns}} \sigma_{\mathrm{x}}^{\mathrm{sk}} \mathrm{A}_{\mathrm{sk}} \mathrm{y}_{\mathrm{sk}} \\
\mathrm{N}=\sum_{\mathrm{k}=1}^{\mathrm{Nc}} \sigma_{\mathrm{x}}^{\mathrm{c}} \mathrm{b}_{\mathrm{w}} \mathrm{t}_{\mathrm{ck}}+\sum_{\mathrm{k}=1}^{\mathrm{Ns}} \sigma_{\mathrm{x}}^{\mathrm{sk}} \mathrm{A}_{\mathrm{sk}}
\end{gathered}
$$


onde $\mathrm{N}_{\mathrm{c}}$ é o número de camadas de concreto, $\mathrm{y}_{\mathrm{ck}}$ é a posição da camada de concreto e $\mathrm{t}_{\mathrm{ck}}$ a altura da camada de concreto. As demais variáveis são de acordo com as equações (3.10) e (3.11).

Os módulos tangentes do concreto, $\mathrm{D}_{\mathrm{ci}}$, e do aço, $\mathrm{D}_{\mathrm{si}}$, necessários às matrizes de rigidez da estrutura, SILVA (1995), na fatia k é obtido através da primeira derivada das relações constitutivas em relação as deformações, ou seja:

$$
D_{\mathrm{ci}}=\frac{\partial \sigma_{\mathrm{ci}}}{\partial \varepsilon_{\mathrm{ci}}} \quad \mathrm{D}_{\mathrm{si}}=\frac{\partial \sigma_{\mathrm{si}}}{\partial \varepsilon_{\mathrm{si}}}
$$

Para o cálculo dos esforços em pontos internos aos elementos finitos foram introduzidos pontos de Gauss ao longo de cada elemento finito. Em cada seção transversal correspondente aos pontos de Gauss, as deformações e consequentemente tensões são determinados utilizando o método das camadas. O desenvolvimento detalhado desse item encontra-se em SILVA (1995).

De uma forma resumida, faz-se o seguinte procedimento para determinar a deformação de cada camada da seção transversal, em cada ponto de Gauss ao longo do elemento:

$\checkmark$ calculam-se os deslocamentos (U) do incremento de carga nas coordenadas globais;

$\checkmark$ transformam-se os deslocamentos (U) para o sistema coordenadas-deslocamentos naturais no sistema local corrotacional (Q) (determinados nas extremidades do elemento);

$\checkmark$ obtêm-se as deformações através das funções de forma e ponderação de Gauss.

A tensão de cada camada da seção transversal em cada ponto de Gauss do elemento é determinada através das leis constitutivas adotadas por substituição direta das deformações correspondentes.

\subsubsection{Equações constitutivas para o concreto.}

Inicialmente foram adotadas duas relações para descrever o comportamento tensão-deformação do concreto. A primeira foi a proposta pela NBR-6118. Embora se saiba que essa relação constitutiva não representa bem o material em estudo, ela foi utilizada com o intuito de possibilitar a análise estatística de respostas estruturais segundo a norma brasileira NBR-6118.

A segunda relação constitutiva utilizada foi a proposta no CEB MC 90 
adicionada de um trecho na tração que considera o concreto entre fissuras ("tensionstiffening”). É oportuno lembrar que esse modelo não simula o descarregamento.

Foram, em seguida, introduzidas novas relações constitutivas para o concreto armado, como mostrados no final do trabalho. Além disso, o software foi desenvolvido de forma a facilitar a introdução de novos modelos.

Na NBR-6118 é adotada como relação constitutiva para o concreto a seguinte expressão:

$$
\begin{aligned}
\sigma_{\mathrm{c}}=-\mathrm{f}_{\mathrm{cm}}\left[2\left(\frac{\varepsilon_{\mathrm{c}}}{\varepsilon_{0}}\right)-\left(\frac{\varepsilon_{\mathrm{c}}}{\varepsilon_{0}}\right)^{2}\right] & \Leftrightarrow \varepsilon>\varepsilon_{0} \\
\sigma_{\mathrm{c}}=-\mathrm{f}_{\mathrm{cm}} & \Leftrightarrow \varepsilon<\varepsilon_{0}
\end{aligned}
$$

$\mathrm{f}_{\mathrm{cm}}$ : valor médio da resistência à compressão obtida em ensaios uniaxiais de tensão;

$\sigma_{\mathrm{c}}:$ tensão no concreto;

$\varepsilon_{0}$ : deformação correspondente à tensão máxima, $\mathrm{f}_{\mathrm{cm}},\left(\varepsilon_{0} \cong-0,002\right)$;

$\varepsilon_{\mathrm{c}}$ : deformação no concreto.

Pela própria equação constitutiva, observa-se que o concreto apresenta um comportamento elástico não-linear para $\varepsilon>\varepsilon_{0}$ e plástico para $\varepsilon<\varepsilon_{0}$.

Para o concreto em tração uniaxial, pode-se relacionar a resistência característica à tração com a própria à compressão através da seguinte expressão:

$$
\begin{aligned}
& \mathrm{f}_{\mathrm{tk}(\mathrm{MPa})}=\frac{\mathrm{f}_{\mathrm{ck}(\mathrm{MPa})}}{10} \Rightarrow \mathrm{f}_{\mathrm{ck}} \leq 18 \mathrm{MPa} \\
& \mathrm{f}_{\mathrm{tk}(\mathrm{MPa})}=0,06 \mathrm{f}_{\mathrm{ck}(\mathrm{MPa})}+0,7 \Rightarrow \mathrm{f}_{\mathrm{ck}}>18 \mathrm{MPa}
\end{aligned}
$$

A NBR-6118 não apresenta uma relação constitutiva para o concreto à tração.

A visualização gráfica destas equações será explícita junto às equações propostas pelo CEB MC 90 e o trecho que considera o concreto entre fissuras, com o objetivo de melhor compará-las, Gráfico 3.2.

As equações propostas pela NBR 6118 não representam bem o comportamento real do material, portanto, dispõe-se desse segundo conjunto de equações que serão descritas neste item para obter respostas mais precisas da estrutura. Segundo Muller 
\& Hilsdorf (1991), appud SILVA (1995), as relações utilizadas pelo CEB MC 90 foram adotadas por duas razões. Primeiro, esse modelo descreve muito bem o ramo ascendente da curva tensão-deformação; segundo, este modelo também pode ser usado como base para calcular diagramas tensão-deformação para estado multiaxial de tensões.

O CEB MC 90 adota como relação constitutiva para o concreto em compressão a seguinte expressão:

$$
\begin{gathered}
\sigma_{\mathrm{c}}=-\mathrm{f}_{\mathrm{cm}} \frac{\frac{\mathrm{E}_{\mathrm{c}}}{\mathrm{E}_{\mathrm{c} 1}} \frac{\varepsilon_{\mathrm{c}}}{\varepsilon_{\mathrm{c} 1}}-\left(\frac{\varepsilon_{\mathrm{c}}}{\varepsilon_{\mathrm{c} 1}}\right)^{2}}{1+\left(\frac{\mathrm{E}_{\mathrm{c}}}{\mathrm{E}_{\mathrm{c} 1}}-2\right) \frac{\varepsilon_{\mathrm{c}}}{\varepsilon_{\mathrm{c} 1}}} \Rightarrow \varepsilon>\varepsilon_{\mathrm{cu}} \\
\sigma_{\mathrm{c}}=-\mathrm{f}_{\mathrm{cm}}\left[\left(\frac{1}{\frac{\varepsilon_{\mathrm{cu}}}{\varepsilon_{\mathrm{c} 1}}} \xi-\frac{2}{\left(\frac{\varepsilon_{\mathrm{cu}}}{\varepsilon_{\mathrm{c} 1}}\right)^{2}}\right)\left(\frac{\varepsilon_{\mathrm{c}}}{\varepsilon_{\mathrm{c} 1}}\right)^{2}+\left(\frac{4}{\frac{\varepsilon_{\mathrm{cu}}}{\varepsilon_{\mathrm{cl} 1}}}-\xi\right) \frac{\varepsilon_{\mathrm{c}}}{\varepsilon_{\mathrm{c} 1}}\right]^{-1} \Rightarrow \varepsilon<\varepsilon_{\mathrm{cu}}
\end{gathered}
$$

Enquanto que para o concreto não fissurado em tração tem-se: 


$$
\varepsilon_{\mathrm{cu}}=0,25 \varepsilon_{\mathrm{c} 1} \frac{\mathrm{E}_{\mathrm{c}}+2 \mathrm{E}_{\mathrm{c} 1}+\sqrt{\mathrm{E}_{\mathrm{c}}{ }^{2}+4 \mathrm{E}_{\mathrm{c}} \mathrm{E}_{\mathrm{c} 1}-4 \mathrm{E}_{\mathrm{c} 1}^{2}}}{\mathrm{E}_{\mathrm{c} 1}}
$$

sendo $\xi$ dado pela expressão que segue:

$$
\xi=\frac{4\left[\left(\frac{\varepsilon_{\mathrm{cu}}}{\varepsilon_{\mathrm{c} 1}}\right)^{2}\left(\frac{\varepsilon_{\mathrm{c}}}{\varepsilon_{\mathrm{c} 1}}-2\right)+2 \frac{\varepsilon_{\mathrm{cu}}}{\varepsilon_{\mathrm{c} 1}}-\frac{\mathrm{E}_{\mathrm{c}}}{\mathrm{E}_{\mathrm{c} 1}}\right]}{\left[\frac{\varepsilon_{\mathrm{cu}}}{\varepsilon_{\mathrm{c} 1}}\left(\frac{\mathrm{E}_{\mathrm{c}}}{\mathrm{E}_{\mathrm{c} 1}}-2\right)+1\right]^{2}}
$$

A equação fornecida pelo CEB MC 90 que relaciona a resistência média à tração com a resistência à compressão para o concreto em tração uniaxial é:

$$
\mathrm{f}_{\mathrm{ctm}(\mathrm{MPa})}=0,30 \mathrm{f}_{\mathrm{ck}(\mathrm{MPa})}^{2 / 3}
$$

De acordo com FIGUEIRAS (1983), para representar o efeito do enrijecimento devido à presença do concreto intacto entre fissuras ("tension-stiffening”), utiliza-se a seguinte expressão:

$$
\begin{aligned}
& \sigma_{\mathrm{c}}=\alpha_{\mathrm{ct}} \mathrm{f}_{\mathrm{ctm}}\left(1,0-\frac{\varepsilon_{\mathrm{c}}}{\varepsilon_{\mathrm{ctmax}}}\right) \Rightarrow 0,00015<\varepsilon_{\mathrm{c}} \leq \varepsilon_{\mathrm{ctmax}} \\
& \sigma_{\mathrm{c}}=0,0 \quad \Rightarrow \varepsilon_{\mathrm{c}}>\varepsilon_{\mathrm{ct} \max }
\end{aligned}
$$

onde: $\begin{aligned} & \alpha_{\mathrm{ct}}=0,7 \\ & \varepsilon_{\mathrm{ct} \max }=0,002\end{aligned}$

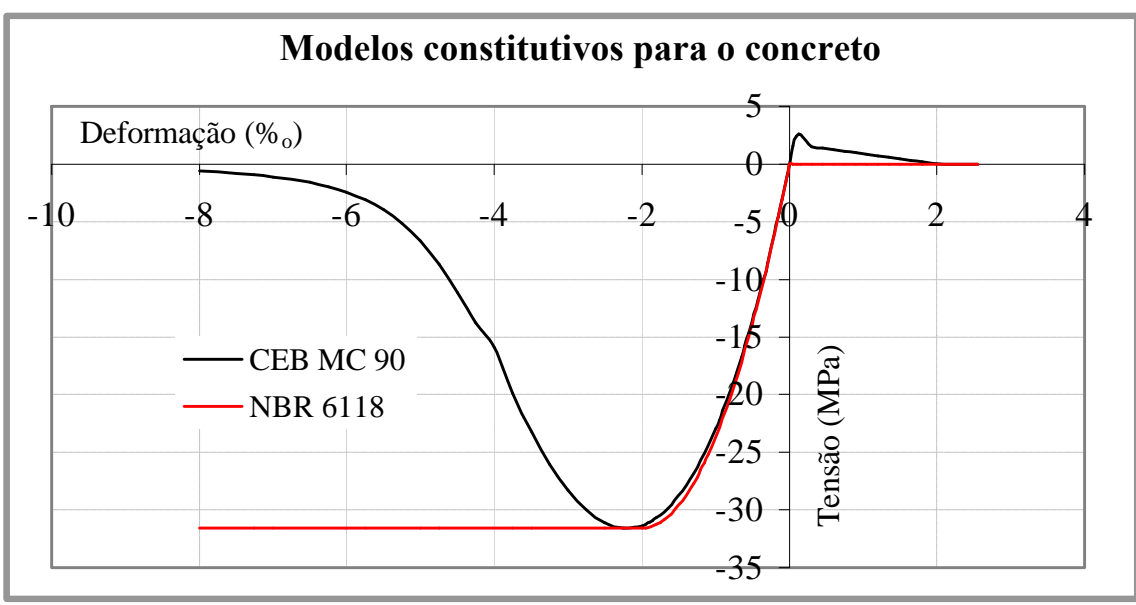

Gráfico 3.2 Leis constitutivas para o concreto, CEB MC90 e NBR 6118

No Gráfico 3.3 é apresentado um exemplo de variação estatística para a relação uniaxial tensão-deformação do concreto. 


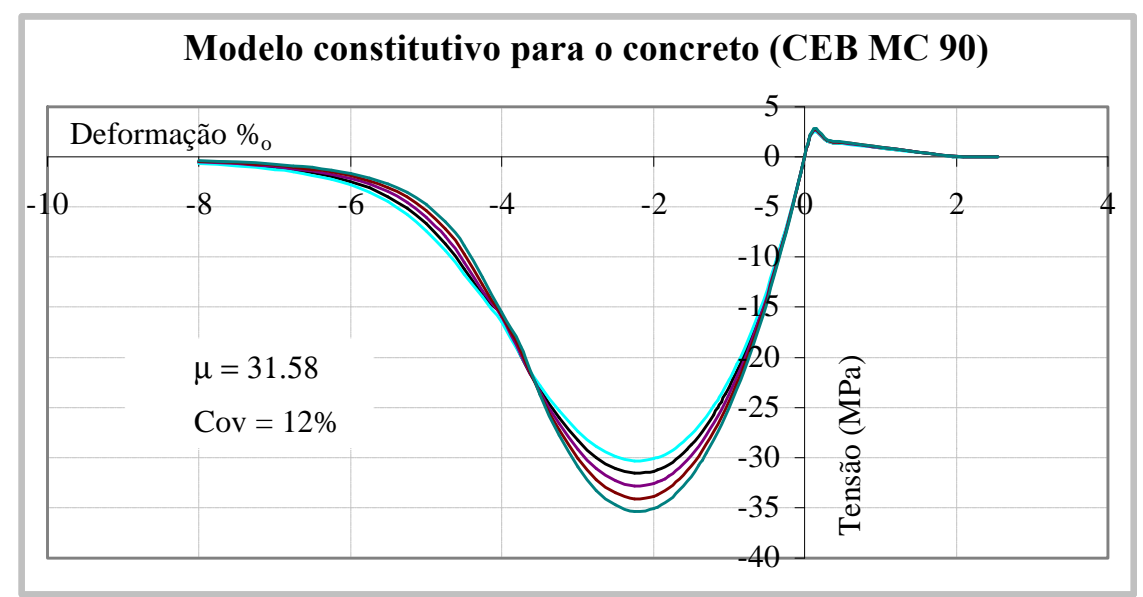

Gráfico 3.3 Variação estatística de um modelo constitutivo do concreto

\subsubsection{Equações constitutivas para o aço}

Para o aço foi utilizado o diagrama adotado pela NBR-6118 adicionando-se um encruamento de $10 \%$ no patamar de escoamento. Caso considere o aço com comportamento elastoplástico perfeito o modelo numérico não é capaz de computar a solicitação última da estrutura. O modelo elastoplástico perfeito apresenta derivada nula no patamar de escoamento, inviabilizando a solução numérica do problema nessas condições. As equações constitutivas são dadas pelas expressões:

$$
\begin{gathered}
\sigma_{\mathrm{s}}=\mathrm{E}_{\mathrm{s}} \varepsilon_{\mathrm{s}} \quad \Rightarrow-\varepsilon_{\mathrm{y}}<\varepsilon_{\mathrm{s}}<\varepsilon_{\mathrm{y}} \\
\sigma_{\mathrm{s}}=10 \% \mathrm{E}_{\mathrm{s}} \varepsilon_{\mathrm{s}} \quad \Rightarrow\left|\varepsilon_{\mathrm{y}}\right|<\left|\varepsilon_{\mathrm{s}}\right|<10 \%_{0}
\end{gathered}
$$

onde: $\rho_{\mathrm{s}}$ : tensão na armadura; $\varepsilon_{\mathrm{s}}$ : deformação na armadura; $\mathrm{E}_{\mathrm{s}}$ : módulo de elasticidade do aço; $\varepsilon_{y}$ : deformação correspondente a deformação de escoamento.

A expressão (3.23) e (3.24) são aplicadas apenas para o aço tipo A. A extenção para se considerar comportamentos mais complexos do material pode ser implementada com facilidade.

No Gráfico 3.4 é mostrado um exemplo de variação estatística para a relação uniaxial tensão-deformação do aço. 


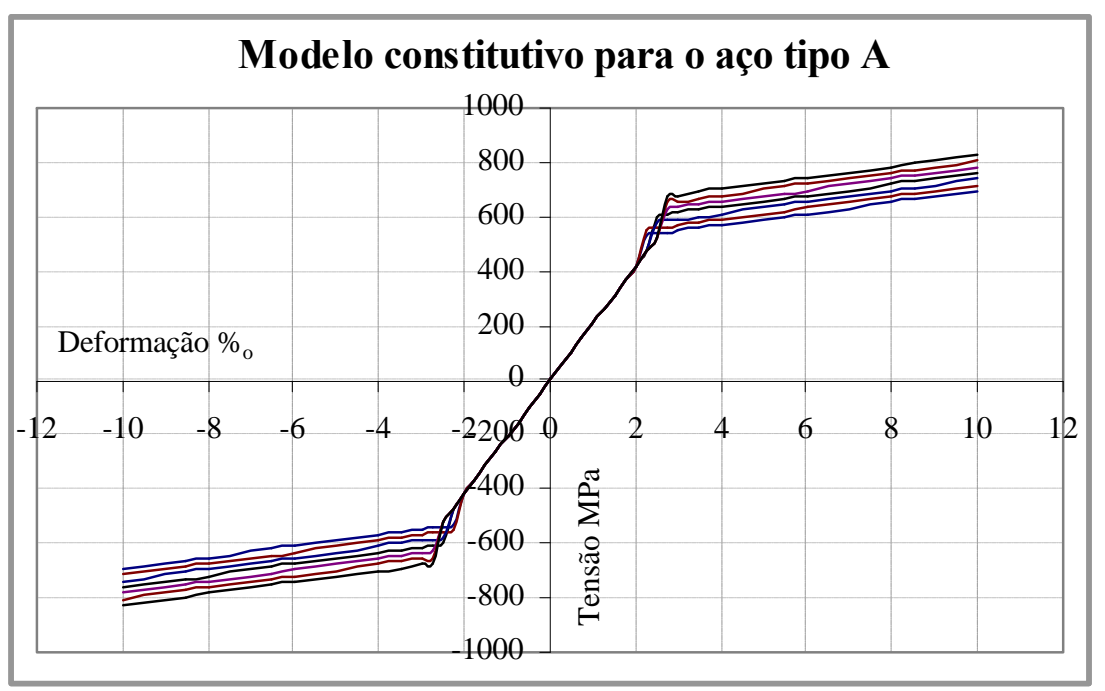

Gráfico 3.4 Variação estatística do modelo constitutivo do aço 


\section{Capítulo 4 Um método de simulação}

A escolha de uma probabilidade de se atingir um Estado Limite não é corrente na elaboração de projetos de Engenharia, embora fosse recomendável. Na literatura também não se encontram trabalhos que mostrem procedimentos para se atngir uma metodologia desse tipo. Mesmo a escolha ou definição de coeficientes parciais de segurança para cálculo estrutural não tem sido feito com bases claras procurando-se aproximar de uma probalbilidade de ruína ou relativa a um outro estado limite. Em geral, os pesquisadores buscam estudar modelos probabilísticos, determinar índices de confiabilidade para determinadas estruturas com características próprias, quantificar riscos, desenvolver modelos que consumam menos tempo de processamento, que é um grande problema na estatística, estudar a percepção humana de risco, etc. Acredita-se que o principal objetivo da pesquisa em confiabilidade estrutural é obter uma confiabilidade constante na resposta estrutural, que é a principal característica do procedimento desenvolvido neste capítulo.

De acordo com Lemaire, M. ${ }^{4}$ e Augusti, G. ${ }^{5}$, o procedimento apresentado em seguida pode ser classificado como calibração estocástica de coeficientes parciais.

Grande parte das pesquisas que têm como objetivo determinar o índice de confiabilidade $(\beta)$ de uma determinada estrutura utiliza métodos de integração por simulações, que muitas vezes são oriundos do método de simulação de Monte Carlo. Na primeira versão do STST (programa desenvolvido no âmbito desse trabalho), optou-se pelo método de simulação de Monte Carlo com amostra reduzida (método escolhido não poderia ser diferente). Esse método foi inicialmente escolhido por apresentar as seguintes características: simples fundamentação matemática; e resultados com bom grau de precisão, uma vez que o número de aproximações utilizadas é reduzido. A principal característica que conduziu a pesquisa à

\footnotetext{
${ }^{4}$ Professor do IFMA, "Institut Français de Mécanique Avancée”, Clermont Ferrant, França.
} 
necessidade de implementação posterior de outros métodos, versões posteriores do STST, foi a exigência de um grande custo computacional; o tempo de processamento exigido muitas vezes inviabiliza o método em termos práticos.

A proposta apresentada neste capítulo é a determinação de coeficientes parciais de segurança a serem utilizados no cálculo estrutural, para os estados limites de serviço, e último, utilizando simulação de Monte Carlo com amostra reduzida, utilizando respostas estruturais satisfatórias em termos de probabilidade.

\subsection{Princípio do modelo}

Assume-se que as características estatísticas tais como as funções de distribuição e os dois primeiros momentos estatísticos das variáveis de projeto são previamente conhecidos, caracterizando essa fase do trabalho como determinística. Tais dados podem ser determinados em laboratórios ou encontrados em bibliografia adequada; e, uma vez definidos, facilmente se determinam as amostras viabilizandose a análise estatística.

Conhecidas as amostras das variáveis de entrada, utiliza-se um gerador aleatório interno a um loopping com o qual se geram as amostras de respostas da estrutura. Nessa fase, tem-se um processo probabilístico.

Através dessas amostras e índices de confiabilidade aceitos por Normas, índices predefinidos, determina-se a resposta da estrutura para este nível de probabilidade de falha. Utilizando-se um processo iterativo determinístico, determinam-se as variáveis do problema que gerariam aquela resposta com confiabilidade predeterminada. Como o índice de confiabilidade é predeterminado, pode-se analisar a resposta da estrutura no estado limite último e/ou de serviço.

Pode-se dizer que o procedimento desenvolvido é um processo semiprobabilístico, onde os dados do problema são determinísticos, o processo de cálculo da estrutura é determinístico e o loopping de geração da amostra é probabilístico.

Ao desenvolver o procedimento descrito acima para diferentes dados de entrada das variáveis de projeto, e para um mesmo tipo estrutural, como pilares por exemplo, tem-se uma superfície de resposta para uma determinada estrutura.

\footnotetext{
${ }^{5}$ Professor da "Universitá di Roma, La Sapienza", Roma, Itália.
} 
Podendo gerar um modelo que represente esta estrutura num determinado estado limite com uma confiabilidade em resposta predefinida e com uma certa uniformidade, que é o objeto de todo pesquisador nessa área atualmente. $\mathrm{O}$ ideal seria uma confiabilidade constante para os tipos estruturais, mas isso é praticamente impossível devido ao número de incertezas envolvidas. $\mathrm{O}$ mais perto que se pode chegar do ideal é uma confiabilidade mais uniforme que a apresentada nos dias atuais.

Desenvolvendo ainda mais o raciocínio, se, além de variar os dados de entrada das variáveis de projeto, variar-se também o tipo estrutural, ainda mantendo estruturas de barra, aumentando apenas o grau de hiperasticidade por exemplo, podese formular um modelo para determinado tipo estrutural com confiabilidade mais uniforme nas respostas.

$\mathrm{Na}$ primeira versão do STST foi implementado o cálculo de índices de confiabilidade em esforços e deslocamentos (quantificar a probabilidade de falha nos estados limite último e de serviço) utilizando o método de simulação de Monte Carlo com amostra reduzida. Foram processadas várias estruturas para testar o programa, em particular pilares e corpos de prova devido ao custo computacional, verificandose coerência entre os resultados, validando assim o algoritmo proposto e a metodologia adotada.

\subsection{Gerador Aleatório}

Para a análise estatística baseada num método de simulação de Monte Carlo é necessário o emprego de um gerador aleatório para definir as amostras que serão utlizidados durante o processo. É oportuno lembrar que o gerador deve ser aleatório e não-viciado.

Desenvolveu-se um gerador baseado em três diferentes funções: linear, exponencial e gaussiana, cabendo ao usuário escolher a adequada. Como as respostas geradas por essas funções devem ser aleatórias, qualquer uma levará a resultados satisfatórios. Salienta-se que devido à amostra ser grande e ao gerador ser aleatório os resultados serão os mesmos independente da função utilizada. Porém, a escolha da função pode interferir no custo computacional.

$\mathrm{O}$ gerador funciona da seguinte forma: assume-se um número inteiro inicial, $\mathrm{x}^{\mathrm{t}}$ 
ou $\mathrm{x}^{0}$, o qual será substituído na função desejada, o resultado apresentado por esta função será um número real, $\mathrm{y}^{\mathrm{t}}$, com quantas casas decimais necessite para o problema.

$$
f_{\left(x^{t}\right)}=y^{t} \quad x^{t} \in I ; y^{t} \in R
$$

De acordo com o tamanho da amostra, utilizam-se os primeiros termos da parte decimal de $\mathrm{y}^{\mathrm{t}}$ para gerar o número aleatório $\mathrm{z}^{\mathrm{t}}$. Por exemplo: se o tamanho da amostra é de 3 dígitos, utilizam-se os três primeiros dígitos da parte decimal de $\mathrm{y}^{\mathrm{t}}$ como sendo o número inteiro e aleatório $z^{t}$ gerado. Para o próximo valor de $\mathrm{x}, \mathrm{x}^{\mathrm{t}+\Delta \mathrm{t}}$, que gerará um novo número aleatório $\mathrm{y}^{\mathrm{t}+\Delta \mathrm{t}}$, faz-se $\mathrm{x}^{\mathrm{t}+\Delta \mathrm{t}}=\mathrm{z}^{\mathrm{t}}$, e assim sucessivamente.

Para evitar-se que o gerador seja viciado, assume-se como valor inicial para o número $\mathrm{x}^{0}$, que alimenta o gerador, o contador do computador.

\subsection{Algoritmo proposto}

Pretende-se gerar gerar uma amostra de solicitações últimas probabilística a partir de características estatísticas determinísticas das variáveis de entrada que serão consideradas aleatórias. Através da amostra de solicitações últimas, determina-se uma solicitação para uma probabilidade pré-estabelecida. Para esta solicitação, determinam-se as variáveis aleatórias equivalentes $x^{*}$, com as quais garante-se a probabilidade de ruína predefinida.

As amostras determinísticas são de tamanhos quaisquer, feitas para quantis em valor percentual equivalente ao inverso do tamanho da amostra. Verificou-se através de testes numéricos que um tamanho razoável para a amostra é 100, feita portanto para quantis de $1 \%$. Para obtenção dos valores das amostras determinísticas faz-se integração numérica dos intervalos das funções de densidade de probabilidade adotadas para as variáveis através da quadratura de Gauss, utilizando 10 pontos. Estas amostras são armazenadas numa matriz, VA.

$$
\mathrm{VA}=\left[\begin{array}{cccc}
\mathrm{x}_{11} & \mathrm{x}_{12} & \cdots & \mathrm{x}_{1 \mathrm{n}} \\
\mathrm{x}_{21} & \mathrm{x}_{22} & \cdots & \mathrm{x}_{2 \mathrm{n}} \\
\cdots & \cdots & \cdots & \cdots \\
\mathrm{x}_{\mathrm{k} 1} & \mathrm{x}_{\mathrm{k} 2} & \cdots & \mathrm{x}_{\mathrm{kn}}
\end{array}\right]
$$

onde: $\mathrm{n}$ : tamanho das amostras; 
k: número de variáveis aleatórias.

Para uma única variável aleatória $\mathrm{x}$, os valores da matriz VA são apresentados na Figura 4.1. A matriz passa então a ser: $\mathrm{VA}=\left[\begin{array}{lllll}\mathrm{x}_{1} & \cdots & \mathrm{x}_{\mathrm{i}} & \cdots & \mathrm{x}_{\mathrm{n}}\end{array}\right]$, onde $\mu$ e $\sigma$ são a média e o desvio padrão de x, respectivamente, e a f.d.p. é representada pela linha vermelha. Observe-se que as áreas hachuradas devem ter o mesmo valor, ou seja, quantis fixos.

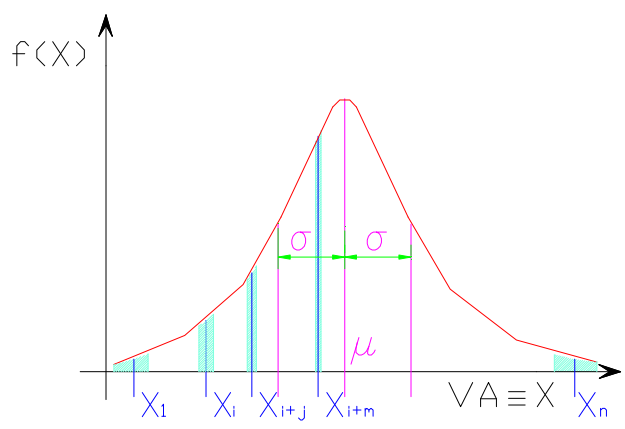

Figura 4.1 Amostra determinística de uma VA

Conhecidas as amostras determinísticas, dado do problema, a amostra de solicitações últimas $\mathrm{P}_{\text {crit }}$ (probabilística) é obtida através de $\mathbf{m}$ gerações aleatórias, formando uma amostra probabilística de tamanho m. A construção de $\mathrm{P}_{\text {crit }}$ é feita da seguinte forma: para a geração de cada evento $\left(\mathrm{P}_{\text {crit }}\right)$ determina-se um posicionamento aleatório em cada amostra determinística, ou seja, em cada linha da matriz VA. Portanto, definidos os valores das variáveis de resistência e/ou ações externas (variáveis que são consideradas aleatórias), determina-se a solicitação última referente às mesmas, formando assim a amostra de solicitações últimas, $\mathrm{P}_{\text {crit }}$.

$$
\mathrm{P}_{\text {crit }}\left(\mathrm{p}_{1}, \ldots, \mathrm{p}_{\mathrm{m}}\right)
$$

$\mathrm{O}$ tamanho do vetor $\mathrm{P}_{\text {crit }}$ é determinado de certa forma que não haja variação significativa nos resultados do problema. Isto é, se a amostra for de tamanho maior que m não haverá variação significativa nos resultados, uma vez que nessa situação os momentos estatísticos permanecem praticamente inalterados. No caso de pilares com apenas a resistência à compressão como variável aleatória foram feitos ensaios numéricos, concluindo-se que m igual a 2000 fornece resultados satisfatórios.

A amostra probabilística de solicitação última ou deslocamento último, caso de análise em serviço, é sujeita ao teste Kolmogorov-Smirnov descrito em PRESS et al. (1994), que determina, entre algumas distribuições possíveis escolhidas 
deterministicamente, qual a distribuição mais adequada. Dentre as distribuições testadas pelo programa nesta versão estão a normal, log-normal, beta, exponencialPDF, exponencial-CDF, constante e uma curva numérica desenvolvida pelo autor.

Conhecida a amostra das solicitações últimas assim como suas características, determinam-se os momentos estatísticos da mesma e gera-se a distribuição que melhor se adapta a essa amostra. Com esta distribuição, determina-se uma solicitação para uma probabilidade de ruína predefinida. Neste estudo, inicialmente foi utilizado a probabilidade definida abaixo, valor proposto pelo Eurocode.

$$
\mathrm{P}\left(\mathrm{p}^{*}=\mathrm{p}\right)=0,7230 \mathrm{E}-4
$$

Conhecido o valor de $\mathrm{p}^{*}$, através de um processo determinístico iterativo, calculam-se as variáveis de projeto equivalentes $\mathrm{x}^{*}$, que fazem coincidir a solicitação última dessas variáveis com o valor de $\mathrm{p}^{*}$. Ou seja,

$$
\mathrm{p}=\mathrm{p}^{*} \therefore \mathrm{x}=\mathrm{x}^{*}
$$

Dessa forma, determinam-se variáveis de resistência e/ou ações externas da estrutura com probabilidade de ruína em solicitação última.

Resumindo-se o procedimento de cálculo: parte-se de um processo determinístico que é a geração de dados de entrada do programa, amostra inicial das variáveis isoladas; passa-se por um processo probabilístico, no qual é gerada a amostra da resposta estrutural; e finalmente retorna-se a um processo determinístico para determinar a resposta estatística da amostra.

Com o intuito de compreender o método descrito neste capítulo, será dada uma interpretação do algoritmo desenvolvido para apenas uma variável aleatória $\mathrm{x}$. Supõe-se conhecidos o valor médio $\mu$, desvio padrão $\sigma$ e f.d.p. da variável aleatória. Supõe-se ainda que x é uma VA de resistência. O procedimento pode ser descrito nos seguintes passos:

1. Construir a amostra de entrada $X$ : para quantis prefixados, por exemplo $1 \%$, verificam-se os valores de $\mathrm{x}$ que correspondem a esses quantis (processo descrito na Figura 4.1). Esses valores são armazenados em $X . X=\left\{x_{1}, x_{2}, \cdots, x_{100}\right\}$

2. Construir a amostra de respostas $P_{\text {crit }}$ : para cada valor de $\mathrm{X}$, calcula-se a resposta mecânica da estrutura e armazena em $P_{\text {crit }}$, Figura 4.2. Os valores de $\mathrm{X}$ devem 
variar aleatoriamente. Ou seja:

$$
\left\{\begin{array}{lllll}
\mathrm{x}_{\mathrm{i}} & \mathrm{x}_{\mathrm{j}} & \ldots & \mathrm{x}_{\mathrm{n}} & \mathrm{x}_{\mathrm{v}}
\end{array}\right\} \rightarrow\left\{\begin{array}{lllll}
\mathrm{p}_{1} & \mathrm{p}_{2} & \ldots & \mathrm{p}_{\mathrm{m}-1} & \mathrm{p}_{\mathrm{m}}
\end{array}\right\}
$$

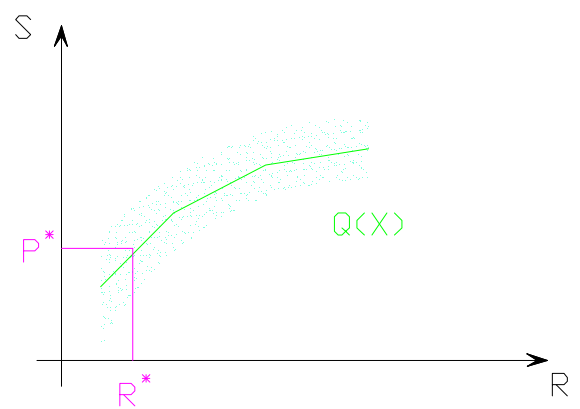

Figura 4.2 Estimativa da resposta estrutural

3. Determinar a f.d.p. da resposta $P_{\text {crit }}$ : verificar qual a f.d.p. que mais se aproxima da amostra de respostas. Conhecida a f.d.p. e suas características, como média e desvio padrão, traça-se a curva de resposta e verifica-se qual a probabilidade de falha equivalente a uma distância predefinida do centro do sistema de coordenadas (para uma variável essa distância equivale ao índice de confiabilidade). Essa probabilidade é a área sob a p.d.f. estimada, Figura 4.3.

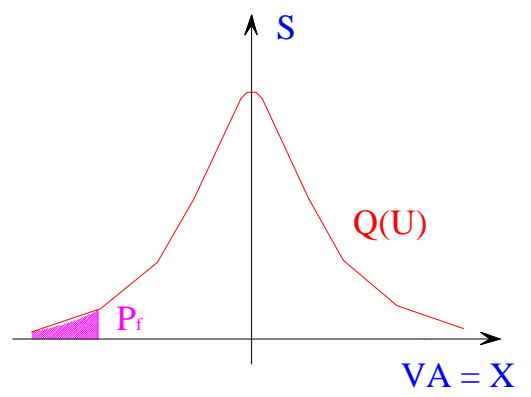

Figura 4.3 Estimativa da Probabilidade de Falha 


\section{Capítulo 5 Método de superfície de resposta (RSM)}

Como já comentado anteriormente, o método de simulação de Monte Carlo na prática é muitas vezes inviável devido ao elevado custo computacional. Portanto para eleiminar esse inconveniente, propõe-se um método analítico de busca do índice de confiabilidade. Esse método, como qualquer outro, apresenta vantagens e desvantagens que serão discutidas no decorrer do trabalho. Dentre as principais características pode-se considerar como a principal vantagem o reduzido custo computacional. Como desvantagens citam-se as aproximações implícitas no método.

A respeito dessas aproximações, a maior dificuldade é definir uma superfície de ruína para a estrutura, uma vez que as estruturas são em geral hiperestáticas e apresentam respostas mecânicas não-lineares. Essa dificuldade leva a uma fração razoável dos centros de pesquisa a trabalhar com superfícies de ruína de estruturas predefinidas, viabilizando apenas a análise de casos simples com comportamento bem conhecido. Para superar esta dificuldade e generalizar o método para estruturas mais complexas, é seguido um processo aproximado para a obtenção da superfície de ruína da estrutura em função de sua resposta mecânica como indicado nas referências: Maurice Lemaire ${ }^{6}$, Alaa Mohamed $^{7}$.

Uma vez definida esta superfície, existem vários algoritmos encontrados na literatura para calcular o índice de confiabilidade de uma estrutura. Entre eles, os mais utilizados são os algoritmos de Rackwitz \& Fiessler, de Madsen et al., de ThoftChristensen e Murotsu, ou simplesmente métodos clássicos de otimização. Conhecido o índice de confiabilidade, facilmente estima-se a probabilidade de ruína da estrutura por métodos como o FORM (first order reliability method) e o SORM (second order reliability method).

Independente do método utilizado, para o cálculo da confiabilidade é sempre

\footnotetext{
${ }^{6}$ Professor do IFMA, "Institut Français de Mécanique Avancée”, Clermont Ferrant, França.
} 
necessário encontrar várias soluções mecânicas da estrutura em análise, isto é, um número importante de realizações da função de estado limite. Cada método pode resultar de um modelo complexo, com solução também complexa e de alto custo computacional, sendo necessário procurar limitar o número total de realizações. Com o objetivo de minimizar o número de realizações mecânicas, um dos métodos possíveis é construir uma representação analítica simples (polinômio) na vizinhança do ponto de concepção ou ponto de projeto. A estes métodos é dado o nome de Métodos de Superfícies de Resposta (RSM). Tais métodos permitem que o cálculo da confiabilidade seja bastante simplificado e tenha um custo computacional quase nulo; a dificuldade desses métodos é justificar a aproximação adotada para um domínio definido. Têm sido usados como uma alternativa para a análise da confiabilidade estrutural, que são fundamentados sobre uma aproximação da função de estado limite para um polinômio de variáveis aleatórias onde os coeficientes são desconhecidos.

Portanto, o objetivo é construir uma resposta aproximada explicita da função de estado limite em torno do ponto de ruína mais provável. Para isso, é necessário repetir o cálculo determinístico para um certo número de pontos selecionados na vizinhança do ponto de concepção e em seguida fazer uma análise de interpolação ou regressão. O nível de aproximação depende do nível de conhecimento do ponto de concepção e do grau de não-linearidade da função de estado limite relacionada. Então, dois problemas precisam ser resolvidos:

$\checkmark$ escolha da forma da superfície de resposta (RS), e identificar os coeficientes desconhecidos;

$\checkmark$ desenvolvimento da RS em torno do ponto de ruína mais provável.

Segundo MACIAS (1994), o desenvolvimento dos métodos de superfícies de resposta iniciou-se nos anos 50, com o objetivo de dar credibilidade a modelos empíricos adicionados de experimentações seqüenciais, para analisar um certo domínio de interesse e para descobrir e analisar as variáveis mais importantes. Nos dias atuais, existem software de tratamento estatístico que utilizam esta metodologia (Statgraphics, por exemplo).

Pode-se utilizar métodos de superfícies de resposta para fornecer a solução das

\footnotetext{
${ }^{7}$ Pesquisador do IFMA, "Institut Français de Mécanique Avancée”, Clermont Ferrant, França.
} 
seguintes questões:

$\checkmark$ Como uma resposta é influenciada por um conjunto de variáveis em um domínio definido?

$\checkmark$ Qual o conjunto de variáveis que produzem um máximo (ou um mínimo) da resposta?

$\checkmark$ Qual a forma da superfície na vizinhança desta resposta máxima (ou mínima)?

Há diferentes maneiras de se aplicar um método de superfície de resposta. As diferenças essenciais são: o grau do polinômio, a escolha do ponto para a construção da superfície, o número de pontos, o conjunto de pontos, etc. Alguns desses métodos necessitam de técnicas de planos de experiência para escolher o conjunto de pontos.

\subsection{Forma da superfície de resposta}

Segundo MOHAMED et al. (1997), podem ser considerados três casos para definir a forma da superfície de resposta (RS), dependendo das informações disponíveis.

1- O modelo mecânico conduz a uma forma explícita da RS, que dependente de $n$ coeficientes. É suficiente, então, definirem-se os $n$ coeficientes à partir de $n$ cálculos, observando-se que o sistema de equações deve ser bem condicionado.

2- Um estudo teórico fornece indicação sobre a forma da RS. É o caso, por exemplo, de um desenvolvimento limitado da resposta em torno de um ponto (série de Taylor, desenvolvimento assintótico).

3- Na falta de informações, a RS deve ser construída em função das respostas conhecidas para determinados pontos. Uma base é escolhida a priori e os coeficientes são identificados por interpolação ou regressão. É o caso adequado para estruturas hiperestáticas com respostas não-lineares.

O caso número três é o que melhor se adequa a este trabalho. Devido à hiperasticidade e as respostas não-lineares da estrutura, não é possível conhecer a priori qualquer informação sobre sua RS.

Um dos maiores problemas atualmente para calcular a confiabilidade de estruturas de concreto armado considerando a não-linearidade da estrutura e do material é o custo computacional. Para encontrar uma simples resposta mecânica necessitam-se muitas iterações, sendo portanto muito importante obter-se uma RS 
para a estrutura utilizando um número mínimo de cálculos mecânicos. De acordo com LEMAIRE (1998), o desenvolvimento construído por uma expansão polinomial é o mais eficiente no caso de falta de informações sobre a forma da RS. Esta escolha é feita pela maioria dos pesquisadores que utilizam os RSM. Polinômios de grau 2 (Superfície de Resposta Quadrática (QRS)) são uma boa solução, desde que seja incluído um possível cálculo de curvaturas da RS. A Utilização de polinômios de graus elevados entretanto pode oscilar ou variar muito no domínio do problema. Portanto, conclui-se que é aconselhável trabalhar com superfícies de resposta com polinômio de ordem baixa, segunda ou terceira ordem.

No QRSM (Quadratic Response Surface Method) a superfície de resposta da estrutura é aproximada por um polinômio do $2^{\underline{o}}$ grau. Caso deseje-se utilizar o CRSM (Cubic Response Surface Method), o desenvolvimento do algoritmo é semelhante ao QRSM, sendo a única diferença a ordem do polinômio aproximador e consequentemente o número de pontos do plano de experiência utilizado.

Dentre os métodos mecânico-probabilísticos implementados, o QRSM parece ser o mais consistente e exige um menor custo computacional, características suficientes que fosse o método adotado para a versão final do STST. Por facilidade de notação e até mesmo generalização, o QRSM será citado simplesmente por RSM no restante da tese.

\subsection{Desenvolvimento da superfície de resposta}

Uma vez definida a forma da RS, propõe-se com o RSM desenvolve-la em torno do ponto de ruína mais provável $\left(\mathrm{P}^{*}\right)$, que tem posição desconhecida. A solução proposta consiste em procurar uma seqüência de pontos $\mathrm{P}^{*(\mathrm{k})}$ associada a uma seqüência de $\mathrm{RS}^{(\mathrm{k})}$ na qual o domínio de definição contém $\mathrm{P}^{*(\mathrm{k})}$. Este procedimento não garante uma convergência para um mínimo global. Não se deve esquecer, portanto, que a existência de mínimos locais pode induzir a contribuições significativas na probabilidade de ruína. Pontos de mínimos locais podem ser futuras ruínas quando utilizam-se técnicas ETA e FTA. Em todos os casos, deve ser feita uma análise dos resultados para validá-los.

Em uma outra possibilidade natural proposta neste trabalho sugere-se o uso de polinômios com graus elevados que representem bem a resposta estrutural em todo 
domínio de validade do problema, que é a diferença básica entre o método original e o RSM. Tentar representar as respostas estruturais utilizando um único polinômio valido para todo domínio do problema foi uma idéia original, mas não teve sucesso pela falta de consistência na convergência do método, sendo consequentemente abandonada posteriormente.

\subsection{Construção de uma superfície de resposta}

A construção de uma RS de acordo com o RSM pode ser dividida em algumas etapas, que serão descritas a seguir.

\subsubsection{Definição do espaço de trabalho}

Há duas possibilidades para construir uma RS: no espaço físico e no espaço reduzido ou normal padrão.

O espaço físico apresenta a vantagem de poder obter diretamente uma solução física para o problema, de acordo com a experiência do projetista. Entretanto, a escolha de pontos físicos pode conduzir a pontos padronizados situados muito longe da origem no espaço normal padrão (U) se o desvio padrão for inapto ou os pontos forem próximos das margens. Além disso, o projetista conhece bem a média da área processada (área sobre os pontos), mas pode ter dificuldades para realizações em torno da ruína a ser identificada. Finalmente, a qualidade da solução de confiabilidade depende do desenvolvimento da função de estado limite obtido por variáveis normalizadas.

O espaço físico é mais favorável para a sensibilidade em torno da média que à confiabilidade a ser estudada.

Trabalhar diretamente no espaço reduzido garante uma escolha de realizações de um número de desvios padrão bem controlado. O domínio de validade da RS é então bem conhecido. Entretanto, o ponto físico original deve ser admissível. As soluções físicas inadequadas devem ser eliminadas e os caracteres realísticos, ou não, dos pontos físicos de cálculo devem ser verificados.

Um estudo a priori de domínios admissíveis das variáveis físicas induz, através de transformações isoprobabilísticas, ao domínio padronizado no qual é válido o ponto de projeto. 
Regras de correlação, composição e truncamento de variáveis podem conduzir a transformações isoprobabilísticas que não são únicas. Uma realização $u_{i}{ }^{(r)}$ sempre tem uma realização física original $\mathrm{x}_{i}{ }^{(\mathrm{r})}$, mas o inverso não é verdadeiro. Finalmente, com variáveis normalizadas, os índices são adimensionais, facilitando suas interpretações.

De acordo com as características citadas acima, conclui-se que é mais razoável para o estudo de confiabilidade trabalhar no espaço normal padrão.

Uma superfície de resposta deve ser construída em uma vizinhança física aceitável e conter pontos suficientemente repartidos no espaço reduzido. A ida e volta, ou troca de espaços, entre os pontos físicos e os pontos normalizados é indispensável. A ida e volta entre as variáveis físicas e normalizadas é independente do modelo mecânico e podem ser efetuadas largamente a um custo computacional quase nulo.

\subsubsection{Princípio}

As respostas de um modelo mecânico em torno de $\mathrm{P}^{*}$ são estimadas por um processo de passos sucessivos que contêm convergências mecânicas e de confiabilidade.

$\checkmark$ Passos sucessivos: quaisquer RS são construídas devido a uma evolução do centro da RS que converge para um mínimo. Este mínimo deve pertencer ao domínio de construção da RS, ele é em geral um mínimo absoluto sobre a RS, mas não necessariamente um mínimo para o problema original. Então, é necessário fazer um processo iterativo tal que as duas últimas RS apresentem o mesmo ponto de mínimo.

$\checkmark$ Convergência mecânica: o modelo mecânico é verificado à medida dos passos, ou em cada passo. É inútil utilizar soluções mais refinadas nas primeiras realizações.

$\checkmark$ Convergência de confiabilidade: o índice de confiabilidade é obtido a cada passo.

\subsection{Transformações de distribuições de probabilidade}

Como já foi discutido, é mais conveniente trabalhar no espaço normal padrão, 
só que as variáveis de projeto são fornecidas e interpretadas no espaço físico. Portanto, necessitam-se transformações isoprobabilísticas no desenvolvimento do modelo de confiabilidade utilizado. Além do mais, o índice de confiabilidade de Hasofer\&Lind ( $\beta$ ), que expressa o nível de confiabilidade do problema, é calculado no espaço normal padrão não correlacionado, e as distribuições marginais das variáveis e suas características são fornecidas no espaço físico. É, portanto, necessário um largo uso de transformações, ou mudança de espaços de trabalho, em cada loopping de busca do índice de confiabilidade. Portanto, é essencial para a análise mecânica-probabilística a construção de uma transformação T, que passa as variáveis do espaço físico, representado por x, para o normal padrão, representado por u, e vice-versa.

A seguir, serão comentados vários métodos de transformação isoprobabilística, cabendo ao analista escolher o método mais adequado ao problema.

Um grande número de distribuições de probabilidade utilizadas na engenharia podem ser encontradas no Anexo B. Todas as distribuições contidas nesse Anexo foram implementadas no STST.

Variáveis aleatórias independentes ou não correlacionadas são aquelas cujas características estatísticas não se alteram devido à presença de uma outra variável. Por exemplo, o aço e o concreto quando o concreto armado é estudado. Em geral, a maioria das variáveis da análise estrutural pertence a esse grupo.

Variáveis aleatórias dependentes ou correlacionadas são aquelas que alteram suas características estatísticas com a presença de outra variável. Por exemplo, o concreto e o agregado, ou o concreto armado e a oxidação do aço.

\subsubsection{Variáveis aleatórias independentes}

Nos casos onde as variáveis aleatórias de base são independentes, a transformação é feita para cada variável independentemente, apenas igualando-se as funções de repartição:

$$
\Phi\left(\mathrm{u}_{\mathrm{i}}\right)=\mathrm{F}_{\mathrm{x}_{\mathrm{i}}}\left(\mathrm{x}_{\mathrm{i}}\right)
$$

A transformação direta é então:

$$
\mathrm{T}(\mathrm{X}) \quad \Rightarrow \quad \mathrm{u}_{\mathrm{i}}=\Phi^{-1}\left(\mathrm{~F}_{\mathrm{x}_{\mathrm{i}}}\left(\mathrm{x}_{\mathrm{i}}\right)\right) \quad \mathrm{i}=1, \ldots, \mathrm{n}
$$


A transformação inversa é:

$$
\mathrm{T}^{-1}(\mathrm{U}) \quad \Rightarrow \quad \mathrm{x}_{\mathrm{i}}=\mathrm{F}_{\mathrm{x}_{\mathrm{i}}}^{-1}\left(\Phi\left(\mathrm{u}_{\mathrm{i}}\right)\right) \quad \mathrm{i}=1, \ldots, \mathrm{n}
$$

Em notação matricial:

$$
\begin{aligned}
& \mathrm{U}=\{\mathrm{u}\}=\left\{\Phi^{-1}\left(\mathrm{~F}_{\{\mathrm{x}\}}(\{\mathrm{x}\})\right)\right\} \\
& \mathrm{X}=\{\mathrm{x}\}=\left\{\mathrm{F}_{\{\mathrm{x}\}}^{-1}(\Phi(\{\mathrm{u}\}))\right\}
\end{aligned}
$$

onde $x_{i}$ e $u_{i}$ representam as variáveis aleatórias no espaço físico e reduzido, respectivamente.

Na prática, o índice de confiabilidade $(\beta)$ é calculado no espaço normal padrão, ou seja, a variável $u_{i}$ é representada por uma distribuição normal com média nula e desvio padrão unitário. Desta forma, a função que representa $u_{i}$ não é integrável analiticamente, sendo necessária uma integração numérica da função. Baseado em testes, aconselha-se utilizar um procedimento gausseano, com a região de integração dividida em sub-regiões. Para integrar cada sub-região deve-se utilizar dez pontos de Gauss. No caso, foram utilizadas 20 sub-regiões.

As funções de distribuição acumuladas adequadas às variáveis de engenharia, mesmo no espaço físico, em geral não são possíveis de se integrar analiticamente, sendo necessário o uso de integração numérica.

Um exemplo de transformação isoprobabilística de variáveis aleatórias independentes pode ser visto no Apêndice I.

\subsubsection{Distribuição normal equivalente}

Este método foi descrito em MOHAMED (1999). Consiste em fazer a transformação das variáveis uma a uma, apresentando solução exata apenas nos casos em que as variáveis aleatórias são independentes. Após encontrarem-se os parâmetros da distribuição normal equivalente à distribuição original, facilmente fazem-se transformações isoprobabilística do espaço normal equivalente para o espaço normal padrão e vice-versa. Pode-se dizer que esta é a forma mais simples de se transformarem as variáveis para os espaço reduzido.

Para encontrar os parâmetros da distribuição normal equivalente $\mu_{\mathrm{i}}$ e $\sigma_{\mathrm{i}}$, para a variável $\mathrm{x}_{\mathrm{i}}$, com uma função de densidade $\mathrm{f}_{\mathrm{x}_{\mathrm{i}}}\left(\mathrm{x}_{\mathrm{i}}\right)$ e uma função de distribuição acumulada $\mathrm{F}_{\mathrm{x}_{\mathrm{i}}}\left(\mathrm{x}_{\mathrm{i}}\right)$, deve ser feito o procedimento descrito a seguir. $\Phi$ e $\varphi$ 
representam, respectivamente, as funções de distribuição acumulada e de densidade normal equivalente.

Igualar as funções de distribuição acumuladas no ponto considerado:

$$
\Phi\left(\frac{\mathrm{x}_{\mathrm{i}}-\mu_{\mathrm{i}}}{\sigma_{\mathrm{i}}}\right)=\mathrm{F}_{\mathrm{x}_{\mathrm{i}}}\left(\mathrm{x}_{\mathrm{i}}\right)
$$

Igualar as funções de densidade no mesmo ponto, que é obtida derivando-se a expressão(5.5) em relação a $\mathrm{x}_{\mathrm{i}}$ :

$$
\frac{1}{\sigma_{i}} \varphi\left(\frac{x_{i}-\mu_{i}}{\sigma_{i}}\right)=f_{x_{i}}\left(x_{i}\right)
$$

De (5.5) tem-se:

$$
\frac{\mathrm{x}_{\mathrm{i}}-\mu_{\mathrm{i}}}{\sigma_{\mathrm{i}}}=\Phi^{-1}\left[\mathrm{~F}_{\mathrm{x}_{\mathrm{i}}}\left(\mathrm{x}_{\mathrm{i}}\right)\right]
$$

Substituindo-se a relação (5.7) na (5.6), pode-se determinar uma expressão para o desvio padrão da distribuição normal equivalente:

$$
\sigma_{\mathrm{i}}=\frac{\varphi\left(\Phi^{-1}\left[\mathrm{~F}_{\mathrm{x}_{\mathrm{i}}}\left(\mathrm{x}_{\mathrm{i}}\right)\right]\right)}{\mathrm{f}_{\mathrm{x}_{\mathrm{i}}}\left(\mathrm{x}_{\mathrm{i}}\right)}
$$

Reorganizando-se (5.5), tem-se a média da distribuição normal equivalente:

$$
\mu_{\mathrm{i}}=\mathrm{x}_{\mathrm{i}}-\sigma_{\mathrm{i}} \Phi^{-1}\left[\mathrm{~F}_{\mathrm{x}_{\mathrm{i}}}\left(\mathrm{x}_{\mathrm{i}}\right)\right]
$$

Um exemplo desse procedimento pode ser visto no Apêndice II.

\subsubsection{Variáveis aleatórias correlacionadas}

Quando as variáveis de base não são mutuamente independentes, pode-se usar a transformação isoprobabilística de Rosenblatt ou a de Nataf. Segundo MOHAMED (1997), a transformação de Rosenblatt é a melhor solução, mas ela necessita do conhecimento da lei de distribuição conjunta do vetor das variáveis aleatórias $\mathrm{X}$, que na maioria dos casos reais não é conhecida. Em geral, o valor médio das variáveis aleatórias $\overline{\mathrm{x}}_{\mathrm{i}}$, o desvio padrão $\sigma_{\mathrm{i}}$, a matriz de correlação $\rho_{\mathrm{ij}} \mathrm{e}$ as funções de distribuição marginal de X são conhecidos. Quando se conhece apenas esses dados, pode ser utilizada a transformação de Nataf.

A matriz de correlação no espaço físico $\rho_{\mathrm{ij}}$ é determinada através de ensaios em laboratórios. Em geral as variáveis estruturais não são correlacionadas. 


\subsubsection{Transformação de Rosenblatt}

Para fazer uma transformação para o espaço normalizado independente, Hohenbichler e Rackwitz, apud MOHAMED (1999), sugeriram a transformação de Rosenblatt.

$$
\{\mathrm{U}\}=\mathrm{T}(\{\mathrm{X}\})
$$

com:

$$
\mathrm{T}(\mathrm{X}) \Rightarrow\left\{\begin{array}{l}
\mathrm{u}_{1}=\Phi^{-1}\left[\mathrm{~F}_{\mathrm{x}_{1}}\left(\mathrm{x}_{1}\right)\right] \\
\mathrm{u}_{2}=\Phi^{-1}\left[\mathrm{~F}_{\mathrm{x}_{2}}\left(\mathrm{x}_{2} \backslash \mathrm{x}_{1}\right)\right] \\
\cdots \cdots \cdots \cdots \cdots \cdots \cdots \\
\mathrm{u}_{\mathrm{i}}=\Phi^{-1}\left[\mathrm{~F}_{\mathrm{x}_{\mathrm{i}}}\left(\mathrm{x}_{\mathrm{i}} \backslash \mathrm{x}_{1}, \mathrm{x}_{2}, \ldots, \mathrm{x}_{\mathrm{i}-1}\right)\right] \\
\cdots \cdots \cdots \cdots \cdots \cdots \cdots \\
\mathrm{u}_{\mathrm{n}}=\Phi^{-1}\left[\mathrm{~F}_{\mathrm{x}_{\mathrm{n}}}\left(\mathrm{x}_{\mathrm{n}} \backslash \mathrm{x}_{1}, \mathrm{x}_{2}, \ldots, \mathrm{x}_{\mathrm{n}-1}\right)\right]
\end{array}\right.
$$

onde $\mathrm{F}_{\mathrm{x}_{\mathrm{i}}}\left(\mathrm{x}_{\mathrm{i}} \backslash \mathrm{x}_{1}, \mathrm{x}_{2}, \ldots, \mathrm{x}_{\mathrm{i}-1}\right)$ é a função de distribuição condicional de $\mathrm{x}_{\mathrm{i}}$; isto é determinado por:

$$
F_{x_{i}}\left(x_{i} \backslash x_{1}, x_{2}, \ldots, x_{i-1}\right)=\frac{\int_{-\infty}^{x_{i}} f_{x_{i}, \ldots, x_{i-1}, t}\left(x_{1}, \ldots, x_{i-1}, t\right) d t}{f_{x_{i}, \ldots, x_{i-1}}\left(x_{1}, \ldots, x_{i-1}\right)}
$$

A transformação de Rosenblatt é exata, entretanto não é independente da ordem da variável, consequentemente a forma da superfície de ruína pode ser modificada. De acordo com Madsen, appud MOHAMED (1999), para uso prático o erro devido a essa possível modificação na superfície de ruína é pequeno.

A transformação inversa é dada por:

$$
\mathrm{T}^{-1}(\mathrm{U}) \Rightarrow\left\{\begin{array}{l}
\mathrm{x}_{1}=\mathrm{F}_{\mathrm{x}_{1}}^{-1}\left[\Phi\left(\mathrm{u}_{1}\right)\right] \\
\mathrm{x}_{2}=\mathrm{F}_{\mathrm{x}_{2}}^{-1}\left[\Phi\left(\mathrm{u}_{2} \backslash \mathrm{u}_{1}\right)\right] \\
\cdots \cdots \cdots \cdots \cdots \cdots \cdots \cdots \cdots \cdots \cdots \cdots \cdots \cdots \cdots \cdots \cdots \cdots \cdots \cdots \cdots \cdots \cdots \cdots \\
\mathrm{x}_{\mathrm{i}}=\mathrm{F}_{\mathrm{x}_{\mathrm{i}}}^{-1}\left[\Phi\left(\mathrm{u}_{\mathrm{i}} \backslash \mathrm{u}_{1}, \mathrm{u}_{2}, \ldots, \mathrm{u}_{\mathrm{i}-1}\right)\right] \\
\cdots \cdots \cdots \cdots \cdots \cdots \cdots \cdots \\
\mathrm{x}_{\mathrm{n}}=\mathrm{F}_{\mathrm{x}_{\mathrm{n}}}^{-1}\left[\Phi\left(\mathrm{u}_{\mathrm{n}} \backslash \mathrm{u}_{1}, \mathrm{u}_{2}, \ldots, \mathrm{u}_{\mathrm{n}-1}\right)\right]
\end{array}\right.
$$

\subsubsection{Transformação de Nataf}

Para descrever a transformação de Nataf foi realizada uma compilação de 
MOHAMED (1999) e MOHAMED et al. (1997). Considere duas variáveis aleatórias correlacionadas, $\mathrm{x}_{1}$ e $\mathrm{x}_{2}$, cujas funções marginais $\mathrm{F}_{\mathrm{x}_{\mathrm{i}}}\left(\mathrm{x}_{\mathrm{i}}\right)$ são conhecidas. $\hat{\mathrm{u}}_{1}$ e $\hat{\mathrm{u}}_{2}$ são as variáveis normais padronizadas, correlacionadas, obtidas pela transformação:

$$
\hat{\mathrm{u}}_{\mathrm{i}}=\Phi^{-1}\left(\mathrm{~F}_{\mathrm{x}_{\mathrm{i}}}\left(\mathrm{x}_{\mathrm{i}}\right)\right), \quad \mathrm{i}=1,2
$$

De acordo com Nataf, pode-se associar uma função de densidade conjunta às variáveis $\mathrm{x}_{1}$ e $\mathrm{x}_{2}$.

$$
\mathrm{f}_{\mathrm{x}_{1}, \mathrm{x}_{2}}\left(\mathrm{x}_{1}, \mathrm{x}_{2}\right)=\varphi_{2}\left(\hat{\mathrm{u}}_{1}, \hat{\mathrm{u}}_{2}, \rho_{0,12}\right) \frac{\mathrm{f}_{\mathrm{x}_{1}}\left(\mathrm{x}_{1}\right) \mathrm{f}_{\mathrm{x}_{2}}\left(\mathrm{x}_{2}\right)}{\varphi\left(\hat{\mathrm{u}}_{1}\right) \varphi\left(\hat{\mathrm{u}}_{2}\right)}
$$

onde $\mathrm{f}_{\mathrm{x}_{\mathrm{i}}}\left(\mathrm{x}_{\mathrm{i}}\right)=\frac{\mathrm{dF}_{\mathrm{x}_{\mathrm{i}}}\left(\mathrm{x}_{\mathrm{i}}\right)}{\mathrm{dx}_{\mathrm{i}}}$ e $\varphi_{2}\left(\hat{\mathrm{u}}_{1}, \hat{\mathrm{u}}_{2}, \rho_{0,12}\right)$ é a função de densidade padrão de dimensão 2, com média nula, desvio padrão unitário e correlação igual a $\rho_{0,12}$.

A relação entre $\rho_{0,12}$ (correlação no espaço normal padrão) e $\rho_{12}$ (correlação no espaço físico) é obtida a partir da definição de correlação, podendo assim exprimir $\rho_{0,12}$ em função das densidades marginais de $x_{i}$, ou seja:

$$
\rho_{12}=\int_{-\infty}^{\infty} \int_{-\infty}^{\infty}\left(\frac{x_{1}-\mu_{1}}{\sigma_{1}}\right)\left(\frac{x_{2}-\mu_{2}}{\sigma_{2}}\right) \varphi_{2}\left(\hat{u}_{1}, \hat{u}_{2}, \rho_{0,12}\right) d \hat{u}_{1} d \hat{u}_{2}
$$

O modelo é válido se as seguintes condições forem satisfeitas:

$\checkmark$ A transformação é feita uma a uma; isso é possível se todas as funções de distribuição marginais são continuas e crescentes.

$\checkmark$ Os valores de $\rho_{0,12}$ são entre -1 e +1 . De acordo com Der Hiureghian e Liu, apud MOHAMED (1999), os valores de $\rho_{0,12}$ são fechados para os $\rho_{12}$.

Para simplificar os cálculos, considera-se a seguinte relação:

$$
\mathrm{f}=\frac{\rho_{0,12}}{\rho_{12}}
$$

onde f é um coeficiente calculado através de expressões que são funções dos coeficientes de variação $(\mathrm{CV})$, dos coeficientes de correlação $\left(\rho_{\mathrm{ij}}\right)$ e das distribuições marginais de ambas as variáveis. As expressões utilizadas para o cálculo de f encontram-se no Anexo C.

Determina-se f para cada par de variáveis correlacionadas, obtendo-se assim a matriz de correlação equivalente ou matriz de correlação no espaço normal padrão, 
dada por:

$$
\left[\rho_{0}\right] \equiv \rho_{0, \mathrm{ij}}=\mathrm{f} \cdot \rho_{\mathrm{ij}}
$$

Em seguida, passa-se do espaço normal padrão correlacionado (û) para o espaço normal padrão não correlacionado (u), ou variáveis gaussianas normais centradas reduzidas. Isto é feito através da triangularização de Cholesky:

$$
\left[\rho_{0}\right]=[\mathrm{L}] \cdot[\mathrm{L}]^{\mathrm{t}}
$$

fazendo

$$
\left[\Gamma_{0}\right]=[\mathrm{L}]^{-1}
$$

As variáveis normais centradas reduzidas são:

$$
\mathrm{u}_{\mathrm{i}}=\mathrm{T}_{\mathrm{i}}\left(\mathrm{x}_{\mathrm{j}}\right)=\Gamma_{0, \mathrm{ij}} \quad \hat{\mathrm{u}}_{\mathrm{j}}=\Gamma_{0, \mathrm{ij}} \quad \Phi^{-1}\left(\mathrm{~F}_{\mathrm{x}_{\mathrm{j}}}\left(\mathrm{x}_{\mathrm{j}}\right)\right)
$$

onde $\left[\Gamma_{0}\right]$ é a inversa da matriz triangular inferior da decomposição de Cholesky de $\left[\rho_{0}\right]$.

O esquema da transformação de Nataf apresenta-se em (5.22) e na Figura 5.1.

$$
\mathrm{f}(\mathrm{x}) \rightarrow \zeta(\hat{\mathrm{u}}, \rho) \rightarrow \varphi(\mathrm{u})
$$

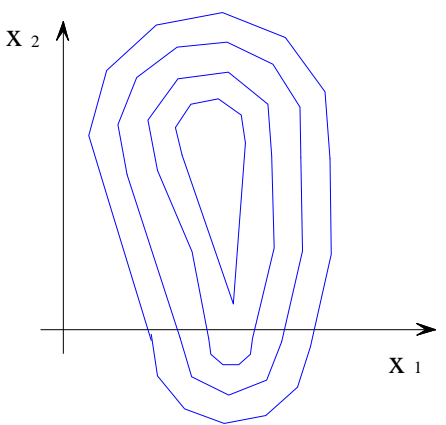

Espaço físico

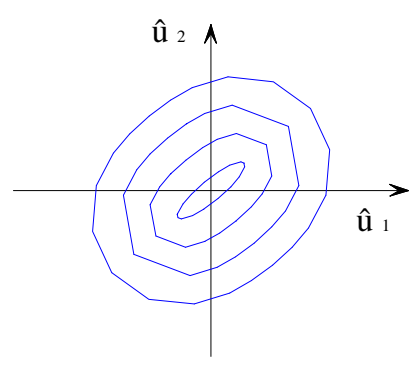

Espaço normal

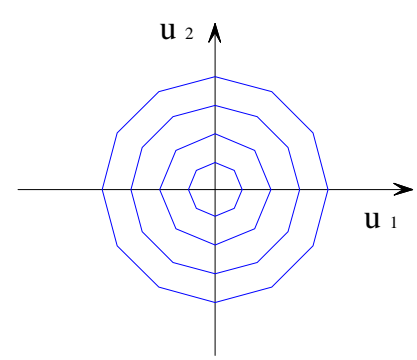

Espaço normal padrão

Figura 5.1 Transformação de espaços

Apresenta-se a seguir a transformação escrita em forma matricial:

$$
\{\mathrm{u}\}=\left[\Gamma_{0}\right] .\{\hat{\mathrm{u}}\}=\left[\Gamma_{0}\right] \cdot\left\{\Phi^{-1}\left(\mathrm{~F}_{\{\mathrm{x}\}}(\{\mathrm{x}\})\right)\right\}
$$

e a inversa é a seguinte:

$$
\begin{gathered}
\{\hat{\mathrm{u}}\}=\left[\Gamma_{0}\right]^{-1} \quad\{\mathrm{u}\}=[\mathrm{L}] \cdot\{\mathrm{u}\} \\
\{\mathrm{x}\}=\left\{\mathrm{F}_{\{\mathrm{x}\}}^{-1}(\Phi(\{\hat{\mathrm{u}}\}))\right\}=\left\{\mathrm{F}_{\{\mathrm{x}}^{-1}(\Phi([\mathrm{L}] \cdot\{\mathrm{u}\}))\right\}
\end{gathered}
$$




\subsection{Plano de experiência}

A evolução do RSM baseia-se em superfícies de resposta da estrutura válidas apenas em torno da solução do problema, que a priori não é conhecida. Portanto, utiliza-se um processo iterativo no qual as RS convergem para a solução. Para construir a RS de cada iteração necessita-se de um conjunto de situações da estrutura, que é construído variando as características das variáveis aleatórias do problema. Essa variação das variáveis de projeto obedece um critério predeterminado denominado plano de experiência $(\mathrm{EP})$.

Os planos de experiência são os principais responsáveis pela convergência do algoritmo e pelo custo computacional do modelo proposto. Na bibliografia há uma grande busca de novos planos de experiência para melhorar essas características, podendo dizer que qualquer proposta de um novo EP que forneça melhorias no custo computacional e que garanta a convergência do algoritmo ao menos para determinadas estruturas é aceita nas melhores revistas internacionais.

Os planos de experiência podem ser classificados em duas grandes categorias: o plano de experiência numérico e o plano de experiência aleatório. A diferença entre um EP numérico e um EP aleatório ou naturalista, é que, para duas experiências com dados idênticos, ao utilizar um EP numérico a igualdade entre os resultados é total, o que não acontece com planos de experiência naturalistas.

Os planos de experiência aleatórios podem conduzir a singularidades no sistema, exigindo um número maior de pontos para evitar essa singularidade. Uma outra característica é que os pontos não se localizam necessariamente em torno da solução devido a aleatoriedade, podendo necessitar de mais superfícies de resposta para a convergência do modelo. Entretanto, para problemas com elevado número de variáveis aleatórias pode se tornar difícil estabelecer um EP numérico que garanta convergência. Nessas situações o EP aleatório pode ser mais indicado.

Foram implementados planos de experiência aleatórios e numéricos no STST. A seguir descrevem-se procedimentos para planos de experiência numéricos, que foram mais largamente utilizados nesta tese. O procedimento para os planos de experiência aleatórios é semelhante, diferenciando apenas na geração dos pontos que nesse caso é aleatória. 
Plano de experiência numérico é um conjunto de valores determinísticos com os quais será aproximada a hipersuperfície da resposta estrutural. Ou seja, supõe-se um sistema de coordenadas, onde cada uma delas equivale a uma variável aleatória de resistência e uma outra equivale à resposta estrutural. O EP é responsável pela variação determinística das variáveis aleatórias para gerar a hipersuperfície da resposta estrutural também determinística, a qual definirá a hipersuperfície de ruína do problema mecânico-probabilístico.

Existem várias formas de EPs disponíveis em bibliografias. Entretanto, necessita-se definir seus coeficientes que melhor se adequam ao problema estudado. Os planos de experiência implementados no STST (estrela, hiper-cubo, fatorial completo, mínimo e composto) e seus coeficientes encontram-se no Anexo D. Estes EPs se classificam como planos de experiência numéricos clássicos e podem ser vistos na Figura 5.2, que por motivo didático foram impressos para duas ou três variáveis aleatórias apenas. É importante observar-se que os EPs são construídos no espaço reduzido. 

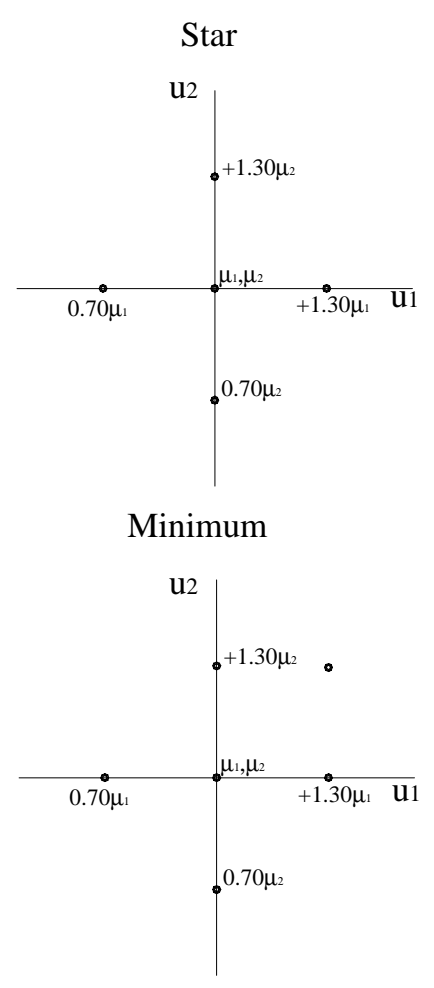

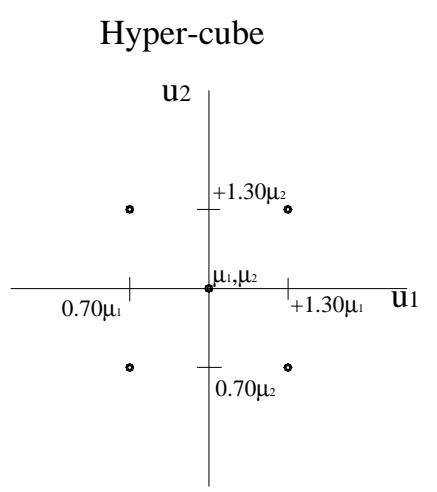

Composite

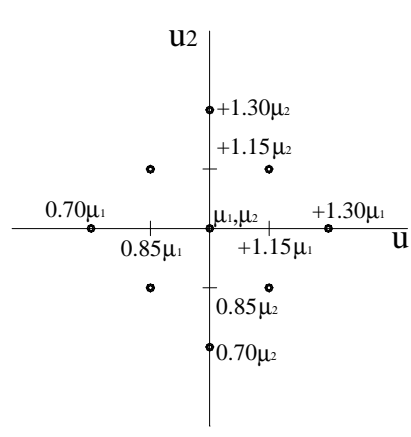

Complete factorial

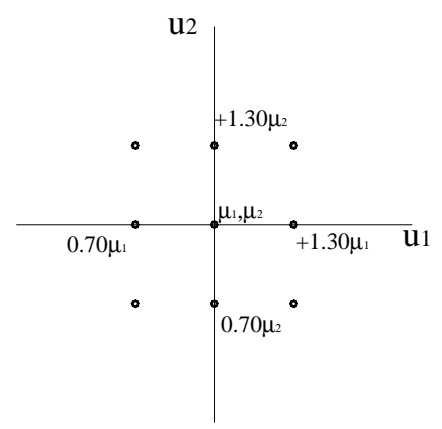

Complete factorial

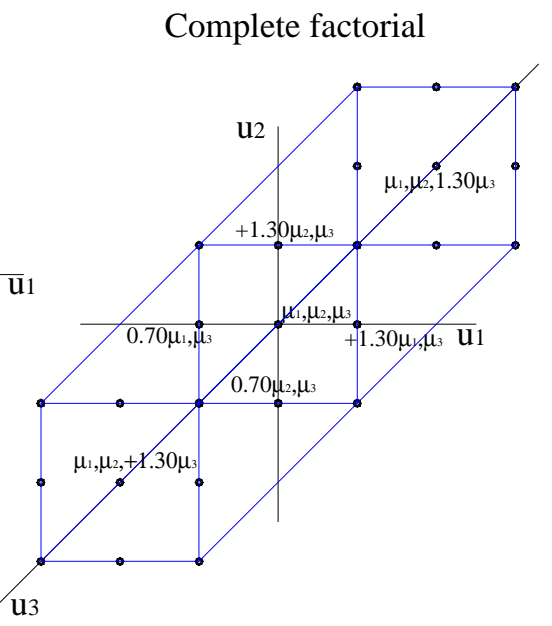

Figura 5.2 Planos de experiência numéricos adotados no presente trabalho

Os planos de experiência para um número de variáveis aleatórias superior a duas são semelhantes aos listados na Figura 5.2, acrescentados de pontos posicionados como os descritos nos dois primeiros eixos, $\mathrm{U}_{1}$ e $\mathrm{U}_{2}$. $\mathrm{O}$ número de novos pontos depende do número de coeficientes do polinômio aproximador $\left(\mathrm{n}_{\mathrm{c}}\right)$ da superfície de resposta.

A seguir lista-se o número de pontos $\left(\mathrm{n}_{\mathrm{p}}\right)$ de cada plano, que é função do número de coeficientes $\mathrm{n}_{\mathrm{c}}$ do polinômio aproximador da $\mathrm{RS}$ e do número de variáveis aleatórias $\left(\mathrm{n}_{\mathrm{va}}\right)$. Para um polinômio aproximador do segundo grau, tem-se a seguinte relação entre o número de VA e o número de coeficientes:

\begin{tabular}{|c|c|c|c|c|c|c|}
\hline $\mathrm{n}^{\mathrm{o}} \mathrm{VA}=\mathrm{n}_{\mathrm{va}}$ & 1 & 2 & 3 & 4 & 5 & 6 \\
\hline $\mathrm{nc}$ & 3 & 6 & 10 & 15 & 21 & 28 \\
\hline
\end{tabular}

$\checkmark$ Plano estrela: $\left\{\begin{array}{l}\mathrm{n}_{\mathrm{va}}=1 \therefore \mathrm{n}_{\mathrm{p}}=\mathrm{n}_{\mathrm{c}} \\ \mathrm{n}_{\mathrm{va}}>1 \therefore \mathrm{n}_{\mathrm{p}}=\mathrm{n}_{\mathrm{c}}-1\end{array}\right.$

$\checkmark$ Plano estrela 45 ou hiper-cubo: $\left\{\begin{array}{l}\mathrm{n}_{\mathrm{va}}=1 \therefore \mathrm{n}_{\mathrm{p}}=\mathrm{n}_{\mathrm{c}} \\ \mathrm{n}_{\mathrm{va}}>1 \therefore \mathrm{n}_{\mathrm{p}}=\mathrm{n}_{\mathrm{c}}-1\end{array}\right.$ 
$\checkmark$ Plano fatorial completo: $\quad\left\{n_{p}=3^{n_{\text {va }}}\right.$

$\checkmark$ Plano mínimo: $\quad\left\{\mathrm{n}_{\mathrm{p}}=\mathrm{n}_{\mathrm{c}}\right.$

$\checkmark$ Plano composto: $\left\{\begin{array}{l}\mathrm{n}_{\mathrm{va}}=1 \therefore \mathrm{n}_{\mathrm{p}}=5 \\ \mathrm{n}_{\mathrm{va}}>1 \therefore \mathrm{n}_{\mathrm{p}}=9\left(\mathrm{n}_{\mathrm{va}}-1\right)\end{array}\right.$

Além dos EPs numéricos clássicos, há os planos de experiência numéricos tabulados e orientados. Os tabulados utilizam tabelas predefinidas, tipo Taguchi, os quais pedem informações sobre interações das variáveis. Já os EPs orientados têm informações sobre a qualidade das variáveis, ou seja, sobre a posição provável da solução do problema representada por $\mathrm{P}^{*}$.

Os planos de experiência são responsáveis pelas superfícies de resposta adaptativas requeridas pelo RSM desde o início do processo iterativo até a convergência. A velocidade de convergência, ou custo computacional do método depende de uma boa escolha desses planos. A definição do melhor plano a ser utilizado deve ser feita caso a caso.

Em cada plano implementado há duas possibilidades para a evolução das superfícies adaptativas: com ou sem ponto de adaptação, procedimentos descritos a seguir.

Quando se usa ponto de adaptação, é eliminado apenas um ponto do plano de experiência de uma iteração para a outra. O ponto eliminado é o ponto mais afastado do último resultado, ou seja, do resultado da última iteração. Dessa forma, falta apenas um ponto para gerar a nova RS, e a este ponto serão atribuídas as características do resultado da última iteração. Este procedimento pode ser visto na Figura 5.3, onde o plano de experiência adotado foi o composto. $\mathrm{H}(\mathrm{U})$ é a função aproximadora no espaço reduzido da hipersuperfície limite FS que é obtida diretamente da RS; U representa as variáveis aleatórias no espaço normal padrão e $\mathrm{P}^{*}$ o ponto de projeto. 

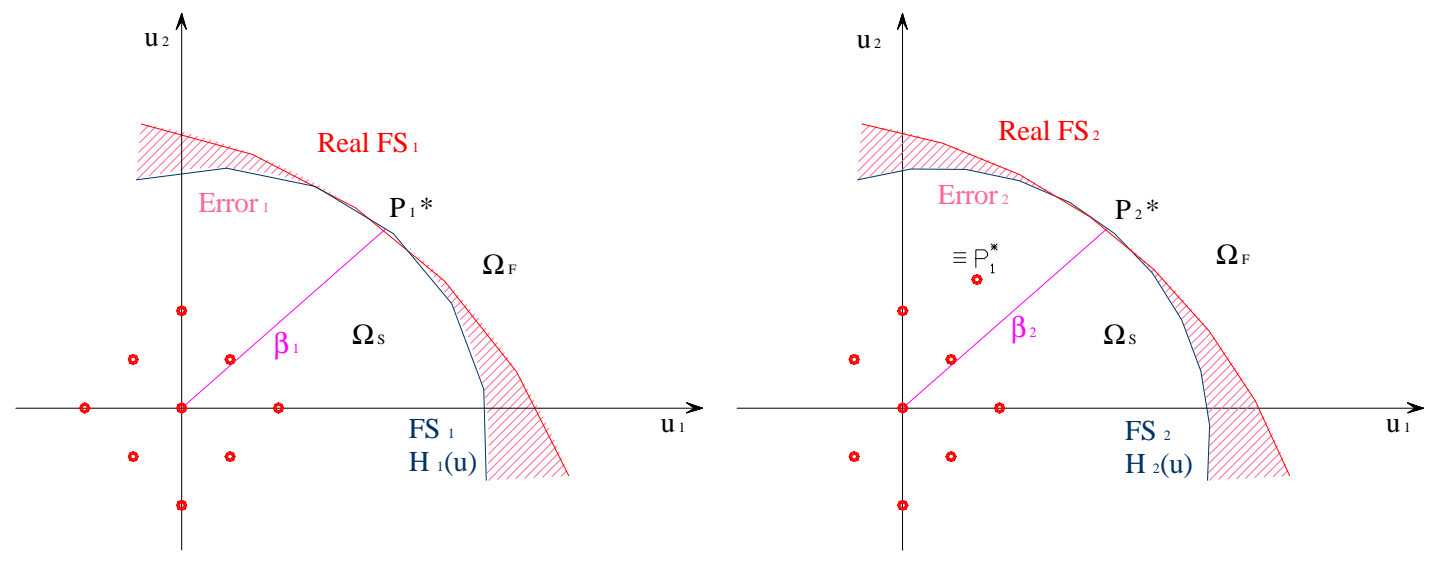

Figura 5.3 Evolução das superfícies de resposta utilizando ponto de adaptação. Plano de experiência Composto

Quando não se utiliza ponto de adaptação, são eliminados todos os pontos da iteração anterior. Então, é necessário definir todos os pontos da RS novamente. O ponto médio do plano de experiência, localizado no centro do sistema de coordenadas do EP no espaço reduzido, assume as características do resultado da última iteração, e os demais continuam de acordo com o EP adotado. Ou seja, o plano de experiência é transladado para o resultado da última iteração. Esse procedimento pode ser visto na Figura 5.4.
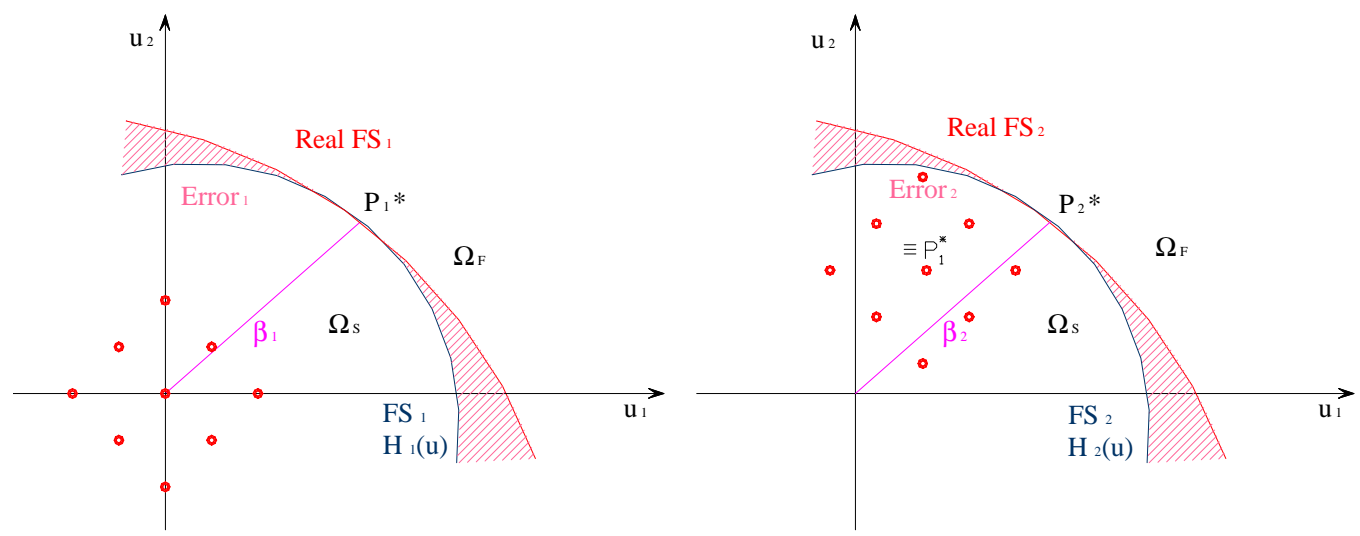

Figura 5.4 Evolução das superfícies de resposta sem ponto de adaptação

A escolha do plano de experiência numérico é a questão mais delicada do RSM. Não tem como generalizar qual EP é mais adequado para os problemas de confiabilidade estrutural, necessitando-se introduzir o conhecimento do engenheiro. É importante ter o máximo de informações a cada etapa para verificar a validação e adequação do EP escolhido.

Um exemplo prático de utilização de EP pode ser visto no Apêndice III. 


\subsection{Aproximações de pontos a uma superfície}

No caso da falta de informações sobre a FS, é necessário utilizar-se um método de regressão para determinar as constantes do polinômio aproximador (forma escolhida para aproximar a RS) da hipersuperfície de estado limite. Já foi visto também que a nuvem de pontos necessária para a regressão é fornecida pelo plano de experiência a cada iteração do RSM. Portanto, falta mostrar um método de regressão para um polinômio de dimensão e ordem quaisquer, definido no espaço de dimensão igual ao número de variáveis aleatórias mais um. Conhecendo-se esse procedimento, facilmente determina-se uma expressão para representar a superfície de estado limite da estrutura válida em torno do ponto de projeto.

A regressão é feita segundo o método dos mínimos quadrados, ou seja, minimiza o quadrado das distâncias entre as respostas reais e as aproximadas pelo polinômio. Por facilidade de compreensão, inicialmente mostra-se como fazer uma regressão para um polinômio do segundo grau e dimensão n. Posteriormente, o método é generalizado para polinômio de ordem qualquer.

Representam-se o polinômio por $\mathrm{Q}(\mathrm{X})$ e as respostas ou pontos, que dão origem à regressão, por $\mathrm{R}_{\mathrm{i}}$, que no caso equivalem às respostas mecânicas da estrutura. Então, $\mathrm{Q}(\mathrm{X})$ pode ser escrito da seguinte forma:

$$
\mathrm{Q}(\mathrm{X})=\mathrm{a}_{0}+\sum_{\mathrm{i}=1}^{\mathrm{n}} \mathrm{a}_{\mathrm{i}} \mathrm{x}_{\mathrm{i}}+\sum_{\mathrm{i}=1}^{\mathrm{n}} \sum_{\mathrm{j}=1}^{\mathrm{n}} \mathrm{b}_{\mathrm{ij}} \mathrm{x}_{\mathrm{i}} \mathrm{x}_{\mathrm{j}}
$$

onde $\mathbf{n}$ é o número de variáveis que define a dimensão do polinômio.

A regressão tem como objetivo minimizar a distância entre os pontos e a superfície aproximada, que é a incógnita. Então, o problema da regressão passa a ser um problema de minimização da seguinte forma:

$$
\min _{\mathrm{d}}=\min \sum_{\mathrm{k}=1}^{\mathrm{np}}\left(\mathrm{Q}\left(\mathrm{X}^{\mathrm{k}}\right)-\mathrm{R}^{\mathrm{k}}\right)^{2}
$$

onde np é o número de respostas ou pontos conhecidos.

Pode-se escrever $\mathrm{Q}(\mathrm{X})$ da seguinte forma:

$$
\mathrm{Q}(\mathrm{X})=\{\mathrm{A}\}^{\mathrm{t}}\{\mathrm{X}\}
$$

onde: 


$$
\begin{aligned}
& \{A\}^{t}=\left\{a_{0}, a_{1}, \ldots, a_{n}, b_{11}, \ldots, b_{n n}, b_{12}, \ldots, b_{(n-1) n}\right\} \\
& \{x\}^{t}=\left\{1, x_{1}, \ldots, x_{n}, x_{1}^{2}, \ldots, x_{n}^{2}, x_{1} x_{2}, \ldots, x_{(n-1)} x_{n}\right\}
\end{aligned}
$$

Então, a função de minimização passa a ser escrita como segue:

$$
\mathrm{d}=\min \sum_{\mathrm{k}=1}^{\mathrm{np}}\left(\left(\{\mathrm{A}\}^{\mathrm{t}}\left\{\mathrm{X}^{\mathrm{k}}\right\}-\mathrm{R}^{\mathrm{k}}\right)\left(\left\{\mathrm{X}^{\mathrm{k}}\right\}^{\mathrm{t}}\{\mathrm{A}\}-\mathrm{R}^{\mathrm{k}}\right)\right)
$$

Desenvolvendo-se (5.31):

$$
\left.\mathrm{d}=\min \sum_{\mathrm{k}=1}^{\mathrm{np}}\left(\{\mathrm{A}\}^{\mathrm{t}}\left\{\mathrm{X}^{\mathrm{k}}\right\} \mathrm{X}^{\mathrm{k}}\right\}^{\mathrm{t}}\{\mathrm{A}\}-2 \mathrm{R}^{\mathrm{k}}\{\mathrm{A}\}^{\mathrm{t}}\left\{\mathrm{X}^{\mathrm{k}}\right\}+\mathrm{R}^{\mathrm{k}^{2}}\right)
$$

Para obter um mínimo, basta anular o gradiente de d em relação aos coeficientes $\mathbf{a}_{\mathbf{i}}$. Ou seja:

$$
\nabla \mathrm{d}(\mathrm{A})=\frac{\partial \mathrm{d}(\mathrm{A})}{\partial\{\mathrm{A}\}^{\mathrm{t}}}=0
$$

Desenvolvendo-se (5.33):

$$
\left.\nabla \mathrm{d}(\mathrm{A})=\sum_{\mathrm{k}=1}^{\mathrm{np}}\left(2\left\{\mathrm{X}^{\mathrm{k}}\right\} \mathrm{X}^{\mathrm{k}}\right\}^{\mathrm{t}}\{\mathrm{A}\}-2 \mathrm{R}^{\mathrm{k}}\left\{\mathrm{X}^{\mathrm{k}}\right\}\right)=0
$$

ou, (5.34) pode ser escrito na forma:

$$
\left.\nabla \mathrm{d}(\mathrm{A})=\sum_{\mathrm{k}=1}^{\mathrm{np}}\left(\left\{\mathrm{X}^{\mathrm{k}}\right\} \mathrm{X}^{\mathrm{k}}\right\}^{\mathrm{t}}\{\mathrm{A}\}-\mathrm{R}^{\mathrm{k}}\left\{\mathrm{X}^{\mathrm{k}}\right\}\right)=0
$$

Fazendo-se:

$$
\begin{gathered}
\left.[P]=\sum_{k=1}^{n p}\left(\left\{X^{k}\right\} X^{k}\right\}^{T}\right) \\
\{V\}=\sum_{k=1}^{n p}\left(R^{k}\left\{X^{k}\right\}\right)
\end{gathered}
$$

Encontra-se o sistema de equações (5.38), onde $\{\mathrm{A}\}$ é o vetor incógnita ou o vetor dos coeficientes do polinômio:

$$
[\mathrm{P}]\{\mathrm{A}\}=\{\mathrm{V}\} \quad \text { ou } \quad\{\mathrm{A}\}=[\mathrm{P}]^{\mathrm{t}}\{\mathrm{V}\}
$$

Para expandir o raciocínio para um polinômio de ordem qualquer, o procedimento permanece o mesmo, mudam apenas os vetores $\{\mathrm{A}\}^{\mathrm{t}}$ e $\{\mathrm{X}\}^{\mathrm{t}}$; basta considerar:

$$
\{\mathrm{A}\}^{\mathrm{t}}=\left\{\mathrm{a}_{0}, \mathrm{a}_{1}, \ldots, \mathrm{a}_{\mathrm{m}}\right\}
$$




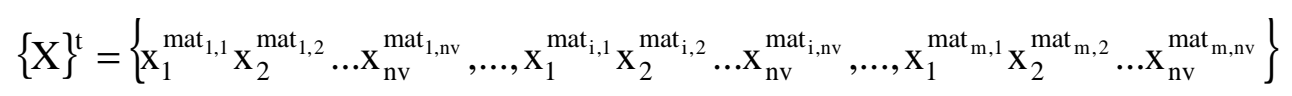

onde:

$$
[\mathrm{mat}]_{\mathrm{mxnv}}=\left[\begin{array}{cccccc}
\mathrm{i}_{11} & \mathrm{i}_{12} & \cdots & \mathrm{i}_{1 \mathrm{j}} & \cdots & \mathrm{i}_{1 \mathrm{nv}} \\
\mathrm{i}_{21} & \mathrm{i}_{22} & \cdots & \mathrm{i}_{2 \mathrm{j}} & \cdots & \mathrm{i}_{2 \mathrm{nv}} \\
\vdots & \vdots & & \vdots & & \vdots \\
\mathrm{i}_{\mathrm{k} 1} & \mathrm{i}_{\mathrm{k} 2} & \cdots & \mathrm{i}_{\mathrm{kj}} & \cdots & \mathrm{i}_{\mathrm{knv}} \\
\vdots & \vdots & & \vdots & & \vdots \\
\mathrm{i}_{\mathrm{m} 1} & \mathrm{i}_{\mathrm{m} 2} & \cdots & \mathrm{i}_{\mathrm{mj}} & \cdots & \mathrm{i}_{\mathrm{mnv}}
\end{array}\right] \backslash \mathrm{i} \in \mathrm{I} ; \sum_{\mathrm{j}=0}^{\mathrm{nv}} \mathrm{i}_{\mathrm{kj}} \leq \mathrm{ngp} ; \mathrm{i}=0,1, \ldots, \mathrm{ngp}
$$

[mat $]=$ matriz dos expoentes do polinômio;

$\mathrm{i}=$ expoente de $\mathrm{x}$

$\mathrm{m}=$ número de coeficientes do polinômio;

nv = número de variáveis, a dimensão do polinômio é nv +1 ;

ngp $=$ grau do polinômio.

Para 2 VA e polinômio do segundo grau, tem-se: [mat $]_{\mathrm{mxnv}}=\left[\begin{array}{cc}0 & 0 \\ 0 & 1 \\ 0 & 2 \\ 1 & 0 \\ 1 & 1 \\ 2 & 0\end{array}\right]$

\subsection{Cálculo do índice de confiabilidade}

Na maioria dos métodos utilizados para análise da confiabilidade necessita-se de um algoritmo de otimização para encontrar o ponto de projeto, ou a solução do problema. Nesses métodos, a otimização é utilizada para encontrar a mínima distância entre o ponto de projeto e o centro do sistema de coordenadas no espaço normal padrão não correlacionado.

Antes de comentar alguns algoritmos de otimização aplicados ao cálculo do índice de confiabilidade, serão introduzidas algumas notações:

$\checkmark$ x: variável aleatória (VA) no espaço físico;

$\checkmark$ u: variável aleatória no espaço normal padrão não correlacionado;

$\checkmark$ X, U: vetores das VA no espaço físico e normal padrão não correlacionado;

$\checkmark \mu, \sigma$ : média e desvio padrão das VA;

$\checkmark \alpha$ : cosseno diretor da VA no espaço normal padrão não correlacionado; 
$\checkmark \quad \beta$ : índice de confiabilidade;

$\checkmark \quad$ *: solução do problema;

$\checkmark$ G(.): função que representa a superfície limite (FS) da estrutura no espaço físico,

$$
\left\{\begin{array}{l}
\mathrm{G}(.)<0 \therefore \Omega_{\mathrm{f}} \\
\mathrm{G}(.)>0 \therefore \Omega_{\mathrm{s}} \\
\mathrm{G}(.)=0 \therefore \text { limite }
\end{array}\right.
$$

$\checkmark \quad \mathrm{H}($.$) : função que representa a FS da estrutura no espaço normal padrão;$

$\checkmark$ E[.]: média.

Grande parte dos algoritmos de otimização podem se classificar em dois grupos: SQP (Sequential Quadratic Program) e $S Q P$ direct. Os algoritmos $S Q P$ trabalham com a primeira derivada da função que se deseja otimizar, $\nabla \mathrm{G}(\mathrm{X})$, enquanto os $S Q P$ direct utilizam a primeira e segunda derivada da função, $\nabla \mathrm{G}(\mathrm{X})$ e $\nabla^{2} \mathrm{G}(\mathrm{X})$. Os dois grupos de algoritmos têm bom desempenho, dependem da situação ou tipo do problema. O $S Q P$ exige menor esforço matemático, pois trabalha apenas com o gradiente de $\mathrm{G}(\mathrm{X})$. Em algumas situações pode ser que o $S Q P$ direct tenha uma convergência mais rápida, uma vez que utiliza a hessiana de $G(X)$, entretanto é necessário calcular essa hessiana que apresenta muito mais expressões que o gradiente. Cada algoritmo tem suas vantagens e desvantagens, requerendo portanto uma análise caso a caso para a definição de sua utilização.

O método para cálculo da confiabilidade utilizado na versão final do software STST foi o método de superfície de resposta quadrática QRSM, ou mesmo cúbica CRSM. Para o QRSM é melhor utilizar algoritmos de otimização SQP. No QRSM, $\mathrm{G}(\mathrm{X})$ é representada por um polinômio do segundo grau, cuja derivada segunda é constante, levando a uma má convergência do $S Q P$ direct. Na versão final da tese propõe-se o uso para determinar a confiabilidade de uma estrutura.

Em seguida mostram-se alguns algoritmos de otimização que podem ser utilizados para encontrar o índice de confiabilidade de Hasofer \& Lind.

\subsubsection{Algoritmo de Rackwitz \& Fiessler}

Um dos algoritmos mais conhecidos no campo da confiabilidade é o algoritmo de Rackwitz \& Fiessler, que permite uma rápida determinação do ponto de projeto 
P*. Entretanto, há várias situações onde esse processo é falho: se houver muitos pontos de mínimo local; se a superfície de ruína for esférica portanto todos os pontos são mínimos; se a superfície de ruína apresenta ponto de sela pode haver oscilação na convergência para um mínimo global; se as derivadas da função de falha não forem contínuas.

Embora esse algoritmo requeira o cálculo das derivadas parciais da função de falha, função que representa a superfície de ruína da estrutura, que pode apresentar elevado custo computacional, especialmente para um número elevado de variáveis de projeto, tem bom desempenho quanto à convergência.

Cosidera-se nesse algoritmo que a reta entre a origem do sistema de coordenadas $\mathrm{U}$ e o ponto de projeto é normal à superfície de ruína no ponto de projeto, ou seja:

$$
u_{i}^{*}=\beta \alpha_{i}^{*}
$$

O algoritmo é organizado em 5 passos:

1. Escolha do ponto inicial. Geralmente:

$$
\mathrm{X}^{0}=\mathrm{E}[\mathrm{X}]
$$

2. Calcular:

$$
\begin{gathered}
G^{j}=G\left(x_{1}^{j}, x_{2}^{j}, \ldots, x_{n}^{j}\right) \\
\left.\nabla G_{i}^{j}=\frac{\partial G\left(x_{1}, x_{2}, \ldots, x_{n}\right)}{\partial x_{i}}\right]^{j} \\
\left.\sigma_{i}^{j}=\frac{\varphi\left[\Phi^{-1}\left(F_{x_{i}}\left(x_{i}\right)\right)\right]}{f_{x_{i}}\left(x_{i}\right)}\right]^{j} \\
\mu_{i}^{j}=x_{i}-\sigma_{i} \Phi^{-1}\left[F_{x_{i}}\left(x_{i}\right)\right]^{j}
\end{gathered}
$$

onde i é o índice da variável aleatória e j o índice da iteração. Ou seja: i $=1, \ldots, \mathrm{n}^{\mathrm{o}}$ de VA e $\mathrm{j}=0, \ldots$, até a convergência.

3. Calcular:

$$
\mathrm{x}^{\mathrm{j}}=\left.\left.\sum_{\mathrm{i}=1}^{\mathrm{n}} \nabla \mathrm{G}_{\mathrm{i}} \mathrm{x}_{\mathrm{i}}\right|_{;} ^{\mathrm{j}} \quad \mu_{\mathrm{x}}\right|^{\mathrm{j}}=\left.\left.\sum_{\mathrm{i}=1}^{\mathrm{n}} \nabla \mathrm{G}_{\mathrm{i}} \mu_{\mathrm{i}}\right|_{;} ^{\mathrm{j}} \quad \sigma_{\mathrm{x}}^{2}\right|^{\mathrm{j}}=\left.\sum_{\mathrm{i}=1}^{\mathrm{n}} \nabla \mathrm{G}_{\mathrm{i}}^{2} \sigma_{\mathrm{i}}^{2}\right|^{\mathrm{j}}
$$

4. Calcular: 


$$
\begin{gathered}
\alpha_{i}^{j}=\left.\frac{\nabla G_{i} \sigma_{i}}{\sigma_{x}}\right|^{j} \\
\beta^{j}=-\left.\frac{x-G-\mu_{x}}{\sigma_{x}}\right|^{j} \\
x_{i}^{j+1}=\mu_{i}+\left.\alpha_{i} \beta \sigma_{i}\right|^{j}
\end{gathered}
$$

5. Repete os passos 2, 3 e 4 até a convergência. Obtém os valores finais:

$$
\beta_{\mathrm{HL}}, \alpha_{\mathrm{i}}^{*}, \mathrm{u}_{\mathrm{i}}^{*}, \mathrm{x}_{\mathrm{i}}^{*}
$$

No caso de trabalhar diretamente no espaço normal padrão, o algoritmo resume-se à:

1. Escolha do ponto inicial. Geralmente:

$$
\mathrm{U}^{0}=\mathrm{E}[\mathrm{U}]=0
$$

2. Calcular:

$$
\begin{gathered}
\mathrm{H}^{\mathrm{j}}=\mathrm{H}\left(\mathrm{u}_{1}^{\mathrm{j}}, \mathrm{u}_{2}^{\mathrm{j}}, \ldots, \mathrm{u}_{\mathrm{n}}^{\mathrm{j}}\right) \\
\nabla \mathrm{H}_{\mathrm{i}}^{\mathrm{j}}=\left.\frac{\partial \mathrm{H}\left(\mathrm{u}_{1}, \mathrm{u}_{2}, \ldots, \mathrm{u}_{\mathrm{n}}\right)}{\partial \mathrm{u}_{\mathrm{i}}}\right|^{\mathrm{j}} ;\|\nabla\|^{\mathrm{j}}
\end{gathered}
$$

3. Calcular:

$$
\begin{gathered}
\alpha_{i}^{\mathrm{j}}=\frac{\nabla \mathrm{H}_{\mathrm{i}}^{\mathrm{j}}}{\|\nabla\|^{\mathrm{j}}} \quad ; \quad \beta^{\mathrm{j}}=+\frac{\mathrm{H}^{\mathrm{j}}-\left\{\nabla \mathrm{H}_{\mathrm{i}}^{\mathrm{j}}\right\}^{\mathrm{T}}\left\{\mathrm{u}_{\mathrm{i}}^{\mathrm{j}}\right\}}{\|\nabla \mathrm{H}\|^{\mathrm{j}}} \\
u_{\mathrm{i}}^{\mathrm{j}+1}=-\beta^{\mathrm{j}} \alpha_{\mathrm{i}}^{\mathrm{j}}
\end{gathered}
$$

4. Repetem-se os passos 2 e 3 até a convergência. Obtém os valores finais: $\beta_{\mathrm{HL}}, \alpha_{\mathrm{i}}^{*}, \mathrm{u}_{\mathrm{i}}^{*}$. Os valores de $\mathrm{x}_{\mathrm{i}}^{*}$ são obtidos através da transformação do espaço normal padrão $u_{i}^{*}$ para o espaço físico.

\subsubsection{Algoritmo de Madsen et al}

Este algoritmo foi apresentado em MOHAMED (1999). Baseia-se no desenvolvimento da série de Taylor no espaço normalizado $U$, apresentando uma seqüência próxima da utilizado no método de Newton-Raphson.

Considere: 


$$
\begin{gathered}
\nabla \mathrm{H}(\mathrm{u})=\left[\begin{array}{c}
\frac{\partial \mathrm{H}(\mathrm{u})}{\partial \mathrm{u}_{1}} \\
\frac{\partial \mathrm{H}(\mathrm{u})}{\partial \mathrm{u}_{2}} \\
\cdots \ldots . . . \\
\frac{\partial \mathrm{H}(\mathrm{u})}{\partial \mathrm{u}_{\mathrm{n}}}
\end{array}\right] \\
\alpha^{\mathrm{j}}=\frac{\nabla \mathrm{H}(\mathrm{u})}{\|\nabla \mathrm{H}(\mathrm{u})\|_{\mathrm{u}=\mathrm{u}^{\mathrm{j}}}}
\end{gathered}
$$

O desenvolvimento em primeira ordem da função de ruína fornece:

$$
H\left(u^{j}\right)+\left.\sum_{i=1}^{n} \frac{\partial H(u)}{\partial u_{i}}\right|_{u=u^{j}}\left(u_{i}-u_{i}^{j}\right)=0
$$

Então, o próximo ponto é:

$$
u^{j+1}=\left(\left(u^{j}\right)^{t} \cdot \alpha^{j}\right) \cdot \alpha^{j}+\left.\frac{H(u)}{\|H(u)\|}\right|_{u=u^{j}} \cdot \alpha^{j}
$$

O processo iterativo deve ser feito até a convergência:

$$
\mathrm{u}^{*}=\beta \alpha^{*} \quad \mathrm{H}\left(\mathrm{u}^{*}\right)=0
$$

\subsubsection{Algoritmo de Thoft-Christensen e Murotsu}

Este algoritmo foi apresentado em MOHAMED (1999). Procura-se a solução do seguinte problema:

$$
\mathrm{H}\left(\beta \alpha_{1}, \beta \alpha_{2}, \ldots, \beta \alpha_{n}\right)=0
$$

onde os cossenos diretores são definidos da seguinte forma:

$$
\alpha_{i}=-\frac{1}{k} \frac{\partial H\left(\beta \alpha_{j}\right)}{\partial u_{i}} \quad i=1,2, \ldots, n
$$

sendo o coeficiente $\mathrm{k}$ é dado por:

$$
k=\sqrt{\sum_{i=1}^{n}\left[\frac{\partial H\left(\beta \alpha_{j}\right)}{\partial u_{i}}\right]^{2}}
$$

O procedimento é descrito a seguir:

1. Escolha dos valores iniciais para: $\beta, \alpha_{1}, \alpha_{2}, \ldots, \alpha_{n}$.

2. Através da equação (5.63) calcula-se $\beta$. 
3. Para este valor de $\beta$ calcula-se a derivada parcial: $\partial \mathrm{H}(\beta \alpha) / \partial \mathrm{u}_{\mathrm{i}}$.

4. Calcula-se o coeficiente $\mathrm{k}$.

5. Calculam-se os cossenos diretores: $\alpha_{i}$.

6. Repetem-se os passos 2 ao 5 até a convergência.

\subsubsection{Método do Gradiente utilizando a hessiana do problema de otimização}

A superfície de resposta da estrutura no espaço normal padrão descrita pela equação (5.28) pode ser escrita da seguinte forma:

$$
\tilde{Q}(U)=\sum_{j}\left(a_{j} \cdot \prod_{i=1}^{n v} u_{i}^{m^{2} t_{j i}}\right)
$$

com: nv: número de variáveis aleatórias, exceto a solicitação, se ela for aleatória;

$\mathrm{j}$ : número de coeficientes do polinômio que representa a RS.

Conhecida a superfície de resposta, por definição a superfície de ruína é:

$$
\mathrm{H}(\mathrm{U})=\tilde{\mathrm{Q}}(\mathrm{U})-\mathrm{P}(\mathrm{u})=\sum_{\mathrm{j}}\left(\mathrm{a}_{\mathrm{j}} \cdot \prod_{\mathrm{i}=1}^{\mathrm{nv}} \mathrm{u}_{\mathrm{i}}^{\mathrm{mat}_{\mathrm{ji}}}\right)-\mathrm{u}_{\mathrm{P}}
$$

onde $\mathrm{P}$ é a solicitação no espaço reduzido, representado por $\mathrm{u}_{\mathrm{P}}$, e $\mathrm{a}_{\mathrm{j}}$ são os coeficientes do polinômio aproximador também nesse espaço.

A aleatoriedade das variáveis é introduzida na transformação do espaço físico para o espaço normal padrão. Desta forma, o problema de otimização a ser resolvido é explicitado por:

$$
\text { Minimize } d=\sqrt{\sum_{\mathrm{i}=1}^{\text {nva }} \mathrm{u}_{\mathrm{i}}^{2}} \quad \backslash \quad \mathrm{H}(\mathrm{U}) \leq 0 \quad \mathrm{u} \in \mathrm{R}^{\mathrm{nva}}
$$

onde: nva: número de variáveis aleatórias incluindo as solicitações.

O problema de otimização com restrição indicado em (5.68) pode ser resolvido como um problema de otimização sem restrição através da introdução de um multiplicador de Lagrange $\lambda$, resultando no seguinte sistema de equações e inequações:

$$
\begin{aligned}
& \nabla \mathrm{F}_{(\mathrm{u})}+\lambda \nabla \mathrm{H}_{(\mathrm{u})}=0 \\
& \lambda \mathrm{H}_{(\mathrm{u})}=0 \\
& \lambda \geq 0
\end{aligned}
$$

Admitindo-se que $\lambda$ é diferente de zero, pois isto levaria a solução trivial que 
não interessa, o sistema de equações (5.69) pode ser explicito na forma:

$$
\left[\frac{1}{\sqrt{\sum_{\mathrm{i}=1}^{\text {nva }} \mathrm{u}_{\mathrm{i}}^{2}}} \mathrm{u}_{\mathrm{k}}+\lambda \cdot \frac{1}{\mathrm{u}_{\mathrm{k}}} \sum_{\mathrm{j}} \mathrm{a}_{\mathrm{j}} \cdot \mathrm{mat}_{\mathrm{jk}} \prod_{\mathrm{i}=1}^{\mathrm{nv}} \mathrm{u}_{\mathrm{i}}^{\text {mat }_{\mathrm{ji}}}\right]=[0]
$$

onde k é a linha do sistema de equações correspondente a cada variável aleatória.

Para resolver o sistema de equações não-linear (5.70), pode-se utilizar um método numérico, como o processo iterativo de Newton Raphson, brevemente descrito nos seguintes passos (PROENÇA, 1989):

1. Assume-se valores iniciais para $\mathrm{U}^{\mathrm{t}}$;

2. calcula-se o vetor secante, $\mathrm{S}^{\mathrm{t}}$;

3. calcula-se o resíduo, $\phi^{\mathrm{t}}$;

4. verifica-se o erro. O processo adotado resume-se essencialmente em anular a função resíduo;

5. calcula-se a matriz tangente, $\mathrm{T}^{\mathrm{t}}$;

6. calcula-se o incremento $\Delta \mathrm{U}: \quad \mathrm{T}^{\mathrm{t}} \Delta \mathrm{U}=\phi^{\mathrm{t}}$

7. atualiza-se o vetor $\mathrm{U}: \quad \mathrm{U}^{\mathrm{t}+\Delta \mathrm{t}}=\mathrm{U}^{\mathrm{t}}+\Delta \mathrm{U}$

8. retorna-se ao passo 2 até que o resíduo se anule.

A seguir explicitam-se o vetor secante (S) e a função resíduo $(\phi)$.

$$
\begin{gathered}
S=\left[\frac{1}{\sqrt{\sum_{\mathrm{i}=1}^{\text {nva }} \mathrm{u}_{\mathrm{i}}^{2}}} \mathrm{u}_{\mathrm{k}}+\lambda \cdot \frac{1}{\mathrm{u}_{\mathrm{k}}} \sum_{\mathrm{j}} \mathrm{a}_{\mathrm{j}} \cdot \mathrm{mat}_{\mathrm{jk}} \prod_{\mathrm{i}=1}^{\mathrm{nv}} \mathrm{u}_{\mathrm{i}}^{\mathrm{mat}_{\mathrm{ji}}}\right. \\
\phi=\left\{\begin{array}{l}
0 \\
\vdots \\
P
\end{array}\right\}-\{S\}=\left\{\begin{array}{l}
\varphi_{1} \\
\vdots \\
\varphi_{\text {nva }+1}
\end{array}\right\}
\end{gathered}
$$

A matriz tangente (T) é obtida através do gradiente da função resíduo, ou seja: 


$$
\mathrm{T}=\left[\begin{array}{cccc}
\frac{\partial \varphi_{\mathrm{k}}}{\partial \mathrm{u}_{\ell}} & \cdots & \frac{\partial \varphi_{\mathrm{k}}}{\partial \mathrm{u}_{\mathrm{p}}} & \frac{\partial \varphi_{\mathrm{k}}}{\partial \lambda} \\
\vdots & & \vdots & \vdots \\
\frac{\partial \varphi_{\mathrm{k}}}{\partial \mathrm{u}_{\mathrm{p}}} & \cdots & & \\
\frac{\partial \varphi_{\mathrm{k}}}{\partial \lambda} & \cdots & &
\end{array}\right]
$$

onde:

$$
\begin{gathered}
\frac{\partial \varphi_{\mathrm{k}}}{\partial \mathrm{u}_{\ell}}=\frac{-1}{\sqrt{\left(\sum_{\mathrm{i}=1}^{\mathrm{nva}} \mathrm{u}_{\mathrm{i}}^{2}\right)^{3}}} \mathrm{u}_{\mathrm{k}} \mathrm{u}_{\ell}+\lambda \frac{1}{\mathrm{u}_{\mathrm{k}} \mathrm{u}_{\ell}} \sum_{\mathrm{j}} \mathrm{a}_{\mathrm{j}} \cdot \mathrm{n}_{\mathrm{jk}} \cdot \mathrm{n}_{\mathrm{j} \ell} \prod_{\mathrm{i}=1}^{\mathrm{nv}} \mathrm{u}_{\mathrm{i}}^{\mathrm{n}_{\mathrm{ji}}} \quad \mathrm{k}, \ell=1, \cdots, \mathrm{nv} \\
\frac{\partial \varphi_{\mathrm{k}}}{\partial \mathrm{u}_{\mathrm{p}}}=\frac{-1}{\sqrt{\left(\sum_{\mathrm{i}=1}^{\mathrm{nva}} \mathrm{u}_{\mathrm{i}}^{2}\right)^{3}}} \mathrm{u}_{\mathrm{k}} \mathrm{u}_{\mathrm{p}} \\
\frac{\partial \varphi_{\mathrm{k}}}{\partial \lambda}=\frac{1}{\mathrm{u}_{\mathrm{k}}} \sum_{\mathrm{j}} \mathrm{a}_{\mathrm{j}} \cdot \mathrm{n}_{\mathrm{jk}} \prod_{\mathrm{i}=1}^{\mathrm{nv}} \mathrm{u}_{\mathrm{i}}^{\mathrm{n}_{\mathrm{i} i}}
\end{gathered}
$$

Resolvendo-se o processo iterativo, determina-se $\mathrm{u}_{\mathrm{i}}$.

\subsection{Cálculo da probabilidade de ruína}

Os métodos mais utilizados para estimar a probabilidade de ruína de uma estrutura quando já foi determinado o seu índice de confiabilidade é o FORM (First Order Reliability Method) e o SORM (Second Order Reliability Method). A seguir descrevem-se esses dois métodos, onde uma variedade de aproximações SORM é apresentada.

\subsubsection{Método de confiabilidade de primeira ordem - FORM}

O método de confiabilidade de primeira ordem fornece uma estimativa da probabilidade de ruína linearizando a superfície de ruína (ou superfície de estado limite) no ponto de projeto $u_{i}^{*}$ no espaço normal padrão, ou seja:

$$
\mathrm{H}\left(\mathrm{u}_{\mathrm{i}}\right) \approx \mathrm{H}\left(\mathrm{u}_{\mathrm{i}}^{*}\right)+\left.\frac{\partial \mathrm{H}\left(\mathrm{u}_{\mathrm{j}}\right)}{\partial \mathrm{u}_{\mathrm{i}}}\right|_{\mathrm{u}_{\mathrm{j}}=\mathrm{u}_{\mathrm{j}}^{*}}\left(\mathrm{u}_{\mathrm{i}}-\mathrm{u}_{\mathrm{i}}^{*}\right) \approx \mathrm{H}\left(\mathrm{u}_{\mathrm{i}}^{*}\right)+\alpha_{\mathrm{i}}^{*}\left(\mathrm{u}_{\mathrm{i}}-\mathrm{u}_{\mathrm{i}}^{*}\right)
$$

Como a superfície de ruína é nula, $\mathrm{H}\left(\mathrm{u}_{\mathrm{i}}^{*}\right)=0$, tem-se: 


$$
\mathrm{H}\left(\mathrm{u}_{\mathrm{i}}\right) \approx \alpha_{\mathrm{i}}^{*} \mathrm{u}_{\mathrm{i}}-\alpha_{\mathrm{i}}^{*} \mathrm{u}_{\mathrm{i}}^{*} \approx \alpha_{\mathrm{i}}^{*} \mathrm{u}_{\mathrm{i}}+\beta
$$

A expressão (5.78) fornece a equação do hiperplano tangente para a superfície de ruína no ponto de projeto.

A probabilidade de ruína é dada por:

$$
\begin{aligned}
& \mathrm{P}_{\mathrm{f}}=\mathrm{P}\left[\mathrm{H}\left(\mathrm{x}_{\mathrm{i}}\right) \leq 0\right]=\mathrm{P}\left[\mathrm{H}\left(\mathrm{u}_{\mathrm{i}}\right) \leq 0\right] \\
& \mathrm{P}_{\mathrm{f}} \cong \mathrm{P}\left[\alpha_{\mathrm{i}}^{*} \mathrm{u}_{\mathrm{i}}+\beta \leq 0\right]=\mathrm{P}\left[\alpha_{\mathrm{i}}^{*} \mathrm{u}_{\mathrm{i}} \leq-\beta\right]=\Phi[-\beta]
\end{aligned}
$$

onde $\Phi[\cdot]$ é a função de distribuição acumulada padrão de apenas uma variável. Então, a aproximação FORM da probabilidade de ruína é:

$$
\mathrm{P}_{\mathrm{f}} \cong \Phi[-\beta]
$$

Por facilidade didática, facilmente entende-se o método em questão quando utiliza-se apenas uma única variável aleatória. Portanto, nesse caso, tem-se o seguinte procedimento:

$$
\mathrm{i}=1 \quad \therefore \quad \alpha_{\mathrm{i}}=1 \quad \rightarrow \quad \mathrm{H}\left(\mathrm{u}_{1}\right) \approx \mathrm{u}_{1}+\beta
$$

Nessa situação, a probabilidade de ruína é dada por:

$$
\begin{aligned}
& \mathrm{P}_{\mathrm{f}}=\mathrm{P}\left[\mathrm{H}\left(\mathrm{x}_{1}\right) \leq 0\right]=\mathrm{P}\left[\mathrm{H}\left(\mathrm{u}_{1}\right) \leq 0\right] \\
& \mathrm{P}_{\mathrm{f}} \cong \mathrm{P}\left[\mathrm{u}_{1}+\beta \leq 0\right]=\mathrm{P}\left[\mathrm{u}_{1} \leq-\beta\right]=\Phi[-\beta]
\end{aligned}
$$

Na superfície limite, $\mathrm{H}\left(\mathrm{u}_{1}\right)=0$, portanto:

$$
\begin{aligned}
& \mathrm{P}_{\mathrm{f}}=\mathrm{P}\left[\mathrm{H}\left(\mathrm{x}_{1}\right)=0\right]=\mathrm{P}\left[\mathrm{H}\left(\mathrm{u}_{1}\right)=0\right] \\
& \mathrm{P}_{\mathrm{f}} \cong \mathrm{P}\left[\mathrm{u}_{1}+\beta=0\right]=\mathrm{P}\left[\mathrm{u}_{1}=-\beta\right]=\Phi[-\beta]
\end{aligned}
$$

De acordo com a expressão (5.83), no caso de apenas uma variável na situação limite, o valor do índice de confiabilidade se confunde com o valor da abscissa no espaço normal padrão com o sinal trocado, ver Figura 5.5.

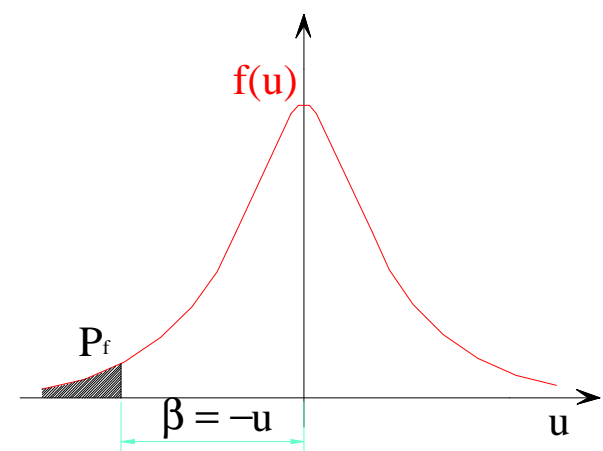

Figura 5.5 Interpretação gráfica do FORM no caso de apenas 1 variável aleatória.

O sinal do erro na aproximação FORM depende se a superfície de ruína é 
côncava (a favor da segurança) ou convexa (contra a segurança), Figura 5.6. Uma aproximação FORM é suficiente se a curvatura da superfície de ruína é pequena (não há maiores problemas em linearizar a FS) e a probabilidade de ruína é um valor muito pequeno (a variação dos quantis nas extremidades da curva normal padrão não é relativamente sensível à abscissa do sistema de coordenadas). Na prática da engenharia geralmente ocorrem casos como esses.

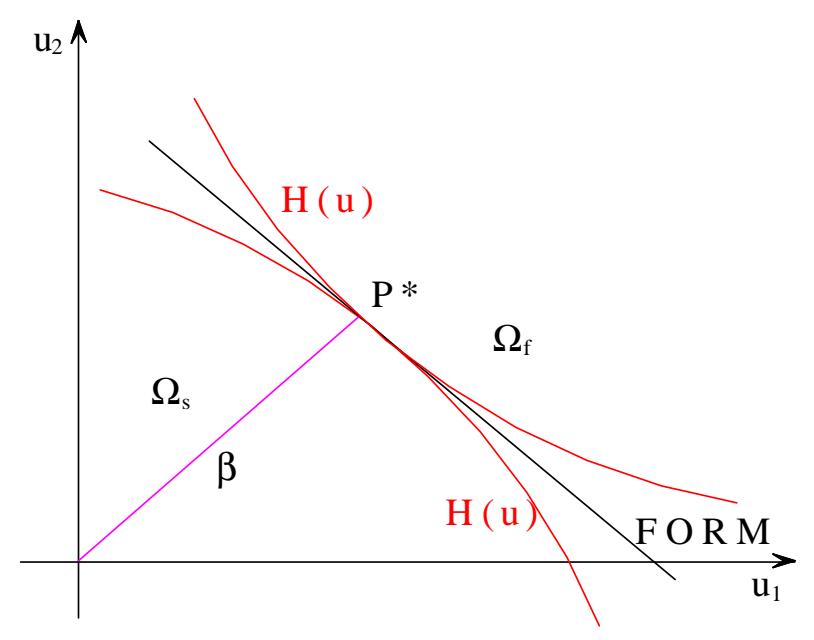

Figura 5.6 Sinal do erro na aproximação FORM

\subsubsection{Método de confiabilidade de segunda ordem - SORM}

Para melhorar a qualidade das aproximações introduz-se o SORM, baseado na idéia original do FORM. O SORM necessita-se de mais informações sobre a superfície de ruína em comparação com o FORM, além do índice de confiabilidade, necessário para ambos os métodos; no SORM são necessários anda conhecimentos sobre as curvaturas principais da superfície de ruína. É utilizada uma superfície quadrática no lugar do plano tangente utilizado no FORM.

Segundo MOHAMED (1999), para o ponto de projeto $\mathrm{P}^{*}$, a superfície quadrática deve ter as seguintes características:

$\checkmark$ Deve ser contínua e duas vezes diferenciável.

$\checkmark$ Deve ter o mesmo plano tangente que a superfície de ruína.

$\checkmark$ Deve ter a curvatura principal que a superfície de ruína.

São disponíveis várias aproximações para a superfície quadrática utilizada no SORM, sendo a escolha do tipo dependente do interesse da relação precisão versos 
custo. A seguir citam-se algumas dessas aproximações descritas em MOHAMED (1999).

A aproximação esférica da superfície de ruína é a mais simples utilizada no SORM. Para curvatura convexa, a probabilidade de ruína sobre a fronteira é determinada por uma hiperesfera centrada na origem. Esta fronteira é dada por:

$$
\mathrm{H}\left(\mathrm{u}_{\mathrm{i}}^{*}\right) \approx \sum_{\mathrm{i}=1}^{\mathrm{n}} \mathrm{u}_{\mathrm{i}}^{* 2}-\beta^{2}=\chi_{\mathrm{n}}^{2}-\beta^{2}
$$

A probabilidade de ruína é dada por:

$$
\begin{aligned}
& \mathrm{P}_{\mathrm{f}}=\mathrm{P}\left[\mathrm{H}\left(\mathrm{u}_{\mathrm{i}}\right) \leq 0\right] \\
& \mathrm{P}_{\mathrm{f}} \cong \mathrm{P}\left[\chi_{\mathrm{n}}^{2}-\beta^{2} \leq 0\right]=\mathrm{P}\left[\chi_{\mathrm{n}}^{2} \leq \beta^{2}\right]=1-\chi_{\mathrm{n}}^{2}\left(\beta^{2}\right)
\end{aligned}
$$

onde $\chi_{\mathrm{n}}^{2}(\cdot)$ é a distribuição Chi-quadrada com $\mathrm{n}$ graus de liberdade.

O número de graus de liberdade é igual ao número de eixos do sistema de coordenadas da superfície de resposta da estrutura, ou seja, o número de variáveis aleatórias mais um.

Segundo MOHAMED (1999), a melhor aproximação é obtida por hiper-esfera excêntrica com raio $\mathrm{R}$ igual a média da curvatura principal do estado limite no ponto de projeto; o centro é então tomado pela linha reta definida pelo cosseno diretor $\alpha_{i}$. A probabilidade de ruína é aproximada por:

$$
\mathrm{P}_{\mathrm{f}} \cong 1-\chi_{\mathrm{n}, \delta}^{2}\left(\mathrm{R}^{2}\right)
$$

onde $\chi_{\mathrm{n}, \delta}^{2}($.$) é a distribuição Chi-quadrada com n graus de liberdade e parâmetro de$ excentricidade $\delta=\mathrm{R}+\beta$, e R é o raio da esfera.

Esses métodos são baseados em aproximações parabólicas da superfície de ruína. Geralmente apresentam boa aproximação da probabilidade de ruína. Para o seu desenvolvimento devem ser feitas duas rotações no espaço normal padrão, descritas a seguir:

$\checkmark$ No plano de rotação, deve-se girar o eixo $n$ (eixo das respostas estruturais) na direção do ponto de projeto, ou seja, na direção definida pelos cossenos diretores. 
$\checkmark$ Fora do plano de rotação, deve-se girar todos os eixos, com exceção do eixo n, nas direções das curvaturas principais da FS.

A intenção dessas rotações é eliminar os termos cruzados e deduzir expressões analíticas.

Breitung, apud MOHAMED (1999), desenvolveu uma expressão simples baseado em expressões assintóticas da probabilidade de ruína no espaço multinormal para grandes valores de índices de confiabilidade. A superfície de ruína é aproximada por uma superfície parabólica com as mesmas curvaturas principais no ponto de projeto. De acordo com Breitung, o desenvolvimento assintótico fornece:

$$
\mathrm{P}_{\mathrm{f}} \cong \Phi(-\beta) \prod_{\mathrm{i}=1}^{\mathrm{n}-1}\left(1+\beta \mathrm{k}_{\mathrm{i}}\right)^{-1 / 2}
$$

onde $\mathrm{k}_{\mathrm{i}}$ são as curvaturas principais da superfície de ruína no ponto de projeto. A expressão (5.87) é conhecida como fórmula de Breitung, que pode ser compreendida como um fator de correção que multiplica o FORM, $\Phi(-\beta)$. Esta expressão converge para a solução exata quando $\beta$ tende a infinito. Não é aplicável é quando $\beta \mathrm{k}_{\mathrm{i}} \leq-1$.

Para valores pequenos do índice de confiabilidade, Tvedt apud MOHAMED (1999), desenvolveu uma expressão assintótica melhor que a anterior, baseada na expansão da série de Taylor:

$$
\begin{gathered}
\mathrm{P}_{\mathrm{f}} \cong \mathrm{T}_{1}+\mathrm{T}_{2}+\mathrm{T}_{3} \\
\mathrm{~T}_{1}=\Phi(-\beta) \prod_{\mathrm{i}=1}^{\mathrm{n}-1}\left(1+\beta \mathrm{k}_{\mathrm{i}}\right)^{-1 / 2} \\
\mathrm{~T}_{2}=[\beta \Phi(-\beta)-\varphi(-\beta)]\left[\prod_{\mathrm{i}=1}^{\mathrm{n}-1}\left(1+\beta \mathrm{k}_{\mathrm{i}}\right)^{-1 / 2}-\prod_{\mathrm{i}=1}^{\mathrm{n}-1}\left(1-(1+\beta) \mathrm{k}_{\mathrm{i}}\right)^{-1 / 2}\right] \\
\mathrm{T}_{3}=(1+\beta)[\beta \Phi(-\beta)-\varphi(-\beta)]\left[\prod_{\mathrm{i}=1}^{\mathrm{n}-1}\left(1+\beta \mathrm{k}_{\mathrm{i}}\right)^{-1 / 2}-\operatorname{Re}\left[\prod_{\mathrm{i}=1}^{\mathrm{n}-1}\left(1-(\mathrm{j}+\beta) \mathrm{k}_{\mathrm{i}}\right)^{-1 / 2}\right]\right]
\end{gathered}
$$

onde $\operatorname{Re}[\cdot]$ é a parte real da expressão e $\mathrm{j}=\sqrt{-1}$ é o número imaginário.

Note que o termo $\mathrm{T}_{1}$ é o mesmo dado por Breitung.

Segundo KIUREGHIAN \& DAKESSIAN (1998), observou-se através de experiências que aproximações FORM e SORM são suficientemente precisas para 
problemas de engenharia.

\subsection{Formulação do Problema}

Seja $\mathrm{X}$ o vetor de variáveis aleatórias e $\mathrm{G}(\mathrm{X})$ a função de estado limite, onde:

$>\mathrm{G}(\mathrm{X})>0$ é uma realização de sucesso, $\mathrm{x}_{\mathrm{i}} \in \Omega_{\mathrm{s}}$, domínio de segurança;

$>\mathrm{G}(\mathrm{X})<0$ é uma realização de ruína, $\mathrm{x}_{\mathrm{i}} \in \Omega_{\mathrm{f}}$, domínio de ruína;

$>\mathrm{G}(\mathrm{X})=0$ é a função de estado limite.

Se a função aproximadora da RS é representada por $\mathrm{Q}(\mathrm{X})$, a função de estado limite é determinada por:

$$
\mathrm{G}(\mathrm{X})=\mathrm{Q}(\mathrm{X})-\mathrm{P}_{\mathrm{S}}
$$

onde $\mathrm{P}_{\mathrm{s}}$ é o esforço solicitante.

O problema de confiabilidade a ser resolvido é definido por:

$$
\operatorname{Prob}\left[\left(\mathrm{Q}(\mathrm{X})-\mathrm{P}_{\mathrm{S}}\right) \leq 0\right]
$$

Para calcular o índice de confiabilidade, o vetor $\mathrm{X}$ das variáveis aleatórias no espaço físico passa a ser o vetor $U$ das mesmas variáveis no espaço normalizado não correlacionado através de uma transformação isoprobabilística T. O vetor $U$ é composto de variáveis normais padronizadas não correlacionadas, $\mathrm{N}(0,1)$. A transformação $\mathrm{T}$ deve ser capaz de incluir todos os casos possíveis (independência, truncação, correlação e composição), e as dimensões $m$ e $n$ dos espaços padronizados e físicos podem ser diferentes.

O índice de confiabilidade Hasofer \& Lind ( $\beta$ ) é então calculado resolvendo-se o problema de otimização (5.94):

$$
\begin{aligned}
& \beta=\min \left(\sqrt{\sum_{\mathrm{i}=1}^{m} \mathrm{u}_{\mathrm{i}}^{2}}\right) \\
& \text { restriçao } \mathrm{H}\left(\mathrm{u}_{\mathrm{i}}\right) \leq 0
\end{aligned}
$$

A solução fornece o valor do índice de confiabilidade, a coordenada $u_{i}{ }^{*}$ do ponto de projeto $\mathrm{P}^{*}$, e o cosseno diretor $\alpha_{i}$ da direção $\mathrm{P}^{*} \mathrm{O}$ no espaço padronizado que é o fator de sensibilidade. A interpretação gráfica do problema encontra-se na Figura

\section{7 .}




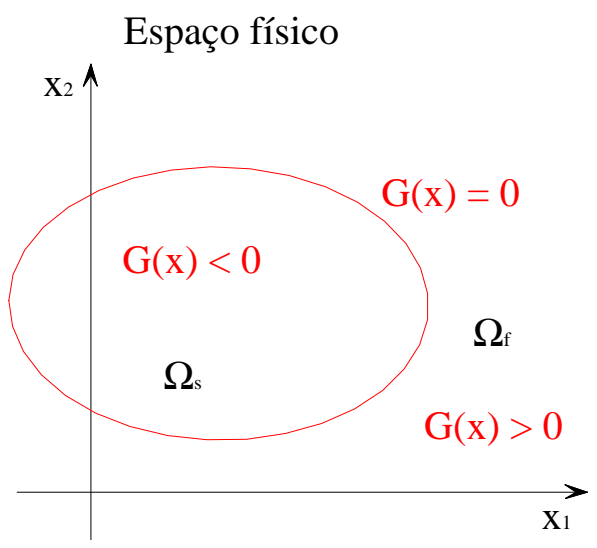

Espaço normal padrão

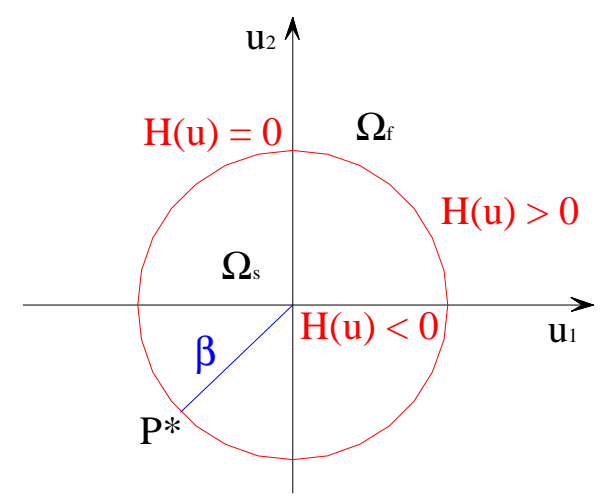

Figura 5.7 Interpretação gráfica do problema de confiabilidade estrutural $\beta$ é a mínima distância da origem $O$ à superficie $H\left(u_{i}\right)=0$

\subsection{Metodologia da versão final do STST}

A seguir comenta-se o desenvolvimento da terceira e última versão do software STST, no qual a solução do problema mecânico-confiabilístico é dada pela união do FEM com RSM podendo ser considerado como SFEM.

Antes de descrever a determinação de $\mathrm{S}$ e $\mathrm{R}$, deixa-se claro que é preciso definir o estado limite de trabalho. O software permite o cálculo mecânicoconfiabilístico no estado limite último ou no estado limite de serviço. Caso deseje-se implementar outro estado limite, isso pode ser feito facilmente.

No estado limite de serviço, tanto a RS como S (quando for o caso de estudo de coeficientes parciais de segurança), são definidos pelo limite de deslocamento de um determinado nó da malha de elementos finitos. Para verificar esse limite, é feita uma análise em todos os nós da estrutura. Salienta-se que a convergência do RSM não é boa se forem utilizados deslocamentos para construção do problema, deve-se utilizar coeficientes de carga como será descrito posteriormente.

No estado limite último, tanto a RS como $\mathrm{S}$ (quando for o caso de estudo de coeficientes parciais de segurança), são definidos pela singularidade da matriz de rigidez global da estrutura, ou seja, pela instabilidade global da estrutura.

Para calcular a confiabilidade de qualquer estrutura é necessário conhecer uma solicitação $\mathrm{S}$ e uma resistência $\mathrm{R}$, brevemente descritas nos próximos dois itens. 


\subsubsection{Busca da solicitação (S)}

O valor atribuído a S é o coeficiente de carga (coeficiente com o qual as ações externas são multiplicadas), definido de duas formas no software STST:

$\checkmark$ Caso no qual deseje-se verificar a confiabilidade de uma determinada estrutura, S é o coeficiente de carga equivalente ao próprio carregamento externo médio, ou seja, S é igual a unidade.

$\checkmark$ Se o objetivo é calcular índices de confiabilidade para os coeficientes parciais propostos por diferentes Normas, o valor de $\mathrm{S}$ é definido pelo coeficiente de carga que conduz a estrutura ao estado limite quando essa é calculada com resistências e solicitações alteradas por coeficientes parciais de segurança. Este procedimento é descrito a seguir.

Para resistências de cálculo $\mathrm{f}_{\mathrm{cd}}$ e $\mathrm{f}_{\mathrm{yd}}$, calcula-se o coeficiente de carga limite global da estrutura $\left(\mathrm{S}^{*}\right)$ através do software de análise mecânica não-linear (parte do conjunto de programas desenvolvidos nessa tese). Para este coeficiente obtido, a condição de projeto é dada pela inequação: $\gamma_{\mathrm{f}} \mathrm{S} \leq \mathrm{S}^{*}$. A respeito do coeficiente de carga limite, tem-se: $\mathrm{S}=\mathrm{S}^{*} / \gamma_{\mathrm{f}}$, onde $\mathrm{S}$ é o coeficiente de carga externa. Com esse procedimento, é possível encontrar o índice de confiabilidade $\beta$ relativo aos coeficientes parciais utilizados na prática da engenharia.

Resumindo o procedimento acima, é fácil notar que $\mathrm{S}^{*}$ é o coeficiente de carga limite determinado pelo modelo mecânico com resistência reduzida por coeficientes parciais, como $\gamma_{\mathrm{c}}$ e $\gamma_{\mathrm{s}}$, ou seja:

$$
\mathrm{f}_{\mathrm{cd}}, \mathrm{f}_{\mathrm{yd}}, \mathrm{V} \rightarrow \text { modelo mecânico } \rightarrow \mathrm{S}^{*}
$$

$\mathrm{V}$ = restante das variáveis estruturais tais como geometria, condições de contorno, etc.

Finalmente, $S$ é determinado por: $S=S^{*} / \gamma_{f}$

\subsubsection{Busca da resistência $(R)$}

O esforço resistente é representado pela superfície de resposta da estrutura (RS). Se a RS for elaborada com as respostas da estrutura no estado limite, pode-se dizer que a superfície de resposta se confunde com a superfície limite da estrutura. 
Para encontrar a RS utiliza-se a seqüência seguinte:

$\checkmark$ Define-se o plano de experiência a ser utilizado.

$\checkmark$ Encontram-se as respostas mecânicas referentes ao plano de experiência, isso é feito pelo software STST. As respostas mecânicas são escritas em termos de coeficientes de carga que conduzem a estrutura ao estado limite. Estas respostas mecânicas são obtidas sem considerar coeficientes parciais. Os pontos, ou respostas, são definidos no espaço físico.

$\checkmark$ Faz-se a transformação isoprobabilística com o método de Nataf, passar do espaço físico para o reduzido.

$\checkmark$ Utiliza-se uma regressão para encontrar os coeficientes do polinômio aproximador da RS no espaço reduzido.

$\checkmark$ Verifica-se o erro entre a RS real e a RS aproximada. Isto é feito para todos os pontos nos quais se conhece a resposta real da estrutura.

$\checkmark \quad$ Imprimir os resultados parciais para controle do processo.

\subsubsection{Cálculo do índice de confiabilidade $\beta$}

Para calcular o índice de confiabilidade utiliza-se o algoritmo de Rackwitz \& Fiessler. A superfície de ruína FS que representa o estado limite é definido pela RS subtraída da solicitação S, ou seja:

$$
\mathrm{FS}=\mathrm{RS}-\mathrm{S}
$$

\subsection{Exemplo de aplicação do RSM}

Um exemplo detalhado do RSM é apresentado no Apêndice IV.

\subsection{Conclusões}

Conclui-se que o Método de Superfície de Resposta, utilizando polinômios de ordem baixa como função aproximadora representativa da superfície de ruína, é recomendado para calcular o índice de confiabilidade $\beta$ em estruturas de concreto armado considerando não-linearidades do material e geométrica. Entretanto, esse método apresenta uma forte dependência do plano de experiência adotado.

O método que aproxima todo domínio do problema a uma única superfície de resposta representada por um único polinômio de ordem elevada, ordem maior ou 
igual a 5, foi exaustivamente testado em pilares isostáticos. Devido as características apresentadas no estudo, esse modelo parece não ser adequado para estruturas com alto grau de hiperasticidade. Para as amostras de pilares estudadas, cerca de $90 \%$ dos casos convergiram para valores corretos, o restante teve variações significativas nos resultados. A validação do método foi verificada com a simulação de Monte Carlo e pelo RSM com polinômios de $2^{\underline{o}}$ grau (versão final do STST). Para utilizar um único polinômio que represente todo domínio foram feitos testes e concluiu-se que, ao menos para pilares, polinômios de grau 5 apresentam bons resultados e não há necessidade de preocupação com a curvatura da RS. Embora utilizar modelos analíticos com aproximações polinomiais de ordem elevada para buscar o índice de confiabilidade seja muito mais rápido que métodos de simulação, esses modelos são lentos para situações que comportam mais que 4 variáveis aleatórias. $\mathrm{O}$ aumento do custo computacional é altamente influenciado pelo número de variáveis aleatórias e pelo grau do polinômio aproximador.

Conclui-se que os RSM, utilizando polinômios de baixa ordem (2 ou 3), são métodos bastante eficientes para análise estatística de estruturas de concreto armado considerando-se comportamento elástico não-linear do material e efeitos de segunda ordem. O custo computacional apresentado por esses métodos nessas condições é bastante reduzido, apresentando as respostas com precisão satisfatória.

O ponto crítico dos métodos baseados em superfícies de resposta é o custo computacional do modelo mecânico. Qualquer melhoria em diminuir o número de pontos dos planos de experiência, como consequência diminuir o número de respostas mecânicas necessárias para verificar-se a convergência do método é de grande aceitação no meio técnico. Portanto, caso deseje-se melhorar um RSM devese tentar diminuir o número de respostas mecânicas para construção da RS. Isso pode ser feito otimizando a distribuição dos pontos dos EPs. Com relação à obtenção do polinômio aproximador das respostas mecânicas, acredita-se que o método dos mínimos quadrados é o mais adequado.

Os processos de otimização para determinar o índice de confiabilidade descritos nesse capítulo são bastante eficientes, acarretando custo computacional desprezível no algoritmo mecânico-confiabilístico. Mesmo comentário pode ser feito 
para o FORM e o SORM, utilizados para estimar a probabilidade de falha dado o índice de confiabilidade da estrutura.

Finalmente, acredita-se que os RSM são adequados para estimar índices de confiabilidade em qualquer tipo de estrutura, composta por qualquer material ou conjunto de materiais de comportamento linear ou não-linear. Esta conclusão é feita devido aos algoritmos de busca das respostas mecânicas e estatísticas serem acoplados, porém independentes.

Conforme comentado na literatura, os RSM podem ter má convergência quando existe um número muito elevado de variáveis aleatórias, superior a 20. Outros assuntos discutidos são com relação a problemas com elevado número de pontos de projeto e problemas com várias superfícies de resposta consequentes de vários estados limites, superior a 5.

Problemas com elevado número de variáveis aleatórias conduz a trabalhar no espaço com um número elevado de dimensões. Isso pode trazer problemas para definição do EP escolhido para governar o algoritmo. Nessas condições, a utilização de um EP elaborado através de algoritmos meméticos ${ }^{8}$ pode ser a mais adequada, eliminado-se a dificuldade imposta pela condição de elevado número de variáveis aleatórias.

O número elevado de pontos de projeto, nesse caso mínimos locais, acontece quando há uma maior sensibilidade da FS. Nessa condição, a utilização de algoritmos meméticos pode resolver a dificuldade apresentada.

Em problemas de engenharia é natural trabalhar-se com elevado número de FS, por exemplo ao mesmo tempo a estrutura pode ter limites de instabilidade global, instabilidade local, deformação, fissuração, etc. Nessa situação, a utilização de técnicas ETA e FTA acopladas com o SFEM apresentado nesta tese podem ser utilizadas para resolver o problema.

\footnotetext{
${ }^{8}$ Degeneração dos algoritmos genéticos.
} 


\section{Capítulo 6 Análise de sensibilidade das variáveis}

Para conhecer o peso de cada uma das variáveis de projeto é necessário estudar a influência de sua variação sobre o sistema. O começo desse estudo é identificar as variáveis mais significativas, as que permitem melhor controlar os aspectos mecânicos, econômicos e de confiabilidade. Sobre o plano de confiabilidade, as variáveis influentes devem assumir o controle da qualidade proposta, enquanto que as menos influentes podem ser menos controladas e mesmo serem supostas determinísticas para simplificar a análise mecânico-probabilística.

A importância de uma variável é definida por dois estudos:

$\checkmark$ Estudo da sensibilidade mecânica: estuda a variação da função de desempenho (função que representa a superfície de falha da estrutura) para os valores de funcionamento ou variáveis de projeto. Esse estudo é puramente determinístico, traduzindo o comportamento mecânico do sistema.

$\checkmark$ Estudo da sensibilidade da confiabilidade: estuda a variação do índice de confiabilidade do sistema em relação às variáveis de projeto. Interessa a variação da confiabilidade da estrutura, caracterizando-se como um estudo estatístico ou semi-probabilístico.

\subsection{Estudo da sensibilidade mecânica}

O objetivo desse estudo é avaliar a variação da função de desempenho com a evolução de uma variável. A sensibilidade mecânica $\mathrm{s}_{\mathrm{i}}$ é então a derivada parcial da função de desempenho $\mathrm{G}\left(\mathrm{X}_{\mathrm{k}}\right)$ em relação a seus parâmetros elementares $\mathrm{X}_{\mathrm{i}}$. $\mathrm{O}$ índice k refere-se à FS da iteração $\mathbf{k}$ e o índice $\mathbf{i}$ refere-se à variável aleatória.

$$
\mathrm{s}_{\mathrm{i}}=\frac{\partial \mathrm{G}\left(\mathrm{x}_{\mathrm{k}}\right)}{\partial \mathrm{x}_{\mathrm{i}}}
$$

Ao utilizar-se a expressão (6.1) para calcular as sensibilidades, percebe-se claramente que os resultados dependem dos valores numéricos ou do sistema de 
unidade utilizado. Para evitar essa dependência e possível engano na análise dos resultados pode-se trabalhar no espaço normalizado, evitando-se a dependência das unidades utilizadas. Portanto, a expressão (6.1) passa a ser:

$$
\mathrm{s}_{\mathrm{i}}=\frac{\partial \mathrm{H}\left(\mathrm{U}_{\mathrm{k}}\right)}{\partial \mathrm{u}_{\mathrm{i}}}
$$

Se o objetivo é determinar a importância de uma variável y de nível inferior, a sensibilidade é dada pelo desenvolvimento clássico da derivada.

$$
s_{i}=\frac{\partial G\left(x_{k}\right)}{\partial y_{i}}=\frac{\partial G\left(x_{k}\right)}{\partial x_{j}} \frac{\partial x_{j}}{\partial y_{i}}
$$

Em geral, as análises das sensibilidades mecânicas são efetuadas para valores de funcionamento das diferentes variáveis, conhecidos sobre os nomes "valores característicos" ou "valores nominais". Caso deseje-se trabalhar no espaço físico, como já foi mencionado, o valor de (6.1) é subjetivo podendo causar enganos no estudo de diferentes variáveis já que depende do valor numérico da variável analisada. Com o objetivo de poder fazer comparações mais significativas entre as variáveis, é interessante explicitarem-se os resultados na forma:

$$
\bar{s}_{i}=\frac{\partial G\left(x_{k}\right)}{\partial x_{i}} \frac{x_{i}}{G\left(x_{k}\right)}
$$

\subsection{Medidas de sensibilidade da confiabilidade}

As medidas de sensibilidade indicam ao projetista o melhor caminho para aumentar a segurança ou reduzir custos sem afetar a segurança. Existem várias medidas importantes: cosseno diretor do vetor cujo módulo é o índice de confiabilidade $\beta$; sensibilidade dos parâmetros de distribuição, sensibilidade da probabilidade de falha, sensibilidade dos parâmetros da função de desempenho e elasticidade dos parâmetros.

$\checkmark$ Cosseno diretor ( $\alpha$ ): este parâmetro define o aumento ou diminuição da função de falha devido a variação das variáveis normalizadas.

$\checkmark$ Sensibilidade: são parâmetros importantes, fornecem a variação do índice de confiabilidade quando algum parâmetro de projeto é perturbado.

$\checkmark$ Elasticidade: é uma forma padrão da sensibilidade. É muito usado em 
comparação numérica de diferentes variáveis por ser um parâmetro adimensional.

\subsubsection{Cosseno diretor $(\alpha)$}

Os cossenos diretores representam as sensibilidades da função de desempenho no espaço reduzido. Eles indicam o peso de cada uma das variáveis aleatórias normalizadas sobre a função de desempenho.

Para a variável $u_{i}$, o cosseno diretor é definido pela equação:

$$
\alpha_{\mathrm{i}}=\frac{\frac{\partial \mathrm{H}\left(\mathrm{U}_{\mathrm{k}}\right)}{\partial \mathrm{u}_{\mathrm{i}}}}{\left\|\frac{\partial \mathrm{H}\left(\mathrm{U}_{\mathrm{k}}\right)}{\partial \mathrm{u}_{\mathrm{j}}}\right\|_{\mathrm{U}_{\mathrm{k}}^{*}}^{*}} \mid \therefore \quad \mathrm{u}_{\mathrm{i}}^{*}=-\beta \alpha_{\mathrm{i}}
$$

onde $U_{k}^{*}$ são as coordenadas no espaço normalizado do ponto de falha mais provável, ou ponto de concepção.

Propriedade geométrica dos cossenos diretores:

$$
\alpha_{1}^{2}+\alpha_{2}^{2}+\ldots+\alpha_{n}^{2}=1
$$

Pode-se também considerar os cossenos diretores como fatores de sensibilidade, que podem ser interpretados como medidas de importância relativas das variáveis no espaço físico.

$$
\frac{\partial \beta(U)}{\partial u_{i}}=\frac{\partial}{\partial u_{i}} \sqrt{\sum_{j=1}^{n} u_{j}^{2}}=\left.\alpha_{i}\right|_{U=U^{*}}
$$

Note que a ordem de grandeza das variáveis pode modificar de uma forma significativa quando se passa ao espaço físico.

$$
\alpha_{i}^{\text {Phy }}=\frac{\frac{\partial G\left(X_{k}\right)}{\partial x_{i}}}{\left\|\frac{\partial H\left(X_{k}\right)}{\partial x_{j}}\right\| \|_{X_{k}^{*}}} \quad ; \quad \frac{\partial G\left(X_{k}\right)}{\partial x_{i}}=\frac{\partial H\left(U_{k}\right)}{\partial u_{j}} \frac{\partial u_{j}}{\partial x_{i}}=\alpha_{j} \frac{\partial T_{j}\left(X_{r}\right)}{\partial x_{i}}\left\|\frac{\partial H\left(U_{k}\right)}{\partial u_{s}}\right\|
$$

Através da expressão (6.8) pode-se observar que a expressão para estimar a sensibilidade no espaço físico incorpora os gradientes da transformação isoprobabilística; como consequência a regra das distribuições e das correlações pode 
amplificar a influência de certas variáveis e vice-versa.

\subsubsection{Sensibilidade dos parâmetros de distribuição}

O cálculo da sensibilidade dos parâmetros de distribuição permite identificar as medidas que devem ser consideradas para controlar ou não a qualidade. A variação do índice de confiabilidade $\beta$ devido a variação de algum parâmetro p é definida pela relação seguinte:

$$
\alpha_{\mathrm{p}_{\mathrm{i}}}=\left.\frac{\partial \beta}{\partial \mathrm{p}_{\mathrm{i}}}\right|_{\mathrm{U}_{\mathrm{k}}^{*}}
$$

onde $\mathrm{p}_{\mathrm{i}}$ é o parâmetro $\mathrm{p}$ da variável $\mathrm{x}_{\mathrm{i}}$. $\mathrm{O}$ índice de confiabilidade é dado por:

$$
\beta=\sqrt{\sum_{i=1}^{n}\left(u_{i}^{*}\right)^{2}}
$$

Admite-se que os parâmetros de uma variável não interferem na definição das outras variáveis, portanto pode-se escrever:

$$
\alpha_{p_{i}}=\left.\frac{\partial \beta}{\partial u_{j}} \frac{\partial u_{j}}{\partial p_{i}}\right|_{U_{k}^{*}}=\left.\frac{\partial \beta}{\partial u_{i}} \frac{\partial u_{i}}{\partial p_{i}}\right|_{u_{i}^{*}}=\left.\frac{u_{i}^{*}}{\beta} \frac{\partial T_{i}\left(x_{k}, p_{m}\right)}{\partial p_{i}}\right|_{x_{i}^{*}}
$$

onde T é uma transformação isoprobabilística.

Por exemplo, no caso da variável $\mathrm{x}_{1}$ normalmente distribuída com média $\mu_{1} \mathrm{e}$ desvio padrão $\sigma_{1}$, a transformação é definida por:

$$
\mathrm{U}_{1}=\mathrm{T}\left(\mathrm{x}_{1}\right)=\frac{\mathrm{x}_{1}-\mu_{1}}{\sigma_{1}}
$$

A sensibilidade da média é dada por:

$$
\alpha_{\mu}=\frac{\partial \beta}{\partial \mu_{1}}=\frac{1}{\beta} u_{1}^{*} \cdot \frac{\partial\left(\frac{x_{1}-\mu_{1}}{\sigma_{1}}\right)}{\partial \mu_{1}}=-\frac{u_{1}^{*}}{\beta \sigma_{1}}
$$

E a sensibilidade do desvio padrão por:

$$
\alpha_{\sigma}=\frac{\partial \beta}{\partial \sigma_{1}}=\frac{1}{\beta} u_{1}^{*} \cdot \frac{\partial\left(\frac{x_{1}-\mu_{1}}{\sigma_{1}}\right)}{\partial \sigma_{1}}=-\frac{\left(u_{1}^{*}\right)^{2}}{\beta \sigma_{1}}
$$

De uma maneira geral, as sensibilidades são calculadas da seguinte forma:

Variáveis independentes 


$$
\alpha_{p_{i}}=\left.\frac{\partial \beta}{\partial p_{i}}\right|_{U_{k}^{*}}=\left.\frac{\partial \beta}{\partial u_{i}} \frac{\partial u_{i}}{\partial p_{i}}\right|_{U_{k}^{*}}=\left.\frac{u_{i}^{*}}{\beta} \frac{\partial\left[\Phi^{-1}\left[F_{x_{i}}\left(x_{i}, p_{m}\right)\right]\right.}{\partial p_{i}}\right|_{x_{i}^{*}}
$$

Variáveis correlacionadas

$$
\alpha_{p_{i}}=\left.\frac{\partial \beta}{\partial p_{i}}\right|_{U_{k}^{*}}=\left.\frac{\partial \beta}{\partial u_{j}} \frac{\partial u_{j}}{\partial p_{i}}\right|_{U_{k}^{*}}=\left.\Gamma_{0, j i} \frac{u_{j}^{*}}{\beta} \frac{\partial\left[\Phi^{-1}\left[F_{x_{i}}\left(x_{i}, p_{m}\right)\right]\right]}{\partial p_{i}}\right|_{x_{i}^{*}}
$$

Variáveis compostas

$$
\alpha_{p_{i}}=\left.\frac{\partial \beta}{\partial p_{i}}\right|_{U_{k}^{*}}=\left.\frac{\partial \beta}{\partial u_{j}} \frac{\partial u_{j}}{\partial p_{i}}\right|_{U_{k}^{*}}=\left.\frac{u_{j}^{*}}{\beta} \frac{\partial\left[\Phi^{-1}\left[F_{x_{j}^{C k} \backslash x_{r}^{N}, x_{b}^{C h<k}}\left(x_{j} \backslash x_{r}^{N}, x_{b}^{C h<k}\right)\right]\right]}{\partial p_{i}}\right|_{x_{m}^{*}}
$$

Ao analisar-se a sensibilidade dos parâmetros de distribuição, foram considerados os parâmetros das leis de distribuição. Estes parâmetros intervêm unicamente na transformação isoprobabilística.

\subsubsection{Sensibilidade da probabilidade de falha}

Admitindo-se uma aproximação de primeira ordem para a probabilidade de falha, sabe-se que:

$$
\mathrm{P}_{\mathrm{f}}=\Phi(-\beta)
$$

A variação de $\mathrm{P}_{\mathrm{f}}$ relativa ao parâmetro $\mathrm{p}_{\mathrm{i}}$ pode ser obtida por:

$$
\frac{\partial \mathrm{P}_{\mathrm{f}}}{\partial \mathrm{p}_{\mathrm{i}}}=-\left.\phi(\beta) \frac{\partial \beta}{\partial \mathrm{p}_{\mathrm{i}}}\right|_{\mathrm{U}_{\mathrm{k}}^{*}}
$$

onde $\phi(\cdot)$ é a função de densidade padrão.

\subsubsection{Sensibilidade dos parâmetros da função de desempenho}

Nesse item examinam-se os casos de parâmetros que intervêm na função de estado limite $G(X)$ (a resposta mecânica). Sendo assim, interessa a evolução do ponto de concepção no momento da variação do parâmetro $\mathrm{p}_{\mathrm{i}}$. Como o ponto de concepção deve ficar sobre o estado limite, a derivada total em relação ao parâmetro é sempre nula. 


$$
\frac{d G\left(X_{k}, p_{m}\right)}{d p_{i}}=\frac{d H\left(U_{k}, p_{m}\right)}{d p_{i}}=\frac{d H\left(U_{k}, p_{m}\right)}{d p_{i}}+\frac{d H\left(U_{k}, p_{m}\right)}{d u_{j}} \frac{d u_{j}}{d p_{i}}=0
$$

Dividindo-se a expressão (6.20) pela norma do vetor dos gradientes pode-se obter:

$$
\frac{1}{\left.\| \partial \mathrm{H}_{(\mathrm{k}}, \mathrm{p}_{\mathrm{m}}\right) / \partial \mathrm{u}_{\mathrm{j}} \|} \frac{\partial \mathrm{H}\left(\mathrm{U}_{\mathrm{k}}, \mathrm{p}_{\mathrm{m}}\right)}{\partial \mathrm{p}_{\mathrm{i}}}+\alpha_{\mathrm{j}} \frac{\partial \mathrm{u}_{\mathrm{j}}}{\partial \mathrm{p}_{\mathrm{i}}}=0
$$

O índice de confiabilidade é definido por:

$$
\beta=-\alpha_{j} u_{j}=-\frac{\partial H\left(U_{k}, p_{m}\right) / \partial u_{j}}{\left\|\partial H\left(U_{k}, p_{m}\right) / \partial u_{r}\right\|} u_{j}
$$

Derivando-se a expressão (6.22):

$$
\frac{\partial \beta}{\partial p_{i}}=-u_{j} \frac{\partial \alpha_{j}}{\partial p_{i}}-\alpha_{j} \frac{\partial u_{j}}{\partial p_{i}}=\alpha_{j} \beta \frac{\partial \alpha_{j}}{\partial p_{i}}-\alpha_{j} \frac{\partial u_{j}}{\partial p_{i}}
$$

Como os vetores $\alpha_{j}$ e $\frac{\partial \alpha_{j}}{\partial p_{i}}$ são ortogonais, tem-se:

$$
\alpha_{j} \alpha_{j}=1 \quad \therefore \quad \frac{\partial\left(\alpha_{j} \alpha_{j}\right)}{\partial p_{i}}=2 \alpha_{j} \frac{\partial \alpha_{j}}{\partial p_{i}}=0
$$

Então:

$$
\frac{\partial \beta}{\partial p_{i}}=-\alpha_{j} \frac{\partial u_{j}}{\partial p_{i}}
$$

Introduzindo-se a expressão (6.25) na expressão (6.20), derivada total de estado limite, pode-se obter:

$$
\frac{\partial \beta}{\partial p_{i}}=\frac{1}{\left\|\partial H\left(U_{k}, p_{m}\right) / \partial u_{j}\right\|} \frac{\partial H\left(U_{k}, p_{m}\right)}{\partial p_{i}}
$$

\subsubsection{Elasticidade dos parâmetros}

A desvantagem da medida de sensibilidade é que seu valor é ponderado pelo índice de confiabilidade e o valor do parâmetro p. Para eliminar-se essa ponderação, pode-se usar a medida de elasticidade, definida por:

$$
\mathrm{e}_{\mathrm{p}_{\mathrm{i}}}=\left.\frac{\mathrm{p}_{\mathrm{i}}}{\beta} \frac{\partial \beta}{\partial \mathrm{p}_{\mathrm{i}}}\right|_{\mathrm{U}_{\mathrm{k}}^{*}}=\left.\frac{\mathrm{p}_{\mathrm{i}} \mathrm{u}_{\mathrm{i}}^{*}}{\beta^{2}} \frac{\partial \mathrm{T}_{\mathrm{i}}\left(\mathrm{X}_{\mathrm{k}}, \mathrm{p}_{\mathrm{m}}\right)}{\partial \mathrm{p}_{\mathrm{i}}}\right|_{\mathrm{x}_{\mathrm{i}}^{*}}
$$

Para o mesmo exemplo anterior, a elasticidade é medida por: 
Elasticidade da média:

$$
\mathrm{e}_{\mu_{1}}=\frac{\mu_{1}}{\beta} \frac{\partial \beta}{\partial \mu_{1}}=\frac{\mu_{1}}{\beta} \frac{1}{\beta} \mathrm{u}_{1}^{*} \cdot \frac{\partial\left(\frac{\mathrm{x}_{1}-\mu_{1}}{\sigma_{1}}\right)}{\partial \mu_{1}}=-\frac{\mu_{1} \mathrm{u}_{1}^{*}}{\beta^{2} \sigma_{1}}=\frac{\mu_{1} \alpha_{\mu}}{\beta \sigma_{1}}
$$

Elasticidade do desvio padrão:

$$
\mathrm{e}_{\sigma_{1}}=\frac{\sigma_{1}}{\beta} \frac{\partial \beta}{\partial \sigma_{1}}=\frac{\sigma_{1}}{\beta} \frac{1}{\beta} \mathrm{u}_{1}^{*} \cdot \frac{\partial\left(\frac{\mathrm{x}_{1}-\mu_{1}}{\sigma_{1}}\right)}{\partial \sigma_{1}}=-\frac{\sigma_{1}\left(\mathrm{u}_{1}^{*}\right)^{2}}{\beta^{2} \sigma_{1}}=-\alpha_{\sigma}^{2}
$$

\subsection{Análise de sensibilidade utilizando um SFEM}

Descreve-se a análise de sensibilidade inserida no FEM de acordo com LEMAIRE (1997). Para facilitar a compreensão desse tópico, utiliza-se o método dos elementos finitos com a hipótese de comportamento elástico linear. Comportamento elástico não-linear pode ser igualmente levado em consideração combinando o algoritmo probabilístico e um método de solução não-linear como por exemplo Newton-Raphson.

De acordo com a formulação clássica do FEM, a equação de equilíbrio é:

$$
\mathrm{K} . \mathrm{U}=\mathrm{F}
$$

onde: $\mathrm{K}$ é a matriz de rigidez; $\mathrm{U}$ é o vetor de deslocamentos nodais; $\mathrm{F}$ é o vetor de forças nodais equivalentes.

A matriz de rigidez $\mathrm{K}$ e os componentes conhecidos do ponto de vista mecânico, F e U, são funções de variáveis aleatórias $\mathrm{X}$ cujas realizações são xi, $\mathrm{i}=1$, $\ldots, \mathrm{n}$,

Essas variáveis aleatórias representam:

$\checkmark$ dados aleatórios da geometria: dimensões, posicionamento de cargas, etc.;

$\checkmark$ dados aleatórios de materiais: módulos de elasticidade, relações constitutivas, etc.;

$\checkmark$ dados aleatórios das ações externas impostas: forças e deslocamentos prescritos, etc..

É conveniente introduzirem-se variáveis aleatórias centradas, $\alpha_{i}$, deduzidas de $\mathrm{X}_{\mathrm{i}}$ por translação: 


$$
\alpha_{i}=x_{i}-\bar{x}_{i}
$$

onde $\overline{\mathrm{x}}_{\mathrm{i}}$ é a média da variável em questão. A equação (6.30) passa a ser:

$$
\mathrm{K}\left(\alpha_{\mathrm{i}}\right) \cdot \mathrm{U}\left(\alpha_{\mathrm{i}}\right)=\mathrm{F}\left(\alpha_{\mathrm{i}}\right)
$$

Devido a probabilidade envolvida ser muito pequena, as variáveis aleatórias, $\alpha_{i}$, são consideradas como infinitamente pequenas na expressão de Taylor. A expressão é desenvolvida em segunda ordem e calculada com três termos. Numa primeira aproximação, a primeira ordem pode ser mantida sozinha.

Para uma variável v:

$$
\left.\frac{\partial \mathrm{v}}{\partial \alpha_{i}}\right|_{\alpha=0}=v_{i}^{I} \quad \text { e }\left.\quad \frac{\partial^{2} v}{\partial \alpha_{i} \partial \alpha_{j}}\right|_{\alpha=0}=v_{i j}^{I I}
$$

Desenvolvendo-se em torno do ponto médio, denotado por ${ }^{0}$ :

$$
\begin{gathered}
\mathrm{K}=\mathrm{K}^{0}+\sum_{\mathrm{k}=1}^{\mathrm{n}} \mathrm{K}_{\mathrm{k}}^{\mathrm{I}} \alpha_{\mathrm{k}}+\frac{1}{2} \sum_{\mathrm{k}=1 \mathrm{i}=1}^{\mathrm{n}} \sum_{\mathrm{ki}}^{\mathrm{n}} \mathrm{K}_{\mathrm{k}}^{\mathrm{II}} \alpha_{\mathrm{i}}+\ldots \\
\mathrm{F}=\mathrm{F}^{0}+\sum_{\mathrm{k}=1}^{\mathrm{n}} \mathrm{F}_{\mathrm{k}}^{\mathrm{I}} \alpha_{\mathrm{k}}+\frac{1}{2} \sum_{\mathrm{k}=1 \mathrm{i}=1}^{\mathrm{n}} \sum_{\mathrm{ki}}^{\mathrm{II}} \alpha_{\mathrm{k}} \alpha_{\mathrm{i}}+\ldots \\
\mathrm{U}=\mathrm{U}^{0}+\sum_{\mathrm{k}=1}^{\mathrm{n}} \mathrm{U}_{\mathrm{k}}^{\mathrm{I}} \alpha_{\mathrm{k}}+\frac{1}{2} \sum_{\mathrm{k}=1}^{\mathrm{n}} \sum_{\mathrm{i}=1}^{\mathrm{n}} \mathrm{U}_{\mathrm{ki}}^{\mathrm{II}} \alpha_{\mathrm{k}} \alpha_{\mathrm{i}}+\ldots
\end{gathered}
$$

Utilizando-se a equação (6.32) é possível determinar os componentes de U de ordem $^{0},{ }^{\mathrm{I}} \mathrm{e}^{\mathrm{II}}$ :

$$
\begin{gathered}
\mathrm{U}^{0}=\left[\mathrm{K}^{0}\right]^{-1} \mathrm{~F}^{0} \\
\mathrm{U}_{\mathrm{k}}^{\mathrm{I}}=\left[\mathrm{K}^{0}\right]^{-1}\left[\mathrm{~F}_{\mathrm{k}}^{\mathrm{I}}-\mathrm{K}_{\mathrm{k}}^{\mathrm{I}} \mathrm{U}^{0}\right] \\
\mathrm{U}_{\mathrm{ki}}^{\mathrm{II}}=\left[\mathrm{K}^{0}\right]^{-1}\left[\mathrm{~F}_{\mathrm{ki}}^{\mathrm{II}}-\left(\mathrm{K}_{\mathrm{k}}^{\mathrm{I}} \mathrm{U}_{\mathrm{i}}^{\mathrm{I}}+\mathrm{K}_{\mathrm{i}}^{\mathrm{I}} \mathrm{U}_{\mathrm{k}}^{\mathrm{I}}+\mathrm{K}_{\mathrm{ki}}^{\mathrm{II}} \mathrm{U}^{0}\right)\right]
\end{gathered}
$$

$\mathrm{O}$ interessante dessas equações é que a mesma matriz $\mathrm{K}^{0}$ é usada para determinar $\mathrm{U}^{0}, \mathrm{U}_{\mathrm{k}}^{\mathrm{I}}, \mathrm{U}_{\mathrm{ki}}^{\mathrm{II}}, \ldots$ Isso resulta num ganho de tempo de cálculo. Conhecido o vetor $U$, deformações e tensões para cada elemento podem facilmente ser calculadas. Usando-se uma técnica padrão de elementos finitos, o vetor de deformações é:

$$
\varepsilon=\mathrm{BU}
$$

onde B é a matriz de incidência cinemática, que depende apenas das coordenadas fixadas. O vetor de deformações é desenvolvido em uma expansão em série: 


$$
\varepsilon=\varepsilon^{0}+\sum_{\mathrm{k}=1}^{\mathrm{n}} \varepsilon_{\mathrm{k}}^{\mathrm{I}} \alpha_{\mathrm{k}}+\frac{1}{2} \sum_{\mathrm{k}=1 \mathrm{i}=1}^{\mathrm{n}} \sum_{\mathrm{ki}}^{\mathrm{n}} \varepsilon_{\mathrm{k}}^{\mathrm{II}} \alpha_{\mathrm{i}}+\ldots
$$

com:

$$
\varepsilon^{0}=\mathrm{BU}^{0} \quad \varepsilon_{\mathrm{k}}^{\mathrm{I}}=\mathrm{BU}_{\mathrm{k}}^{\mathrm{I}} \quad \varepsilon_{\mathrm{ki}}^{\mathrm{II}}=\mathrm{BU}_{\mathrm{ki}}^{\mathrm{II}}
$$

O cálculo de tensão levando em consideração uma possível variabilidade aleatória da lei de Hooke (H) é:

$$
\sigma=\mathrm{H \varepsilon}
$$

que é similarmente desenvolvido como uma expansão em série:

$$
\mathrm{H}=\mathrm{H}^{0}+\sum_{\mathrm{k}=1}^{\mathrm{n}} \mathrm{H}_{\mathrm{k}}^{\mathrm{I}} \alpha_{\mathrm{k}}+\frac{1}{2} \sum_{\mathrm{k}=1 \mathrm{i}=1}^{\mathrm{n}} \sum_{\mathrm{ki}}^{\mathrm{n}} \mathrm{H}_{\mathrm{k}}^{\mathrm{II}} \alpha_{\mathrm{i}}+\ldots
$$

$\mathrm{H}^{0}$ é a matriz elástica, determinada com $\alpha_{\mathrm{k}}=0$. Enfim, desenvolvendo-se o vetor das tensões:

$$
\begin{gathered}
\sigma=\sigma^{0}+\sum_{\mathrm{k}=1}^{\mathrm{n}} \sigma_{\mathrm{k}}^{\mathrm{I}} \alpha_{\mathrm{k}}+\frac{1}{2} \sum_{\mathrm{k}=1 \mathrm{i}=1}^{\mathrm{n}} \sum_{\mathrm{ki}}^{\mathrm{II}} \alpha_{\mathrm{k}} \alpha_{\mathrm{i}}+\ldots \\
\sigma^{0}=\mathrm{H}^{0} \varepsilon^{0} \\
\sigma_{\mathrm{k}}^{\mathrm{I}}=\mathrm{H}^{0} \varepsilon_{\mathrm{k}}^{\mathrm{I}}+\mathrm{H}_{\mathrm{k}}^{\mathrm{I}} \varepsilon^{0} \\
\sigma_{\mathrm{ki}}^{\mathrm{II}}=\mathrm{H}^{0} \varepsilon_{\mathrm{ki}}^{\mathrm{II}}+\mathrm{H}_{\mathrm{k}}^{\mathrm{I}} \varepsilon_{\mathrm{i}}^{\mathrm{I}}+\mathrm{H}_{\mathrm{i}}^{\mathrm{I}} \varepsilon_{\mathrm{k}}^{\mathrm{I}}+\mathrm{H}_{\mathrm{ki}}^{\mathrm{II}} \varepsilon^{0}
\end{gathered}
$$

Os dois primeiros momentos estatísticos da resposta, a média E[.] e a covariância Cov[.], podem agora ser obtidos. No caso de deslocamentos U:

$$
\begin{gathered}
E[U]=U^{0}+\frac{1}{2} \sum_{k=1}^{n} \sum_{i=1}^{n} U_{k i}^{I I} E\left[\alpha_{k} \alpha_{i}\right] \\
\operatorname{Cov}[U]=E\left[\left(U-U^{0}\right)\left(U-U^{0}\right)\right]_{+} \\
+\frac{1}{4} \sum_{k=1}^{n} \sum_{i=1}^{n} \sum_{j=1}^{n} \sum_{m=1}^{n} U_{k i}^{I I} U_{j m}^{I I I} \cdot\left(E\left[\alpha_{k} \alpha_{m}\right] E\left[\alpha_{i} \alpha_{j}\right]+E\left[\alpha_{k} \alpha_{j}\right] E\left[\alpha_{i} \alpha_{m}\right]\right)
\end{gathered}
$$

Esse procedimento só é válido para variáveis aleatórias gaussianas, ou que obedeçam uma função de distribuição normal. No caso de distribuições não gaussianas há necessidade de transformar a lei de distribuição dessa variável em Gaussiana através de uma transformação isoprobabilística.

Essa análise torna possível determinar os dois primeiros momentos estatísticos da resposta de um sistema mecânico cujo modelo é formulado de acordo com o 
método dos elementos finitos. Esse procedimento de cálculo necessita da primeira derivada ( e possivelmente da segunda no caso de ordem ${ }^{\text {II }}$ ) da matriz de rigidez e dos vetores de força e deslocamento. Essa análise não é entretanto uma aproximação correta para o problema de confiabilidade, pois a expansão de Taylor é calculada em torno do ponto médio, não em torno de um ponto específico. O ponto de falha mais provável deve ser definido no estudo da análise de confiabilidade.

Ao procedimento descrito acima pode-se denominar como um método de elementos finitos estocásticos (SFEM). A utilização de SFEM trabalhando com os momentos estatísticos inseridos diretamente nos vetores e matrizes do sistema como indicado nesse item pode se tornar difícil devido à complexidade das expressões envolvidas na análise de sensibilidade e confiabilidade de problemas não-lineares. Utilizar SFEM nesses casos pode acarretar em sérios problemas de convergência na busca do equilíbrio da estrutura. 


\section{Capítulo 7 Calibração de coeficientes parciais de segurança}

Com a idéia de obter respostas estruturais com confiabilidade uniforme, pelo menos o mais uniforme possível, pensa-se em utilizar conceitos de confiabilidade para determinar coeficientes parciais de segurança para as variáveis de projeto.

Antes de introduzir a idéia, é oportuno salientar a classificação dos níveis de aproximações de segurança, que são descritos em ordem crescente:

Nível $1 \rightarrow$ coeficientes parciais de segurança, $\gamma$

Nível $2 \rightarrow$ índice de confiabilidade $\beta$ desconhecida a f.d.p. da VA

Nível $3 \rightarrow$ probabilidade de falha, $\mathrm{P}_{\mathrm{f}}$

Nível $\mathbf{4} \rightarrow$ probabilidade de falha acrescido de otimização

Portanto, não teria sentido o uso de teorias mais avançadas, como as utilizadas para calcular $\beta$ ou $\mathrm{P}_{\mathrm{f}}$, quando na prática utiliza-se uma teoria mais simples baseada em coeficientes parciais. Em problemas práticos, devido ao custo computacional e principalmente ao insuficiente conhecimento técnico dos engenheiros, ainda não é possível aplicar conceitos de confiabilidade, muito menos de probabilidade de falha. Então, 'Encontrar coeficientes parciais de segurança, de utilização corrente na prática, baseado em conceitos de confiabilidade e probabilidade de falha' é ainda um procedimento plenamente justificável.

Baseado na capacidade de efetuar um cálculo de confiabilidade sobre o melhor modelo mecânico possível, introduz-se uma aproximação científica na determinação de coeficientes parciais para regras de dimensionamento das estruturas. Hoje, o método dos elementos finitos oferece uma resposta mecânica satisfatória para a maior parte das situações, podendo ser utilizado em conjunto com um método de confiabilidade (RM) para se estudar coeficientes parciais. A utilização do FEM em conjunto com um RM apresenta uma dificuldade quando a função de estado limite considerada não é uma função explicita das variáveis aleatórias de concepção. Muitos 
métodos permitem gerar a função de estado limite considerando a aleatoriedade das variáveis, como exemplo tem-se: o uso direto do código FEM por um algoritmo de confiabilidade como no método dos elementos finitos estocásticos (SFEM) descrito sucintamente no capítulo anterior, item 6.3, e com maiores detalhes em MACIAS (1994); o método de superfície de respostas (RSM) largamente explorado nessa tese, etc.

\subsection{Princípios de métodos de calibração}

Os coeficientes parciais existem atualmente em todas as regras de dimensionamento. Eles foram ajustados sucessivamente pela experiência dos engenheiros, construtores e calculistas. O princípio desenvolvido aqui consiste em procurar de forma lógica um conjunto de coeficientes baseado no conhecimento estatístico das variáveis. Mas como esse conhecimento não é perfeito, um procedimento puramente algorítmico é insuficiente e a calibração é então efetuada por um índice de confiabilidade igual ao índice de confiabilidade implícito no código existente (faz-se a calibração baseado em índices de confiabilidade da resposta). Dessa forma, a calibração de coeficientes baseada em resultados garante um nível de confiabilidade, mas há necessidade do conhecimento da estrutura em análise (qual a sensibilidade da confiabilidade para cada variação da estrutura?).

Segundo LEMAIRE (1999), a priori é possível conceber um formato de um código probabilístico, à partir da probabilidade de falha:

$$
P_{f}=\int_{G\left(X_{i}\right) \leq 0} f_{X}\left(x_{i}\right) d x_{1} d x_{2} \cdots d x_{n} \leq P_{f_{-} \text {admissível }}
$$

mas é necessário uma codificação das leis de distribuição das variáveis contidas dentro da densidade de probabilidade conjunta $f_{X}\left(x_{i}\right)$. Essa codificação até $o$ momento ainda não foi elaborada. A forma habitualmente utilizada é um formato semi-probabilístico, caracterizado pela escolha de uma regra e por seus valores codificados, que são supostos aqui ser os valores característicos:

$$
\mathrm{G}\left(\left\{\gamma_{\mathrm{S}_{\mathrm{i}}} \mathrm{S}_{\mathrm{ik}}\right\},\left\{\mathrm{R}_{\mathrm{jk}} / \gamma_{\mathrm{R}_{\mathrm{j}}}\right\}\right)>0
$$

onde:

$S_{\mathrm{ik}}$ : valor característico da variável de solicitação;

$\mathrm{R}_{\mathrm{ik}}$ : valor característico da variável de resistência. 
A representação (7.2) visa obter coeficientes parciais superiores a unidade, independente do tipo da variável.

Para uma situação dada, se uma análise de confiabilidade é efetuada, pode-se associar a cada variável um valor característico e um coeficiente parcial. A calibração procura o comportamento dos coeficientes aplicados a um conjunto de situações. Dessa forma, o engenheiro conhece o nível de confiabilidade mínima associado à um tipo estrutural, sem ter que efetuar um cálculo complexo de confiabilidade.

Para utilizar uma mesma regra em um conjunto de situações correspondentes a uma classe de estruturas, procura-se um comportamento único dos coeficientes parciais que represente melhor o conjunto de situações. Com esse procedimento, o procedimento de calibração, proposto por LEMAIRE (1999), resulta na solução do seguinte problema:

$$
\begin{aligned}
& \min _{\gamma_{i}} W\left(\gamma_{i}\right)=\sum_{j=1}^{\ell} w_{j}\left(\beta_{j}\left(\gamma_{i}\right)-\beta_{0}\right)^{2} \\
& G_{j}\left(x_{k}, \gamma_{i}\right)>0 \quad j=1, \ell
\end{aligned}
$$

onde procura-se minimizar a função $\mathrm{W}\left(\gamma_{\mathrm{i}}\right)$ para todas as situações $\mathrm{j}$ com peso respectivo $\mathrm{w}_{\mathrm{j}}$, para um índice alvo ou objetivo $\beta_{0}$. $\beta_{\mathrm{j}}\left(\gamma_{\mathrm{i}}\right)$ é o índice de confiabilidade correspondente à situação ótima do problema de dimensionamento $G_{j}\left(x_{k}, \gamma_{i}\right)>0$ relativo a situação $\mathrm{j}$. $E\left(\beta_{\mathrm{j}}\left(\gamma_{\mathrm{i}}\right)-\beta_{0}\right)^{2}$ constitui uma função de penalidade.

\subsection{Procedimentos de métodos de calibração}

Segundo LEMAIRE (1999), vários autores apresentaram métodos de calibração, podendo-se resumir as idéias em 6 etapas:

1) Escolher a classe de estruturas cujos coeficientes serão calibrados, essa classe deve ser escolhida definindo:

$\checkmark$ modelos de falha;

$\checkmark$ as variáveis de concepção da estrutura;

$\checkmark$ os campos de variação das variáveis.

2) Selecionar um certo número de situações de concepção e resolver seus pesos, $w_{i}$.

3) Definir um índice de confiabilidade objetivo $\beta_{0}$ (índice que se deseje alcançar).

4) Dimensionar cada situação de concepção i ajustando uma variável de concepção de tal maneira que $\beta_{i}=\beta_{0}$ e calcular as sensibilidades $\alpha_{i}$. 
5) Escolher uma função de penalidade $M$ e procurar $\vec{\delta}$ para a minimização de:

$$
\Delta=\sum \sum \sum \sum \mathrm{w}_{\mathrm{i}} \mathrm{M}\left(\tilde{\beta}_{\mathrm{i}}, \beta_{0}\right) \quad \text { com } \quad \tilde{\beta}_{\mathrm{i}}=\beta_{0} \overrightarrow{\alpha_{\mathrm{i}}} \cdot \vec{\delta}
$$

6) Calcular os coeficientes parciais de segurança por:

$$
\gamma_{X}=\frac{x^{*}}{x_{k}} \quad \text { ou } \quad \gamma_{X}=\frac{x_{k}}{x^{*}}
$$

dependendo se a variável x é uma solicitação ou uma resistência. Ou ainda,

$$
\mathrm{x}^{*}=\mathrm{F}_{\mathrm{X}}\left(\phi\left(-\beta_{0} \delta\right)\right)
$$

onde: $\delta$ : componente de $\vec{\delta}$ associado à variável $\mathrm{x}$;

$\mathrm{x}^{*}$ : valor de concepção;

$\mathrm{x}_{\mathrm{k}}$ : valor característico.

Esse processo não foi implementado e consequentemente há a possibilidade da necessidade de alterações a serem feitas, aqui foi apresentada apenas a proposta original de Lemaire no âmbito global da pesquisa.

Uma outra possibilidade para calibrar coeficientes parciais é através da análise paramétrica de uma determinada classe estrutural, que é válida apenas para o domínio de variação dos parâmetros da estrutura. 


\section{Capítulo 8 Otimização e confiabilidade estrutural acopladas}

A idealização de um projeto estrutural se dá ao conseguir uma estrutura com um objetivo extremado satisfazendo critérios mínimos satisfatórios de segurança. A idéia básica desse capítulo é mostrar como construir um algoritmo de otimização que garanta níveis aceitáveis de segurança à estrutura.

Antes de buscar a solução de um problema de otimização é preciso definir a função que se deseja extremar (função objetivo) e as restrições impostas ao problema. Como função objetivo, opta-se pelo custo dos elementos estruturais. Para as restrições consideram-se percentuais mínimos e máximos de taxa das armadura e restrição imposta pelo índice de confiabilidade como será descrito posteriormente. As restrições mecânicas estão implícitas na restrição de confiabilidade.

Para resolver o problema de otimização, divide-se a estrutura em grupos de elementos (por convenção tem-se n grupos) que têm a mesma seção transversal, inclusive taxa de armadura. As variáveis do problema são a altura e as áreas de aço (tração e compressão) das seções transversais de cada grupo, chamamadas convenientemente de:

$$
\mathrm{h}_{\mathrm{i}}=\mathrm{x}_{1} \quad ; \quad \mathrm{A}_{\mathrm{s}}=\mathrm{x}_{2} \quad ; \quad \mathrm{A}_{\mathrm{s}}^{\prime}=\mathrm{x}_{3}
$$

A função objetivo que deseja-se minimizar é dada por:

$$
\mathrm{f}(\mathrm{x})=\sum_{\mathrm{i}=1}^{\mathrm{n}}\left[\mathrm{b}_{\mathrm{wi}} \cdot \mathrm{h}_{\mathrm{i}} \cdot \ell_{\mathrm{i}} \cdot \mathrm{C}_{\mathrm{V}}+\left(\mathrm{b}_{\mathrm{wi}}+2 \cdot \mathrm{h}_{\mathrm{i}}\right) \cdot \ell_{\mathrm{i}} \cdot \mathrm{C}_{\mathrm{F}}+\left(\mathrm{A}_{\mathrm{si}}+\mathrm{A}_{\mathrm{si}}^{\prime}\right) \cdot \ell_{\mathrm{i}} \cdot \rho_{\mathrm{s}} \cdot \mathrm{C}_{\mathrm{S}}\right]
$$

Que pode ser escrita como:

$$
\mathrm{f}(\mathrm{x})=\sum_{\mathrm{i}=1}^{\mathrm{n}}\left[\mathrm{b}_{\mathrm{wi}} \cdot \mathrm{x}_{1 \mathrm{i}} \cdot \ell_{\mathrm{i}} \cdot \mathrm{C}_{\mathrm{V}}+\left(\mathrm{b}_{\mathrm{wi}}+2 \cdot \mathrm{x}_{1 \mathrm{i}}\right) \cdot \ell_{\mathrm{i}} \cdot \mathrm{C}_{\mathrm{F}}+\left(\mathrm{x}_{2 \mathrm{i}}+\mathrm{x}_{3 \mathrm{i}}\right) \cdot \ell_{\mathrm{i}} \cdot \rho_{\mathrm{s}} \cdot \mathrm{C}_{\mathrm{S}}\right]
$$

onde: n: número de conjuntos ou grupos de elementos finitos a serem otimizados;

$\mathrm{b}_{\mathrm{w}}$ : base da seção transversal do grupo;

$\ell$ : comprimento do conjunto de elementos finitos do grupo; 
$\rho_{\mathrm{s}}:$ peso específico do aço;

$\mathrm{C}_{\mathrm{V}}$ : custo do volume de concreto no elemento estrutural pronto;

$\mathrm{C}_{\mathrm{F}}$ : custo da forma no elemento estrutural pronto;

$\mathrm{C}_{\mathrm{S}}$ : custo do aço no elemento estrutural pronto;

\%: taxa de armadura (mínima e máxima).

A restrição de taxa mínima de armadura é dada por:

$$
\mathrm{h}_{1}(\mathrm{x})=\% \min -\left[\frac{\left(\mathrm{x}_{2 \mathrm{i}}+\mathrm{x}_{3 \mathrm{i}}\right)}{\left(\mathrm{b}_{\mathrm{wi}} \cdot \mathrm{x}_{1 \mathrm{i}}\right)}\right] \leq 0 \quad \backslash \quad \mathrm{i}=1, \ldots, \mathrm{n}
$$

A restrição de taxa máxima de armadura é dada por:

$$
\mathrm{h}_{2}(\mathrm{x})=\left[\frac{\left(\mathrm{x}_{2 \mathrm{i}}+\mathrm{x}_{3 \mathrm{i}}\right)}{\left(\mathrm{b}_{\mathrm{wi}} \cdot \mathrm{x}_{1 \mathrm{i}}\right)}\right]-\% \text { máx } \leq 0 \quad \backslash \quad \mathrm{i}=1, \ldots, \mathrm{n}
$$

A terceira restrição é expressa em termos de índice de confiabilidade:

$$
\mathrm{h}_{3}(\mathrm{x})=\beta_{0}-\beta(\mathrm{x}) \leq 0
$$

onde: $\beta(\mathrm{x})$ : hipersuperfície que representa o índice de confiabilidade da estrutura em função das variáveis de otimização;

$\beta_{0}$ : índice de confiabilidade prescrito ou desejado.

Para construir $\beta(\mathrm{x})$ adota-se um procedimento semelhante ao utilizado para construir a FS no problema de confiabilidade. Assume-se um Plano de Experiência para as variáveis de otimização, portanto o EP gerará um conjunto de combinações determinística das variáveis de otimização. Para cada combinação de variáveis de otimização, ou seja, para cada ponto do plano de experiência de otimização calculase o índice de confiabilidade da estrutura como demonstrado em capítulo anterior, utilizando-se o RSM. De posse do vetor de índices de confiabilidade e do conjunto de combinações das variáveis de otimização definido pelo EP, faz-se uma regressão pelo método dos mínimos quadrados para determinar $\beta(\mathrm{x})$, aproximado por um polinômio do segundo grau dado forma:

$$
\beta(x)=\sum_{i=1}^{n}\left[\begin{array}{l}
a_{0 i} x_{1 i}^{0} x_{2 i}^{0} x_{3 i}^{0}+a_{1 i} x_{1 i}^{0} x_{2 i}^{0} x_{3 i}^{1}+a_{2 i} x_{1 i}^{0} x_{2 i}^{1} x_{3 i}^{0}+a_{3 i} x_{1 i}^{1} x_{2 i}^{0} x_{3 i}^{0}+ \\
a_{4 i} x_{1 i}^{0} x_{2 i}^{0} x_{3 i}^{2}+a_{5 i} x_{1 i}^{0} x_{2 i}^{2} x_{3 i}^{0}+a_{6 i} x_{1 i}^{2} x_{2 i}^{0} x_{3 i}^{0}+a_{7 i} x_{1 i}^{0} x_{2 i}^{1} x_{3 i}^{1}+ \\
a_{8 i} x_{1 i}^{1} x_{2 i}^{0} x_{3 i}^{1}+a_{9 i} x_{1 i}^{1} x_{2 i}^{1} x_{3 i}^{0}
\end{array}\right]
$$

Portanto, o problema de otimização é definido da seguinte forma: 
Minimize $\mathrm{f}(\mathrm{x}) \quad$ Sujeito à $\mathrm{h}(\mathrm{x}) \leq 0$

Uma vez definido o problema de otimização, há vários caminhos para solucioná-lo. Uma possibilidade é utilizar métodos que baseiam-se em gradientes para direcionar a busca da solução ótima. Nessa categoria de métodos, pode-se utilizar o método do gradiente, no qual, de acordo com as condições de KuhnTucker, LUENBERGER (1989), a solução de (8.8) é a solução do seguinte sistema de inequações:

$$
\begin{aligned}
& \nabla \mathrm{f}\left(\mathrm{x}^{*}\right)+\sum_{\mathrm{i}=1}^{\mathrm{n}} \lambda_{1 \mathrm{i}}^{\mathrm{T}} \nabla \mathrm{h}_{1 \mathrm{i}}\left(\mathrm{x}^{*}\right)+\sum_{\mathrm{i}=1}^{\mathrm{n}} \lambda_{2 \mathrm{i}}^{\mathrm{T}} \nabla \mathrm{h}_{2 \mathrm{i}}\left(\mathrm{x}^{*}\right)+\lambda_{3}^{\mathrm{T}} \nabla \mathrm{h}_{3}\left(\mathrm{x}^{*}\right)=0 \\
& \lambda_{1 \mathrm{i}}^{\mathrm{T}} \mathrm{h}_{1 \mathrm{i}}\left(\mathrm{x}^{*}\right)=0 \quad \backslash \quad \mathrm{i}=1, \ldots, \mathrm{n} \\
& \lambda_{2 \mathrm{i}}^{\mathrm{T}} \mathrm{h}_{2 \mathrm{i}}\left(\mathrm{x}^{*}\right)=0 \quad \backslash \quad \mathrm{i}=1, \ldots, \mathrm{n} \\
& \lambda_{3}^{\mathrm{T}} \mathrm{h}_{3}\left(\mathrm{x}^{*}\right)=0 \\
& \lambda_{1 \mathrm{i}}, \lambda_{2 \mathrm{i}}, \lambda_{3} \geq 0 \quad \backslash \quad \mathrm{i}=1, \ldots, \mathrm{n}
\end{aligned}
$$

sendo $\lambda$ são multiplicadores de Lagrange.

Para solucionar o sistema de inequações (8.9), considera-se $\mathbf{n}$ o número de grupos de elementos finitos a serem otimizados e nev o número de elementos de cada grupo de elementos finitos a ser otimizado. Desenvolvendo-se os termos da expressão (8.9) tem-se:

$$
\begin{gathered}
\nabla f(x)=\left\{\begin{array}{c}
\sum_{\mathrm{i}=1}^{\text {nev }}\left[\mathrm{b}_{\mathrm{wi}} \cdot \ell_{\mathrm{i}} \cdot \mathrm{C}_{\mathrm{V}}+2 \cdot \ell_{\mathrm{i}} \cdot \mathrm{C}_{\mathrm{F}}\right]_{\mathrm{k}} \\
\sum_{\mathrm{i}=1}^{\mathrm{nev}}\left[\ell_{\mathrm{i}} \cdot \rho_{\mathrm{s}} \cdot \mathrm{C}_{\mathrm{S}}\right]_{\mathrm{k}} \\
\sum_{\mathrm{i}=1}^{\text {nev }}\left[\ell_{\mathrm{i}} \cdot \rho_{\mathrm{s}} \cdot \mathrm{C}_{\mathrm{S}}\right]_{\mathrm{k}}
\end{array}\right\} \backslash \mathrm{k}=1, \ldots, \mathrm{n} \\
\nabla \mathrm{h}_{1}(\mathrm{x})=\left\{\begin{array}{c}
\mathrm{i}=1\left[\frac{\mathrm{x}_{2 \mathrm{i}}+\mathrm{x}_{3 \mathrm{i}}}{\mathrm{b}_{\mathrm{wi}} \cdot \mathrm{x}_{1 \mathrm{i}}{ }^{2}}\right]_{\mathrm{k}} \\
-\sum_{\mathrm{i}=1}^{\mathrm{nev}}\left[\frac{1}{\mathrm{~b}_{\mathrm{wi}} \cdot \mathrm{x}_{1 \mathrm{i}}}\right]_{\mathrm{k}} \\
-\sum_{\mathrm{i}=1}^{\mathrm{nev}}\left[\frac{1}{\mathrm{~b}_{\mathrm{wi}} \cdot \mathrm{x}_{1 \mathrm{i}}}\right]_{\mathrm{k}}
\end{array}\right\} \quad \mathrm{k}=1, \ldots, \mathrm{n}
\end{gathered}
$$




$$
\begin{gathered}
\nabla h_{2}(x)=\left\{\begin{array}{c}
-\sum_{i=1}^{n e v}\left[\frac{x_{2 i}+x_{3 i}}{b_{w i} \cdot x_{1 i}^{2}}\right]_{k} \sum_{i=1}^{n e v}\left[\frac{1}{b_{w i} \cdot x_{1 i}}\right]_{k} \\
+\sum_{i=1}^{n e v}\left[\frac{1}{b_{w i} \cdot x_{1 i}}\right]_{k}
\end{array}\right\} \backslash \quad \mathrm{k}=1, \ldots, n \\
\nabla h_{3}(x)=\left\{\begin{array}{l}
-\left[a_{3}+2 \cdot a_{6} x_{1}^{1}+a_{8} x_{3}^{1}+a_{9} x_{2}^{1}\right]_{k} \\
-\left[a_{2}+2 \cdot a_{5} x_{2}^{1}+a_{7} x_{3}^{1}+a_{9} x_{1}^{1}\right]_{k} \\
-\left[a_{1}+2 \cdot a_{4} x_{3}^{1}+a_{7} x_{2}^{1}+a_{8} x_{1}^{1}\right]_{k}
\end{array}\right\} \quad \backslash \quad k=1, \ldots, n
\end{gathered}
$$

Assume-se um vetor S no qual cada linha associa-se as equações da expressão (8.9). A solução do problema de otimização é portanto resolver o sistema de equações (8.14) para $\mathrm{k}=1, \ldots ., \mathrm{n}$.

$$
\mathrm{S}=\left\{\begin{array}{c}
\mathrm{S}_{1 \mathrm{k}} \\
\mathrm{S}_{2 \mathrm{k}} \\
\mathrm{S}_{3 \mathrm{k}} \\
\vdots \\
\mathrm{S}_{4 \mathrm{k}} \\
\mathrm{S}_{5 \mathrm{k}} \\
\vdots \\
\mathrm{S}_{6}
\end{array}\right\}=\left\{\begin{array}{c}
\frac{\partial \mathrm{f}\left(\mathrm{x}^{*}\right)}{\partial \mathrm{x}_{1 \mathrm{k}}}+\lambda_{1 \mathrm{k}} \frac{\partial \mathrm{h}_{1 \mathrm{k}}\left(\mathrm{x}^{*}\right)}{\partial \mathrm{x}_{1 \mathrm{k}}}+\lambda_{2 \mathrm{k}} \frac{\partial \mathrm{h}_{2 \mathrm{k}}\left(\mathrm{x}^{*}\right)}{\partial \mathrm{x}_{1 \mathrm{k}}}+\lambda_{3} \frac{\partial \mathrm{h}_{3}\left(\mathrm{x}^{*}\right)}{\partial \mathrm{x}_{1 \mathrm{k}}} \\
\frac{\partial \mathrm{f}\left(\mathrm{x}^{*}\right)}{\partial \mathrm{x}_{2 \mathrm{k}}}+\lambda_{1 \mathrm{k}} \frac{\partial \mathrm{h}_{1 \mathrm{k}}\left(\mathrm{x}^{*}\right)}{\partial \mathrm{x}_{2 \mathrm{k}}}+\lambda_{2 \mathrm{k}} \frac{\partial \mathrm{h}_{2 \mathrm{k}}\left(\mathrm{x}^{*}\right)}{\partial \mathrm{x}_{2 \mathrm{k}}}+\lambda_{3} \frac{\partial \mathrm{h}_{3}\left(\mathrm{x}^{*}\right)}{\partial \mathrm{x}_{2 \mathrm{k}}}+\lambda_{1 \mathrm{k}} \frac{\partial \mathrm{h}_{1 \mathrm{k}}\left(\mathrm{x}^{*}\right)}{\partial \mathrm{x}_{3 \mathrm{k}}}+\lambda_{2 \mathrm{k}} \frac{\partial \mathrm{h}_{2 \mathrm{k}}\left(\mathrm{x}^{*}\right)}{\partial \mathrm{x}_{3 \mathrm{k}}}+\lambda_{3} \frac{\partial \mathrm{h}_{3}\left(\mathrm{x}^{*}\right)}{\partial \mathrm{x}_{3 \mathrm{k}}} \\
\vdots \\
\lambda_{1 \mathrm{k}} \mathrm{h}_{1 \mathrm{k}}\left(\mathrm{x}^{*}\right) \\
\lambda_{2 \mathrm{k}} \mathrm{h}_{2 \mathrm{k}}\left(\mathrm{x}^{*}\right) \\
\vdots \\
\lambda_{3} \mathrm{~h}_{3}\left(\mathrm{x}^{*}\right)
\end{array}\right\}=\left\{\begin{array}{c}
0 \\
0 \\
0 \\
\vdots \\
0 \\
0 \\
\vdots \\
0
\end{array}\right\}
$$

ou

$$
\begin{gathered}
\mathrm{S}_{1 \mathrm{k}}=\sum_{\mathrm{i}=1}^{\mathrm{nev}}\left[\mathrm{b}_{\mathrm{wi}} \cdot \ell_{\mathrm{i}} \cdot \mathrm{C}_{\mathrm{V}}+2 \cdot \ell_{\mathrm{i}} \cdot \mathrm{C}_{\mathrm{F}}\right]_{\mathrm{k}}+\lambda_{1 \mathrm{k}} \sum_{\mathrm{i}=1}^{\mathrm{nev}}\left[\frac{\mathrm{x}_{2 \mathrm{i}}+\mathrm{x}_{3 \mathrm{i}}}{\mathrm{b}_{\mathrm{wi}} \cdot \mathrm{x}_{1 \mathrm{i}}{ }^{2}}\right]_{\mathrm{k}}-\lambda_{2 \mathrm{k}} \sum_{\mathrm{i}=1}^{\mathrm{nev}}\left[\frac{\mathrm{x}_{2 \mathrm{i}}+\mathrm{x}_{3 \mathrm{i}}}{\mathrm{b}_{\mathrm{wi}} \cdot \mathrm{x}_{1 \mathrm{i}}{ }^{2}}\right]_{\mathrm{k}} \\
-\lambda_{3}\left[\mathrm{a}_{3}+2 \cdot \mathrm{a}_{6} \mathrm{x}_{1}^{1}+\mathrm{a}_{8} \mathrm{x}_{3}^{1}+\mathrm{a}_{9} \mathrm{x}_{2}^{1}\right]_{\mathrm{k}} \\
\mathrm{S}_{2 \mathrm{k}}=\sum_{\mathrm{i}=1}^{\mathrm{nev}}\left[\ell_{\mathrm{i}} \cdot \rho_{\mathrm{s}} \cdot \mathrm{C}_{\mathrm{S}}\right]-\lambda_{\mathrm{k}} \sum_{\mathrm{i}=1}^{\mathrm{nev}}\left[\frac{1}{\mathrm{~b}_{\mathrm{wi}} \cdot \mathrm{x}_{1 \mathrm{i}}}\right]_{\mathrm{k}}+\lambda_{2 \mathrm{k}} \sum_{\mathrm{i}=1}^{\mathrm{nev}}\left[\frac{1}{\mathrm{~b}_{\mathrm{wi}} \cdot \mathrm{x}_{1 \mathrm{i}}}\right]_{\mathrm{k}} \\
-\lambda_{3}\left[\mathrm{a}_{2}+2 \cdot \mathrm{a}_{5} \mathrm{x}_{2}^{1}+\mathrm{a}_{7} \mathrm{x}_{3}^{1}+\mathrm{a}_{9} \mathrm{x}_{1}^{1}\right]_{\mathrm{k}}
\end{gathered}
$$




$$
\begin{aligned}
& S_{3 k}=\sum_{i=1}^{n e v}\left[\ell_{i} \cdot \rho_{s} \cdot C_{S}\right]_{k}-\lambda_{1 k} \sum_{i=1}^{n e v}\left[\frac{1}{b_{w i} \cdot x_{1 i}}\right]_{k}+\lambda_{2 k} \sum_{i=1}^{n e v}\left[\frac{1}{b_{w i} \cdot x_{1 i}}\right]_{k} \\
& -\lambda_{3}\left[a_{1}+2 \cdot a_{4} x_{3}^{1}+a_{7} x_{2}^{1}+a_{8} x_{1}^{1}\right]_{k} \\
& \mathrm{~S}_{4 \mathrm{k}}=\lambda_{1 \mathrm{k}}\left[\% \min -\left[\frac{\left(\mathrm{x}_{2}+\mathrm{x}_{3}\right)}{\left(\mathrm{b}_{\mathrm{w}} \cdot \mathrm{x}_{1}\right)}\right]\right]_{\mathrm{k}} \\
& \mathrm{S}_{5 \mathrm{k}}=\lambda_{2 \mathrm{i}}\left[\left[\frac{\left(\mathrm{x}_{2}+\mathrm{x}_{3}\right)}{\left(\mathrm{b}_{\mathrm{w}} \cdot \mathrm{x}_{1}\right)}\right]-\% \text { máx }\right]_{\mathrm{k}} \\
& S_{6}=\lambda_{3}\left[\beta_{0}-\sum\left[\begin{array}{l}
a_{0} x_{1}^{0} x_{2}^{0} x_{3}^{0}+a_{1} x_{1}^{0} x_{2}^{0} x_{3}^{1}+a_{2} x_{1}^{0} x_{2}^{1} x_{3}^{0}+a_{3} x_{1}^{1} x_{2}^{0} x_{3}^{0}+ \\
a_{4} x_{1}^{0} x_{2}^{0} x_{3}^{2}+a_{5} x_{1}^{0} x_{2}^{2} x_{3}^{0}+a_{6} x_{1}^{2} x_{2}^{0} x_{3}^{0}+a_{7} x_{1}^{0} x_{2}^{1} x_{3}^{1}+ \\
a_{8} x_{1}^{1} x_{2}^{0} x_{3}^{1}+a_{9} x_{1}^{1} x_{2}^{1} x_{3}^{0}
\end{array}\right]_{k}\right]
\end{aligned}
$$

Para resolver o sistema de equações (8.14), ou seja, determinar os extremos da função, pode-se utilizar o processo iterativo de Newton Raphson. A solução do problema não-linear é elaborada utilizando o gradiente do vetor $\mathrm{S}$, representado por $\mathrm{T}$.

$$
\mathrm{T}=\left[\begin{array}{cccccccc}
\frac{\partial \mathrm{S}_{1 \mathrm{k}}}{\partial \mathrm{x}_{1 \mathrm{k}}} & \frac{\partial \mathrm{S}_{1 \mathrm{k}}}{\partial \mathrm{x}_{2 \mathrm{k}}} & \frac{\partial \mathrm{S}_{1 \mathrm{k}}}{\partial \mathrm{x}_{3 \mathrm{k}}} & \cdots & \frac{\partial \mathrm{S}_{1 \mathrm{k}}}{\partial \lambda_{1 \mathrm{k}}} & \frac{\partial \mathrm{S}_{1 \mathrm{k}}}{\partial \lambda_{2 \mathrm{k}}} & \cdots & \frac{\partial \mathrm{S}_{1 \mathrm{k}}}{\partial \lambda_{3}} \\
\frac{\partial \mathrm{S}_{2 \mathrm{k}}}{\partial \mathrm{x}_{1 \mathrm{k}}} & \frac{\partial \mathrm{S}_{2 \mathrm{k}}}{\partial \mathrm{x}_{2 \mathrm{k}}} & \frac{\partial \mathrm{S}_{2 \mathrm{k}}}{\partial \mathrm{x}_{3 \mathrm{k}}} & \cdots & \frac{\partial \mathrm{S}_{2 \mathrm{k}}}{\partial \lambda_{1 \mathrm{k}}} & \frac{\partial \mathrm{S}_{2 \mathrm{k}}}{\partial \lambda_{2 \mathrm{k}}} & \cdots & \frac{\partial \mathrm{S}_{2 \mathrm{k}}}{\partial \lambda_{3}} \\
\frac{\partial \mathrm{S}_{3 \mathrm{k}}}{\partial \mathrm{x}_{1 \mathrm{k}}} & \frac{\partial \mathrm{S}_{3 \mathrm{k}}}{\partial \mathrm{x}_{2 \mathrm{k}}} & \frac{\partial \mathrm{S}_{3 \mathrm{k}}}{\partial \mathrm{x}_{3 \mathrm{k}}} & \cdots & \frac{\partial \mathrm{S}_{3 \mathrm{k}}}{\partial \lambda_{1 \mathrm{k}}} & \frac{\partial \mathrm{S}_{3 \mathrm{k}}}{\partial \lambda_{2 \mathrm{k}}} & \cdots & \frac{\partial \mathrm{S}_{3 \mathrm{k}}}{\partial \lambda_{3}} \\
\vdots & \vdots & \vdots & & \vdots & \vdots & & \vdots \\
\frac{\partial \mathrm{S}_{4 \mathrm{k}}}{\partial \mathrm{x}_{1 \mathrm{k}}} & \frac{\partial \mathrm{S}_{4 \mathrm{k}}}{\partial \mathrm{x}_{2 \mathrm{k}}} & \frac{\partial \mathrm{S}_{4 \mathrm{k}}}{\partial \mathrm{x}_{3 \mathrm{k}}} & \cdots & \frac{\partial \mathrm{S}_{4 \mathrm{k}}}{\partial \lambda_{1 \mathrm{k}}} & \frac{\partial \mathrm{S}_{4 \mathrm{k}}}{\partial \lambda_{2 \mathrm{k}}} & \cdots & \frac{\partial \mathrm{S}_{4 \mathrm{k}}}{\partial \lambda_{3}} \\
\frac{\partial \mathrm{S}_{5 \mathrm{k}}}{\partial \mathrm{x}_{1 \mathrm{k}}} & \frac{\partial \mathrm{S}_{5 \mathrm{k}}}{\partial \mathrm{x}_{2 \mathrm{k}}} & \frac{\partial \mathrm{S}_{5 \mathrm{k}}}{\partial \mathrm{x}_{3 \mathrm{k}}} & \cdots & \frac{\partial \mathrm{S}_{5 \mathrm{k}}}{\partial \lambda_{1 \mathrm{k}}} & \frac{\partial \mathrm{S}_{5 \mathrm{k}}}{\partial \lambda_{2 \mathrm{k}}} & \cdots & \frac{\partial \mathrm{S}_{5 \mathrm{k}}}{\partial \lambda_{3}} \\
\vdots & \vdots & \vdots & & \vdots & \vdots & & \vdots \\
\frac{\partial \mathrm{S}_{6}}{\partial \mathrm{x}_{1 \mathrm{k}}} & \frac{\partial \mathrm{S}_{6}}{\partial \mathrm{x}_{2 \mathrm{k}}} & \frac{\partial \mathrm{S}_{6}}{\partial \mathrm{x}_{3 \mathrm{k}}} & \cdots & \frac{\partial \mathrm{S}_{6}}{\partial \lambda_{1 \mathrm{k}}} & \frac{\partial \mathrm{S}_{6}}{\partial \lambda_{2 \mathrm{k}}} & \cdots & \frac{\partial \mathrm{S}_{6}}{\partial \lambda_{3}}
\end{array}\right]
$$

Para explicitar os termos de (8.21) consideram-se os seguintes desenvolvimentos:

$$
\nabla^{2} f(x)=\left[\begin{array}{ccc}
0 & 0 & 0 \\
0 & 0 & 0 \\
0 & 0 & 0
\end{array}\right]
$$




$$
\begin{aligned}
& \nabla^{2} h_{1}(x)=\left[\begin{array}{ccc}
-\sum_{i=1}^{n e v}\left[2 \cdot \frac{x_{2 i}+x_{3 i}}{b_{w i} \cdot x_{1 i}^{3}}\right]_{k} & +\sum_{i=1}^{n e v}\left[\frac{1}{b_{w i} \cdot x_{1 i}^{2}}\right]_{k} & +\sum_{i=1}^{n e v}\left[\frac{1}{b_{w i} \cdot x_{1 i}^{2}}\right]_{k} \\
+\sum_{i=1}^{n e v}\left[\frac{1}{b_{w i} \cdot x_{1 i}^{2}}\right]_{k} & 0 & 0 \\
+\sum_{i=1}^{n e v}\left[\frac{1}{b_{w i} \cdot x_{1 i}^{2}}\right]_{k} & 0 & 0
\end{array}\right]
\end{aligned}
$$

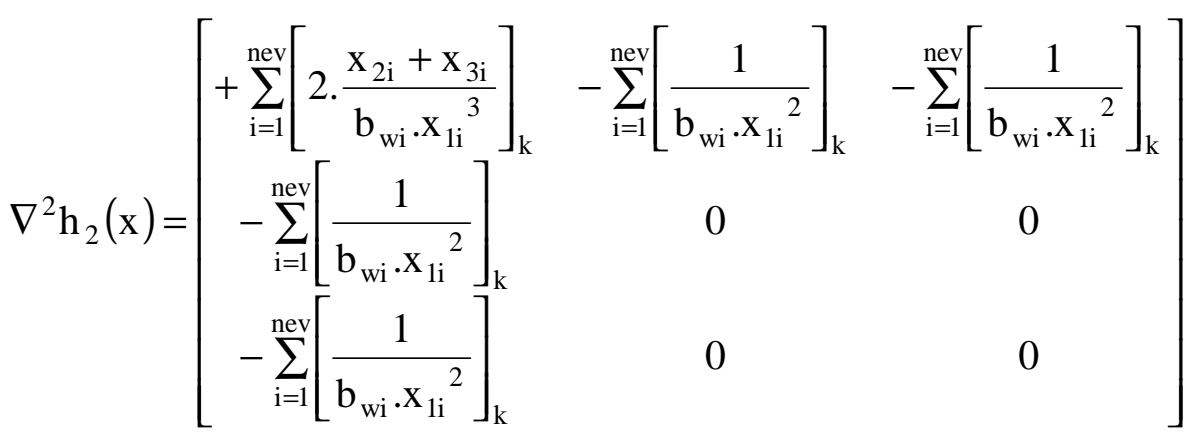

$$
\begin{aligned}
& \nabla^{2} h_{3}(x)=-\left[\begin{array}{ccc}
\frac{\partial^{2} \beta(x)}{\partial x_{1}^{2}} & \frac{\partial^{2} \beta(x)}{\partial x_{1} \partial x_{2}} & \frac{\partial^{2} \beta(x)}{\partial x_{1} \partial x_{3}} \\
\frac{\partial^{2} \beta(x)}{\partial x_{2} \partial x_{1}} & \frac{\partial^{2} \beta(x)}{\partial x_{2}^{2}} & \frac{\partial^{2} \beta(x)}{\partial x_{2} \partial x_{3}} \\
\frac{\partial^{2} \beta(x)}{\partial x_{3} \partial x_{1}} & \frac{\partial^{2} \beta(x)}{\partial x_{3} \partial x_{2}} & \frac{\partial^{2} \beta(x)}{\partial x_{3}^{2}}
\end{array}\right]
\end{aligned}
$$

Portanto, de forma explícita, cada termo da matriz $\mathrm{T}$ é representado por:

$$
\begin{gathered}
\frac{\partial S_{1 k}}{\partial x_{1 k}}=-\lambda_{1 k} \sum_{i=1}^{n e v}\left[2 \cdot \frac{x_{2 i}+x_{3 i}}{b_{w i} \cdot x_{1 i}{ }^{3}}\right]_{k}+\lambda_{2 k} \sum_{i=1}^{n e v}\left[2 \cdot \frac{x_{2 i}+x_{3 i}}{b_{w i} \cdot x_{1 i}{ }^{3}}\right]_{k}-\lambda_{3} \frac{\partial^{2} \beta(x)}{\partial x_{1}^{2}} \\
\frac{\partial S_{2 k}}{\partial x_{2 k}}=-\lambda_{3} \frac{\partial^{2} \beta(x)}{\partial x_{2}^{2}} \\
\frac{\partial S_{3 k}}{\partial x_{3 k}}=-\lambda_{3} \frac{\partial^{2} \beta(x)}{\partial x_{3}^{2}} \\
\frac{\partial S_{1 k}}{\partial x_{2 k}}=\frac{\partial S_{2 k}}{\partial x_{1 k}}=+\lambda_{1 k} \sum_{i=1}^{n e v}\left[\frac{1}{b_{w i} \cdot x_{1 i}^{2}}\right]_{k}-\lambda_{2 k} \sum_{i=1}^{n e v}\left[\frac{1}{b_{w i} \cdot x_{1 i}^{2}}\right]_{k}-\lambda_{3} \frac{\partial^{2} \beta(x)}{\partial x_{1} \partial x_{2}} \\
\frac{\partial S_{1 k}}{\partial x_{3 k}}=\frac{\partial S_{3 k}}{\partial x_{1 k}}=+\lambda_{1 k} \sum_{i=1}^{n e v}\left[\frac{1}{b_{w i} \cdot x_{1 i}{ }^{2}}\right]_{k}-\lambda_{2 k} \sum_{i=1}^{n e v}\left[\frac{1}{b_{w i} \cdot x_{1 i}^{2}}\right]_{k}-\lambda_{3} \frac{\partial^{2} \beta(x)}{\partial x_{1} \partial x_{3}}
\end{gathered}
$$




$$
\begin{aligned}
& \frac{\partial S_{2 k}}{\partial x_{3 k}}=\frac{\partial S_{3 k}}{\partial x_{2 k}}=-\lambda_{3} \frac{\partial^{2} \beta(x)}{\partial x_{2} \partial x_{3}} \\
& \frac{\partial S_{1 k}}{\partial \lambda_{1 k}}=+\sum_{i=1}^{n e v}\left[\frac{x_{2 i}+x_{3 i}}{b_{w i} \cdot x_{1 i}^{2}}\right]_{k} \\
& \frac{\partial S_{1 k}}{\partial \lambda_{2 k}}=-\sum_{i=1}^{n e v}\left[\frac{x_{2 i}+x_{3 i}}{b_{w i} \cdot x_{1 i}^{2}}\right]_{k} \\
& \frac{\partial S_{2 k}}{\partial \lambda_{1 k}}=\frac{\partial S_{3 k}}{\partial \lambda_{1 k}}=-\sum_{i=1}^{n e v}\left[\frac{1}{b_{w i} \cdot x_{1 i}}\right]_{k} \\
& \frac{\partial S_{2 k}}{\partial \lambda_{2 k}}=\frac{\partial S_{3 k}}{\partial \lambda_{2 k}}=+\sum_{i=1}^{n e v}\left[\frac{1}{b_{w i} \cdot x_{1 i}}\right]_{k} \\
& \frac{\partial \mathrm{S}_{4 \mathrm{k}}}{\partial \mathrm{x}_{1 \mathrm{k}}}=+\lambda_{1 \mathrm{k}} \sum_{\mathrm{i}=1}^{\mathrm{nev}}\left[\frac{\mathrm{x}_{2 \mathrm{i}}+\mathrm{x}_{3 \mathrm{i}}}{\mathrm{b}_{\mathrm{wi}} \cdot \mathrm{x}_{1 \mathrm{i}}{ }^{2}}\right]_{\mathrm{k}} \\
& \frac{\partial S_{4 k}}{\partial x_{2 k}}=\frac{\partial S_{4 k}}{\partial x_{3 k}}=-\lambda_{1 k} \sum_{i=1}^{n e v}\left[\frac{1}{b_{w i} \cdot x_{1 i}}\right]_{k} \\
& \frac{\partial S_{5 k}}{\partial x_{1 k}}=-\lambda_{2 k} \sum_{i=1}^{n e v}\left[\frac{x_{2 i}+x_{3 i}}{b_{w i} \cdot x_{1 i}^{2}}\right]_{k} \\
& \frac{\partial S_{5 k}}{\partial x_{2 k}}=\frac{\partial S_{5 k}}{\partial x_{3 k}}=+\lambda_{2 k} \sum_{i=1}^{n e v}\left[\frac{1}{b_{w i} \cdot x_{1 i}}\right]_{k} \\
& \frac{\partial \mathrm{S}_{4 \mathrm{k}}}{\partial \lambda_{1 \mathrm{k}}}=\sum_{\mathrm{i}=1}^{\mathrm{nev}}\left[\% \min -\frac{\mathrm{x}_{2 \mathrm{i}}+\mathrm{x}_{3 \mathrm{i}}}{\mathrm{b}_{\mathrm{wi}} \cdot \mathrm{x}_{1 \mathrm{i}}}\right]_{\mathrm{k}} \\
& \frac{\partial \mathrm{S}_{5 \mathrm{k}}}{\partial \lambda_{2 \mathrm{k}}}=\sum_{\mathrm{i}=1}^{\mathrm{nev}}\left[\frac{\mathrm{x}_{2 \mathrm{i}}+\mathrm{x}_{3 \mathrm{i}}}{\mathrm{b}_{\mathrm{wi}} \cdot \mathrm{x}_{1 \mathrm{i}}}-\% \max \right]_{\mathrm{k}} \\
& \frac{\partial S_{4 k}}{\partial \lambda_{2 k}}=\frac{\partial S_{5 k}}{\partial \lambda_{1 k}}=0 \\
& \frac{\partial \mathrm{S}_{6}}{\partial \mathrm{x}_{1 \mathrm{k}}}=-\lambda_{3} \frac{\partial \beta(\mathrm{x})}{\partial \mathrm{x}_{1 \mathrm{k}}} \\
& \frac{\partial S_{6}}{\partial x_{2 k}}=-\lambda_{3} \frac{\partial \beta(x)}{\partial x_{2 k}}
\end{aligned}
$$




$$
\begin{gathered}
\frac{\partial S_{6}}{\partial x_{3 \mathrm{k}}}=-\lambda_{3} \frac{\partial \beta(\mathrm{x})}{\partial \mathrm{x}_{3 \mathrm{k}}} \\
\frac{\partial \mathrm{S}_{4 \mathrm{k}}}{\partial \lambda_{3}}=\frac{\partial \mathrm{S}_{5 \mathrm{k}}}{\partial \lambda_{3}}=\frac{\partial \mathrm{S}_{6}}{\partial \lambda_{1 \mathrm{k}}}=\frac{\partial \mathrm{S}_{6}}{\partial \lambda_{2 \mathrm{k}}}=0 \\
\frac{\partial \mathrm{S}_{1 \mathrm{k}}}{\partial \lambda_{3}}=-\frac{\partial \beta(\mathrm{x})}{\partial \mathrm{x}_{1 \mathrm{k}}} \\
\frac{\partial \mathrm{S}_{2 \mathrm{k}}}{\partial \lambda_{3}}=-\frac{\partial \beta(\mathrm{x})}{\partial \mathrm{x}_{2 \mathrm{k}}} \\
\frac{\partial \mathrm{S}_{3 \mathrm{k}}}{\partial \lambda_{3}}=-\frac{\partial \beta(\mathrm{x})}{\partial \mathrm{x}_{3 \mathrm{k}}} \\
\frac{\partial \mathrm{S}_{6}}{\partial \lambda_{3}}=\beta_{0}-\beta(\mathrm{x})
\end{gathered}
$$

No algoritmo de otimização proposto assume-se que a hipersuperfície de confiabilidade é válida apenas em torno da solução do problema e a mesma é aproximada a um polinômio do segundo grau. Devido a essa hipótese, após encontrar os extremos da função custo, é necessário retornar e fazer todo o procedimento outra vez até que em dois passos consecutivos o custo seja o mesmo, a menos de uma tolerância preestabelecida. Lembra-se que este procedimento foi o mesmo utilizado para verificar a convergência do índice de confiabilidade ao utilizar o RSM. Portanto, utiliza-se, para otimizar uma estrutura garantindo uma confiabilidade préestabelecida, o processo utilizado no RSM para estimar a confiabilidade. Funciona como um RSM interno a outro; no primeiro busca-se o índice de confiabilidade onde a FS é construída com as respostas mecânicas da estrutura enquanto que no segundo busca-se a solução do problema de otimização onde a FS é construída com os índices de confiabilidade.

Foram testados exemplos e verificado a convergência do procedimento descrito acima apenas em situações particulares. Segundo a bibliografia e experiência do autor, utilizar algoritmos baseados em derivadas para resolver problemas de otimização acoplados com confiabilidade não é o caminho mais indicado. Problemas desse tipo podem apresentar duas características decisivas na escolha do algoritmo: alta sensibilidade em torno da solução e múltiplos pontos de falha. A primeira característica deixa métodos que utilizam gradientes para direcionar a busca 
perdidos, não há direção coerente da derivada de uma iteração para a seguinte. A respeito de múltiplos pontos de falha, algoritmos desse tipo podem convergir para mínimos locais. Portanto, deixa-se claro que métodos que utilizam gradiente não são aconselháveis para problemas de otimização acoplada com confiabilidade. Foi descrito um método utilizando gradiente apenas para mostrar uma solução possível. Pode-se constatar porém que esses métodos não garantem a convergência no tipo de problema abordado.

Uma outra solução possível para o problema (8.8) é utilizar métodos heurísticos. Os algoritmos genéticos são os mais utilizados nas referencias bibliográficas. Esses tipos de algoritmos evitam o trabalho com derivadas eliminando os principais problemas que surgem com o acoplamento da confiabilidade, múltipla solução e sensibilidade da superfície de resposta. Para evitar-se a aleatoriedade dos algoritmos genéticos, sugere-se trabalhar com algoritmos meméticos, nos quais a geração de filhos é conduzida por leis definidas pelo pesquisador.

Ao utilizar métodos heurísticos não há necessidade de aproximar a superfície de confiabilidade a um polinômio, portanto, a restrição (8.6) pode ser escrita como:

$$
\mathrm{h}_{3}(\mathrm{x})=\beta_{0}-\beta^{*} \leq 0
$$

Onde $\beta^{*}$ é o índice de confiabilidade para cada cruzamento proposto pelo algoritmo.

Portanto, o problema de otimização passa a ser escrito como:

Minimize

$$
\mathrm{f}(\mathrm{x})=\sum_{\mathrm{i}=1}^{\mathrm{n}}\left[\mathrm{b}_{\mathrm{wi}} \cdot \mathrm{x}_{1 \mathrm{i}} \cdot \ell_{\mathrm{i}} \cdot \mathrm{C}_{\mathrm{V}}+\left(\mathrm{b}_{\mathrm{wi}}+2 \cdot \mathrm{x}_{1 \mathrm{i}}\right) \cdot \ell_{\mathrm{i}} \cdot \mathrm{C}_{\mathrm{F}}+\left(\mathrm{x}_{2 \mathrm{i}}+\mathrm{x}_{3 \mathrm{i}}\right) \cdot \ell_{\mathrm{i}} \cdot \rho_{\mathrm{s}} \cdot \mathrm{C}_{\mathrm{S}}\right]
$$

Sujeito à

$$
\begin{gathered}
\mathrm{h}_{1}(\mathrm{x})=\% \min -\left[\frac{\left(\mathrm{x}_{2 \mathrm{i}}+\mathrm{x}_{3 \mathrm{i}}\right)}{\left(\mathrm{b}_{\mathrm{wi}} \cdot \mathrm{x}_{1 \mathrm{i}}\right)}\right] \leq 0 \quad \backslash \quad \mathrm{i}=1, \ldots, \mathrm{n} \\
\mathrm{h}_{2}(\mathrm{x})=\left[\frac{\left(\mathrm{x}_{2 \mathrm{i}}+\mathrm{x}_{3 \mathrm{i}}\right)}{\left(\mathrm{b}_{\mathrm{wi}} \cdot \mathrm{x}_{1 \mathrm{i}}\right)}\right]-\% \operatorname{máx} \leq 0 \quad \backslash \quad \mathrm{i}=1, \ldots, \mathrm{n} \\
\mathrm{h}_{3}(\mathrm{x})=\beta_{0}-\beta^{*} \leq 0
\end{gathered}
$$

O estudo de algoritmos de otimização acoplados com confiabilidade é um assunto bastante atual, vários pesquisadores buscam soluções para esses problemas aplicados a diversas áreas. O desenvolvimento de algoritmos dessa categoria por si só 
pode gerar uma boa tese. 


\section{Capítulo 9 Análise estatística de colunas de concreto armado}

Neste capítulo, pretende-se estudar o comportamento estatístico de colunas de concreto armado, apresentadas na Figura 9.1, cujas características encontram-se na Tabela 9.1 à Tabela 9.3. É importante salientar que toda e qualquer conclusão apresentada nos resultados é válida apenas para os domínios das variáveis abordados.

As respostas mecânicas das colunas são obtidas utilizando-se o método dos elementos finitos, com as colunas sendo discretizadas em 4 elementos lineares com 3 graus de liberdade por nó. Para representar a não-linearidade do material utilizam-se modelos constitutivos escritos em termos de diagramas uniaxiais tensão deformação, onde a região comprimida do concreto é representada pelo modelo proposto pelo $\mathrm{CEB}$ MC90, enquanto que a região tracionada é representada pelo modelo proposto por FIGUEIRAS (1983). O aço é representado pelo diagrama adotado pela NBR 6118, para aço tipo A. No concreto não é imposto qualquer limite de deformação (o próprio diagrama tensão - deformação se encarrega da limitação), porém o aço é limitado em 10\% . Efeitos de segunda ordem são considerados através de sistemas de coordenadas corrotacionais descrito no capítulo Capítulo 3.

O método estatístico utilizado para estimar o índice de confiabilidade é o descrito no Capítulo 5.

O limite estabelecido para o Estado Limite Último (ULS) é definido pela singularidade da matriz de rigidez global da estrutura. Para o Estado Limite de Serviço (SLS), o limite é estabelecido pelo máximo deslocamento admitido no ponto de maior relação deslocamento real por deslocamento admitido. Nessa análise considerou-se como deslocamento máximo admitido a seguinte relação: $\mathrm{u}_{\text {máx }}=\mathrm{L} / 150$, onde $\mathrm{L}$ refere-se ao comprimento da coluna. 

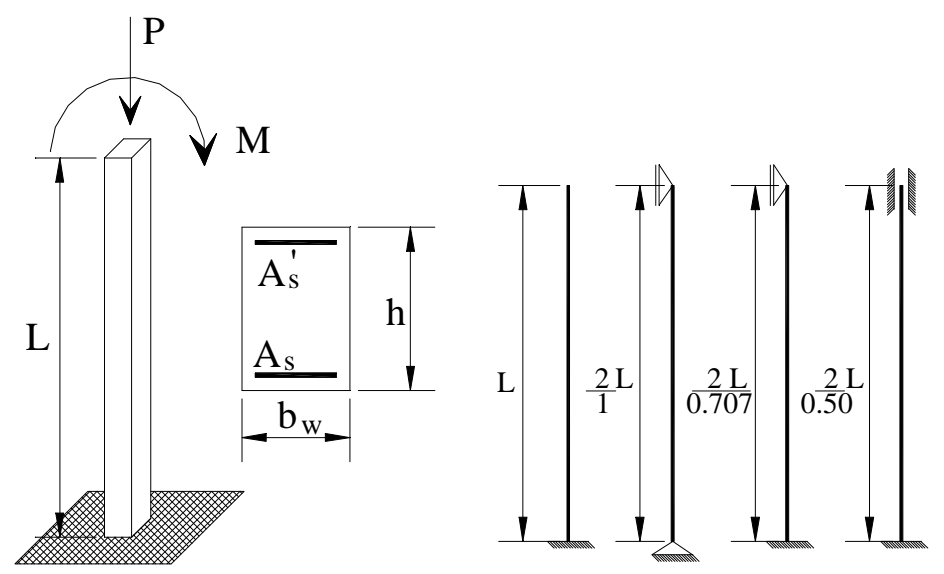

Figura 9.1 Coluna de referência com comprimentos equivalentes para uma mesma flambagem com diferentes condições de contorno

Tabela 9.1 Características mecânicas. ( $\mathrm{kN}$ e cm)

\begin{tabular}{|c|c|}
\hline Base da seção transversal (direção de menor inércia), $\mathrm{b}_{\mathrm{w}}$ & 25.00 \\
\hline Altura da seção transversal (direção de maior inércia), $\mathrm{h}$ & 25.00 \\
\hline Taxa de armadura, $\mathrm{A}_{\mathrm{s}} /\left(\mathrm{b}_{\mathrm{w}} \cdot \mathrm{h}\right)$ & $0.80 \% \leq \mathrm{A}_{\mathrm{s}} /\left(\mathrm{b}_{\mathrm{w}} \cdot \mathrm{h}\right) \leq 2.40 \%$ \\
\hline Índice de esbeltez, $\lambda$ & $0 \leq \lambda \leq 140$ \\
\hline Excentricidade inicial, $\mu / \mathrm{v}$ & $0.08 \leq \mu / \mathrm{v} \leq 0.60$ \\
\hline
\end{tabular}

Tabela 9.2 Características estatísticas. $(\mathrm{kN} \mathrm{e} \mathrm{cm})$

\begin{tabular}{|c|c|c|c|c|}
\hline Parâmetro de projeto & $\begin{array}{c}\text { Média } \\
\mu\end{array}$ & $\begin{array}{c}\text { Desvio padrão } \\
\sigma\end{array}$ & $\begin{array}{c}\text { Coeficiente de Variação } \\
\text { CV }\end{array}$ & Lei \\
\hline \multirow{4}{*}{$\begin{array}{l}\text { Resistência à compressão } \\
\text { do concreto }\end{array}$} & \multirow{4}{*}{$2.50 \leq \mathrm{f}_{\mathrm{cm}} \leq 5.00$} & 0.40 & & $\mathrm{~N}$ \\
\hline & & 0.55 & & $\mathrm{~N}$ \\
\hline & & 0.70 & & $\mathrm{~N}$ \\
\hline & & & $8 \% \leq \mathrm{CV}_{\mathrm{c}} \leq 20 \%$ & $\mathrm{~N}$ \\
\hline Resistência do aço & $f_{y m}=50.00$ & & $6 \%$ & $\mathrm{~N}$ \\
\hline $\begin{array}{c}\text { Posição da armadura } \\
\text { relativa ao CG }\end{array}$ & $\begin{aligned} Y_{\text {infm }} & =-10.00 \\
Y_{\text {supm }} & =+10.00\end{aligned}$ & & $4 \%$ & $\mathrm{~N}$ \\
\hline
\end{tabular}

Tabela 9.3 Coeficientes parciais de segurança

\begin{tabular}{|c|c|c|c|c|c|}
\hline Caso & Concreto & Aço & Carga permanente & Carga acidental & Carga de vento \\
\hline 1 & 1.40 & 1.15 & 1.40 & 1.40 & 1.40 \\
\hline 2 & 1.40 & 1.15 & 1.00 & 1.00 & 1.00 \\
\hline 3 & 1.40 & 1.15 & 1.00 & 1.00 & 0.00 \\
\hline 4 & 1.40 & 1.15 & 1.00 & 1.00 & 3.33 \\
\hline
\end{tabular}

Ao considerarem-se diferentes condições de contorno para as colunas, verificou-se através de vários exemplos analisados que é viável extrapolar os resultados obtidos na análise da coluna apresentada na Figura 9.1 para a mesma coluna com diferentes condições de contorno, desde que ao mudar as condições de contorno o diagrama de momentos e o comprimento de flambagem da coluna permaneçam os mesmos. Os efeitos devidos a não-linearidade do material fazem com 
que a posição deformada da coluna deixe de ser senoidal. Os resultados finais, entretanto, apresentaram diferenças desprezíveis ao considerar-se a NLF, validando a concepção de se considerar a deformada como senoidal, ou seja, os comprimentos de flambagem propostos ao conceber apenas a NLG.

Embora sejam utilizados atualmente valores constantes para os coeficientes parciais, é coerente presumir que esses valores devam mudar com as características da coluna, assim como com a concepção de cálculo adotada. Nesse contexto, faz-se a análise de alguns coeficientes parciais de segurança utilizados correntemente na prática de projetos estruturais, Tabela 9.3.

Já se sabe que a probabilidade de falha das estruturas quando utilizam-se códigos modelos baseados em coeficientes parciais não é uniforme e nem quantificável. Entretanto, trabalhar diretamente com probabilidade de falha em projetos práticos ainda não é viável devido ao custo computacional e ao nível de conhecimentos técnicos dos projetistas. Embora deva se acreditar que num futuro próximo isso será possível. A análise paramétrica desenvolvida nesse capítulo tentará mostrar a variação da probabilidade da estrutura de atingir um determinado limite quando são utilizados coeficientes parciais de segurança constantes. São analisados os desvios padrão do concreto os quais estão diretamente relacionados com a variação da probabilidade de ruína das estruturas. Concluindo-se nessa análise a necessidade de fixar coeficientes de variação constante para o concreto, não desvio padrão constante como é proposto atualmente. Também serão analisados alguns coeficientes parciais de segurança para o concreto. É necessário deixar claro que as conclusões tiradas para coeficientes de segurança são parciais e válidas no âmbito dessa análise.

\subsection{Variação do índice de confiabilidade em colunas de CA segundo normas propostas}

Verifica-se nessa primeira análise a confiabilidade em colunas de concreto armado (CA) que alguns modelos de cálculo propostos por normas oferecem ao variar os coeficientes parciais de segurança das ações e o desvio padrão do concreto. Serão motivo de análise os Estados Limites Último e de Serviço.

Os gráficos são elaborados variando-se a resistência à compressão média do 
concreto, o índice de esbeltez da coluna, a taxa geométrica de armadura e a excentricidade de primeira ordem representada pela razão $\mu / v$ definida por:

$$
\frac{\mu}{v}=\frac{M_{d} /\left(b_{w} \cdot h \cdot h \cdot f_{c d}\right)}{N_{d} /\left(b_{w} \cdot h \cdot f_{c d}\right)}=\frac{\left(N_{d} \cdot e x c\right) /\left(b_{w} \cdot h \cdot h \cdot f_{c d}\right)}{N_{d} /\left(b_{w} \cdot h \cdot f_{c d}\right)}=\frac{\operatorname{exc}}{h}
$$

Como o processo numérico envolve um grande número de variáveis e algumas aproximações, eventualmente algumas respostas podem não pertencer ao comportamento global da respectiva variável. Portanto, pontos que estão fora das curvas não devem ser levados em consideração para as possíveis conclusões. Intencionalmente mantiveram-se os valores com comportamento diferente do restante, eles possibilitam ao analista verificar o desempenho do algoritmo. 


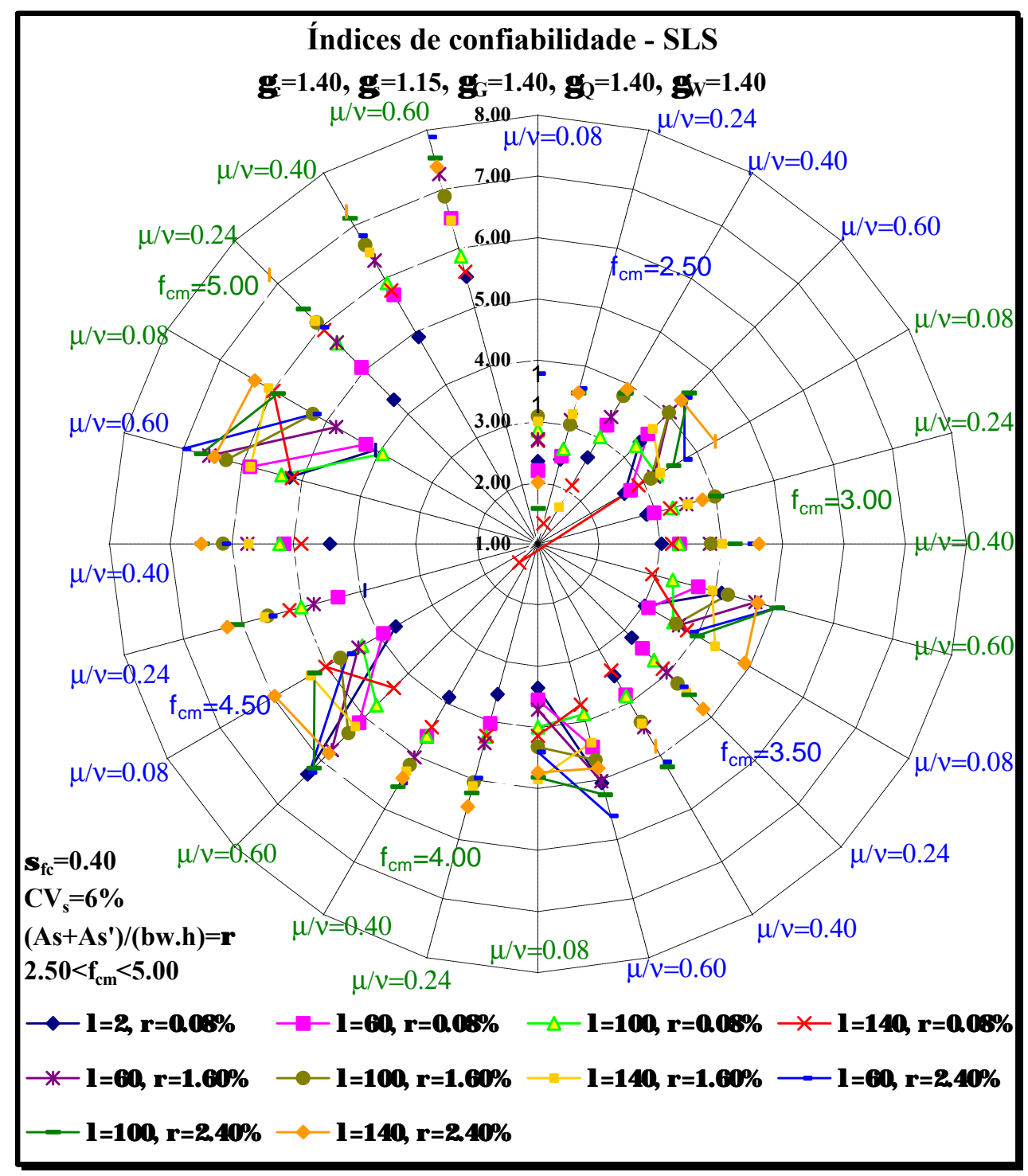

Gráfico 9.1 Confiabilidade em colunas de CA

Como pode ser observado no Gráfico 9.1 ao Gráfico 9.7, há um aumento significativo no índice de confiabilidade com o aumento da resistência média do concreto. Isso ocorre devido ao desvio padrão desse material ser constante e consequentemente o coeficiente de variação, razão do desvio padrão pelo valor médio, diminuir à medida que a resistência média aumente. 


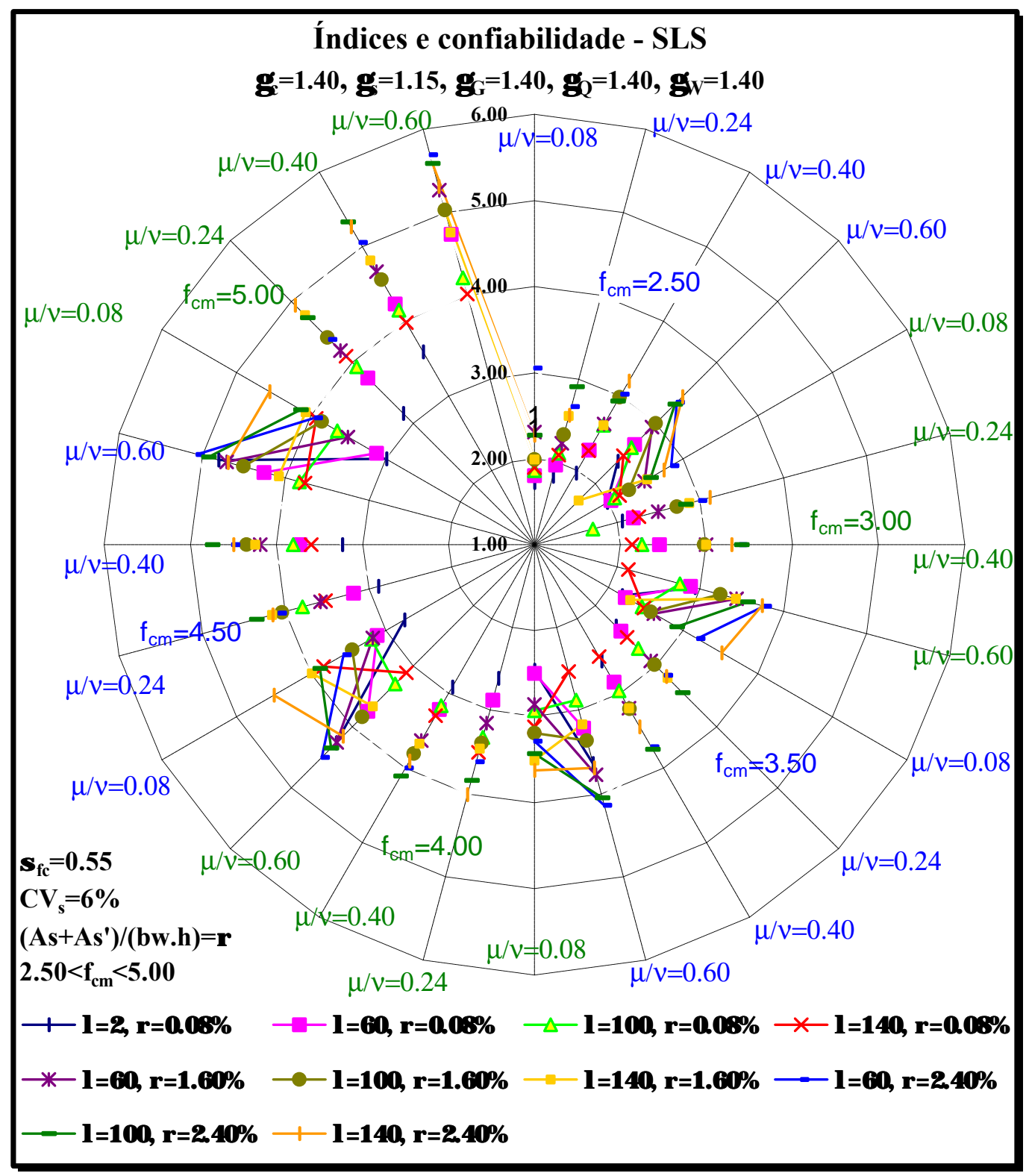

Gráfico 9.2 Confiabilidade em colunas de CA

As recomendações internacionais sugerem que um valor adequado para o índice de confiabilidade no SLS seja tomado em torno de 1.50. A análise realizada mostra que esse valor não foi ultrapassado em nenhum dos resultados, concluindo-se, nesse caso, que as estruturas encontram-se com sobra na segurança, podendo significar estruturas anti-econômicas.

O aumento do índice de confiabilidade com a taxa geométrica de armadura é natural já que o aço é um material com coeficiente de variação bem menor que o concreto. 


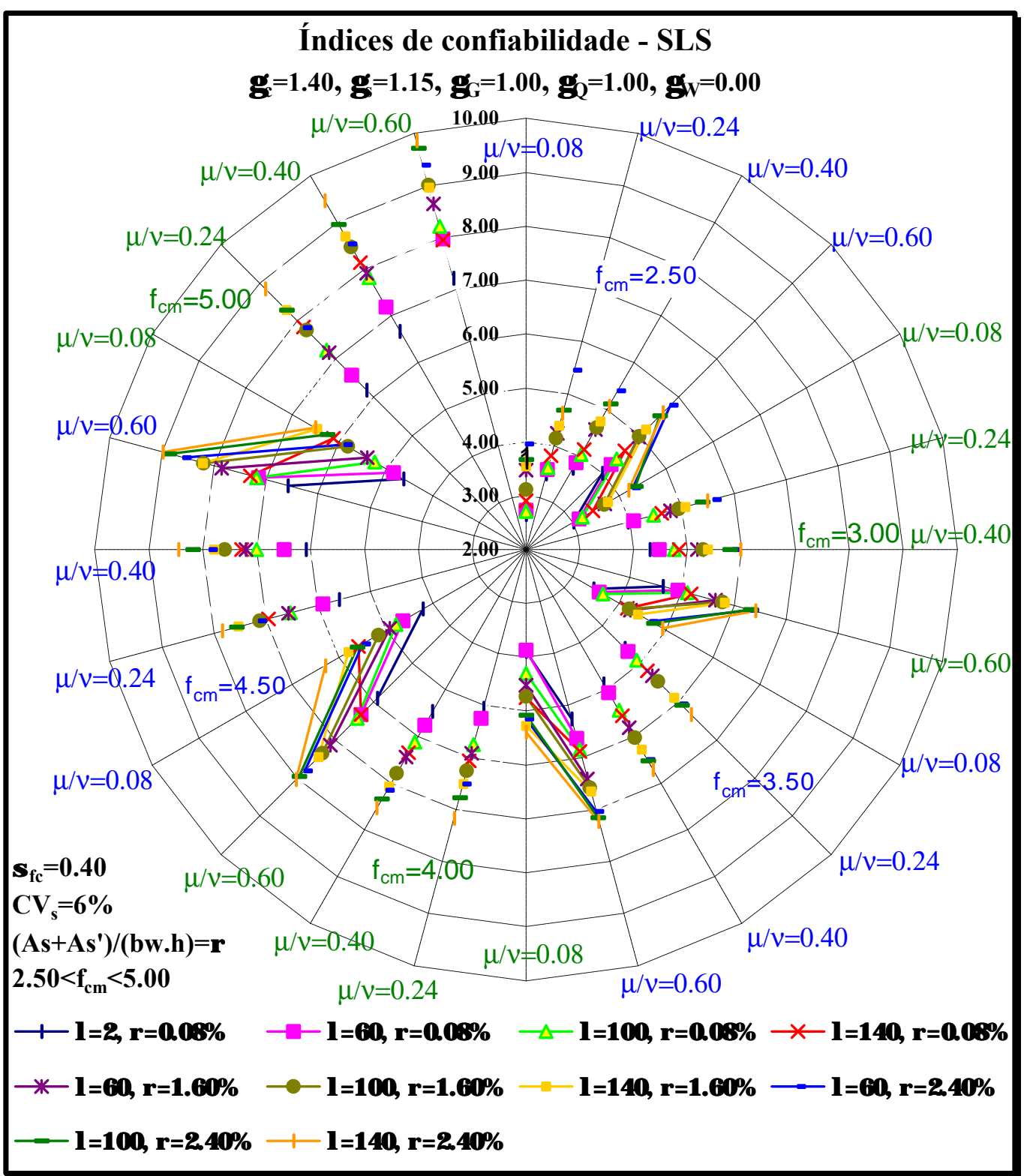

Gráfico 9.3 Confiabilidade em colunas de CA

Ao variarem-se os coeficientes parciais de segurança das ações externas nota-se que, para concretos com baixa resistência média à compressão, a variação no índice de confiabilidade é bem pequena, oposto do que ocorre com resistências elevadas. Como se sabe o índice de confiabilidade refere-se a uma probabilidade de ruína da estrutura, para índices de valores maiores a sensibilidade do índice diminui. 


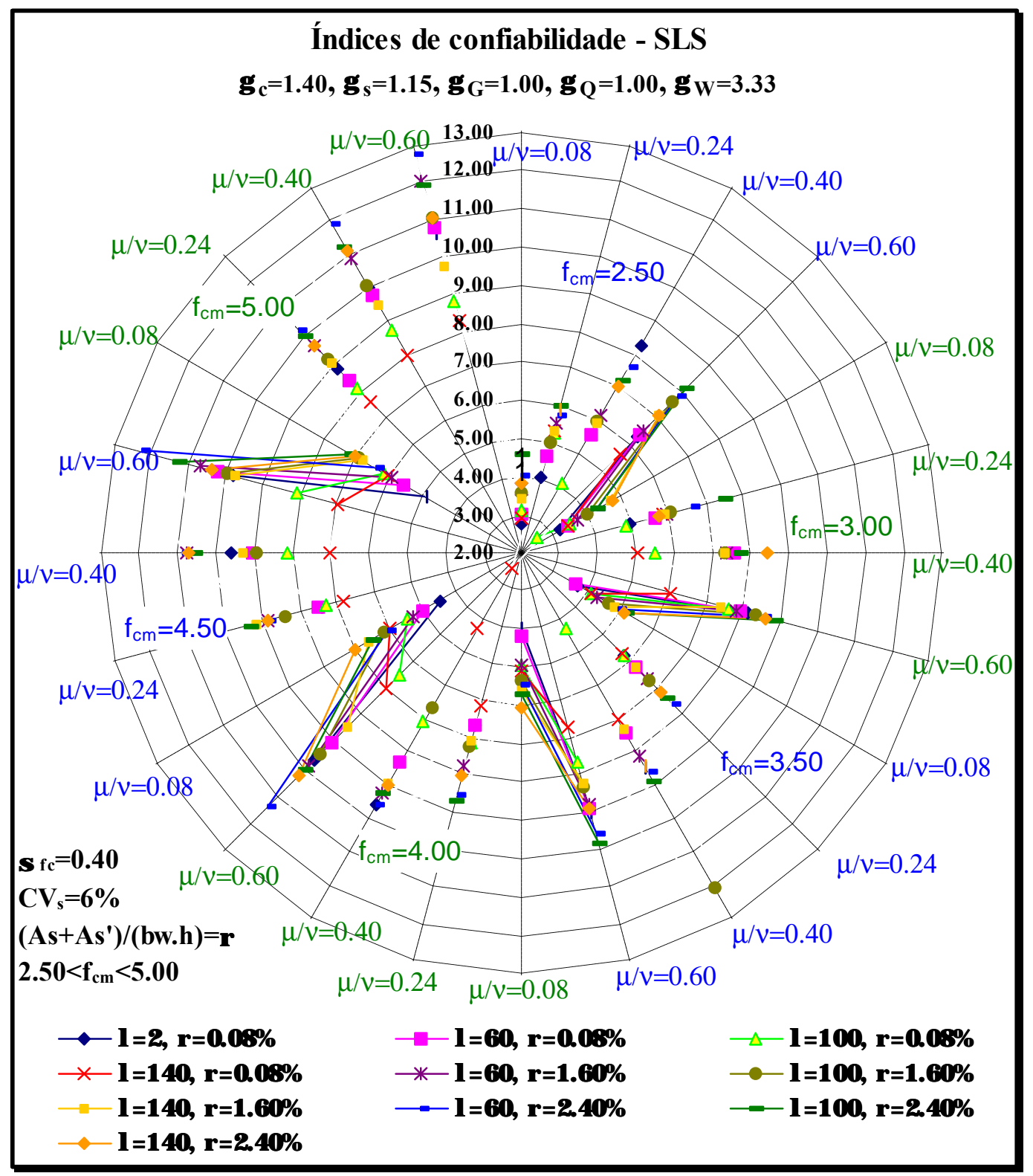

Gráfico 9.4 Confiabilidade em colunas de CA

É evidente também o aumento da confiabilidade com a importância dos efeitos de segunda ordem, explicitados em termos de índice de esbeltez e relação adimensional da excentricidade inicial. Quando a coluna é mais esbelta ou a excentricidade de primeira ordem é elevada, a relação entre os esforços de segunda e primeira ordem é mais elevada. Sabe-se que os esforços de segunda ordem dependem diretamente do deslocamento da coluna, que por sua vez depende da rigidez do elemento também dependente das ações aplicadas à estrutura. Utilizar coeficientes parciais de segurança, introduzidos para minorar a resistência do material e majorar as ações externas, leva a introdução de segurança nos esforços de segunda ordem de 
forma duplicada (reduz resistência dos materiais que aumenta o deslocamento, e amplia as ações externas que também aumenta deslocamento).

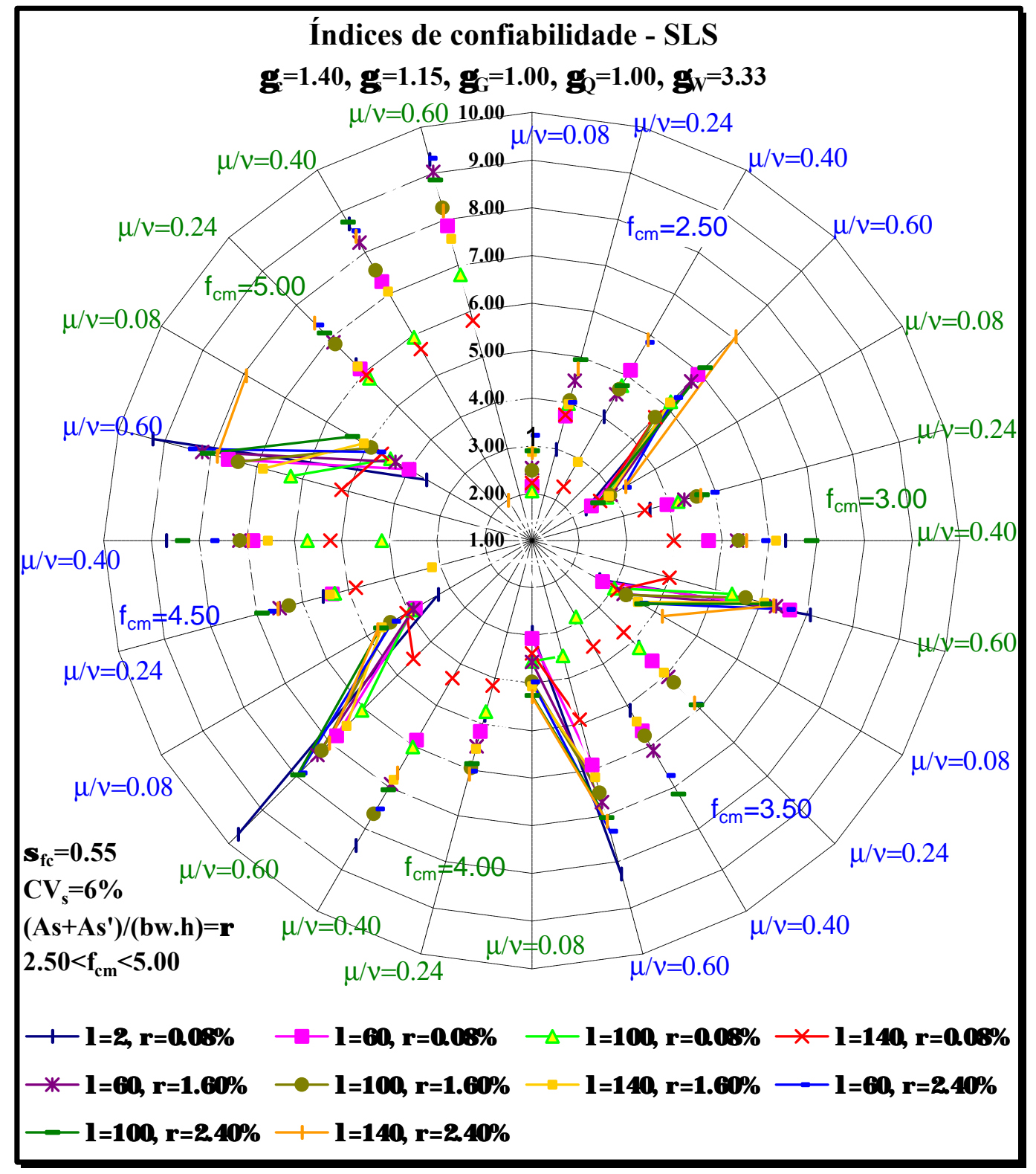

Gráfico 9.5 Confiabilidade em colunas de CA

Um um valor adequado para o índice de confiabilidade no ULS é em torno de 3.80 de acordo com recomendações internacionais. Utilizando desvio padrão constante com valor $4,00 \mathrm{MPa}$ (concreto com qualidade rigorosa segundo a NB1), observa-se no Gráfico 9.6 que os índices de confiabilidade obtidos com coeficientes de segurança parcial padrões são superiores ao desejado. Concluindo-se assim que com relação ao ULS e ao domínio assumido das variáveis, as estruturas encontram-se em muitos casos com sobra na segurança, podendo significar estruturas anti- 
econômicas (mesma observação feita para o SLS).

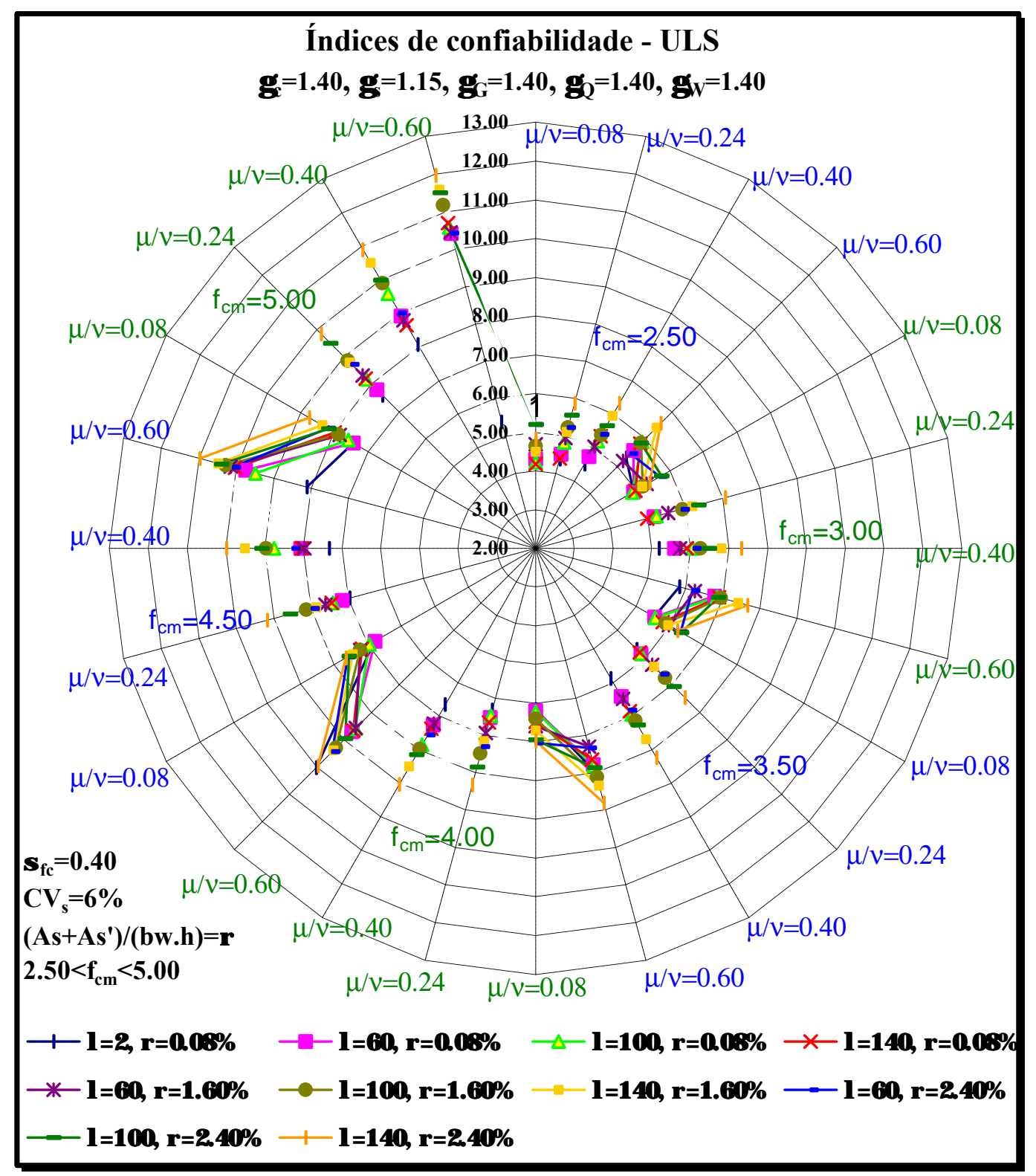

Gráfico 9.6 Confiabilidade em colunas de CA

Ao utilizar desvio padrão para o concreto com valor $5,50 \mathrm{MPa}$ (concreto com qualidade moderada segundo a NB1), observa-se no Gráfico 9.7 que para resistência à compressão média inferior a $25,00 \mathrm{MPa}$ a probabilidade de falha é superior a desejada, mostrando incoerência em dimensionar colunas nessa situação (situação desfavorável a segurança esperada). 


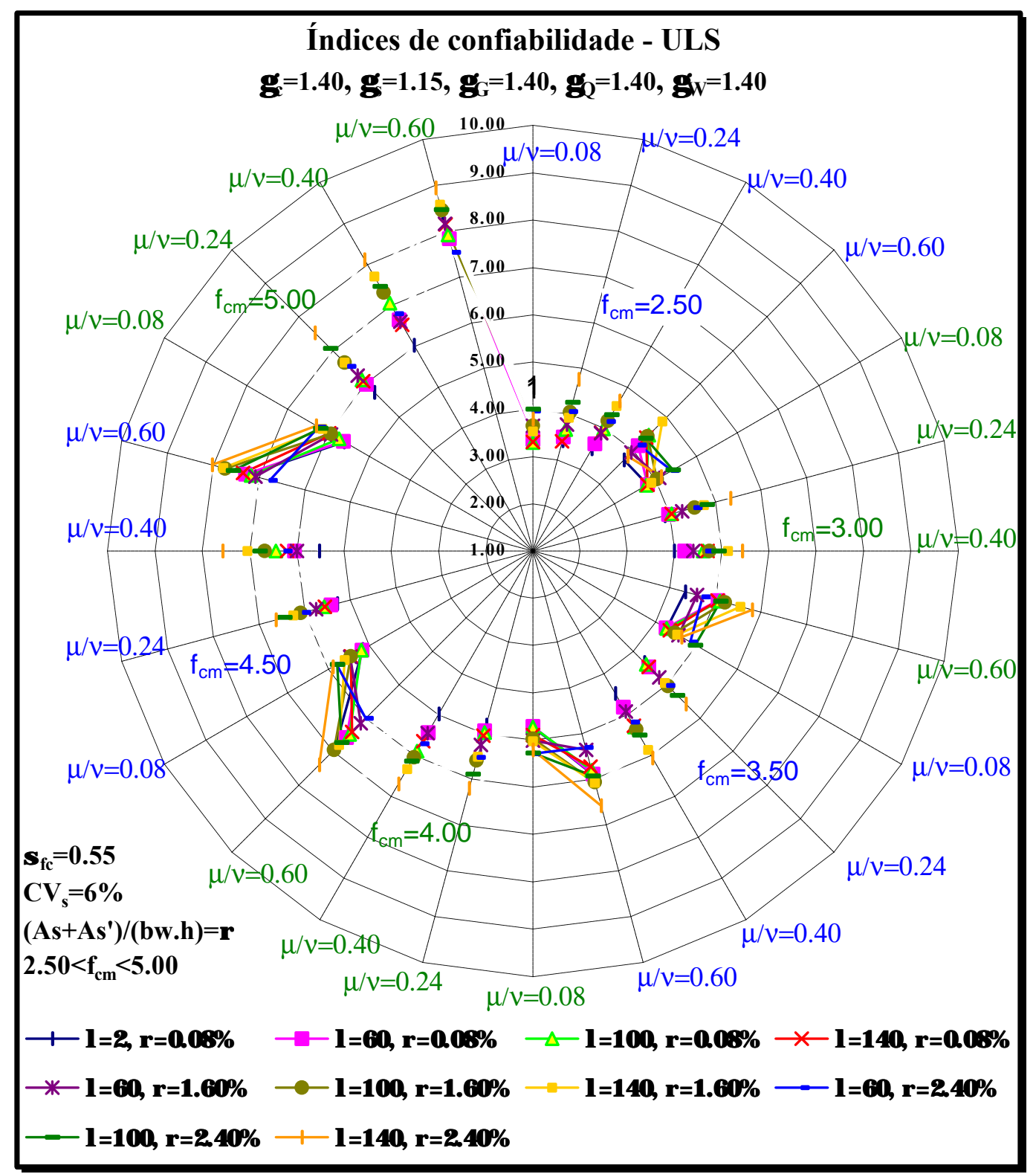

Gráfico 9.7 Confiabilidade em colunas de CA

Em outros exemplos analisados verificou-se que quando a excentricidade de primeira ordem é superior ao comprimento do lado sa seção transversal com índice de esbeltez em torno de 180, o índice de confiabilidade apresenta um ligeiro decréscimo.

Analiticamente pode-se demonstrar inconsistência ao considerar coeficientes parciais de segurança e desvio padrão das variáveis com valores constantes. Como se sabe, a probabilidade de falha pode ser quantitativamente expressa pela equação (9.2): 


$$
P_{f}=P[G(X) \leq 0]=\int_{G(X) \leq 0} \ldots \int_{X} f_{X}(x) d x
$$

No caso particular do concreto armado, as propriedades do aço e concreto são variáveis não correlacionadas, portanto a probabilidade de falha desse material pode ser definida como:

$$
P_{f}\left(x_{1}=f_{c d}, x_{2}=f_{y d}\right)=\int_{-\infty}^{f_{c d}} \int_{-\infty}^{f_{y d}} f\left(x_{1}\right) f\left(x_{2}\right) d x_{1} d x_{2}=\int_{-\infty}^{f_{c d}} f\left(x_{1}\right) d x_{1} \cdot \int_{-\infty}^{f_{y d}} f\left(x_{2}\right) d x_{2}
$$

Podendo-se portanto estudar os dois termos da expressão independentemente.

A transformação isoprobabilística do espaço físico para o reduzido, no caso do concreto, é dada por:

$$
\mathrm{u}=\frac{\mathrm{f}_{\mathrm{cd}}-\mathrm{f}_{\mathrm{cm}}}{\sigma_{\mathrm{c}}}
$$

A probabilidade de falha da resistência característica do concreto é definida como:

$$
P_{f}\left(x=f_{c k}\right)=\int_{-\infty}^{f_{c k}} f(x) d x=\int_{-\infty}^{f_{c m}-1.645 \sigma_{c}} f(x) d x=5 \%
$$

Com relação à resistência minorada pelo coeficiente representado por $\gamma_{c}$., resistência de cálculo, a probabilidade de falha dada pela equação (9.5) é escrita da seguinte forma:

$$
P_{f}\left(x=f_{c d}\right)=\int_{-\infty}^{f_{c d}} f(x) d x=\int_{-\infty}^{\left(f_{c m}-1.645 \sigma_{c}\right) / \gamma_{c}} f(x) d x
$$

No espaço reduzido, a expressão (9.6) é escrita como:

$$
\mathrm{P}_{\mathrm{f}}\left(\mathrm{x}=\mathrm{f}_{\mathrm{cd}}\right)=\int_{-\infty}^{\left(\mathrm{f}_{\mathrm{cd}}-\mathrm{f}_{\mathrm{cm}}\right) / \sigma_{\mathrm{c}}} \varphi(\mathrm{u}) \mathrm{du}=\int_{-\infty}^{\left[\left(\mathrm{f}_{\mathrm{cm}}-1.645 \sigma_{\mathrm{c}}\right) / \gamma_{\mathrm{c}}-\mathrm{f}_{\mathrm{cm}}\right] / \sigma_{\mathrm{c}}} \varphi(\mathrm{u}) \mathrm{du}
$$

Trabalhando-se a expressão (9.7) tem-se:

$$
P_{\mathrm{f}}\left(\mathrm{x}=\mathrm{f}_{\mathrm{cd}}\right)=\int_{-\infty}^{\left(\left(1 / \gamma_{\mathrm{c}}\right)-1\right) \mathrm{f}_{\mathrm{cm}} / \sigma_{\mathrm{c}}-1.645 / \gamma_{\mathrm{c}}} \varphi(\mathrm{u}) \mathrm{du}
$$

Supondo-se que $\sigma_{c}$ e $\gamma_{c}$. sejam constantes como sugerido por recomendações e normas internacionais, inclusive a brasileira, o resultado da expressão (9.8) depende da resistência média do concreto. Porém, sabe-se que é desejável que a probabilidade de ruína da estrutura seja independente dos valores numéricos das resistências dos materiais.

A expressão (9.8) pode ser trabalhada de duas formas para garantir uma 
probabilidade de ruína uniforme, modificando-se a concepção do coeficiente parcial de segurança ou a aceitação do desvio padrão, sendo a segunda mais fácil de ser implementada. A expressão (9.8) escrita em termos de coeficiente de variação do concreto é:

$$
\mathrm{P}_{\mathrm{f}}\left(\mathrm{x}=\mathrm{f}_{\mathrm{cd}}\right)=\int_{-\infty}^{1 / \mathrm{CV}_{\mathrm{c}}\left(\left(1 / \gamma_{\mathrm{c}}\right)-1\right)-1.645 / \gamma_{\mathrm{c}}} \varphi(\mathrm{u}) \mathrm{du}
$$

Considerando-se que o coeficiente de variação do concreto e o $\gamma_{c}$ são constantes, o resultado da expressão (9.9) não depende do valor numérico adotado para a resistência média do material. Portanto, demonstra-se analiticamente que é adequado em termos de teoria da probabilidade aceitar coeficientes de variação constantes para o concreto, não desvio padrão constante como parte das normas sugerem atualmente.

Assim, como demostrado para o concreto, a análise pode ser estendida para qualquer variável aleatória, no caso particular a resistência do aço.

Como foi observado, há uma elevada variação no índice de confiabilidade das colunas quando calculado a partir do sugerido atualmente (desvio padrão constante segundo a NBR e coeficientes parciais de segurança constantes segundo as normas de uma forma geral). Em vista disso, propõe-se a seguir duas formas de minimizar a variação do índice de confiabilidade das colunas. Essas propostas podem ser extrapoladas para outras estruturas de concreto armado e também de outros materiais. Lembra-se ainda que para adaptá-las a outros materiais é necessário um estudo caso a caso, pois a análise estatística é válida apenas para o cenário no qual foi desenvolvido o estudo.

\subsection{Proposta de coeficiente de variação constante para o concreto}

Conforme foi visto no item anterior, a probabilidade de ruína das colunas é bastante variada quando adotam-se as concepções de cálculo atuais. Apresenta-se em seguida uma possibilidade de tornar mais uniforme a confiabilidade das colunas.

A respeito da definição resistência de cálculo do concreto da NBR-6118 e de várias outras normas e recomendações internacionais, nota-se que há incoerências segundo teorias básicas da estatística. Em geral, tem-se um coeficiente único de redução da resistência característica para obtenção da resistência à compressão de 
cálculo, que parece ser incoerente por não levar em consideração a estrutura que está sendo analisada. Uma outra incoerência, que por sua vez é bem mais fácil de ser corrigida, é aceitar valores constantes para o desvio padrão do concreto de acordo com seu nível de qualidade. Ao considerar o desvio padrão constante independentemente do valor médio na curva de distribuição Normal, percebe-se claramente que o coeficiente de variação da variável diminui com o aumento da média, trazendo como conseqüência maior confiabilidade para a variável que muitas vezes não é desejável ou não representa a realidade. O desvio padrão é uma variável de projeto de importância similar a própria tensão média por ser determinante na segurança da estrutura. Nesse item busca-se um coeficiente de variação adequado para o concreto, que de acordo com muitos testes realizados deve ser constante, não variável com a resistência.

A diferença em termos de probabilidade de falha quando assume-se desvio padrão ou coeficiente de variação constante para a variável envolvida pode ser vista no Gráfico 9.8 e no Gráfico 9.9 respectivamente. No primeiro, verifica-se que há um decréscimo do coeficiente de variação com o acréscimo do valor médio, acarretando uma diminuição da probabilidade de falha com o valor médio da variável envolvida.

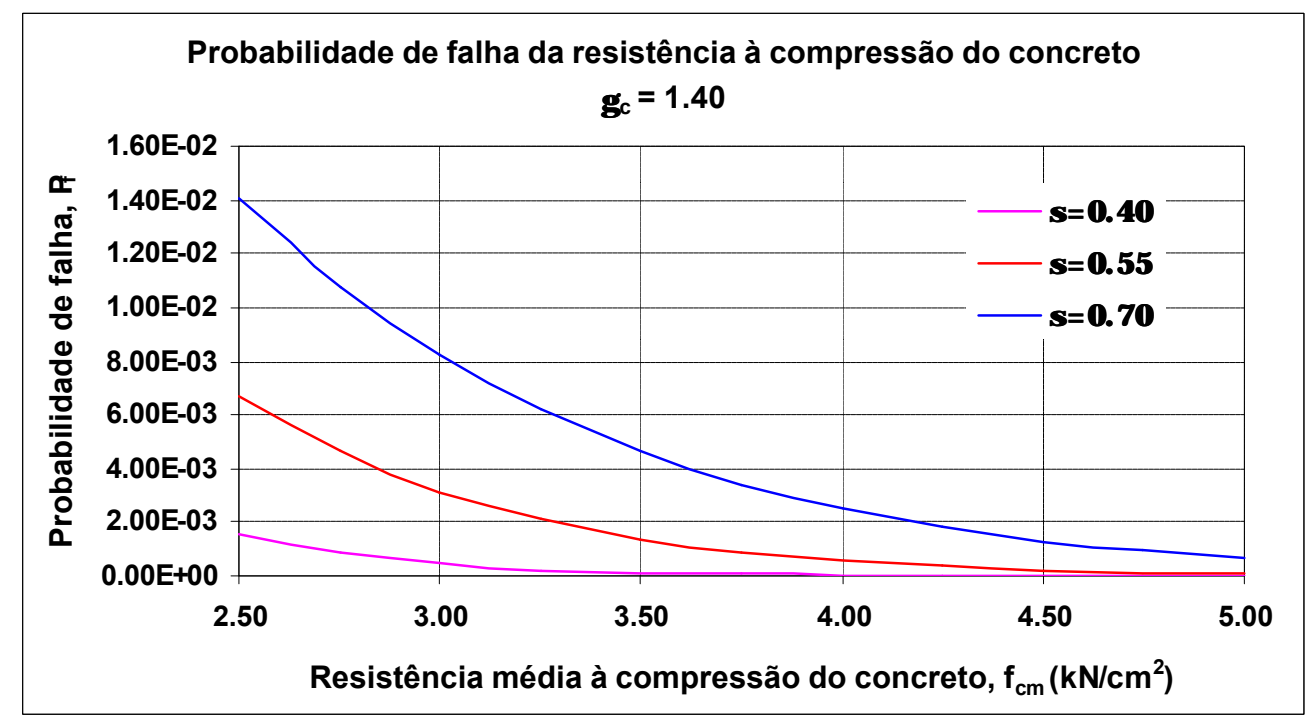

Gráfico 9.8 Probabilidade de falha da resistência à compressão do concreto, desvio padrão constante

No Gráfico 9.9, diferentemente do anterior, verifica-se que independente do valor médio da variável a probabilidade de falha é a mesma. Os valores de probabilidade de falha das diferentes resistências médias do concreto se sobrepõem, 
esses dependem exclusivamente do coeficiente de variação e do coeficiente parcial adotados.

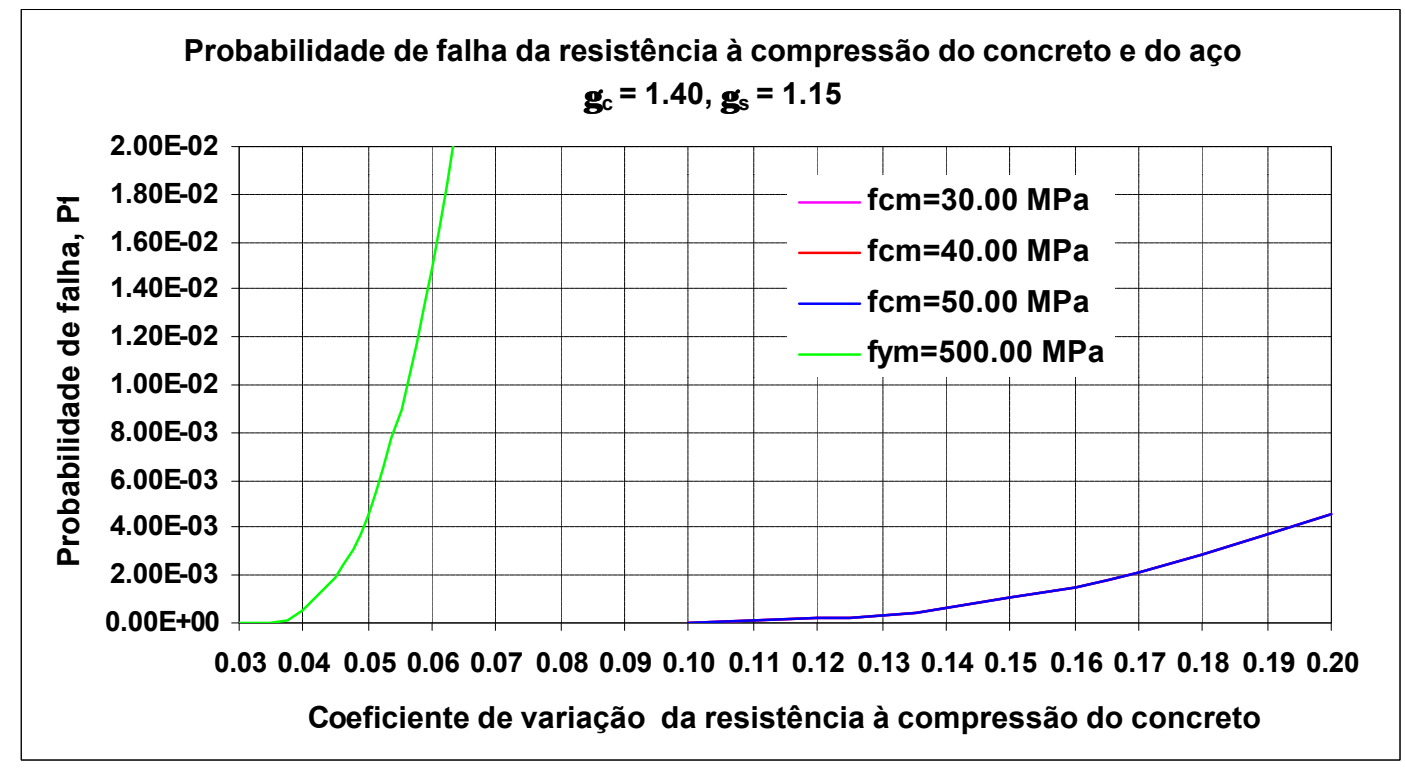

Gráfico 9.9 Probabilidade de falha da resistência à compressão do concreto e do aço

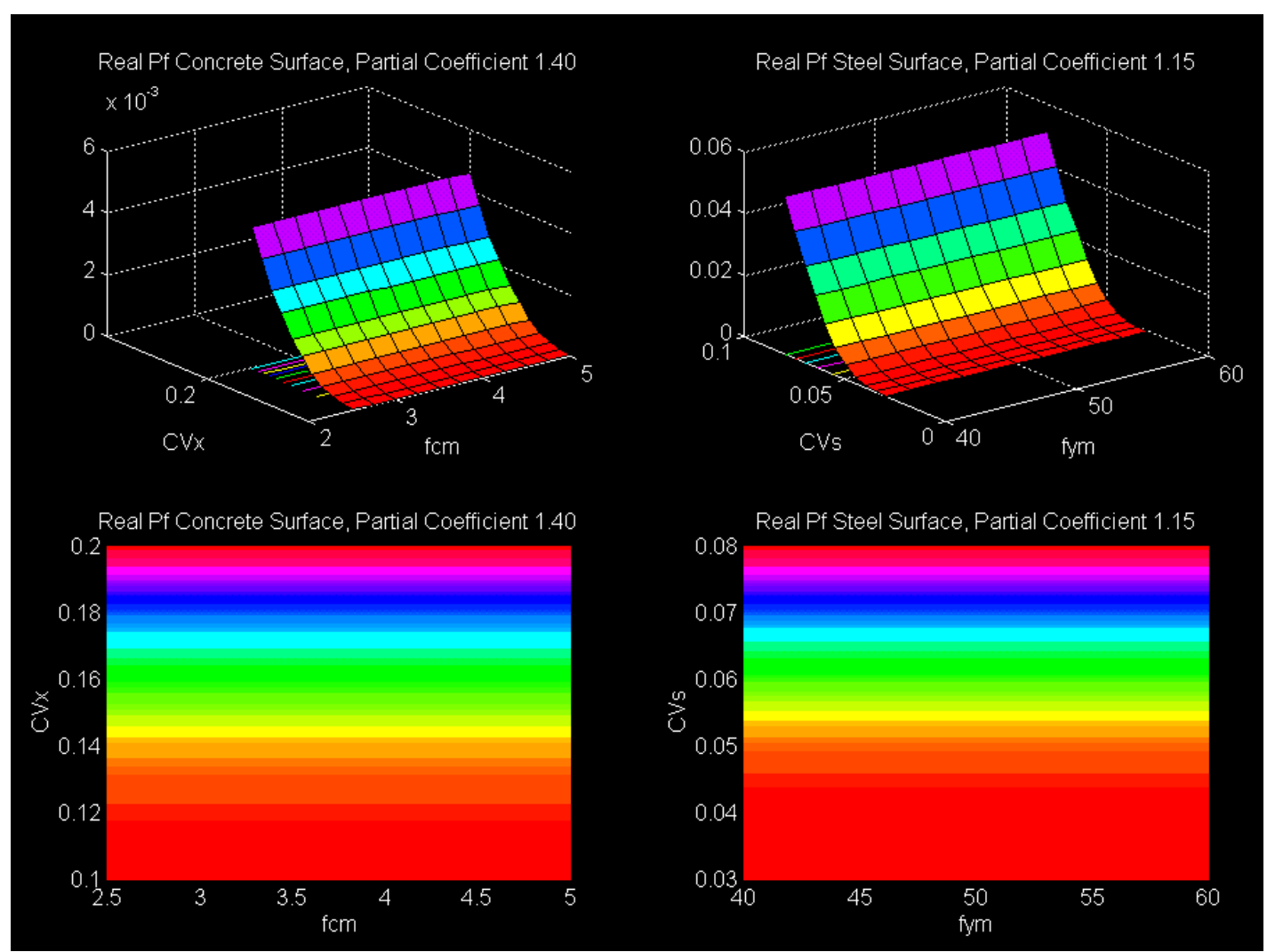

Gráfico 9.10 Superfícies de probabilidade de falha da resistência à compressão do concreto e do aço

As superfícies apresentadas no Gráfico 9.10 representam as probabilidades de 
falha de resistências do concreto à compressão com $\gamma_{c}=1.40$ e do aço com $\gamma_{\mathrm{s}}=1.15$. Nas abscissas encontram-se os valores médios das resistências e nas ordenadas os coeficientes de variação da variável analisada. Percebe-se claramente nessas superfícies que a probabilidade de falha do material é constante para cada valor do coeficiente de variação, independe do valor médio da variável.

Como já visto na equação (9.3), a probabilidade de falha do material concreto armado é o produto das probabilidades de falha do concreto e do aço. Portanto, temse um problema bem definido, no qual são incógnitas para cada material envolvido: o coeficiente de variação e o coeficiente parcial de segurança, que são correlacionados com a probabilidade de falha.

Um valor adequado para o coeficiente de variação do concreto pode ser estimado com o auxílio do Gráfico 9.11 e da Tabela 9.4, onde valores limites do índice de confiabilidade são sugeridos para diferentes estados limites.

Tabela 9.4 Correlação entre $\beta e \mathrm{P}_{\mathrm{f}}$ (vida útil da estrutura)

\begin{tabular}{|c|c|c|}
\hline & Estado Limite Último & Estado Limite de Serviço \\
\hline Eurocode (1991) & $\beta=3.80 \leftrightarrow \mathrm{P}_{\mathrm{f}}=0,7230 \mathrm{E}-4$ & $\beta=1.50 \leftrightarrow \mathrm{P}_{\mathrm{f}}=0,6681 \mathrm{E}-1$ \\
\hline
\end{tabular}

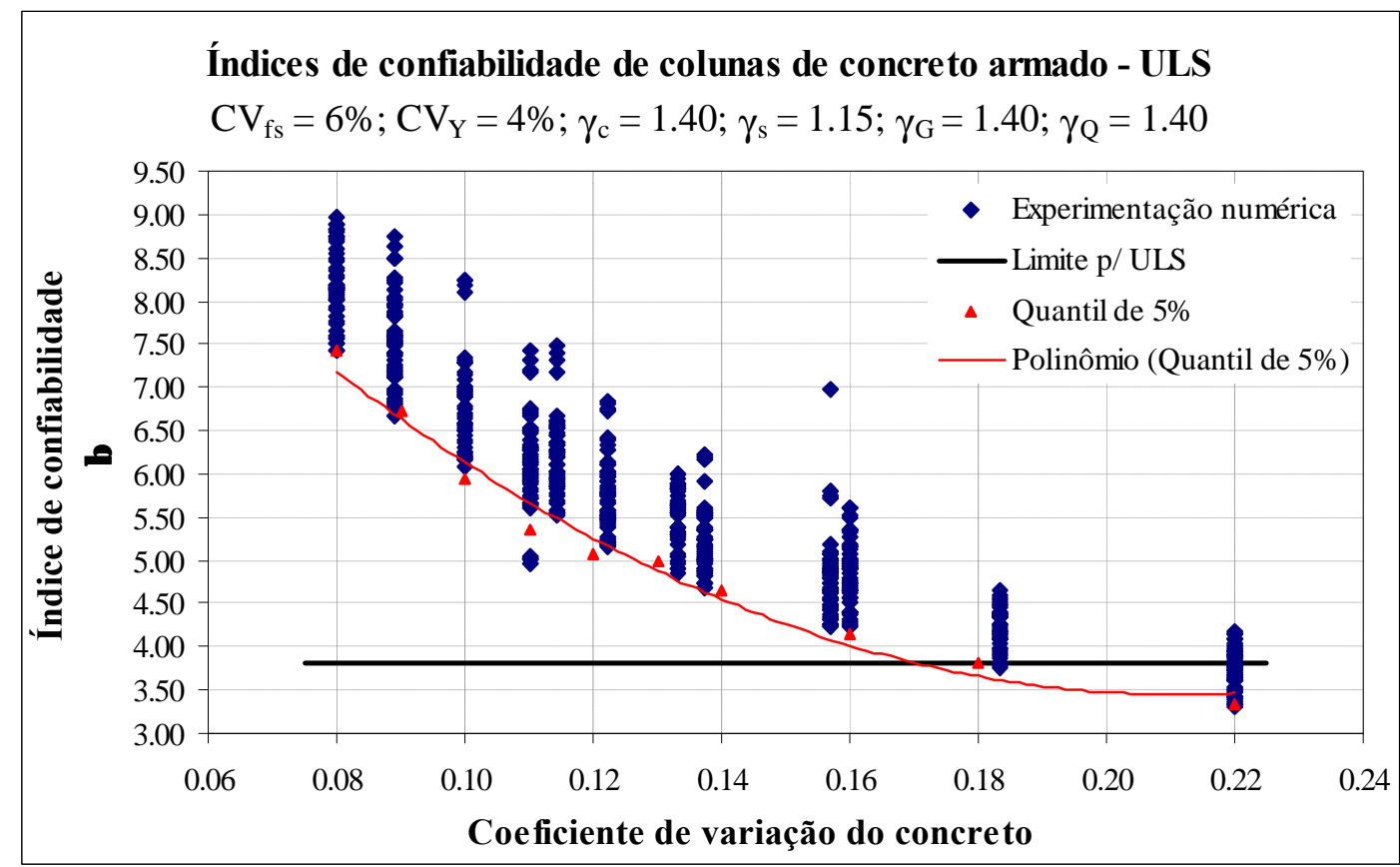

Gráfico 9.11 Proposta para coeficientes de variação do concreto

O Gráfico 9.11 foi elaborado a partir de uma amostra de 580 colunas. Os pontos em triângulos vermelhos foram estimados para um quantil de 5\% das curvas 
Normal elaboradas com os conjuntos de valores dos índices de confiabilidade para cada coeficientes de variação utilizado na análise. De posse desses pontos, fez-se uma regressão numérica obtendo-se o polinômio, representado pela linha fina e contínua. Sugere-se para estimar o coeficiente de variação do concreto valores próximos a esse polinômio.

Analisando-se o Gráfico 9.11 percebe-se que um valor limite adequado para o coeficiente de variação do concreto é 18\%. Entretanto, devido as inúmeras aleatoriedades envolvidas que não foram computadas, baseado em inúmeros exemplos analisados e sempre tendendo a ficar no domínio seguro e para análise no ULS, sugerem-se, como valores adequados para coeficientes de variação do concreto e do aço, os indicados em (9.10):

$$
\mathrm{CV}_{\mathrm{c}}=15 \% \leftrightarrow \mathrm{CV}_{\mathrm{s}}=6 \%
$$

As bibliografias internacionais indicam valores menores para o coeficiente de variação do concreto, cerca de $12 \%$, o que levaria a valores do coeficiente parcial de segurança menores que o estabelecido na análise precedente.

É importante salientar que a proposta dessa tese para aceitação do concreto na obra não vincula-se a qualidade do concreto como a proposta da norma atual. $\mathrm{O}$ projetista deve escolher o coeficiente de variação para o concreto de acordo com o nível de confiabilidade que se deseja para a obra. O Gráfico 9.11 indica valores para coeficientes de variação em função do índice de confiabilidade desejado.

No Gráfico 9.12 ao Gráfico 9.15 pode-se observar parte dos resultados da análise desenvolvida para a proposição de coeficientes de variação do concreto. Para imprimir esses gráficos utilizaram-se amostras com milhares de colunas variando suas características físicas de acordo com o cenário estabelecido no início do capítulo. A diferença entre os gráficos encontra-se nos coeficientes parciais adotados, nas variáveis aleatórias envolvidas e nos estados limites considerados. 


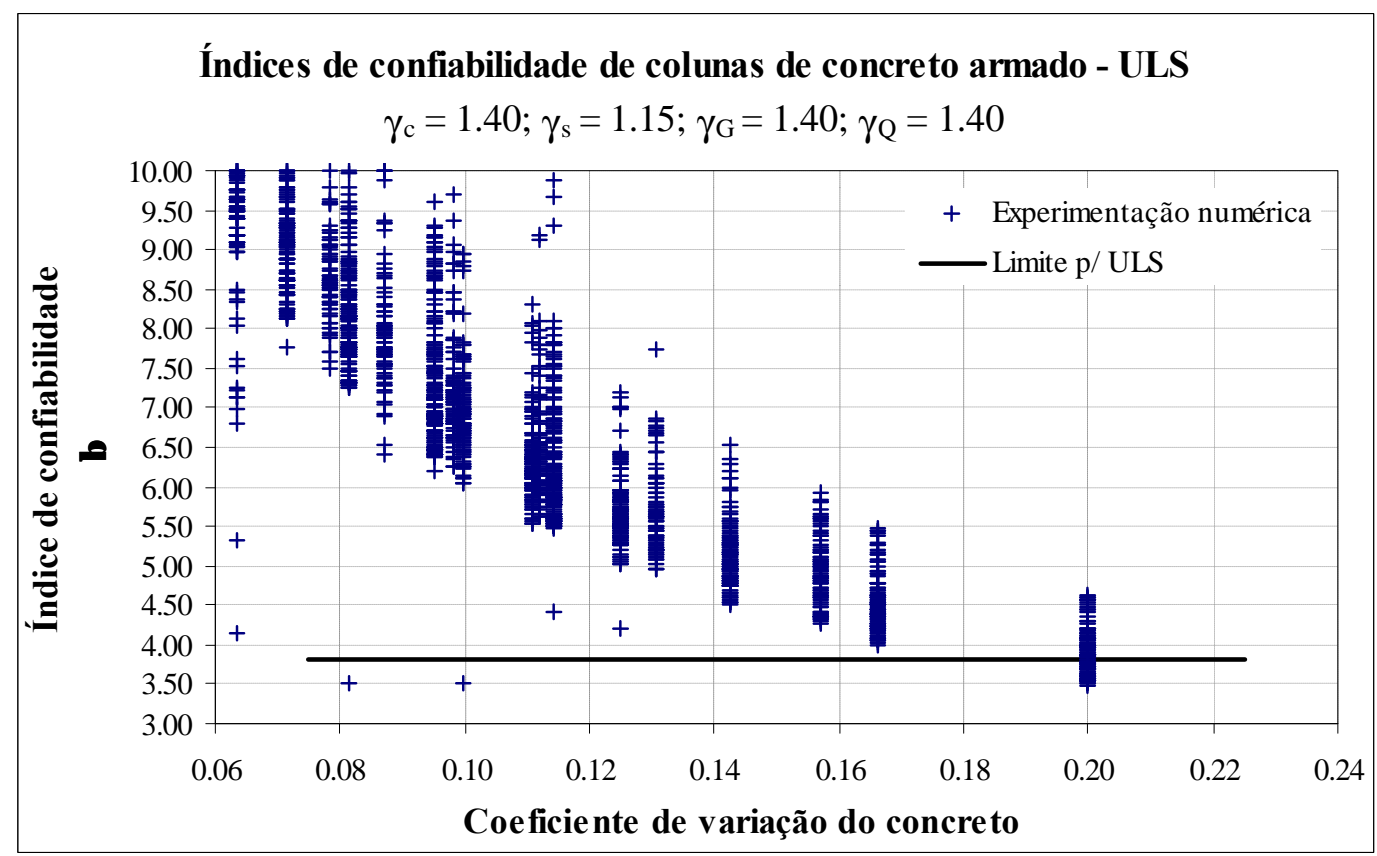

Gráfico 9.12 Variação do índice de confiabilidade com CV do concreto

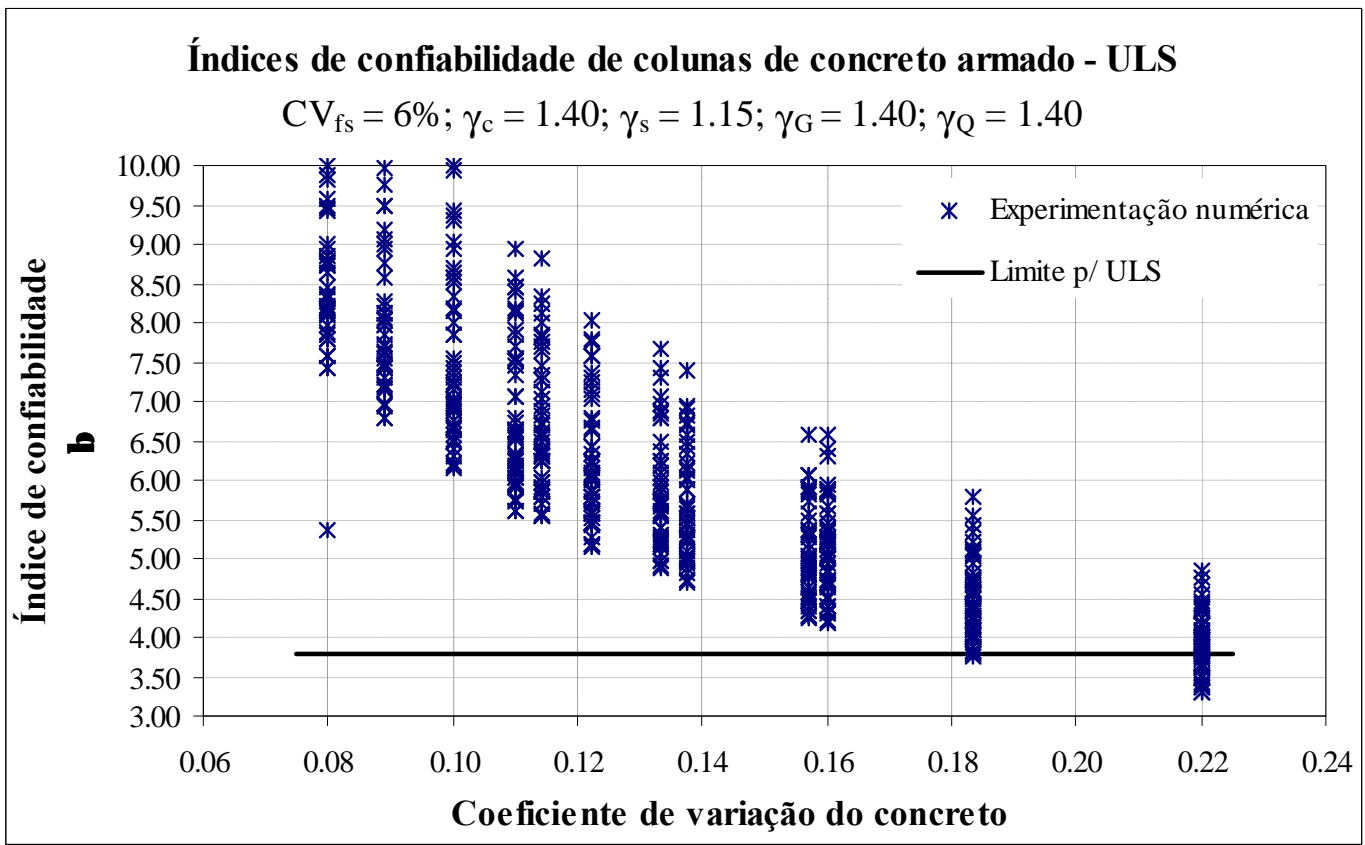

Gráfico 9.13 Variação do índice de confiabilidade com CV do concreto

Observa-se no Gráfico 9.14 e no Gráfico 9.15 que os coeficientes de variação para o concreto e o aço sugeridos em (9.10) também são coerentes para o estado limite de utilização, podendo ser generalizados para ambos os estados limites estudados. 


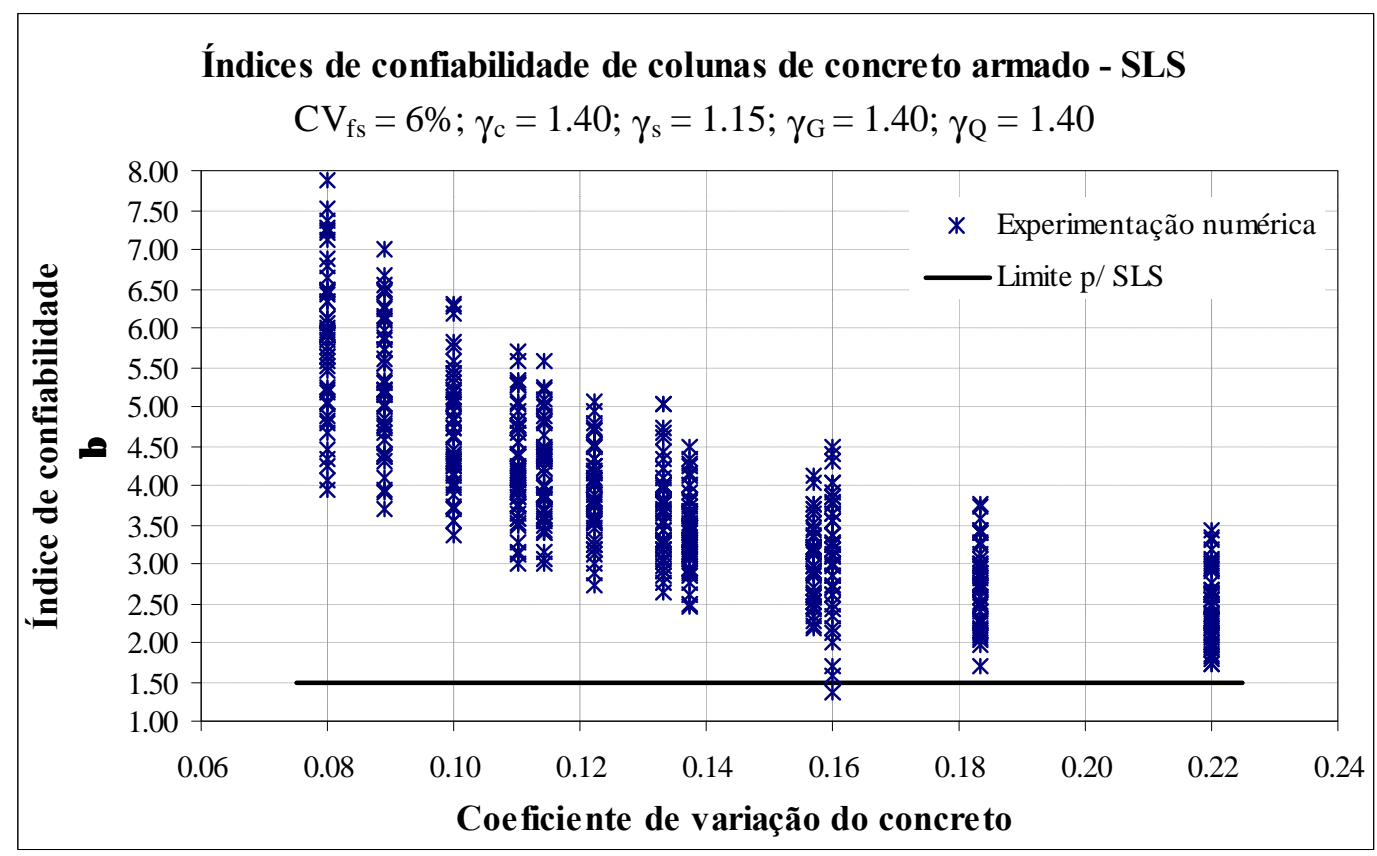

Gráfico 9.14 Variação do índice de confiabilidade com CV do concreto

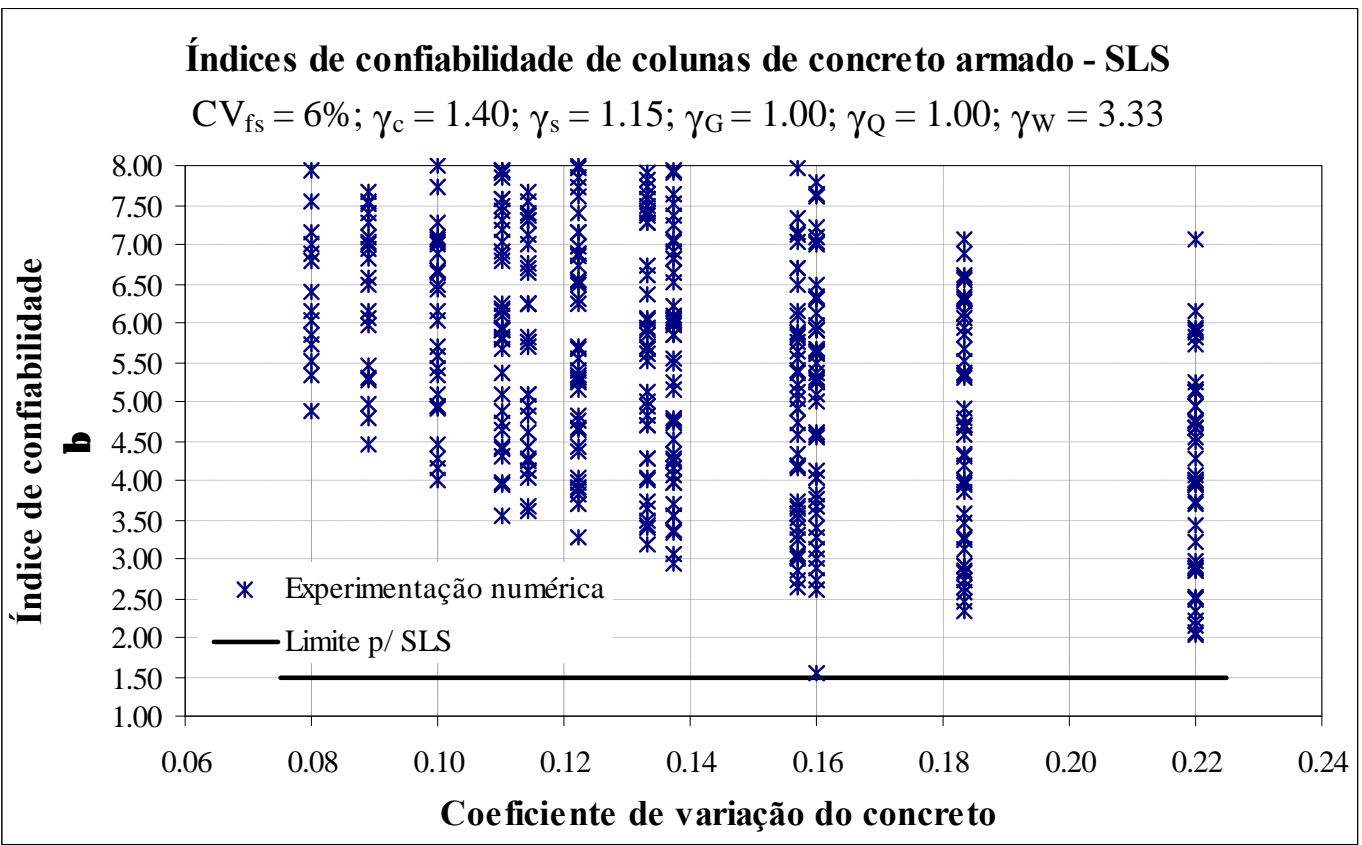

Gráfico 9.15 Variação do índice de confiabilidade com CV do concreto

No Gráfico 9.16 compararam-se os valores médios de resistência do concreto à compressão obtidos através de valores de resistências características definidas pelo projetista. Os valores médios foram calculados considerando-se os diferentes valores de desvio padrão sugeridos pela NBR 6118 e considerando-se também dois coeficientes de variação pertencentes ao domínio da proposta para essas variáveis. Ao analisar-se esse gráfico verifica-se que, comparando a proposta com a do modelo 
atual, ao aumentar a resistência característica do concreto o tecnologista pode aumentar o desvio padrão desse material, por outro lado necessita-se um maior aumento da resistência média para obter a mesma resistência característica.

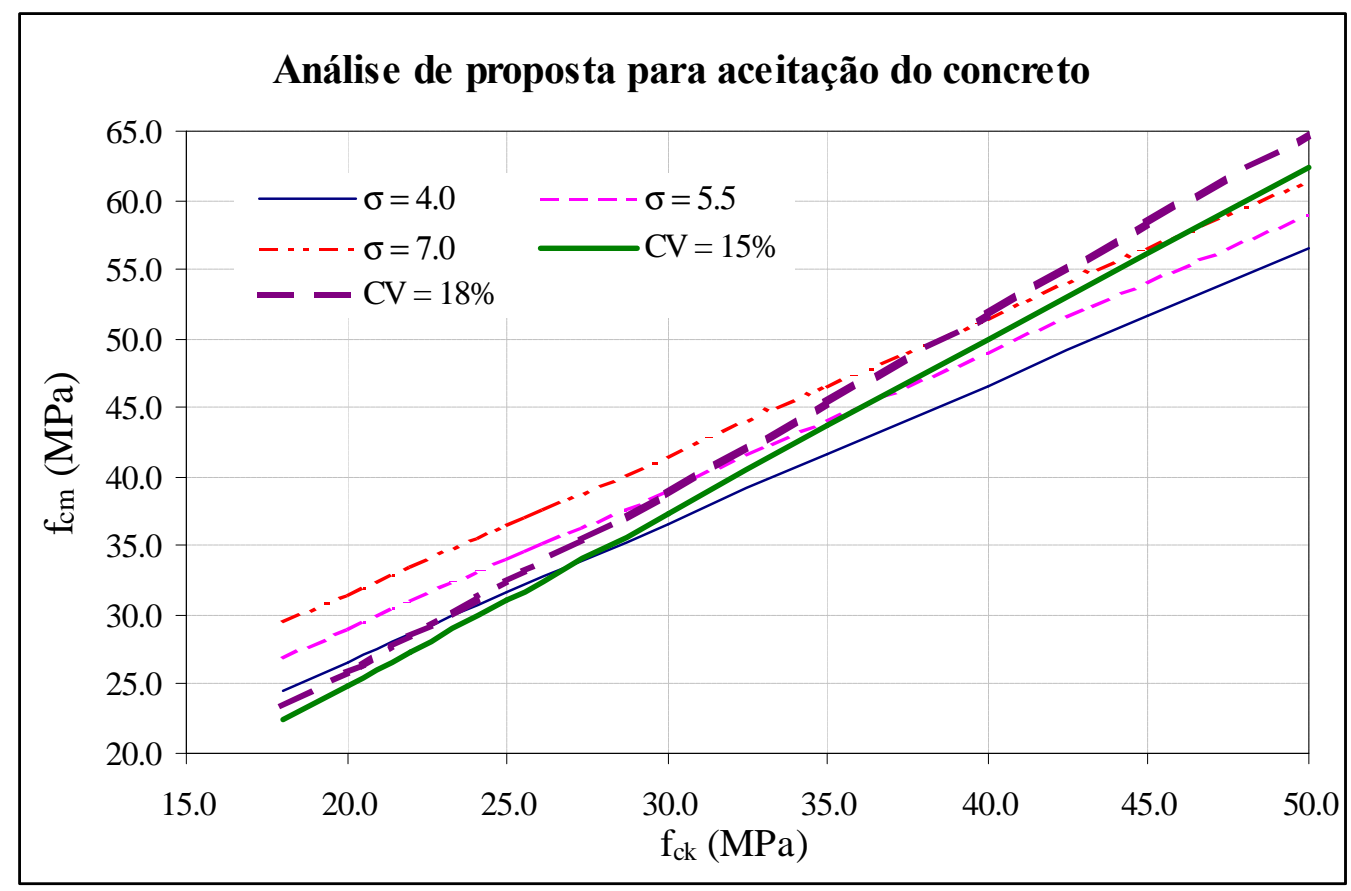

Gráfico 9.16 Análise de proposta para aceitação do concreto

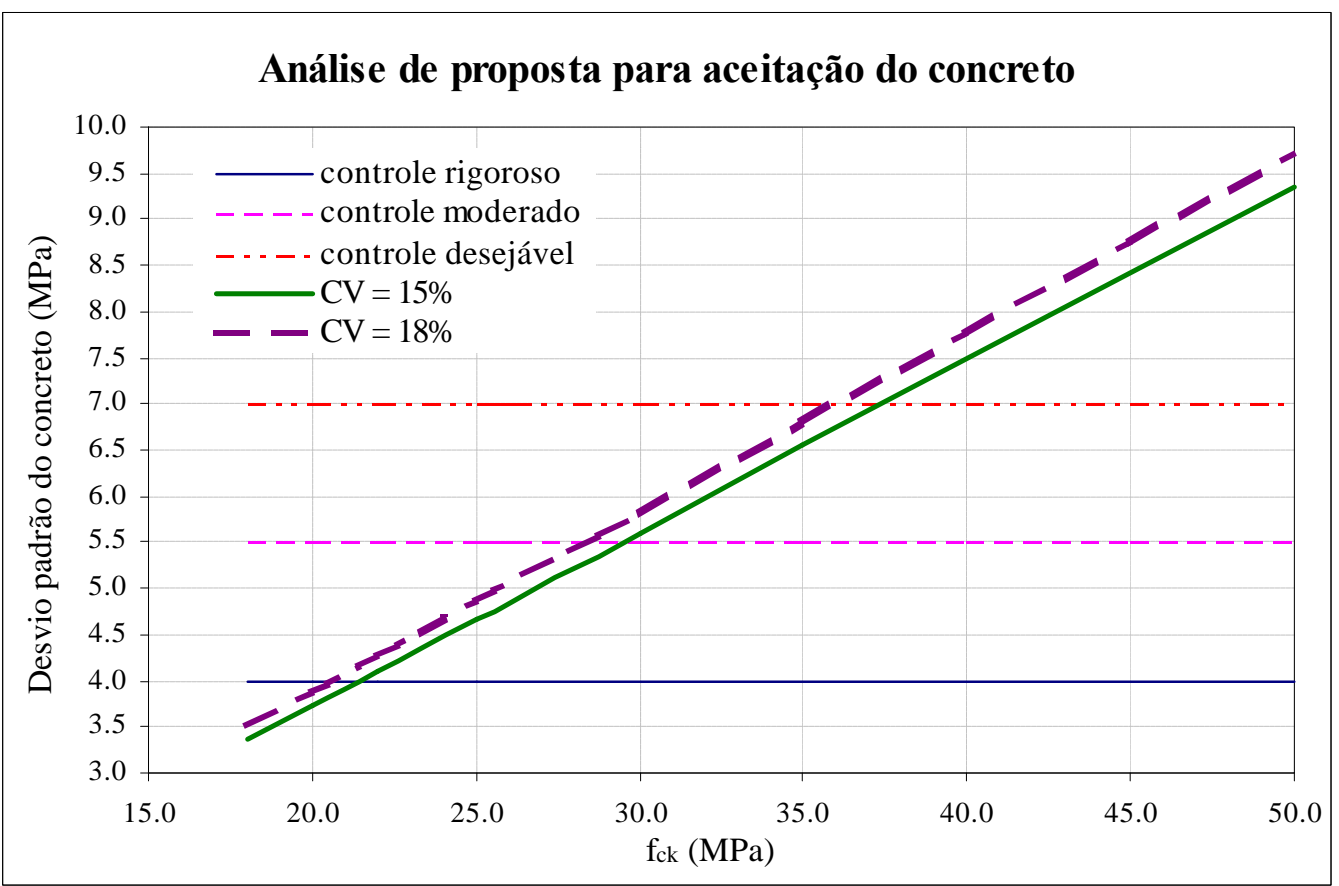

Gráfico 9.17 Desvio padrão para o concreto, proposta

Analisando o Gráfico 9.16 e o Gráfico 9.17, nota-se que os valores adotados atualmente para o desvio padrão do concreto não diferem muito da proposta da tese. 
Entretanto, em termos de probabilidade de falha do material, a variação é bastante significativa.

Índices de confiabilidade em colunas nos estados limites último e de serviço com coeficiente de variação do concreto constante são apresentados no Gráfico 9.18 ao Gráfico 9.21.

No SLS verifica-se que os índices de confiabilidade para $\mathrm{CV}_{\mathrm{c}}=20 \%$ são maiores que o mínimo exigido pela população.

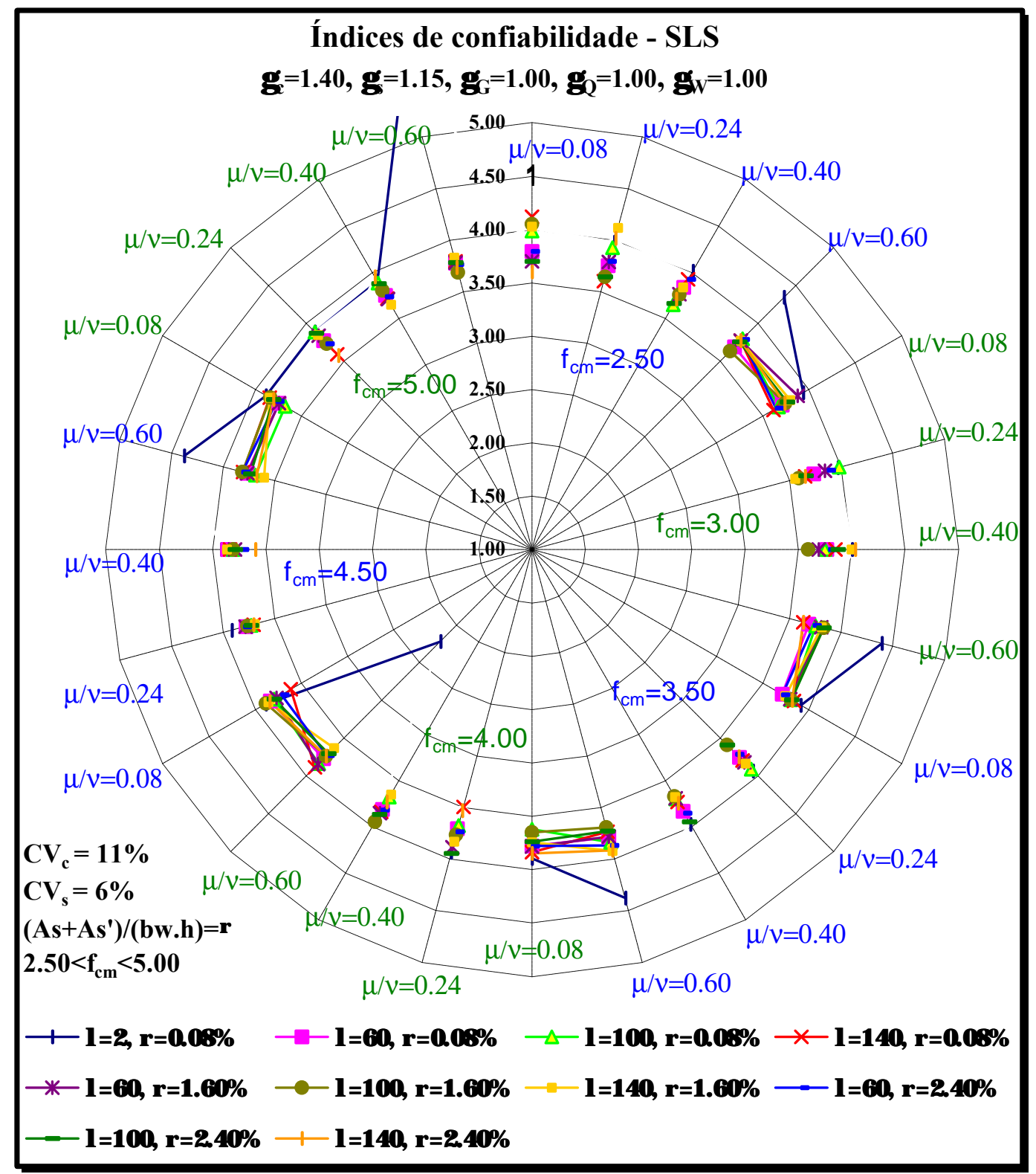

Gráfico 9.18 Índices de confiabilidade p/ colunas de CA com CV do concreto constante

É importante observar que há uma grande uniformidade nos índices de 
confiabilidade quando utilizam-se coeficientes de variação para os materiais constantes.

Para o SLS nota-se que praticamente não há variação no índice de confiabilidade quando as características das colunas são alteradas. Nesses casos, o grau de não-linearidade do problema não influi significativamente na segurança da estrutura.

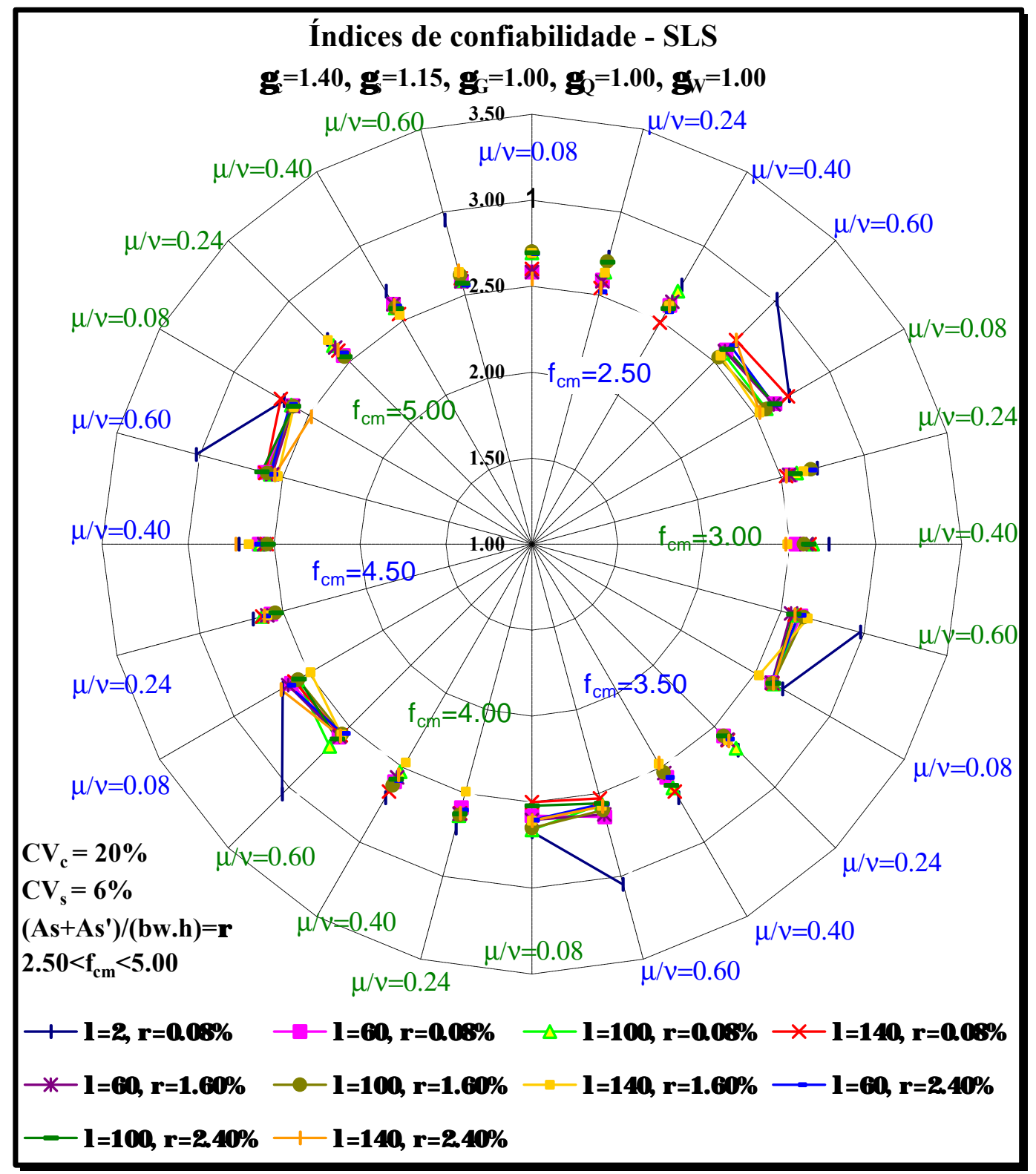

Gráfico 9.19 Índices de confiabilidade p/ colunas de CA com CV do concreto constante

Na análise no ULS, há uma sensível variação no índice de confiabilidade com o grau de não-linearidade do problema. Nessa análise, a taxa geométrica de armadura 
também é um fator importante a ser considerado para estimar a segurança. Nos gráficos seguintes é importante observar que para uma mesma coluna com resistências à compressão do concreto diferentes a confiabilidade é praticamente a mesma, mostrando a coerência de utilizar coeficientes de variação constantes para os materiais.

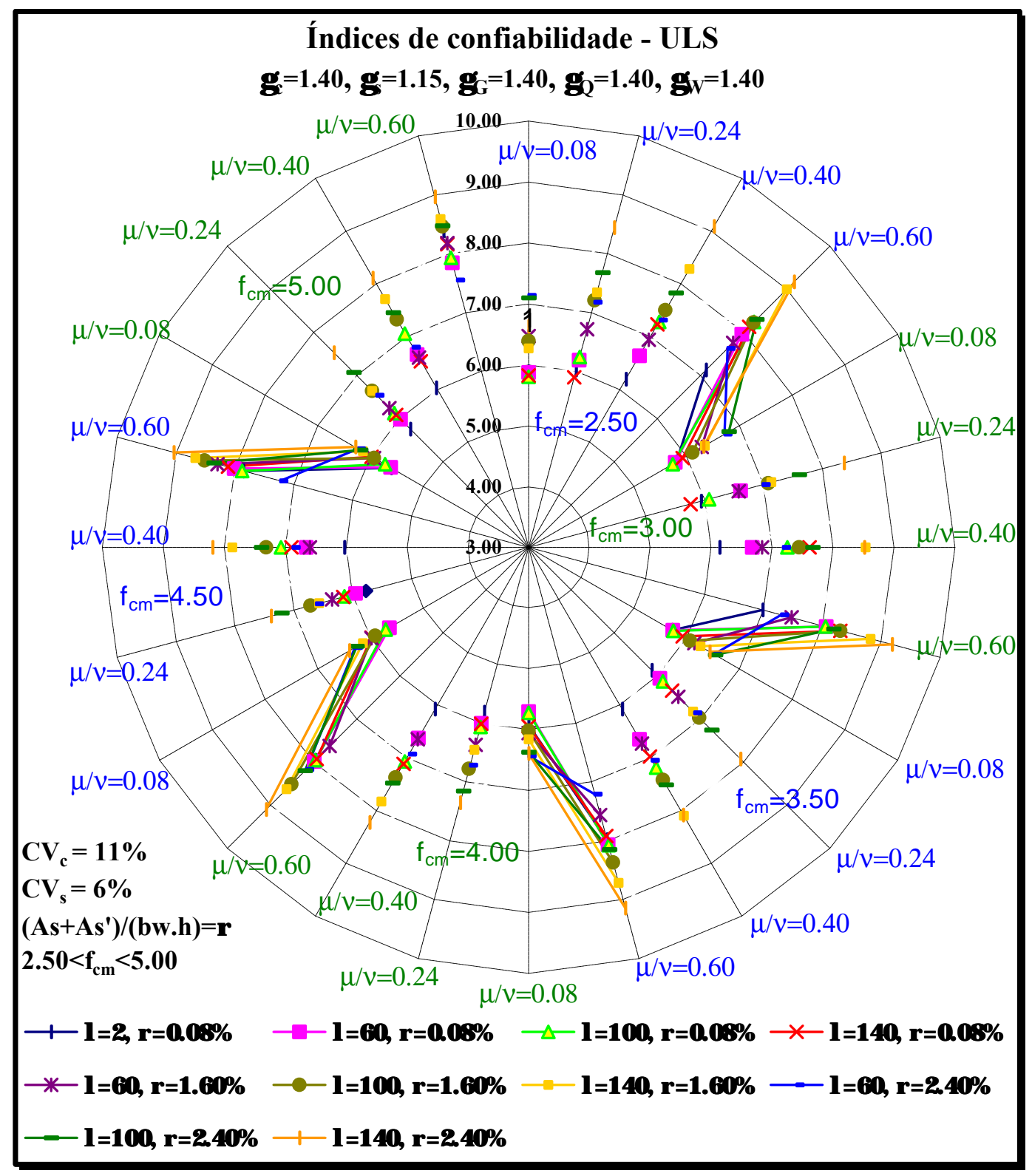

Gráfico 9.20 Índices de confiabilidade p/ colunas de CA com CV do concreto constante

Os índices de confiabilidade no ULS para $\mathrm{CV}_{\mathrm{c}}=11 \%$ são maiores que os mínimos sugeridos na bibliografia. Por outro lado, $\mathrm{CV}_{\mathrm{c}}=20 \%$ em algumas situações são menores que o mínimo caracterizando colunas com segurança não satisfatória. 


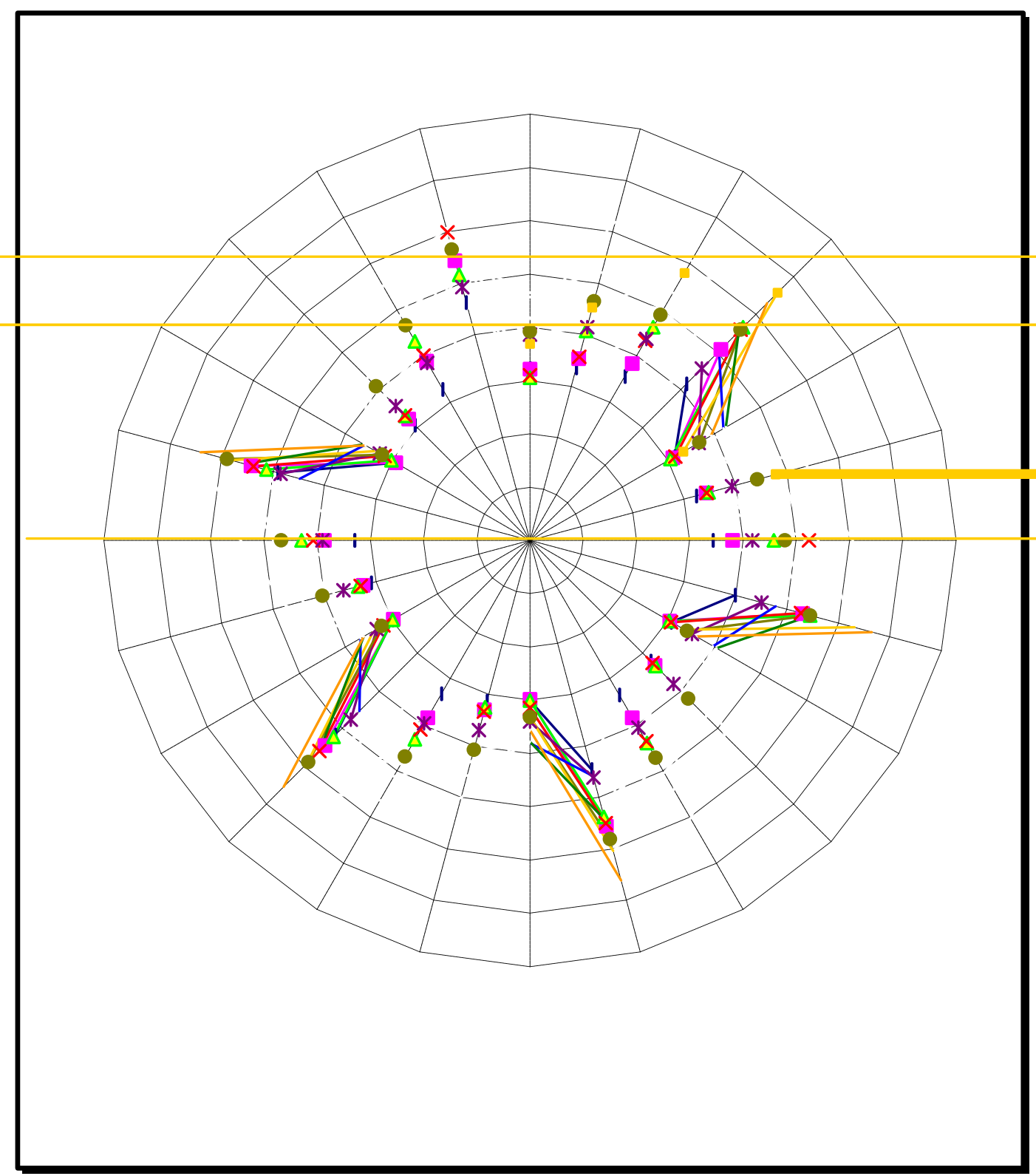




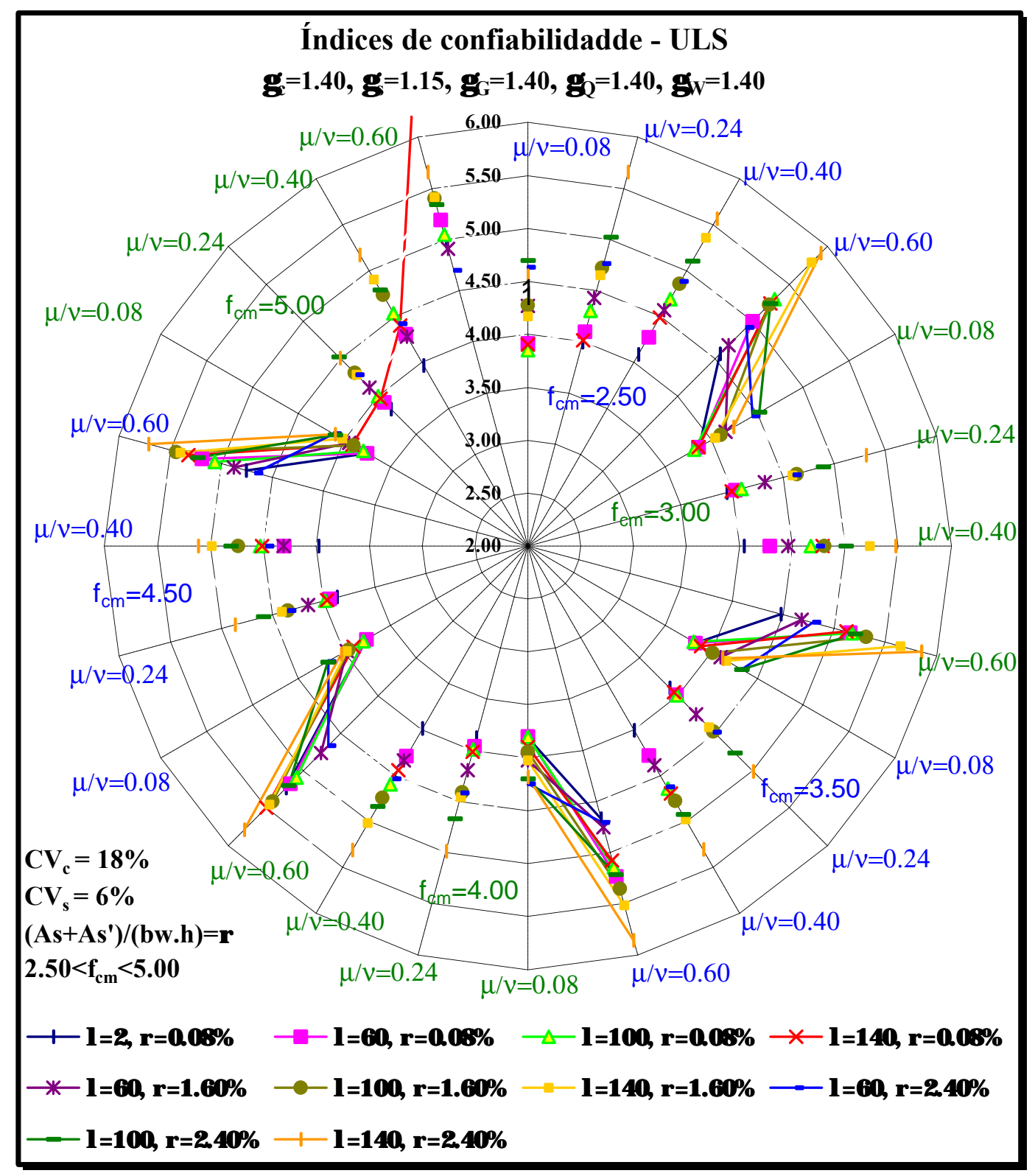

Gráfico 9.22 Índices de confiabilidade p/ colunas de CA com CV do concreto constante

Conclui-se que para obter confiabilidade mais uniforme para as colunas, a qualidade do concreto aceito na obra não deve ser verificada através do desvio padrão. Deve ser utilizado como verificador da qualidade do material seu coeficiente de variação, que não deve ultrapassar $18 \%$ para o concreto e $6 \%$ para o aço no caso de edifícios residenciais.

Como proposta para um modelo razoável sugere-se utilizar a relação constitutiva proposta pelo CEB MC 90 adicionada do trecho na tração que considera o concreto entre fissuras proposto por FIGUEIRAS (1983) para o concreto, enquanto 
que para o aço tipo A pode-se utilizar o diagrama adotado pela NBR 6118. Em ambos os materiais devem ser utilizados os coeficientes de variação sugeridos no Gráfico 9.11, que adequam-se ao nível de confiabilidade exigido para a obra.

\subsection{Análise de coeficiente de segurança parcial variado para o concreto}

Uma outra forma de tentar uniformizar o índice de confiabilidade das estruturas de concreto armado é deixar o desvio padrão do material constante e variar o coeficiente parcial de segurança. Este item dedica-se a essa hipótese. A análise seguinte consiste em estimar coeficientes parciais de segurança para o concreto no ULS considerando comportamento não-linear que proporcionem valores de índices de confiabilidade predeterminados por análise em primeira ordem. Como as normas atuais em geral estabelecem para a aceitação do concreto desvio padrão constante, a análise do Gráfico 9.23 e do Gráfico 9.24 é elaborada considerando-se desvio padrão constante.

Predefinir um valor para o índice de confiabilidade é uma tarefa difícil, uma vez que sempre há algumas características das variáveis de projeto que não são consideradas na análise. Portanto, a primeira dificuldade é estabelecer índices de confiabilidade em torno dos quais será feita a análise. Para isso, foram elaboradas colunas de referência, as quais contêm as características descritas na Tabela 9.1 e na Tabela 9.2 com exceção dos comprimentos, que foram considerados de tal forma que seus índices de esbeltez tendessem a zero. Para essas colunas foram calculados os respectivos índices de confiabilidade utilizando como introdutores da segurança os coeficientes parciais descritos na Tabela 9.3, caso 1. Esses índices de confiabilidade serão denominados índices de confiabilidade de referência. Observe-se que os índices de confiabilidade de referência independem das características das colunas, referem-se apenas às colunas com efeitos de primeira ordem.

O procedimento proposto para a análise consiste em partir-se dos índices de confiabilidade de referência e buscarem-se, a partir de um processo iterativo, coeficientes parciais para o concreto que proporcionem índices de confiabilidade iguais aos índices de referência. Para cada coluna faz-se variar o índice de esbeltez de zero a infinito; nessa etapa apenas consideram-se os coeficientes parciais do aço e das ações externas descritos na Tabela 9.3, caso 1 . 
A variação dos índices de confiabilidade de referência é apresentada na Tabela 9.5. Os valores mínimos dos índices de confiabilidade de referência referem-se a colunas com menores resistência à compressão média e taxa geométrica de armadura. O oposto é verdade para os valores máximos dos índices de confiabilidade de referência.

Tabela 9.5 Variação dos índices de confiabilidade de referência

\begin{tabular}{|c|c|c|}
\hline $\begin{array}{c}\text { Desvio padrão do concreto } \\
\sigma_{\mathrm{fc}}\end{array}$ & Índice de confiabilidade & Índice de confiabilidade \\
\hline 0.40 & $\beta_{\text {mínimo }}$ & $\beta_{\text {máximo }}$ \\
\hline 0.55 & 4.31 & 8.71 \\
\hline
\end{tabular}

Os coeficientes parciais propostos devem ser divisores do $\mathrm{f}_{\mathrm{ck}}$, ou seja, são valores propostos para substituir o coeficiente parcial do concreto clássico apresentado pelas Normas, $\gamma_{c}$. 


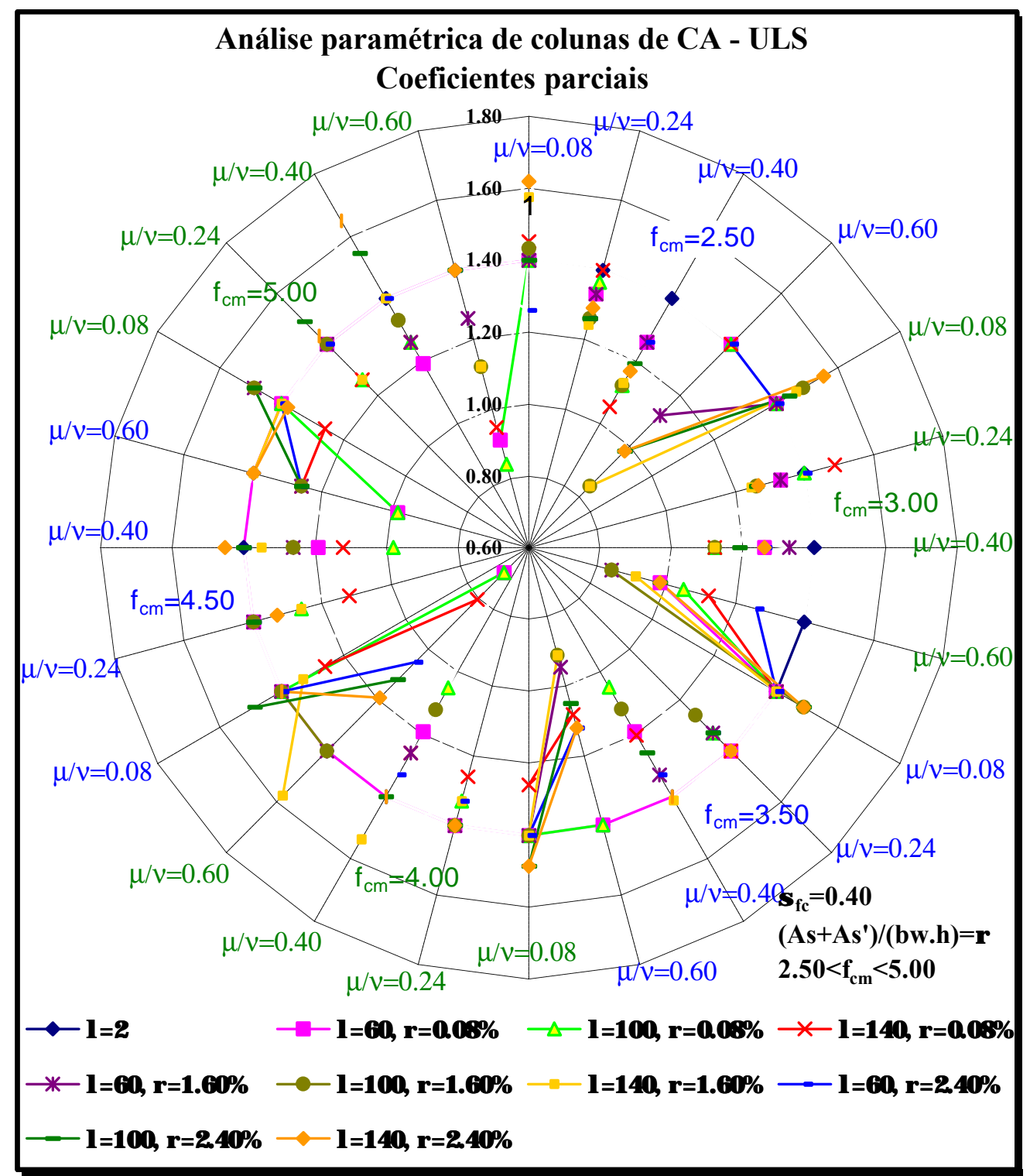

Gráfico 9.23 Coeficientes de segurança parcial para o concreto, confiabilidade uniforme

Como já era de se esperar, na maioria das situações ou casos estudados, os coeficientes estão entre 1.00 e 1.40. A tendência dos valores serem menores que 1.40 é clara a partir do momento que, da forma que os coeficientes parciais são impostos, a segurança é considerada duas vezes devido ao comportamento não-linear ou perda de rigidez da estrutura (os esforços são funções das ações externas e dos deslocamentos que por sua vez dependem da rigidez a qual é função do material). 


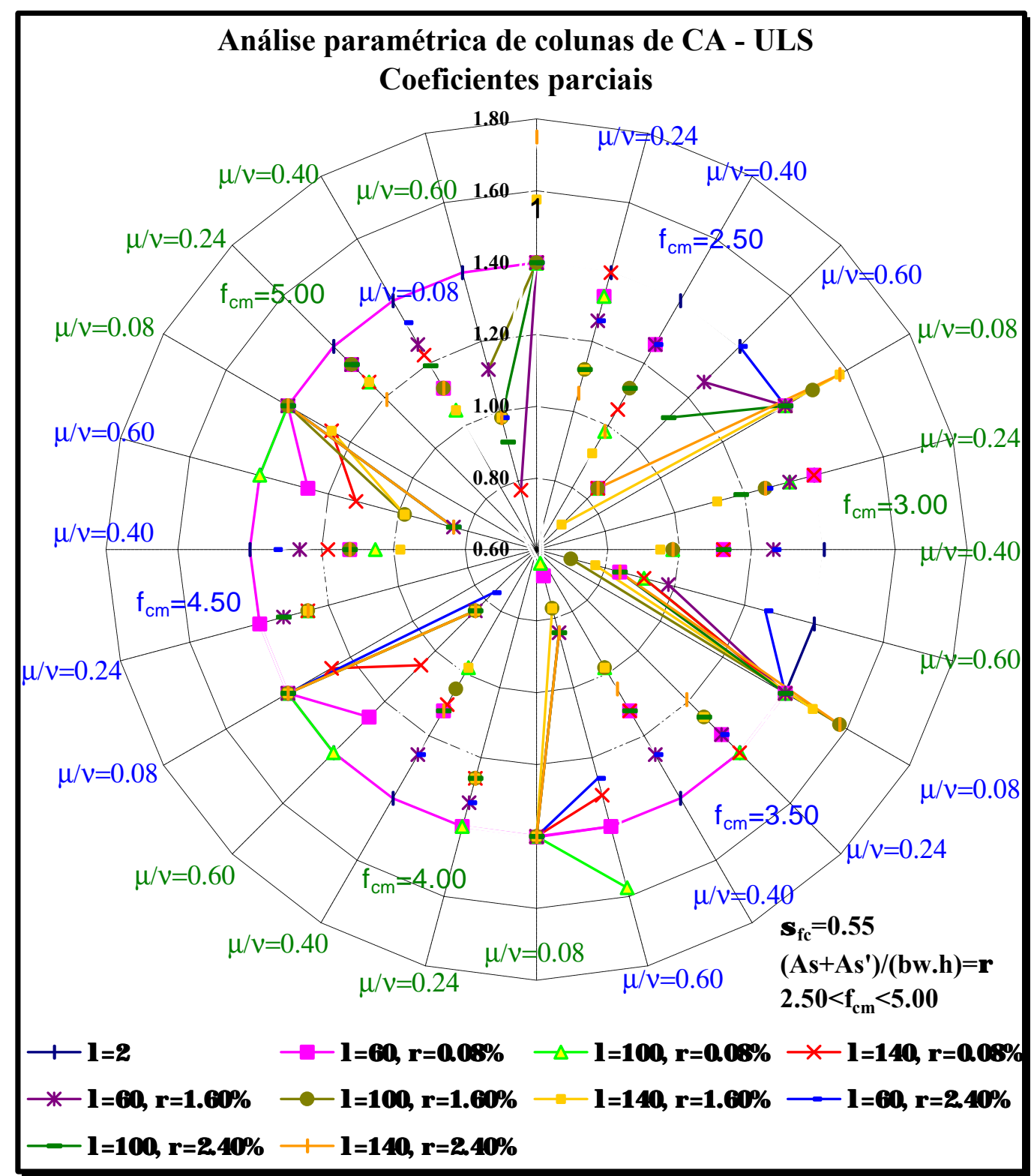

Gráfico 9.24 Coeficientes de segurança parcial para o concreto, confiabilidade uniforme

Como o índice de confiabilidade de referência foi obtido para colunas com índice de esbeltez igual a 2, o coeficiente parcial para esse índice equivale ao pré determinado na Tabela 9.3, caso 1 .

Devido ao desvio padrão do concreto ser constante, o coeficiente parcial diminui significativamente para os concretos de resistências elevadas. Em colunas com concreto de baixa resistência à compressão, aumenta-se a importância do aço para suportar os esforços axiais. Nessas condições, o coeficiente parcial do concreto tem menor importância nos resultados finais em termos de confiabilidade, 
justificando uma menor alteração de seus valores. Percebe-se ainda que algumas vezes os coeficientes parciais chegam a ser superior a 1.40, mostrando que nessa situação atualmente as colunas são dimensionadas contra a segurança.

A medida que aumenta-se a taxa de aço o coeficiente parcial do concreto aumenta, mostrando que o concreto perde importância perante o aço nessa situação. Ao observarem-se o Gráfico 9.23 e o Gráfico 9.24 verifica-se que os coeficientes parciais são menores quando o desvio padrão do concreto é aumentado. Isto aparentemente parece ser errado ou ilógico, entretanto, os valores dos índices de confiabilidade de referência quando utilizam-se desvios padrões maiores são menores. Qualitativamente esses gráficos têm a mesma forma.

Nos casos extremos, os coeficientes parciais chegam a ser menores que a unidade, permitindo o uso de resistências de cálculo para o concreto com valores superiores ao próprio $\mathrm{f}_{\mathrm{ck}}$.

Os modelos utilizados para calcular a resposta mecânica da estrutura e estimar a probabilidade de ruína da mesma apresentam simplificações. Além disso, em alguns casos a sensibilidade do índice de confiabilidade com o coeficiente parcial é pequena. Consequentemente, dentre as várias colunas estudadas verificou-se que há uma variação de aproximadamente $10 \%$ na precisão dos coeficientes parciais apresentados. Essa variação ocorre principalmente em colunas com elevadas taxas geométrica de armadura e elevados índices de esbeltez.

Conclui-se portanto que não é possível estimar um único coeficiente parcial para o concreto. A variação com as características das colunas é muito intensa, chegando a variar de 0.70 à 1.60 aproximadamente. $\mathrm{O}$ que indica que quanto mais intenso os efeitos de segunda ordem perante os de primeira ordem, menor pode ser o coeficiente parcial do concreto. Ainda, quanto maior a taxa de armadura da coluna, maior o coeficiente parcial do concreto. Salienta-se que utilizar o valor da resistência de cálculo igual ao da resistência característica quando consideram-se efeitos de segunda ordem nos cálculos é contra a segurança em vários casos.

Essas conclusões foram elaboradas para análise da confiabilidade dos efeitos de segunda ordem perante os efeitos de primeira ordem, por isso utilizaram-se valores de índices de confiabilidade de referência. O ideal para estudar a segurança das 
estruturas seria fazer o mesmo estudo para um valor de $\beta$ constante e único. Mas, ao fazer isso, facilmente acarreta-se inconsistências na análise devido a falta de informações sobre as variáveis de projeto tais como a curva de distribuição a considerar, o coeficiente de variação, etc.

Embora seja ainda questionável a possibilidade real de se predefinir um valor para o índice de confiabilidade e estimar coeficientes parciais para esse valor, um estudo nessa linha desenvolvido pelo autor e por pesquisadores do IFMA pode ser visto em (MOHAMED, SOARES \& VENTURINI, 2001 ${ }^{9}$ ). Embora ainda muito cedo para a proposição de expressões de coeficientes parciais em função das características da estrutura, o trabalho tem o mérito de abordar o problema propondo o procedimento que poderá ser utilizado em análise futura mais detalhada.

Facilmente verificou-se que o caminho mais fácil de obter confiabilidade mais uniforme nas colunas de CA é vincular ao projeto coeficientes de variação constantes para os materiais.

\subsection{Redução consistente do módulo de elasticidade secante do concreto}

Como se sabe, o cálculo de estruturas considerando as devidas não-linearidades física e geométrica ainda não é empregado em projetos de estruturas de concreto armado devido a vários fatores tais como: custo computacional, falta de conhecimento do projetista, falta de programas que considerem tais efeitos, etc. Trabalhos recentes propõe redução do módulo de elasticidade para simular efeitos devido as não-linearidades quando o projeto da estrutura é realizado com base no regime elástico linear. Essas propostas de reduções da rigidez eliminam a maior parte das dificuldades apresentadas na análise não-linear e deixam a análise estrutural relativamente simples. Entretanto, os coeficientes de redução de rigidez não foram embasados em qualquer análise estatística. Nesse item propõe-se coeficientes redutores do módulo de elasticidade secante do concreto $(\alpha)$ baseados nas características das colunas e que garantam um mínimo de confiabilidade desejada.

O domínio de validade da análise é o mesmo até o instante definido para colunas de concreto armado, podendo ser extrapolado para estruturas mais 
complexas. Os coeficientes parciais de segurança utilizados estão descritos na Tabela 9.3 , caso 2.

Foram considerados como variáveis aleatórias a resistência à compressão do concreto e a resistência do aço. De acordo com o estudo precedente, optou-se por considerar ambas as variáveis com função de distribuição de probabilidade Normal e com coeficiente de variação igual a $15 \%$ e $6 \%$ respectivamente. Anteriormente concluiu-se que o coeficiente de variação utilizado para a resistência do concreto deve ser inferior ou igual a $18 \%$. Optando-se por $15 \%$ permanece em uma faixa mais segura e não tão rigirosa se a opção fosse $12 \%$ como sugerido em muitos trabalhos recentes. É interessante ser um pouco conservador uma vez que há ainda que se considerar a existência de diversas variáveis que não foram consideradas aleatórias que poderiam modificar os resultados da análise.

O estudo concentrou-se na análise em serviço, não sendo aplicado à análise no estado limite último, embora algum tipo de verificação seja necessário neste âmbito. A análise no estado limite último pode ser inviabilizada devido a sensibilidade do coeficiente de redução do módulo de elasticidade secante ser bem elevada.

Os parâmetros de projeto variáveis na análise são: índice de esbeltez da coluna $(\lambda)$; parâmetro adimensional de excentricidade de primeira ordem $(\mu / v)$; resistência à compressão média do concreto $\left(\mathrm{f}_{\mathrm{cm}}\right)$; taxa geométrica de armadura ( $\rho$ ) e $\mathrm{o}$ adimensional $v$ definido na equação (9.1).

Analisando-se os resultados, verifica-se que a probabilidade de falha não varia significativamente quando varia a resistência média à compressão do concreto. Isso ocorre pela hipótese de assumir coeficiente de variação constante para a variável. A variação do índice de confiabilidade das colunas com a resistência média à compressão do concreto pode ser vista no Gráfico 9.25, no Gráfico 9.26 e no Gráfico 9.27 .

\footnotetext{
${ }^{9}$ A. MOHAMED, R. SOARES and W. VENTURINI (2001) Partial safety factors for homogeneous reliability of nonlinear reinforced concrete columns. Structural Safety. (submitted).
} 


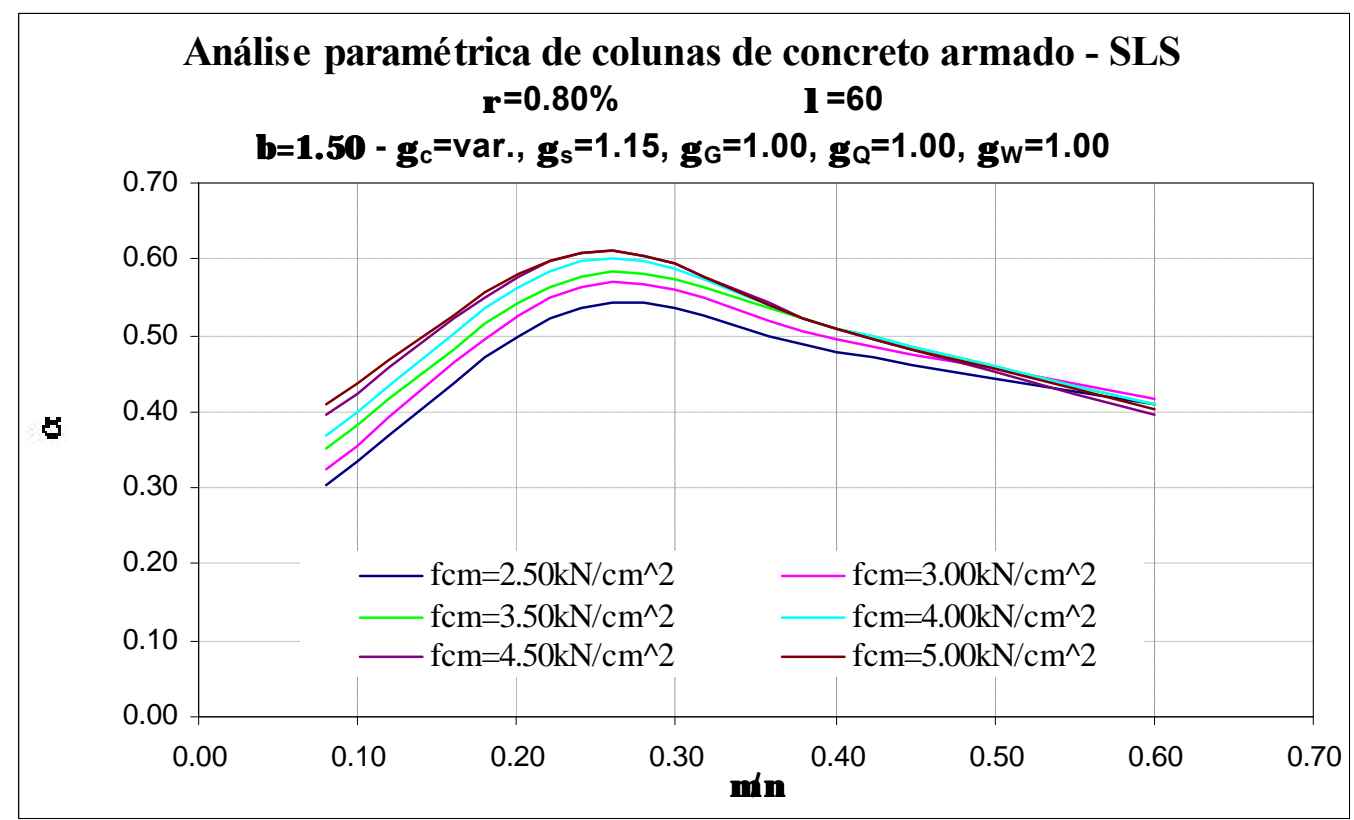

Gráfico 9.25 Redução do módulo de elasticidade secante para diversos $\mathrm{f}_{\mathrm{cm}}$

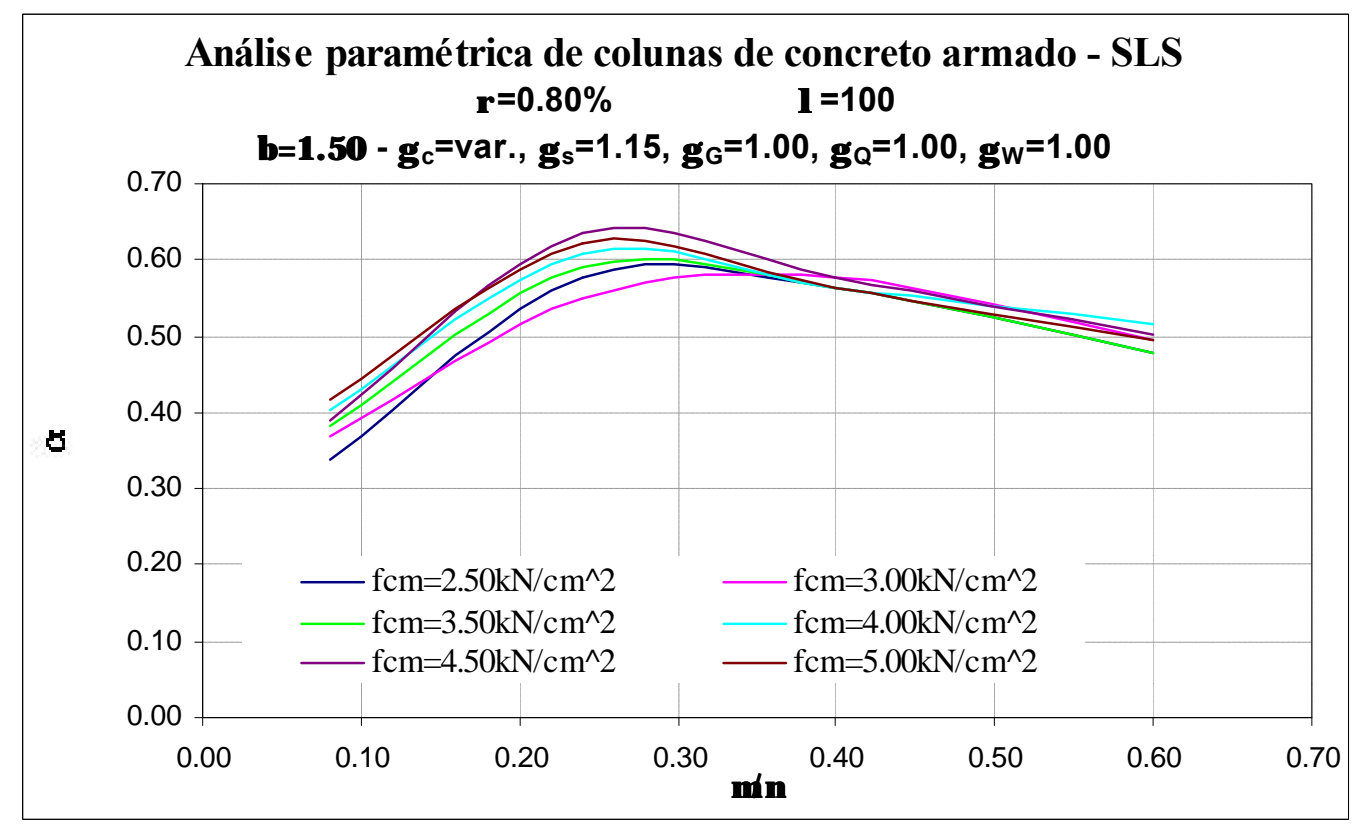

Gráfico 9.26 Redução do módulo de elasticidade secante para diversos $\mathrm{f}_{\mathrm{cm}}$ 


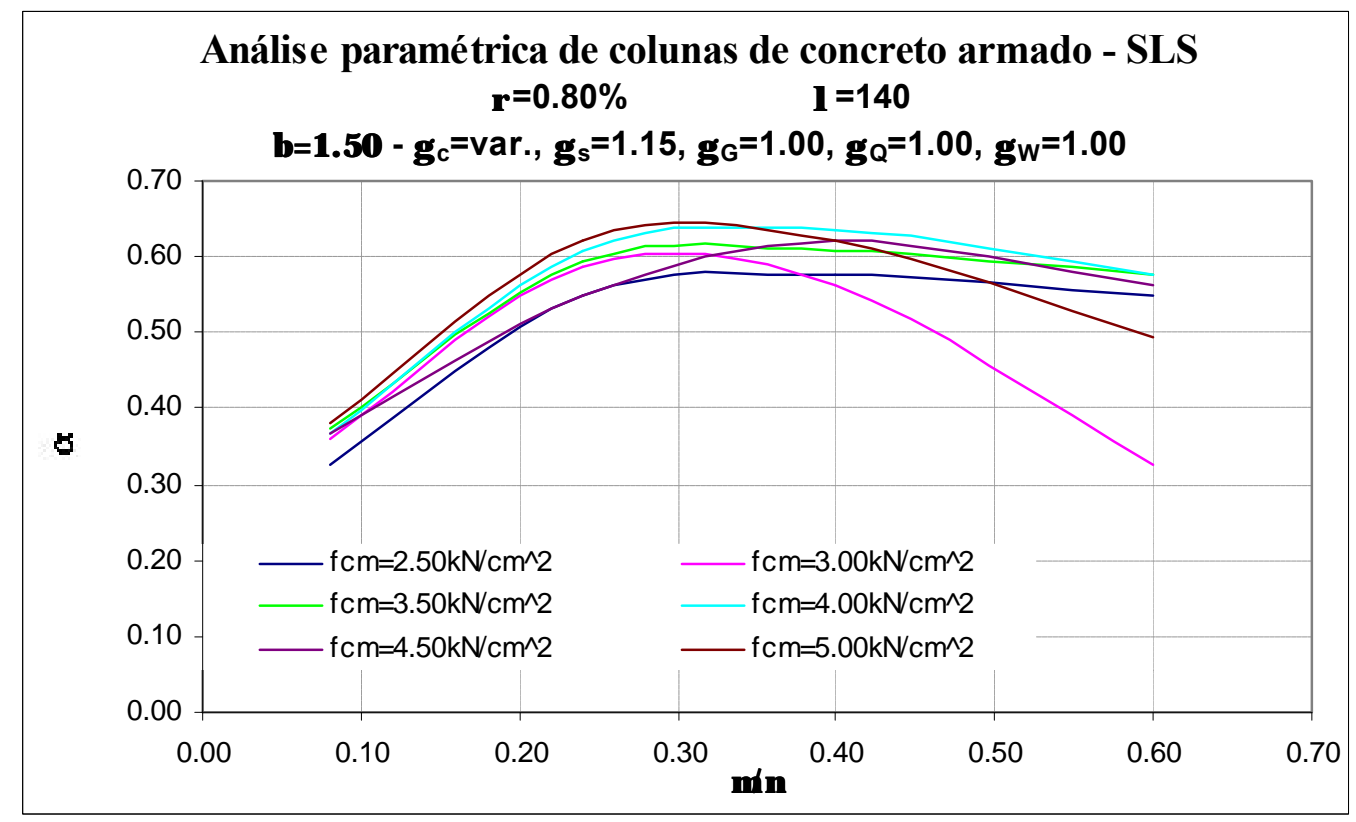

Gráfico 9.27 Redução do módulo de elasticidade secante para diversos $\mathrm{f}_{\mathrm{cm}}$

Como pode ser visto no Gráfico 9.28, Gráfico 9.29 e Gráfico 9.30, há uma grande variação do coeficiente redutor da rigidez dos elementos lineares de concreto armado. A redução da rigidez não é simples como indica a NBR, sendo função das várias variáveis envolvidas no projeto. Definir-se um valor único para pilares ou vigas pode ser incoerente, levando a estrutura a não economia ou até mesmo a não segurança.

O que se pode concluir a respeito dos valores sugeridos pela NBR para reduzir a rigidez é que em geral eles são coerentes em termos de segurança da estrutura, embora em determinadas situações não satisfazem critérios desejados de segurança. As situações críticas que podem apresentar índices de confiabilidade não satisfatórios felizmente são em peças onde a flexão predomina, o elemento linear já aproxima-se de uma viga.

Utilizar os coeficientes de redução da NBR pode muitas vezes conduzir à estruturas antieconômicas. A distância da redução que conduz a estrutura ao ponto ótimo em termos de confiabilidade aumenta para baixa excentricidade de primeira ordem, baixa taxa de armadura e baixo valor do adimensional $v$.

As três faixas de maior espessura no Gráfico 9.28, Gráfico 9.29 e Gráfico 9.30 referem-se à situações de atingir probabilidades limites aceitáveis para o estado limite de utilização. Portanto, para essas situações não foram fixados valores para $v$, esses 
valores foram definidos pelo critério de limite de utilização da estrutura.

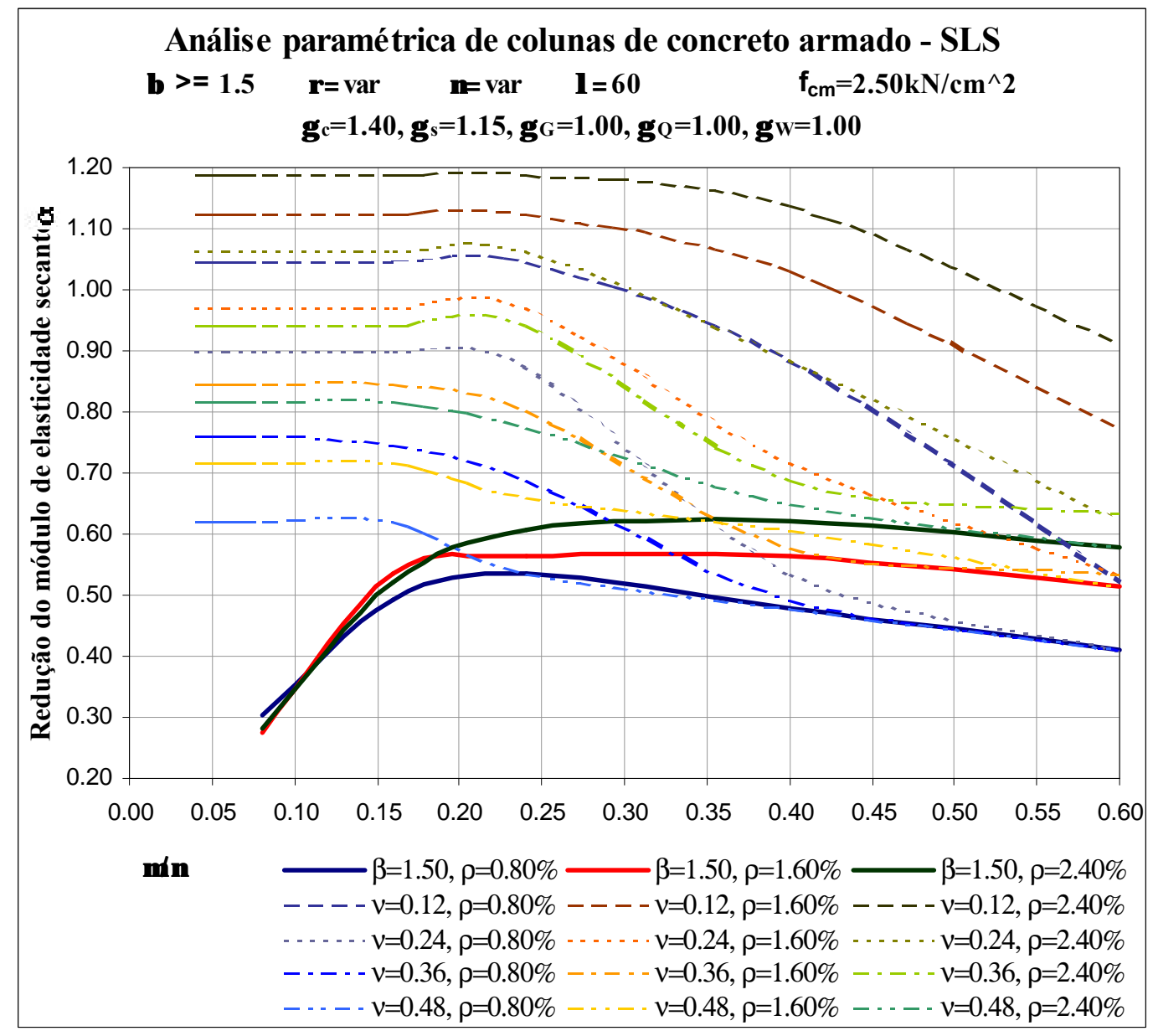

Gráfico 9.28 Proposta consistente para redução do módulo de elasticidade secante

Nas situações onde as curvas tracejadas localizam-se acima das curvas contínuas o estado limite último foi atingido antes do estado limite de utilização, trazendo como consequiência índices de confiabilidade superiores aos desejados para o SLS.

O Gráfico 9.28, elaborado para baixo índice de esbeltez, apresenta curvas de correção do módulo de elasticidade secante bem comportadas. Ao aumentar o índice de esbeltez, Gráfico 9.29, há uma perturbação na curva referente a baixa taxa geométrica de armadura e elevado valor de v. Perturbação que também ocorre para a curva limite de mesma taxa de armadura. Em colunas com elevado índice de esbeltez, Gráfico 9.30, as curvas não são bem comportadas, principalmente para colunas sujeitas a elevados valores de esforço normal e excentricidade de primeira ordem. É fácil compreender esse comportamento; em colunas muito esbeltas a 
sensibilidade dos esforços devido à não-linearidade é bem mais elevada do que em colunas curtas.

Nota-se que a sensibilidade da variação da taxa de armadura não é significativa, o que não se pode dizer da sensibilidade da variável $v$.

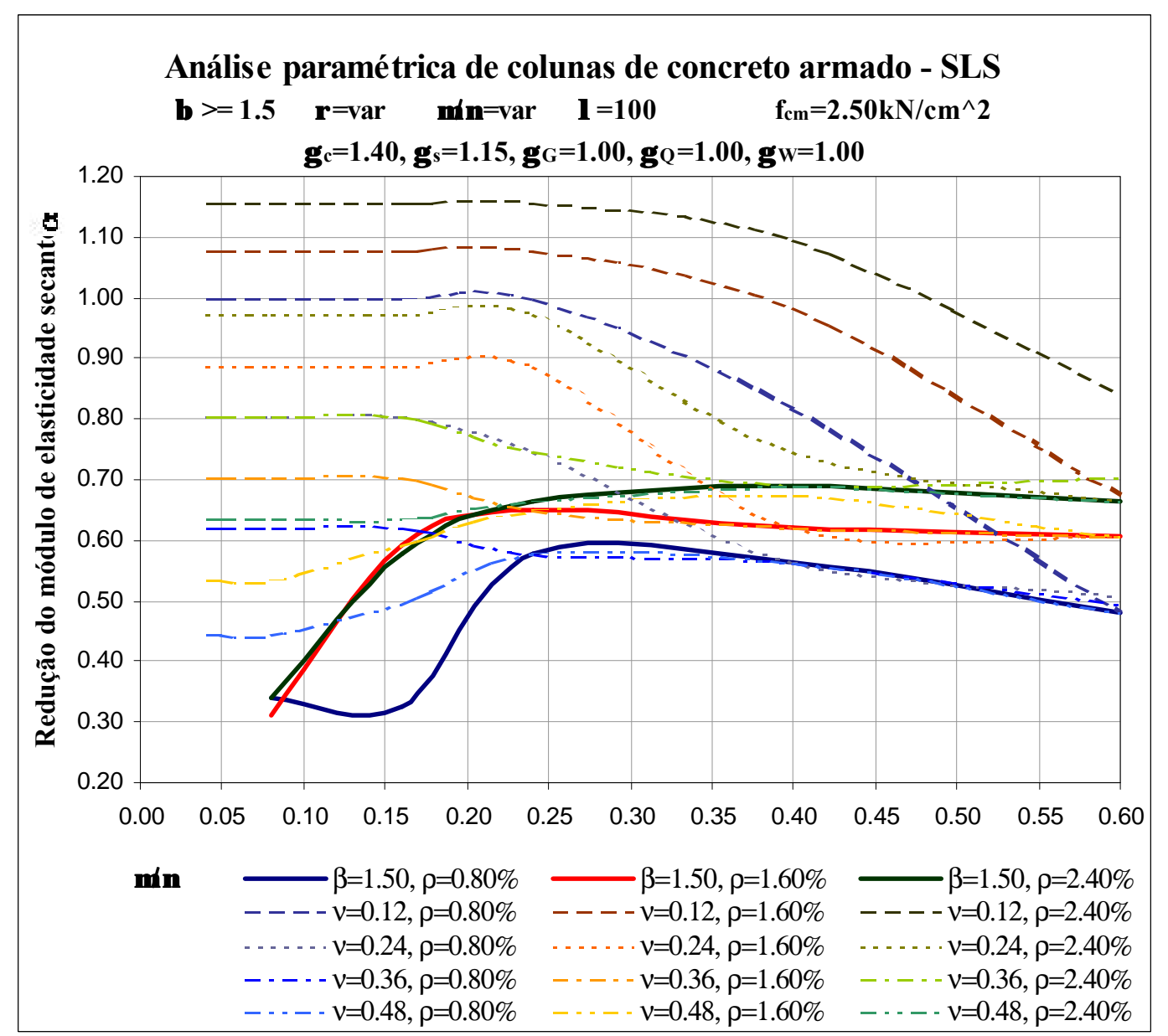

Gráfico 9.29 Proposta consistente para redução do módulo de elasticidade secante

Uma das propostas dessa tese é um coeficiente redutor do módulo de elasticidade secante para substituir o cálculo não-linear de elementos lineares pelo cálculo linear, conduzindo aos mesmos resultados e satisfazendo níveis mínimos de confiabilidade no SLS. A seguir mostra-se o modelo proposto.

O módulo de elasticidade secante deve ser reduzido pelo coeficiente $\alpha$ descrito no Gráfico 9.28, Gráfico 9.29 e Gráfico 9.30. Portanto, esse parâmetro deve ser calculado como:

$$
\mathrm{E}_{\mathrm{c}}=\alpha \cdot 0,85.5600 \cdot \sqrt{\mathrm{f}_{\mathrm{ck}}} \quad \backslash \mathrm{f}_{\mathrm{ck}}(\mathrm{MPa})
$$

A tensão relaciona-se diretamente com a deformação pela expressão: 


$$
\mathrm{f}_{\mathrm{c}}=\mathrm{E}_{\mathrm{c}} \varepsilon_{\mathrm{c}} \quad \Rightarrow-\infty<\varepsilon_{\mathrm{s}}<0
$$

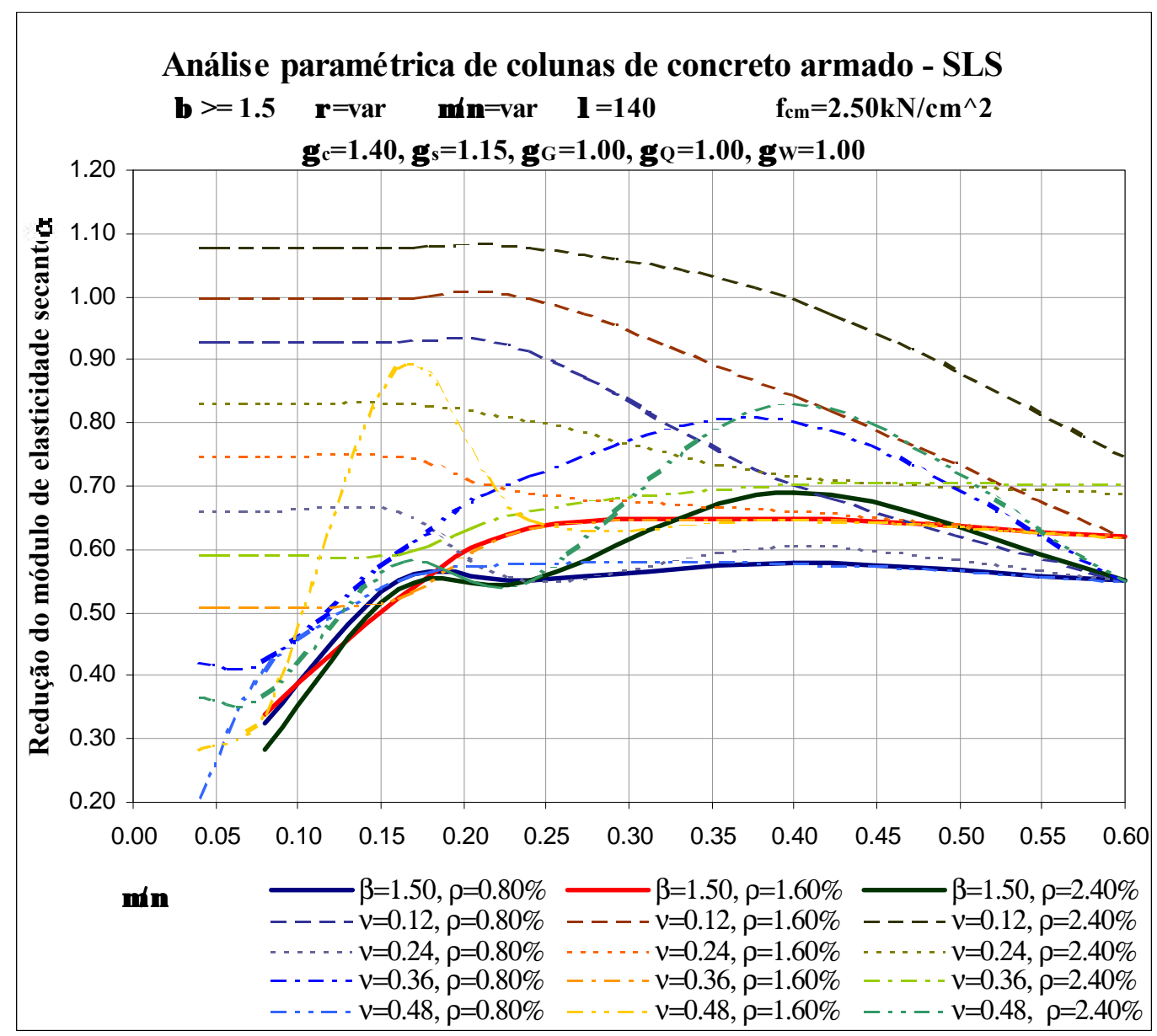

Gráfico 9.30 Proposta consistente para redução do módulo de elasticidade secante

\subsection{Análise de sensibilidade de colunas de concreto armado}

Na primeira etapa da análise de sensibilidade foram simuladas 3522 colunas com características diferentes. Foi feita uma regressão pelo método dos mínimos quadrados e encontrada uma hipersuperfície que representa o índice de confiabilidade das colunas estudadas.

A qualidade da regressão pode ser verificada através do coeficiente $\mathbf{r}$ expresso em (9.13).

$$
\mathrm{r}=\sqrt{1-\frac{\sum_{\mathrm{i}=1}^{\mathrm{n}}\left(\mathrm{H}_{\mathrm{i}}-\tilde{\mathrm{H}}_{\mathrm{i}}\right)^{2}}{\tilde{\mathrm{H}}_{\mathrm{i}}^{2}}}
$$

onde: $\quad \mathrm{n}$ : numero de pontos utilizados na regressão;

H: resposta real com a qual será feita a regressão; 
$\widetilde{\mathrm{H}}$ : resposta obtida através da hipersuperfície aproximada.

Para facilitar a expressão final do $\beta$ faz-se a seguinte associação das variáveis: $\mathrm{x}_{1}$ : resistência média do concreto; $\mathrm{x}_{2}$ : índice de esbeltez da coluna; $\mathrm{x}_{3}$ : taxa de armadura, $\mathrm{A}_{\mathrm{s}} /\left(\mathrm{b}_{\mathrm{w}} \cdot \mathrm{h}\right) ; \mathrm{x}_{4}$ : adimensional da excentricidade inicial, $\mu / \mathrm{v} ; \mathrm{x}_{5}$ : desvio padrão do concreto.

O índice de confiabilidade para a coluna apresentada no presente estudo pode ser expresso pela expressão (9.14):

$$
\beta=A^{\mathrm{T}} X
$$

onde A e X são fornecidos em (9.15):

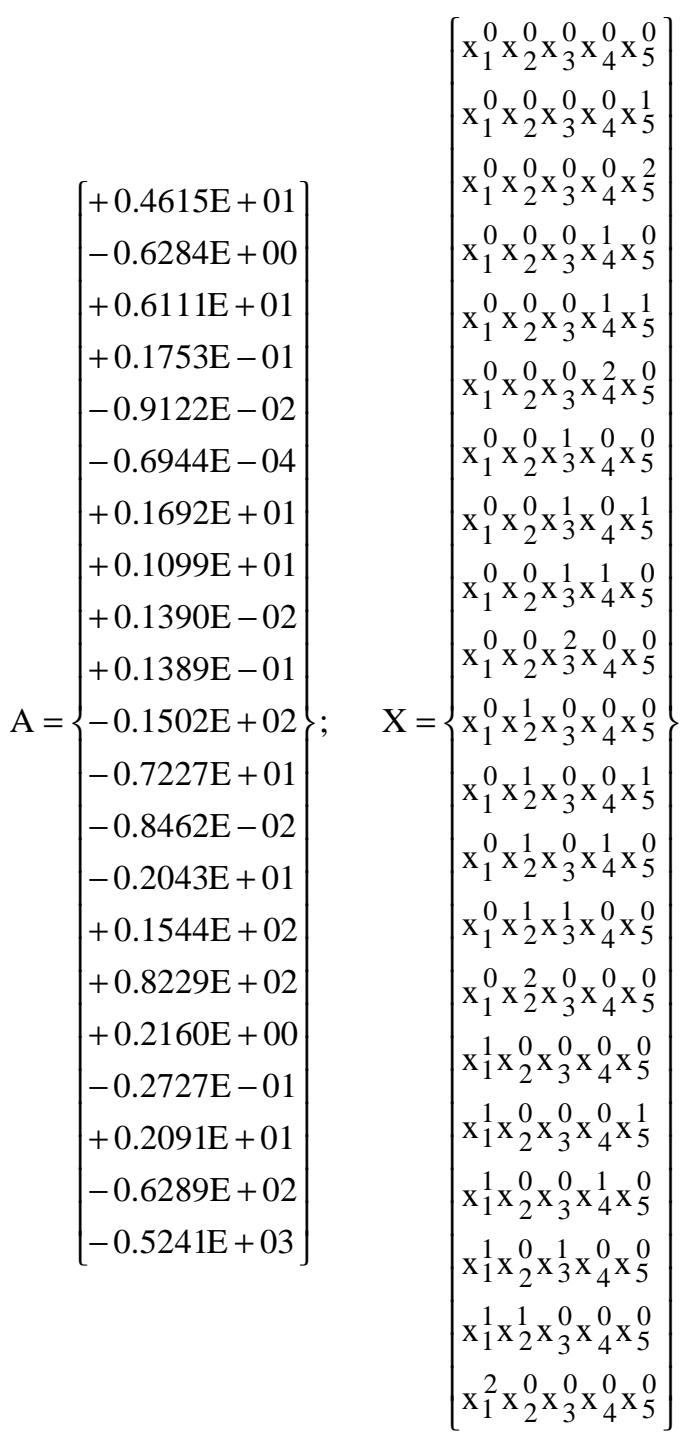

Para a aproximação da resposta do índice de confiabilidade quando utiliza-se um polinômio do segundo grau, expresso em (9.14), o valor de r é: $r=0.995619$. 
Uma interpretação gráfica da expressão (9.14) é expressa na Figura 9.2.

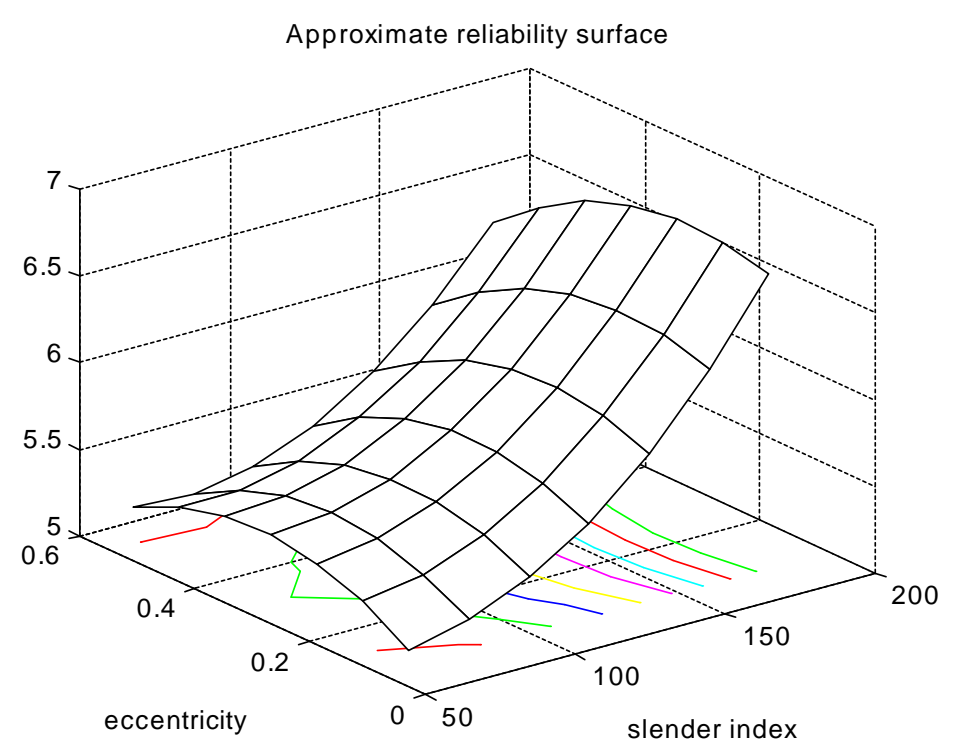

Figura 9.2 Exemplo de uma superfície aproximada do índice de confiabilidade variando a excentricidade e o índice de esbeltez da coluna

O estudo de sensibilidade das variáveis envolvidas é feito através da derivada da função que representa o índice de confiabilidade em relação a cada uma das variáveis,

$$
\alpha_{i}=\frac{\partial \beta}{\partial x_{i}}
$$

onde $\alpha_{i}$ é a sensibilidade do índice de confiabilidade em relação à variável i.

Para o problema em análise, tem-se:

$$
\left\{\begin{array}{l}
\alpha_{1} \\
\alpha_{2} \\
\alpha_{3} \\
\alpha_{4} \\
\alpha_{5}
\end{array}\right\}=C\left\{\begin{array}{l}
1 \\
x_{1} \\
x_{2} \\
x_{3} \\
x_{4} \\
x_{5}
\end{array}\right\}
$$

$\mathrm{C}=\left[\begin{array}{cccccc}+0.8229 \mathrm{E}+02 & -1.0482 \mathrm{E}+03 & -0.6289 \mathrm{E}+02 & +0.2091 \mathrm{E} 01 & -0.2727 \mathrm{E}-01 & 0.2160 \mathrm{E}+00 \\ -0.1502 \mathrm{E}+02 & -0.6289 \mathrm{E}+02 & +0.3088 \mathrm{E}+02 & -0.2043 \mathrm{E}+01 & -0.8462 \mathrm{E}-02 & -0.7227 \mathrm{E}+01 \\ +0.1692 \mathrm{E}+01 & +0.2091 \mathrm{E}+01 & -0.2043 \mathrm{E}+01 & +0.2778 \mathrm{E}-01 & +0.1390 \mathrm{E}-02 & +0.1099 \mathrm{E}+01 \\ +0.1753 \mathrm{E}-01 & -0.2727 \mathrm{E}-01 & -0.8462 \mathrm{E}-02 & +0.1390 \mathrm{E}-02 & -1.3888 \mathrm{E}-04 & -0.9122 \mathrm{E}-02 \\ -0.6284 \mathrm{E}+00 & +0.2160 \mathrm{E}+00 & -0.7227 \mathrm{E}+01 & +0.1099 \mathrm{E}+01 & -0.9122 \mathrm{E}-02 & +1.2222 \mathrm{E}+01\end{array}\right]$

O valor da matriz $\mathbf{C}$ é subjetivo, pois depende do valor numérico da variável analisada, podendo causar enganos na análise. Com o objetivo de poder fazer 
comparações mais significativas entre as variáveis, é interessante explicitar os resultados de $\mathbf{C}$ na forma (9.18).

$$
\widetilde{\alpha}_{i}=\frac{\partial \beta\left(x_{k}\right)}{\partial x_{i}} \frac{x_{i}}{\beta\left(x_{k}\right)}=C_{i k} x_{k} \frac{x_{i}}{\beta\left(x_{k}\right)}
$$

Pode-se tomar como exemplo $\mathrm{x}_{\mathrm{k}}{ }^{\mathrm{T}}=\left\{\begin{array}{lllll}4 & 80 & 0.024 & 0.32 & 0.70\end{array}\right\}$

Portanto, substituindo-se os valores na expressão (9.18), determina-se $C_{i k} x_{k}$, expresso em (9.19).

$$
\left[\begin{array}{l}
-9141.5173424 \\
2198.70936016 \\
-152.61358848 \\
-.7749064816 \\
-569.34554304
\end{array}\right]:=\left[\begin{array}{cccccc}
82.29 & -1048.2 & -62.89 & 2.091 & -0.02727 & 0.2160 \\
-15.02 & -62.89 & 30.88 & -2.043 & -0.008462 & -7.227 \\
1.692 & 2.091 & -2.043 & 0.02778 & 0.001390 & 1.099 \\
0.01753 & -0.02727 & -0.008462 & 0.001390 & -0.00013888 & -0.009122 \\
-0.6284 & 0.2160 & -7.227 & 1.099 & -0.009122 & 12.222
\end{array}\right] \cdot\left[\begin{array}{c}
1 \\
4 \\
80 \\
0.024 \\
0.32 \\
0.70
\end{array}\right]
$$

Substituindo-se (9.19) e os valores admitidos para $\mathrm{x}_{\mathrm{k}}$ em (9.14), na expressão (9.18), determina-se a sensibilidade de $\beta$ expressa em (9.20).

$$
\left[\begin{array}{r}
-6471.8706848849557527 \\
31132.167931469026548 \\
-.64827011035752212389 \\
-.04388850869238938053 \\
-70.53838586336283185 \oint
\end{array}\right]=\left[\begin{array}{r}
-9141.5173424 \frac{4}{5.65} \\
2198.7093601 \frac{80}{5.65} \\
-152.61358848 \frac{0.024}{5.65} \\
-.7749064816 \frac{0.32}{5.65} \\
-569.34554304 \frac{0.70}{5.65}
\end{array}\right]
$$

Através dos valores obtidos em (9.20), verifica-se que, para os valores adotados para $\mathrm{x}_{\mathrm{k}}$, o grau de sensibilidade do índice de confiabilidade em relação as variáveis de projeto em ordem decrescente é: índice de esbeltez da coluna $\left(\mathrm{x}_{2}\right)$; resistência do concreto $\left(\mathrm{x}_{1}\right)$; desvio padrão do concreto $\left(\mathrm{x}_{5}\right)$; taxa de armadura $\left(\mathrm{x}_{3}\right)$; adimensional da excentricidade inicial $\left(\mathrm{x}_{4}\right)$.

Encontrar expressões polinomiais para representar uma superfície aproximada do índice de confiabilidade das colunas não é aconselhável para determinar seus índices de confiabilidade. Esses polinômios podem ser utilizados apenas para análise da sensibilidade do índice de confiabilidade em relação as variáveis de projeto, como descrito nesse item. 


\subsection{Confiabilidade entre modelos para concreto}

$\mathrm{Na}$ análise realizada até o instante, utiliza-se para a resistência do concreto o modelo do CEB na região comprimida e um modelo proposto por FIGUEIRAS (1983) para representar a rigidez entre fissuras do concreto tracionado.

Para verificar a validade de se considerar o modelo constitutivo da NBR 6118 foi realizado uma série de ensaios numéricos, dos quais uma parte é apresentada na Tabela 9.6. Cada ensaio da série consistiu-se na procura da resistência de cálculo do concreto, segundo a NBR 6118, que levaria a estrutura a mesma carga de ruína quando esta é calculada segundo o modelo do CEB acrescentado da tension-stiffening (modelo de comparação) para uma resistência de cálculo de $2.01 \mathrm{kN} / \mathrm{cm}^{2}$. As resistências de cálculo do concreto segundo a NBR 6118 equivalentes à $2.01 \mathrm{kN} / \mathrm{cm}^{2}$ segundo o modelo de comparação são apresentamdas na Tabela 9.6.

Tabela 9.6 Variação da resistência do concreto, modelo da NBR 6118, com a excentricidade de primeira ordem e o índice de esbeltez da coluna da Figura 9.1

\begin{tabular}{|c|c|c|c|c|c|c|}
\hline \multicolumn{1}{|c|}{ Exc. } & 0.08 & 0.16 & 0.24 & 0.32 & 0.40 & 0.60 \\
\hline 80 & 2.13 & 2.26 & 2.26 & 2.26 & 2.59 & 2.59 \\
\hline 100 & 2.26 & 2.50 & 2.59 & 2.59 & 2.59 & 3.03 \\
\hline 150 & 2.69 & 3.33 & 4.10 & 4.63 & 3.93 & 3.56 \\
\hline
\end{tabular}

Como pode-se observar através da Tabela 9.6, há uma folga na segurança ao utilizar-se o modelo da NBR 6118, uma vez que todos os valores apresentados são maiores que o de referência utilizado pelo modelo de comparação. Percebe-se também que a sobra na segurança cresce com a excentricidade de primeira ordem e o índice de esbeltez, concluindo que quanto mais não-linear for o comportamento da coluna mais segura será a mesma ao utilizar o modelo da NBR 6118. Quando o nível de não-linearidade é muito alto, a flexão é bastante predominante sobre o esforço axial fazendo com que a coluna tenha um comportamento mais próximo de uma viga, a segurança reduz-se um pouco, porém ainda oferece bastante folga com relação a coluna calculada com o modelo de comparação.

Como já era esperado, conclui-se com essa análise que ao calcular colunas com o modelo da NBR 6118 aparece esforços na estrutura maiores do que são na realidade, trazendo como conseqüência estruturas mais conservadoras a respeito da segurança. 


\subsection{Conclusões}

A utilização de coeficientes parciais de segurança como adotado por grande parte das recomendações e normas internacionais, inclusive a brasileira, fornece probabilidade de falha das estruturas bastante variada. Há várias formas de minimizar essa variação, dentre elas algumas sugeridas no presente texto. Acredita-se que uma forma bastante simples de tornar mais uniforme a segurança nas estruturas de concreto armado é mudar os critérios de aceitação do desvio padrão, passando este a ser um valor percentual do valor médio da variável, não mais um valor constante.

Calibrar coeficientes parciais de segurança para uniformizar a confiabilidade das estruturas de concreto armado é uma tarefa bastante difícil. Além do elevado número de variáveis envolvidas, as respostas não-lineares das estruturas pertencentes a essa classe não facilitam a calibração estocástica. Portanto, o mais indicado é dimensionar as estruturas no nível 3 ou 4 de classificação de segurança. Esses níveis não impõem a segurança estrutural através de coeficientes parciais, propõem o dimensionamento da estrutura a partir de sua probabilidade de ruína.

Um fator bastante influente na segurança das estruturas é o seu nível de nãolinearidade. Entre as várias estruturas analisadas verificou-se que pelo procedimento de introdução da segurança através de coeficientes parciais, quanto maior for o nível de não-linearidade do problema menor é a probabilidade de ruína da estrutura.

De forma geral, as prescrições das normas que foram abordadas nesse estudo quanto a imposição da segurança são razoáveis porém sempre conservadoras. Existem situações onde não se observa margens de segurança excessiva, porém, não foi verificado qualquer situação onde a segurança estrutural está abaixo dos limites aceitáveis.

Foi proposto uma nova forma de aceitação do desvio padrão do concreto. A proposta baseia-se em coeficientes de variação da resistência do concreto, que estabelece o desvio padrão adequado ao nível de confiabilidade desejado e a intensidade da resistência característica do material.

Uma outra proposta foi uma redução consistente do módulo de elasticidade secante do concreto, a qual garante níveis mínimos de segurança da estrutura no estado limite de serviço. 
Embora a introdução do conceito estatístico nas variáveis de projeto já tenha se iniciado há algum tempo, há cerca de 4 décadas, a utilização prática dessa ferramenta ainda não é utilizada devido ao elevado custo computacional. Métodos modernos têm diminuído significativamente o custo da análise mecânica-confiabilística, mas ainda há um longo trabalho para a implementação do dimensionamento das estruturas nos níveis 3 e 4 de segurança. 


\section{Capítulo 10 Estudo estatístico de pórticos de concreto armado}

Uma outra análise a ser abordada nessa tese é a avaliação da segurança em pórticos planos de concreto armado. Não se pretende com esse estudo definir novos coeficientes parciais de segurança ou mesmo qualquer modificação da NBR6118. Pretende-se apenas analisar alguns pórticos visando entender a variação de sua confiabilidade ou probabilidade de ruína com a variação de seus parâmetros de projeto.

Os pórticos analisados estão sujeitos a esforços axiais e de flexão. O modelo mecânico-probabilístico empregado é o mesmo adotado para a análise das colunas descrita no Capítulo 9.

A ruína da estrutura é estabelecida de duas formas, no estado limite último e em serviço. A ruína no estado limite último é estabelecida pela singularidade da matriz de rigidez global da estrutura. Ou seja, dar-se um incremento de carga na estrutura até que a matriz de rigidez se torne singular; nesse instante determina-se a carga última que o pórtico suporta. Pode-se verificar que a ruína não é definida para uma seção isolada, verifica-se a capacidade de suporte de toda a estrutura. Já a ruína no estado limite de serviço é estabelecida pelo máximo deslocamento admitido pela NBR 6118 para cada nó da estrutura. A verificação é feita no nó de maior relação deslocamento calculado/deslocamento admitido.

As dimensões, resistências e ações externas das estruturas são definidas de tal forma que abranjam um grande leque de variedades estruturais. 

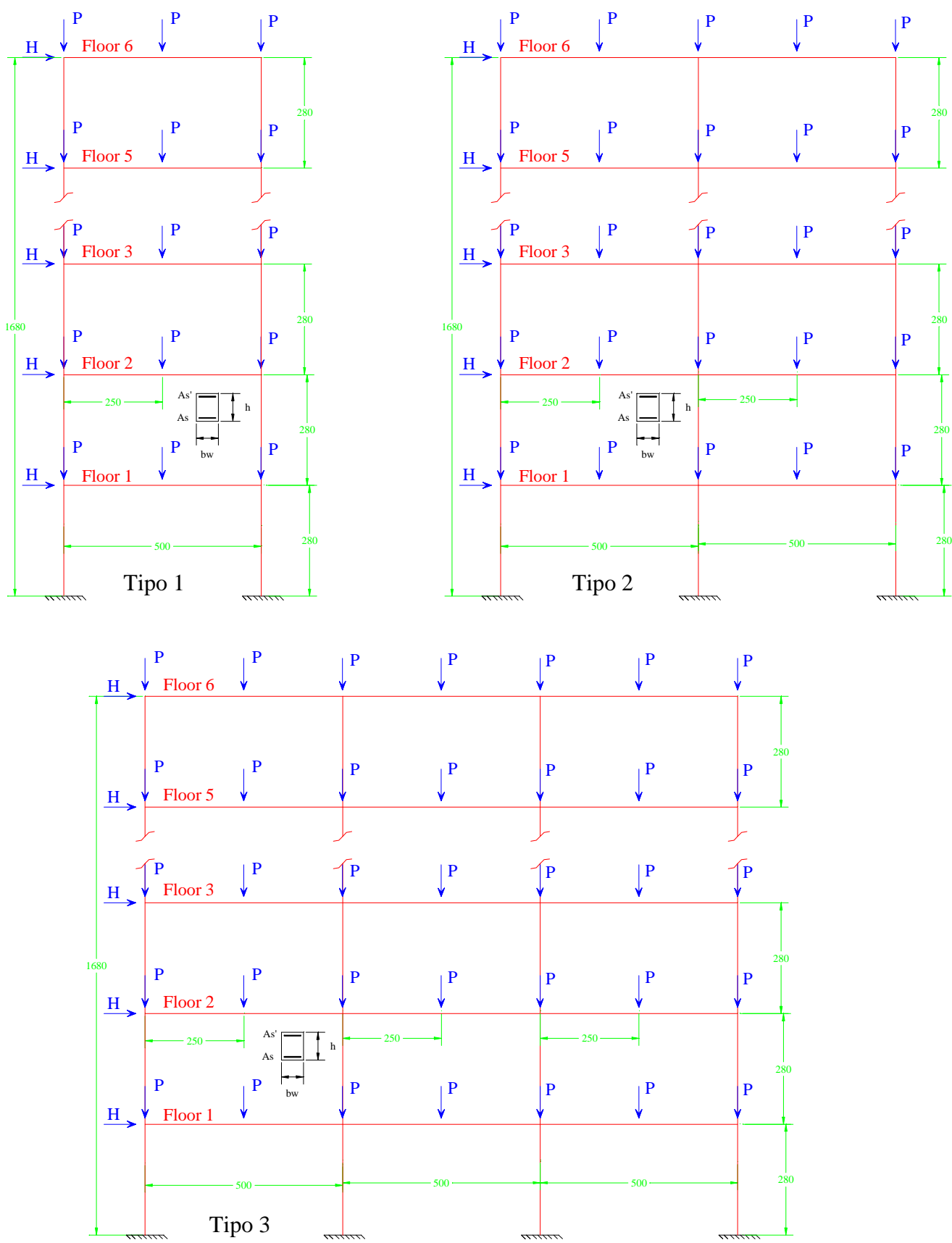

Figura 10.1 Pórticos utilizados na análise paramétrica

A princípio faz-se uma análise no ULS dos pórticos para observar a variação do índice de confiabilidade com as características principais da estrutura. Para o desenvolvimento da análise, consideram-se três pórticos com diferente número de colunas, denominados tipos 1, 2 e 3 apresentados na Figura 10.1, definidos para avaliar a influência do grau de hiperasticidade da estrutura. Com o objetivo de verificar a importância das armaduras consideram-se três hipóteses de taxa 
geométrica de armadura: elementos com baixa taxa geométrica, média e fortemente armados, Tabela 10.2. Dois casos de desvio padrão definidos pela NBR 6118 para o concreto são considerados, Tabela 10.3, para avaliar a influência desse parâmetro no índice de confiabilidade da estrutura. Objetivando-se também atingir o domínio de resistências do concreto utilizado na prática da engenharia estrutural, Tabela 10.4, analisam-se quatro 'classes' de resistência do concreto.

A respeito das ações externas aplicadas na estrutura, estas são definidas pela máxima ação (minorada pelo coeficiente parcial de carga) que leve a estrutura ao seu limite, considerando as resistências minoradas pelos coeficientes parciais. A relação entre ações externas verticais e horizontais é $\mathrm{H}=24 \% \mathrm{P}$. Portanto, a análise paramétrica dos pórticos baseia-se em 72 casos de diferentes estruturas.

As características dos pórticos da Figura 10.1 são apresentadas em tabelas distribuídas ao longo do capítulo.

Tabela 10.1 Coeficientes parciais utilizados na análise

\begin{tabular}{|c|c|c|}
\hline Concreto, $\gamma_{\mathrm{c}}$ & Aço, $\gamma_{\mathrm{s}}$ & Carga, $\gamma_{\mathrm{f}}$ \\
\hline 1.40 & 1.15 & 1.40 \\
\hline
\end{tabular}

Tabela 10.2 Características das variáveis determinísticas dos pórticos da Figura 10.1 $(\mathrm{kN} \mathrm{e} \mathrm{cm})$

\begin{tabular}{|c|c|c|c|c|c|c|}
\hline & \multicolumn{2}{|c|}{ Hipótese 1 } & \multicolumn{2}{c|}{ Hipótese 2 } & \multicolumn{2}{c|}{ Hipótese 3 } \\
\hline Elemento estrutural & Colunas & Vigas & Colunas & Vigas & Colunas & Vigas \\
\hline Base da seção transversal, $\mathrm{b}_{\mathrm{w}}$ & 20.00 & 15.00 & 20.00 & 15.00 & 20.00 & 15.00 \\
\hline Altura da seção transversal, $\mathrm{h}$ & 50.00 & 45.00 & 50.00 & 45.00 & 50.00 & 45.00 \\
\hline $\begin{array}{c}\text { Posição média da armadura } \\
\text { em relação ao CG, Y = Y' }\end{array}$ & \pm 20.00 & \pm 18.00 & \pm 20.00 & \pm 18.00 & \pm 20.00 & \pm 18.00 \\
\hline $\begin{array}{c}\text { Taxa geométrica de } \\
\text { armadura, } \mathrm{A}_{\mathrm{s}}=\mathrm{A}_{\mathrm{s}}^{\text {(case 1) }}\end{array}$ & $0.80 \%$ & $1.48 \%$ & $1.60 \%$ & $1.48 \%$ & $2.40 \%$ & $1.48 \%$ \\
\hline $\begin{array}{c}\text { Resistência média } \\
\text { do aço, } \mathrm{fm}_{\mathrm{ym}}\end{array}$ & 50.00 & 50.00 & 50.00 & 50.00 & 50.00 & 50.00 \\
\hline $\begin{array}{c}\text { Módulo de elasticidade } \\
\text { do aço, } \mathrm{E}_{\mathrm{s}}\end{array}$ & 21000.00 & 21000.00 & 21000.00 & 21000.00 & 21000.00 & 21000.00 \\
\hline
\end{tabular}

Tabela 10.3 Característica estatísticas das variáveis $(\mathrm{kN}$ e cm)

\begin{tabular}{|c|c|c|c|c|}
\hline $\begin{array}{c}\text { Random } \\
\text { variable }\end{array}$ & $\begin{array}{c}\text { Coeficiente } \\
\text { de variação }\end{array}$ & $\begin{array}{c}\text { Função de } \\
\text { distribuição }\end{array}$ & $\begin{array}{c}\text { Coeficiente } \\
\text { de variação }\end{array}$ & $\begin{array}{c}\text { Função de } \\
\text { distribuição }\end{array}$ \\
\hline $\mathrm{f}_{\mathrm{cm}}$ & $0.40 / \mathrm{f}_{\mathrm{cm}}$ & Normal & $0.55 / \mathrm{f}_{\mathrm{cm}}$ & Normal \\
\hline $\mathrm{f}_{\mathrm{ym}}$ & $6 \%$ & Normal & $6 \%$ & Normal \\
\hline
\end{tabular}


Tabela 10.4 Variação das resistências médias do concreto ( $\mathrm{kN}$ e cm)

\begin{tabular}{|c|c|}
\hline Classe & $\mathrm{f}_{\mathrm{cm}}$ \\
\hline 1 & 3.00 \\
\hline 2 & 3.50 \\
\hline 3 & 4.00 \\
\hline 4 & 4.50 \\
\hline
\end{tabular}

Na Tabela 10.5 são apresentados índices de confiabilidade para os pórticos da Figura 10.1 e suas respectivas colunas equivalentes. As dimensões das chamadas colunas equivalentes foram estabelecidas de tal forma que uma ação externa unitária aplicada na direção horizontal no topo da estrutura provoque o mesmo deslocamento do topo do pórtico e da coluna, quando estes são calculados no regime elástico linear. Podendo-se dizer então que a coluna apresenta rigidez equivalente ao pórtico apenas em regime linear.

Analisando-se os resultados da Tabela 10.5 verifica-se que não é coerente substituir um pórtico por uma coluna equivalente para estimar seu índice de confiabilidade. Isso é facilmente interpretado ao conceber a estrutura, pois o pórtico é hiperestático e consequentemente suporta ações externas de maior amplitude que a coluna que é isostática e não permite redistribuição de esforços.

Tabela 10.5 Índices de confiabilidade dos pórticos da Figura 10.1 e das respectivas colunas equivalentes

\begin{tabular}{|c|c|c|c|c|c|c|c|c|}
\hline \multicolumn{2}{|c|}{} & \multicolumn{2}{|c|}{ Tipo 1 } & \multicolumn{2}{|c|}{ Tipo 2 } & \multicolumn{2}{|c|}{ Tipo 3 } \\
\hline$\sigma_{\mathrm{c}}$ & $\%$ & $\mathrm{f}_{\mathrm{cm}}$ & $\beta_{\text {pórtico }}$ & $\beta_{\text {coluna equivalente }}$ & $\beta_{\text {pórtico }}$ & $\beta_{\text {coluna equivalente }}$ & $\beta_{\text {pórtico }}$ & $\beta_{\text {coluna equivalente }}$ \\
\hline 0.55 & $0.80 \%$ & 3.00 & 4.44 & 6.96 & 4.12 & 7.29 & 3.97 & 6.99 \\
\hline 0.55 & $0.80 \%$ & 3.50 & 5.26 & 7.51 & 4.71 & 7.41 & 4.62 & 7.60 \\
\hline 0.55 & $0.80 \%$ & 4.00 & 6.01 & 7.90 & 5.45 & 7.69 & 5.27 & 8.05 \\
\hline 0.55 & $0.80 \%$ & 4.50 & 8.31 & 8.39 & 7.99 & 8.44 & 6.17 & 8.92 \\
\hline 0.55 & $1.60 \%$ & 3.00 & 4.97 & 6.32 & 4.54 & 7.29 & 4.53 & 7.42 \\
\hline 0.55 & $1.60 \%$ & 3.50 & 4.90 & 7.17 & 5.93 & 7.42 & 5.32 & 7.36 \\
\hline 0.55 & $1.60 \%$ & 4.00 & 5.39 & 5.59 & 7.07 & 7.54 & 6.27 & 7.67 \\
\hline 0.55 & $1.60 \%$ & 4.50 & 8.32 & 7.50 & 8.38 & 7.68 & 8.08 & 7.36 \\
\hline 0.55 & $2.40 \%$ & 3.00 & 6.02 & 6.66 & 5.50 & 6.75 & 5.13 & 6.79 \\
\hline 0.55 & $2.40 \%$ & 3.50 & 6.37 & 6.95 & 6.20 & 6.97 & 5.93 & 7.38 \\
\hline 0.55 & $2.40 \%$ & 4.00 & 7.45 & 7.02 & 5.18 & 6.43 & 6.52 & 6.72 \\
\hline 0.55 & $2.40 \%$ & 4.50 & 7.63 & 7.05 & 8.09 & 7.26 & 7.85 & 7.34 \\
\hline
\end{tabular}

Os valores da Tabela 10.5 são plotados no Gráfico 10.1, Gráfico 10.2 e Gráfico 10.3 . 


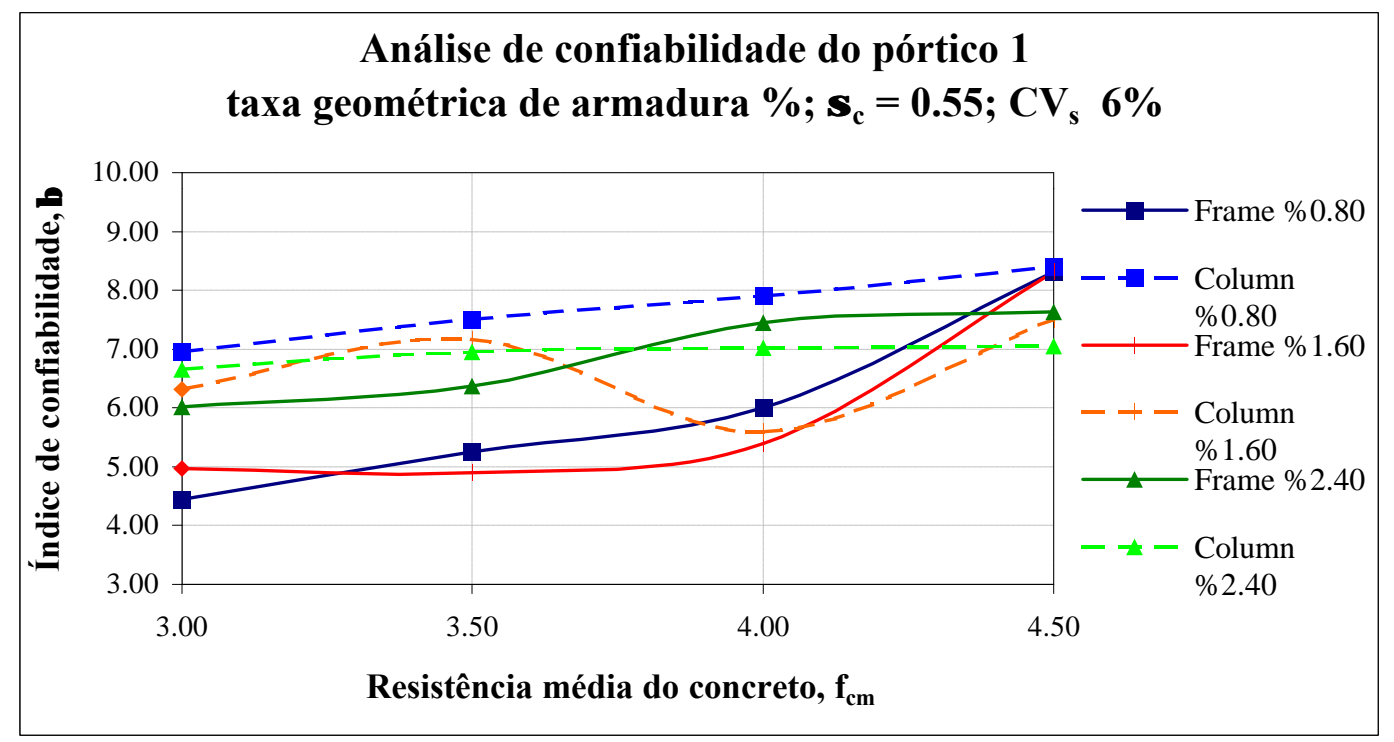

Gráfico 10.1 Índices de confiabilidade para o pórtico tipo 1 da Figura 10.1 e respectiva coluna equivalente

O Gráfico 10.1 mostra que para o pórtico tipo 1, quando se utiliza taxa geométrica de armadura mais elevada as respostas obtidas com o modelo da coluna equivalente aproximam-se das obtidas com as do pórtico. O oposto ocorre para baixas taxas geométricas de armadura. Esse fato é amenizado a medida que aumentase o número de colunas dos pórticos, ver Gráfico 10.2 e Gráfico 10.3. Isso é facilmente entendido uma vez que, quanto menor o número de colunas do pórtico mais o mesmo se aproxima de uma coluna isolada.

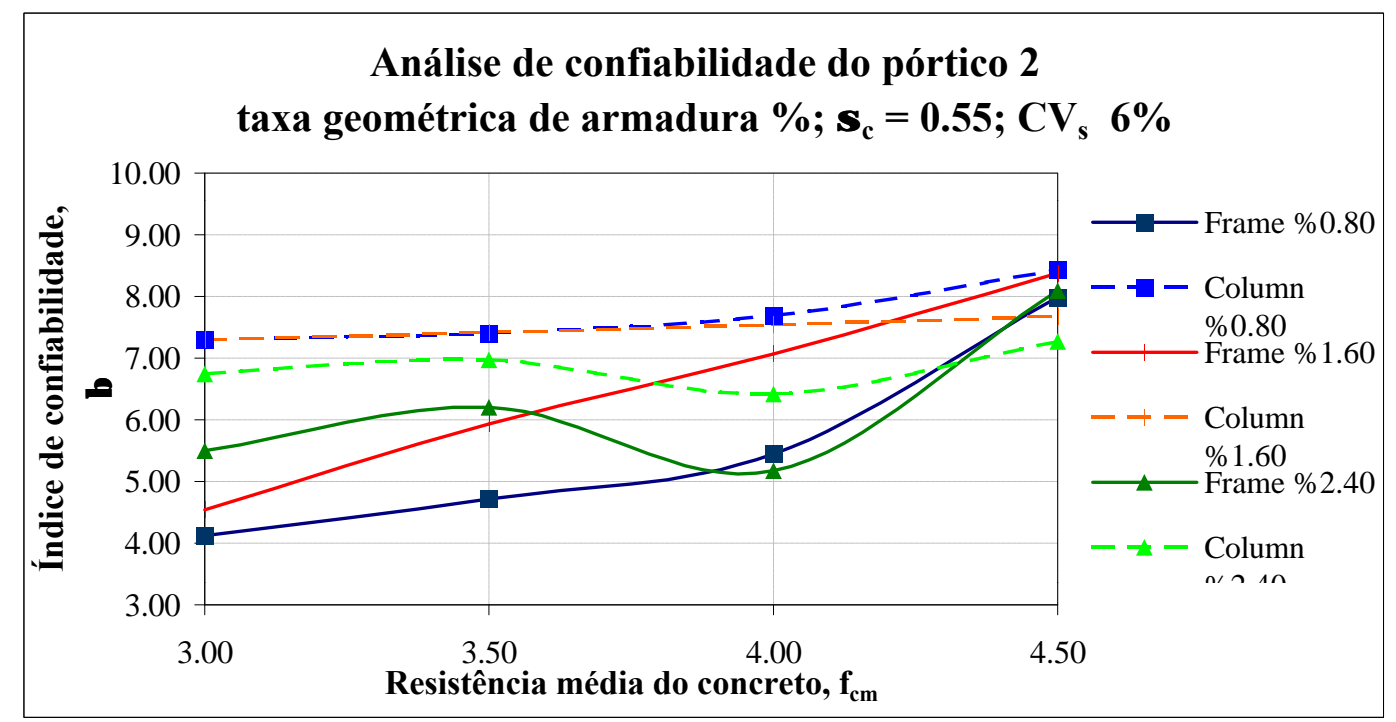

Gráfico 10.2 Índices de confiabilidade para o pórtico tipo 2 da Figura 10.1 e respectiva coluna equivalente

À medida que se aumenta o número de colunas do pórtico verifica-se que há 
um aumento relativo no índice de confiabilidade obtido utilizando o modelo de coluna equivalente comparado com o obtido diretamente do pórtico. Concluindo-se portanto que, utilizar o modelo de coluna equivalente para estimar o índice de confiabilidade de pórticos é contra a segurança. Isso também é facilmente interpretado, pois, sabe-se que em geral quanto mais hiperestática a estrutura mais segura ela é.

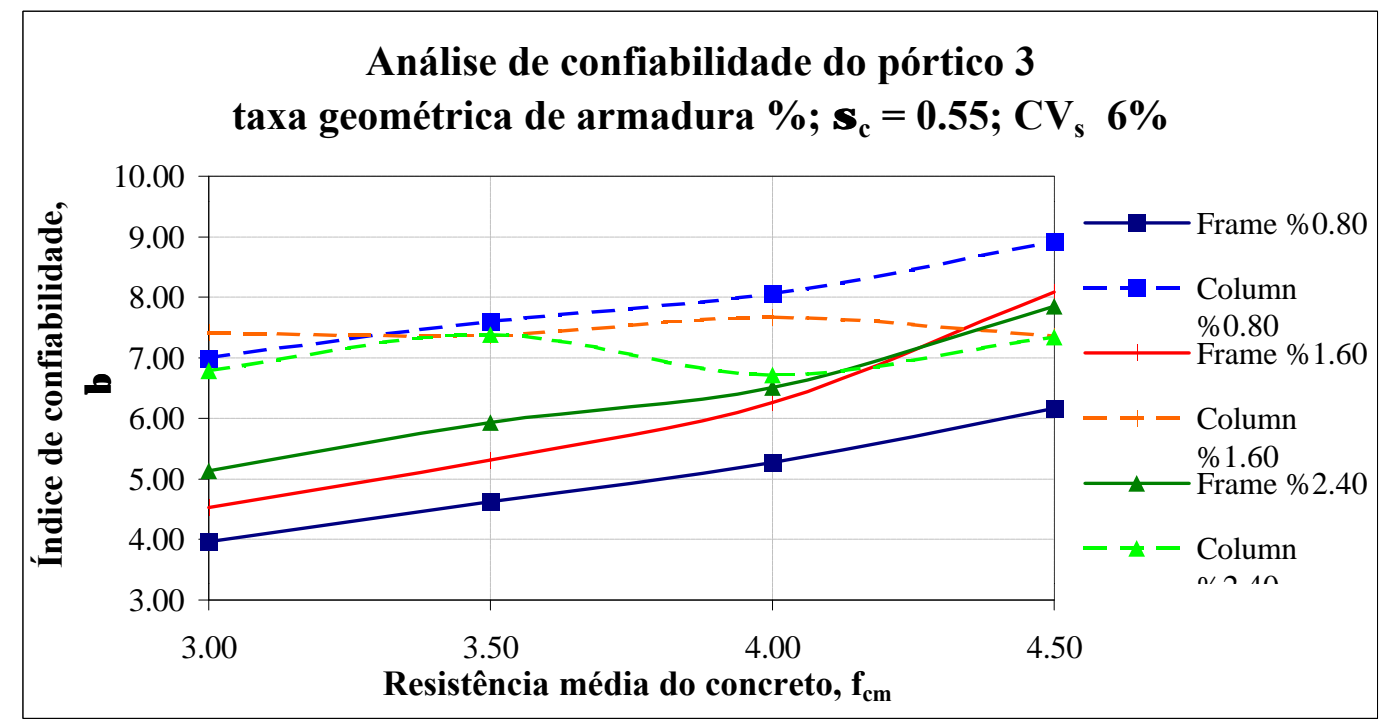

Gráfico 10.3 Índices de confiabilidade para o pórtico tipo 3 da Figura 10.1 e respectiva coluna equivalente 
Tabela 10.6 Índices de confiabilidade e sensibilidade do pórtico tipo 1 da Figura 10.1

\begin{tabular}{|c|c|c|c|c|c|c|c|c|c|}
\hline$\sigma_{\mathrm{c}}$ & $\%$ & $\mathrm{f}_{\mathrm{cm}}$ & $\beta$ & $\alpha_{\mathrm{fc}}$ & $\alpha_{\mathrm{fy}}$ & $\mathrm{e}_{\mathrm{fcm}}$ & $\mathrm{e}_{\mathrm{fym}}$ & $\mathrm{e}_{\sigma \mathrm{c}}$ & $\mathrm{e}_{\sigma \mathrm{v}}$ \\
\hline 0.55 & $0.80 \%$ & 3.00 & 4.44 & 0.9991 & 0.0426 & 1.2268 & 0.1597 & -0.9982 & -0.0018 \\
\hline 0.55 & $0.80 \%$ & 3.50 & 5.26 & 0.9945 & 0.1043 & 1.2044 & 0.3308 & -0.9891 & -0.0109 \\
\hline 0.55 & $0.80 \%$ & 4.00 & 6.01 & 0.9917 & 0.1288 & 1.2003 & 0.3573 & -0.9834 & -0.0166 \\
\hline 0.55 & $0.80 \%$ & 4.50 & 8.31 & 0.6894 & 0.7244 & 0.6787 & 1.4528 & -0.4753 & -0.5247 \\
\hline 0.55 & $1.60 \%$ & 3.00 & 4.97 & 0.9496 & 0.3134 & 1.0418 & 1.0507 & -0.9018 & -0.0982 \\
\hline 0.55 & $1.60 \%$ & 3.50 & 4.90 & -0.8799 & 0.4751 & -1.1420 & 1.6150 & -0.7742 & -0.2258 \\
\hline 0.55 & $1.60 \%$ & 4.00 & 5.39 & -0.1386 & 0.9904 & -0.1870 & 3.0625 & -0.0192 & -0.9808 \\
\hline 0.55 & $1.60 \%$ & 4.50 & 8.32 & 0.3186 & 0.9479 & 0.3133 & 1.8987 & -0.1015 & -0.8985 \\
\hline 0.55 & $2.40 \%$ & 3.00 & 6.02 & 0.8901 & 0.4558 & 0.8061 & 1.2614 & -0.7923 & -0.2077 \\
\hline 0.55 & $2.40 \%$ & 3.50 & 6.37 & 0.0463 & 0.9989 & 0.0462 & 2.6148 & -0.0021 & -0.9979 \\
\hline 0.55 & $2.40 \%$ & 4.00 & 7.45 & 0.3362 & 0.9418 & 0.3282 & 2.1070 & -0.1130 & -0.8870 \\
\hline 0.55 & $2.40 \%$ & 4.50 & 7.63 & 0.0938 & 0.9956 & 0.1006 & 2.1747 & -0.0088 & -0.9912 \\
\hline 0.36 & $0.80 \%$ & 3.00 & 6.61 & 0.9979 & 0.0649 & 1.2573 & 0.1636 & -0.9958 & -0.0042 \\
\hline 0.42 & $0.80 \%$ & 3.50 & 6.72 & 0.9975 & 0.0709 & 1.2367 & 0.1759 & -0.9950 & -0.0050 \\
\hline 0.48 & $0.80 \%$ & 4.00 & 6.82 & 0.9985 & 0.0552 & 1.2200 & 0.1349 & -0.9970 & -0.0030 \\
\hline 0.54 & $0.80 \%$ & 4.50 & 8.63 & 0.5346 & 0.8451 & 0.5161 & 1.6320 & -0.2858 & -0.7142 \\
\hline 0.36 & $1.60 \%$ & 3.00 & 8.26 & 0.4596 & 0.8881 & 0.4638 & 1.7922 & -0.2113 & -0.7887 \\
\hline 0.42 & $1.60 \%$ & 3.50 & 8.44 & 0.6075 & 0.7943 & 0.6001 & 1.5693 & -0.3691 & -0.6309 \\
\hline 0.48 & $1.60 \%$ & 4.00 & 8.40 & 0.5149 & 0.8573 & 0.5109 & 1.7012 & -0.2651 & -0.7349 \\
\hline 0.54 & $1.60 \%$ & 4.50 & 8.36 & 0.3191 & 0.9477 & 0.3183 & 1.8905 & -0.1018 & -0.8982 \\
\hline 0.36 & $2.40 \%$ & 3.00 & 6.38 & 0.5137 & 0.8580 & 0.6715 & 2.2431 & -0.2639 & -0.7361 \\
\hline 0.42 & $2.40 \%$ & 3.50 & 9.45 & 0.4364 & 0.8997 & 0.3847 & 1.5863 & -0.1905 & -0.8095 \\
\hline 0.48 & $2.40 \%$ & 4.00 & 3.28 & 0.9611 & 0.2763 & 2.4392 & 1.4024 & -0.9237 & -0.0763 \\
\hline 0.54 & $2.40 \%$ & 4.50 & 7.31 & -0.0617 & 0.9981 & -0.0704 & 2.2768 & -0.0038 & -0.9962 \\
\hline
\end{tabular}

Tabela 10.7 Índices de confiabilidade e sensibilidade do pórtico tipo 2 da Figura 10.1

\begin{tabular}{|c|c|c|c|c|c|c|c|c|c|}
\hline$\sigma_{\mathrm{c}}$ & $\%$ & $\mathrm{f}_{\mathrm{cm}}$ & $\beta$ & $\alpha_{\mathrm{fc}}$ & $\alpha_{\mathrm{fy}}$ & $\mathrm{e}_{\mathrm{fcm}}$ & $\mathrm{e}_{\mathrm{fym}}$ & $\mathrm{e}_{\sigma \mathrm{cc}}$ & $\mathrm{e}_{\sigma \mathrm{v}}$ \\
\hline 0.55 & $0.80 \%$ & 3.00 & 4.12 & 0.9928 & 0.1198 & 1.3130 & 0.4841 & -0.9856 & -0.0144 \\
\hline 0.55 & $0.80 \%$ & 3.50 & 4.71 & 0.9883 & 0.1528 & 1.3351 & 0.5407 & -0.9766 & -0.0234 \\
\hline 0.55 & $0.80 \%$ & 4.00 & 5.45 & 0.9873 & 0.1588 & 1.3180 & 0.4857 & -0.9748 & -0.0252 \\
\hline 0.55 & $0.80 \%$ & 4.50 & 7.99 & 0.8055 & 0.5926 & 0.8251 & 1.2364 & -0.6489 & -0.3511 \\
\hline 0.55 & $1.60 \%$ & 3.00 & 4.54 & 0.9553 & 0.2958 & 1.1475 & 1.0856 & -0.9125 & -0.0875 \\
\hline 0.55 & $1.60 \%$ & 3.50 & 5.93 & -0.4478 & 0.8942 & -0.4808 & 2.5148 & -0.2005 & -0.7995 \\
\hline 0.55 & $1.60 \%$ & 4.00 & 7.07 & 0.6501 & 0.7599 & 0.6684 & 1.7905 & -0.4226 & -0.5774 \\
\hline 0.55 & $1.60 \%$ & 4.50 & 8.38 & 0.3942 & 0.9190 & 0.3848 & 1.8279 & -0.1554 & -0.8446 \\
\hline 0.55 & $2.40 \%$ & 3.00 & 9.08 & 0.0111 & 0.9999 & 0.0066 & 1.8361 & -0.0001 & -0.9999 \\
\hline 0.55 & $2.40 \%$ & 3.50 & 6.20 & 0.9034 & 0.4288 & 0.9271 & 1.1525 & -0.8161 & -0.1839 \\
\hline 0.55 & $2.40 \%$ & 4.00 & 5.18 & -0.2446 & 0.9696 & -0.3435 & 3.1210 & -0.0598 & -0.9402 \\
\hline 0.55 & $2.40 \%$ & 4.50 & 8.09 & 0.2400 & 0.9708 & 0.2429 & 2.0013 & -0.0576 & -0.9424 \\
\hline 0.36 & $0.80 \%$ & 3.00 & 6.03 & 0.9920 & 0.1264 & 1.3701 & 0.3493 & -0.9840 & -0.0160 \\
\hline 0.42 & $0.80 \%$ & 3.50 & 6.07 & 0.9967 & 0.0814 & 1.3686 & 0.2235 & -0.9934 & -0.0066 \\
\hline 0.48 & $0.80 \%$ & 4.00 & 6.19 & 0.9997 & 0.0238 & 1.3456 & 0.0639 & -0.9994 & -0.0006 \\
\hline 0.54 & $0.80 \%$ & 4.50 & 8.47 & 0.4496 & 0.8932 & 0.4424 & 1.7582 & -0.2021 & -0.7979 \\
\hline 0.36 & $1.60 \%$ & 3.00 & 6.75 & -0.6600 & 0.7512 & -0.8148 & 1.8548 & -0.4357 & -0.5643 \\
\hline 0.42 & $1.60 \%$ & 3.50 & 6.83 & 0.9719 & 0.2352 & 1.1855 & 0.5738 & -0.9447 & -0.0553 \\
\hline 0.48 & $1.60 \%$ & 4.00 & 6.14 & -0.8057 & 0.5923 & -1.0933 & 1.6074 & -0.6492 & -0.3508 \\
\hline 0.54 & $1.60 \%$ & 4.50 & 7.44 & 0.9057 & 0.4238 & 1.0152 & 0.9501 & -0.8204 & -0.1796 \\
\hline 0.36 & $2.40 \%$ & 3.00 & 7.71 & 0.9319 & 0.3627 & 1.0077 & 0.7845 & -0.8684 & -0.1316 \\
\hline 0.42 & $2.40 \%$ & 3.50 & 7.66 & 0.9114 & 0.4115 & 0.9919 & 0.8956 & -0.8307 & -0.1693 \\
\hline 0.48 & $2.40 \%$ & 4.00 & 7.78 & 0.1125 & 0.9936 & 0.1206 & 2.1298 & -0.0127 & -0.9873 \\
\hline 0.54 & $2.40 \%$ & 4.50 & 8.13 & 0.4473 & 0.8944 & 0.4586 & 1.8341 & -0.2001 & -0.7999 \\
\hline
\end{tabular}


Tabela 10.8 Índices de confiabilidade e sensibilidade do pórtico tipo 3 da Figura 10.1

\begin{tabular}{|c|c|c|c|c|c|c|c|c|c|}
\hline$\sigma_{\mathrm{c}}$ & $\%$ & $\mathrm{f}_{\mathrm{cm}}$ & $\beta$ & $\alpha_{\mathrm{fc}}$ & $\alpha_{\mathrm{fy}}$ & $\mathrm{e}_{\mathrm{fcm}}$ & $\mathrm{e}_{\mathrm{fym}}$ & $\mathrm{e}_{\sigma c}$ & $\mathrm{e}_{\sigma \mathrm{v}}$ \\
\hline 0.55 & $0.80 \%$ & 3.00 & 3.97 & 1.0000 & 0.0017 & 1.3734 & 0.0070 & -1.0000 & -.00000 \\
\hline 0.55 & $0.80 \%$ & 3.50 & 4.62 & 0.9719 & 0.2356 & 1.3395 & 0.8504 & -0.9445 & -0.0555 \\
\hline 0.55 & $0.80 \%$ & 4.00 & 5.27 & 0.9886 & 0.1506 & 1.3642 & 0.4761 & -0.9773 & -0.0227 \\
\hline 0.55 & $0.80 \%$ & 4.50 & 6.17 & 0.3144 & 0.9493 & 0.4169 & 2.5638 & -0.0989 & -0.9011 \\
\hline 0.55 & $1.60 \%$ & 3.00 & 4.53 & 0.9470 & 0.3212 & 1.1401 & 1.1818 & -0.8968 & -0.1032 \\
\hline 0.55 & $1.60 \%$ & 3.50 & 5.32 & 0.9261 & 0.3773 & 1.1078 & 1.1819 & -0.8577 & -0.1423 \\
\hline 0.55 & $1.60 \%$ & 4.00 & 6.27 & 0.8978 & 0.4404 & 1.0417 & 1.1712 & -0.8060 & -0.1940 \\
\hline 0.55 & $1.60 \%$ & 4.50 & 8.08 & 0.2854 & 0.9584 & 0.2889 & 1.9760 & -0.0815 & -0.9185 \\
\hline 0.55 & $2.40 \%$ & 3.00 & 5.13 & 0.9265 & 0.3764 & 0.9846 & 1.2223 & -0.8583 & -0.1417 \\
\hline 0.55 & $2.40 \%$ & 3.50 & 5.93 & 0.9314 & 0.3639 & 0.9998 & 1.0230 & -0.8676 & -0.1324 \\
\hline 0.55 & $2.40 \%$ & 4.00 & 6.52 & 0.7370 & 0.6759 & 0.8225 & 1.7286 & -0.5432 & -0.4568 \\
\hline 0.55 & $2.40 \%$ & 4.50 & 7.85 & 0.3632 & 0.9317 & 0.3788 & 1.9790 & -0.1319 & -0.8681 \\
\hline
\end{tabular}

O Gráfico 10.4 e o Gráfico 10.5 resultam da Tabela 10.6, Tabela 10.7 e Tabela 10.8, que apresentam índices de confiabilidade para os pórticos da Figura 10.1. Os sinais presentes nos eixos desses gráficos não devem ser levados em consideração; eles existem apenas para possibilitar a plotagem dos resultados num único gráfico. Portanto, considere os valores como positivos.

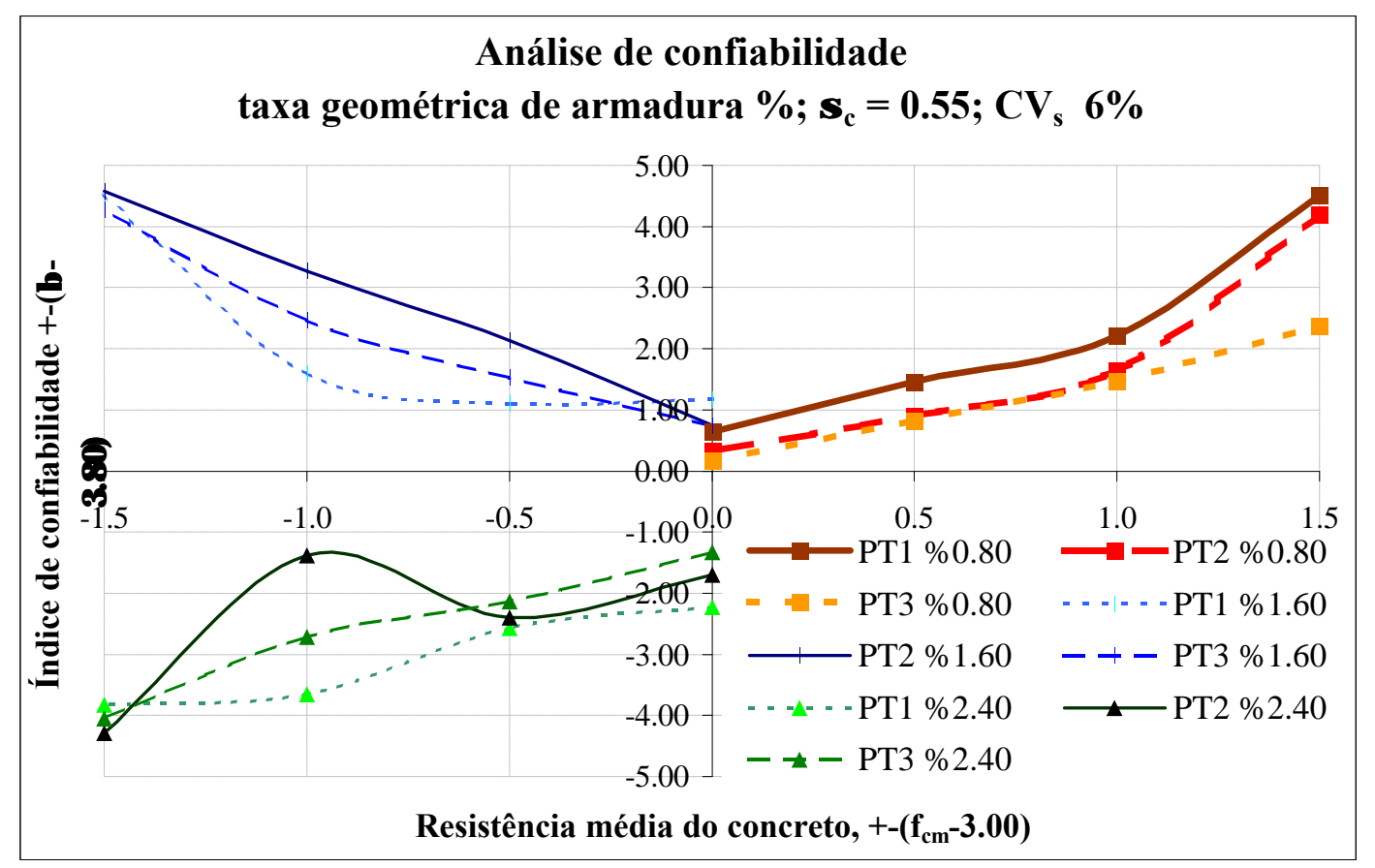

Gráfico 10.4 Índices de confiabilidade dos pórticos

Para elaboração do Gráfico 10.4 foi utilizado desvio padrão para o concreto constante, isso resulta, assim como já concluído para as colunas isoladas, um aumento da confiabilidade com a resistência média à compressão do concreto. 
Ao considerar-se o coeficiente de variação do concreto constante, Gráfico 10.5, naturalmente deixa de haver aumento da confiabilidade com a resistência média à compressão do concreto. Portanto são as mesmas conclusões verificadas para colunas isoladas.

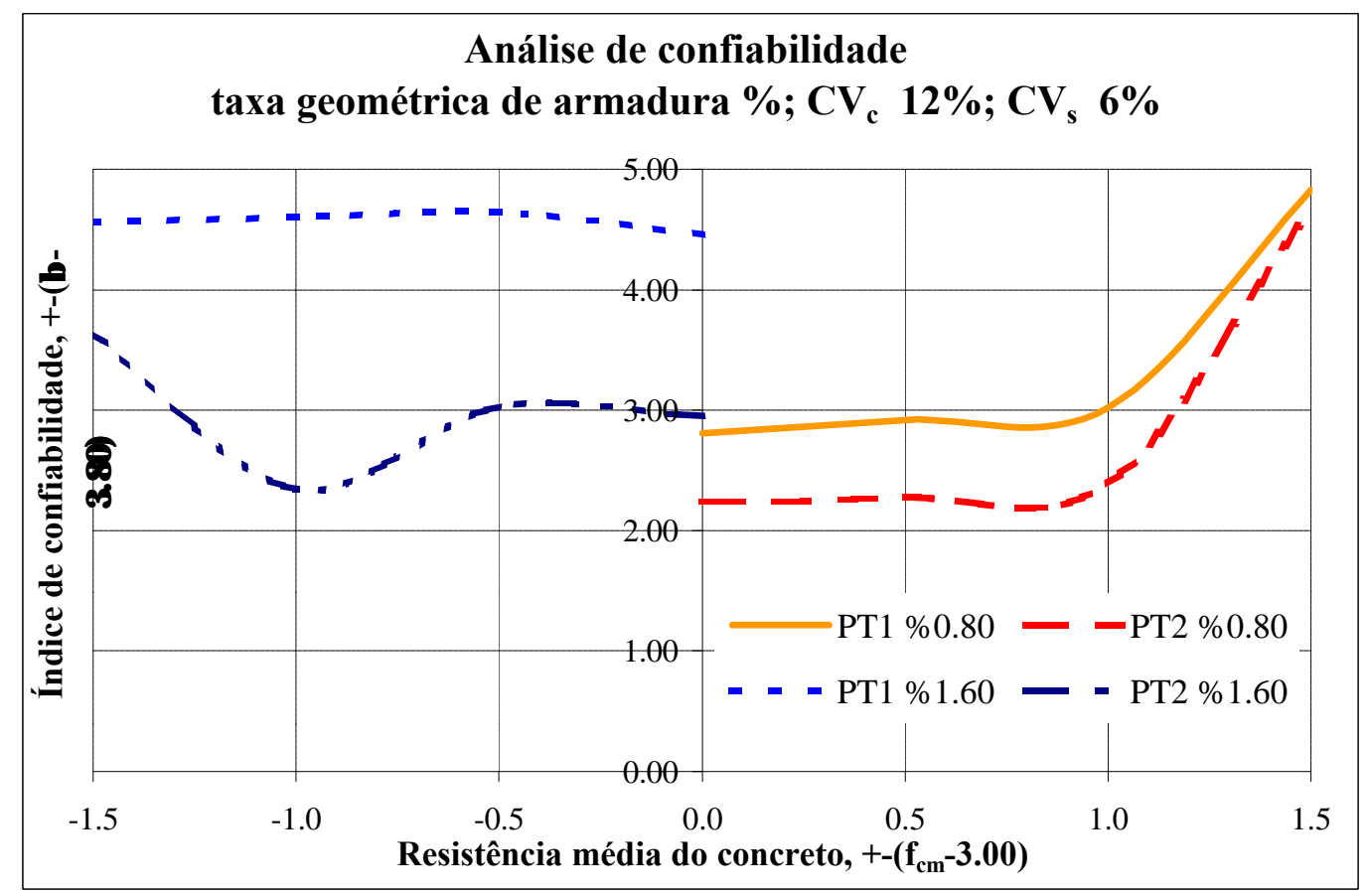

Gráfico 10.5 Índices de confiabilidade dos pórticos

De acordo com o Gráfico 10.4 e o Gráfico 10.5 em uma primeira análise podese dizer que o índice de confiabilidade, para os coeficientes parciais utilizados, varia pouco com o grau de hiperestaticidade dos pórticos. A princípio pode-se concluir que como a confiabilidade é estimada relativa a uma situação última de ruína (FS) e uma outra solicitação também última, porém com as resistências minoradas e as ações majoradas por coeficientes (S), ambos se deslocam com a variação do grau de hiperestaticidade. Consequentemente, a variação do grau de hiperestaticidade nessa ordem de grandeza não altera significativamente no índice de confiabilidade do problema.

Os índices de confiabilidade obtidos com colunas equivalentes são distantes dos reais, não sendo portanto adequado utilizar modelos de colunas equivalentes para os pórticos estudados.

Apresenta-se no Gráfico 10.6, Gráfico 10.7 e Gráfico 10.8 uma breve análise de sensibilidade das seguintes variáveis: resistência à compressão do concreto $\left(\mathrm{f}_{\mathrm{cm}}\right)$; 
resistência do aço $\left(\mathrm{f}_{\mathrm{ym}}\right)$; desvio padrão do concreto (sc); desvio padrão do aço (sy). Como medida de sensibilidade utiliza-se a elasticidade dos parâmetros.

No Gráfico 10.6, caso em que a taxa geométrica de armadura dos elementos é baixa, verifica-se que a sensibilidade de cada parâmetro não varia para os três tipos de pórticos utilizados. O parâmetro mais sensível é a resistência média à compressão do concreto, e o menos sensível o desvio padrão do aço. A sensibilidade do concreto tende a diminuir para resistências elevadas, isso ocorre devido ao seu coeficiente de variação ser variável; nesse estudo em particular o desvio padrão do concreto é constante. A sensibilidade do aço tende a aumentar quando a resistência à compressão do concreto é elevada. Diferente do concreto, o coeficiente de variação do aço foi considerado constante.

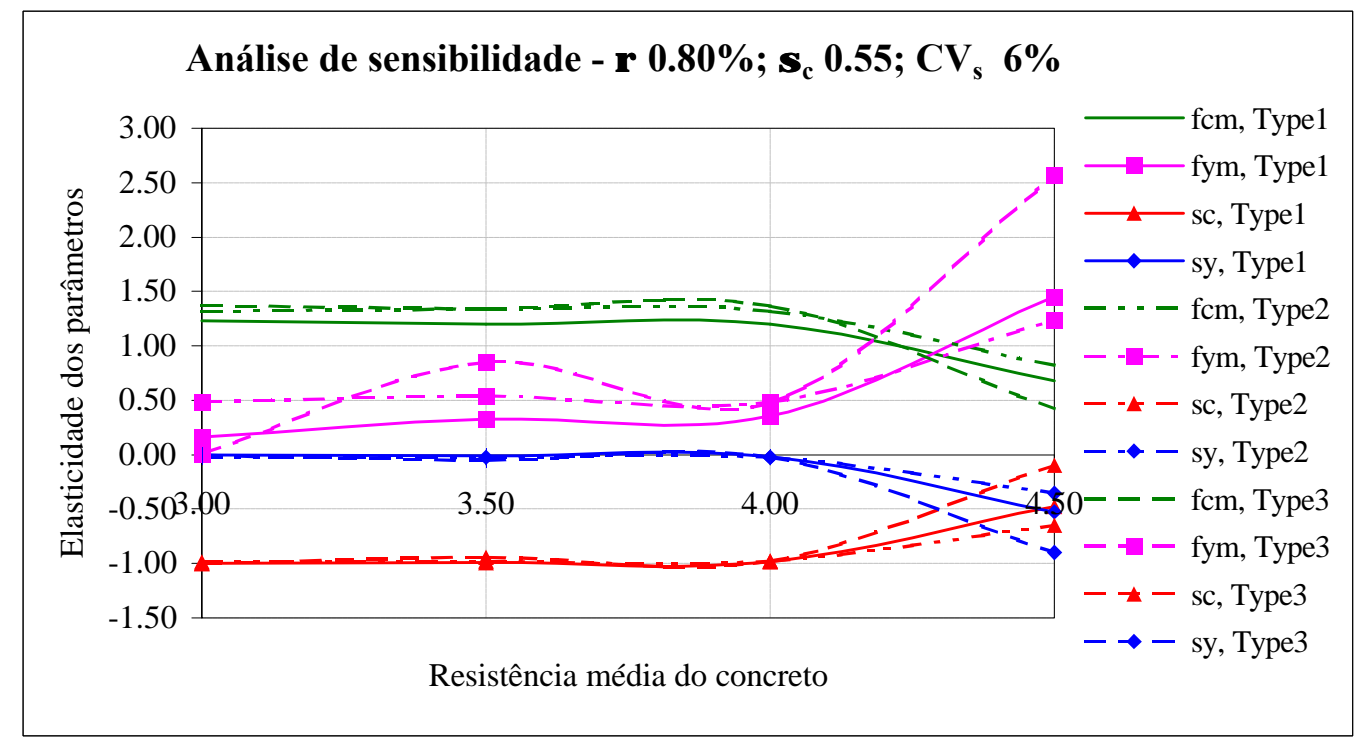

Gráfico 10.6 Parâmetros de elasticidade para os pórticos da Figura 10.1

Ao aumentar-se a taxa geométrica de armadura dos elementos estruturais dos pórticos, Gráfico 10.7, é facilmente compreensível o aumento da sensibilidade do aço. 


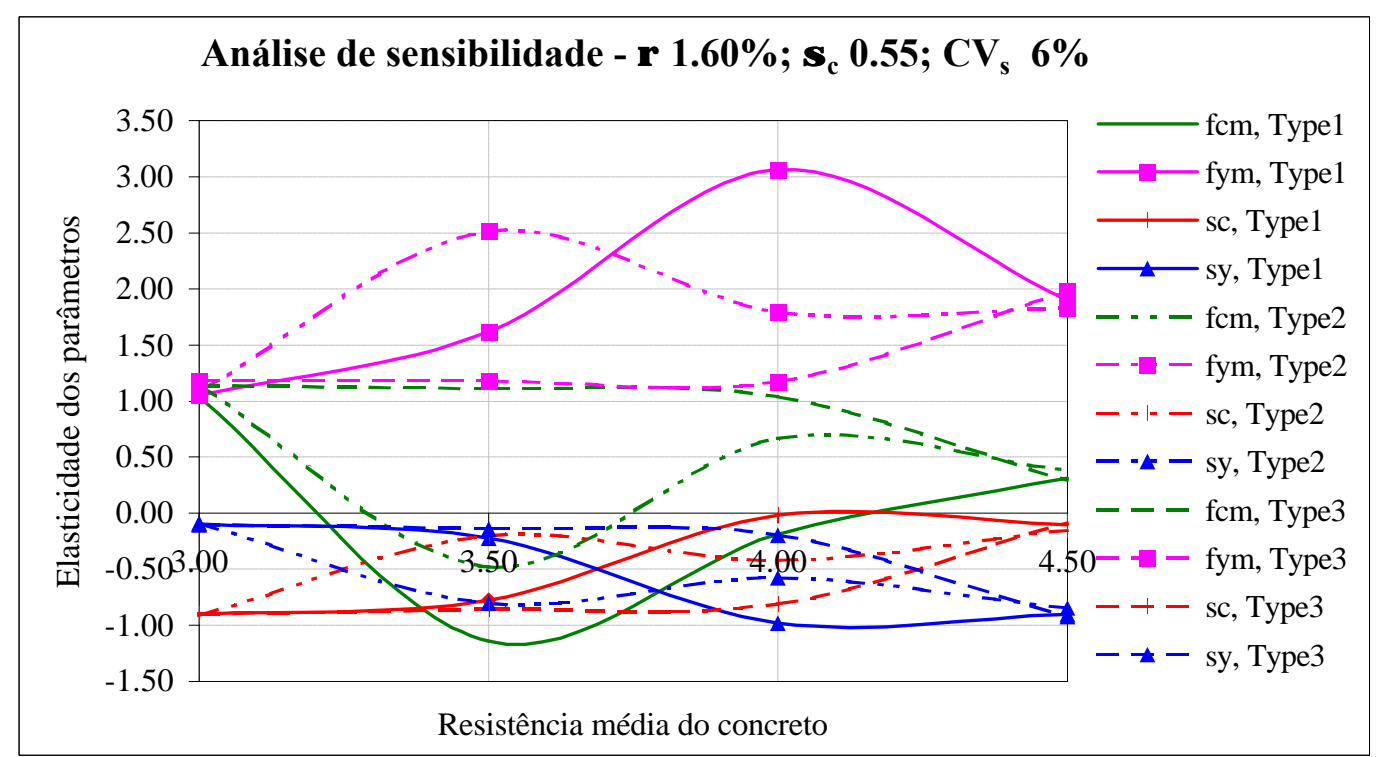

Gráfico 10.7 Parâmetros de elasticidade para os pórticos da Figura 10.1

Para a situação na qual a taxa geométrica de armadura é moderada, Gráfico 10.7, o grau de hiperestaticidade do pórtico influencia fortemente na sensibilidade das variáveis. Para essa taxa geométrica de armadura ou superior, pode-se observar que a variável mais sensível é a resistência do aço.

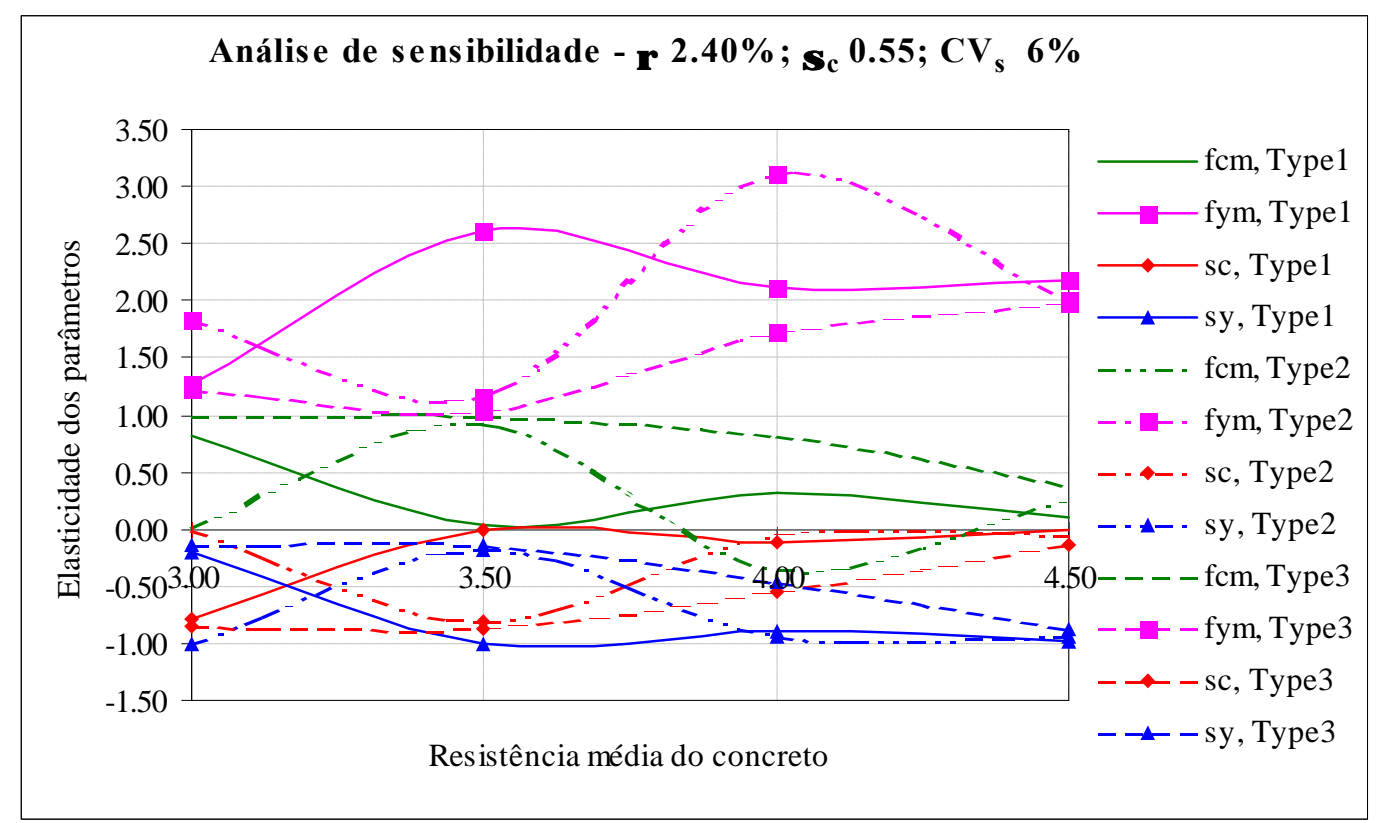

Gráfico 10.8 Parâmetros de elasticidade para os pórticos da Figura 10.1

No Gráfico 10.8, situação na qual utiliza-se maior taxa geométrica de armadura, há uma grande variação na sensibilidade das variáveis com o grau de hiperestaticidade dos pórticos e com o aumento da resistência média à compressão do 
concreto.

Como já comentado na análise das colunas e na própria análise de confiabilidade dos pórticos, conclui-se que não é possível generalizar a priori a sensibilidade das variáveis de projeto em estruturas de concreto com comportamento não-linear. Necessita-se estudar caso a caso, tanto para estimara confiabilidade quanto para conhecer a sensibilidade das variáveis. 


\section{Capítulo 11 Desempenho do RSM}

Neste capítulo é apresentado um procedimento análises de confiabilidade e sensibilidade, mostrando ao mesmo tempo o desempenho do RSM.

É oportuno resaltar que o modelo mecânico-confiabilístico desenvolvido foi exaustivamente testado e comparado com o modelo baseado em simulação de Monte Carlo pura e com amostra por importância. O erro relativo das repostas obtidas entre os modelos pode ser considerado desprezível, não superiores a $4 \%$.

Nos exemplos seguintes adotou-se como modelo mecânico para representar o material o proposto no CEB MC90 acrescido da rigidez entre fissuras. A nãolinearidade geométrica foi considerada através de um modelo corrotacional. Toda modelagem mecânica foi descrita com detalhes no Capítulo 3.

\subsection{Pórtico 1}

Neste exemplo analisa-se uma estrutura hipotética de um pórtico de um estádio de esportes; objetiva-se verificar a desempenho do STST e seu comportamento para diferentes planos de experiência.

A geometria do pórtico é apresentada na Figura 11.1 e suas características apresentam-se na Tabela 11.1 e na Tabela 11.2. 


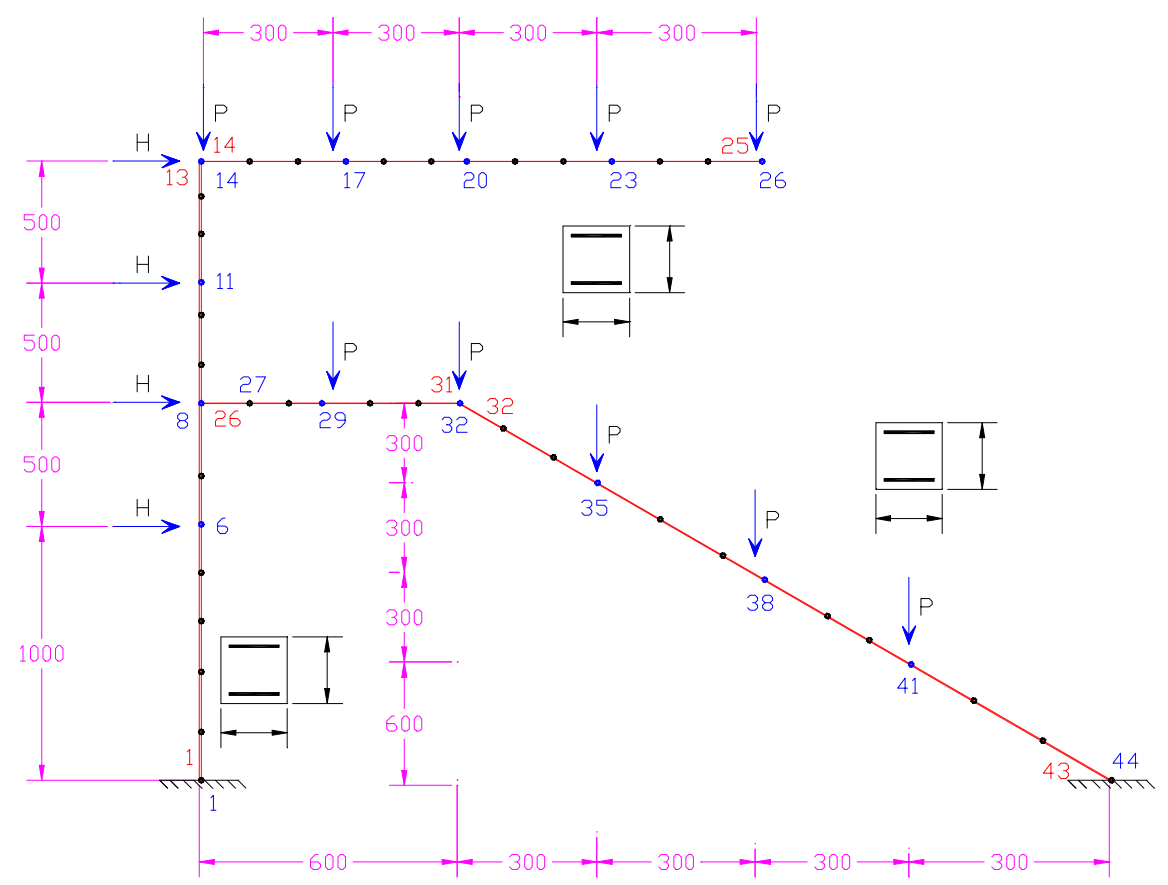

Figura 11.1 Pórtico 1

Tabela 11.1 Características mecânicas do pórtico $1(\mathrm{kN}$ e $\mathrm{cm})$

\begin{tabular}{|c|c|c|c|c|c|c|c|c|c|c|c|}
\hline & $\mathrm{b}_{\mathrm{w}}$ & $\mathrm{h}$ & $\mathrm{Y}_{\text {inf }}$ & $\mathrm{Y}_{\text {sup }}$ & $\mathrm{A}_{\mathrm{s}}$ & $\mathrm{A}_{\mathrm{s}}{ }^{\prime}$ & $\gamma_{\mathrm{c}}$ & $\gamma_{\mathrm{s}}$ & $\gamma_{\mathrm{f}}$ & $\mathrm{f}_{\mathrm{cm}}$ & $\mathrm{f}_{\mathrm{ym}}$ \\
\hline Coluna & 100 & 100 & 42 & 42 & 40 & 40 & 1,89 & 1,15 & 1,40 & 3,50 & 50,00 \\
\hline Viga mezanino & 50 & 150 & 65 & 65 & 80 & 40 & 1,89 & 1,15 & 1,40 & 3,50 & 50,00 \\
\hline Viga superior & 50 & 130 & 58 & 55 & 24 & 80 & 1,89 & 1,15 & 1,40 & 3,50 & 50,00 \\
\hline
\end{tabular}

Tabela 11.2 Características estatísticas do pórtico $1(\mathrm{kN}$ e $\mathrm{cm})$

\begin{tabular}{|c|c|c|c|}
\hline VA & $\mu$ & $\mathrm{CV}$ & Lei \\
\hline $\mathrm{f}_{\mathrm{c}}$ & Valor nominal & $12,00 \%$ & $\mathrm{~N}$ \\
\hline $\mathrm{f}_{\mathrm{y}}$ & Valor nominal & $6,00 \%$ & $\mathrm{~N}$ \\
\hline $\mathrm{Y}$ & Valor nominal & $4,00 \%$ & $\mathrm{~N}$ \\
\hline Carga permanente, G & Valor nominal & $10,00 \%$ & $\mathrm{~N}$ \\
\hline Carga acidental, $\mathrm{Q}$ & Valor nominal & $20,00 \%$ & $\mathrm{~N}$ \\
\hline
\end{tabular}

As solicitações externas $(\mathrm{P}$ e H) aplicadas à estrutura são obtidas pelos valores que conduzem à singularidade da matriz de rigidez global, definida por valores de cálculo das resistências dos materiais, reduzidas pelo coeficiente parcial $\gamma_{f}$. Os valores de cálculo do concreto e do aço são obtidos pela razão dos respectivos valores médios por seus coeficientes parciais $\gamma_{c}$ e $\gamma_{s}$. Resumindo, as cargas externas aplicadas a estrutura são as cargas últimas que a estrutura suporta reduzidas por coeficientes parciais do concreto, aço e ação externa.

A relação entre $\mathrm{P}$ e $\mathrm{H}$ é: $\mathrm{P}=5 \times \mathrm{H}$.

A relação entre carga permanente e acidental é: 


$$
P \Rightarrow\left\{\begin{array}{l}
G=60 \% P \\
Q=40 \% P
\end{array} ; \quad H \Rightarrow\left\{\begin{array}{l}
G=40 \% H \\
Q=60 \% H
\end{array}\right.\right.
$$

O primeiro objetivo é analisar qual é o melhor plano de experiência a ser utilizado para calcular o índice de confiabilidade $\beta$ do pórtico da Figura 11.1.

Nessa análise, dois parâmetros são considerados como os mais importantes: o número de respostas mecânicas $(\mathrm{MR})$ e o número de superfícies de falha aproximadas (FS). O número de MR é importante afim de verificar o tempo de convergência do método, pois nesse tipo de análise o principal responsável pelo custo computacional é o processamento mecânico. Através do número de FS pode-se verificar o desempenho do plano de experiência adotado assim como o desempenho do método de superfícies de resposta.

Analisaram-se cinco planos de experiência numéricos, considerando ponto de adaptação e não considerando adaptação. Com exceção dos planos estrela e hipercubo com e sem ponto de adaptação, os demais planos ofereceram boa convergência. A não convergência de alguns planos foi devido a singularidade do sistema de equações formado para determinar os coeficientes do polinômio aproximador. Como já comentado, para cada exemplo é necessário verificar quais planos de experiência melhor se adaptam a situação.

Apresentam-se na Tabela 11.3 e na Tabela 11.4 alguns resultados numéricos da análise para os diferentes planos de experiência que convergiram. Pode-se observar os excelentes resultados obtidos com o RSM. 
Tabela 11.3 Valores finais dàs variáveis de projeto e fatores de sensibilidade

\begin{tabular}{|c|c|c|c|c|c|c|c|c|c|c|c|c|c|c|}
\hline \multicolumn{5}{|c|}{ Espaço físico } & \multicolumn{5}{|c|}{ Espaço normal padrão, u } & \multicolumn{5}{|c|}{ Fator de sensibilidade, $\alpha$} \\
\hline $\mathrm{f}_{\mathrm{c}}$ & $f_{y}$ & $\mathrm{Y}$ & $\mathrm{G}$ & Q & $f_{c}$ & $f_{y}$ & $\mathrm{Y}$ & G & Q & $f_{c}$ & $\mathrm{f}_{\mathrm{y}}$ & $\mathrm{Y}$ & $\mathrm{G}$ & $\mathrm{Q}$ \\
\hline \multicolumn{15}{|c|}{ Plano de experiência: $\quad$ fatorial completo sem ponto de adaptação } \\
\hline 3.45 & 49.07 & 64.51 & 0.86 & 0.78 & -0.113 & -0.309 & -0.189 & 0.000 & 2.290 & 0.048 & 0.133 & 82 & 0.000 & -0.9 \\
\hline 34 & 46.79 & .05 & 0.86 & 00 & 0.378 & -1.071 & 135 & 0.000 & 4.325 & 0.082 & 0.232 & 46 & 000 & 0.937 \\
\hline 3.35 & 46.67 & 62.05 & 0.86 & .00 & -0.348 & -1.110 & -1.135 & 0.000 & 4.343 & 0.075 & 239 & & & 0.937 \\
\hline \multicolumn{15}{|c|}{ to com ponto } \\
\hline 3.45 & 49.07 & 64.51 & 0.86 & 0.78 & $\mid-0.113$ & -0.309 & -0.189 & 0.000 & 2.290 & 0.048 & & & 00 & -0.9 \\
\hline 3.44 & 48.79 & $\overline{9}$ & 0.86 & .77 & 0.145 & -0.404 & -0.236 & 0.000 & 2.213 & 0.064 & 8 & 4 & 00 & -0.976 \\
\hline 3.45 & 49.07 & 51 & 0.86 & 78 & -0.112 & -0.309 & -0.189 & 0.000 & 2.289 & 0.048 & 0.133 & 0. & 0.000 & -0.987 \\
\hline 3.45 & 49.07 & 64.51 & 0.86 & 0.78 & $\mid-0.114$ & -0.310 & -0.189 & 0.000 & 2.293 & \begin{tabular}{|c|}
0.049 \\
\end{tabular} & 0.133 & 0.081 & 0.000 & -0.986 \\
\hline \multicolumn{15}{|c|}{ mínimo sem ponto de adaptação } \\
\hline 3.46 & 49.07 & 64.52 & 0.86 & 0.78 & -0.105 & -0.309 & -0.183 & 0.000 & 2.280 & 0.046 & 0.134 & 0.079 & 0.000 & -0.987 \\
\hline 3.46 & 49.08 & 64.52 & 0.86 & 0.78 & -0.105 & -0.307 & -0.183 & 0.000 & 2.281 & 0.045 & 0.133 & 0.079 & 0.000 & -0.987 \\
\hline \multicolumn{15}{|c|}{ Plano de experiência: } \\
\hline 3.46 & 49.07 & 64.52 & 0.86 & 0.78 & -0.105 & -0.309 & -0.183 & 0.000 & 2.280 & 0.046 & 0.134 & 0.079 & 0.000 & -0.9 \\
\hline 3.49 & 49.12 & 64.52 & 0.86 & 0.78 & -0.034 & -0.294 & -0.184 & 0.000 & 2.288 & 0.015 & 0.127 & 0.080 & 0.000 & -0.989 \\
\hline \multicolumn{15}{|c|}{ Plano de experiência: } \\
\hline 3.46 & 49.06 & 64.53 & 0.86 & 0.78 & -0.105 & -0 & -0.182 & 0.000 & 2.284 & 0.045 & 0.135 & 0.078 & 0.000 & -0.98 \\
\hline 3.46 & 49.08 & 64.53 & 0.86 & 0.78 & -0.102 & -0.308 & -0.179 & 0.000 & 2.277 & 0.044 & 0.133 & 0.078 & 0.000 & -0.98 \\
\hline \multicolumn{15}{|c|}{ Plano de experiência: } \\
\hline 3.46 & 49.06 & 64.53 & 0.86 & 0.78 & .105 & 0.3 & 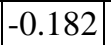 & 0.000 & 2.284 & 0.045 & 0.13 & 0.078 & 0.000 & 0.9 \\
\hline .46 & 49.06 & 64.53 & 0.86 & 0.78 & -0.105 & -0.314 & -0.182 & 0.000 & 2.284 & 0.046 & 0.136 & 0.079 & 0.000 & -0.98 \\
\hline
\end{tabular}

Tabela 11.4 Análise de convergência do RSM

\begin{tabular}{|l|c|c|c|c|}
\hline Plano de experiência & $\mathrm{n}_{-}^{0}$ de FS & $\mathrm{n}_{-}^{\circ}$ de MR & $\beta$ & erro $\beta(\%)$ \\
\hline fatorial completo sem ponto de adaptação & 1 & 27 & 2.3220 & \\
\cline { 2 - 5 } & 2 & 54 & 4.6140 & 49.6749 \\
\cline { 2 - 5 } & 3 & 81 & 4.6370 & 0.4960 \\
\hline fatorial completo com ponto de adaptação & 1 & 27 & 2.3220 & \\
\cline { 2 - 5 } & 2 & 28 & 2.2670 & 2.4261 \\
\cline { 2 - 5 } & 3 & 29 & 2.3200 & 2.2845 \\
\cline { 2 - 5 } & 4 & 30 & 2.3240 & 0.1721 \\
\hline \multirow{2}{*}{ mínimo sem ponto de adaptação } & 1 & 10 & 2.3100 & \\
\cline { 2 - 5 } & 2 & 20 & 2.3110 & 0.0433 \\
\cline { 2 - 5 } & 1 & 10 & 2.3100 & \\
\hline \multirow{2}{*}{ composto sem ponto de adaptação } & 1 & 11 & 2.3140 & 0.1729 \\
\cline { 2 - 5 } & 2 & 36 & 2.3140 & \\
\hline composto com ponto de adaptação & 1 & 18 & 2.3140 & 0.3034 \\
\cline { 2 - 5 } & 2 & 19 & 2.3150 & 0.0432 \\
\hline
\end{tabular}

No Gráfico 11.1 é apresentada uma seqüência de RS do pórtico de referência 1 quando o plano de experiência fatorial completo com ponto de adaptação é utilizado para estimar o índice de confiabilidade. Foram mostradas apenas três dimensões do problema, embora a dimensão real do problema seja 6. As dimensões um e dois representam as resistências do concreto e do aço respectivamente, e a dimensão 3 a 
resposta estrutural. Embora as demais variáveis aleatórias não tenham sido representadas nos gráficos, elas foram consideradas para traçar as hipersuperfícies.
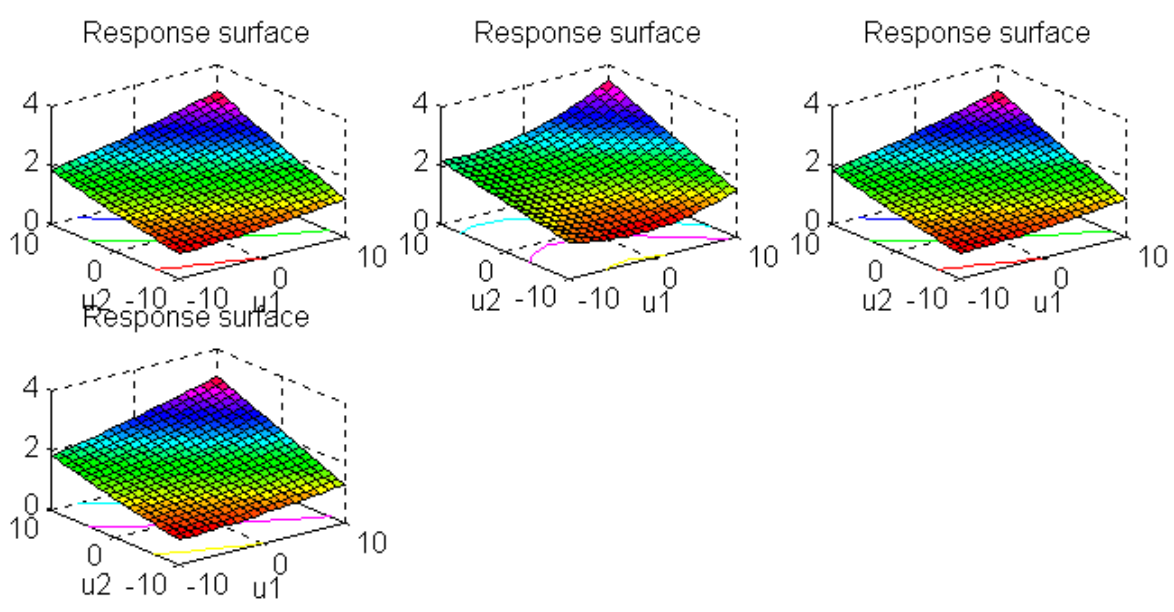

Gráfico 11.1 Desenvolvimento das superfícies de resposta

No segundo quadrante do Gráfico 11.2 apresentam-se as respostas reais no espaço físico para a última iteração no desenvolvimento do RSM; no primeiro quadrante, as mesmas respostas no espaço normalizado. No terceiro e quarto quadrantes, apresentam-se as FS em torno do ponto de projeto.

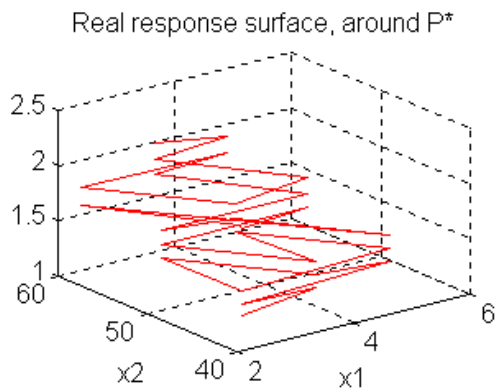

Approximate failure surface, around $\mathrm{P}^{*}$

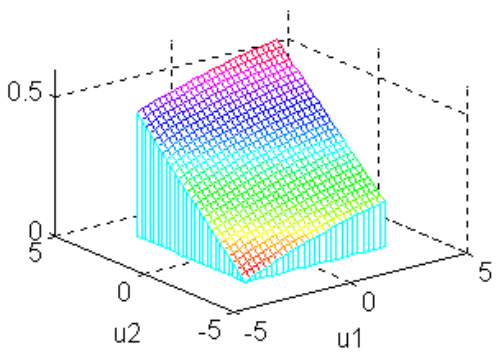

Real response surface, around $\mathrm{P}^{*}$

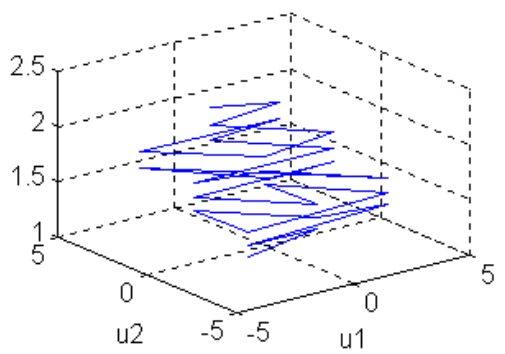

Approximate failure surface, around $\mathrm{P}^{*}$

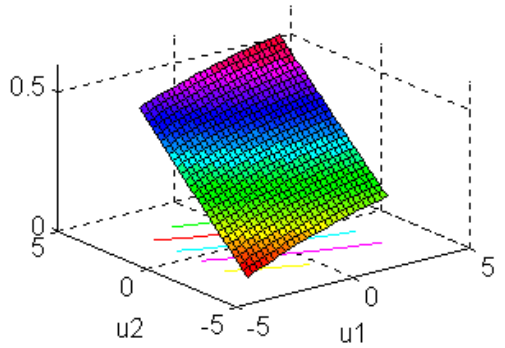

Gráfico 11.2 Superfícies de resposta e superfícies de falha da estrutura

A convergência do RSM é ilustrada no Gráfico 11.3, onde o primeiro desenho 
refere-se a convergência do índice de confiabilidade, o segundo dá os erros relativos de todas as respostas mecânicas das superfícies de ruína aproximadas durante as iterações do RSM.
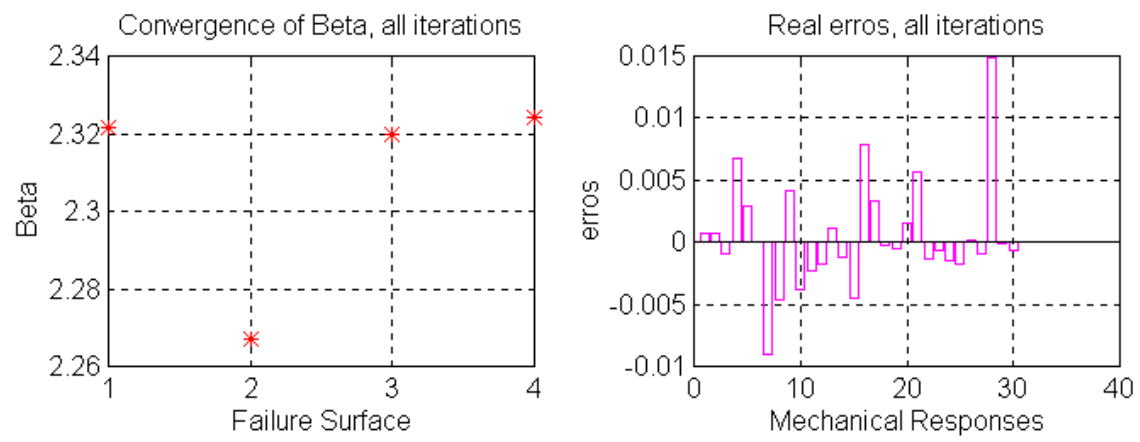

Gráfico 11.3 Convergência do RSM

Pode-se observar através do Gráfico 11.4 que o plano de experiência fatorial completo sem ponto de adaptação exige um número bem maior de respostas mecânicas que os demais, portanto demonstrando não ser este o plano mais adequado para encontrar a confiabilidade da estrutura estudada. Os outros planos apresentaram bons resultados, sendo todos adequados, destacando-se o plano mínimo com ponto de adaptação.

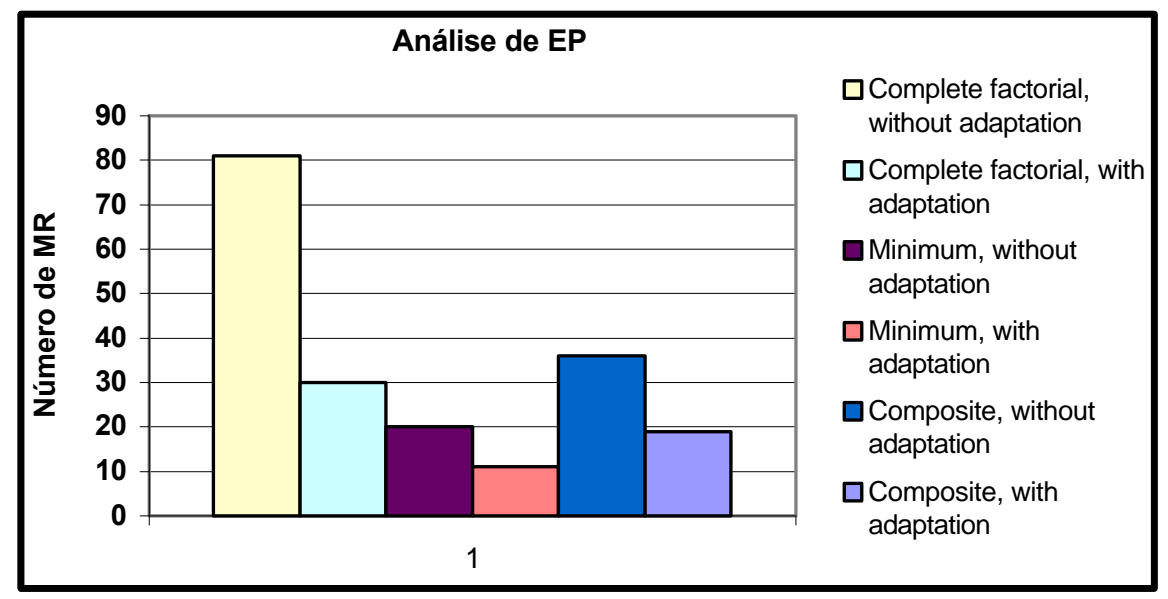

Gráfico 11.4 Número de MR para diferentes planos de experiência

A respeito do número de superfícies de falha, Gráfico 11.5, todos os planos parecem ser adequados, mostrando uma rápida convergência, uma vez que o número mínimo de FS é 2. 


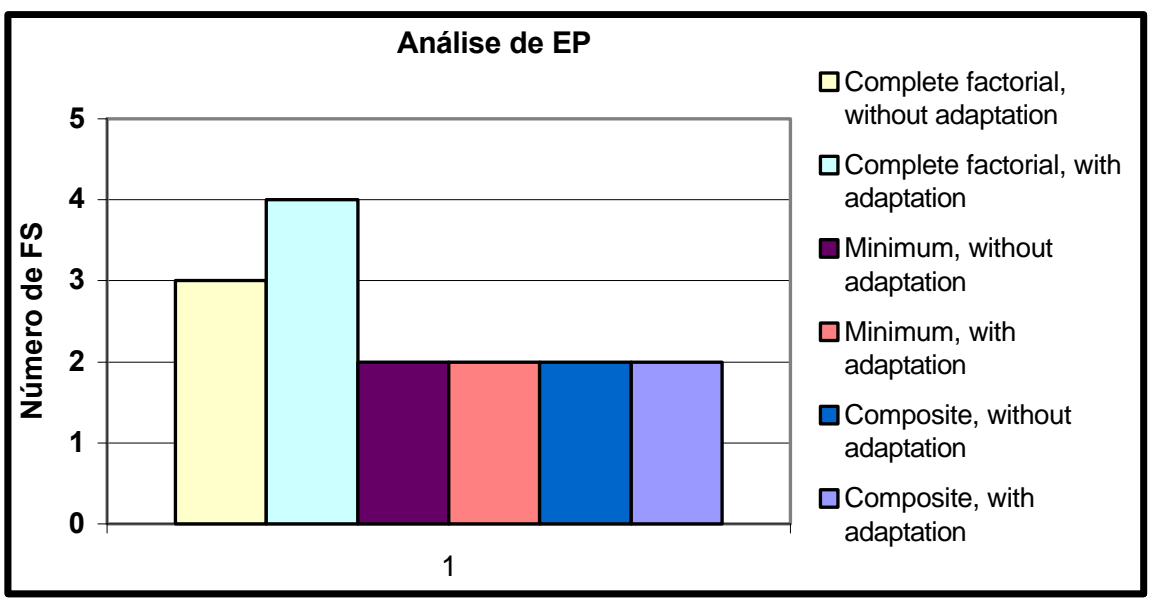

Gráfico 11.5 Número de FS para diferentes planos de experiência

Conclui-se mais uma vez que o RSM é adequado para problemas mecânicoprobabilísticos de estruturas de concreto armado considerando a não-linearidade do material e efeitos de segunda ordem. Com relação a melhor adequação do EP, necessita-se estudar caso a caso.

\subsection{Coluna}

Considere a coluna descrita na Figura 11.2 cujas características encontram-se na Tabela 11.5 e na Tabela 11.6. A coluna está sujeita uma força vertical $\mathrm{P}$ e ao momento $\mathrm{M}$ aplicado na extremidade superior como indica a Figura 11.2. As ações externas equivalem às ações últimas da coluna reduzidas pelos coeficientes parciais indicados na Tabela 11.5.

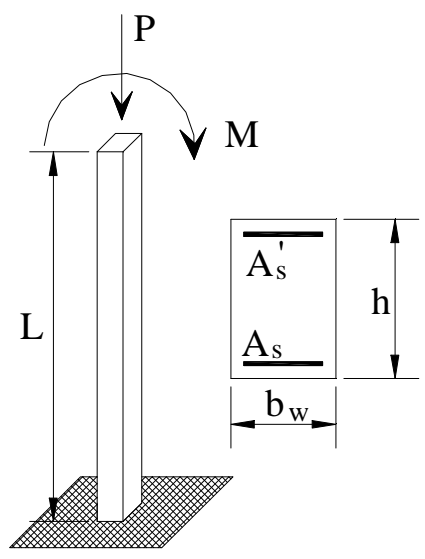

Figura 11.2 Coluna de referência 
Tabela 11.5 Características mecânicas da coluna $(\mathrm{kN}$ e $\mathrm{cm})$

\begin{tabular}{|c|c|c|c|c|c|c|c|c|c|c|c|}
\hline $\mathrm{b}_{\mathrm{w}}$ & $\mathrm{h}$ & $\mathrm{Y}_{\text {inf }}$ & $\mathrm{Y}_{\text {sup }}$ & $\mathrm{d}$ & $\mathrm{A}_{\mathrm{s}}$ & $\mathrm{A}_{\mathrm{s}}{ }^{\prime}$ & $\gamma_{\mathrm{c}}$ & $\gamma_{\mathrm{s}}$ & $\gamma_{\mathrm{f}}$ & $\lambda$ & exc \\
\hline 25.00 & 25.00 & 10.00 & 10.00 & 20.00 & 2.50 & 2.50 & 1.40 & 1.15 & 1.40 & 68.00 & 0.50 \\
\hline
\end{tabular}

Tabela 11.6 Características estatísticas da coluna $(\mathrm{kN}$ e $\mathrm{cm})$

\begin{tabular}{|c|c|c|c|}
\hline $\mathrm{VA}$ & $\mu$ & $\sigma$ & Lei \\
\hline $\mathrm{f}_{\mathrm{cm}}$ & 3.5048 & 0.4935 & $\mathrm{~N}$ \\
\hline $\mathrm{f}_{\mathrm{ym}}$ & 50.0000 & 2.6786 & $\mathrm{~N}$ \\
\hline
\end{tabular}

O custo computacional do exemplo pode ser verificado através do número de MR no Gráfico 11.6. O desempenho do RSM é verificado através do número de FS apresentado no Gráfico 11.7.

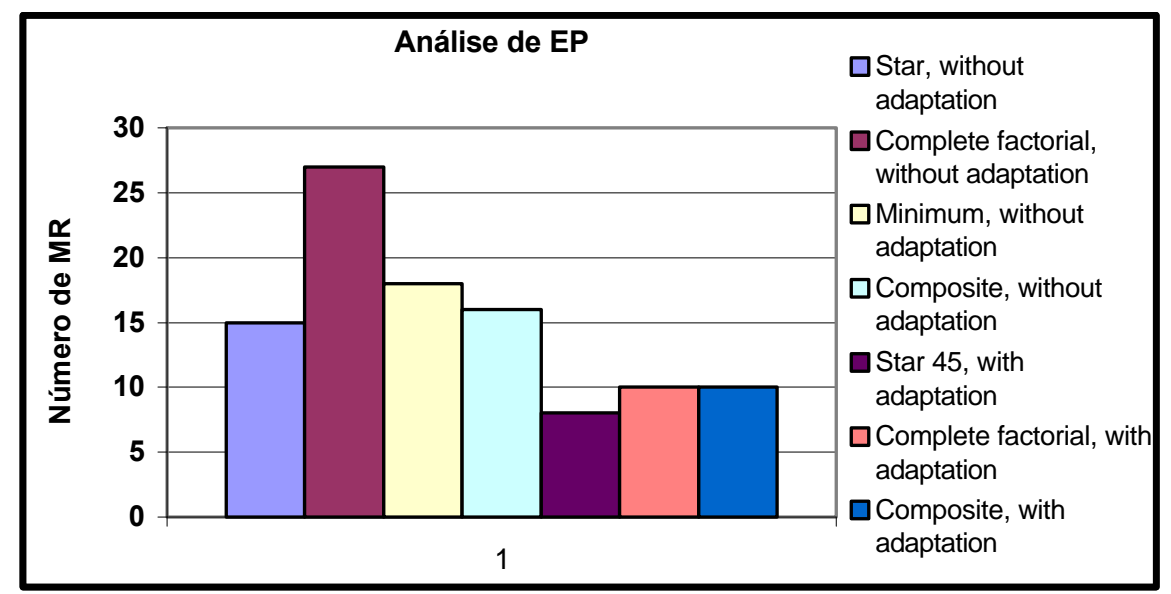

Gráfico 11.6 Número de respostas mecânicas para diferentes planos de experiência

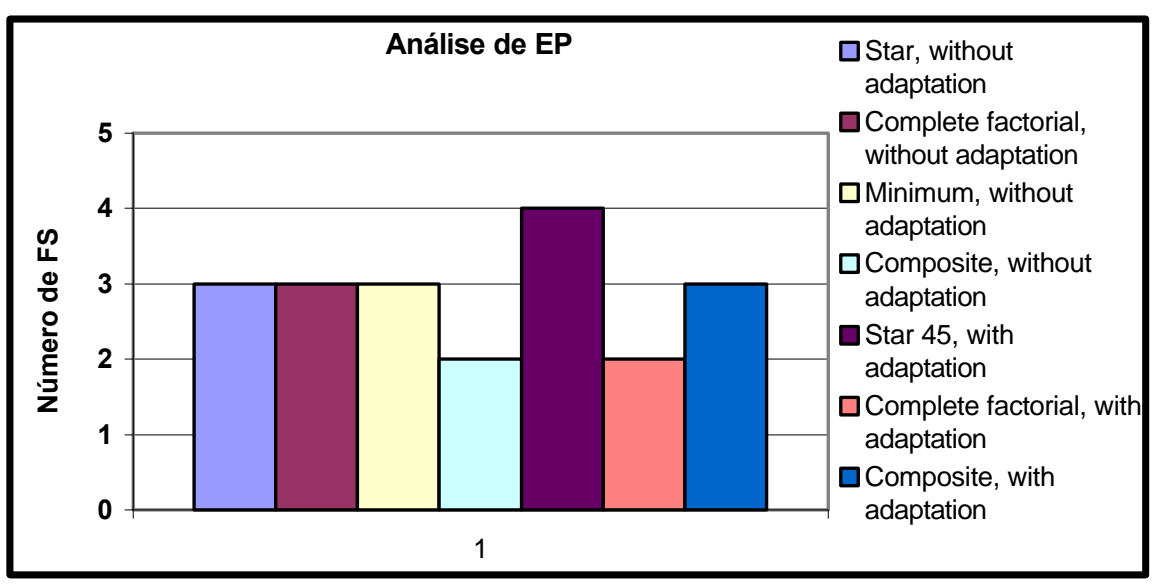

Gráfico 11.7 Número de superfícies de ruína para diferentes planos de experiência

Embora para esse exemplo o plano de experiência Estrela 45 sem ponto de adaptação não conduz o procedimento à convergência, este mesmo EP considerando ponto de adaptação é a melhor opção para encontrar a solução do problema proposto. 
Entretanto, o EP Fatorial Completo e o EP Composto, ambos com ponto de adaptação, conduziram o procedimento a uma rápida convergência, e ambos os EP também forneceram convergência ao não considerar pontos de adaptação.

No Gráfico 11.7 observa-se que, dentre os EP que conduzem a convergência, o número máximo de FS é 4, demonstrando ótimo desempenho, uma vez que o número mínimo de FS para o procedimento é 2.

Tabela 11.7 Valores numéricos da análise (--- não houve convergência)

\begin{tabular}{|c|c|c|c|c|c|c|c|c|c|c|}
\hline Planos de experiência & $\operatorname{exc} /(d / 2)$ & MR & FS & tempo & tempo & $\mathrm{u} 1$ & $\mathrm{u} 2$ & $\alpha 1$ & $\alpha 2$ & $\beta$ \\
\hline & & $\mathrm{n}^{\mathrm{o}}$ & $\mathrm{n}^{\mathrm{o}}$ & $(\mathrm{mn})$ & (s) & concreto & aço & & & \\
\hline Estrela $^{*}$ & 0,400 & 15 & 3 & 0 & 51 & $-4,025$ & 0,000 & 1,000 & 0,000 & 4,025 \\
\hline Estrela $45^{*}$ & 0,400 & --- & --- & --- & --- & --- & --- & --- & --- & --- \\
\hline Fatorial completo ${ }^{*}$ & 0,400 & 27 & 3 & 1 & 32 & $-4,013$ & 0,000 & 1,000 & 0,000 & 4,013 \\
\hline Mínimo ${ }^{*}$ & 0,400 & 18 & 3 & 1 & 4 & $-4,025$ & 0,000 & 1,000 & 0,000 & 4,025 \\
\hline Composto $^{*}$ & 0,400 & 16 & 2 & 0 & 57 & $-4,042$ & 0,000 & 1,000 & 0,000 & 4,042 \\
\hline Estrela & 0,400 & --- & $\begin{array}{ll}-- \\
-\end{array}$ & $\begin{array}{c}-- \\
\end{array}$ & --- & $\begin{array}{ll}-- \\
-\end{array}$ & --- & $\begin{array}{c}-- \\
\end{array}$ & --- & --- \\
\hline Estrela 45 & 0,400 & 8 & 4 & 0 & 28 & $-4,037$ & $-0,017$ & 1,000 & 0,004 & 4,037 \\
\hline Fatorial completo & 0,400 & 10 & 2 & 0 & 36 & $-4,048$ & $-0,021$ & 1,000 & 0,005 & 4,048 \\
\hline Mínimo & 0,400 & --- & --- & --- & --- & --- & --- & --- & --- & --- \\
\hline Composto & 0,400 & 10 & 3 & 0 & 34 & $-4,003$ & $-0,001$ & 1,000 & 0,000 & 4,003 \\
\hline Estrela $^{*}$ & 0,800 & 15 & 3 & 0 & 32 & $-4,971$ & $-0,425$ & 0,996 & 0,085 & 4,989 \\
\hline Estrela $45^{*}$ & 0,800 & --- & --- & -- & --- & --- & -- & -- & --- & -- \\
\hline Fatorial completo ${ }^{*}$ & 0,800 & 27 & 3 & 0 & 55 & $-4,963$ & $-0,364$ & 0,997 & 0,073 & 4,976 \\
\hline Mínimo ${ }^{*}$ & 0,800 & 18 & 3 & 0 & 38 & $-4,989$ & \begin{tabular}{|l|}
$-0,317$ \\
\end{tabular} & 0,998 & 0,063 & 4,999 \\
\hline Composto $^{*}$ & 0,800 & 24 & 3 & 0 & 50 & $-5,038$ & \begin{tabular}{|l|}
$-0,413$ \\
\end{tabular} & 0,997 & 0,082 & 5,055 \\
\hline Estrela & 0,800 & --- & $\begin{array}{ll}-- \\
\end{array}$ & --- & --- & --- & --- & --- & --- & --- \\
\hline Estrela 45 & 0,800 & 8 & 4 & 0 & 16 & $-4,941$ & $-0,387$ & 0,997 & 0,078 & 4,956 \\
\hline Fatorial completo & 0,800 & 11 & 3 & 0 & 22 & $-4,940$ & $-0,403$ & 0,997 & 0,081 & 4,956 \\
\hline Mínimo & 0,800 & 12 & 7 & 0 & 24 & $-4,689$ & \begin{tabular}{|l|}
$-1,374$ \\
\end{tabular} & 0,960 & 0,281 & 4,886 \\
\hline Composto & 0,800 & 10 & 3 & 0 & 20 & $-4,895$ & \begin{tabular}{|l|}
$-0,335$ \\
\end{tabular} & 0,998 & 0,068 & 4,907 \\
\hline Composto & 0,080 & 9 & 2 & 0 & 42 & $-3,793$ & $-0,103$ & 1,000 & 0,027 & 3,796 \\
\hline Composto & 0,240 & 9 & 2 & 0 & 40 & $-3,841$ & 0,016 & 1,000 & $\begin{array}{c}- \\
0,004 \\
\end{array}$ & 3,841 \\
\hline Composto & 0,400 & 10 & 3 & 0 & 34 & $-4,003$ & $-0,001$ & 1,000 & 0,000 & 4,003 \\
\hline Composto & 0,560 & 10 & 3 & 0 & 28 & $-4,466$ & 0,014 & 1,000 & $\begin{array}{c} \\
0,003 \\
\end{array}$ & 4,466 \\
\hline Composto & 0,720 & 10 & 3 & 0 & 23 & $-4,745$ & $-0,223$ & 0,999 & 0,047 & 4,751 \\
\hline Composto & 0,880 & 13 & 6 & 0 & 24 & $-5,149$ & $-0,267$ & 0,999 & 0,052 & 5,156 \\
\hline Composto & 1,040 & 14 & 7 & 0 & 23 & $-5,513$ & $-0,844$ & 0,988 & 0,151 & 5,577 \\
\hline Composto & 1,200 & 14 & 7 & 0 & 21 & $-5,857$ & \begin{tabular}{|l|}
$-0,716$ \\
\end{tabular} & 0,993 & 0,121 & 5,900 \\
\hline Composto & 1,360 & 9 & 2 & 0 & 12 & $-5,874$ & $-2,320$ & 0,930 & 0,367 & 6,315 \\
\hline Composto & 1,520 & --- & --- & --- & --- & --- & --- & --- & --- & --- \\
\hline
\end{tabular}

Apresenta-se na Tabela 11.7 uma análise para excentricidade de primeira

* Plano de experiência sem ponto de adaptação 
ordem variada, que pode ser vista no Gráfico 11.8.

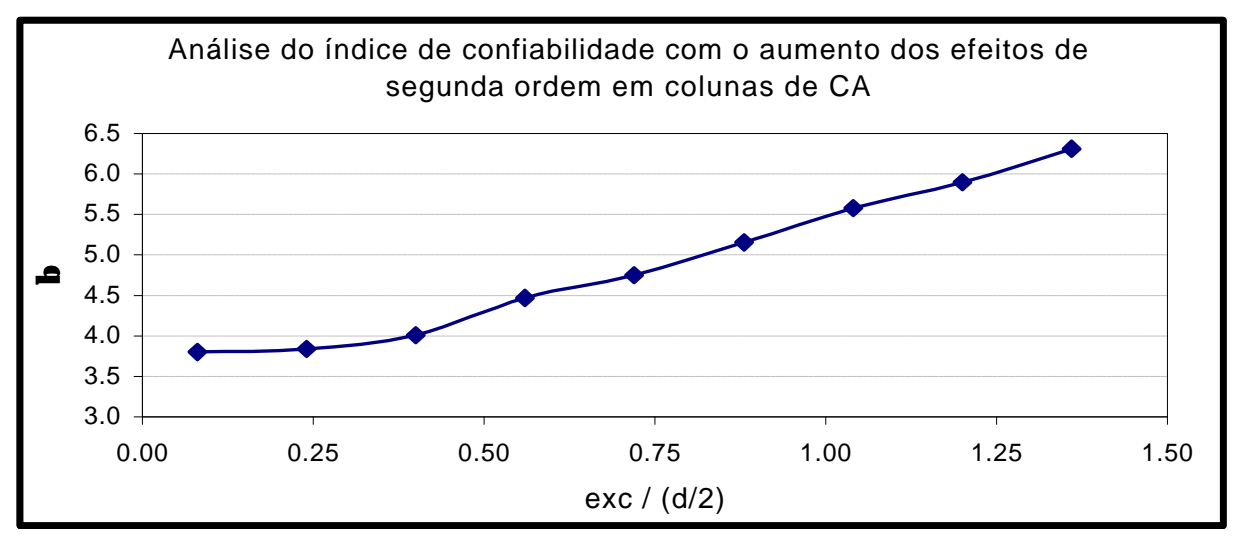

Gráfico 11.8 Aumento do índice de confiabilidade com os efeitos de segunda ordem

\subsection{Pórtico 2}

Este exemplo consiste na análise de um pórtico, Figura 11.3, cujas características encontram-se na Tabela 11.8 e na Tabela 11.9.

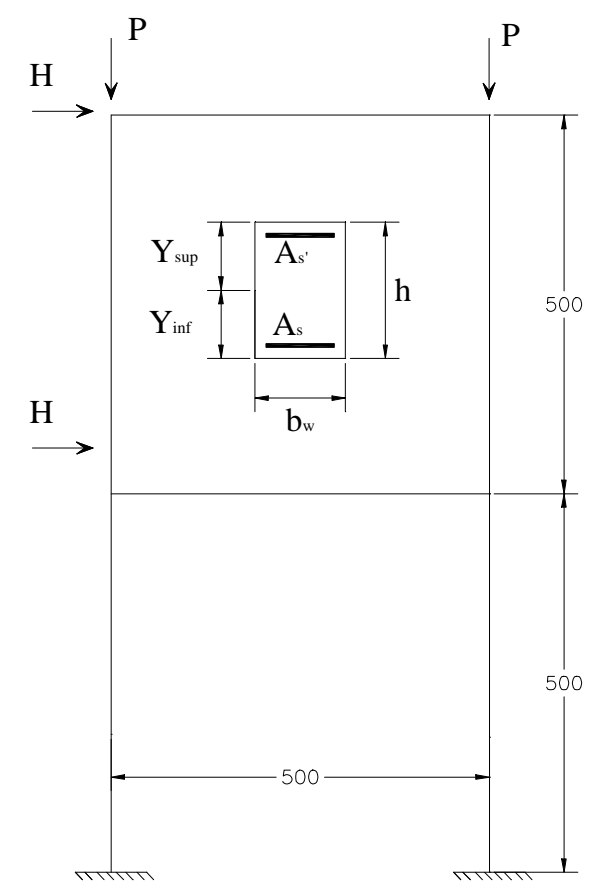

Figura 11.3 Pórtico de referência 2

Tabela 11.8 Características mecânicas do pórtico de referência $2(\mathrm{kN} \mathrm{e} \mathrm{cm)}$

\begin{tabular}{|c|c|c|c|c|c|c|c|c|c|c|}
\hline & $\mathrm{b}_{\mathrm{w}}$ & $\mathrm{h}$ & $\mathrm{Y}_{\text {inf }}$ & $\mathrm{Y}_{\text {sup }}$ & $\mathrm{d}$ & $\mathrm{A}_{\mathrm{s}}$ & $\mathrm{A}_{\mathrm{s}}{ }^{\prime}$ & $\gamma_{\mathrm{c}}$ & $\gamma_{\mathrm{s}}$ & $\gamma_{\mathrm{f}}$ \\
\hline colunas & 15.00 & 50.00 & 12.00 & 12.00 & 40.00 & 6.30 & 6.30 & 1.40 & 1.15 & 1.40 \\
\hline vigas & 15.00 & 60.00 & 27.00 & 27.00 & 48.00 & 10.05 & 10.05 & & & \\
\hline
\end{tabular}

\footnotetext{
* Plano de experiência sem ponto de adaptação
} 
Tabela 11.9 Características estatísticas do pórtico de referência $2(\mathrm{kN} \mathrm{e} \mathrm{cm})$

\begin{tabular}{|c|c|c|c|}
\hline $\mathrm{VA}$ & $\mu$ & $\sigma$ & lei \\
\hline $\mathrm{f}_{\mathrm{cm}}$ & 3.0000 & 0.4224 & $\mathrm{~N}$ \\
\hline $\mathrm{f}_{\mathrm{ym}}$ & 40.0000 & 2.1410 & $\mathrm{~N}$ \\
\hline
\end{tabular}

A solicitação externa é definida com o mesmo procedimento dos exemplos anteriores, com exceção da excentricidade inicial que é imposta de duas maneiras diferentes. Para uma primeira análise considera-se $\mathrm{P}=12 \% \mathrm{H}$, fazendo-se em seguida $\mathrm{H}=12 \% \mathrm{P}$.

Os resultados da primeira suposição são apresentados no Gráfico 11.9, Gráfico 11.10, Gráfico 11.11 e na Tabela 11.10.

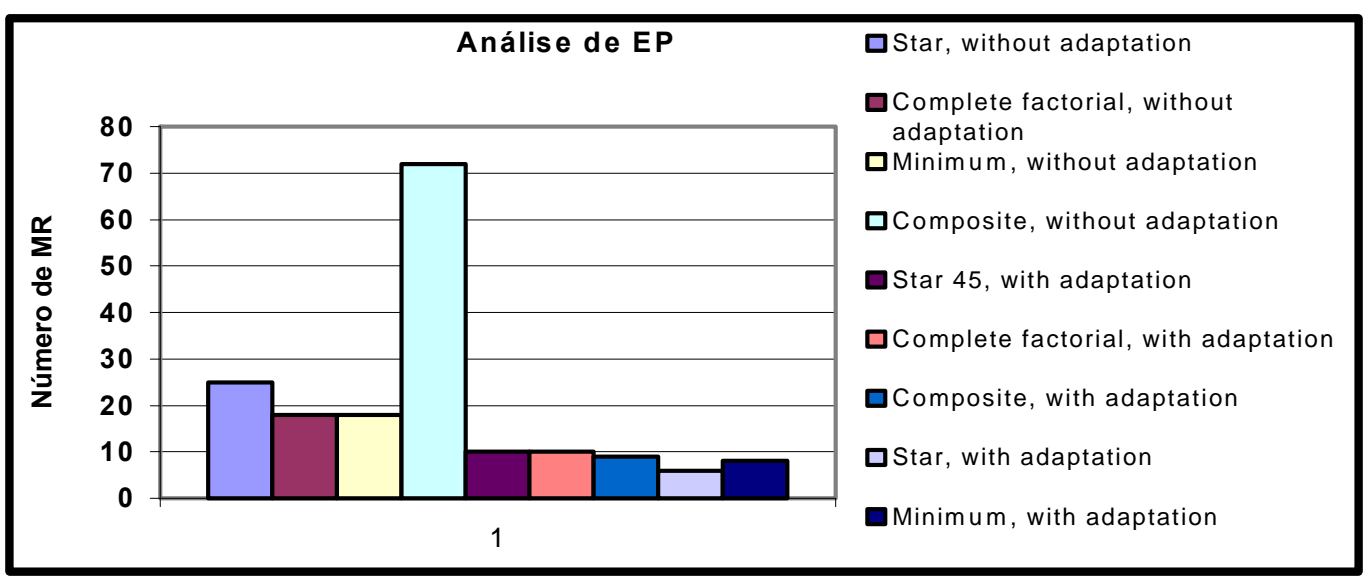

Gráfico 11.9 Número de MR para diferentes planos de experiência, $\mathrm{P}=12 \% \mathrm{H}$

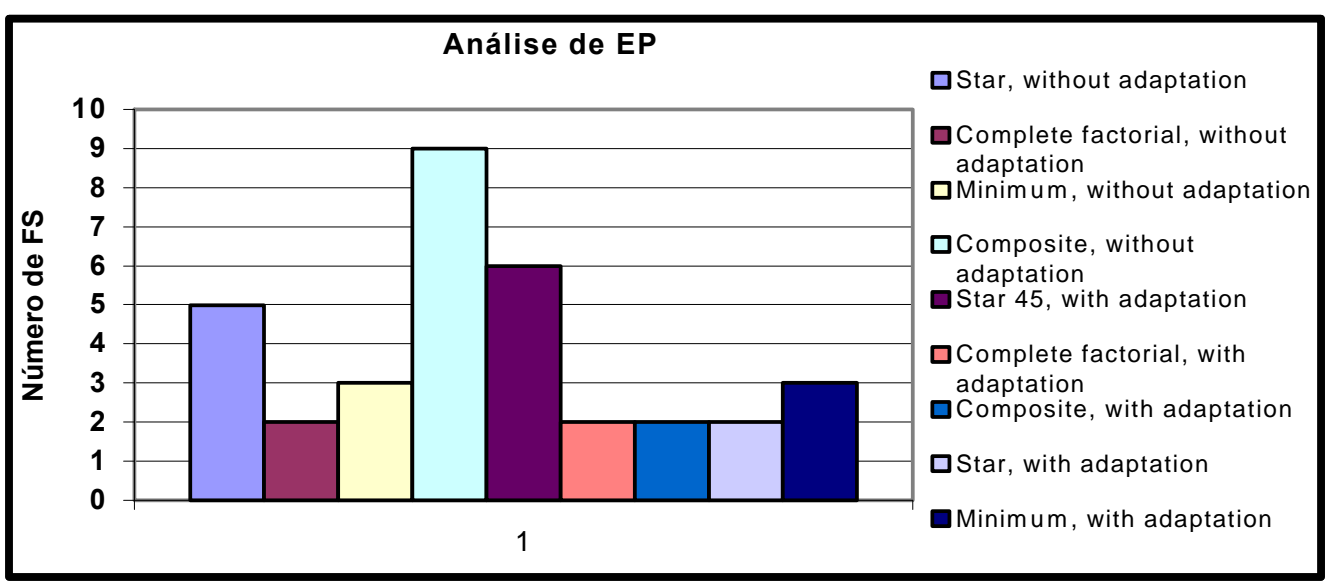

Gráfico 11.10 Número de FS para diferentes planos de experiência, $\mathrm{P}=12 \% \mathrm{H}$ 


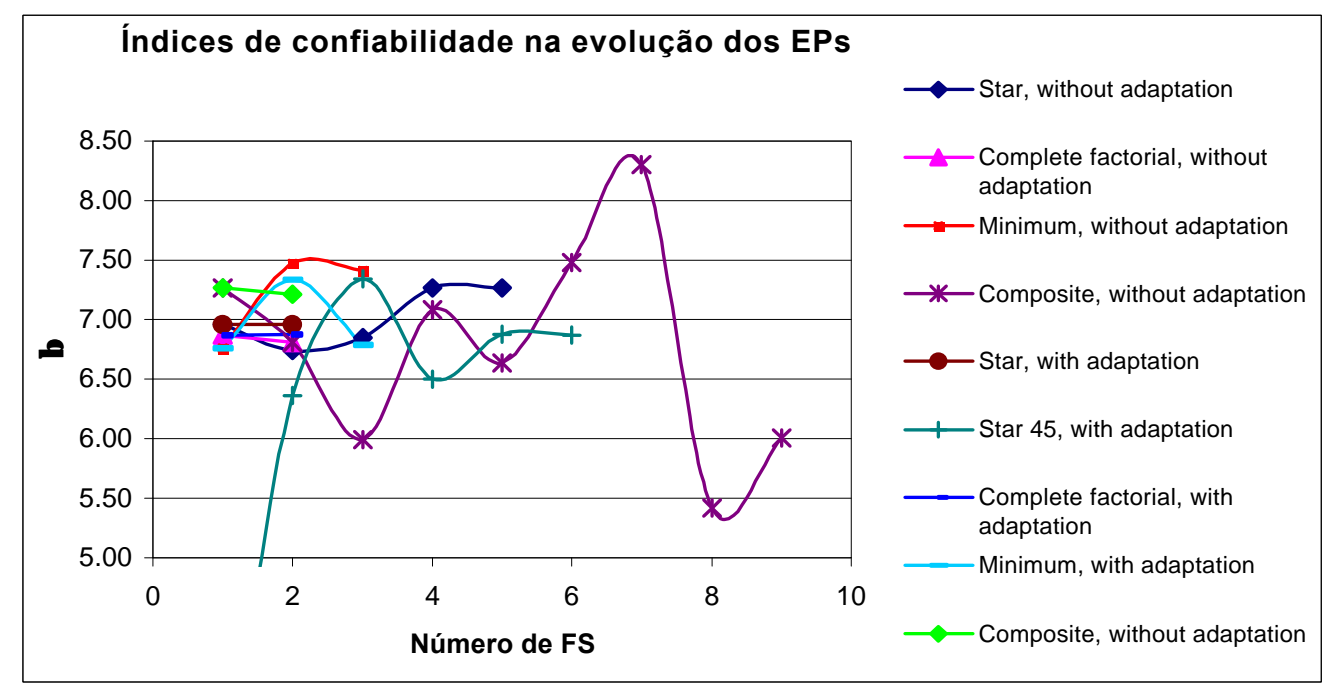

Gráfico 11.11 Índices de confiabilidade durante a evolução do RSM para diferentes $\mathrm{EP}, \mathrm{P}=12 \% \mathrm{H}$

Tabela 11.10 Respostas do pórtico de referência 2 para $\mathrm{P}=12 \%$ H (--- não converge)

\begin{tabular}{|c|c|c|c|c|c|c|c|c|c|}
\hline Planos de experiência & MR & FS & tempo & tempo & u1 & u2 & $\alpha 1$ & $\alpha 2$ & $\beta$ \\
\hline & $\mathrm{n}^{\mathbf{0}}$ & $\mathrm{n}^{\mathrm{o}}$ & $(\mathrm{mn})$ & $(\mathrm{s})$ & concreto & aço & & & \\
\hline Estrela $^{*}$ & 25 & 5 & 4 & 45 & $-6,037$ & $-4,040$ & 0,831 & 0,556 & 7,264 \\
\hline Estrela 45 $^{*}$ & --- & --- & --- & --- & --- & --- & --- & --- & --- \\
\hline Fatorial completo $^{*}$ & 18 & 2 & 3 & 25 & $-5,108$ & $-4,503$ & 0,750 & 0,661 & 6,809 \\
\hline Mínimo $^{*}$ & 18 & 3 & 3 & 41 & $-6,213$ & $-4,038$ & 0,838 & 0,545 & 7,410 \\
\hline Composto $^{*}$ & 72 & 9 & 13 & 42 & $-4,699$ & $-3,741$ & 0,782 & 0,623 & 6,006 \\
\hline Estrela $^{*}$ & 6 & 2 & 1 & 12 & $-5,672$ & $-4,028$ & 0,815 & 0,579 & 6,957 \\
\hline Estrela 45 & 10 & 6 & 1 & 42 & $-5,669$ & $-3,879$ & 0,825 & 0,565 & 6,869 \\
\hline Fatorial completo & 10 & 2 & 1 & 56 & $-5,542$ & $-4,074$ & 0,806 & 0,592 & 6,879 \\
\hline Mínimo & 8 & 3 & 1 & 38 & $-6,611$ & $-1,548$ & 0,974 & 0,228 & 6,790 \\
\hline Composto & 9 & 2 & 1 & 49 & $-5,807$ & $-4,274$ & 0,805 & 0,593 & 7,211 \\
\hline
\end{tabular}

Os resultados da segunda suposição são apresentados no Gráfico 11.12, Gráfico 11.13 e na Tabela 11.11. O único EP que não conduziu a convergência foi o estrela 45 sem ponto de adaptação. Os demais EP apresentaram boa convergência.

\footnotetext{
* Plano de experiência sem ponto de adaptação
} 


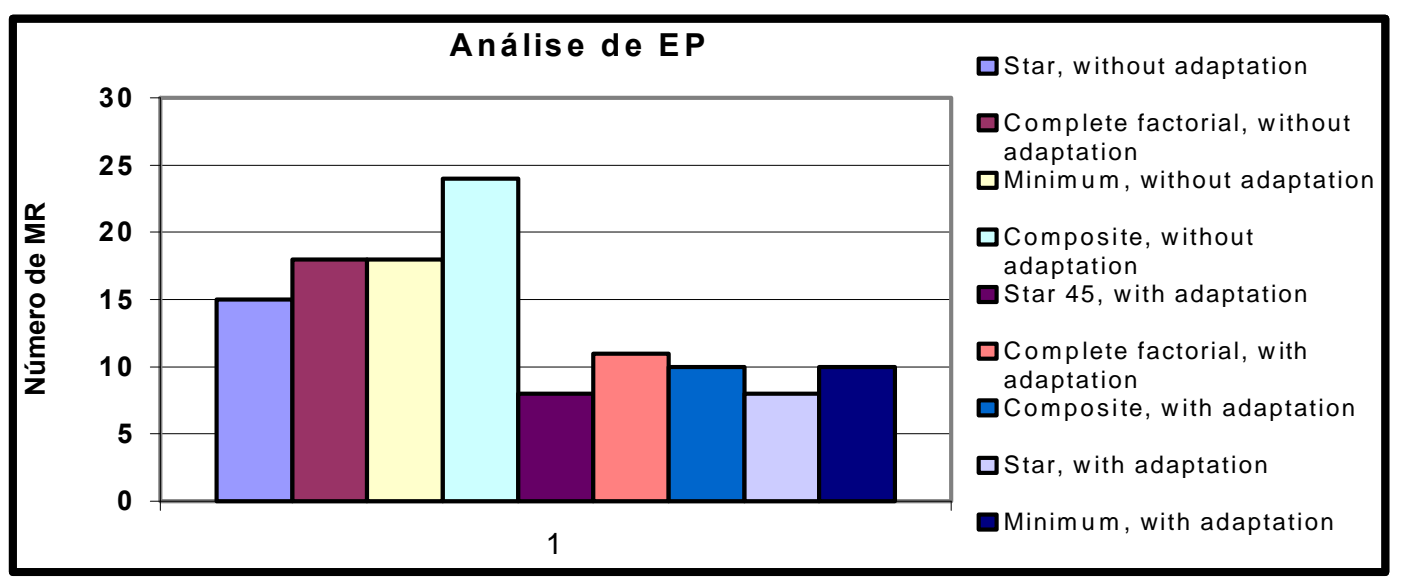

Gráfico 11.12 Número de MR para diferentes planos de experiência, $\mathrm{H}=12 \% \mathrm{P}$

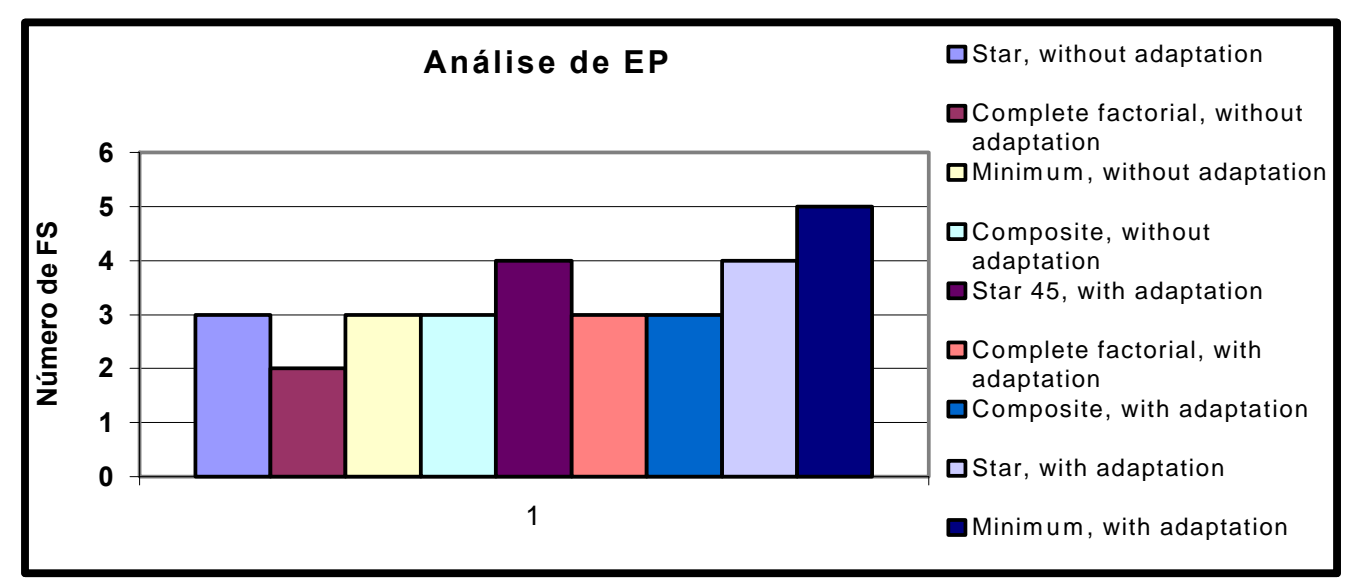

Gráfico 11.13 Número de FS para diferentes planos de experiência, $\mathrm{H}=12 \% \mathrm{P}$

Tabela 11.11 Respostas do pórtico de referência 2 para $\mathrm{H}=12 \% \mathrm{P}$ (--- não converge)

\begin{tabular}{|c|c|c|c|c|c|c|c|}
\hline Plano de experiência & MR & FS & u1 & $\mathrm{u} 2$ & $\alpha 1$ & $\alpha 2$ & $\beta$ \\
\hline & $\mathrm{n}^{\mathbf{0}}$ & $\mathrm{n}^{\mathbf{0}}$ & concreto & aço & & & \\
\hline Estrela $^{*}$ & 15 & 3 & $-4,711$ & $-0,141$ & 1,000 & 0,030 & 4,713 \\
\hline${\text { Estrela } 45^{*}}^{*}$ & --- & --- & --- & --- & --- & --- & --- \\
\hline Fatorial completo $^{*}$ & 18 & 2 & $-4,759$ & $-0,435$ & 0,996 & 0,091 & 4,778 \\
\hline Mínimo $^{*}$ & 18 & 3 & $-4,704$ & $-0,092$ & 1,000 & 0,019 & 4,705 \\
\hline Composto $^{*}$ & 24 & 3 & $-4,702$ & $-0,288$ & 0,998 & 0,061 & 4,711 \\
\hline Estrela & 8 & 4 & $-4,756$ & $-0,208$ & 0,999 & 0,044 & 4,710 \\
\hline Estrela 45 & 8 & 4 & $-4,692$ & $-0,340$ & 0,997 & 0,072 & 4,704 \\
\hline Fatorial completo & 11 & 3 & $-4,702$ & $-0,453$ & 0,995 & 0,096 & 4,724 \\
\hline Mínimo & 10 & 5 & $-4,690$ & $-0,350$ & 0,997 & 0,074 & 4,703 \\
\hline Composto & 10 & 3 & $-4,687$ & $-0,466$ & 0,995 & 0,099 & 4,710 \\
\hline
\end{tabular}

\footnotetext{
* Plano de experiência sem ponto de adaptação
} 


\section{Capítulo 12 Conclusões e idéias a serem desenvolvidas em trabalhos futuros}

Usualmente há dois aspectos principais a se considerar em um modelo de projeto adequado para ser aplicado às estruturas. O primeiro aspecto importante é a possibilidade do modelo de poder quantificar a confiabilidade das estruturas no estado limite de utilização e no estado limite último, garantindo assim uma probabilidade de falha predefinida. O segundo aspecto importante é com relação ao modelo mecânico, onde as condições de equilíbrio e compatibilidade geométrica devem ser satisfeitas junto com os modelos adotados para descrever o comportamento dos materiais. O modelo mecânico deve ser escolhido de tal forma que represente o mais fielmente possível o comportamento atual da estrutura. Por outro lado, o modelo de confiabilidade deve ser escolhido para estimar precisamente probabilidades de falha, levando-se em consideração o aspecto computacional que pode restringir sua aplicabilidade.

Como observado ao longo do texto, o trabalho apresentado pode ser incluído em algumas áreas tais como: métodos numéricos, modelos estatísticos e material concreto armado. Também já foi mencionado que a principal contribuição da tese é mostrar o acoplamento de modelos não-lineares de materiais, o método dos elementos finitos para resposta mecânica da estrutura e modelos estatísticos baseados em Superfícies de Resposta. A junção dessas técnicas forma um algoritmo robusto para estimar a confiabilidade de estruturas.

Além de estimar a confiabilidade das estruturas, verificou-se que os métodos adotados também podem ser utilizados para otimizar a estrutura garantindo um mínimo de segurança.

Um outro aspecto importante abordado no texto refere-se ao estudo para a aceitação do concreto na obra. Propõe-se modificar os critérios propostos pela norma brasileira para a aceitação do desvio padrão do concreto, esse estudo detalhado pode 
ser visto no item 9.2.

Um outro estudo realizado propõe coeficientes de redução de rigidez de barras mais consistentes. Esse estudo ainda precisa ser mais detalhado para qualquer proposta de norma, entretanto uma idéia geral de variação desses coeficientes pode ser vista no item 9.4.

\subsection{Modelos mecânicos e dos materiais}

A definição de modelos não-linear confiáveis para representar as estruturas é um dos aspectos mais importantes pesquisados atualmente. Os elementos estruturais são usualmente esbeltos forçando aos projetistas a adotarem um modelo adequado para considerar não-linearidades geométricas. Mais importante, entretanto, são as suposições à respeito de modelos confiáveis para considerar o comportamento dos materiais, redução de rigidez dos elementos durante a fase de construção e ainda durante a vida útil da estrutura. Em geral, simples suposições cinemáticas para considerar a configuração de equilíbrio final são suficientes para computar precisamente as forças internas finais à nível do elemento estrutural.

Usualmente, a análise de estruturas de edifícios é realizada utilizando conceitos de pequenas deformações e rotações. Para descrever a troca de posição geométrica dos nós dos elementos estruturais durante a análise, as coordenadas Lagrangeanas total e atualizada são os procedimentos mais comuns adotados nos processos incremental-iterativos recomendados para esse tipo de problema. Para a concepção dos efeitos de segunda ordem seguiu-se a formulação baseada em conceitos corrotacionais, CRISFIELD (1990) e HSIAO (1987), junto com as coordenadas Lagrangeana atualizada, mostrando essa formulação ser bastante adequada ao tipo estrutural pesquisado.

Ao utilizar um modelo corrotacional para representar a NLG, não há mais a necessidade de se preocupar com os níveis de deformações e rotações quando os elementos estruturais são discretizados adequadamente. É um modelo um pouco mais difícil de ser implementado que o comentado no próximo parágrafo, mas sua implementação é completamente viável (não apresenta grandes dificuldades). Oferece uma rápida convergência, parecendo ser o modelo ideal para representar a NLG. 
O modelo para concepção da não-linearidade geométrica baseado em matrizes incrementais é de fácil implementação, porém é limitado a pequenas rotações. Embora as estruturas de concreto na maioria das vezes têm suas deformações e rotações limitadas pela não-linearidade física, ao utilizar modelos limitados há a necessidade de verificar a validade dos resultados.

A redução de rigidez dos elementos de concreto armado é sem dúvida o aspecto mais importante à respeito do comportamento mecânico de estruturas de edifícios. Nos últimos 40 anos houve muitos estudos onde o principal objetivo foi a proposição de modelos aproximados para estimar a rigidez dos elementos de concreto armado individualmente e consequentemente o comportamento global da estrutura. $\mathrm{O}$ comportamento elastoplástico é a escolha natural a ser assumida para o concreto e para a armadura. Para considerar o concreto intacto entre fissuras afim de estimar corretamente a rigidez global da mesma, sugere-se utilizar modelos baseados em trabalhos básicos sobre a mecânica do dano, LEMAITRE (1985) e MAZARS (1984) e modelos específicos para representa o concreto LA BORDERIE (1991),COMI (2000) ou ainda modelos mais elaborados com a consideração de anisotropia. Esses modelos são mais adequados para representar a redução de rigidez e o processo de microfissuras internas particularmente observadas na zona de tração. Eles são capazes de considerar a deformação média sobre a zona tracionada sobre as quais fissuras podem ser distribuídas. Para as hipótese consideradas no presente trabalho, o modelo apresentado por FIGUEIRAS (1983) foi suficiente.

O modelo mecânico para representar a não-linearidade física do material baseado em inércias equivalentes não apresentou qualquer vantagem sobre os baseados em relações tensãoxdeformação.

Os modelos mecânicos para representar a não-linearidade física do material baseados em leis constitutivas apresentaram as seguintes características: rápida convergência, consistência nos resultados, facilidade para compreensão do desenvolvimento das deformações e tensões nos elementos finitos, fácil implementação de um novo modelo, facilidade para acoplagem da estatística das variáveis envolvidas.

Entre os exemplos processados verificou-se que há uma grande falta de 
uniformidade na confiabilidade das respostas estruturais. Pode notar que o uso de coeficientes parciais constantes como indicam as normas atuais não é o mais indicado a nível de probabilidade de falha uniforme.

Uma procedimento possível para trabalhos futuros é a análise da confiabilidade e consequentemente nível de segurança que eles oferecem. É necessário também definirem-se os parâmetros estatísticos (desvio padrão e distribuições) para os modelos que garantam uma confiabilidade mais uniforme e aceita pela sociedade. Esse estudo deve ser feito separadamente para os Estados limites Último e de Serviço.

Após conhecer bem os modelos atuais pode-se pensar em propor novos modelos, a princípio vinculado ao estado limite, baseados na estatística das variáveis.

Por fim, no caso de utilização de coeficientes parciais de segurança, um estudo amplo deve ser feito. Os coeficientes de redução das resistências dos materiais da forma que são impostos hoje não conduzem a estrutura a uma probabilidade de falha uniforme, sendo esta muitas vezes insatisfatórias.

\subsection{Modelos de confiabilidade}

De uma forma grosseira, pode-se classificar métodos de confiabilidade de duas formas: métodos aleatórios e métodos não-aleatórios.

Os métodos aleatórios são largamente utilizados na bibliografia, embora esses métodos apresentem um elevado custo computacional. Em problemas práticos, muitas vezes eles são usados para aferir métodos não-aleatórios. Métodos que dependem de geradores aleatórios como Simulações de Monte Carlo, Amostra por Importância, Algoritmos Genéticos, Fuzzy Set, etc., em geral têm sua utilização penalizada na prática da engenharia estrutural devido ao elevado custo computacional. O ideal é sempre buscar a utilização de métodos não-aleatórios.

Entre os métodos aleatórios, o mais antigo e ainda base para os demais métodos é o Método de Simulação de Monte Carlo. Ele oferece resultados com ótimo nível de aproximação e é de fácil compreensão para o engenheiro. Não há necessidade de conhecimentos matemáticos mais complexos, podendo ser compreendido fisicamente.

À respeito dos métodos não-aleatórios, um dos principais passos é estimar a 
Superfície Limite da estrutura. Embora muitos trabalhos predefinem a FS da estrutura baseados nos conhecimentos do projetista, em geral as estruturas apresentam respostas mecânicas não-lineares e consequentemente é impossível se conhecer $a$ priori sua FS.

Os métodos baseados em Superfícies de Respostas são robustos para estimar a FS da estrutura com comportamento não-linear. Esse tipo de método pode ser utilizado para resolver qualquer problema de confiabilidade para qualquer tipo estrutural com qualquer material (estruturas de concreto armado, aço, materiais compósitos, iteração solo/estrutura, etc). Quando aplicados a estruturas, a FS deve incorporar o comportamento mecânico da estrutura sobre as considerações assumidas. A grande vantagem desses métodos é o baixíssimo custo computacional. O RSM associado a um algoritmo de otimização pode ser utilizado para estimar o índice de confiabilidade da estrutura. Métodos de Confiabilidade de Primeira e Segunda Ordem, FORM e SORM, respectivamente, são algoritmos que podem estimar a probabilidade de falha da estrutura quando já se conhece seu índice de confiabilidade.

O Método de Superfícies de Respostas aplicado na tese conduz a excelentes resultados, com rápida convergência e consistência. Esse método tem suas desvantagens, como qualquer outro, a principal delas é a extrema dependência do plano de experiência adotado para o desenvolvimento. Uma outra desvantagem para o engenheiro é que exige o emprego de conhecimentos matemáticos mais complexos, entretanto uma vez implementada esse problema deixa de existir.

Utilizar polinômios de ordem elevada para representar a superfície de resposta da estrutura em todo domínio de validade do problema, não apenas em torno da solução, apresenta resultados corretos na maioria dos exemplos. Mas, além da convergência ser mais lenta do que quando utilizam-se polinômios de ordem 2 ou 3 válido apenas em torno da solução, o processo nem sempre garante a convergência, portanto não é um modelo adequado a não ser que haja outros avanços.

Métodos de confiabilidade são aplicados em estruturas de concreto armado desde 1947 quando FREUDENTHAL (1947) publicou seu primeiro trabalho com conceitos de confiabilidade aplicados a projetos estruturais. Depois disso, 
praticamente todos os códigos de projeto internacionais têm proposto incorporar conceitos de confiabilidade, como pode-se ver no Eurocode 1, assim como em muitas recomendações do CEB (SARGIN (1971); CEB 191 (1988); CEN 229 (1995)).

Nos tempos modernos, têm sido estudados e propostos modelos mais realísticos para incorporar a confiabilidade em projetos de concreto armado. Têm sido observados muitos avanços na tentativa de projetar as estruturas diretamente com conceitos de confiabilidade. Análise de confiabilidade aplicada a elementos de concreto armado usualmente aparece associada ao Estado Limite Último e raramente estudam-se estruturas no Estado Limite de Serviço. Pouquíssimos trabalhos em pórticos de concreto armado considerando análise de confiabilidade têm aparecido na literatura.

\subsection{Modelos mecânico-confiabilísticos}

Com o objetivo de se uniformizar a probabilidade de falha da estrutura de concreto armado foram propostos alguns modelos. Um primeiro item que merece atenção e modificação diz respeitoa critérios de aceitação do desvio padrão da resistência do concreto. Nessa linha foram propostos valores de desvio padrão em função da confiabilidade desejada para a estrutura, abandonando a idéia de desvio padrão vinculado ao controle do concreto. A proposta baseia-se em aceitar coeficientes de variação constantes para o concreto.

Um outro modelo proposto foi para a análise de estruturas de concreto em serviço. Propõe-se uma redução consistente para o módulo de elasticidade secante do concreto para utilizar modelos lineares e obter respostas equivalentes a modelos nãolineares garantindo níveis mínimos de confiabilidade. A redução do módulo de elasticidade é função de vários parâmetros de projeto.

Propõe-se ainda um software mecânico-confiabilístico chamado STST elaborado com o acoplamento do FEM não-linear, o RSM e o FORM e SORM. Através da análise de vários exemplos numéricos e de dados obtidos na literatura pode-se verificar que os modelos adotados são eficientes e computacionalmente eficientes, evidenciando serem os ideais para o problema.

Conclui-se que a utilização de Método de Superfícies de Resposta acoplado com o Método dos Elementos Finitos para estimar a confiabilidade de estruturas 
sujeitas a comportamento não-linear é plenamente viável e recomendável. Em vista do alto desempenho desse acoplamento e baseado no conhecimento de métodos estatísticos e mecânicos, acredita-se que a utilização de RSM com o Método dos Elementos de Contorno (BEM) ou com o FEM/BEM acoplados é de igual eficácia que o RSM com o FEM. Considerando-se o desempenho observado nas diversas aplicaçãoes, pode-se dizer que o RSM pode ser utilizado para estimar a confiabilidade de qualquer tipo de material. Tais conclusões podem ser feitas devido ser a obtenção das respostas mecânicas independente do RSM.

Com relação a trabalhos futuros, o RSM pode ser melhorado no que diz respeito a definição de Planos de Experiência. Sabe-se que qualquer ganho no custo computacional é de grande importância, e a maior contribuição do RSM para o custo computacional vem do tempo de processamento da resposta mecânica. Portanto, quanto menor o número de respostas mecânicas necessárias para desenvolver o RSM, melhor será. Uma possibilidade é utilizar processos de otimização para definir os pontos dos EP. 


\section{Anexo A Trabalhos recentes em confiabilidade estrutural}

Tabela 1 Trabalhos recentes em confiabilidade estrutural

\begin{tabular}{|c|c|c|c|}
\hline Referência & Tipo estrutural & Técnica & Descrição \\
\hline $\begin{array}{l}\text { Apostolakis, G.E.; } \\
\text { Soares, C.G.; } \\
\text { Kondo, S. (1998) }\end{array}$ & Geral & Análise de risco & $\begin{array}{c}\text { Percepção de risco versos análise de } \\
\text { risco }\end{array}$ \\
\hline $\begin{array}{l}\text { Aven, T. and Kurt, } \\
\text { P. (1998) }\end{array}$ & Geral & Análise de risco & $\begin{array}{l}\text { Interpretação dos resultados de } \\
\text { análises de riscos quantitativos }\end{array}$ \\
\hline $\begin{array}{l}\text { Aven, T. e } \\
\text { Pitblado, R. } \\
\text { (1998) }\end{array}$ & $\begin{array}{l}\text { Atividades de } \\
\text { petróleo }\end{array}$ & Não comentado & $\begin{array}{l}\text { Princípios chaves e ferramentas de } \\
\text { administração de segurança }\end{array}$ \\
\hline $\begin{array}{c}\text { Barsa, G. e } \\
\text { Kirwan, B. (1998) }\end{array}$ & Offshore & Erro humano & $\begin{array}{c}\text { Erros humanos em arquivos de } \\
\text { probabilidade de offshore }\end{array}$ \\
\hline Bea, R.G. (1998) & Offshore & Erro humano & $\begin{array}{l}\text { Aproximações de engenharia e } \\
\text { conceitos que podem ser usados em } \\
\text { como implementar confiabilidade } \\
\text { em sistemas estruturais de offshore }\end{array}$ \\
\hline $\begin{array}{l}\text { Bohnenblust, H. et } \\
\text { all (1998) }\end{array}$ & Não comentado & Análise de risco & $\begin{array}{l}\text { Percepção de risco do público, } \\
\text { análises técnicas de risco }\end{array}$ \\
\hline $\begin{array}{l}\text { Caers, J.; Maes, } \\
\text { M.A. (1998) }\end{array}$ & Geral & $\begin{array}{c}\text { Modelos } \\
\text { probabilísticos }\end{array}$ & $\begin{array}{l}\text { Identifica calda, limites e pontos das } \\
\text { extremidades das variáveis aleatórias }\end{array}$ \\
\hline $\begin{array}{l}\text { Cheok, M.C.; } \\
\text { Parry, G.W.; } \\
\text { Sherry, R.R. } \\
\quad(1998)\end{array}$ & Geral & Análise de risco & $\begin{array}{l}\text { Uso de medidas importantes para } \\
\text { analisar resultados de QRA }\end{array}$ \\
\hline $\begin{array}{l}\text { Cohen, B.L. } \\
\text { (1998) }\end{array}$ & $\begin{array}{l}\text { Geral, usina } \\
\text { nuclear }\end{array}$ & Análise de risco & $\begin{array}{l}\text { Percepção de risco do público versos } \\
\text { resultados científicos de Análise de } \\
\text { risco }\end{array}$ \\
\hline $\begin{array}{l}\text { Cooper, J.A. } \\
\text { (1998) }\end{array}$ & Geral & $\begin{array}{c}\text { Modelos } \\
\text { probabilísticos }\end{array}$ & $\begin{array}{c}\text { Problema de implementação } \\
\text { computacional das restrições } \\
\text { inerentes à definição do problema }\end{array}$ \\
\hline Cross, F.B. (1998) & Não comentado & Análise de risco & Percepção de risco do público \\
\hline $\begin{array}{l}\text { Devooght, J. } \\
\text { (1998) }\end{array}$ & $\begin{array}{l}\text { Geral, aplicado à } \\
\text { transporte de água }\end{array}$ & $\begin{array}{l}\text { Modelos } \\
\text { probabilísticos }\end{array}$ & $\begin{array}{c}\text { Modelo de incerteza versos modelo } \\
\text { impreciso }\end{array}$ \\
\hline $\begin{array}{l}\text { Dey, A.; } \\
\text { Mahadevan, S. } \\
\quad(1998)\end{array}$ & $\begin{array}{l}\text { Geral, aplicado à } \\
\text { pórticos. }\end{array}$ & $\begin{array}{l}\text { Amostra por } \\
\text { importância }\end{array}$ & $\begin{array}{l}\text { Apresenta uma técnica híbrida para } \\
\text { estimar a confiabilidade de sistemas } \\
\text { eficientes de estruturas de barra com } \\
\text { grande ductilidade }\end{array}$ \\
\hline
\end{tabular}




\begin{tabular}{|c|c|c|c|}
\hline Referência & Tipo estrutural & Técnica & Descrição \\
\hline $\begin{array}{l}\text { Frangopol, D.M.; } \\
\text { Ide, Y.; Spacone, } \\
\text { E.; Iwaki, I. } \\
\quad(1996)\end{array}$ & $\begin{array}{l}\text { Colunas de } \\
\text { concreto }\end{array}$ & $\begin{array}{l}\text { Modelo } \\
\text { probabilístico, } \\
\text { Monte Carlo }\end{array}$ & $\begin{array}{l}\text { Resposta em normal e momento } \\
\text { médio para índices de confiabilidade } \\
\text { determinísticos considerando as } \\
\text { variáveis aleatórias. Curvas de } \\
\text { isoconfiabilidade, propostas para } \\
\text { superfícies limites. }\end{array}$ \\
\hline $\begin{array}{l}\text { Garrick, B.J. } \\
\text { (1998) }\end{array}$ & $\begin{array}{c}\text { Geral, industria } \\
\text { nuclear e química }\end{array}$ & Análise de risco & Percepção de risco do público \\
\hline $\begin{array}{l}\text { Gordon, R.P.E. } \\
\text { (1998) }\end{array}$ & Offshore & Erro humano & $\begin{array}{l}\text { Visão geral de como os fatores } \\
\text { humanos contribuem para acidentes } \\
\text { nas industrias de óleo em offshore }\end{array}$ \\
\hline $\begin{array}{l}\text { Graham, L.; } \\
\text { Deodatis, G } \\
\quad(1998)\end{array}$ & Placas fletidas & $\begin{array}{c}\text { Modelos } \\
\text { probabilísticos }\end{array}$ & $\begin{array}{l}\text { Método de integral ponderado e } \\
\text { conceito de variabilidade da função } \\
\text { de resposta aplicado à placa fletida. }\end{array}$ \\
\hline $\begin{array}{c}\text { Guo-Kang Er } \\
\text { (1998) }\end{array}$ & Geral & $\begin{array}{c}\text { Modelos } \\
\text { probabilísticos }\end{array}$ & $\begin{array}{c}\text { Método para estimar a PDF de } \\
\text { variáveis aleatórias }\end{array}$ \\
\hline $\begin{array}{l}\text { Hilton, H.H. et all } \\
\text { (1997) }\end{array}$ & $\begin{array}{l}\text { Colunas elásticas e } \\
\text { viscoelásticas }\end{array}$ & Análise sensitiva & $\begin{array}{c}\text { Análise sensitiva de delaminaçao } \\
\text { determinística e estocástica em } \\
\text { colunas compósitas }\end{array}$ \\
\hline $\begin{array}{l}\text { Hoegberg, L. } \\
\text { (1998) }\end{array}$ & nuclear & Análise de risco & $\begin{array}{c}\text { Discute o quanto a segurança é } \\
\text { suficientemente segura }\end{array}$ \\
\hline $\begin{array}{l}\text { Hokstad, P.; Oien, } \\
\text { K.; Reinertsen, R. } \\
\quad \text { (1998) }\end{array}$ & Offshore & Expert judgment & $\begin{array}{l}\text { Proporciona conselhos no processo } \\
\text { de estabelecimento dos dados de } \\
\text { entrada para segurança e } \\
\text { confiabilidade em engenharia } \\
\text { quando não existe ou existe poucos } \\
\text { dados de projeto. }\end{array}$ \\
\hline Hong, H.P. (1998) & Geral & $\begin{array}{c}\text { Modelos } \\
\text { probabilísticos }\end{array}$ & $\begin{array}{c}\text { Método para calcular os momentos } \\
\text { estatísticos de uma quantidade } \\
\text { aleatória }\end{array}$ \\
\hline $\begin{array}{c}\text { Horlick-Jones, T. } \\
\text { (1998) }\end{array}$ & Não comentado & Análise de risco & $\begin{array}{l}\text { Análise da construção de risco como } \\
\text { um processo social }\end{array}$ \\
\hline Jasanoff, S. (1998) & Não comentado & Análise de risco & $\begin{array}{c}\text { Percepção de risco, risco obtido } \\
\text { como medida ou como experiência } \\
\text { de um especialista }\end{array}$ \\
\hline $\begin{array}{l}\text { Kiureghian, A.D.; } \\
\text { Dakessian, T. } \\
\quad(1998)\end{array}$ & Geral & $\begin{array}{l}\text { Modelos } \\
\text { probabilísticos }\end{array}$ & $\begin{array}{l}\text { Desenvolvimento de um método } \\
\text { para encontrar sucessivamente os } \\
\text { pontos de projeto múltiplos de um } \\
\text { problema de confiabilidade }\end{array}$ \\
\hline $\begin{array}{l}\text { Lemaire, M. } \\
\text { (1997) }\end{array}$ & $\begin{array}{l}\text { Geral, aplicado a } \\
\text { plataforma de } \\
\text { petróleo }\end{array}$ & $\begin{array}{c}\text { Análise sensitiva e } \\
\text { Análise de } \\
\text { confiabilidade } \\
\end{array}$ & $\begin{array}{l}\text { Princípios de Análise sensitiva e } \\
\text { Análise de confiabilidade }\end{array}$ \\
\hline $\begin{array}{c}\text { Lemaire, M. et all } \\
(1995)\end{array}$ & Geral & FORM/SORM & $\begin{array}{c}\text { Propagação de incertezas num } \\
\text { sistema }\end{array}$ \\
\hline $\begin{array}{c}\text { Lemaire, M. et all } \\
\text { (1995) }\end{array}$ & Geral & SORM & Aproximação p/ integrais SORM \\
\hline $\begin{array}{l}\text { Lemaire, M. } \\
\text { (1998) }\end{array}$ & Geral & $\begin{array}{l}\text { Modelos } \\
\text { probabilísticos }\end{array}$ & $\begin{array}{l}\text { Combina o FEM com resolução de } \\
\text { probabilidade de ruína por métodos } \\
\text { FORM e SORM }\end{array}$ \\
\hline
\end{tabular}




\begin{tabular}{|c|c|c|c|}
\hline Referência & Tipo estrutural & Técnica & Descrição \\
\hline $\begin{array}{l}\text { Lin, K.Y. and } \\
\text { Frangopol, D.M. } \\
\text { (1996) }\end{array}$ & $\begin{array}{l}\text { Viga } \mathrm{T} \text { de ponte de } \\
\text { auto-estrada }\end{array}$ & $\begin{array}{c}\text { Otimização } \\
\text { baseada em } \\
\text { confiabilidade }\end{array}$ & $\begin{array}{l}\text { Minimização do custo de uma seção } \\
\text { transversal de uma viga incluindo } \\
\text { restrições de confiabilidade. }\end{array}$ \\
\hline $\begin{array}{l}\text { Ling, J. and Pan, } \\
\text { J. (1998) }\end{array}$ & Geral & $\begin{array}{l}\text { Modelos } \\
\text { probabilísticos }\end{array}$ & $\begin{array}{l}\text { Método de otimização para estimar } \\
\text { parâmetros. Procedimento para } \\
\text { selecionar distribuição da população }\end{array}$ \\
\hline $\begin{array}{l}\text { Marcellier, P.; } \\
\text { Lemaire, M.; } \\
\text { Goyet, J. (1999) }\end{array}$ & Navio & $\begin{array}{c}\text { Elementos finitos e } \\
\text { cálculo de } \\
\text { confiabilidade } \\
\end{array}$ & $\begin{array}{l}\text { Calibração de coeficientes parciais } \\
\text { para dimensionamento. }\end{array}$ \\
\hline $\begin{array}{l}\text { McDaniels, T.L. } \\
\text { (1998) }\end{array}$ & Não comentado & Análise de risco & Proposições para percepção de risco \\
\hline $\begin{array}{c}\text { Nilsen, T.; } \\
\text { Gudmestad O.T.; } \\
\text { Dalane, J.I.; } \\
\text { Rettedal, W.K.; } \\
\text { Aven, T. (1998) }\end{array}$ & $\begin{array}{l}\text { Geral, aplicado à } \\
\text { offshore }\end{array}$ & Análise de risco & $\begin{array}{c}\text { Discute o uso de métodos } \\
\text { desenvolvidos para o cálculo de } \\
\text { confiabilidade de estruturas como } \\
\text { uma ferramenta geral para calcular } \\
\text { probabilidades com o contexto de } \\
\text { análise quantitativa de risco } \\
\end{array}$ \\
\hline Oien, K. (1998) & Não comentado & Expert judgment & $\begin{array}{l}\text { Importância do uso de } \\
\text { conhecimentos de engenheiros em } \\
\text { modelos de manutenção }\end{array}$ \\
\hline Okrent, D. (1998) & Não coment & Análise de risco & Percepção de risco do público \\
\hline $\begin{array}{c}\text { Pandey, M.D. } \\
(1998) \\
\end{array}$ & Geral & $\begin{array}{c}\text { Modelos } \\
\text { probabilísticos }\end{array}$ & $\begin{array}{l}\text { Aproximação para resolver integrais } \\
\text { multi-normais }\end{array}$ \\
\hline $\begin{array}{c}\text { Papazoglou, I.A. } \\
\text { (1998) }\end{array}$ & Geral & Event trees & $\begin{array}{c}\text { Fundamentação matemática dos } \\
\text { primeiros princípios de "event trees" }\end{array}$ \\
\hline $\begin{array}{l}\text { Papazoglou, I.A. } \\
\text { (1998) }\end{array}$ & Geral & Event trees & $\begin{array}{c}\text { Diagrama de blocos funcionais como } \\
\text { alternativa p/ representar "event } \\
\text { trees" }\end{array}$ \\
\hline $\begin{array}{c}\text { Pidgeon, N. } \\
(1998)\end{array}$ & Não com & Análise de risco & Percepçao de risco do público \\
\hline $\begin{array}{c}\text { Regan, P.J. and } \\
\text { Pate-Cornell, M.E. } \\
\text { (1997) }\end{array}$ & Geral & $\begin{array}{l}\text { Administração de } \\
\text { risco }\end{array}$ & $\begin{array}{l}\text { Projeto de administração de risco } \\
\text { visando: diagnósticos, evolução } \\
\text { dinâmica, decisão a ser tomada e } \\
\text { coleta de informações } \\
\end{array}$ \\
\hline $\begin{array}{c}\text { Schofield, S. } \\
(1998)\end{array}$ & Offshore & Análise de risco & $\begin{array}{l}\text { Discussão sobre uso da avaliação de } \\
\text { risco quantitativo } \\
\end{array}$ \\
\hline $\begin{array}{l}\text { Shetty, N.K. et al } \\
\text { (1998) }\end{array}$ & Offshore & Análise de risco & $\begin{array}{l}\text { Aproximação probabilística para } \\
\text { avaliação da segurança ao fogo }\end{array}$ \\
\hline $\begin{array}{l}\text { Simola, K. E } \\
\text { Pulkkinen, U. } \\
\text { (1998) }\end{array}$ & $\begin{array}{l}\text { Geral, aplicado à } \\
\text { fissuras }\end{array}$ & $\begin{array}{l}\text { Modelos } \\
\text { probabilísticos }\end{array}$ & $\begin{array}{l}\text { Uso de modelos estatísticos p/ } \\
\text { estimar a confiabilidade de } \\
\text { inspeções não-destrutivas. } \\
\text { Construção de modelos }\end{array}$ \\
\hline $\begin{array}{l}\text { Sinnamon, R.M.; } \\
\text { Andrews, J.D. } \\
\text { (1997) }\end{array}$ & Geral & Fault trees & $\begin{array}{l}\text { Uso de um diagrama de decisão } \\
\text { binaria para análises de "Fault trees" }\end{array}$ \\
\hline Slovic, P. (1998) & $\begin{array}{l}\text { Geral, industria } \\
\text { nuclear e química }\end{array}$ & Análise de risco & Decisões de administração de risco \\
\hline
\end{tabular}




\begin{tabular}{|c|c|c|c|}
\hline Referência & Tipo estrutural & Técnica & Descrição \\
\hline $\begin{array}{l}\text { Soares, C.G. } \\
\quad(1997)\end{array}$ & $\begin{array}{l}\text { Materiais } \\
\text { compósitos }\end{array}$ & $\begin{array}{l}\text { Modelos } \\
\text { probabilísticos }\end{array}$ & $\begin{array}{l}\text { Aproximações probabilísticas } \\
\text { utilizadas para representar a } \\
\text { resistência de materiais compósitos } \\
\text { (fibras armadas) }\end{array}$ \\
\hline Vatn, J. (1998) & $\begin{array}{l}\text { Atividades de } \\
\text { petróleo }\end{array}$ & Análise de risco & $\begin{array}{c}\text { Aspectos filosóficos sobre critérios } \\
\text { de aceitação de risco }\end{array}$ \\
\hline $\begin{array}{l}\text { Vinnem, J.E. } \\
\text { (1998) }\end{array}$ & Offshore & Análise de risco & $\begin{array}{c}\text { Evolução da metodologia da } \\
\text { avaliação de risco quantitativo em } \\
\text { operações de offshore }\end{array}$ \\
\hline $\begin{array}{l}\text { Li, C.Q.; Pham, L. } \\
\text { (1995) }\end{array}$ & Geral & $\begin{array}{c}\text { Confiabilidade, } \\
\text { Otimização }\end{array}$ & $\begin{array}{c}\text { Busca do projeto ótimo baseado em } \\
\text { confiabilidade }\end{array}$ \\
\hline $\begin{array}{l}\text { Sang-Hyo Kim; } \\
\text { Seong-Won Na } \\
\quad(1997)\end{array}$ & Geral & $\begin{array}{l}\text { Método de } \\
\text { superfície de } \\
\text { resposta sequencial }\end{array}$ & $\begin{array}{c}\text { Propõe um método que utiliza o } \\
\text { método de projeção de gradiente } \\
\text { para selecionar os pontos da amostra } \\
\text { da superfície de resposta }\end{array}$ \\
\hline $\begin{array}{c}\text { Dimitri Val; } \\
\text { Bljuger, F.; } \\
\text { Yankelevsky, D. } \\
\text { (1997) }\end{array}$ & $\begin{array}{c}\text { Estruturas planas } \\
\text { de barras }\end{array}$ & $\begin{array}{c}\text { Método } \\
\text { probabilístico, } \\
\text { NFEM e FORM }\end{array}$ & $\begin{array}{l}\text { Estimativa de confiabilidade em } \\
\text { análise não-linear de estruturas de } \\
\text { concreto armado }\end{array}$ \\
\hline $\begin{array}{l}\text { Vrijling, J.K. et al } \\
\text { (1998) }\end{array}$ & Geral & Análise de risco & $\begin{array}{c}\text { Um conjunto possível de regras que } \\
\text { podem servir como base mais } \\
\text { racional e objetiva para projetos } \\
\text { tecnológicos }\end{array}$ \\
\hline
\end{tabular}




\section{Anexo B Distribuições de probabilidade}

Para se determinar o índice de confiabilidade de uma estrutura, conhecer as funções de distribuição associadas às variáveis de projeto é de fundamental importância. São conhecidas várias funções de distribuição, cabendo ao engenheiro escolher a função mais adequada a ser adotada no cálculo estatístico das estruturas. A determinação de qual função deve ser adotada pode ser feita a partir de ensaios em laboratórios.

De uma forma geral, as funções mais adotadas para as variáveis de projeto, assim como suas principais características encontradas em bibliografias são:

$\checkmark$ Ações Permanente: Log-normal ou Normal $\therefore \mathrm{cv}=8 \%$ a $15 \%$

$\checkmark$ externas: Acidental: Gumbel ou Weibull $\therefore \mathrm{cv}=10 \%$ a $30 \%$

$\checkmark \quad$ Onda (oceano ou mar): Gumbel ou Weibull $\therefore \mathrm{cv}=40 \%$

$\checkmark$ Concreto: Tensão: Log-normal ou Normal $\therefore \mathrm{cv}=10 \%$ a $25 \%$

$\checkmark \quad$ Módulo de elasticidade: Log-normal ou Normal $\therefore \mathrm{cv}=15 \%$

$\checkmark$ Aço: Tensão: Log-normal ou Normal $\therefore \mathrm{cv}=6 \%$ a $12 \%$

$\checkmark \quad$ Módulo de elasticidade: Log-normal ou Normal $\therefore \mathrm{cv}=8 \%$ a $15 \%$

$\checkmark$ Fissura: Tamanho ou abertura entre fissuras: Exponencial

$\checkmark \quad$ Homogeneidade: Weibull

$\checkmark$ Deterioração: Exponencial

$\checkmark$ Erro: $\quad$ Modelo: Normal $(0, \sigma)$

$\checkmark$ Geometria: base: Log-normal ou Normal $\therefore \sigma=0,5 \mathrm{~cm}$

$\checkmark \quad$ Altura: Log-normal ou Normal $\therefore \sigma=0,5 \mathrm{~cm}$

$\checkmark$ Cobrimento da armadura: Uniforme $\therefore \sigma= \pm 2,0 \mathrm{~cm}$

$\checkmark \quad$ onde: $\mathrm{cv}=\frac{\sigma}{\mu}$

A seguir explicitam-se as f.d.p. de apenas uma variável, disponíveis no 
programa STST. Estas funções foram retiradas de MOHAMED (1999).

\section{Retangular ou linear}

$$
\begin{array}{ll}
\text { Função densidade: } & f(x)=\frac{1}{b-a} \\
\text { Função de distribuição: } & F(x)=\frac{x-a}{b-a}
\end{array}
$$

Região de validade: $\mathrm{a} \leq \mathrm{x} \leq \mathrm{b}$

Restrição de parâmetro: $a<b$

Média: $\frac{\mathrm{a}+\mathrm{b}}{2}$

Desvio padrão: $\frac{\mathrm{b}-\mathrm{a}}{\sqrt{12}}$

\section{Normal ou Gauss}

$$
\begin{array}{ll}
\text { Função densidade: } & \mathrm{f}(\mathrm{x})=\frac{1}{\sigma} \varphi\left(\frac{\mathrm{x}-\mu}{\sigma}\right)=\frac{1}{\sqrt{2 \pi} \sigma} \mathrm{e}^{-\frac{1}{2}\left(\frac{\mathrm{x}-\mu}{\sigma}\right)^{2}} \\
\text { Função de distribuição: } & \mathrm{F}(\mathrm{x})=\Phi\left(\frac{\mathrm{x}-\mu}{\sigma}\right)=\int_{-\infty}^{\frac{\mathrm{x}-\mu}{\sigma}} \varphi(\mathrm{u}) \mathrm{du}
\end{array}
$$

Região de validade: $-\infty \leq \mathrm{x} \leq \infty$

Restrição de parâmetro: $\sigma>0$

Média: $\mu \quad$; $\quad$ Desvio padrão: $\sigma$

\section{Lognormal}

$$
\begin{array}{ll}
\text { Função densidade: } & f(x)=\frac{1}{\sigma} \varphi\left(\frac{\ln x-\mu}{\sigma}\right)=\frac{1}{\sqrt{2 \pi} \times \delta} e^{-\frac{1}{2}\left(\frac{\ln (\mathrm{x} / \xi)}{\delta}\right)^{2}} \\
\text { Função de distribuição: } & \mathrm{F}(\mathrm{x})=\Phi\left(\frac{\ln \mathrm{x}-\mu}{\sigma}\right)
\end{array}
$$

Região de validade: $0 \leq \mathrm{x} \leq \infty$

Restrição de parâmetro: $\delta>0$, e $\xi>0$

Média: $\xi \mathrm{e}^{\delta^{2} / 2}$

Desvio padrão: $\sigma$ 


\section{Exponencial}

Função densidade: $\quad f(x)=\lambda e^{-\lambda(x-\tau)}$

Função de distribuição: $\quad F(x)=1-e^{-\lambda(x-\tau)}$

Região de validade: $\tau \leq \mathrm{x} \leq \infty$

Restrição de parâmetro: $\lambda>0$

Média: $\tau+\frac{1}{\lambda}$

Desvio padrão: $\frac{1}{\lambda}$

\section{Gamma}

$$
\text { Função densidade: } \quad f(x)=\frac{1}{\Gamma(k)} \lambda(\lambda x)^{k-1} e^{-\lambda x}
$$

Região de validade: $0 \leq \mathrm{x} \leq \infty$

Restrição de parâmetro: $\lambda>0$ e $\mathrm{k}>0$

Média: $\frac{\mathrm{k}}{\lambda}$

Desvio padrão: $\frac{\sqrt{\mathrm{k}}}{\lambda}$

\section{Beta}

$$
\text { Função densidade: } \quad f(x)=\frac{\left(\frac{x-a}{b-a}\right)^{r-1}\left(1-\frac{x-a}{b-a}\right)^{t-1}}{B(r, t)(b-a)}
$$

Região de validade: $\mathrm{a} \leq \mathrm{x} \leq \mathrm{b}$

Restrição de parâmetro: $a<b ; r>0$ e t $>0$

Média: $a+(b-a) \frac{r}{r+t}$

Desvio padrão: $(b-a) \sqrt{\frac{r t}{(r+t)^{2}(r+t+1)}}$ 


\section{Gumbel (max, Type I)}

Função densidade: $\quad \mathrm{f}(\mathrm{x})=\alpha \mathrm{e}^{-\alpha(\mathrm{x}-\mathrm{u})-\mathrm{e}^{-\alpha(\mathrm{x}-\mathrm{u})}}$

Região de validade: $-\infty \leq \mathrm{x} \leq \infty$

Restrição de parâmetro: $\alpha>0$

Média: $\mathrm{u}+\frac{\mathrm{C}}{\alpha}$

Desvio padrão: $\frac{1}{\alpha} \frac{\pi}{\sqrt{6}}$

\section{Ferchet (max, Type II)}

$$
\text { Função densidade: } \quad f(x)=\frac{k}{(v-\tau)}\left(\frac{v-\tau}{x-\tau}\right)^{k+1} e^{-\left(\frac{v-\tau}{x-\tau}\right)^{k}}
$$

Região de validade: $\tau \leq \mathrm{x} \leq \infty$

Restrição de parâmetro: $v>\tau$ e $k>0$

Média: $(v-\tau) \Gamma\left(1-\frac{1}{\mathrm{k}}\right)+\tau \quad$ para $(\mathrm{k}>1)$

Desvio padrão: $(v-\tau) \sqrt{\Gamma\left(1-\frac{2}{\mathrm{k}}\right)-\Gamma^{2}\left(1+\frac{1}{\mathrm{k}}\right)} \quad$ para $(\mathrm{k}>2)$

\section{Weibull (max, Type III)}

$$
\text { Função densidade: } \quad f(x)=\frac{k}{(w-\tau)}\left(\frac{x-\tau}{w-\tau}\right)^{k-1} e^{-\left(\frac{x-\tau}{w-\tau}\right)^{k}}
$$

Região de validade: $\tau \leq \mathrm{x} \leq \infty$

Restrição de parâmetro: $w>\tau$ e $k>0$

Média: $(\mathrm{w}-\tau) \Gamma\left(1-\frac{1}{\mathrm{k}}\right)+\tau$

Desvio padrão: $(\mathrm{w}-\tau) \mathrm{b} \sqrt{\Gamma\left(1+\frac{2}{\mathrm{k}}\right)-\Gamma^{2}\left(1+\frac{1}{\mathrm{k}}\right)}$ 


\section{Shifted Lognormal}

$$
\text { Função densidade: } \quad \mathrm{f}(\mathrm{x})=\frac{1}{\sqrt{2 \pi}(\mathrm{x}-\tau) \delta} \mathrm{e}^{-\frac{1}{2}\left(\frac{\ln ((\mathrm{x}-\tau) / \xi)}{\delta}\right)^{2}}
$$

Região de validade: $\tau \leq \mathrm{x} \leq \infty$

Restrição de parâmetro: $\delta>0$ e $\xi>0$

Média: $\tau+\xi \mathrm{e}^{\delta^{2} / 2}$

Desvio padrão: $\xi \mathrm{e}^{\delta^{2} / 2} \sqrt{\mathrm{e}^{\delta^{2}}-1}$

\section{Rayleigh}

Função densidade: $\quad f(x)=\frac{x-\tau}{\alpha^{2}} e^{-\frac{(x-\tau)^{2}}{2 \alpha^{2}}}$

Região de validade: $\tau \leq \mathrm{x} \leq \infty$

Restrição de parâmetro: $\alpha>0$

Média: $\tau+\alpha \sqrt{\frac{\pi}{2}}$

Desvio padrão: $\alpha \sqrt{2-\frac{\pi}{2}}$

\section{Standard Student}

$$
\text { Função densidade: } \quad f(x)=\frac{1}{\sqrt{v \pi}} \frac{\Gamma\left(\frac{v+1}{2}\right)}{\Gamma\left(\frac{v}{2}\right)}\left(1+\frac{x^{2}}{v}\right)^{-\frac{v+1}{2}}
$$

Região de validade: $-\infty \leq \mathrm{x} \leq \infty$

Restrição de parâmetro: $v>0$

Média: 0

Desvio padrão: $\sqrt{\frac{v}{v-2}} \quad$ para $v>2$ 


\section{Trapezoidal}

Função densidade: $\quad \mathrm{f}(\mathrm{x})$ corresponde à partes da função linear

Região de validade: $\mathrm{a} \leq \mathrm{x} \leq \mathrm{d}$

Restrição de parâmetro: $\mathrm{a}<\mathrm{b}<\mathrm{c}<\mathrm{d}$

Média:

Desvio padrão:

\section{Birnbaum/Saunders}

Função densidade: $\quad f(x)=\frac{\beta^{1 / 2}\left(1+\frac{x}{\beta}\right)}{2 \alpha x^{3 / 2}} \varphi\left[\frac{1}{\alpha}\left(\left(\frac{x}{\beta}\right)^{1 / 2}-\left(\frac{x}{\beta}\right)^{-1 / 2}\right)\right]$

Região de validade: $0 \leq \mathrm{x} \leq \infty$

Restrição de parâmetro: $\alpha>0$ e $\beta>0$

Média: $\beta\left(1+\frac{\alpha^{2}}{2}\right)$

Desvio padrão: $\alpha \beta \sqrt{1+\frac{5 \alpha^{2}}{4}}$

\section{Cauchy}

$$
\text { Função densidade: } \quad \mathrm{f}(\mathrm{x})=\frac{1}{\pi \lambda\left[1+\left(\frac{(\mathrm{x}-\theta)}{\lambda}\right)^{2}\right]}
$$

Região de validade: $-\infty \leq \mathrm{x} \leq \infty$

Restrição de parâmetro: $\lambda>0$

Média: não existe, infinito

Desvio padrão: não existe, infinito

\section{Shifted Gamma}

Função densidade: $\quad \mathrm{f}(\mathrm{x})=\frac{1}{\Gamma(\mathrm{k})} \lambda(\lambda(\mathrm{x}-\tau))^{\mathrm{k}-1} \mathrm{e}^{-\lambda(\mathrm{x}-\tau)}$

Região de validade: $\tau \leq \mathrm{x} \leq \infty$ 
Restrição de parâmetro: $\lambda>0$ e $\mathrm{k}>0$

Média: $\tau+\frac{\mathrm{k}}{\lambda}$

Desvio padrão: $\frac{\sqrt{\mathrm{k}}}{\lambda}$

\section{Gauss Inversa}

$$
\text { Função densidade: } \quad f(x)=\sqrt{\frac{\lambda}{2 \pi x^{3}}} e^{-\frac{\lambda(x-\mu)^{2}}{2 \mu^{2} x}}
$$

Região de validade: $0 \leq \mathrm{x} \leq \infty$

Restrição de parâmetro: $\lambda>0$ e $\mu>0$

Média: $\mu$

Desvio padrão: $\frac{\mu^{3 / 2}}{\sqrt{\lambda}}$

\section{Gumbel (min, Type I)}

Função densidade: $\quad f(x)=\alpha e^{\alpha(x-u)-e^{\alpha(x-u)}}$

Região de validade: $-\infty \leq \mathrm{x} \leq \infty$

Restrição de parâmetro: $\alpha>0$

Média: $\mathrm{u}-\frac{\mathrm{C}}{\alpha}$

Desvio padrão: $\frac{1}{\alpha} \frac{\pi}{\sqrt{6}}$

\section{Ferchet (min, Type II)}

$$
\text { Função densidade: } \quad f(x)=\frac{k}{(w-v)}\left(\frac{w-v}{w-x}\right)^{k+1} e^{-\left(\frac{w-v}{w-x}\right)^{k}}
$$

Região de validade: $-\infty \leq \mathrm{x} \leq \mathrm{w}$

Restrição de parâmetro: $\mathrm{w}>\mathrm{v}$ e $\mathrm{k}>0$

Média: $\mathrm{w}-(\mathrm{w}-\mathrm{v}) \Gamma\left(1-\frac{1}{\mathrm{k}}\right)+\tau$ para $(\mathrm{k}>1)$ 
Desvio padrão: $(\mathrm{w}-\tau) \sqrt{\Gamma\left(1-\frac{2}{\mathrm{k}}\right)-\Gamma^{2}\left(1-\frac{1}{\mathrm{k}}\right)} \quad$ para $(\mathrm{k}>2)$

\section{Weibull (min, Type III)}

$$
\text { Função densidade: } \quad f(x)=\frac{k}{(w-v-\tau)}\left(\frac{w-x}{w-v}\right)^{k-1} e^{-\left(\frac{w-x}{w-v}\right)^{k}}
$$

Região de validade: $-\infty \leq \mathrm{x} \leq \mathrm{w}$

Restrição de parâmetro: $\mathrm{w}>\mathrm{v}$ e $\mathrm{k}>0$

Média: $w-(w-v) \Gamma\left(1+\frac{1}{\mathrm{k}}\right)$

Desvio padrão: $(\mathrm{w}-\mathrm{v}) \sqrt{\Gamma\left(1+\frac{2}{\mathrm{k}}\right)-\Gamma^{2}\left(1+\frac{1}{\mathrm{k}}\right)}$

\section{Pareto}

$$
\text { Função densidade: } \quad f(x)=\frac{a^{a}}{x^{a+1}}
$$

Região de validade: $\mathrm{k} \leq \mathrm{x}$

Restrição de parâmetro: $a>0$ e k >0

Média: $\frac{\mathrm{ak}}{\mathrm{a}-1}$ para a $>1$

Desvio padrão: $\frac{k}{a-1} \sqrt{\frac{a}{a-2}} \quad$ para $a>2$

\section{Laplace}

$$
\text { Função densidade: } \quad \mathrm{f}(\mathrm{x})=\frac{1}{2 \phi} \mathrm{e}^{-\frac{|\mathrm{x}-\theta|}{\phi}}
$$

Região de validade: $-\infty \leq \mathrm{x} \leq \infty$

Restrição de parâmetro: $\phi>0$

Média: $\theta$

Desvio padrão: $\sqrt{2} \phi$ 


\section{Logistic}

$$
\text { Função densidade: } \quad f(x)=\frac{\pi}{\sigma \sqrt{3}} \frac{e^{-\pi \frac{x-\mu}{\sigma \sqrt{3}}}}{\left.1+e^{-\pi \frac{x-\mu}{\sigma \sqrt{3}}}\right]}
$$

Região de validade: $-\infty \leq \mathrm{x} \leq \infty$

Restrição de parâmetro: $\sigma>0$

Média: $\mu$

Desvio padrão: $\sigma$

\section{Halfnormal}

$$
\text { Função densidade: } \quad f(x)=\frac{2}{\sigma} \varphi\left(\frac{x-\mu}{\sigma}\right)=\frac{2}{\sqrt{2 \pi} \sigma} e^{-\frac{1}{2}\left(\frac{x-\mu}{\sigma}\right)^{2}}
$$

Região de validade: $\mu \leq \mathrm{x} \leq \infty$

Restrição de parâmetro: $\sigma, \mu>0$

Média: $\mu+\sqrt{\frac{2}{\pi}} \sigma$

Desvio padrão: $\sigma \sqrt{1-\frac{2}{\pi}}$

\section{Central Chi-Square}

$$
\text { Função densidade: } \quad f(x)=\frac{2^{v / 2}}{\Gamma(v / 2)} x^{v / 2-1} e^{-x / 2}
$$

Região de validade: $0 \leq \mathrm{x} \leq \infty$ Restrição de parâmetro: $v>0$

Média: v

Desvio padrão: $\sqrt{2 v}$ 


\section{Central Fisher $F$}

$$
\text { Função densidade: } \quad f(x)=\frac{\Gamma\left(\frac{v_{1}+v_{2}}{2}\right)\left(\frac{v_{1}}{v_{2}}\right)^{v_{1} / 2} x^{v_{1} / 2-1}}{\Gamma\left(\frac{v_{1}}{2}\right) \Gamma\left(\frac{v_{2}}{2}\right)\left(1+\frac{v_{1}}{v_{2}} x\right)^{\left(\frac{v_{1}+v_{2}}{2}\right)}}
$$

Região de validade: $0 \leq \mathrm{x} \leq \infty$

Restrição de parâmetro: $v_{1}, v_{2}>0$

Média: $\frac{v_{2}}{v_{2}-2}$

para $v_{2}>2$

Desvio padrão: $\frac{2 v_{2}^{2}\left(v_{1}+v_{2}-2\right)}{v_{1}\left(v_{2}-2\right)^{2}\left(v_{2}-4\right)}$ para $v_{2}>4$

\section{Student}

Função densidade: $\quad f(x)=\frac{1}{\sqrt{v \pi}} \frac{\Gamma\left(\frac{v+1}{2}\right)}{\sigma \Gamma\left(\frac{v}{2}\right)}\left(1+\frac{t^{2}}{v}\right)^{-\frac{v+1}{2}} ; t=\frac{x-\mu}{\sigma}$

Região de validade: $-\infty \leq \mathrm{x} \leq \infty$

Restrição de parâmetro: $v, \sigma>0$

Média: $\mu$

para $v>1$

Desvio padrão: $\sigma \sqrt{\frac{v}{v-2}}$

para $v>2$

\section{Neville}

$$
\text { Função densidade: } \quad f(x)=\frac{k}{r} \frac{\rho(x)^{k-1}}{\left(1+\rho(x)^{k}\right)^{2}} ; \quad \rho(x)=\frac{x-\tau}{r}
$$

Região de validade: $\mathrm{r} \leq \mathrm{x} \leq \infty$

Restrição de parâmetro: $\mathrm{k}, \mathrm{r}>0$

Média: não analítica

para $\mathrm{k}>1$

Desvio padrão: não analítica

$$
\text { para } \mathrm{k}>2
$$


29. Hermite

Função densidade: $\quad \mathrm{f}(\mathrm{x})=\frac{1}{\sigma} \varphi(\mathrm{y})\left[1+\frac{\gamma}{6}\left(\mathrm{y}^{2}-1\right)+\frac{\varepsilon-3}{24}\left(\mathrm{y}^{3}-3 \mathrm{y}\right)\right]$;

$$
y=\frac{x-\mu}{\sigma}
$$

Região de validade: $-\infty \leq \mathrm{x} \leq \infty$

Restrição de parâmetro: $\varepsilon, \sigma>0$

Média: $\mu$

Desvio padrão: $\sigma$ 


\section{Anexo C Coeficiente f, transformação de Nataf}

Na transformação isoprobabilística de Nataf aparece a seguinte expressão:

$$
\rho_{12}=\int_{-\infty}^{\infty} \int_{-\infty}^{\infty}\left(\frac{x_{1}-\mu_{1}}{\sigma_{1}}\right)\left(\frac{x_{2}-\mu_{2}}{\sigma_{2}}\right) \varphi_{2}\left(\hat{u}_{1}, \hat{u}_{2}, \rho_{0,12}\right) d \hat{u}_{1} d \hat{u}_{2}
$$

onde:

$\mathrm{x}_{1}$ e $\mathrm{x}_{2}$ são duas variáveis aleatórias correlacionadas;

$\hat{\mathrm{u}}_{1} \mathrm{e} \hat{\mathrm{u}}_{2}$ são as variáveis normais padronizadas, correlacionadas, correspondentes à $\mathrm{x}_{1} \mathrm{e}$ $\mathrm{x}_{2}$;

$\mu_{\mathrm{i}}$ e $\sigma_{\mathrm{i}}$ são, respectivamente a média e o desvio padrão das duas variáveis;

$\varphi_{2}\left(\hat{\mathrm{u}}_{1}, \hat{\mathrm{u}}_{2}, \rho_{0,12}\right)$ é a função densidade padrão de dimensão 2 , com média nula, desvio padrão unitário;

$\rho_{0,12}$ é o coeficiente de correlação entre as variáveis que pode ser obtido através de ensaios em laboratórios, os quais variam entre -1 e +1 ;

$\rho_{12}$ é a correlação no espaço físico.

De acordo com a transformação de Nataf, para simplificarem-se os cálculos da expressão (1), introduziu-se um coeficiente $\mathrm{f}$ definido pela seguinte expressão:

$$
\mathrm{f}=\frac{\rho_{0,12}}{\rho_{12}} \quad \therefore \quad \rho_{12}=\frac{\rho_{0,12}}{\mathrm{f}}
$$

Conhecendo-se as distribuições marginais das variáveis $x_{i}$ e $x_{j}$, os coeficientes $f$ são fornecidos na Tabela 2 à Tabela 6, as quais foram extraídas de MOHAMED (1999). As expressões que fornecem $\mathrm{f}$ são funções dos coeficientes de variação $C V x_{i}$, dos coeficientes de correlação $\rho_{\mathrm{ij}}$ e das distribuições marginais de ambas as variáveis.

As distribuições marginais são divididas em dois grupos:

$\checkmark$ Grupo I: Uniforme $(U)$, Exponencial $(E)$, Rayleigh $(R)$, Extremo tipo 1-max $(E 1 M)$ e Extremo tipo 1-min $(E 1 m)$.

$\checkmark$ Grupo II: Lognormal $(L N)$, Gamma $(G)$, Extremo tipo II $(E 2 M)$ e 
Extremo tipo III $(W)$.

Tabela $2 \mathrm{f}=$ cte, xi é normalmente distribuído e xj pertence ao grupo I

\begin{tabular}{|c|c|}
\hline Distribuição & Valor de $\mathrm{f}$ \\
\hline$U$ & 1.023 \\
\hline$E$ & 1.107 \\
\hline$R$ & 1.014 \\
\hline$E 1 M$ & 1.031 \\
\hline$E 1 m$ & 1.031 \\
\hline
\end{tabular}

Tabela $3 \mathrm{f}=\mathrm{f}\left(\mathrm{CVx}_{\mathrm{j}}\right)$, xi é normalmente distribuído e $\mathrm{xj}$ pertence ao grupo II

\begin{tabular}{|c|c|}
\hline Distribuição & Valor de $\mathrm{f}$ \\
\hline$L N$ & $\mathrm{CVx}_{\mathrm{j}} / \sqrt{\ln \left(1+\mathrm{CVx}_{\mathrm{j}}^{2}\right)}$ \\
\hline$G$ & $1.001-0.007 \mathrm{CVx}_{\mathrm{j}}+0.118 \mathrm{CVx}_{\mathrm{j}}^{2}$ \\
\hline$E 2 M$ & $1.030+0.238 \mathrm{CVx}_{\mathrm{j}}+0.364 \mathrm{CVx}_{\mathrm{j}}^{2}$ \\
\hline$W$ & $1.031-0.195 \mathrm{CVx}_{\mathrm{j}}+0.328 \mathrm{CVx}_{\mathrm{j}}^{2}$ \\
\hline
\end{tabular}

Tabela $4 \mathrm{f}=\mathrm{f}\left(\rho_{\mathrm{ij}}\right)$, xi e xj pertencem ao grupo I

\begin{tabular}{|c|c|c|c|}
\hline Distribuição & $U$ & $E$ & $E 1 M$ \\
\hline$U$ & $1.047-0.047 \rho^{2}$ & $1.133+0.029 \rho^{2}$ & $1.055+0.015 \rho^{2}$ \\
\hline$E$ & $1.133+0.029 \rho^{2}$ & $1.229-0.367 \rho+0.153 \rho^{2}$ & $1.142-0.154 \rho+0.031 \rho^{2}$ \\
\hline$E 1 M$ & $1.055+0.015 \rho^{2}$ & $1.142-0.154 \rho+0.031 \rho^{2}$ & $1.064-0.069 \rho+0.005 \rho^{2}$ \\
\hline
\end{tabular}

Tabela $5 \mathrm{f}=\mathrm{f}\left(\rho_{\mathrm{ij}}, \mathrm{CVx_{j }}\right)$, xi pertence ao grupo I e xj pertence ao grupo II

\begin{tabular}{|c|c|}
\hline Distribuição & $1.019+0.014 \mathrm{CVx}_{\mathrm{j}}+0.010 \rho^{2}+0.249 \mathrm{CVx}_{\mathrm{j}}^{2}$ \\
\hline$L N$ & $1.023-0.007 \mathrm{CVx}_{\mathrm{j}}+0.002 \rho^{2}+0.127 \mathrm{CVx}_{\mathrm{j}}^{2}$ \\
\hline$G$ & $1.061-0.237 \mathrm{CVx}_{\mathrm{j}}-0.005 \rho^{2}+0.379 \mathrm{CVx}_{\mathrm{j}}^{2}$ \\
\hline$W$ & $E$ \\
\hline Distribuição & $1.098+0.003 \rho+0.019 \mathrm{CVx}_{\mathrm{j}}+0.025 \rho^{2}+0.303 \mathrm{CVx}_{\mathrm{j}}^{2}-0.437 \rho C V \mathrm{x}_{\mathrm{j}}$ \\
\hline$L N$ & $1.104+0.003 \rho-0.008 \mathrm{CVx}{ }_{\mathrm{j}}+0.014 \rho^{2}+0.173 \mathrm{CVx}_{\mathrm{j}}^{2}-0.296 \rho C V \mathrm{x}_{\mathrm{j}}$ \\
\hline$G$ & $1.147+0.145 \rho-0.271 C V \mathrm{x}_{\mathrm{j}}+0.010 \rho^{2}+0.459 \mathrm{CVx}_{\mathrm{j}}^{2}-0.467 \rho C V \mathrm{x}_{\mathrm{j}}$ \\
\hline$W$ & $1.029+0.001 \rho+0.014 \mathrm{CVx}_{\mathrm{j}}+0.004 \rho^{2}+0.233 \mathrm{CVx}_{\mathrm{j}}^{2}-0.197 \rho C V \mathrm{x}_{\mathrm{j}}$ \\
\hline Distribuição & $1.031+0.001 \rho-0.007 \mathrm{CVx}{ }_{\mathrm{j}}+0.004 \rho^{2} \mathrm{CVx}_{\mathrm{j}} \rho^{2} \mathrm{CVx}_{\mathrm{j}} \rho^{2}$ \\
\hline$L N$ & $1.064+0.065 \rho-0.210 \mathrm{CVx}{ }_{\mathrm{j}}+0.003 \rho^{2}+0.356 \mathrm{CVx}_{\mathrm{j}}^{2}-0.211 \rho C V \mathrm{x}_{\mathrm{j}}$ \\
\hline$G$
\end{tabular}


Tabela $6 \mathrm{f}=\mathrm{f}\left(\rho_{\mathrm{ij}}, \mathrm{CVx}_{\mathrm{i}}, \mathrm{CVx}_{\mathrm{j}}\right)$, xi e xj pertencem ao grupo II

\begin{tabular}{|c|c|}
\hline Distribuição & $L N$ \\
\hline \multirow[t]{2}{*}{$L N$} & $\ln \left(1+\rho C V x_{i} C V x_{j}\right)$ \\
\hline & $\rho \sqrt{\ln \left(1+\rho C V x_{i}^{2}\right) \ln \left(1+\rho C V x_{j}^{2}\right)}$ \\
\hline \multirow[t]{2}{*}{$G$} & $1.001+0.033 \rho+0.004 \mathrm{CVx}_{\mathrm{i}}-0.016 \mathrm{CVx}_{\mathrm{j}}+0.002 \rho^{2}+0.223 \mathrm{CVx}_{\mathrm{i}}^{2}$ \\
\hline & $+0.130 \mathrm{CVx}_{\mathrm{j}}^{2}-0.104 \rho C V \mathrm{x}_{\mathrm{i}}-0.119 \rho \mathrm{CV} \mathrm{x}_{\mathrm{j}}+0.029 \mathrm{CVx_{ \textrm {i } }} \mathrm{CVx}_{\mathrm{j}}$ \\
\hline \multirow[t]{2}{*}{$W$} & $1.031+0.052 \rho+0.011 \mathrm{CVx}_{\mathrm{i}}-0.210 \mathrm{CVx}_{\mathrm{j}}+0.002 \rho^{2}+0.220 \mathrm{CVx}_{\mathrm{i}}^{2}$ \\
\hline & $+0.350 C V x_{j}^{2}+0.005 \rho C V x_{i}-0.174 \rho C V x_{j}+0.009 C V x_{i} C V x_{j}$ \\
\hline Distribuição & $G$ \\
\hline \multicolumn{2}{|l|}{$L N$} \\
\hline \multirow[t]{2}{*}{ G } & $1.002+0.022 \rho-0.012\left(\mathrm{CVx}_{\mathrm{i}}+\mathrm{CVx}_{\mathrm{j}}\right)+0.001 \rho^{2}+0.125\left(\mathrm{CVx}_{\mathrm{i}}^{2}+\mathrm{CVx}_{\mathrm{j}}^{2}\right)$ \\
\hline & $-0.077 \rho\left(\mathrm{CVx}_{\mathrm{i}}+\mathrm{CVx_{j }}\right)-0.140 \mathrm{CVx_{i }} \mathrm{CVx}_{\mathrm{j}}$ \\
\hline \multirow[t]{2}{*}{$W$} & $1.032+0.034 \rho-0.007 \mathrm{CVx}_{\mathrm{i}}-0.202 \mathrm{CVx}_{\mathrm{j}}+0.121 \mathrm{CVx_{ \textrm {i } } ^ { 2 }}$ \\
\hline & $+0.339 \mathrm{CVx}_{\mathrm{j}}^{2}-0.006 \rho C V \mathrm{x}_{\mathrm{i}}-0.111 \rho \mathrm{CV} \mathrm{x}_{\mathrm{j}}+0.003 \mathrm{CV} \mathrm{x}_{\mathrm{i}} \mathrm{CVx}_{\mathrm{j}}$ \\
\hline Distribuição & $W$ \\
\hline \multicolumn{2}{|l|}{$L N$} \\
\hline \multicolumn{2}{|l|}{$G$} \\
\hline$W$ & $1.063-0.004 \rho-0.200\left(\mathrm{CVx}_{\mathrm{i}}+\mathrm{CVx}_{\mathrm{j}}\right)-0.001 \rho^{2}+0.337\left(\mathrm{CVx}_{\mathrm{i}}^{2}+\mathrm{CVx}_{\mathrm{j}}^{2}\right)$ \\
\hline & $+0.007 \rho\left(\mathrm{CVx}_{\mathrm{i}}+\mathrm{CVx}_{\mathrm{j}}\right)-0.007 \mathrm{CVx}_{\mathrm{i}} \mathrm{CVx}_{\mathrm{j}}$ \\
\hline
\end{tabular}




\section{Anexo D Plano de experiência}

Existem várias formas de planos de experiência disponíveis na literatura, das quais algumas são descritas em seguida para problemas bidimensionais. É necessário calibrar cada EP para o tipo de estrutura em análise. As propostas de coeficientes citadas nos próximos itens para a construção de planos de experiência foram testadas para estruturas de barras bidimensionais com comportamento não-linear, mostrando ser adequadas para este tipo de estrutura. Os coeficientes propostos são adequados para uma aproximação quadrática e cúbica no RSM.

É importante observar-se que o EP é construído no espaço reduzido para garantir que o EP inicial do processo iterativo do RSM esteja localizado em torno da média, acelerando a convergência.

$\mathrm{Na}$ construção de um EP é interessante ponderar seus coeficientes com características implícitas das variáveis aleatórias. No caso, optou-se por construir os planos de experiência ponderando seus coeficientes com os momentos estatísticos das variáveis aleatórias envolvidas. Para isso, considere a variável definida na expressão (3).

$$
\delta_{\mathrm{i}}=\frac{\sigma_{\mathrm{i}}}{\overline{\mathrm{x}}_{\mathrm{i}}}
$$

onde $\bar{x}_{\mathrm{i}}$ e $\sigma_{\mathrm{i}}$ referem-se a média e o desvio padrão da variável i, respectivamente.

O número de pontos $\left(\mathrm{n}_{\mathrm{pr}}\right)$ para a construção de um EP depende do número de coeficientes $\left(\mathrm{n}_{\mathrm{c}}\right)$ do polinômio aproximador da superfície de resposta, que por sua vez depende do número de variáveis aleatórias envolvidas no problema. A seguir lista-se o número de pontos $\left(\mathrm{n}_{\mathrm{pr}}\right)$ de cada plano descrido neste anexo. Para um polinômio aproximador do segundo grau, tem-se a seguinte relação entre o número de variáveis aleatórias e o número de coeficientes:

\begin{tabular}{|c|c|c|c|c|c|c|}
\hline $\mathrm{n}^{\mathrm{o}} \mathrm{VA}=\mathrm{n}_{\mathrm{va}}$ & 1 & 2 & 3 & 4 & 5 & 6 \\
\hline $\mathrm{n}_{\mathrm{c}}$ & 3 & 6 & 10 & 15 & 21 & 28 \\
\hline
\end{tabular}


$\checkmark$ Plano estrela: $\left\{\begin{array}{l}\mathrm{n}_{\mathrm{va}}=1 \therefore \mathrm{n}_{\mathrm{pr}}=\mathrm{n}_{\mathrm{c}} \\ \mathrm{n}_{\mathrm{va}}>1 \therefore \mathrm{n}_{\mathrm{pr}}=\mathrm{n}_{\mathrm{c}}-1\end{array}\right.$

$\checkmark$ Plano estrela 45 ou hiper-cubo: $\left\{\begin{array}{l}\mathrm{n}_{\mathrm{va}}=1 \therefore \mathrm{n}_{\mathrm{pr}}=\mathrm{n}_{\mathrm{c}} \\ \mathrm{n}_{\mathrm{va}}>1 \therefore \mathrm{n}_{\mathrm{pr}}=\mathrm{n}_{\mathrm{c}}-1\end{array}\right.$

$\checkmark$ Plano fatorial completo: $\quad\left\{n_{\text {pr }}=3^{n_{\text {va }}}\right.$

$\checkmark$ Plano mínimo: $\quad\left\{\mathrm{n}_{\mathrm{pr}}=\mathrm{n}_{\mathrm{c}}\right.$

$\checkmark$ Plano composto: $\left\{\begin{array}{l}\mathrm{n}_{\mathrm{va}}=1 \therefore \mathrm{n}_{\mathrm{pr}}=5 \\ \mathrm{n}_{\mathrm{va}}>1 \therefore \mathrm{n}_{\mathrm{pr}}=9\left(\mathrm{n}_{\mathrm{va}}-1\right)\end{array}\right.$

\section{Plano de experiência numérico Estrela}

A forma do EP Estrela para casos bidimensionais pode ser vista na Figura 1.

\section{Estrela}

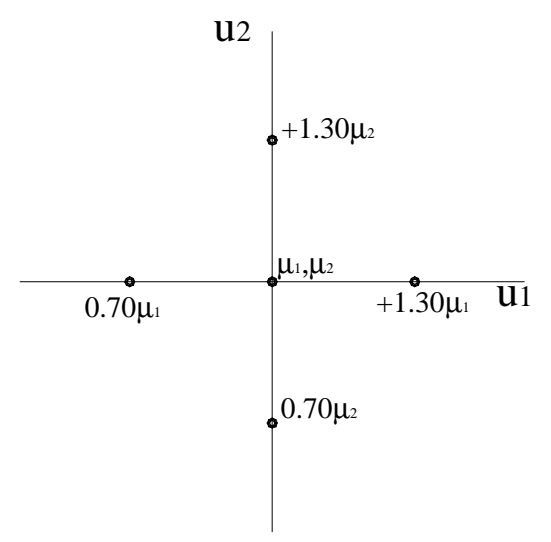

Figura 1 Plano de experiência Estrela

Uma observação a ser feita para os planos de experiência Estrela e Hiper-cubo é com relação ao seus números de pontos. Nota-se que o número de pontos é menor que o número de coeficientes do polinômio de segundo grau utilizado para aproximar a RS da estrutura. Portanto, para encontrar os coeficientes do polinômio através de regressão alguns de seus termos devem ser eliminados para evitar a singularidade do sistema de equações. Preferencialmente não deve ser eliminado o termo independente nem os termos que dependem exclusivamente de uma única variável aleatória. Como não se conhecem as respostas do problema a eliminação desses termos pode empobrecer o algoritmo.

Os coeficientes propostos para problemas com 1 variável aleatória são: 


$$
\left\{\overline{\mathrm{x}}_{1} \quad \overline{\mathrm{x}}_{1}\left(1-3 \delta_{1}\right) \quad \overline{\mathrm{x}}_{1}\left(1+3 \delta_{1}\right)\right\}
$$

Os coeficientes propostos para problemas com 2 variáveis aleatórias são:

$$
\left[\begin{array}{cc}
\overline{\mathrm{x}}_{1} & \overline{\mathrm{x}}_{2} \\
\overline{\mathrm{x}}_{1}\left(1-3 \delta_{1}\right) & \overline{\mathrm{x}}_{2} \\
\overline{\mathrm{x}}_{1}\left(1+3 \delta_{1}\right) & \overline{\mathrm{x}}_{2} \\
\overline{\mathrm{x}}_{1} & \overline{\mathrm{x}}_{2}\left(1-3 \delta_{2}\right) \\
\overline{\mathrm{x}}_{1} & \overline{\mathrm{x}}_{2}\left(1+3 \delta_{2}\right)
\end{array}\right]
$$

Os coeficientes propostos para problemas com 3 variáveis aleatórias são:

$$
\left[\begin{array}{ccc}
\overline{\mathrm{x}}_{1} & \overline{\mathrm{x}}_{2} & \overline{\mathrm{x}}_{3} \\
\overline{\mathrm{x}}_{1}\left(1-3 \delta_{1}\right) & \overline{\mathrm{x}}_{2} & \overline{\mathrm{x}}_{3} \\
\overline{\mathrm{x}}_{1}\left(1+3 \delta_{1}\right) & \overline{\mathrm{x}}_{2} & \overline{\mathrm{x}}_{3} \\
\overline{\mathrm{x}}_{1} & \overline{\mathrm{x}}_{2}\left(1-3 \delta_{2}\right) & \overline{\mathrm{x}}_{3} \\
\overline{\mathrm{x}}_{1} & \overline{\mathrm{x}}_{2}\left(1+3 \delta_{2}\right) & \overline{\mathrm{x}}_{3} \\
\overline{\mathrm{x}}_{1} & \overline{\mathrm{x}}_{2} & \overline{\mathrm{x}}_{3}\left(1-3 \delta_{3}\right) \\
\overline{\mathrm{x}}_{1}\left(1-3 \delta_{1}\right) & \overline{\mathrm{x}}_{2} & \overline{\mathrm{x}}_{3}\left(1-3 \delta_{3}\right) \\
\overline{\mathrm{x}}_{1}\left(1+3 \delta_{1}\right) & \overline{\mathrm{x}}_{2} & \overline{\mathrm{x}}_{3}\left(1-3 \delta_{3}\right) \\
\overline{\mathrm{x}}_{1} & \overline{\mathrm{x}}_{2}\left(1-3 \delta_{2}\right) & \overline{\mathrm{x}}_{3}\left(1-3 \delta_{3}\right)
\end{array}\right]
$$

Os coeficientes propostos para problemas com 4 variáveis aleatórias são:

$$
\left[\begin{array}{cccc}
\overline{\mathrm{x}}_{1} & \overline{\mathrm{x}}_{2} & \overline{\mathrm{x}}_{3} & \overline{\mathrm{x}}_{4} \\
\overline{\mathrm{x}}_{1}\left(1-3 \delta_{1}\right) & \overline{\mathrm{x}}_{2} & \overline{\mathrm{x}}_{3}\left(1-3 \delta_{3}\right) & \overline{\mathrm{x}}_{4}\left(1-3 \delta_{4}\right) \\
\overline{\mathrm{x}}_{1}\left(1+3 \delta_{1}\right) & \overline{\mathrm{x}}_{2} & \overline{\mathrm{x}}_{3}\left(1-3 \delta_{3}\right) & \overline{\mathrm{x}}_{4}\left(1-3 \delta_{4}\right) \\
\overline{\mathrm{x}}_{1} & \overline{\mathrm{x}}_{2}\left(1-3 \delta_{2}\right) & \overline{\mathrm{x}}_{3}\left(1-3 \delta_{3}\right) & \overline{\mathrm{x}}_{4}\left(1-3 \delta_{4}\right) \\
\overline{\mathrm{x}}_{1} & \overline{\mathrm{x}}_{2}\left(1+3 \delta_{2}\right) & \overline{\mathrm{x}}_{3}\left(1-3 \delta_{3}\right) & \overline{\mathrm{x}}_{4}\left(1-3 \delta_{4}\right) \\
\overline{\mathrm{x}}_{1} & \overline{\mathrm{x}}_{2} & \overline{\mathrm{x}}_{3}\left(1+3 \delta_{3}\right) & \overline{\mathrm{x}}_{4}\left(1+3 \delta_{4}\right) \\
\overline{\mathrm{x}}_{1}\left(1-3 \delta_{1}\right) & \overline{\mathrm{x}}_{2} & \overline{\mathrm{x}}_{3}\left(1+3 \delta_{3}\right) & \overline{\mathrm{x}}_{4}\left(1+3 \delta_{4}\right) \\
\overline{\mathrm{x}}_{1}\left(1+3 \delta_{1}\right) & \overline{\mathrm{x}}_{2} & \overline{\mathrm{x}}_{3}\left(1+3 \delta_{3}\right) & \overline{\mathrm{x}}_{4}\left(1+3 \delta_{4}\right) \\
\overline{\mathrm{x}}_{1} & \overline{\mathrm{x}}_{2}\left(1-3 \delta_{2}\right) & \overline{\mathrm{x}}_{3}\left(1+3 \delta_{3}\right) & \overline{\mathrm{x}}_{4}\left(1+3 \delta_{4}\right) \\
\overline{\mathrm{x}}_{1} & \overline{\mathrm{x}}_{2}\left(1+3 \delta_{2}\right) & \overline{\mathrm{x}}_{3}\left(1+3 \delta_{3}\right) & \overline{\mathrm{x}}_{4}\left(1+3 \delta_{4}\right) \\
\overline{\mathrm{x}}_{1} & \overline{\mathrm{x}}_{2} & \overline{\mathrm{x}}_{3}\left(1-1.5 \delta_{3}\right) & \overline{\mathrm{x}}_{4}\left(1-1.5 \delta_{4}\right) \\
\overline{\mathrm{x}}_{1}\left(1-3 \delta_{1}\right) & \overline{\mathrm{x}}_{2} & \overline{\mathrm{x}}_{3}\left(1-1.5 \delta_{3}\right) & \overline{\mathrm{x}}_{4}\left(1-1.5 \delta_{4}\right) \\
\overline{\mathrm{x}}_{1}\left(1+3 \delta_{1}\right) & \overline{\mathrm{x}}_{2} & \overline{\mathrm{x}}_{3}\left(1-1.5 \delta_{3}\right) & \overline{\mathrm{x}}_{4}\left(1-1.5 \delta_{4}\right) \\
\overline{\mathrm{x}}_{1} & \overline{\mathrm{x}}_{2}\left(1-3 \delta_{2}\right) & \overline{\mathrm{x}}_{3}\left(1-1.5 \delta_{3}\right) & \overline{\mathrm{x}}_{4}\left(1-1.5 \delta_{4}\right)
\end{array}\right]
$$

Os coeficientes propostos para problemas com 5 variáveis aleatórias são: 


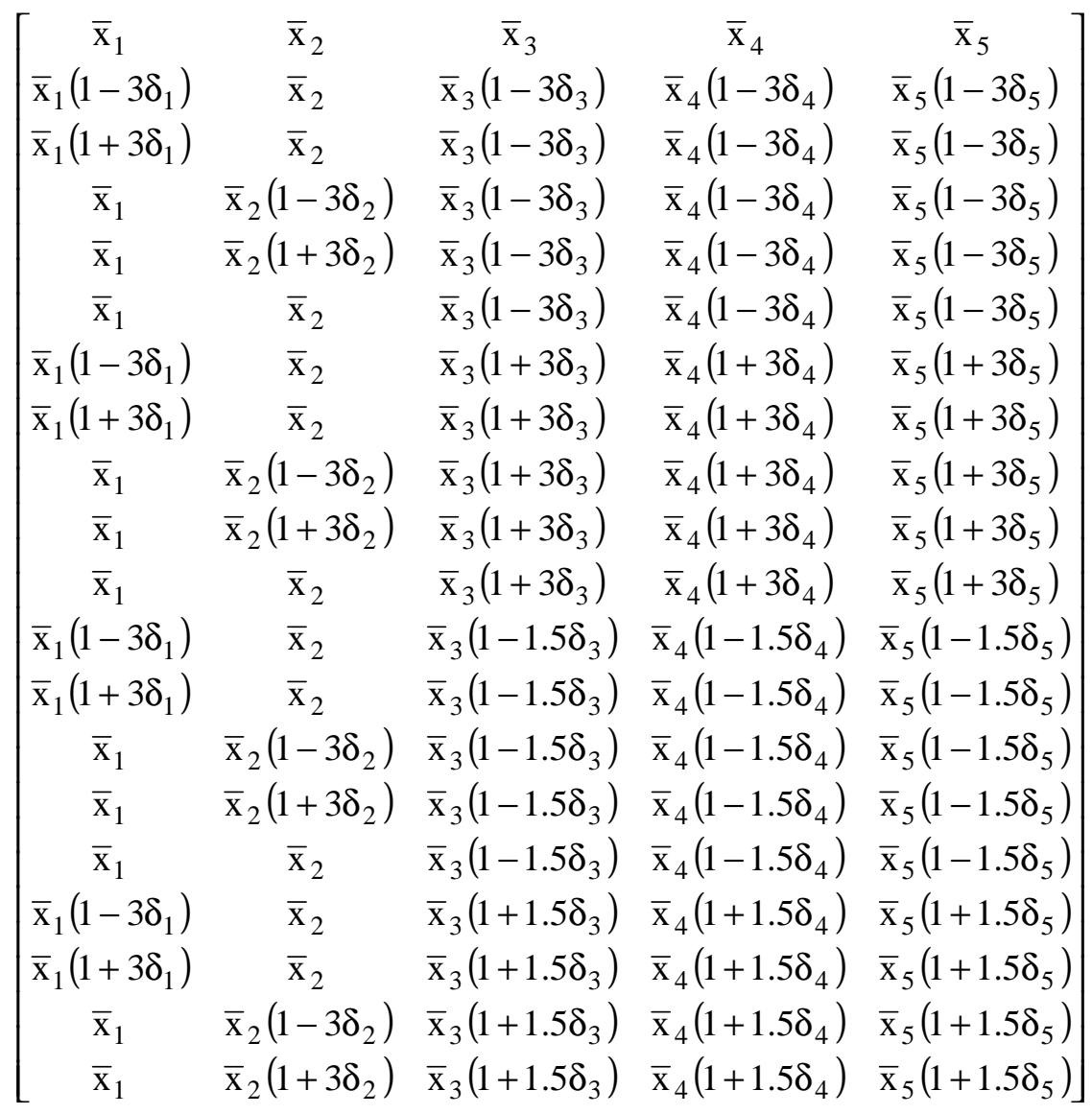

Os coeficientes propostos para problemas com 6 variáveis aleatórias são: 


\begin{tabular}{|c|c|c|c|c|c|}
\hline $\bar{x}_{1}$ & $\overline{\mathrm{x}}_{2}$ & $\bar{x}_{3}$ & $\overline{\mathrm{x}}_{4}$ & $\bar{x}_{5}$ & $\bar{x}_{6}$ \\
\hline $\bar{x}_{1}\left(1-3 \delta_{1}\right)$ & $\overline{\mathrm{x}}_{2}$ & $\bar{x}_{3}\left(1-3 \delta_{3}\right)$ & $\overline{\mathrm{x}}_{4}\left(1-3 \delta_{4}\right)$ & $\bar{x}_{5}\left(1-3 \delta_{5}\right)$ & $\bar{x}_{6}\left(1-3 \delta_{6}\right)$ \\
\hline $\bar{x}_{1}\left(1+3 \delta_{1}\right)$ & $\overline{\mathrm{x}}_{2}$ & $\overline{\mathrm{x}}_{3}\left(1-3 \delta_{3}\right)$ & $\overline{\mathrm{x}}_{4}\left(1-3 \delta_{4}\right)$ & $\overline{\mathrm{x}}_{5}\left(1-3 \delta_{5}\right)$ & $\bar{x}_{6}\left(1-3 \delta_{6}\right)$ \\
\hline$\overline{\mathrm{x}}_{1}$ & $\bar{x}_{2}\left(1-3 \delta_{2}\right)$ & $\bar{x}_{3}\left(1-3 \delta_{3}\right)$ & $\overline{\mathrm{x}}_{4}\left(1-3 \delta_{4}\right)$ & $\overline{\mathrm{x}}_{5}\left(1-3 \delta_{5}\right)$ & $\overline{\mathrm{x}}_{6}\left(1-3 \delta_{6}\right)$ \\
\hline$\overline{\mathrm{x}}_{1}$ & $\bar{x}_{2}\left(1+3 \delta_{2}\right)$ & $\overline{\mathrm{x}}_{3}\left(1-3 \delta_{3}\right)$ & $\overline{\mathrm{x}}_{4}\left(1-3 \delta_{4}\right)$ & $\overline{\mathrm{x}}_{5}\left(1-3 \delta_{5}\right)$ & $\bar{x}_{6}\left(1-3 \delta_{6}\right)$ \\
\hline$\overline{\mathrm{x}}_{1}$ & $\bar{x}_{2}$ & $\bar{x}_{3}\left(1-3 \delta_{3}\right)$ & $\bar{x}_{4}\left(1-3 \delta_{4}\right)$ & $\bar{x}_{5}\left(1-3 \delta_{5}\right)$ & $\bar{x}_{6}\left(1-3 \delta_{6}\right)$ \\
\hline $\bar{x}_{1}\left(1-3 \delta_{1}\right)$ & $\overline{\mathrm{x}}_{2}$ & $\bar{x}_{3}\left(1+3 \delta_{3}\right)$ & $\bar{x}_{4}\left(1+3 \delta_{4}\right)$ & $\overline{\mathrm{x}}_{5}\left(1+3 \delta_{5}\right)$ & $\bar{x}_{6}\left(1+3 \delta_{6}\right)$ \\
\hline $\bar{x}_{1}\left(1+3 \delta_{1}\right)$ & $\overline{\mathrm{x}}_{2}$ & $\bar{x}_{3}\left(1+3 \delta_{3}\right)$ & $\bar{x}_{4}\left(1+3 \delta_{4}\right)$ & $\bar{x}_{5}\left(1+3 \delta_{5}\right)$ & $\bar{x}_{6}\left(1+3 \delta_{6}\right)$ \\
\hline$\overline{\mathrm{x}}_{1}$ & $\bar{x}_{2}\left(1-3 \delta_{2}\right)$ & $\overline{\mathrm{x}}_{3}\left(1+3 \delta_{3}\right)$ & $\overline{\mathrm{x}}_{4}\left(1+3 \delta_{4}\right)$ & $\overline{\mathrm{x}}_{5}\left(1+3 \delta_{5}\right)$ & $\bar{x}_{6}\left(1+3 \delta_{6}\right)$ \\
\hline $\bar{x}_{1}$ & $\bar{x}_{2}\left(1+3 \delta_{2}\right)$ & $\bar{x}_{3}\left(1+3 \delta_{3}\right)$ & $\bar{x}_{4}\left(1+3 \delta_{4}\right)$ & $\bar{x}_{5}\left(1+3 \delta_{5}\right)$ & $\bar{x}_{6}\left(1+3 \delta_{6}\right)$ \\
\hline$\overline{\mathrm{x}}_{1}$ & $\bar{x}_{2}$ & $\bar{x}_{3}\left(1+3 \delta_{3}\right)$ & $\bar{x}_{4}\left(1+3 \delta_{4}\right)$ & $\bar{x}_{5}\left(1+3 \delta_{5}\right)$ & $\bar{x}_{6}\left(1+3 \delta_{6}\right)$ \\
\hline $\bar{x}_{1}\left(1-3 \delta_{1}\right)$ & $\overline{\mathrm{x}}_{2}$ & $\bar{x}_{3}\left(1-1.5 \delta_{3}\right)$ & $\bar{x}_{4}\left(1-1.5 \delta_{4}\right)$ & $\overline{\mathrm{x}}_{5}\left(1-1.5 \delta_{5}\right)$ & $\bar{x}_{6}\left(1-1.5 \delta_{6}\right)$ \\
\hline $\bar{x}_{1}\left(1+3 \delta_{1}\right)$ & $\overline{\mathrm{x}}_{2}$ & $\bar{x}_{3}\left(1-1.5 \delta_{3}\right)$ & $\overline{\mathrm{x}}_{4}\left(1-1.5 \delta_{4}\right)$ & $\overline{\mathrm{x}}_{5}\left(1-1.5 \delta_{5}\right)$ & $\bar{x}_{6}\left(1-1.5 \delta_{6}\right)$ \\
\hline$\overline{\mathrm{x}}_{1}$ & $\bar{x}_{2}\left(1-3 \delta_{2}\right)$ & $\bar{x}_{3}\left(1-1.5 \delta_{3}\right)$ & $\overline{\mathrm{x}}_{4}\left(1-1.5 \delta_{4}\right)$ & $\overline{\mathrm{x}}_{5}\left(1-1.5 \delta_{5}\right)$ & $\bar{x}_{6}\left(1-1.5 \delta_{6}\right)$ \\
\hline$\overline{\mathrm{x}}_{1}$ & $\bar{x}_{2}\left(1+3 \delta_{2}\right)$ & $\overline{\mathrm{x}}_{3}\left(1-1.5 \delta_{3}\right)$ & $\overline{\mathrm{x}}_{4}\left(1-1.5 \delta_{4}\right)$ & $\overline{\mathrm{x}}_{5}\left(1-1.5 \delta_{5}\right)$ & $\overline{\mathrm{x}}_{6}\left(1-1.5 \delta_{6}\right)$ \\
\hline$\overline{\mathrm{x}}_{1}$ & $\overline{\mathrm{x}}_{2}$ & $\overline{\mathrm{x}}_{3}\left(1-1.5 \delta_{3}\right)$ & $\overline{\mathrm{x}}_{4}\left(1-1.5 \delta_{4}\right)$ & $\overline{\mathrm{x}}_{5}\left(1-1.5 \delta_{5}\right)$ & $\overline{\mathrm{x}}_{6}\left(1-1.5 \delta_{6}\right)$ \\
\hline $\bar{x}_{1}\left(1-3 \delta_{1}\right)$ & $\overline{\mathrm{x}}_{2}$ & $\overline{\mathrm{x}}_{3}\left(1+1.5 \delta_{3}\right)$ & $\overline{\mathrm{x}}_{4}\left(1+1.5 \delta_{4}\right)$ & $\overline{\mathrm{x}}_{5}\left(1+1.5 \delta_{5}\right)$ & $\bar{x}_{6}\left(1+1.5 \delta_{6}\right)$ \\
\hline $\bar{x}_{1}\left(1+3 \delta_{1}\right)$ & $\overline{\mathrm{x}}_{2}$ & $\bar{x}_{3}\left(1+1.5 \delta_{3}\right)$ & $\overline{\mathrm{x}}_{4}\left(1+1.5 \delta_{4}\right)$ & $\overline{\mathrm{x}}_{5}\left(1+1.5 \delta_{5}\right)$ & $\overline{\mathrm{x}}_{6}\left(1+1.5 \delta_{6}\right)$ \\
\hline $\bar{x}_{1}$ & $\bar{x}_{2}\left(1-3 \delta_{2}\right)$ & $\bar{x}_{3}\left(1+1.5 \delta_{3}\right)$ & $\overline{\mathrm{x}}_{4}\left(1+1.5 \delta_{4}\right)$ & $\overline{\mathrm{x}}_{5}\left(1+1.5 \delta_{5}\right)$ & $\bar{x}_{6}\left(1+1.5 \delta_{6}\right)$ \\
\hline $\bar{x}_{1}$ & $\bar{x}_{2}\left(1+3 \delta_{2}\right)$ & $\bar{x}_{3}\left(1+1.5 \delta_{3}\right)$ & $\overline{\mathrm{x}}_{4}\left(1+1.5 \delta_{4}\right)$ & $\overline{\mathrm{x}}_{5}\left(1+1.5 \delta_{5}\right)$ & $\bar{x}_{6}\left(1+1.5 \delta_{6}\right)$ \\
\hline $\bar{x}_{1}$ & $\bar{x}_{2}$ & $\bar{x}_{3}\left(1+1.5 \delta_{3}\right)$ & $\overline{\mathrm{x}}_{4}\left(1+1.5 \delta_{4}\right)$ & $\overline{\mathrm{x}}_{5}\left(1+1.5 \delta_{5}\right)$ & $\bar{x}_{6}\left(1+1.5 \delta_{6}\right)$ \\
\hline $\bar{x}_{1}\left(1-3 \delta_{1}\right)$ & $\bar{x}_{2}$ & $\bar{x}_{3}$ & $\overline{\mathrm{x}}_{4}\left(1-3 \delta_{4}\right)$ & $\bar{x}_{5}\left(1+3 \delta_{5}\right)$ & $\bar{x}_{6}\left(1+3 \delta_{6}\right)$ \\
\hline $\bar{x}_{1}\left(1+3 \delta_{1}\right)$ & $\overline{\mathrm{x}}_{2}$ & $\overline{\mathrm{x}}_{3}$ & $\bar{x}_{4}\left(1-3 \delta_{4}\right)$ & $\bar{x}_{5}\left(1+3 \delta_{5}\right)$ & $\bar{x}_{6}\left(1+3 \delta_{6}\right)$ \\
\hline $\bar{x}_{1}$ & $\bar{x}_{2}\left(1-3 \delta_{2}\right)$ & $\bar{x}_{3}$ & $\bar{x}_{4}\left(1-3 \delta_{4}\right)$ & $\bar{x}_{5}\left(1+3 \delta_{5}\right)$ & $\bar{x}_{6}\left(1+3 \delta_{6}\right)$ \\
\hline $\bar{x}_{1}$ & $\bar{x}_{2}\left(1+3 \delta_{2}\right)$ & $\bar{x}_{3}$ & $\bar{x}_{4}\left(1-3 \delta_{4}\right)$ & $\bar{x}_{5}\left(1+3 \delta_{5}\right)$ & $\bar{x}_{6}\left(1+3 \delta_{6}\right)$ \\
\hline $\bar{x}_{1}$ & $\bar{x}_{2}$ & $\bar{x}_{3}$ & $\bar{x}_{4}\left(1-3 \delta_{4}\right)$ & $\bar{x}_{5}\left(1+3 \delta_{5}\right)$ & $\bar{x}_{6}\left(1+3 \delta_{6}\right)$ \\
\hline $\bar{x}_{1}\left(1-3 \delta_{1}\right)$ & $\overline{\mathrm{x}}_{2}$ & $\bar{x}_{3}$ & $\overline{\mathrm{x}}_{4}\left(1-3 \delta_{4}\right)$ & $\bar{x}_{5}\left(1+3 \delta_{5}\right)$ & $\bar{x}_{6}\left(1+3 \delta_{6}\right)$ \\
\hline
\end{tabular}

\section{Plano de experiência numérico Hiper-cubo ou Estrela 45}

Este plano de experiência equivale ao plano de experiência estrela rotacionado de 45 graus, podendo ser visto para os casos bidimensionais na Figura 2. 
Hiper-cubo

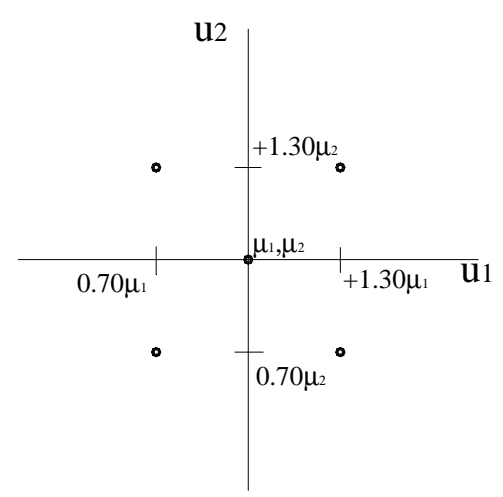

Figura 2 Plano de experiência hiper-cubo ou estrela 45

Os coeficientes propostos para problemas com 1 variável aleatória são:

$$
\left\{\begin{array}{lll}
\bar{x}_{1} & \bar{x}_{1}\left(1-3 \delta_{1}\right) & \bar{x}_{1}\left(1+3 \delta_{1}\right)
\end{array}\right\}
$$

Os coeficientes propostos para problemas com 2 variáveis aleatórias são:

$$
\left[\begin{array}{cc}
\overline{\mathrm{x}}_{1} & \overline{\mathrm{x}}_{2} \\
\overline{\mathrm{x}}_{1}\left(1+3 \delta_{1}\right) & \overline{\mathrm{x}}_{2}\left(1+3 \delta_{2}\right) \\
\overline{\mathrm{x}}_{1}\left(1-3 \delta_{1}\right) & \overline{\mathrm{x}}_{2}\left(1+3 \delta_{2}\right) \\
\overline{\mathrm{x}}_{1}\left(1-3 \delta_{1}\right) & \overline{\mathrm{x}}_{2}\left(1-3 \delta_{2}\right) \\
\overline{\mathrm{x}}_{1}\left(1+3 \delta_{1}\right) & \overline{\mathrm{x}}_{2}\left(1-3 \delta_{2}\right)
\end{array}\right]
$$

Os coeficientes propostos para problemas com 3 variáveis aleatórias são:

$$
\left[\begin{array}{ccc}
\overline{\mathrm{x}}_{1} & \overline{\mathrm{x}}_{2} & \overline{\mathrm{x}}_{3} \\
\overline{\mathrm{x}}_{1}\left(1+3 \delta_{1}\right) & \overline{\mathrm{x}}_{2}\left(1+3 \delta_{2}\right) & \overline{\mathrm{x}}_{3}\left(1-3 \delta_{3}\right) \\
\overline{\mathrm{x}}_{1}\left(1-3 \delta_{1}\right) & \overline{\mathrm{x}}_{2}\left(1+3 \delta_{2}\right) & \overline{\mathrm{x}}_{3}\left(1-3 \delta_{3}\right) \\
\overline{\mathrm{x}}_{1}\left(1-3 \delta_{1}\right) & \overline{\mathrm{x}}_{2}\left(1-3 \delta_{2}\right) & \overline{\mathrm{x}}_{3}\left(1-3 \delta_{3}\right) \\
\overline{\mathrm{x}}_{1}\left(1+3 \delta_{1}\right) & \overline{\mathrm{x}}_{2}\left(1-3 \delta_{2}\right) & \overline{\mathrm{x}}_{3}\left(1-3 \delta_{3}\right) \\
\overline{\mathrm{x}}_{1} & \overline{\mathrm{x}}_{2} & \overline{\mathrm{x}}_{3}\left(1+3 \delta_{3}\right) \\
\overline{\mathrm{x}}_{1}\left(1+3 \delta_{1}\right) & \overline{\mathrm{x}}_{2}\left(1+3 \delta_{2}\right) & \overline{\mathrm{x}}_{3}\left(1+3 \delta_{3}\right) \\
\overline{\mathrm{x}}_{1}\left(1-3 \delta_{1}\right) & \overline{\mathrm{x}}_{2}\left(1+3 \delta_{2}\right) & \overline{\mathrm{x}}_{3}\left(1+3 \delta_{3}\right) \\
\overline{\mathrm{x}}_{1}\left(1-3 \delta_{1}\right) & \overline{\mathrm{x}}_{2}\left(1-3 \delta_{2}\right) & \overline{\mathrm{x}}_{3}\left(1+3 \delta_{3}\right)
\end{array}\right]
$$

Os coeficientes propostos para problemas com 4 variáveis aleatórias são: 


$$
\left[\begin{array}{cccc}
\overline{\mathrm{x}}_{1} & \overline{\mathrm{x}}_{2} & \overline{\mathrm{x}}_{3} & \overline{\mathrm{x}}_{4} \\
\overline{\mathrm{x}}_{1}\left(1+3 \delta_{1}\right) & \overline{\mathrm{x}}_{2}\left(1+3 \delta_{2}\right) & \overline{\mathrm{x}}_{3}\left(1-3 \delta_{3}\right) & \overline{\mathrm{x}}_{4}\left(1-3 \delta_{4}\right) \\
\overline{\mathrm{x}}_{1}\left(1-3 \delta_{1}\right) & \overline{\mathrm{x}}_{2}\left(1+3 \delta_{2}\right) & \overline{\mathrm{x}}_{3}\left(1-3 \delta_{3}\right) & \overline{\mathrm{x}}_{4}\left(1-3 \delta_{4}\right) \\
\overline{\mathrm{x}}_{1}\left(1-3 \delta_{1}\right) & \overline{\mathrm{x}}_{2}\left(1-3 \delta_{2}\right) & \overline{\mathrm{x}}_{3}\left(1-3 \delta_{3}\right) & \overline{\mathrm{x}}_{4}\left(1-3 \delta_{4}\right) \\
\overline{\mathrm{x}}_{1}\left(1+3 \delta_{1}\right) & \overline{\mathrm{x}}_{2}\left(1-3 \delta_{2}\right) & \overline{\mathrm{x}}_{3}\left(1-3 \delta_{3}\right) & \overline{\mathrm{x}}_{4}\left(1-3 \delta_{4}\right) \\
\overline{\mathrm{x}}_{1} & \overline{\mathrm{x}}_{2} & \overline{\mathrm{x}}_{3}\left(1+3 \delta_{3}\right) & \overline{\mathrm{x}}_{4}\left(1+3 \delta_{4}\right) \\
\overline{\mathrm{x}}_{1}\left(1+3 \delta_{1}\right) & \overline{\mathrm{x}}_{2}\left(1+3 \delta_{2}\right) & \overline{\mathrm{x}}_{3}\left(1+3 \delta_{3}\right) & \overline{\mathrm{x}}_{4}\left(1+3 \delta_{4}\right) \\
\overline{\mathrm{x}}_{1}\left(1-3 \delta_{1}\right) & \overline{\mathrm{x}}_{2}\left(1+3 \delta_{2}\right) & \overline{\mathrm{x}}_{3}\left(1+3 \delta_{3}\right) & \overline{\mathrm{x}}_{4}\left(1+3 \delta_{4}\right) \\
\overline{\mathrm{x}}_{1}\left(1-3 \delta_{1}\right) & \overline{\mathrm{x}}_{2}\left(1-3 \delta_{2}\right) & \overline{\mathrm{x}}_{3}\left(1+3 \delta_{3}\right) & \overline{\mathrm{x}}_{4}\left(1+3 \delta_{4}\right) \\
\overline{\mathrm{x}}_{1}\left(1+3 \delta_{1}\right) & \overline{\mathrm{x}}_{2}\left(1-3 \delta_{2}\right) & \overline{\mathrm{x}}_{3}\left(1+3 \delta_{3}\right) & \overline{\mathrm{x}}_{4}\left(1+3 \delta_{4}\right) \\
\overline{\mathrm{x}}_{1} & \overline{\mathrm{x}}_{2} & \overline{\mathrm{x}}_{3}\left(1-1.5 \delta_{3}\right) & \overline{\mathrm{x}}_{4}\left(1-1.5 \delta_{4}\right) \\
\overline{\mathrm{x}}_{1}\left(1+3 \delta_{1}\right) & \overline{\mathrm{x}}_{2}\left(1+3 \delta_{2}\right) & \overline{\mathrm{x}}_{3}\left(1-1.5 \delta_{3}\right) & \overline{\mathrm{x}}_{4}\left(1-1.5 \delta_{4}\right) \\
\overline{\mathrm{x}}_{1}\left(1-3 \delta_{1}\right) & \overline{\mathrm{x}}_{2}\left(1+3 \delta_{2}\right) & \overline{\mathrm{x}}_{3}\left(1-1.5 \delta_{3}\right) & \overline{\mathrm{x}}_{4}\left(1-1.5 \delta_{4}\right) \\
\overline{\mathrm{x}}_{1}\left(1-3 \delta_{1}\right) & \overline{\mathrm{x}}_{2}\left(1-3 \delta_{2}\right) & \overline{\mathrm{x}}_{3}\left(1-1.5 \delta_{3}\right) & \overline{\mathrm{x}}_{4}\left(1-1.5 \delta_{4}\right)
\end{array}\right]
$$

Os coeficientes propostos para problemas com 5 variáveis aleatórias são:

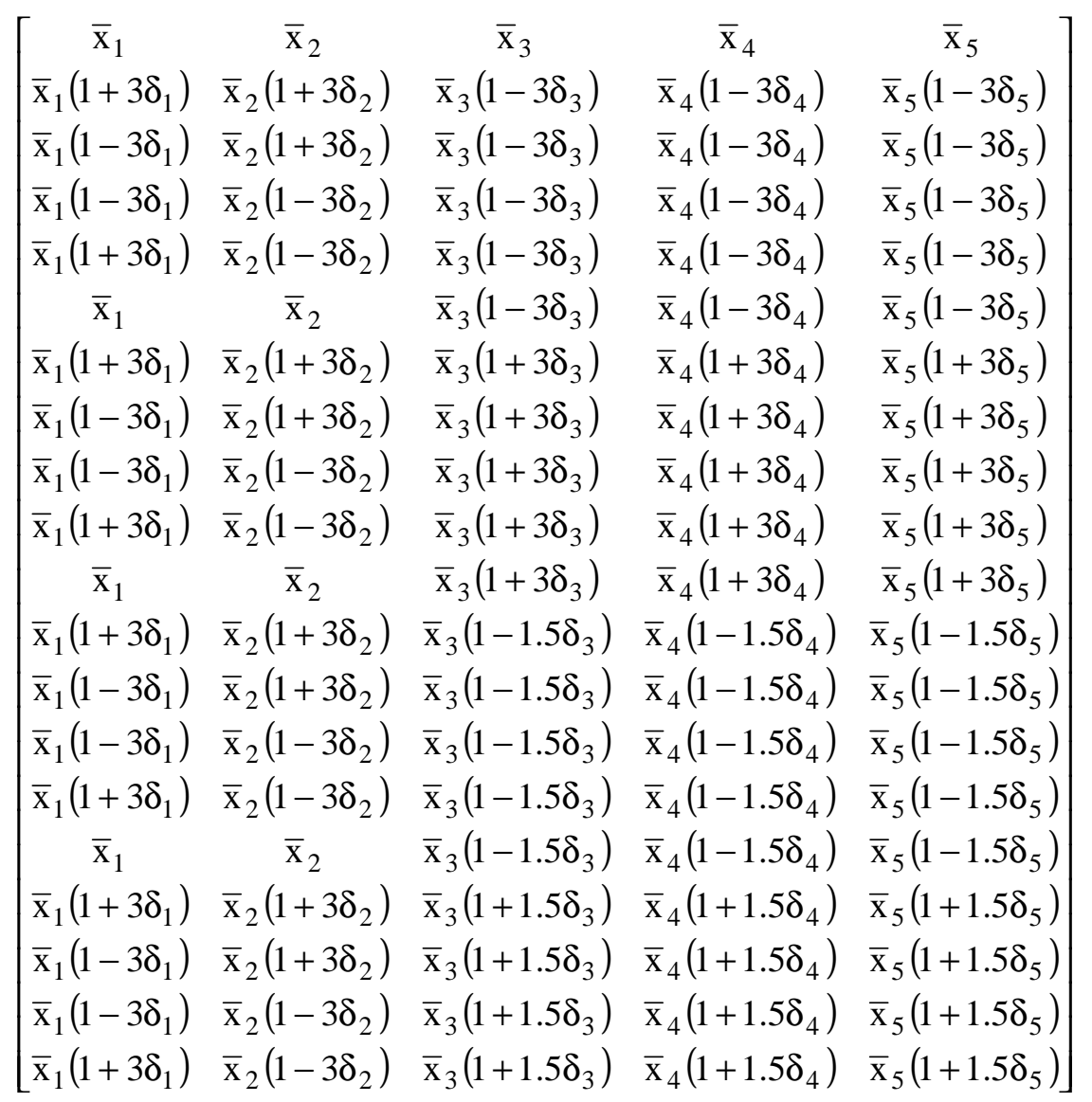

Os coeficientes propostos para problemas com 6 variáveis aleatórias são: 


\begin{tabular}{|c|c|c|c|c|c|}
\hline$\overline{\mathrm{x}}_{1}$ & $\bar{x}_{2}$ & $\bar{x}_{3}$ & $\overline{\mathrm{x}}_{4}$ & $\overline{\mathrm{x}}_{5}$ & $\bar{x}_{6}$ \\
\hline$\overline{\mathrm{x}}_{1}\left(1+3 \delta_{1}\right)$ & $\bar{x}_{2}\left(1+3 \delta_{2}\right)$ & $\bar{x}_{3}\left(1-3 \delta_{3}\right)$ & $\overline{\mathrm{x}}_{4}\left(1-3 \delta_{4}\right)$ & $\overline{\mathrm{x}}_{5}\left(1-3 \delta_{5}\right)$ & $\bar{x}_{6}\left(1-3 \delta_{6}\right)$ \\
\hline$\overline{\mathrm{x}}_{1}\left(1-3 \delta_{1}\right)$ & $\bar{x}_{2}\left(1+3 \delta_{2}\right)$ & $\overline{\mathrm{x}}_{3}\left(1-3 \delta_{3}\right)$ & $\overline{\mathrm{x}}_{4}\left(1-3 \delta_{4}\right)$ & $\overline{\mathrm{x}}_{5}\left(1-3 \delta_{5}\right)$ & $\bar{x}_{6}\left(1-3 \delta_{6}\right)$ \\
\hline$\overline{\mathrm{x}}_{1}\left(1-3 \delta_{1}\right)$ & $\bar{x}_{2}\left(1-3 \delta_{2}\right)$ & $\bar{x}_{3}\left(1-3 \delta_{3}\right)$ & $\overline{\mathrm{x}}_{4}\left(1-3 \delta_{4}\right)$ & $\overline{\mathrm{x}}_{5}\left(1-3 \delta_{5}\right)$ & $\bar{x}_{6}\left(1-3 \delta_{6}\right)$ \\
\hline$\overline{\mathrm{x}}_{1}\left(1+3 \delta_{1}\right)$ & $\bar{x}_{2}\left(1-3 \delta_{2}\right)$ & $\bar{x}_{3}\left(1-3 \delta_{3}\right)$ & $\overline{\mathrm{x}}_{4}\left(1-3 \delta_{4}\right)$ & $\overline{\mathrm{x}}_{5}\left(1-3 \delta_{5}\right)$ & $\bar{x}_{6}\left(1-3 \delta_{6}\right)$ \\
\hline $\bar{x}_{1}$ & $\overline{\mathrm{x}}_{2}$ & $\bar{x}_{3}\left(1-3 \delta_{3}\right)$ & $\bar{x}_{4}\left(1-3 \delta_{4}\right)$ & $\bar{x}_{5}\left(1-3 \delta_{5}\right)$ & $\bar{x}_{6}\left(1-3 \delta_{6}\right)$ \\
\hline $\bar{x}_{1}\left(1+3 \delta_{1}\right)$ & $\bar{x}_{2}\left(1+3 \delta_{2}\right)$ & $\bar{x}_{3}\left(1+3 \delta_{3}\right)$ & $\overline{\mathrm{x}}_{4}\left(1+3 \delta_{4}\right)$ & $\bar{x}_{5}\left(1+3 \delta_{5}\right)$ & $\bar{x}_{6}\left(1+3 \delta_{6}\right)$ \\
\hline $\bar{x}_{1}\left(1-3 \delta_{1}\right)$ & $\bar{x}_{2}\left(1+3 \delta_{2}\right)$ & $\bar{x}_{3}\left(1+3 \delta_{3}\right)$ & $\bar{x}_{4}\left(1+3 \delta_{4}\right)$ & $\overline{\mathrm{x}}_{5}\left(1+3 \delta_{5}\right)$ & $\bar{x}_{6}\left(1+3 \delta_{6}\right)$ \\
\hline $\bar{x}_{1}\left(1-3 \delta_{1}\right)$ & $\bar{x}_{2}\left(1-3 \delta_{2}\right)$ & $\bar{x}_{3}\left(1+3 \delta_{3}\right)$ & $\bar{x}_{4}\left(1+3 \delta_{4}\right)$ & $\bar{x}_{5}\left(1+3 \delta_{5}\right)$ & $\bar{x}_{6}\left(1+3 \delta_{6}\right)$ \\
\hline$\overline{\mathrm{x}}_{1}\left(1+3 \delta_{1}\right)$ & $\bar{x}_{2}\left(1-3 \delta_{2}\right)$ & $\bar{x}_{3}\left(1+3 \delta_{3}\right)$ & $\overline{\mathrm{x}}_{4}\left(1+3 \delta_{4}\right)$ & $\overline{\mathrm{x}}_{5}\left(1+3 \delta_{5}\right)$ & $\bar{x}_{6}\left(1+3 \delta_{6}\right)$ \\
\hline $\bar{x}_{1}$ & $\overline{\mathrm{x}}_{2}$ & $\bar{x}_{3}\left(1+3 \delta_{3}\right)$ & $\bar{x}_{4}\left(1+3 \delta_{4}\right)$ & $\bar{x}_{5}\left(1+3 \delta_{5}\right)$ & $\bar{x}_{6}\left(1+3 \delta_{6}\right)$ \\
\hline$\overline{\mathrm{x}}_{1}\left(1+3 \delta_{1}\right)$ & $\bar{x}_{2}\left(1+3 \delta_{2}\right)$ & $\overline{\mathrm{x}}_{3}\left(1-1.5 \delta_{3}\right)$ & $\overline{\mathrm{x}}_{4}\left(1-1.5 \delta_{4}\right)$ & $\overline{\mathrm{x}}_{5}\left(1-1.5 \delta_{5}\right)$ & $\overline{\mathrm{x}}_{6}\left(1-1.5 \delta_{6}\right)$ \\
\hline$\overline{\mathrm{x}}_{1}\left(1-3 \delta_{1}\right)$ & $\bar{x}_{2}\left(1+3 \delta_{2}\right)$ & $\overline{\mathrm{x}}_{3}\left(1-1.5 \delta_{3}\right)$ & $\overline{\mathrm{x}}_{4}\left(1-1.5 \delta_{4}\right)$ & $\overline{\mathrm{x}}_{5}\left(1-1.5 \delta_{5}\right)$ & $\overline{\mathrm{x}}_{6}\left(1-1.5 \delta_{6}\right)$ \\
\hline$\overline{\mathrm{x}}_{1}\left(1-3 \delta_{1}\right)$ & $\bar{x}_{2}\left(1-3 \delta_{2}\right)$ & $\bar{x}_{3}\left(1-1.5 \delta_{3}\right)$ & $\overline{\mathrm{x}}_{4}\left(1-1.5 \delta_{4}\right)$ & $\overline{\mathrm{x}}_{5}\left(1-1.5 \delta_{5}\right)$ & $\overline{\mathrm{x}}_{6}\left(1-1.5 \delta_{6}\right)$ \\
\hline$\overline{\mathrm{x}}_{1}\left(1+3 \delta_{1}\right)$ & $\bar{x}_{2}\left(1-3 \delta_{2}\right)$ & $\bar{x}_{3}\left(1-1.5 \delta_{3}\right)$ & $\overline{\mathrm{x}}_{4}\left(1-1.5 \delta_{4}\right)$ & $\overline{\mathrm{x}}_{5}\left(1-1.5 \delta_{5}\right)$ & $\overline{\mathrm{x}}_{6}\left(1-1.5 \delta_{6}\right)$ \\
\hline $\bar{x}_{1}$ & $\bar{x}_{2}$ & $\bar{x}_{3}\left(1-1.5 \delta_{3}\right)$ & $\overline{\mathrm{x}}_{4}\left(1-1.5 \delta_{4}\right)$ & $\overline{\mathrm{x}}_{5}\left(1-1.5 \delta_{5}\right)$ & $\overline{\mathrm{x}}_{6}\left(1-1.5 \delta_{6}\right)$ \\
\hline $\bar{x}_{1}\left(1+3 \delta_{1}\right)$ & $\bar{x}_{2}\left(1+3 \delta_{2}\right)$ & $\overline{\mathrm{x}}_{3}\left(1+1.5 \delta_{3}\right)$ & $\overline{\mathrm{x}}_{4}\left(1+1.5 \delta_{4}\right)$ & $\overline{\mathrm{x}}_{5}\left(1+1.5 \delta_{5}\right)$ & $\overline{\mathrm{x}}_{6}\left(1+1.5 \delta_{6}\right)$ \\
\hline $\bar{x}_{1}\left(1-3 \delta_{1}\right)$ & $\bar{x}_{2}\left(1+3 \delta_{2}\right)$ & $\bar{x}_{3}\left(1+1.5 \delta_{3}\right)$ & $\overline{\mathrm{x}}_{4}\left(1+1.5 \delta_{4}\right)$ & $\overline{\mathrm{x}}_{5}\left(1+1.5 \delta_{5}\right)$ & $\overline{\mathrm{x}}_{6}\left(1+1.5 \delta_{6}\right)$ \\
\hline $\bar{x}_{1}\left(1-3 \delta_{1}\right)$ & $\bar{x}_{2}\left(1-3 \delta_{2}\right)$ & $\bar{x}_{3}\left(1+1.5 \delta_{3}\right)$ & $\overline{\mathrm{x}}_{4}\left(1+1.5 \delta_{4}\right)$ & $\overline{\mathrm{x}}_{5}\left(1+1.5 \delta_{5}\right)$ & $\overline{\mathrm{x}}_{6}\left(1+1.5 \delta_{6}\right)$ \\
\hline$\overline{\mathrm{x}}_{1}\left(1+3 \delta_{1}\right)$ & $\bar{x}_{2}\left(1-3 \delta_{2}\right)$ & $\bar{x}_{3}\left(1+1.5 \delta_{3}\right)$ & $\overline{\mathrm{x}}_{4}\left(1+1.5 \delta_{4}\right)$ & $\overline{\mathrm{x}}_{5}\left(1+1.5 \delta_{5}\right)$ & $\overline{\mathrm{x}}_{6}\left(1+1.5 \delta_{6}\right)$ \\
\hline$\overline{\mathrm{x}}_{1}$ & $\overline{\mathrm{x}}_{2}$ & $\overline{\mathrm{x}}_{3}\left(1+1.5 \delta_{3}\right)$ & $\overline{\mathrm{x}}_{4}\left(1+1.5 \delta_{4}\right)$ & $\overline{\mathrm{x}}_{5}\left(1+1.5 \delta_{5}\right)$ & $\overline{\mathrm{x}}_{6}\left(1+1.5 \delta_{6}\right)$ \\
\hline$\overline{\mathrm{x}}_{1}\left(1+3 \delta_{1}\right)$ & $\bar{x}_{2}\left(1+3 \delta_{2}\right)$ & $\bar{x}_{3}$ & $\overline{\mathrm{x}}_{4}\left(1-3 \delta_{4}\right)$ & $\overline{\mathrm{x}}_{5}\left(1+3 \delta_{5}\right)$ & $\bar{x}_{6}\left(1+3 \delta_{6}\right)$ \\
\hline $\bar{x}_{1}\left(1-3 \delta_{1}\right)$ & $\bar{x}_{2}\left(1+3 \delta_{2}\right)$ & $\bar{x}_{3}$ & $\bar{x}_{4}\left(1-3 \delta_{4}\right)$ & $\overline{\mathrm{x}}_{5}\left(1+3 \delta_{5}\right)$ & $\bar{x}_{6}\left(1+3 \delta_{6}\right)$ \\
\hline$\overline{\mathrm{x}}_{1}\left(1-3 \delta_{1}\right)$ & $\bar{x}_{2}\left(1-3 \delta_{2}\right)$ & $\bar{x}_{3}$ & $\overline{\mathrm{x}}_{4}\left(1-3 \delta_{4}\right)$ & $\overline{\mathrm{x}}_{5}\left(1+3 \delta_{5}\right)$ & $\overline{\mathrm{x}}_{6}\left(1+3 \delta_{6}\right)$ \\
\hline $\bar{x}_{1}\left(1+3 \delta_{1}\right)$ & $\bar{x}_{2}\left(1-3 \delta_{2}\right)$ & $\bar{x}_{3}$ & $\overline{\mathrm{x}}_{4}\left(1-3 \delta_{4}\right)$ & $\overline{\mathrm{x}}_{5}\left(1+3 \delta_{5}\right)$ & $\overline{\mathrm{x}}_{6}\left(1+3 \delta_{6}\right)$ \\
\hline $\bar{x}_{1}$ & $\bar{x}_{2}$ & $\bar{x}_{3}$ & $\overline{\mathrm{x}}_{4}\left(1-3 \delta_{4}\right)$ & $\overline{\mathrm{x}}_{5}\left(1+3 \delta_{5}\right)$ & $\bar{x}_{6}\left(1+3 \delta_{6}\right)$ \\
\hline$\overline{\mathrm{x}}_{1}\left(1+3 \delta_{1}\right)$ & $\bar{x}_{2}\left(1+3 \delta_{2}\right)$ & $\bar{x}_{3}$ & $\overline{\mathrm{x}}_{4}\left(1-3 \delta_{4}\right)$ & $\overline{\mathrm{x}}_{5}\left(1+3 \delta_{5}\right)$ & $\bar{x}_{6}\left(1+3 \delta_{6}\right)$ \\
\hline
\end{tabular}

\section{Plano de experiência numérico Fatorial completo}

Como pode-se observar esse plano de experiência, Figura 3, exige um número bem maior de pontos do que o número de coeficientes do polinômio aproximador da RS. A princípio pode-se pensar que planos com essas características podem não ser adequados devido ao aumento do custo computacional exigido. Entretanto, há estruturas que não levam a convergência quando utilizam-se planos com um número menor de pontos. Como já foi comentado, cada caso deve ser analisado isoladamente, podendo apresentar convergência mais rápida mesmo quando o número de pontos inicial é maior. 
Fatorial completo

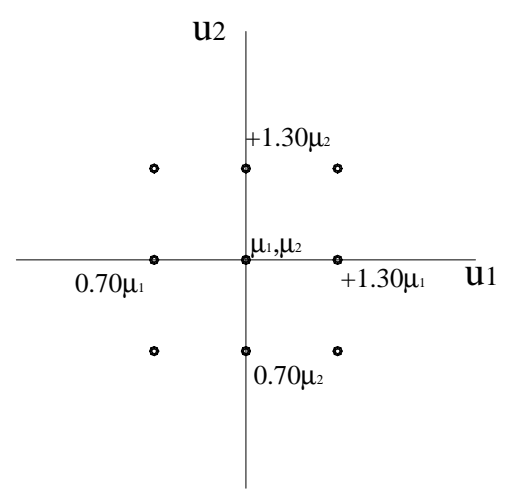

Figura 3 Plano de experiência Fatorial completo

Os coeficientes propostos para problemas com 1 variável aleatória são:

$$
\left\{\begin{array}{lll}
\overline{\mathrm{x}}_{1} & \overline{\mathrm{x}}_{1}\left(1-3 \delta_{1}\right) & \overline{\mathrm{x}}_{1}\left(1+3 \delta_{1}\right)
\end{array}\right\}
$$

Os coeficientes propostos para problemas com 2 ou mais variáveis aleatórias, v_x, são expressos de forma generalizada na expressão (17).

$$
v_{-} x(i, j)=C(L(i, j), j) \quad \backslash \quad i=1, \ldots, n p r ; \quad j=1, \ldots, n v
$$

A matriz C é representada pela expressão (18):

$$
\mathrm{C}=\left[\begin{array}{cccc}
\overline{\mathrm{x}}_{1}\left(1-3 \delta_{1}\right) & \overline{\mathrm{x}}_{2}\left(1-3 \delta_{2}\right) & \ldots & \overline{\mathrm{x}}_{\mathrm{nv}}\left(1-3 \delta_{\mathrm{nv}}\right) \\
\overline{\mathrm{x}}_{1}\left(3 \delta_{1}\right) & \overline{\mathrm{x}}_{2}\left(3 \delta_{2}\right) & \ldots & \overline{\mathrm{x}}_{\mathrm{nv}}\left(3 \delta_{\mathrm{nv}}\right) \\
\overline{\mathrm{x}}_{1}\left(1+3 \delta_{1}\right) & \overline{\mathrm{x}}_{2}\left(1+3 \delta_{2}\right) & \ldots & \overline{\mathrm{x}}_{\mathrm{nv}}\left(1+3 \delta_{\mathrm{nv}}\right)
\end{array}\right]
$$

onde nv refere-se ao número de variáveis aleatórias e npr o número de pontos do plano de experiência. No caso,

$$
\mathrm{npr}=3\left(3^{(\mathrm{nv}-1)}\right)
$$

sendo a matriz L é representada pela expressão(20): 


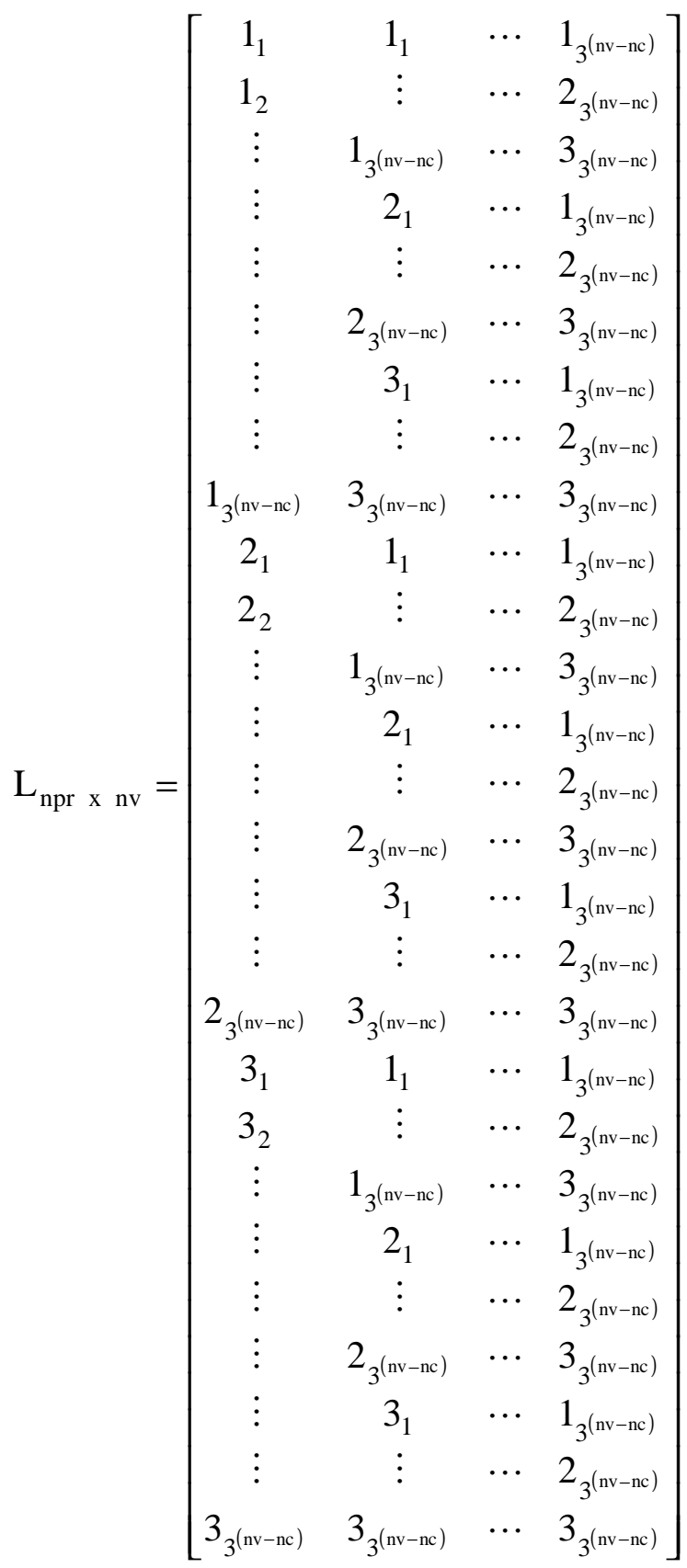

\section{Plano de experiência numérico Mínimo}

Esse plano de experiência, Figura 4, é similar ao plano Estrela, diferenciandose pela presença de pontos adicionais de tal forma que o número total de pontos é igual ao número de coeficientes do polinômio aproximador da RS. 


\section{Mínimo}

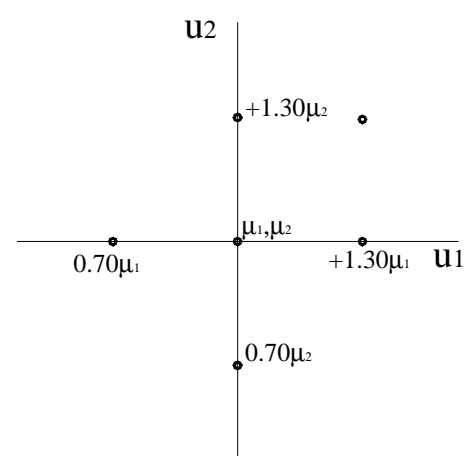

Figura 4 Plano de experiência Mínimo

Os coeficientes propostos para problemas com 1 variável aleatória são:

$$
\left\{\bar{x}_{1} \quad \bar{x}_{1}\left(1-3 \delta_{1}\right) \quad \bar{x}_{1}\left(1+3 \delta_{1}\right)\right\}
$$

Os coeficientes propostos para problemas com 2 variáveis aleatórias são:

$$
\left[\begin{array}{cc}
\overline{\mathrm{x}}_{1} & \overline{\mathrm{x}}_{2} \\
\overline{\mathrm{x}}_{1}\left(1-3 \delta_{1}\right) & \overline{\mathrm{x}}_{2} \\
\overline{\mathrm{x}}_{1}\left(1+3 \delta_{1}\right) & \overline{\mathrm{x}}_{2} \\
\overline{\mathrm{x}}_{1} & \overline{\mathrm{x}}_{2}\left(1-3 \delta_{2}\right) \\
\overline{\mathrm{x}}_{1} & \overline{\mathrm{x}}_{2}\left(1+3 \delta_{2}\right) \\
\overline{\mathrm{x}}_{1}\left(1+3 \delta_{1}\right) & \overline{\mathrm{x}}_{2}\left(1+3 \delta_{2}\right)
\end{array}\right]
$$

Os coeficientes propostos para problemas com 3 variáveis aleatórias são:

$$
\left[\begin{array}{ccc}
\overline{\mathrm{x}}_{1} & \overline{\mathrm{x}}_{2} & \overline{\mathrm{x}}_{3} \\
\overline{\mathrm{x}}_{1}\left(1-3 \delta_{1}\right) & \overline{\mathrm{x}}_{2} & \overline{\mathrm{x}}_{3}\left(1-3 \delta_{3}\right) \\
\overline{\mathrm{x}}_{1}\left(1+3 \delta_{1}\right) & \overline{\mathrm{x}}_{2} & \overline{\mathrm{x}}_{3}\left(1-3 \delta_{3}\right) \\
\overline{\mathrm{x}}_{1} & & \overline{\mathrm{x}}_{3}\left(1-3 \delta_{3}\right) \\
\overline{\mathrm{x}}_{1} & \overline{\mathrm{x}}_{2}\left(1+3 \delta_{2}\right) & \overline{\mathrm{x}}_{3}\left(1-3 \delta_{3}\right) \\
\overline{\mathrm{x}}_{1}\left(1+3 \delta_{1}\right) & \overline{\mathrm{x}}_{2}\left(1+3 \delta_{2}\right) & \overline{\mathrm{x}}_{3}\left(1+3 \delta_{3}\right) \\
\overline{\mathrm{x}}_{1} & \overline{\mathrm{x}}_{2} & \overline{\mathrm{x}}_{3}\left(1+3 \delta_{3}\right) \\
\overline{\mathrm{x}}_{1}\left(1-3 \delta_{1}\right) & \overline{\mathrm{x}}_{2} & \overline{\mathrm{x}}_{3}\left(1+3 \delta_{3}\right) \\
\overline{\mathrm{x}}_{1}\left(1+3 \delta_{1}\right) & \overline{\mathrm{x}}_{2} & \overline{\mathrm{x}}_{3}\left(1+3 \delta_{3}\right) \\
\overline{\mathrm{x}}_{1} & \overline{\mathrm{x}}_{2}\left(1-3 \delta_{2}\right) & \overline{\mathrm{x}}_{3}\left(1+3 \delta_{3}\right)
\end{array}\right]
$$

Os coeficientes propostos para problemas com 4 variáveis aleatórias são: 


$$
\left[\begin{array}{cccc}
\overline{\mathrm{x}}_{1} & \overline{\mathrm{x}}_{2} & \overline{\mathrm{x}}_{3} & \overline{\mathrm{x}}_{4} \\
\overline{\mathrm{x}}_{1}\left(1-3 \delta_{1}\right) & \overline{\mathrm{x}}_{2} & \overline{\mathrm{x}}_{3} & \overline{\mathrm{x}}_{4}\left(1-3 \delta_{4}\right) \\
\overline{\mathrm{x}}_{1}\left(1+3 \delta_{1}\right) & \overline{\mathrm{x}}_{2} & \overline{\mathrm{x}}_{3} & \overline{\mathrm{x}}_{4}\left(1-3 \delta_{4}\right) \\
\overline{\mathrm{x}}_{1} & \overline{\mathrm{x}}_{2}\left(1-3 \delta_{2}\right) & \overline{\mathrm{x}}_{3} & \overline{\mathrm{x}}_{4}\left(1-3 \delta_{4}\right) \\
\overline{\mathrm{x}}_{1} & \overline{\mathrm{x}}_{2}\left(1+3 \delta_{2}\right) & \overline{\mathrm{x}}_{3} & \overline{\mathrm{x}}_{4}\left(1-3 \delta_{4}\right) \\
\overline{\mathrm{x}}_{1}\left(1+3 \delta_{1}\right) & \overline{\mathrm{x}}_{2}\left(1+3 \delta_{2}\right) & \overline{\mathrm{x}}_{3} & \overline{\mathrm{x}}_{4}\left(1+3 \delta_{4}\right) \\
\overline{\mathrm{x}}_{1} & \overline{\mathrm{x}}_{2} & \overline{\mathrm{x}}_{3}\left(1-3 \delta_{3}\right) & \overline{\mathrm{x}}_{4}\left(1+3 \delta_{4}\right) \\
\overline{\mathrm{x}}_{1}\left(1-3 \delta_{1}\right) & \overline{\mathrm{x}}_{2} & \overline{\mathrm{x}}_{3}\left(1-3 \delta_{3}\right) & \overline{\mathrm{x}}_{4}\left(1+3 \delta_{4}\right) \\
\overline{\mathrm{x}}_{1}\left(1+3 \delta_{1}\right) & \overline{\mathrm{x}}_{2} & \overline{\mathrm{x}}_{3}\left(1-3 \delta_{3}\right) & \overline{\mathrm{x}}_{4}\left(1+3 \delta_{4}\right) \\
\overline{\mathrm{x}}_{1} & \overline{\mathrm{x}}_{2}\left(1-3 \delta_{2}\right) & \overline{\mathrm{x}}_{3}\left(1-3 \delta_{3}\right) & \overline{\mathrm{x}}_{4}\left(1+3 \delta_{4}\right) \\
\overline{\mathrm{x}}_{1} & \overline{\mathrm{x}}_{2}\left(1+3 \delta_{2}\right) & \overline{\mathrm{x}}_{3}\left(1+3 \delta_{3}\right) & \overline{\mathrm{x}}_{4}\left(1-1.5 \delta_{4}\right) \\
\overline{\mathrm{x}}_{1}\left(1+3 \delta_{1}\right) & \overline{\mathrm{x}}_{2}\left(1+3 \delta_{2}\right) & \overline{\mathrm{x}}_{3}\left(1+3 \delta_{3}\right) & \overline{\mathrm{x}}_{4}\left(1-1.5 \delta_{4}\right) \\
\overline{\mathrm{x}}_{1} & \overline{\mathrm{x}}_{2} & \overline{\mathrm{x}}_{3}\left(1+3 \delta_{3}\right) & \overline{\mathrm{x}}_{4}\left(1-1.5 \delta_{4}\right) \\
\overline{\mathrm{x}}_{1}\left(1-3 \delta_{1}\right) & \overline{\mathrm{x}}_{2} & \overline{\mathrm{x}}_{3}\left(1+3 \delta_{3}\right) & \overline{\mathrm{x}}_{4}\left(1-1.5 \delta_{4}\right) \\
\overline{\mathrm{x}}_{1}\left(1+3 \delta_{1}\right) & \overline{\mathrm{x}}_{2} & \overline{\mathrm{x}}_{3}\left(1+3 \delta_{3}\right) & \overline{\mathrm{x}}_{4}\left(1-1.5 \delta_{4}\right)
\end{array}\right]
$$

Os coeficientes propostos para problemas com 5 variáveis aleatórias são:

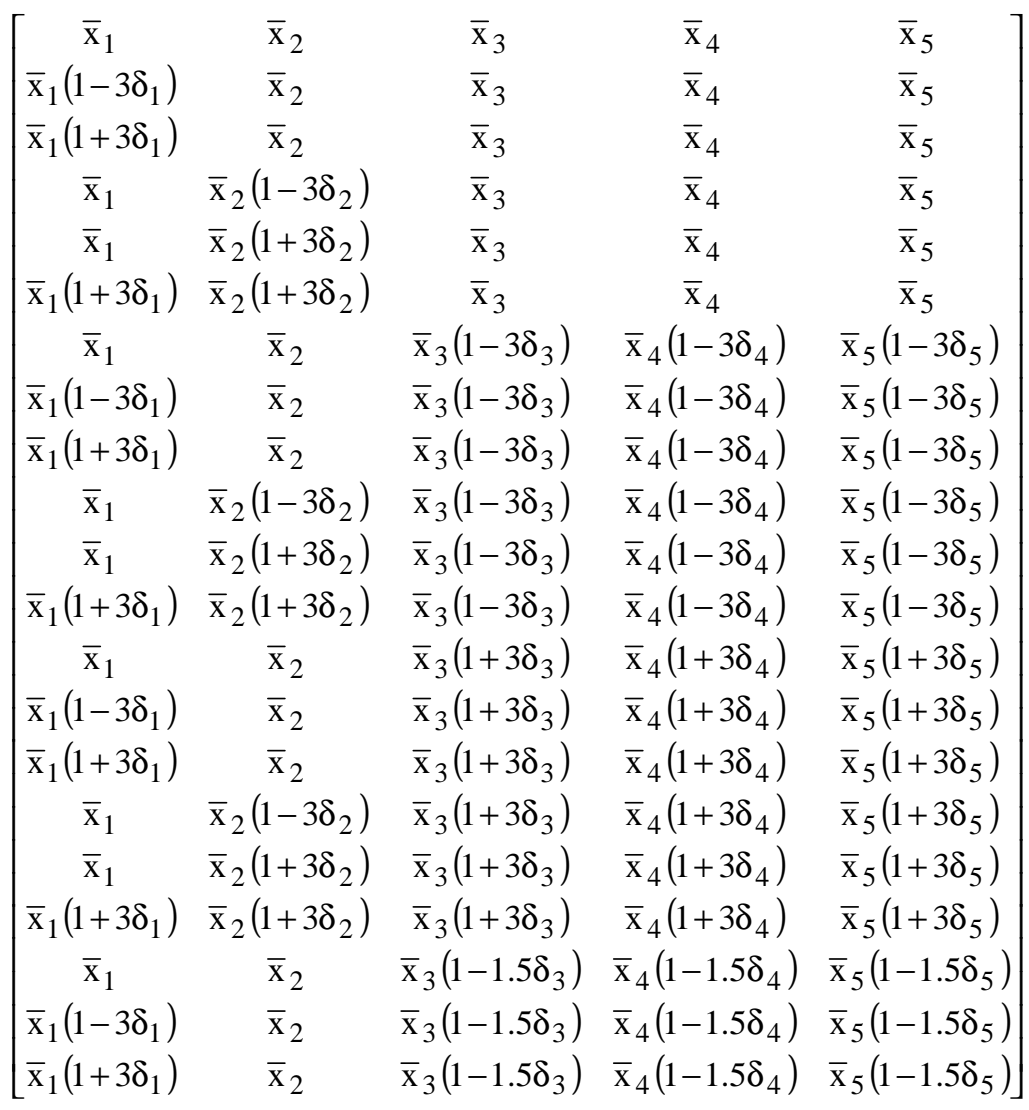

Os coeficientes propostos para problemas com 6 variáveis aleatórias são: 


\begin{tabular}{|c|c|c|c|c|c|}
\hline$\overline{\mathrm{x}}_{1}$ & $\overline{\mathrm{x}}_{2}$ & $\bar{x}_{3}$ & $\overline{\mathrm{x}}_{4}$ & $\bar{x}_{5}$ & $\bar{x}_{6}$ \\
\hline $\bar{x}_{1}\left(1-3 \delta_{1}\right)$ & $\overline{\mathrm{x}}_{2}$ & $\bar{x}_{3}\left(1-3 \delta_{3}\right)$ & $\overline{\mathrm{x}}_{4}\left(1-3 \delta_{4}\right)$ & $\overline{\mathrm{x}}_{5}\left(1-3 \delta_{5}\right)$ & $\bar{x}_{6}\left(1-3 \delta_{6}\right)$ \\
\hline $\bar{x}_{1}\left(1+3 \delta_{1}\right)$ & $\overline{\mathrm{x}}_{2}$ & $\bar{x}_{3}\left(1-3 \delta_{3}\right)$ & $\overline{\mathrm{x}}_{4}\left(1-3 \delta_{4}\right)$ & $\overline{\mathrm{x}}_{5}\left(1-3 \delta_{5}\right)$ & $\bar{x}_{6}\left(1-3 \delta_{6}\right)$ \\
\hline$\overline{\mathrm{x}}_{1}$ & $\bar{x}_{2}\left(1-3 \delta_{2}\right)$ & $\bar{x}_{3}\left(1-3 \delta_{3}\right)$ & $\overline{\mathrm{x}}_{4}\left(1-3 \delta_{4}\right)$ & $\overline{\mathrm{x}}_{5}\left(1-3 \delta_{5}\right)$ & $\bar{x}_{6}\left(1-3 \delta_{6}\right)$ \\
\hline$\overline{\mathrm{x}}_{1}$ & $\bar{x}_{2}\left(1+3 \delta_{2}\right)$ & $\bar{x}_{3}\left(1-3 \delta_{3}\right)$ & $\bar{x}_{4}\left(1-3 \delta_{4}\right)$ & $\overline{\mathrm{x}}_{5}\left(1-3 \delta_{5}\right)$ & $\bar{x}_{6}\left(1-3 \delta_{6}\right)$ \\
\hline $\bar{x}_{1}\left(1+3 \delta_{1}\right)$ & $\bar{x}_{2}\left(1+3 \delta_{2}\right)$ & $\overline{\mathrm{x}}_{3}\left(1-3 \delta_{3}\right)$ & $\overline{\mathrm{x}}_{4}\left(1-3 \delta_{4}\right)$ & $\overline{\mathrm{x}}_{5}\left(1-3 \delta_{5}\right)$ & $\overline{\mathrm{x}}_{6}\left(1-3 \delta_{6}\right)$ \\
\hline$\overline{\mathrm{x}}_{1}$ & $\overline{\mathrm{x}}_{2}$ & $\bar{x}_{3}\left(1-3 \delta_{3}\right)$ & $\overline{\mathrm{x}}_{4}\left(1-3 \delta_{4}\right)$ & $\overline{\mathrm{x}}_{5}\left(1-3 \delta_{5}\right)$ & $\bar{x}_{6}\left(1-3 \delta_{6}\right)$ \\
\hline$\overline{\mathrm{x}}_{1}\left(1-3 \delta_{1}\right)$ & $\overline{\mathrm{x}}_{2}$ & $\overline{\mathrm{x}}_{3}\left(1+3 \delta_{3}\right)$ & $\overline{\mathrm{x}}_{4}\left(1+3 \delta_{4}\right)$ & $\overline{\mathrm{x}}_{5}\left(1+3 \delta_{5}\right)$ & $\overline{\mathrm{x}}_{6}\left(1+3 \delta_{6}\right)$ \\
\hline $\bar{x}_{1}\left(1+3 \delta_{1}\right)$ & $\overline{\mathrm{x}}_{2}$ & $\bar{x}_{3}\left(1+3 \delta_{3}\right)$ & $\bar{x}_{4}\left(1+3 \delta_{4}\right)$ & $\overline{\mathrm{x}}_{5}\left(1+3 \delta_{5}\right)$ & $\bar{x}_{6}\left(1+3 \delta_{6}\right)$ \\
\hline$\overline{\mathrm{x}}_{1}$ & $\bar{x}_{2}\left(1-3 \delta_{2}\right)$ & $\bar{x}_{3}\left(1+3 \delta_{3}\right)$ & $\overline{\mathrm{x}}_{4}\left(1+3 \delta_{4}\right)$ & $\overline{\mathrm{x}}_{5}\left(1+3 \delta_{5}\right)$ & $\bar{x}_{6}\left(1+3 \delta_{6}\right)$ \\
\hline$\overline{\mathrm{x}}_{1}$ & $\bar{x}_{2}\left(1+3 \delta_{2}\right)$ & $\bar{x}_{3}\left(1+3 \delta_{3}\right)$ & $\overline{\mathrm{x}}_{4}\left(1+3 \delta_{4}\right)$ & $\overline{\mathrm{x}}_{5}\left(1+3 \delta_{5}\right)$ & $\bar{x}_{6}\left(1+3 \delta_{6}\right)$ \\
\hline $\bar{x}_{1}\left(1+3 \delta_{1}\right)$ & $\bar{x}_{2}\left(1+3 \delta_{2}\right)$ & $\bar{x}_{3}\left(1+3 \delta_{3}\right)$ & $\overline{\mathrm{x}}_{4}\left(1+3 \delta_{4}\right)$ & $\overline{\mathrm{x}}_{5}\left(1+3 \delta_{5}\right)$ & $\bar{x}_{6}\left(1+3 \delta_{6}\right)$ \\
\hline$\overline{\mathrm{x}}_{1}$ & $\bar{x}_{2}$ & $\bar{x}_{3}\left(1+3 \delta_{3}\right)$ & $\bar{x}_{4}\left(1+3 \delta_{4}\right)$ & $\overline{\mathrm{x}}_{5}\left(1+3 \delta_{5}\right)$ & $\bar{x}_{6}\left(1+3 \delta_{6}\right)$ \\
\hline $\bar{x}_{1}\left(1-3 \delta_{1}\right)$ & $\overline{\mathrm{x}}_{2}$ & $\overline{\mathrm{x}}_{3}\left(1-1.5 \delta_{3}\right)$ & $\overline{\mathrm{x}}_{4}\left(1-1.5 \delta_{4}\right)$ & $\overline{\mathrm{x}}_{5}\left(1-1.5 \delta_{5}\right)$ & $\overline{\mathrm{x}}_{6}\left(1-1.5 \delta_{6}\right)$ \\
\hline $\bar{x}_{1}\left(1+3 \delta_{1}\right)$ & $\overline{\mathrm{x}}_{2}$ & $\overline{\mathrm{x}}_{3}\left(1-1.5 \delta_{3}\right)$ & $\overline{\mathrm{x}}_{4}\left(1-1.5 \delta_{4}\right)$ & $\overline{\mathrm{x}}_{5}\left(1-1.5 \delta_{5}\right)$ & $\overline{\mathrm{x}}_{6}\left(1-1.5 \delta_{6}\right)$ \\
\hline $\bar{x}_{1}$ & $\bar{x}_{2}\left(1-3 \delta_{2}\right)$ & $\overline{\mathrm{x}}_{3}\left(1-1.5 \delta_{3}\right)$ & $\overline{\mathrm{x}}_{4}\left(1-1.5 \delta_{4}\right)$ & $\overline{\mathrm{x}}_{5}\left(1-1.5 \delta_{5}\right)$ & $\overline{\mathrm{x}}_{6}\left(1-1.5 \delta_{6}\right)$ \\
\hline$\overline{\mathrm{x}}_{1}$ & $\bar{x}_{2}\left(1+3 \delta_{2}\right)$ & $\bar{x}_{3}\left(1-1.5 \delta_{3}\right)$ & $\overline{\mathrm{x}}_{4}\left(1-1.5 \delta_{4}\right)$ & $\overline{\mathrm{x}}_{5}\left(1-1.5 \delta_{5}\right)$ & $\overline{\mathrm{x}}_{6}\left(1-1.5 \delta_{6}\right)$ \\
\hline $\bar{x}_{1}\left(1+3 \delta_{1}\right)$ & $\bar{x}_{2}\left(1+3 \delta_{2}\right)$ & $\bar{x}_{3}\left(1-1.5 \delta_{3}\right)$ & $\overline{\mathrm{x}}_{4}\left(1-1.5 \delta_{4}\right)$ & $\overline{\mathrm{x}}_{5}\left(1-1.5 \delta_{5}\right)$ & $\bar{x}_{6}\left(1-1.5 \delta_{6}\right)$ \\
\hline$\overline{\mathrm{x}}_{1}$ & $\overline{\mathrm{x}}_{2}$ & $\overline{\mathrm{x}}_{3}\left(1-1.5 \delta_{3}\right)$ & $\overline{\mathrm{x}}_{4}\left(1-1.5 \delta_{4}\right)$ & $\overline{\mathrm{x}}_{5}\left(1-1.5 \delta_{5}\right)$ & $\overline{\mathrm{x}}_{6}\left(1-1.5 \delta_{6}\right)$ \\
\hline$\overline{\mathrm{x}}_{1}\left(1-3 \delta_{1}\right)$ & $\overline{\mathrm{x}}_{2}$ & $\overline{\mathrm{x}}_{3}\left(1+1.5 \delta_{3}\right)$ & $\overline{\mathrm{x}}_{4}\left(1+1.5 \delta_{4}\right)$ & $\overline{\mathrm{x}}_{5}\left(1+1.5 \delta_{5}\right)$ & $\overline{\mathrm{x}}_{6}\left(1+1.5 \delta_{6}\right)$ \\
\hline$\overline{\mathrm{x}}_{1}\left(1+3 \delta_{1}\right)$ & $\overline{\mathrm{x}}_{2}$ & $\overline{\mathrm{x}}_{3}\left(1+1.5 \delta_{3}\right)$ & $\overline{\mathrm{x}}_{4}\left(1+1.5 \delta_{4}\right)$ & $\overline{\mathrm{x}}_{5}\left(1+1.5 \delta_{5}\right)$ & $\overline{\mathrm{x}}_{6}\left(1+1.5 \delta_{6}\right)$ \\
\hline$\overline{\mathrm{x}}_{1}$ & $\bar{x}_{2}\left(1-3 \delta_{2}\right)$ & $\overline{\mathrm{x}}_{3}\left(1+1.5 \delta_{3}\right)$ & $\overline{\mathrm{x}}_{4}\left(1+1.5 \delta_{4}\right)$ & $\overline{\mathrm{x}}_{5}\left(1+1.5 \delta_{5}\right)$ & $\overline{\mathrm{x}}_{6}\left(1+1.5 \delta_{6}\right)$ \\
\hline$\overline{\mathrm{x}}_{1}$ & $\bar{x}_{2}\left(1+3 \delta_{2}\right)$ & $\overline{\mathrm{x}}_{3}\left(1+1.5 \delta_{3}\right)$ & $\overline{\mathrm{x}}_{4}\left(1+1.5 \delta_{4}\right)$ & $\overline{\mathrm{x}}_{5}\left(1+1.5 \delta_{5}\right)$ & $\overline{\mathrm{x}}_{6}\left(1+1.5 \delta_{6}\right)$ \\
\hline$\overline{\mathrm{x}}_{1}\left(1+3 \delta_{1}\right)$ & $\bar{x}_{2}\left(1+3 \delta_{2}\right)$ & $\overline{\mathrm{x}}_{3}\left(1+1.5 \delta_{3}\right)$ & $\overline{\mathrm{x}}_{4}\left(1+1.5 \delta_{4}\right)$ & $\overline{\mathrm{x}}_{5}\left(1+1.5 \delta_{5}\right)$ & $\overline{\mathrm{x}}_{6}\left(1+1.5 \delta_{6}\right)$ \\
\hline $\bar{x}_{1}$ & $\overline{\mathrm{x}}_{2}$ & $\overline{\mathrm{x}}_{3}\left(1+1.5 \delta_{3}\right)$ & $\overline{\mathrm{x}}_{4}\left(1+1.5 \delta_{4}\right)$ & $\overline{\mathrm{x}}_{5}\left(1+1.5 \delta_{5}\right)$ & $\overline{\mathrm{x}}_{6}\left(1+1.5 \delta_{6}\right)$ \\
\hline $\bar{x}_{1}\left(1-3 \delta_{1}\right)$ & $\bar{x}_{2}$ & $\overline{\mathrm{x}}_{3}$ & $\overline{\mathrm{x}}_{4}\left(1-3 \delta_{4}\right)$ & $\bar{x}_{5}\left(1+3 \delta_{5}\right)$ & $\bar{x}_{6}\left(1+3 \delta_{6}\right)$ \\
\hline $\bar{x}_{1}\left(1+3 \delta_{1}\right)$ & $\bar{x}_{2}$ & $\bar{x}_{3}$ & $\overline{\mathrm{x}}_{4}\left(1-3 \delta_{4}\right)$ & $\bar{x}_{5}\left(1+3 \delta_{5}\right)$ & $\bar{x}_{6}\left(1+3 \delta_{6}\right)$ \\
\hline $\bar{x}_{1}$ & $\bar{x}_{2}\left(1-3 \delta_{2}\right)$ & $\bar{x}_{3}$ & $\bar{x}_{4}\left(1-3 \delta_{4}\right)$ & $\bar{x}_{5}\left(1+3 \delta_{5}\right)$ & $\bar{x}_{6}\left(1+3 \delta_{6}\right)$ \\
\hline
\end{tabular}

\section{Plano de experiência numérico Composto}

Esse plano apresenta uma ótima performance, embora aparentemente tenha pontos em exagero. O EP Composto, Figura 5, para estruturas com elevado grau de não-linearidade, parece ser o mais adequado dentre os planos apresentados. 


\section{Composto}

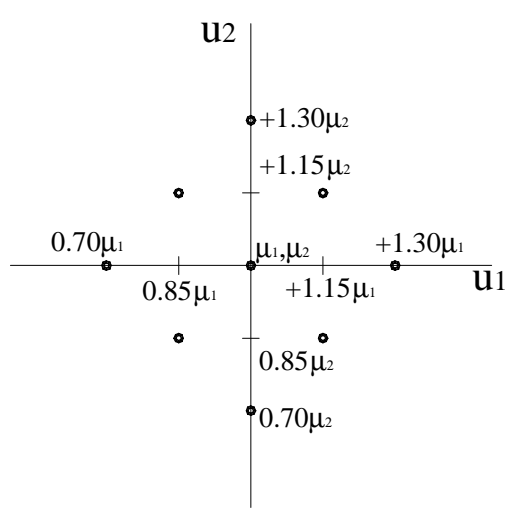

Figura 5 Plano de experiência Composto

Os coeficientes propostos para problemas com 1 variável aleatória são:

$$
\left\{\begin{array}{lllll}
\bar{x}_{1} & \bar{x}_{1}\left(1-3 \delta_{1}\right) & \bar{x}_{1}\left(1-1.5 \delta_{1}\right) & \bar{x}_{1}\left(1+1.5 \delta_{1}\right) & \bar{x}_{1}\left(1+3 \delta_{1}\right)
\end{array}\right\}
$$

Os coeficientes propostos para problemas com 2 variáveis aleatórias são:

$$
\left[\begin{array}{cc}
\overline{\mathrm{x}}_{1} & \overline{\mathrm{x}}_{2}\left(1+3 \delta_{2}\right) \\
\overline{\mathrm{x}}_{1}\left(1-1.5 \delta_{1}\right) & \overline{\mathrm{x}}_{2}\left(1+1.5 \delta_{2}\right) \\
\overline{\mathrm{x}}_{1}\left(1+1.5 \delta_{1}\right) & \overline{\mathrm{x}}_{2}\left(1+1.5 \delta_{2}\right) \\
\overline{\mathrm{x}}_{1}\left(1-3 \delta_{1}\right) & \overline{\mathrm{x}}_{2} \\
\overline{\mathrm{x}}_{1}\left(1+3 \delta_{1}\right) & \overline{\mathrm{x}}_{2} \\
\overline{\mathrm{x}}_{1}\left(1-1.5 \delta_{1}\right) & \overline{\mathrm{x}}_{2}\left(1-1.5 \delta_{2}\right) \\
\overline{\mathrm{x}}_{1}\left(1+1.5 \delta_{1}\right) & \overline{\mathrm{x}}_{2}\left(1-1.5 \delta_{2}\right) \\
\overline{\mathrm{x}}_{1} & \overline{\mathrm{x}}_{2}\left(1-3 \delta_{2}\right) \\
\overline{\mathrm{x}}_{1} & \overline{\mathrm{x}}_{2}
\end{array}\right]
$$

Os coeficientes propostos para problemas com 3 variáveis aleatórias são: 


$$
\left[\begin{array}{ccc}
\overline{\mathrm{x}}_{1} & \overline{\mathrm{x}}_{2}\left(1+3 \delta_{2}\right) & \overline{\mathrm{x}}_{3} \\
\overline{\mathrm{x}}_{1}\left(1-1.5 \delta_{1}\right) & \overline{\mathrm{x}}_{2}\left(1+1.5 \delta_{2}\right) & \overline{\mathrm{x}}_{3} \\
\overline{\mathrm{x}}_{1}\left(1+1.5 \delta_{1}\right) & \overline{\mathrm{x}}_{2}\left(1+1.5 \delta_{2}\right) & \overline{\mathrm{x}}_{3} \\
\overline{\mathrm{x}}_{1}\left(1-3 \delta_{1}\right) & \overline{\mathrm{x}}_{2} & \overline{\mathrm{x}}_{3} \\
\overline{\mathrm{x}}_{1}\left(1+3 \delta_{1}\right) & \overline{\mathrm{x}}_{2} & \overline{\mathrm{x}}_{3} \\
\overline{\mathrm{x}}_{1}\left(1-1.5 \delta_{1}\right) & \overline{\mathrm{x}}_{2}\left(1-1.5 \delta_{2}\right) & \overline{\mathrm{x}}_{3} \\
\overline{\mathrm{x}}_{1}\left(1+1.5 \delta_{1}\right) & \overline{\mathrm{x}}_{2}\left(1-1.5 \delta_{2}\right) & \overline{\mathrm{x}}_{3} \\
\overline{\mathrm{x}}_{1} & \overline{\mathrm{x}}_{2}\left(1-3 \delta_{2}\right) & \overline{\mathrm{x}}_{3} \\
\overline{\mathrm{x}}_{1} & \overline{\mathrm{x}}_{2} & \overline{\mathrm{x}}_{3} \\
\overline{\mathrm{x}}_{1} & \overline{\mathrm{x}}_{2}\left(1+3 \delta_{2}\right) & \overline{\mathrm{x}}_{3}\left(1-3 \delta_{3}\right) \\
\overline{\mathrm{x}}_{1}\left(1-1.5 \delta_{1}\right) & \overline{\mathrm{x}}_{2}\left(1+1.5 \delta_{2}\right) & \overline{\mathrm{x}}_{3}\left(1-3 \delta_{3}\right) \\
\overline{\mathrm{x}}_{1}\left(1+1.5 \delta_{1}\right) & \overline{\mathrm{x}}_{2}\left(1+1.5 \delta_{2}\right) & \overline{\mathrm{x}}_{3}\left(1-3 \delta_{3}\right) \\
\overline{\mathrm{x}}_{1}\left(1-3 \delta_{1}\right) & \overline{\mathrm{x}}_{2} & \overline{\mathrm{x}}_{3}\left(1-3 \delta_{3}\right) \\
\overline{\mathrm{x}}_{1}\left(1+3 \delta_{1}\right) & \overline{\mathrm{x}}_{2} & \overline{\mathrm{x}}_{3}\left(1-3 \delta_{3}\right) \\
\overline{\mathrm{x}}_{1}\left(1-1.5 \delta_{1}\right) & \overline{\mathrm{x}}_{2}\left(1-1.5 \delta_{2}\right) & \overline{\mathrm{x}}_{3}\left(1+3 \delta_{3}\right) \\
\overline{\mathrm{x}}_{1}\left(1+1.5 \delta_{1}\right) & \overline{\mathrm{x}}_{2}\left(1-1.5 \delta_{2}\right) & \overline{\mathrm{x}}_{3}\left(1+3 \delta_{3}\right) \\
\overline{\mathrm{x}}_{1} & \overline{\mathrm{x}}_{2}\left(1-3 \delta_{2}\right) & \overline{\mathrm{x}}_{3}\left(1+3 \delta_{3}\right) \\
\overline{\mathrm{x}}_{1} & \overline{\mathrm{x}}_{2} & \overline{\mathrm{x}}_{3}\left(1+3 \delta_{3}\right)
\end{array}\right]
$$

Os coeficientes propostos para problemas com 4 variáveis aleatórias são: 


\begin{tabular}{|c|c|c|c|}
\hline $\bar{x}_{1}$ & $\bar{x}_{2}\left(1+3 \delta_{2}\right)$ & $\bar{x}_{3}$ & $\overline{\mathrm{x}}_{4}$ \\
\hline$\overline{\mathrm{x}}_{1}\left(1-1.5 \delta_{1}\right)$ & $\bar{x}_{2}\left(1+1.5 \delta_{2}\right)$ & $\bar{x}_{3}$ & $\bar{x}_{4}$ \\
\hline$\overline{\mathrm{x}}_{1}\left(1+1.5 \delta_{1}\right)$ & $\overline{\mathrm{x}}_{2}\left(1+1.5 \delta_{2}\right)$ & $\bar{x}_{3}$ & $\bar{x}_{4}$ \\
\hline $\bar{x}_{1}\left(1-3 \delta_{1}\right)$ & $\bar{x}_{2}$ & $\bar{x}_{3}$ & $\overline{\mathrm{x}}_{4}$ \\
\hline $\bar{x}_{1}\left(1+3 \delta_{1}\right)$ & $\bar{x}_{2}$ & $\bar{x}_{3}$ & $\bar{x}_{4}$ \\
\hline$\overline{\mathrm{x}}_{1}\left(1-1.5 \delta_{1}\right)$ & $\overline{\mathrm{x}}_{2}\left(1-1.5 \delta_{2}\right)$ & $\bar{x}_{3}$ & $\bar{x}_{4}$ \\
\hline$\overline{\mathrm{x}}_{1}\left(1+1.5 \delta_{1}\right)$ & $\bar{x}_{2}\left(1-1.5 \delta_{2}\right)$ & $\bar{x}_{3}$ & $\bar{x}_{4}$ \\
\hline $\bar{x}_{1}$ & $\bar{x}_{2}\left(1-3 \delta_{2}\right)$ & $\bar{x}_{3}$ & $\bar{x}_{4}$ \\
\hline$\overline{\mathrm{x}}_{1}$ & $\bar{x}_{2}$ & $\overline{\mathrm{x}}_{3}$ & $\overline{\mathrm{x}}_{4}$ \\
\hline $\bar{x}_{1}$ & $\bar{x}_{2}\left(1+3 \delta_{2}\right)$ & $\bar{x}_{3}$ & $\bar{x}_{4}\left(1+3 \delta_{4}\right)$ \\
\hline$\overline{\mathrm{x}}_{1}\left(1-1.5 \delta_{1}\right)$ & $\bar{x}_{2}\left(1+1.5 \delta_{2}\right)$ & $\overline{\mathrm{x}}_{3}\left(1-1.5 \delta_{3}\right)$ & $\bar{x}_{4}\left(1+3 \delta_{4}\right)$ \\
\hline$\overline{\mathrm{x}}_{1}\left(1+1.5 \delta_{1}\right)$ & $\bar{x}_{2}\left(1+1.5 \delta_{2}\right)$ & $\overline{\mathrm{x}}_{3}\left(1+1.5 \delta_{3}\right)$ & $\bar{x}_{4}\left(1+3 \delta_{4}\right)$ \\
\hline $\bar{x}_{1}\left(1-3 \delta_{1}\right)$ & $\bar{x}_{2}$ & $\bar{x}_{3}\left(1-3 \delta_{3}\right)$ & $\overline{\mathrm{x}}_{4}\left(1+3 \delta_{4}\right)$ \\
\hline $\bar{x}_{1}\left(1+3 \delta_{1}\right)$ & $\bar{x}_{2}$ & $\bar{x}_{3}\left(1+3 \delta_{3}\right)$ & $\overline{\mathrm{x}}_{4}\left(1+3 \delta_{4}\right)$ \\
\hline$\overline{\mathrm{x}}_{1}\left(1-1.5 \delta_{1}\right)$ & $\overline{\mathrm{x}}_{2}\left(1-1.5 \delta_{2}\right)$ & $\overline{\mathrm{x}}_{3}\left(1-1.5 \delta_{3}\right)$ & $\bar{x}_{4}\left(1-3 \delta_{4}\right)$ \\
\hline$\overline{\mathrm{x}}_{1}\left(1+1.5 \delta_{1}\right)$ & $\bar{x}_{2}\left(1-1.5 \delta_{2}\right)$ & $\overline{\mathrm{x}}_{3}\left(1+1.5 \delta_{3}\right)$ & $\bar{x}_{4}\left(1-3 \delta_{4}\right)$ \\
\hline$\overline{\mathrm{x}}_{1}$ & $\bar{x}_{2}\left(1-3 \delta_{2}\right)$ & $\overline{\mathrm{x}}_{3}$ & $\bar{x}_{4}\left(1-3 \delta_{4}\right)$ \\
\hline$\overline{\mathrm{x}}_{1}$ & $\bar{x}_{2}$ & $\overline{\mathrm{x}}_{3}$ & $\bar{x}_{4}\left(1-3 \delta_{4}\right)$ \\
\hline $\bar{x}_{1}$ & $\bar{x}_{2}\left(1+3 \delta_{2}\right)$ & $\bar{x}_{3}\left(1+3 \delta_{3}\right)$ & $\overline{\mathrm{x}}_{4}\left(1-1.5 \delta_{4}\right)$ \\
\hline$\overline{\mathrm{x}}_{1}\left(1-1.5 \delta_{1}\right)$ & $\overline{\mathrm{x}}_{2}\left(1+1.5 \delta_{2}\right)$ & $\overline{\mathrm{x}}_{3}\left(1+1.5 \delta_{3}\right)$ & $\overline{\mathrm{x}}_{4}\left(1-1.5 \delta_{4}\right)$ \\
\hline$\overline{\mathrm{x}}_{1}\left(1+1.5 \delta_{1}\right)$ & $\overline{\mathrm{x}}_{2}\left(1+1.5 \delta_{2}\right)$ & $\overline{\mathrm{x}}_{3}\left(1+1.5 \delta_{3}\right)$ & $\overline{\mathrm{x}}_{4}\left(1-1.5 \delta_{4}\right)$ \\
\hline $\bar{x}_{1}\left(1-3 \delta_{1}\right)$ & $\bar{x}_{2}$ & $\bar{x}_{3}$ & $\bar{x}_{4}\left(1-1.5 \delta_{4}\right)$ \\
\hline $\bar{x}_{1}\left(1+3 \delta_{1}\right)$ & $\bar{x}_{2}$ & $\bar{x}_{3}$ & $\overline{\mathrm{x}}_{4}\left(1-1.5 \delta_{4}\right)$ \\
\hline$\overline{\mathrm{x}}_{1}\left(1-1.5 \delta_{1}\right)$ & $\bar{x}_{2}\left(1-1.5 \delta_{2}\right)$ & $\overline{\mathrm{x}}_{3}\left(1-1.5 \delta_{3}\right)$ & $\bar{x}_{4}\left(1+1.5 \delta_{4}\right)$ \\
\hline$\overline{\mathrm{x}}_{1}\left(1+1.5 \delta_{1}\right)$ & $\bar{x}_{2}\left(1-1.5 \delta_{2}\right)$ & $\overline{\mathrm{x}}_{3}\left(1-1.5 \delta_{3}\right)$ & $\bar{x}_{4}\left(1+1.5 \delta_{4}\right)$ \\
\hline $\bar{x}_{1}$ & $\bar{x}_{2}\left(1-3 \delta_{2}\right)$ & $\bar{x}_{3}\left(1-3 \delta_{3}\right)$ & $\bar{x}_{4}\left(1+1.5 \delta_{4}\right)$ \\
\hline $\bar{x}_{1}$ & $\bar{x}_{2}$ & $\bar{x}_{3}$ & $\bar{x}_{4}\left(1+1.5 \delta_{4}\right)$ \\
\hline
\end{tabular}

Os coeficientes propostos para problemas com 5 variáveis aleatórias são: 


$\left[\begin{array}{ccccc}\overline{\mathrm{x}}_{1} & \overline{\mathrm{x}}_{2}\left(1+3 \delta_{2}\right) & \overline{\mathrm{x}}_{3} & \overline{\mathrm{x}}_{4} & \overline{\mathrm{x}}_{5} \\ \overline{\mathrm{x}}_{1}\left(1-1.5 \delta_{1}\right) & \overline{\mathrm{x}}_{2}\left(1+1.5 \delta_{2}\right) & \overline{\mathrm{x}}_{3} & \overline{\mathrm{x}}_{4} & \overline{\mathrm{x}}_{5} \\ \overline{\mathrm{x}}_{1}\left(1+1.5 \delta_{1}\right) & \overline{\mathrm{x}}_{2}\left(1+1.5 \delta_{2}\right) & \overline{\mathrm{x}}_{3} & \overline{\mathrm{x}}_{4} & \overline{\mathrm{x}}_{5} \\ \overline{\mathrm{x}}_{1}\left(1-3 \delta_{1}\right) & \overline{\mathrm{x}}_{2} & \overline{\mathrm{x}}_{3} & \overline{\mathrm{x}}_{4} & \overline{\mathrm{x}}_{5} \\ \overline{\mathrm{x}}_{1}\left(1+3 \delta_{1}\right) & \overline{\mathrm{x}}_{2} & \overline{\mathrm{x}}_{3} & \overline{\mathrm{x}}_{4} & \overline{\mathrm{x}}_{5} \\ \overline{\mathrm{x}}_{1}\left(1-1.5 \delta_{1}\right) & \overline{\mathrm{x}}_{2}\left(1-1.5 \delta_{2}\right) & \overline{\mathrm{x}}_{3} & \overline{\mathrm{x}}_{4} & \overline{\mathrm{x}}_{5} \\ \overline{\mathrm{x}}_{1}\left(1+1.5 \delta_{1}\right) & \overline{\mathrm{x}}_{2}\left(1-1.5 \delta_{2}\right) & \overline{\mathrm{x}}_{3} & \overline{\mathrm{x}}_{4} & \overline{\mathrm{x}}_{5} \\ \overline{\mathrm{x}}_{1} & \overline{\mathrm{x}}_{2}\left(1-3 \delta_{2}\right) & \overline{\mathrm{x}}_{3} & \overline{\mathrm{x}}_{4} & \overline{\mathrm{x}}_{5} \\ \overline{\mathrm{x}}_{1} & \overline{\mathrm{x}}_{2} & \overline{\mathrm{x}}_{3} & \overline{\mathrm{x}}_{4} & \overline{\mathrm{x}}_{5} \\ \overline{\mathrm{x}}_{1} & \overline{\mathrm{x}}_{2}\left(1+3 \delta_{2}\right) & \overline{\mathrm{x}}_{3} & \overline{\mathrm{x}}_{4}\left(1+3 \delta_{4}\right) & \overline{\mathrm{x}}_{5}\left(1+3 \delta_{5}\right) \\ \overline{\mathrm{x}}_{1}\left(1-1.5 \delta_{1}\right) & \mathrm{x}_{2}\left(1+1.5 \delta_{2}\right) & \overline{\mathrm{x}}_{3}\left(1-1.5 \delta_{3}\right) & \overline{\mathrm{x}}_{4}\left(1+3 \delta_{4}\right) & \overline{\mathrm{x}}_{5}\left(1+3 \delta_{5}\right) \\ \overline{\mathrm{x}}_{1}\left(1+1.5 \delta_{1}\right) & \overline{\mathrm{x}}_{2}\left(1+1.5 \delta_{2}\right) & \overline{\mathrm{x}}_{3}\left(1+1.5 \delta_{3}\right) & \overline{\mathrm{x}}_{4}\left(1+3 \delta_{4}\right) & \overline{\mathrm{x}}_{5}\left(1+3 \delta_{5}\right) \\ \overline{\mathrm{x}}_{1}\left(1-3 \delta_{1}\right) & \overline{\mathrm{x}}_{2} & \overline{\mathrm{x}}_{3}\left(1-3 \delta_{3}\right) & \overline{\mathrm{x}}_{4}\left(1+3 \delta_{4}\right) & \overline{\mathrm{x}}_{5}\left(1+3 \delta_{5}\right) \\ \overline{\mathrm{x}}_{1}\left(1+3 \delta_{1}\right) & \overline{\mathrm{x}}_{2} & \overline{\mathrm{x}}_{3}\left(1+3 \delta_{3}\right) & \overline{\mathrm{x}}_{4}\left(1+3 \delta_{4}\right) & \overline{\mathrm{x}}_{5}\left(1+3 \delta_{5}\right) \\ \overline{\mathrm{x}}_{1}\left(1-1.5 \delta_{1}\right) & \overline{\mathrm{x}}_{2}\left(1-1.5 \delta_{2}\right) & \overline{\mathrm{x}}_{3}\left(1-1.5 \delta_{3}\right) & \overline{\mathrm{x}}_{4}\left(1+3 \delta_{4}\right) & \overline{\mathrm{x}}_{5}\left(1+3 \delta_{5}\right) \\ \overline{\mathrm{x}}_{1}\left(1+1.5 \delta_{1}\right) & \overline{\mathrm{x}}_{2}\left(1-1.5 \delta_{2}\right) & \overline{\mathrm{x}}_{3}\left(1+1.5 \delta_{3}\right) & \overline{\mathrm{x}}_{4}\left(1+3 \delta_{4}\right) & \overline{\mathrm{x}}_{5}\left(1+3 \delta_{5}\right) \\ \overline{\mathrm{x}}_{1} & \overline{\mathrm{x}}_{2}\left(1-3 \delta_{2}\right) & \overline{\mathrm{x}}_{3} & \overline{\mathrm{x}}_{4}\left(1+3 \delta_{4}\right) & \overline{\mathrm{x}}_{5}\left(1+3 \delta_{5}\right) \\ \overline{\mathrm{x}}_{1} & \overline{\mathrm{x}}_{2} & \overline{\mathrm{x}}_{3} & \overline{\mathrm{x}}_{4}\left(1+3 \delta_{4}\right) & \overline{\mathrm{x}}_{5}\left(1+3 \delta_{5}\right)\end{array} \mid\right.$

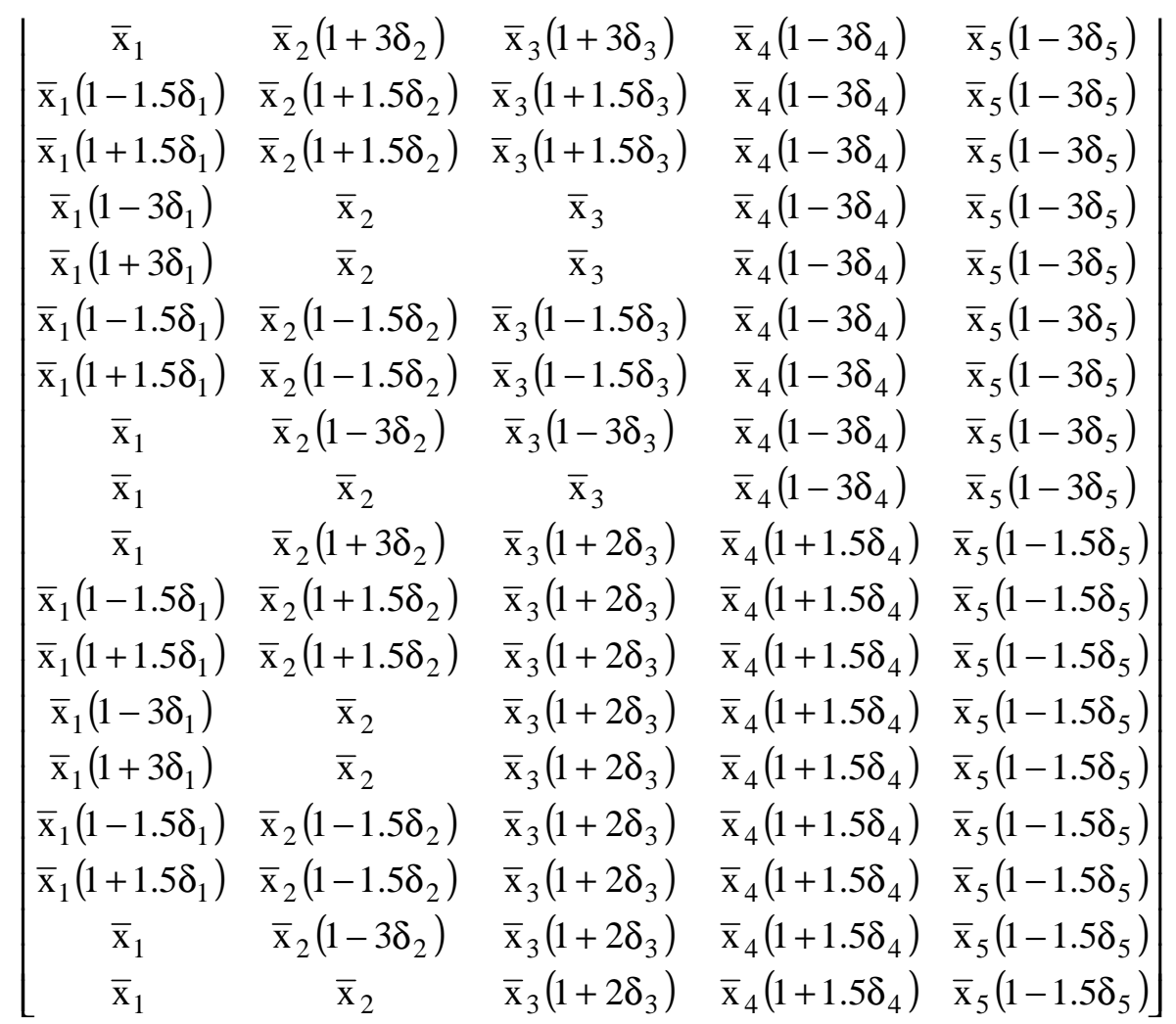

Os coeficientes propostos para problemas com 6 variáveis aleatórias são: 


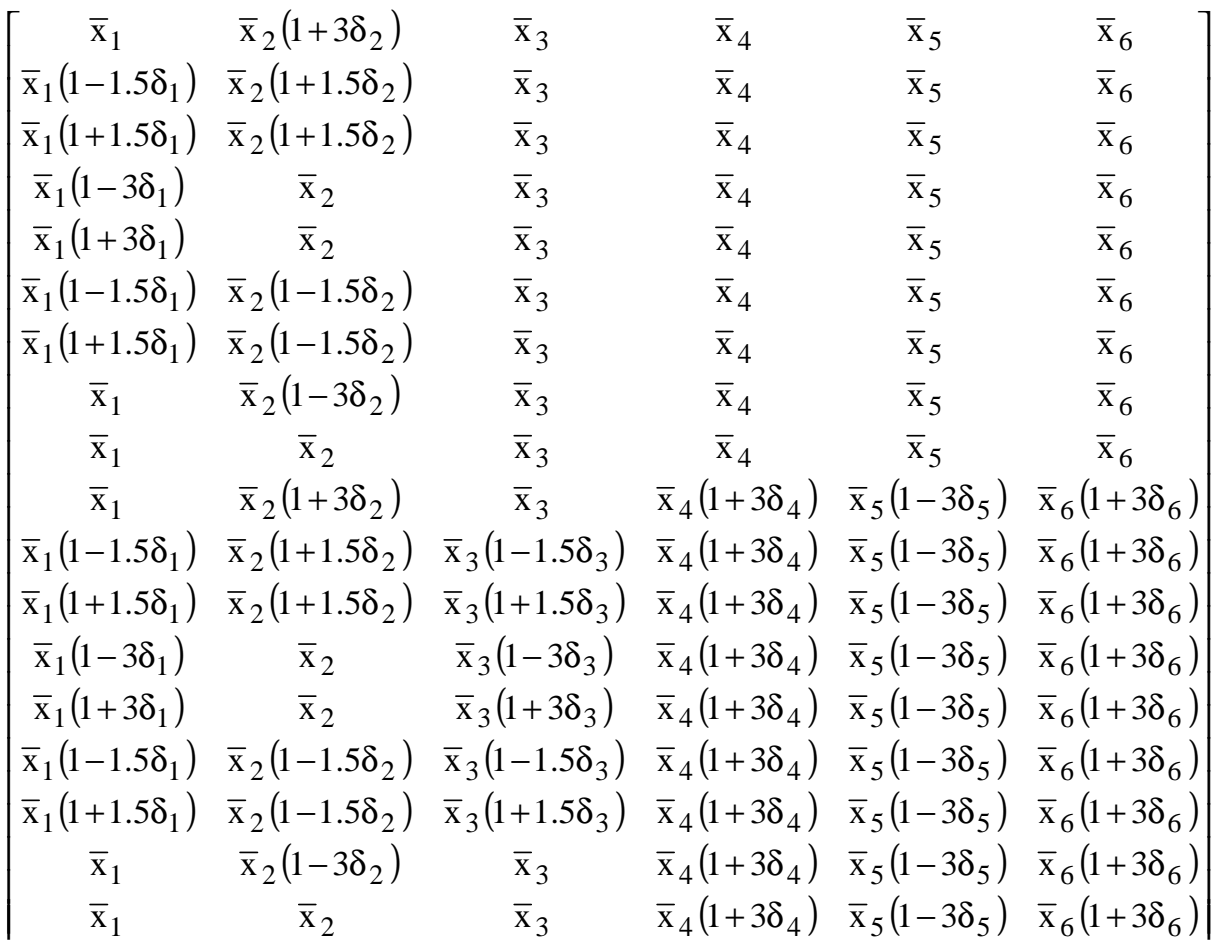

$$
\begin{aligned}
& \left|\begin{array}{cccccc}
\overline{\mathrm{x}}_{1} & \overline{\mathrm{x}}_{2}\left(1+3 \delta_{2}\right) & \overline{\mathrm{x}}_{3}\left(1+3 \delta_{3}\right) & \overline{\mathrm{x}}_{4}\left(1-3 \delta_{4}\right) & \overline{\mathrm{x}}_{5}\left(1+3 \delta_{5}\right) & \overline{\mathrm{x}}_{6}\left(1-3 \delta_{6}\right) \\
\overline{\mathrm{x}}_{1}\left(1-1.5 \delta_{1}\right) & \overline{\mathrm{x}}_{2}\left(1+1.5 \delta_{2}\right) & \overline{\mathrm{x}}_{3}\left(1+1.5 \delta_{3}\right) & \overline{\mathrm{x}}_{4}\left(1-3 \delta_{4}\right) & \overline{\mathrm{x}}_{5}\left(1+3 \delta_{5}\right) & \overline{\mathrm{x}}_{6}\left(1-3 \delta_{6}\right) \\
\overline{\mathrm{x}}_{1}\left(1+1.5 \delta_{1}\right) & \overline{\mathrm{x}}_{2}\left(1+1.5 \delta_{2}\right) & \overline{\mathrm{x}}_{3}\left(1+1.5 \delta_{3}\right) & \overline{\mathrm{x}}_{4}\left(1-3 \delta_{4}\right) & \overline{\mathrm{x}}_{5}\left(1+3 \delta_{5}\right) & \overline{\mathrm{x}}_{6}\left(1-3 \delta_{6}\right) \\
\overline{\mathrm{x}}_{1}\left(1-3 \delta_{1}\right) & \overline{\mathrm{x}}_{2} & \overline{\mathrm{x}}_{3} & \overline{\mathrm{x}}_{4}\left(1-3 \delta_{4}\right) & \overline{\mathrm{x}}_{5}\left(1+3 \delta_{5}\right) & \overline{\mathrm{x}}_{6}\left(1-3 \delta_{6}\right) \\
\overline{\mathrm{x}}_{1}\left(1+3 \delta_{1}\right) & \overline{\mathrm{x}}_{2} & \overline{\mathrm{x}}_{3} & \overline{\mathrm{x}}_{4}\left(1-3 \delta_{4}\right) & \overline{\mathrm{x}}_{5}\left(1+3 \delta_{5}\right) & \overline{\mathrm{x}}_{6}\left(1-3 \delta_{6}\right) \\
\overline{\mathrm{x}}_{1}\left(1-1.5 \delta_{1}\right) & \overline{\mathrm{x}}_{2}\left(1-1.5 \delta_{2}\right) & \overline{\mathrm{x}}_{3}\left(1-1.5 \delta_{3}\right) & \overline{\mathrm{x}}_{4}\left(1-3 \delta_{4}\right) & \overline{\mathrm{x}}_{5}\left(1+3 \delta_{5}\right) & \overline{\mathrm{x}}_{6}\left(1-3 \delta_{6}\right) \\
\overline{\mathrm{x}}_{1}\left(1+1.5 \delta_{1}\right) & \overline{\mathrm{x}}_{2}\left(1-1.5 \delta_{2}\right) & \overline{\mathrm{x}}_{3}\left(1-1.5 \delta_{3}\right) & \overline{\mathrm{x}}_{4}\left(1-3 \delta_{4}\right) & \overline{\mathrm{x}}_{5}\left(1+3 \delta_{5}\right) & \overline{\mathrm{x}}_{6}\left(1-3 \delta_{6}\right) \\
\overline{\mathrm{x}}_{1} & \overline{\mathrm{x}}_{2}\left(1-3 \delta_{2}\right) & \overline{\mathrm{x}}_{3}\left(1-3 \delta_{3}\right) & \overline{\mathrm{x}}_{4}\left(1-3 \delta_{4}\right) & \overline{\mathrm{x}}_{5}\left(1+3 \delta_{5}\right) & \overline{\mathrm{x}}_{6}\left(1-3 \delta_{6}\right) \\
\overline{\mathrm{x}}_{1} & \overline{\mathrm{x}}_{2} & \overline{\mathrm{x}}_{3} & \overline{\mathrm{x}}_{4}\left(1-3 \delta_{4}\right) & \overline{\mathrm{x}}_{5}\left(1+3 \delta_{5}\right) & \overline{\mathrm{x}}_{6}\left(1-3 \delta_{6}\right)
\end{array}\right|
\end{aligned}
$$




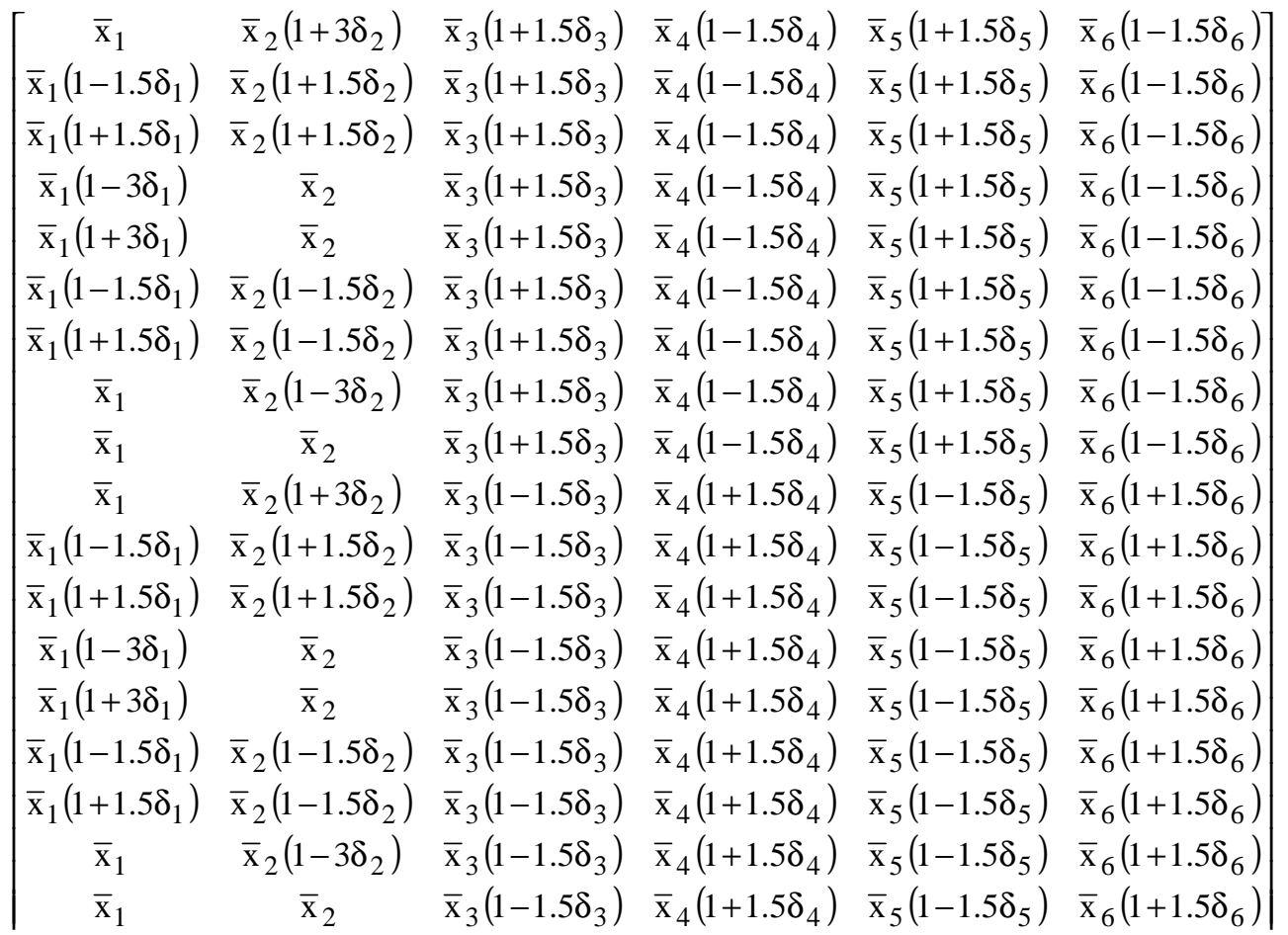

\section{Planos de experiência aleatórios}

O procedimento para os planos de experiência aleatórios é semelhante ao utilizado para gerar os planos de experiência numéricos, diferenciando-se apenas na geração dos pontos que nesse caso é aleatória.

É interessante não deixar que os coeficientes sejam completamente aleatórios. A aleatoriedade dos coeficientes deve pertencer a domínios bem definidos para evitarem-se problemas com a solução mecânica da estrutura. É fácil entender essa observação: imagine se o coeficiente de resistência do material que compõe a estrutura for próximo de zero, nessa situação provavelmente a matriz de rigidez dessa estrutura será singular.

Um caminho bastante interessante para "direcionar" a aleatoriedade dos pontos desses planos é a utilização de algoritmos genéticos, ou mais especificamente algoritmos meméticos. A utilização de algoritmos heurísticos por natureza para gerar novos planos de experiência é a opção mais recomendada quando trata-se de um número elevado de variáveis aleatórias, ou um número elevado de hipersuperfícies limites, ou problemas com elevado número de respostas ou mínimos locais. 


\section{Bibliografia}

[1] ABDO, T.; RACKWITZ, R. (after 1989) A new beta-point algorithm for larger time-invariant and time-variant reliability problems.

[2] AHEARNE, J.F. (1998) How safe is safe enough? Reliability Engineering \& System Safety. v.62, n.1, p. 5-7.

[3] ALLEN, H. G. ; BULSON, P. S. (1980). Background to buckling. London, McGraw-Hill.

[4] ALMEIDA, A.; MAREK, P.; GUSTAR, M. (1997) From partial factors method to simulation-based reliability assessment concepts in structural design. Advances in Safety and Reliability. Proceedings: ESREL'97 INTERNATIONAL CONFERENCE ON SAFETY AND RELIABILITY. Lisbon, Portugal, v.2, p.1279-1285.

[5] AMBARTZUMIAN, R.; KIUREGHIAN, A.D.; OHANIAN, V.; SUKIASIAN, H.(1997) Multinormal probability by sequencional conditioned importance sampling. Advances in Safety and Reliability. Proceedings: ESREL'97 INTERNATIONAL CONFERENCE ON SAFETY AND RELIABILITY. Lisbon, Portugal, v.2, p.1261-1268.

[6] ANG, A.H-S.; TANG, W.H. (1975) Probability Concepts in Engineering Planning and Design. v.1, Wiley.

[7] APOSTOLAKIS, G.E.; SOARES, C.G.; KONDO, S. (1998) Risk perception versus risk analysis. Reliability Engineering \& System Safety. v.59, n.1, p.1-4.

[8] ASSOCIAÇÃO BRASILEIRA DE NORMAS TÉCNICAS (1978/ 1984/ 1986/ 1988/ 1994). NB 1-NB 5/NBR-8681 / NBR 8800 / NBR-6123 / NB-1.

[9] AUGUSTI, G.; BARATA, A.; CASCIATTI, F. (1984). Probabilistic methods in structural engineering. London, Chapman and Hall.

[10] AVEN, T. E PITBLADO, R. (1998) On risk assessment in the petroleum activities on the Norwegian and UK continental Shelves. Reliability Engineering \& System Safety. v.61, n.1-2, p.21-29. 
[11] AVEN, T.; KURT, P. (1998) Expressing and interpreting the results of quantitative risk analysis. Review and discussions. Reliability Engineering \& System Safety. v.61, n.1, p.3-10.

[12] AYYUB, B.M.; GURAN, A.; HALDAR, A. Uncertainty modeling in vibration, control and fuzzy analysis of structural systems. Series on Stability, Vibration and Control of Systems. v.10.

[13] BARSA, G. E KIRWAN, B. (1998) Collection of offshore human error probability data. Reliability Engineering \& System Safety. v.61, n.1-2, p.7793.

[14] BATHE, K. J. (1982) Finite element procedures in engineering analysis. Englewood Cliffs, Prentice Hall.

[15] BATHE, K.J., RAMM, E. \& WILSON, E.L. (1975) Finite element formulation for large deformation dynamic analysis. International Journal of Numerical Methods in Engineering, 9, 353-386.

[16] BEA, R.G. (1998) Human and organization factors: engineering operating safety into offshore structures. Reliability Engineering \& System Safety. v.61, n.1-2, p.109-126.

[17] BECK, H. \& KONIG, G. (1966) Restraing forces in the analysis of tall buildings. In: Symposium on tall buildings, Oxford, 513-536.

[18] BECKJORD, E.S.; CUNNINGHOM, M.A.; MURPHY, J.A. (1990) Probabilistic safety assessment development in the United States. Reliability Engineering \& System Safety. v.39. n.2, p.159-170.

[19] BERNARDO, T.R.R. (1999) Contribuição à análise de confiabilidade em pavimentos de edifícios de concreto armado. Dissertação (mestrado) - Escola de Engenheria de São Carlos, Universidade de São Paulo.

[20] BERTRAND, G.; HAAK, R. (1997) Probabilistic safety design by a generalized two parameter approach. Advances in Safety and Reliability. Proceedings: ESREL'97 International Conference on Safety and Reliability. Lisbon. Portugal. v.2, p.1601-1608.

[21] BOHNENBLUST, H.; SLOVIC, P. (1998) Integrating technical analysis and public values in risk-based decision making. Reliability Engineering \& System Safety. v.59, n.1, p.151-160.

[22] CAERS, J.; MAES, M.A. (1998) Identifying tails, bounds and end-points of random variables. Structural Safety. .v.20, n.1, p.1-23.

[23] CAMPOS F.A.(1986). Estudo de estruturas de concreto armado através do método dos elementos finitos. In: Congresso Latino Americano sobre 
Métodos Computacionais para Engenharia, São Carlos, Anais v.3, p.14131426.

[24] CASCIATI, F.; ROBERTS, B. (1996) Mathematical models for structural reliability analysis, CRC (mathematical modelling series).

[25] CHEN, W. F. \& LUI, E. M. (1988) Plasticity for structural engineers. New York, McGraw-Hill.

[26] CHEN, W. F. (1982) Plasticity in reinforced concrete. McGraw-Hill, New York.

[27] CHEOK, M.C.; PARRY, G.W.; SHERRY, R.R. (1998) Use of importance measures in risk-informed regulatory applications. Reliability Engineering \& System Safety. v.60, n.3, p.213-226.

[28] CIAMPOLI, M. (1989) Reliability Evaluation of Existing Structures: Updating technique to account for experimental data. International Conference on Monitoring, Surveillance and Predictive Maintenance of Plants and Structures. Taormina. Italy, october, p.149-158.

[29] CIAMPOLI, M.; ELLINGWOOD, B. (1996) Probabilistic methods for current and future performance assessment of concrete structures in nuclear power plants. Reunione del Comitato Tecnico. RICEM TC-MLN.

[30] CILONI, A.D.(1993). Sobre o Comportamento em Serviço das Estruturas Planas de concreto armado. São Carlos. Tese (Doutorado) - Escola de Engenharia de São Carlos, Universidade de São Paulo.

[31] COHEN, B.L. (1998) Public perception versus results of scientific risk analysis. Reliability Engineering \& System Safety. v.59, n.1, p.101-106.

[32] COMI, C. (2000) A nonlocal damage model with permanent strains for quase-brittle materials, In: A Benallal ed., Continuous Damage and Fracture, Elsevier.

[33] COMITÉ EURO-INTERNACIONAL DU BÉTON (1977/ 1978/ 1990/ 1993/ 1995/ 1988). Code modèle CEB-FIP. CEB Bulletin D'Information, n. 123/ 124/ 125/ 191/ 195/ 196/ 203/ 204/ 205/ 213/ 214/ 229.

[34] COOKE, R.M. (1996) The design of reliability data bases, part I: review of standard design concepts. Reliability Engineering \& System Safety. v.51, n.1, p.137-146.

[35] COOKE, R.M. (1996) The design of reliability data bases, part II: competing risk and data compression. Reliability Engineering \& System Safety. v.51, n.1, p.209-224. 
[36] COOPER, J.A. (1998) Constrained mathematics evaluation in probabilistic logic analysis. Reliability Engineering \& System Safety. v.60, n.3, p.199-203.

[37] CORRÊA, M.R.S.(1991). Aperfeiçoamento de modelos usualmente empregados no projeto de sistemas estruturais de edifícios. São Carlos. 331p. Tese (Doutorado) - Escola de Engenharia de São Carlos, Univerisidade de São Paulo.

[38] CRISFIELD, M. A. (1990). A consistent co-rotational formulation for nonlinear, three-dimensional, beam-elements. Computer Methods in Applied Mechanics and Engineering, 81, 131-150

[39] CROSS, F.B. (1998) Facts and values in risk assessment. Reliability Engineering \& System Safety. v.59, n.1, p.27-40.

[40] DEVICTOR, N.; MARQUES, M.; LEMAIRE, M. (1997) Adaptative use of response surfaces in the reliability computations of mechanical components. Advances in Safety and Reliability. Proceedings: ESREL'97 International Conference on Safety and Reliability. Lisbon, Portugal, v.2, p.1269-1277.

[41] DEVOOGHT, J. (1998) Model uncertainty and model inaccuracy. Reliability Engineering \& System Safety. v.59, n.2, p.171-186.

[42] DEY, A.; MAHADEVAN, S. (1998) Ductile structural system reliability analysis using adaptive importance sampling. Structural Safety. v.20, n.2, p.137-154.

[43] DIMITRI VAL; BLJUGER, F.; YANKELEVSKY, D. (1997) Reliability evaluation in nonlinear analysis of reinforced concrete structures. Structural Safety. v.19, n.2, p.203-217.

[44] DITLEVSEN, O. (1982) Model uncertainty in structural reliability. Structural Safety. v.1, n.1, p.73-86.

[45] DITLEVSEN, O. (1984) Taylor expansion of series system reliability. Journal of Engineering Mechanics. v.110, n.2, p.293-307.

[46] DITLEVSEN, O.; MADSEN, H.O. (1996) Structural reliability methods, Wiley.

[47] ELLINGWOOD, B.; GALAMBOS, T.V. (1982) Probability based criteria for structural design. Structural Safety. v.1, n.1, p.15-26.

[48] EPAARACHCHI, D.; STEWART, M.G.; ROSOWSKY, D.V. (1996) System risk for multi-storey reinforced concrete building construction. Probabilistic Mechanics \& Structural Reliability. Proceedings: seventh specialty conference. Worcester. Massachusetts, USA, p.230-233.

[49] EUROCODE 1 (1991) Basis of design and actions on structures, Annex A. 
[50] FERSON, S.; GINZBURG, L.R. (1996) Different methods are needed to propagate ignorance and variability. Reliability Engineering \& System Safety. v.54, n.2-3, p.133-144.

[51] FIGUEIRAS, J.A. (1983) Ultimate load analysis of anisotropic and reinforced concrete plates and shells. Tese (doutorado) - University of Wales.

[52] FIGUEIREDO, R. G. (1972). Sobre a instabilidade elástica de pórticos tridimensionais de edifícios. São Carlos. Tese (doutorado) - Escola de Engenharia de São Carlos, Universidade de São Paulo.

[53] FISCHHOFF, B. (1998) Comunicate unto others ... Reliability Engineering \& System Safety. v.59, n.1, p.63-72.

[54] FRAGOLA, J.R. (1996) Reliability and risk analysis data base development: An historical Perspective. Reliability Engineering \& System Safety. v.51, n.1, p.125-136.

[55] FRANGOPOL, D.M.; COROTIS, R.B.; RACKWITZ, R. (1996) Reliability and optimization of strutural systems, Pergamon.

[56] FRANGOPOL, D.M.; F. ASCE; IDE, Y.; IWAKI, I. (1996) Effects of load path and load correlation on the reliability of concrete columns. Probabilistic Mechanics \& Structural Reliability. Proceedings: seventh specialty conference. Worcester. Massachusetts. USA. p.206-209.

[57] FRANGOPOL, D.M.; IDE, Y.; SPACONE, E.; IWAKI, I. (1996) A new look at reliability of reinforced concrete columns. Structural Safety. v.18, n.2/3, p.123-150.

[58] FUSCO, P. B. (1977). Estruturas de concreto. Fundamentos estatísticos da segurança das estruturas. Brasil, McGraw-Hill.

[59] GARRICK, B.J. (1998) Technological stigmatism, risk perception, and truth. Reliability Engineering \& System Safety. v.59, n.1, p.41-46.

[60] GAUDOIN, O.; SOLER, J.L. (1997) Failure rate behavior of components subjected to random stresses. Reliability Engineering \& System Safety. v.58, n.1, p.19-30.

[61] GERE, J. M.; WEAVER JR, W. (1967). Análisis de estructuras reticulares. México, Espanha, Companhia Editorial Continental.

[62] GHALI, A. \& FAVRE, R. (1986) Concrete structures: structures and deformation. London, Chapman \& Hall.

[63] GORDON, R.P.E. (1998) The contribution of human factors to accidents in the offshore oil industry. Reliability Engineering \& System Safety. v.61, n.1-2, p.95-108. 
[64] GRAHAM, L.; DEODATIS, G (1998) Variability response functions for stochastic plate bending problems. Structural Safety. v.20. v.2, p.167-188.

[65] GRIGORIU, M. (1983) Method for approximate reliability analysis. Structural Safety. v.1, n.2, p.155-165.

[66] GUlVANESSIAN, H; HOLICKY, M. (1996) Designers' Handbook to Eurocode 1. Part 1: Basis of Design. Thomas Telford, London.

[67] GUO-KANG ER (1998) A method for multi-parameter PDF estimation of random variables. Structural Safety. v.20, n.1, p.25-36.

[68] GUOLIANG, J.; LIN, C.; JIAMEI, D. (1991) Monte Carlo finite element method of structure reliability analysis. Reliability Engineering \& System Safety. v.40, n.1, p.77-84.

[69] HAIM, M. (1991) The impact of new evidence on State-of-knowledge dependence. Reliability Engineering \& System Safety. v.40, n.1, p.1-4.

[70] HALDAR, A.; GURAN, A.; AYYUB, B.M. Uncertainty modeling in finite element, fatigue and stability of systems. Series on Stability, Vibration and Control of Systems. v.9.

[71] HASOFER,A.M. (1974) Reliability index and Failure probability. Journal of Sructural Mechanical. v.3, n.1, p.25-27.

[72] HASOFER,A.M.; LIND, N.C. (1974) Exact and Invariant Second-Moment Code Format. Journal of the Engineering Mechanical division. February, p.111-121.

[73] HENDERSON, J.R.; BLOCKLEY, D.T. (1983) Logical analysis of assumptions in code calibration. Structural Safety. v.1, n.2, p.123-140.

[74] HILD, F.(1992). De la rupture des materiaux a comportement fragile. Cachan. These de doctorat - E.N.S. de Cachan, C.N.R.S., Université Pierre et Marie Curie.

[75] HILTON, H.H.; SUNG YI; DANYLUK, M.J. (1997) Probabilistic analysis of delamination onset in linear anisotropic elastic and viscoelastic composite columns. Reliability Engineering \& System Safety. v.56, p.237-248.

[76] HOEGBERG, L. (1998) Risk perception, safety goals and regulatory decisionmaking. Reliability Engineering \& System Safety. v.59, n.1, p.135-140.

[77] HOFER, E. (1996) When to separate Uncertainties and when not to separate. Reliability Engineering \& System Safety. v.54, n.2-3, p.113-118.

[78] HOHENBICHLER, M.; RACKWITZ, R. (1983) First-order-concepts in system reliability. Structural Safety. v.1, n.3, p.177-188. 
[79] HOHENBICHLER, M.; RACKWITZ, R. (1985) A bound and approximation to the multivariate normal distribution function. Mathematical Japonica. v.30, n.5, p.821-828.

[80] HOHENBICHLER, M.; RACKWITZ, R. (1986) Asymptotic crossing rate of Gaussian vector processes into intersections of failure domains. Probabilistic Engineering Mechanics. v.1, n.3, p.177-179.

[81] HOKSTAD, P.; OIEN, K.; REINERTSEN, R. (1998) Recommendations on the use of expert judgment in safety and reliability engineering studies. Two offshore case studies. Reliability Engineering \& System Safety. v.61, n.1-2, p.65-76.

[82] HOLICKY, M.; VROUWENVELDER T. (1997) Time variant reliability of a reinforced concrete column. Advances in Safety and Reliability. Proceedings: ESREL'97 International Conference on Safety and Reliability. Lisbon. Portugal. v.2. p.1307-1314.

[83] HONG, H.P. (1998) An efficient point estimate method for probabilistic analysis. Reliability Engineering \& System Safety. v.59, n.3, p.261-267.

[84] HORLICK-JONES, T. (1998) Meaning and contextualisation in risk assessment. Reliability Engineering \& System Safety. v.59, n.1, p.79-90.

[85] HSIAO, K. M.; HORNG, H. J.; CHEN, Y. R. (1987). A corotational procedure that handles large rotations of spatial beam structures. Computers $\&$ Structures, 27, 6.

[86] JASANOFF, S. (1998) The political science of risk perception. Reliability Engineering \& System Safety. v.59, n.1, p.91-100.

[87] JCSS - JOINT COMMITTEE ON STRUCTURAL SAFETY. (1996) Background Documentation. Eurocode 1 (ENV 1991). Part 1: Basis of Design. Working Document. March. n.94. $1^{\mathrm{a}}$ edition.

[88] KELLY, D.L. (1991) Use of constrained lognormal distribution in reliability analysis. Reliability Engineering \& System Safety. v.40, n.1, p.43-48.

[89] KIUREGHIAN, A.D.; ASCE; PEI-LING LIU. (1986) Structural reliability under incomplete probability information. Journal of Engineering Mechanics. v.112, n.1, p.85-104.

[90] KIUREGHIAN, A.D.; DAKESSIAN, T. (1998) Multiple design points in first and second-order reliability. Structural Safety. v.20, n.1, p.37-49.

[91] KONTOGIANNIS, T. (1997) A framework for the analysis of cognitive reliability in complex systems: a recovery centred approach. Reliability Engineering \& System Safety. v.58, n.3, p.233-248. 
[92] LA BORDERIE, C. (1991) Phénomènes unilatéraux dans un matériau endommageable: modélisation et application à l'analyse de structures en béton. Thèse de Doctorat, Universitè Paris VI.

[93] LAVALL, A. C. C. (1988). Análise elástica em segunda-ordem de pórticos planos metálicos. São Carlos. Dissertação (mestrado) - Escola de Engenharia de São Carlos, Universidade de São Paulo.

[94] LEMAIRE, M. (1997) Reliability and mechanical design. Reliability Engineering \& System Safety. v.55, n.1, p.163-170.

[95] LEMAIRE, M. (1998) Finite element and reliability: combined methods by response surface. G.N. Frantziskonis (ed.), PROBAMAT - 21st Century: Probabilities and Materials, p.317-331.

[96] LEMAIRE, M. (1998) Probabilities and Materials Tests, Models and Applications. Probabilities and Materials, p.1-8.

[97] LEMAIRE, M.; ISMAILI, M.A.; BERNARD, P.; SIGNORET, J.P. (1995) Propagation of uncertainties in a system: Application of FORM SORM methods in RAMS engineering. Aplications of Statistics and Probability. ICASP 7. v.2, p.1065-1070.

[98] LEMAIRE, M.; MITTEAU, J.C.; BÉAKOU, A. (1995) Less approximations for Sorm integrals. Aplications of Statistics and Probability. ICASP 7. v.2, p.1003-1010.

[99] LEMAIRE, M.; MOHAMED, A. (1999) Private communication.

[100] LEMAITRE, J.; CHABOCHE, J.L. (1985) Mecanique des Materiaux Solids. Paris, Dunod.

[101] LI, C.Q.; PHAM, L. (1995) A closed-form solution for reliability-based optimised design. Aplications of Statistics and Probability. ICASP 7. v.2, p.875-880.

[102] LIN, K.Y.; FRANGOPOL, D.M. (1996) Reliability-based optimum design of reinforced concrete girders. Structural Safety. v.18. n.2/3, p.239-258.

[103] LIND, N.C. (1995) A measure of vulnerability and damage tolerance. Reliability Engineering \& System Safety. v.48, n.1, p.1-6.

[104] LING, J.; PAN, J. (1998) A new method for selection of population distribution and parameter estimation. Reliability Engineering \& System Safety. v.60. N3, p.247-255.

[105] LIU, W.K.; MANI, A.; BELYTSCHKO, T. (1987) Finite element methods in probabilistic mechanics. Probabilistic Engineering Mechanics. v.2. n.4, p.201-213. 
[106] LUENBERGER, D.L. (1989) Programación lineal y no lineal. Wilmington, Delaware, E.U.A., Addison-Wesley Iberoamericana.

[107] LUSAS: theory manual, versão 10.

[108] LUSAS: verification manual II, versão 11.

[109] MACGREGOR, J. G.; HAGE, S. E. (1970). Stability analysis and design of concrete frames. Journal of the Structural Division, ASCE, n. 103, oct.

[110] MACGREGOR, J.G. (1993). Design of slender concrete columns: Revisited. ACI Structural Journal, v.90, n.3,p.302-309, May-Jun.

[111] MACIAS, A.F. (1994) Modèles fiabilistes et mécaniques: éléments finis stochastiques. Méthodes de couplage et applications. Thèse (doctora) LaRAMA - Laboratoire de Recherches et Applications en Mécanique Avancée. Clermont Ferrant France.

[112] MADSEN, H.O. (1988) Omission sensitivity factors. Structural Safety. v.5, p.35-45.

[113] MARCELLIER, P.; LEMAIRE, M; GOYET, J. (1999) Calibration de coefficients partiels à partir de modèles par éléments finis. IFMA - Laboratoir de Recherches et Applications en Mécanique Avancée. Ainda nao publicado.

[114] MAREK, P.; GUSTAR, M.; ANAGNOS, T. (1996) Simulation-based reliability assessment for structural engineers, CRC (mathematical modelling series).

[115] MASON, R.L.; GUNST, R.F.; HESS, J.L. Statistical design and analysis of experiments, John Wiley \& Sons.

[116] MAZARS, J. (1984) Application de la mécanique de l'endommagement au comportement non lineaire et à la rupture du béton de structure. Thése de Doctorat d'État, Université Paris 6.

[117] MCDANIELS, T.L. (1998) Ten propositions for untangling descriptive and prescriptive lessons in risk perception findings. Reliability Engineering \& System Safety. v.59, n.1, p.129-134.

[118] MELCHERS, R.E. (1998) Load path dependence for directional simulation in the load space. Reliability and Optimization of Structural Systems. Proceedings: eighth IFIP WG7.5 working conference on reliability and optimization of structural systems. Michigan. USA. p.241-248.

[119] MOHAMED, A. (2000) Optimisation des structures pour un niveau de fiabilité cible. LaRAMA - Laboratoire de Recherches et Applications en Mécanique Avancée. Clermont Ferrant, France. 
[120] MOHAMED, A. (1999) RYFES Theoretical manual. version 1.0. LaRAMA Laboratoire de Recherches et Applications en Mécanique Avancée. Clermont Ferrant. France.

[121] MOHAMED, A.; MITTEAU, J.C.; MEYNET, M ET LEMAIRE, M. (1997) Couplage mécano-fiabiliste. Méthodologie pour les variables dépendantes ou corrélées. LaRAMA - Laboratoire de Recherches et Applications en Mécanique Avancée. Clermont Ferrant, France.

[122] MOHAMED, A.M.; LEMAIRE, M., MITTEAU, J.C.; MEISTER, E. (1998) Finite element and reliability: a method for compound variables - application on a cracked heating system. Nuclear Engineering and Design. p.185-202.

[123] MOHAMED, A.M.; MUZEAU, J.P.; LEMAIRE, M. (1994) Reliability method for offshore structures by linearization of mechanical behaviour. Structural Safety \& Reliability. p.527-534.

[124] MOHAMED; LEMAIRE, M. (1998) Discussion on: structural reliability analysis using a standard deterministic finite element code. Structural Safety. v.20, p.391-397.

[125] MOHAMED; LEMAIRE, M. (1999) The use of sensitivity operators in the reliability analysis of strctures. Computational Stochastic Mechanics. p.211220.

[126] MOSES, F. (1982) System reliability developments in structural engineering. Structural Safety. v.1, n.1, p.3-13.

[127] MOSNERON-DUPIN, F.; REER, B.; HESLINGA, G.; STRATER, O.; GERDES, V.; SALIOU, G.; ULLWER, W. (1997) Human-centered modeling in human reliability analysis: soma trends based on case studies. Reliability Engineering \& System Safety. v.58. n.3, p.249-274.

[128] MURZEWSKI, J.W. (1998) A more fundamental reassessment of probabilistic design methods. Reliability and Optimization of Structural Systems. Proceedings: eighth IFIP WG7.5 working conference on reliability and optimization of structural systems. Michigan. USA. p.39-50.

[129] NILSEN, T.; GUDMESTAD O.T.; DALANE, J.I.; RETTEDAL, W.K.; AVEN, T. (1998) Utilisation of principles from structural reliability in quantitative risk analysis: example from an offshore transport problem. Reliability Engineering \& System Safety. v.61, n.1-2, p.127-137.

[130] O'CONNOR, P. (1998) Standards in reliability and safety engineering. Reliability Engineering \& System Safety. v.60. n.2, p.173-178.

[131] OIEN, K. (1998) Improved quality of input data for maintenance optimization using expert judgment. Reliability Engineering \& System Safety. v.60, n.2 p.93-101. 
[132] OKRENT, D. (1998) Risk perception and risk management: on knowledge, resource allocation and equity. Reliability Engineering \& System Safety. v.59, n.1, p.17-26.

[133] PANDEY, M.D. (1998) An effective approximation to evaluate multinormal integrals. Structural Safety. v.20, n.1, p.51-67.

[134] PAPAZAGLOU, I.A. (1998) Functional block diagrams and automated construction of event trees. Reliability Engineering \& System Safety. v.61. n.3, p.185-214.

[135] PAPAZAGLOU, I.A. (1998) Mathematical foundations of event trees. Reliability Engineering \& System Safety. v.61. n.3, p.169-183.

[136] PARKINSON, D.B. (1978) Solution for second moment reliability index. Journal of the Engineering Mechanics Division. v.104, p.1267-1275.

[137] PARRY, G.W. (1996) The characterization of uncertainty in probabilistic risk assessments of complex systems. Reliability Engineering \& System Safety. v.54, n.2-3, p.119-126.

[138] PATE-CORNELL, M.E. (1996) Uncertainties in risk analysis: six levels of Treatment. Reliability Engineering \& System Safety. v.54, n.2-3, p.95-112.

[139] PEI-LING LIU (1991) Optimization algorithms for structural reliability. Structural Safety. v.9, p.161-177.

[140] PIDGEON, N. (1998) Risk assessment, risk values and the social science programme: why we do need risk perception researrch. Reliability Engineering \& System Safety. v.59, n.1, p.5-16.

[141] PIMENTA, P.M. (1996) Análise Não-linear de Pórticos Planos: Teoria Exata vs. Teoria de Segunda Ordem. BT/PEF/9618, São Paulo, Brasil.

[142] PINTO, R.S.(1997). Não-linearidade física e geométrica no projeto de edifícios usuais de concreto armado. São Carlos. Dissertação (Mestrado) Escola de Engenharia de São Carlos, Universidade de São Paulo.

[143] PRESS, W.H. et all (1994) Numerical Recipes in Fortran. The Art of Scientific Computing. Second Edition, Cambridge University Press.

[144] PROENÇA, S.P.B. (1989) Notas sobre análise não-linear física de estruturas Parte I: teoria da plasticidade e técnicas numéricas. Escola de Engenharia de São Carlos, Universidade de São Paulo.

[145] RACKWITZ, R.; FIESSLER, B. (1978) Structural reliability under combined random load sequences. Computers \& Structures. v.9, p.489-494. 
[146] RAMALHO, M.A.(1990). Sistemas para análise de estruturas considerando interação com o meio elástico. São Carlos. 389p. Tese (Doutorado) - Escola de Engenharia de São Carlos, Universidade de São Paulo.

[147] RAMM, E. Strategies for tracing the nonlinear response near limit points. Universität Stuttgart. Germany.

[148] RAUSAND, M.; OIEN, K. (1996) The basic concepts of failure analysis. Reliability Engineering \& System Safety. v.53, n.1, p.73-84.

[149] REGAN, P.J.; PATE-CORNELL, M.E. (1997) Normative engineering risk management systems. Reliability Engineering \& System Safety. v.57, n.2, p.159-170.

[150] REID, S.G. (1996) Strengh and reliability of reinforced concrete columns with sustained loading. Probabilistic Mechanics \& Structural Reliability. Proceedings: seventh specialty conference. Worcester, Massachusetts, USA. p.234-237.

[151] REINERTSEN, R. (1995) Risk measure in practical use: risk reduction has its price, but is it known? Reliability Engineering \& System Safety. v.49, n.1, p.47-50.

[152] RENN, O. (1998) The role of risk perception for risk management. Reliability Engineering \& System Safety. v.59, n.1, p.49-62.

[153] ROSOWSKY, D.V. (1995) Estimation of design loads for reduced reference periods. Structural Safety. v.17, p.17-32.

[154] ROUHIAINEN (1991) Importance of the quality management of safety analysis. Reliability Engineering \& System Safety. v.40, n.1, p.5-16.

[155] RUGGIERO, M. A. G.; LOPES, V. L. R. (1988). Cálculo numérico, aspectos teóricos e computacionais. São Paulo, McGraw-Hill.

[156] SAKAMOTO, J.; MORI, Y.; SEKIOKA, T. (1997) Probability analysis method using Fast Fourier transform and its application. Structural Safety. v.19, n.1, p.21-36.

[157] SANCHES JUNIOR, F. (1998) Análise de Esforços e Deslocamentos em Pisos de Edifícios Considerando-se Modelos do Concreto Armado. Dissertação (Mestrado). Escola de Engenharia de São Carlos, Universidade de São Paulo.

[158] SANG-HYO KIM; SEONG-WON NA (1997) Response surface method using vector projected sampling points. Structural Safety. v.19, n.1, p.3-19.

[159] SANTOS, L. M. (1987). Estado limite último de instabilidade. São Paulo. Monografia - Escola Politécnica, Universidade de São Paulo. 
[160] SANTOS, V.P. E ROMERO, R.A.F. (1994) Utilização do Matlab para o desenvolvimento de redes neurais. Instituto de Ciências Matemáticas de São Carlos, Universidade de São Paulo. Relatórios Técnicos.

[161] SARGIN, M. (1971) Stress-strain relationship for concrete and the analysis of structural concrete sections. S.M. Study No 4, University of Waterloo, Solid Mechanics Division.

[162] SCHEIWILLER, A. (1997) Combining information in the field of structural engineering. Advances in Safety and Reliability. Proceedings: ESREL'97 International Conference on Safety and Reliability. Lisbon, Portugal. v.2, p.1595-1600.

[163] SCHOFIELD, S. (1998) Offshore QRA and the ALARP principle. Reliability Engineering \& System Safety. v.61, n.1-2, p.31-37.

[164] SHETTY, N.K.; SOARES, C.G.; THOFT-CHRISTENSEN, P.; JENSEN, F.M. (1998) Fire safety assessment and optimal design of passive fire protection for offshore structures. Reliability Engineering \& System Safety. v.61, n.1-2, p.139-149.

[165] SHINOZUKA, M.; M. ASCE (1983) Basic analysis of structural safety. Journal of Structural Engineering. v.109. N3. 721-740.

[166] SILVA, R.M.(1996). Analise Não-Linear de Pórticos Planos de concreto armado: Modelagem Numérica e Avaliação dos métodos aproximados. São Carlos. Tese (Doutorado) - Escola de Engenharia de São Carlos, Universidade de São Paulo.

[167] SIMOLA, K. E PULKKINEN, U. (1998) Models for non-destructive inspection data. Reliability Engineering \& System Safety. v.60, n.1, p.1-12.

[168] SINNAMON, R.M.; ANDREWS, J.D. (1997) New approaches to evaluating fault trees. Reliability Engineering \& System Safety. v.58, n.1, p.89-96.

[169] SLOVIC, P. (1998) The risk game. Reliability Engineering \& System Safety. v.59, n.1, p.73-78.

[170] SOARES, C.G. (1997) Probabilistic methods for structural design. Kluwer Academic Publishers.

[171] SOARES, C.G. (1997) Reliability of components in composite materials. Reliability Engineering \& System Safety. v.55, n.1, p.171-177.

[172] SOARES, R.C. (1997) Otimização de seções transversais de vigas de concreto armado: aplicação à pavimentos. Dissertação (mestrado) - Escola de Engenheria de São Carlos, Universidade de São Paulo. 
[173] SPANOS, P.D.; WU, Y.T. (Eds.). (1994) Probabilistic structural mechanics: Advances in structural reliability methods, Springer-Verlag.

[174] SPITZER, C. (1996) Review of probabilistic safety assessment: insights and recommendations regarding further developments. Reliability Engineering \& System Safety. v.52, n.2, p.153-164.

[175] SPOTO, E.D. (1988) Métodos de programação geométrica. Dissertação (mestrado) - Instituto de Ciências Matemáticas de São Carlos, Universidade de São Paulo.

[176] STARK, H.; WOODS, J.H. (1994) Probability, random processes, and estimation theory for engineers, Prentice Hall.

[177] STUART G. REID (1997) Probability-based patterned live loads for design. Structural Safety. v.19, n.1, p.37-52.

[178] TABSH, S.W.; A.M. ASCE (1996) Safety of concrete members designed by ACI 318 chapter 9 and appendix C load combinations. Probabilistic Mechanics \& Structural Reliability. Proceedings: seventh specialty conference. Worcester. Massachusetts. USA. p.218-221.

[179] TAIT, N.R.S. (1991) The use of probability in engineering design - an historical survey. Reliability Engineering \& System Safety. v.40, n.2, p.119132.

[180] TEIGEN, J.G.; FRANGOPOL, D.M.; STURE, S. AND FELIPPA, C.A. (1991) Probabilistic FEM for non-linear concrete structure. I: Theory. Journal of Structural Engineering, ASCE. 117, 2674-2689.

[181] TELLES, J. C. F. (1976). Análise do comportamento não-linear geométrico e físico de pórticos planos de concreto armado. Dissertação (mestrado). COPPE, Rio de Janeiro.

[182] THIEFFRY, P.; MITEAU, J.C.; LEMAIRE, M. (1997) Reliability analysis of the stability of slender structures with geometrical imperfections. Advances in Safety and Reliability. Proceedings: ESREL'97 International Conference on Safety and Reliability. Lisbon. Portugal. v.2, p.1501-1508.

[183] TIBOR, C. (1992) Some parameter-free tests for trend and their application to reliability analysis. Reliability Engineering \& System Safety. v.41, n.3, p.225230.

[184] TICHÝ, M. (1993) Applied methods of structural reliability, Kluwer Academic Publishers.

[185] VAN GROENENDAAL, W.J.H.; KLEIJNEN, J.P.C. (1997) On the assessment of economical risk: factorial design versus Monte Carlo methods. Reliability Engineering \& System Safety. v.57, n.1, p.91-102. 
[186] VARPASUO, P. (1998) A practical method for evaluation of parallel and mixed system reliability by using spreadsheets and workbook approach available in PC software. Reliability and Optimization of Structural Systems. Proceedings: eighth IFIP WG7.5 working conference on reliability and optimization of structural systems. Michigan. USA. p.313-320.

[187] VASCONCELOS, A.C. (1987). Como especificar a segurança quando há efeitos de segunda ordem a considerar. REUNIÃO ANUAL DO IBRACON : Seminário sobre os Aspectos Conflitantes em Normas Brasileiras. São Paulo, 20-24 de jul. Anais.

[188] VATN, J. (1998) A discussion of the acceptable risk problem. Reliability Engineering \& System Safety. v.61, n.1, p.11-19.

[189] VINNEM, J.E. (1998) Evaluation of methodology for QRA in offshore operations. Reliability Engineering \& System Safety. v.61, n.1-2, p.39-52.

[190] VRIJLING, J.K.; HENGEL, W.V.; HOUBEN, R.J. (1998) Acceptable risk as a basis for design. Reliability Engineering \& System Safety. v.59, n.1, p.141150.

[191] WEN, Y.K. (1990) Structural load modeling and combination for performance and safety evaluation. Elsevier Science Publishers, Amsterdam, The Netherlands.

[192] WINKLER, R.L. (1996) Uncertainty in probabilistic risk assessment. Reliability Engineering \& System Safety. v.54, n.2-3, p.127-132.

[193] YAO, J.T.P.; FURUTA, H. (1986) Probabilistic treatment of fuzzy events in civil engineering. Probabilistic Engineering Mechanics. v.1, n.1, p.58-64.

[194] YELLMAN, T.W.; MURRAY, T.M. (1995) Comment on 'the meaning of probability in probabilistic safety analysis'. Reliability Engineering \& System Safety. v.49, n.2, p.201-206. 


\section{Apêndice I Exemplo de transformação isoprobabilística de variáveis aleatórias independentes}

Considera-se uma variável x que tem uma função de distribuição acumulada normal, $\mathrm{N}(\overline{\mathrm{x}}, \sigma)$. Objetiva-se passar para o espaço normal padrão, ou seja, $\mathrm{x} \rightarrow \mathrm{u}$ tal que u obedeça a $\mathrm{N}(0,1)$. Equacionando o problema, tem-se:

$$
\Phi(\mathrm{u})=\mathrm{F}_{\mathrm{x}}(\mathrm{x})
$$

As transformações direta e inversa são obtidas, respectivamente, por:

$$
\begin{aligned}
& \mathrm{T}(\mathrm{X}) \quad \Rightarrow \quad \mathrm{u}=\Phi^{-1}\left(\mathrm{~F}_{\mathrm{x}}(\mathrm{x})\right) \\
& \mathrm{T}^{-1}(\mathrm{U}) \quad \Rightarrow \quad \mathrm{x}=\mathrm{F}_{\mathrm{x}}^{-1}(\Phi(\mathrm{u}))
\end{aligned}
$$

$\mathrm{O}$ primeiro passo é calcular a função de distribuição acumulada $\mathrm{F}_{\mathrm{x}}(\mathrm{x})$, que, como se sabe, é a integral da função de densidade, no caso:

$$
F_{x}(x)=\int_{-\infty}^{x} \frac{1}{\sqrt{2 \pi} \sigma} e^{-\frac{1}{2}\left(\frac{x-\bar{x}}{\sigma}\right)^{2}} d x
$$

Conhecido $\mathrm{F}_{\mathrm{x}}(\mathrm{x})$ através de algum processo de integração numérica, passa-se ao cálculo da inversa de $\Phi$. Por facilidade didática, admite-se que $\mathrm{y}=\mathrm{F}_{\mathrm{x}}(\mathrm{x})$, e então, o problema passa a ser calcular $\Phi^{-1}(\mathrm{y})$. A função normal, como a maior parte das funções que interessam à engenharia, não é inversível analiticamente. É preciso fazer a inversão numericamente através de um processo iterativo, e para isso segue-se o seguinte procedimento: sabe-se que $\Phi^{-1}(\mathrm{y})=\mathrm{u} \therefore \Phi(\mathrm{u})=\mathrm{y}$, onde $\Phi$ e y são conhecidos, e $\Phi^{-1}$ e u são desconhecidos. Então, ao invés de resolver $\Phi^{-1}(\mathrm{y})$ que equivale à $u$, atribuem-se-se valores à u e resolve-se $\Phi(\mathrm{u})$, verificando se houve convergência em y. Deve-se variar u até que $\Phi(\mathrm{u})=\mathrm{F}_{\mathrm{x}}(\mathrm{x})$, que é a própria igualdade de funções de repartição, equação (33). O procedimento descrito neste parágrafo pode ser visto na Figura 6. 

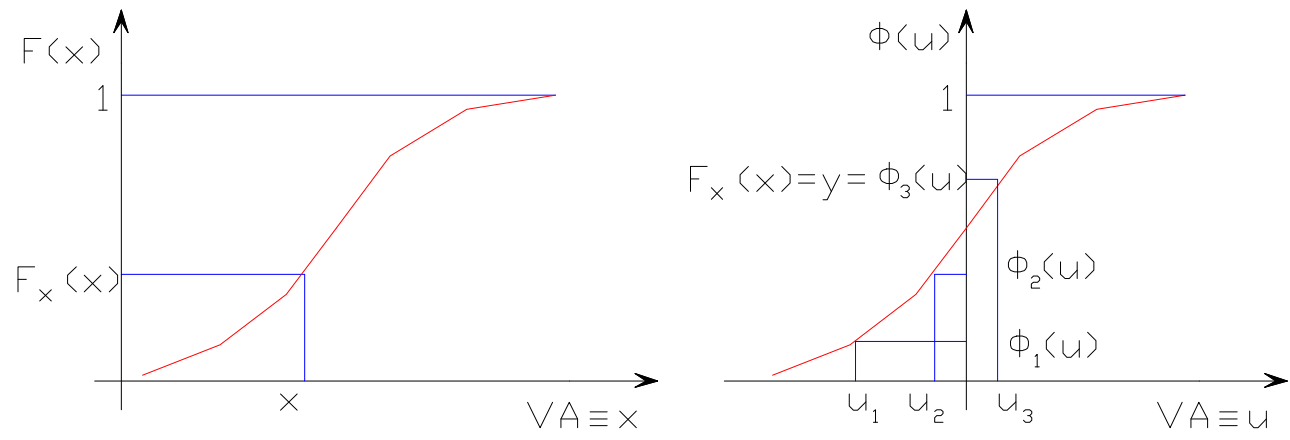

Figura 6 Transformação do espaço físico para o normal padrão não correlacionado 


\section{Apêndice II Exemplo de transformação isoprobabilística utilizando o método de distribuição normal equivalente}

Supõe-se que uma determinada variável x tenha média $\mathrm{m}$, desvio padrão s e f.d.p. exponencial. A transformação isoprobabilística do espaço físico para o espaço reduzido utilizando distribuição normal equivalente é dada da seguinte forma:

Para uma distribuição exponencial, sabe-se que:

$$
f(x)=\frac{1}{s} e^{-\frac{1}{s}\left(x-\left(m-\frac{1}{s}\right)\right)}, \quad F(x)=1-e^{-\frac{1}{s}\left(x-\left(m-\frac{1}{s}\right)\right)}
$$

Considera-se que $\Phi$ e $\varphi$ representam, respectivamente, as funções normais equivalente de distribuição acumulada e de densidade respectivamente. $\mu$ e $\sigma$ representam os parâmetros da distribuição normal equivalente da variável x.

Igualam-se as funções de distribuição acumulada e a f.d.p. no ponto considerado:

$$
\begin{gathered}
\Phi\left(\frac{\mathrm{x}-\mu}{\sigma}\right)=\mathrm{F}_{\mathrm{x}}(\mathrm{x}) \\
\frac{1}{\sigma} \varphi\left(\frac{\mathrm{x}-\mu}{\sigma}\right)=\mathrm{f}_{\mathrm{x}}(\mathrm{x})
\end{gathered}
$$

Desenvolvendo a expressão (37) tem-se:

$$
\frac{\mathrm{x}-\mu}{\sigma}=\Phi^{-1}\left[\mathrm{~F}_{\mathrm{x}}(\mathrm{x})\right]
$$

Substituindo a relação (39) na (38), determina-se uma expressão para $\sigma$ :

$$
\sigma=\frac{\varphi\left(\Phi^{-1}\left[\mathrm{~F}_{\mathrm{x}}(\mathrm{x})\right]\right)}{\mathrm{f}_{\mathrm{x}}(\mathrm{x})}
$$

Reorganizando (37), tem-se a média da distribuição normal equivalente:

$$
\mu=x-\sigma \Phi^{-1}\left[F_{x}(x)\right]
$$

Portanto, no exemplo considerado, o valor de $\mu$ e $\sigma$ são expressos 

equivalente

respectivamente por:

$$
\sigma=\frac{\varphi\left(\Phi^{-1}\left[1-\mathrm{e}^{-\frac{1}{\mathrm{~s}}\left(\mathrm{x}-\left(\mathrm{m}-\frac{1}{\mathrm{~s}}\right)\right.}\right)\right]}{\left.\frac{1}{\mathrm{~s}} \mathrm{e}^{-\frac{1}{\mathrm{~s}}\left(\mathrm{x}-\left(\mathrm{m}-\frac{1}{\mathrm{~s}}\right)\right.}\right)}
$$

E o valor da média equivalente:

$$
\left.\mu=x-\sigma \Phi^{-1}\left[1-e^{-\frac{1}{s}\left(x-\left(m-\frac{1}{s}\right)\right.}\right)\right]
$$

Após calcular os parâmetros da função normal equivalente, a transformação isoprobabilística é facilmente realizada pela expressão (45).

$$
u_{i}=\frac{x_{i}-\mu_{i}}{\sigma_{i}}
$$




\section{Apêndice III Exemplo prático de utilização de plano de experiência}

Para exemplificar a utilização de planos de experiência, supõe-se uma estrutura na qual as resistências do concreto $\mathrm{f}_{\mathrm{c}} \mathrm{e}$ do aço $\mathrm{f}_{\mathrm{y}}$ são variáveis aleatórias, cujos valores médios são representados por $\mu_{\mathrm{c}}$ e $\mu_{\mathrm{y}}$ respectivamente. Supõe-se ainda que $\mathrm{f}_{\mathrm{c}}$ equivale ao eixo 1 e $\mathrm{f}_{\mathrm{y}}$ ao eixo 2 . Considera-se ainda que será utilizado o plano de experiência numérico Estrela. O procedimento é descrito a seguir:

1- Define-se a combinação de valores determinísticos das variáveis aleatórias. Isto pode ser feito assumindo uma variação de $30 \%$ do valor médio da variável, por exemplo. Então, os valores de resistência que irão variar para se obterem as diferentes respostas estruturais são:

$$
\left\{\left(\mu_{\mathrm{fc}}, 130 \% \mu_{\mathrm{fy}}\right),\left(70 \% \mu_{\mathrm{fc}}, \mu_{\mathrm{fy}}\right),\left(\mu_{\mathrm{fc}}, \mu_{\mathrm{fy}}\right),\left(130 \% \mu_{\mathrm{fc}}, \mu_{\mathrm{fy}}\right),\left(\mu_{\mathrm{fc}}, 70 \% \mu_{\mathrm{fy}}\right)\right\}
$$

2- Para cada par de resistências assumido no item 1, calcula-se a resposta mecânica da estrutura, a qual é representada por $\mathrm{H}_{\mathrm{i}}$.

$$
\left\{\begin{array}{l}
\left(\mu_{\mathrm{fc}}, 130 \% \mu_{\mathrm{fy}}\right) \rightarrow \mathrm{H}_{1} \\
\left(70 \% \mu_{\mathrm{fc}}, \mu_{\mathrm{fy}}\right) \rightarrow \mathrm{H}_{2} \\
\left(\mu_{\mathrm{fc}}, \mu_{\mathrm{fy}}\right) \rightarrow \mathrm{H}_{3} \\
\left(130 \% \mu_{\mathrm{fc}}, \mu_{\mathrm{fy}}\right) \rightarrow \mathrm{H}_{4} \\
\left(\mu_{\mathrm{fc}}, 70 \% \mu_{\mathrm{fy}}\right) \rightarrow \mathrm{H}_{5}
\end{array}\right.
$$

3- Portanto, os pontos que pertencem à hipersuperfície (no caso dimensão 3) são:

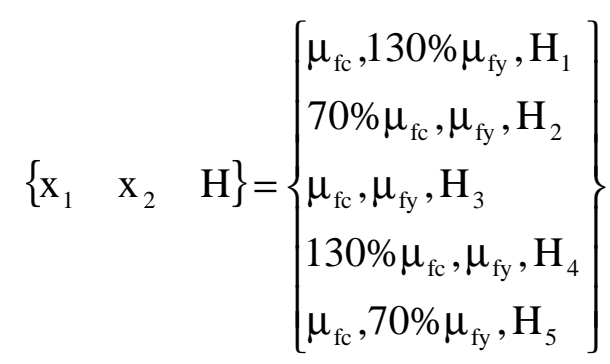




\section{Apêndice IV Exemplo de aplicação do}

Pretende-se determinar o índice de confiabilidade da coluna de concreto armado descrita na Figura 7 cujas características encontram-se na Tabela 7 e na Tabela 8. As unidades são kN e cm.

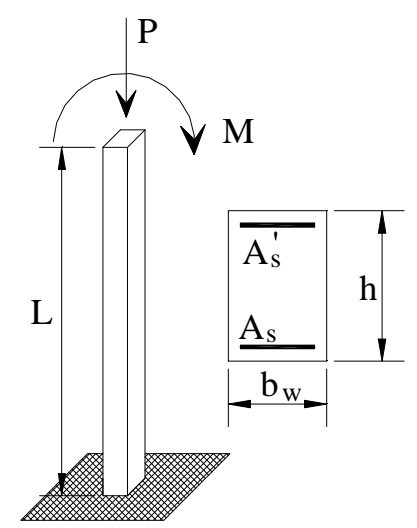

Figura 7 Coluna de referência para exemplo de aplicação do $R S M$

Tabela 7 Características mecânicas determinísticas

\begin{tabular}{|c|c|}
\hline $\begin{array}{c}\text { Base da seção transversal } \\
\text { (direção de menor inércia), } \mathrm{b}_{\mathrm{w}}\end{array}$ & 25.00 \\
\hline $\begin{array}{c}\text { Altura da seção transversal } \\
\text { (direção de maior inércia), } \mathrm{h}\end{array}$ & 25.00 \\
\hline $\begin{array}{c}\text { Posição da armadura tracionada } \\
\text { relativa ao CG, } \mathrm{Y}_{\text {inf }}\end{array}$ & 10.00 \\
\hline $\begin{array}{c}\text { Posição da armadura comprimida } \\
\text { relativa ao CG, } \mathrm{Y}_{\text {sup }}\end{array}$ & 10.00 \\
\hline Comprimento, $\mathrm{L}$ & 254.00 \\
\hline Taxa de armadura, $\mathrm{A}_{\mathrm{s}} /\left(\mathrm{b}_{\mathrm{w}} \mathrm{h}\right)$ & $0.80 \%$ \\
\hline $\begin{array}{c}\text { Excentricidade inicial, } \mu / v \\
\text { coeficiente parcial de segurança do } \\
\text { concreto, } \gamma_{\mathrm{c}}\end{array}$ & 11.00 \\
\hline $\begin{array}{c}\text { Coeficiente parcial de segurança do } \\
\text { aço, } \gamma_{\mathrm{c}}\end{array}$ & 1.40 \\
\hline $\begin{array}{c}\text { Coeficiente parcial de segurança } \\
\text { das ações externas, } \gamma_{c}\end{array}$ & $1 . .40$ \\
\hline
\end{tabular}


Tabela 8 Características estatísticas

\begin{tabular}{|c|c|c|c|}
\hline Variável & Média & Desvio adrão & Lei \\
\hline Resistência do concreto, $\mathrm{f}_{\mathrm{c}}$ & 3.50 & $\sigma=0.42$ & $\mathrm{~N}$ \\
\hline Resistência do aço, $\mathrm{f}_{\mathrm{y}}$ & 50.00 & $\sigma=3.00$ & $\mathrm{~N}$ \\
\hline
\end{tabular}

Inicialmente necessita-se determinarar $S$. Admite-se que a solicitação $S$ é determinada pelo coeficiente de carga que conduz a estrutura a instabilidade. Ou seja, admite-se análise no estado limite último onde a ruína da estrutura é determinada pela singularidade da matriz de rigidez. Portanto, o valor de $\mathrm{S}$ é equivalente ao coeficiente de carga que leva a estrutura a ruína quando esta é calculada considerando as resistências dos materiais reduzidas e as ações externas amplificadas por coeficientes parciais descritos na Tabela 7. Com o auxílio do STST determina-se o valor de $S$, sendo $S=1.5625$. Nota-se que $S$ é um valor puramente determinístico resultado de um simples cálculo mecânico.

Próximo passo é escolher um EP e desenvolve-lo, ou seja, calcular as respostas mecânicas da estrutura para o conjunto de resistências proposto pelo EP. O plano de experiência utilizado é o plano de experiência composto. Para resolver o problema considera-se que a resistência do concreto é a variável aleatória número 1 e a resistência do aço a número 2. Em $(46),\left[X_{R}\right]$ e $\left[U_{R}\right]$ são valores atribuídos às variáveis nos espaços físico e reduzido, respectivamente, os quais são balizados pelo EP escolhido. $\{R\}$ representa as respostas mecânicas no espaço físico para cada conjunto de valores físicos.

$$
\left[\mathrm{X}_{\mathrm{R}}\right]=\left[\begin{array}{cc}
3.50 & 59.00 \\
2.87 & 54.50 \\
4.13 & 54.50 \\
2.24 & 50.00 \\
4.76 & 50.00 \\
2.87 & 45.50 \\
4.13 & 45.50 \\
3.50 & 41.00 \\
3.50 & 50.00
\end{array}\right],\left[\mathrm{U}_{\mathrm{R}}\right]=\left[\begin{array}{cc}
0.00 & 3.00 \\
-1.50 & 1.50 \\
1.50 & 1.50 \\
-3.00 & 0.00 \\
3.00 & 0.00 \\
-1.50 & -1.50 \\
1.50 & -1.50 \\
0.00 & -3.00 \\
0.00 & 0.00
\end{array}\right],\{\mathrm{R}\}=\left\{\begin{array}{l}
2.850000 \\
2.615625 \\
2.978125 \\
2.343750 \\
3.071875 \\
2.515625 \\
2.862500 \\
2.656250 \\
2.759375
\end{array}\right\}
$$

De posse dos valores escritos em (46), próxima etapa é construir o polinômio que representa a RS, o qual pode ser escrito como: 


$$
\mathrm{Q}(\mathrm{X})=\mathrm{c}_{0}+\sum_{\mathrm{i}=1}^{\mathrm{n}} \mathrm{c}_{\mathrm{i}} \mathrm{x}_{\mathrm{i}}+\sum_{\mathrm{i}=1}^{\mathrm{n}} \sum_{\mathrm{j}=1}^{\mathrm{n}} \mathrm{c}_{\mathrm{ij}} \mathrm{x}_{\mathrm{i}} \mathrm{x}_{\mathrm{j}}
$$

Ou ainda:

$$
\mathrm{Q}(\mathrm{X})=\{\mathrm{C}\}^{\mathrm{t}}\{\mathrm{X}\}
$$

Por analogia, no espaço reduzido é escrito como

$$
\mathrm{Q}(\mathrm{U})=\{\mathrm{A}\}^{\mathrm{t}}\{\mathrm{U}\}
$$

$\mathrm{O}$ valores das constantes do polinômio $(\{\mathrm{C}\}$ ou $\{\mathrm{A}\}$ ) podem ser encontrados pelo método de regressão dos mínimos quadrados. Portanto, segue o seguinte procedimento:

Considere-se que

$$
[P]=\sum_{k=1}^{n p}\left(\left\{X^{k}\right\}\left\{X^{k}\right\}^{t}\right) \quad\{V\}=\sum_{k=1}^{n p}\left(R^{k}\left\{X^{k}\right\}\right)
$$

Utilizando-se os valores de $\left[\mathrm{X}_{\mathrm{R}}\right]$ descritos em (46) pode-se determinar $[\mathrm{P}] \mathrm{e}$ $\{\mathrm{V}\}$ nas expressões (50), caso quera trabalhar no espaço físico. Mas como se pretende encontrar a RS no espaço reduzido, utiliza-se $\left[U_{R}\right]$ descrito em (46) nas expressões (51), já escritas na forma do espaço reduzido.

$$
\left.[P]=\sum_{k=1}^{n p}\left(\left\{U^{k}\right\} U^{k}\right\}^{t}\right) \quad\{\mathrm{V}\}=\sum_{k=1}^{n p}\left(R^{k}\left\{U^{k}\right\}\right)
$$

$\{A\}$ e $\{U\}$ podem ser escritos na forma (52) e(53).

$$
\begin{gathered}
\{A\}^{\mathrm{t}}=\left\{\mathrm{a}_{0}, \mathrm{a}_{1}, \mathrm{a}_{2}, \mathrm{a}_{3}, \mathrm{a}_{4}, \mathrm{a}_{5}\right\} \\
\{\mathrm{U}\}^{\mathrm{t}}=\left\{1, \mathrm{u}_{2}, \mathrm{u}_{2}^{2}, \mathrm{u}_{1}, \mathrm{u}_{1} \mathrm{u}_{2}, \mathrm{u}_{1}^{2}\right\}
\end{gathered}
$$

Portanto, para os 9 pontos da RS fornecidos em (46) tem-se:

$$
\begin{aligned}
& \left\{U^{1}\right\}^{t}=\{1.00,3.00,9.00,0.00,0.00,0.00\} \\
& \left\{U^{2}\right\}^{t}=\{1.00,1.50,2.25,-1.50,-2.25,2.25\} \\
& \left\{U^{3}\right\}^{t}=\{1.00,1.50,2.25,1.50,2.25,2.25\} \\
& \vdots \\
& \left\{U^{8}\right\}^{t}=\{1.00,-3.00,9.00,0.00,0.00,0.00\} \\
& \left\{U^{9}\right\}^{t}=\{0.00,0.00,0.00,0.00,0.00,0.00\}
\end{aligned}
$$

Resolvendo as expressões (51), determinam-se $[\mathrm{P}]$ e $\{\mathrm{V}\}$. 


$$
\left.[\mathrm{P}]=\sum_{\mathrm{k}=1}^{9}\left(\left\{\mathrm{U}^{\mathrm{k}}\right\} \mathrm{U}^{\mathrm{k}}\right\}^{\mathrm{t}}\right)=\left[\begin{array}{cccccc}
9.00 & 0.00 & 27.00 & 0.00 & 0.00 & 27.00 \\
0.00 & 27.00 & 0.00 & 0.00 & 0.00 & 0.00 \\
27.00 & 0.00 & 182.25 & 0.00 & 0.00 & 20.25 \\
0.00 & 0.00 & 0.00 & 27.00 & 0.00 & 0.00 \\
0.00 & 0.00 & 0.00 & 0.00 & 20.25 & 0.00 \\
27.00 & 0.00 & 20.25 & 0.00 & 0.00 & 182.25
\end{array}\right]
$$

$$
\{\mathrm{V}\}=\sum_{\mathrm{k}=1}^{\mathrm{np}}\left(\mathrm{R}^{\mathrm{k}}\left\{\mathrm{U}^{\mathrm{k}}\right\}\right)=\left\{\begin{array}{c}
24.65 \\
0.90 \\
74.24 \\
3.25 \\
0.04 \\
73.43
\end{array}\right\}
$$

Conhecido $[\mathrm{P}]$ e $\{\mathrm{V}\}$, determina-se o vetor de coeficientes do polinômio.

$$
\{A\}=[P]^{t}\{\mathrm{~V}\}=\left\{\begin{array}{l}
0.2758 \mathrm{E}+01 \\
0.3351 \mathrm{E}-01 \\
-0.5498 \mathrm{E}-03 \\
0.1203 \mathrm{E}+00 \\
0.1736 \mathrm{E}-02 \\
-0.5584 \mathrm{E}-02
\end{array}\right\}
$$

Portanto Q(U), de acordo com (49), para a primeira superfície de resposta pode ser escrito na forma (58).

$$
\begin{aligned}
\mathrm{Q}(\mathrm{U})= & 2.758+0.03351 \mathrm{u}_{2}-0.0005498 \mathrm{u}_{2}^{2}+ \\
& 0.1203 \mathrm{u}_{1}+0.001736 \mathrm{u}_{1} \mathrm{u}_{2}-0.005584 \mathrm{u}_{1}^{2}
\end{aligned}
$$

Como já foi determinada a RS no espaço reduzido, representada por Q(U), por definição, a FS é escrita como:

$$
\mathrm{H}(\mathrm{U})=\mathrm{Q}(\mathrm{U})-\mathrm{S}
$$

Próximo passo é determinar o índice de confiabilidade da iteração, que é estimado pelo algoritmo iterativo de Rackwitz \& Fiessler descrito a seguir.

1 - Escolhe-se o ponto inicial: $u_{i}^{1}=0$

2 - Desenvolve-se:

$$
\mathrm{H}\left(\mathrm{u}_{\mathrm{i}}\right)^{1}=2.758-1.5625=1.1955
$$




$$
\begin{gathered}
\nabla \mathrm{H}_{\mathrm{i}}^{1}=\left.\frac{\partial \mathrm{H}\left(\mathrm{u}_{1}, \mathrm{u}_{2}, \ldots, \mathrm{u}_{\mathrm{n}}\right)}{\partial \mathrm{u}_{\mathrm{i}}}\right|^{1}=\left\{\begin{array}{l}
0.1203 \\
0.03351
\end{array}\right\} \\
\|\nabla \mathrm{H}\|^{1}=0.1249 \\
\alpha_{\mathrm{i}}^{1}=\frac{\nabla \mathrm{H}_{\mathrm{i}}^{1}}{\|\nabla \mathrm{H}\|^{1}}=\left\{\begin{array}{l}
0.9633 \\
0.2683
\end{array}\right\} \\
\beta^{1}=+\frac{\mathrm{H}^{1}-\left\{\nabla \mathrm{H}_{\mathrm{i}}^{1}\right\}^{\mathrm{T}}\left\{\mathrm{u}_{\mathrm{i}}^{1}\right\}}{\| \nabla \mathrm{H}^{1}}=\frac{1.1955}{0.1249}=9.5717 \\
\mathrm{u}_{\mathrm{i}}^{2}=-\beta^{1} \alpha_{\mathrm{i}}^{1}=\left\{\begin{array}{l}
-9.2204 \\
-2.5681
\end{array}\right\}
\end{gathered}
$$

3 - Caso seja o primeiro passo da iteração, retorna-se ao passo 2 com os novos valores para $\{\mathrm{U}\}$.

4 - Caso contrário, segue o procedimento.

$$
\begin{aligned}
& \mathrm{H}\left(\mathrm{u}_{\mathrm{i}}\right)^{2}=2.758+0.03351 \cdot(-2.5681)-0.0005498 \cdot(-2.5681)^{2} \\
& +0.1203 \cdot(-9.2204)+0.001736 \cdot(-9.2204) \cdot(-2.5681)- \\
& 0.005584 \cdot(-9.2204)^{2}-1.5625=-0.4371 \\
& \nabla \mathrm{H}_{\mathrm{i}}^{2}=\left.\frac{\partial \mathrm{H}\left(\mathrm{u}_{1}, \mathrm{u}_{2}, \ldots, \mathrm{u}_{\mathrm{n}}\right)}{\partial \mathrm{u}_{\mathrm{i}}}\right|^{2}=\left\{\begin{array}{l}
0.2188 \\
0.0203
\end{array}\right\} \\
& \|\nabla \mathrm{H}\|^{2}=0.2198 \\
& \alpha_{\mathrm{i}}^{2}=\frac{\nabla \mathrm{H}_{\mathrm{i}}^{2}}{\|\nabla \mathrm{H}\|^{2}}=\left\{\begin{array}{l}
0.9957 \\
0.0925
\end{array}\right\} \\
& \beta^{2}=+\frac{\mathrm{H}^{2}-\left\{\nabla \mathrm{H}_{\mathrm{i}}^{2}\right\}^{\mathrm{T}}\left\{\mathrm{u}_{\mathrm{i}}^{2}\right\}}{\|\nabla \mathrm{H}\|^{2}}=\frac{1.1747}{0.1694}=7.4275 \\
& u_{i}^{2}=-\beta^{1} \alpha_{i}^{1}=\left\{\begin{array}{l}
-7.3956 \\
-0.0687
\end{array}\right\}
\end{aligned}
$$

5 - Verifica-se o erro em $\beta$, que é determinado por:

$$
\operatorname{erro}_{\beta}=\left|\frac{\beta^{j+1}-\beta^{j}}{\beta^{j+1}}\right|=\left|\frac{\beta^{2}-\beta^{1}}{\beta^{2}}\right|=\left|\frac{7.4275-9.5717}{7.4275}\right|=28.87 \%
$$

5 - Caso o processo não convergiu, retorna ao passo 4. Caso contrário, fim do processo iterativo. 
$\mathrm{O}$ processo iterativo converge quando o erro em $\beta$ atingir uma tolerância satisfatória. Aconselha-se, baseado na experiência de várias estruturas processadas e conversas com autoridades no assunto, utilizar tolerância de $1 \%$ para o erro em $\beta$.

Nesse caso particular, a convergência ocorre no terceiro passo do processo iterativo. Os valores de $\beta$ e U são:

$$
\beta=7.3551 \quad ; \quad U=\left\{\begin{array}{l}
-7.3140 \\
-0.7767
\end{array}\right\}
$$

Percebe-se que até o instante, foi estimado o índice de confiabilidade para uma RS arbitrária e o procedimento é válido apenas para RS construídas em torno do ponto de projeto. Portanto, necessita-se construir outras RS até que em duas RS consecutivas o índice de confiabilidade satisfaça uma determinada tolerância.

O procedimento segue, deve ser construída outra RS trocando o par de valores de resistência mais distante da solução pelo equivalente aos valores de $\{U\}$ encontrados em (73). Portanto, os novos valores para $\left[\mathrm{X}_{\mathrm{R}}\right]$ e $\left[\mathrm{U}_{\mathrm{R}}\right]$ e consequentemente $\{R\}$ são:

$$
\left[\mathrm{X}_{\mathrm{R}}\right]=\left[\begin{array}{cc}
3.50 & 59.00 \\
2.87 & 54.50 \\
4.13 & 54.50 \\
2.24 & 50.00 \\
0.70 & 47.67 \\
2.87 & 45.50 \\
4.13 & 45.50 \\
3.50 & 41.00 \\
3.50 & 50.00
\end{array}\right],\left[\mathrm{U}_{\mathrm{R}}\right]=\left[\begin{array}{cc}
0.00 & 3.00 \\
-1.50 & 1.50 \\
1.50 & 1.50 \\
-3.00 & 0.00 \\
-6.667 & -0.7767 \\
-1.50 & -1.50 \\
1.50 & -1.50 \\
0.00 & -3.00 \\
0.00 & 0.00
\end{array}\right],\{\mathrm{R}\}=\left\{\begin{array}{l}
2.850000 \\
2.615625 \\
2.978125 \\
2.343750 \\
1.450000 \\
2.515625 \\
2.862500 \\
2.656250 \\
2.759375
\end{array}\right\}
$$

O limite inferior considerado para a resistência do concreto foi de $0.70 \mathrm{kN} / \mathrm{cm}^{2}$. Por isso o valor utilizado no vetor na quinta linha de $\left[U_{R}\right],(74)$, não corresponde a $\mathrm{u}_{1}=-7.3140$, e sim a $\mathrm{u}_{1}=-6.667$. No processo de busca de $\mathrm{P}^{*}$ sempre é bom limitar o domínio da pesquisa para evitar problemas numéricos.

Reinicia todo processo de cálculo, (49) em diante, até que os valores dos índices de confiabilidade para duas FS consecutivas sejam iguais a menos de uma tolerância preestabelecida. Conhecido o valor de $\beta$ facilmente obtém-se a probabilidade de ruína da estrutura utilizando métodos como o FORM ou o SORM. 